\title{
Studies on the Synthesis of Marine
}

\section{Natural Product (-)-Zampanolide and its \\ Analogues}

\author{
By \\ Jingjing Wang
}

A thesis submitted to Victoria University of Wellington in fulfilment of the requirements for the degree of Doctor of Philosophy

School of Chemical and Physical Sciences 

Dedicated to my dear husband and best friend,

Marcus Sheerin

for your love and support 



\section{Abstract}

(-)-Zampanolide is a microtubule-stabilising marine natural product, with promise as a cancer drug candidate. The potential therapeutic application of zampanolide has fuelled worldwide interest in its total synthesis, but few analogue studies have been reported. Analogues afford the possibility of examining the structureactivity relationships with a view to optimising for potency and medicinal viability. This project seeks to devise a new route to zampanolide and generate a series of analogues for bioactivity evaluation.

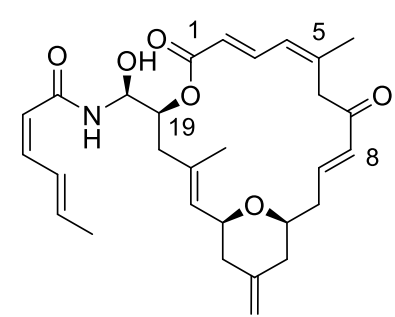

(-)-Zampanolide

The initial approach to zampanolide and a number of designed analogues was through disconnections at $\mathrm{C} 20$ by an $\mathrm{N}$-aldol reaction, at $\mathrm{C} 1$ by Yamaguchi esterification, at $\mathrm{C} 8-\mathrm{C} 9$ by metathesis and at $\mathrm{C} 15-\mathrm{C} 16$ by alkynylation. During the development of fragment syntheses, problems were encountered with protection of the secondary hydroxyl group at C19 and establishment of an aldehyde at C15. Useful natural and analogue fragments were generated during this exploratory phase.

The order of connections was revised, and effort has been put towards the improvement of the synthetic efficiency. A three-component reaction involving (triphenylphosphoranylidene)ketene, also known as Bestmann ylide, as a linchpin was envisaged to provide the dienoate of zampanolide. This is an expanded application of Bestmann ylide and therefore the scope of this linchpin reaction was investigated using simple alcohols and aldehydes. Success in the scoping study fortified this approach, and the coupling of the C3-C8 and C16-C20 fragments of zampanolide proceeded with good yields and stereoselectivity of the E,Z-geometry.

The planned late stage connections were tested on model substrates. The side arm attachment by a chiral boron reagent-promoted aza-aldol reaction failed to produce desired product on a simple model. However, model substrates that better account for the functionality of the zampanolide macrocycle are proposed for subsequent studies. In case these also do not succeed, 
reliable alternative methods described in the literature would be used. Several methods were scanned for the asymmetric alkynylation required for the $\mathrm{C} 15-\mathrm{C} 16$ bond connection. That involving ProPhenol and diethylzinc produced an excellent yield with a model alkyne. Although the stereoselectivity of the alkynylation is yet to be optimized, it was also tested on the full zampanolide fragment generated from the Bestmann ylide reaction. A small amount of the desired product was isolated, establishing 16 out of the 18 carbons of the macrocycle. Formation of a macrocycle is close at hand. 


\section{Acknowledgements}

Doing a $\mathrm{PhD}$ is one of the best decisions I have made in my life. I enjoyed the highs and the lows of research, and the tricky balance of life and work. During it, the awesome people I have met made this journey of $\mathrm{PhD}$ so much more exciting, memorable and fulfilling.

First, I want to give my greatest thanks to my primary supervisor Dr. Joanne Harvey for the guidance and support through the years. There is never a day I remembered Joanne with a low spirit. Her enthusiastic attitude is captivating, and helped me to stay optimistic and motivated, especially when things were not going smooth. Her extensive knowledge on organic chemistry guided me to find solutions in research. Additionally, thanks to Joanne's in-depth editing and comments, it has helped me to improve my writing skill. Joanne not only helped me to learn so much more organic chemistry, but also has been a role model that I can look up to.

I would also like to thank my secondary supervisor Dr. Paul Teesdale-Spittle for his help. I am so fortunate to have worked in such a great research group. We shared knowledge to solve problems, joy for success and great times outside the lab. These are treasured memories. I would like to thank the past and current group members: Sophie Geyrhofer, Thomas Bevan, Sam Ting, Dr. Kalpani Somarathne, Dr. Hemi Cumming, Dr. Mark Bartlett, Peter Moore, Amira Brackovic, Loïc Lassueur, Sarah Brown, Ben Durrant, Dan Phipps, Chris Orme, José Pinedo Rivera, Claire Turner, Dylan Davies, Scott Riordan, Jasmin Riesterer. I especially thank Sophie Geyrhofer, Peter Moore, Chris Hasenöhrl and Chris Orme for proof-reading, Claudia Gray and Sam Ting for all the preliminary work, and Sophie Geyrhofer again for running all my MS samples this years and carrying on the zampanolide project.

The School of Chemical and Physical Sciences at Victoria University of Wellington has been a great place to work, and I would like to thank everybody for the amazing experience I had. In particular, Ian Vorster and Rob Keyzers often helped me with NMR and MS. I do apologise for all the weekend emails and after-hour calls to Ian for NMR problems. I also thank Teresa 
Gen for letting me borrow solvents when the chemical store was closed, and Peter Northcote for useful comments on purification and spectroscopic data. I am extremely grateful for the PhD scholarship from New Zealand Health Research Council, travel and conference grants from VUW, New Zealand Institute of Chemistry, Centre of Biodiscovery, and the thesis submission scholarship from Faculty of Graduate Research. Without the financial support this thesis would not be possible.

Friends and family have also given me huge support. The person deserves the biggest thank you is my husband Marcus Sheerin. He has been taking such good care of me, so that I could concentrate on my work. Without his love and support, especially all the delicious lunches and dinners he cooked for me, I would not have achieved nearly as much or stayed healthy during the time of thesis writing. Sharing a life with Marcus is the best thing in my life. I also want to thank Marcus' bosses Rob, Mike and Fay for arranging Marcus to work from home, so that we could be together in Wellington. My parents and Marcus's family have given us great help. Marcus and I got married during my $\mathrm{PhD}$. Thanks to everybody in Marcus' family, especially Rowene, Brian, David, Alana, Nat and Sharolyn, our wedding was perfect, and I would not have wanted anything different.

Fourteen years ago, my parents Zhigang and Huixia made the decision to use their lifesavings to send me to New Zealand for better education. Because of this decision, I had the chance to experience this very exciting life in New Zealand: finding a passion for chemistry and mountains, meeting Marcus, making lifetime friends and so much more. This achievement is not mine alone, but builds on the years of care, support and guidance from my parents. 


\section{Table of contents}

Abstract $\quad$ i

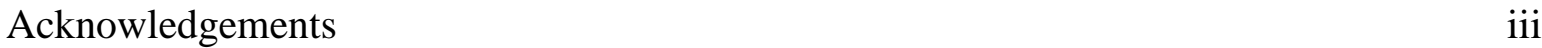

List of contents $\quad$ V

$\begin{array}{ll}\text { Abbreviations } & \text { ix }\end{array}$

Chapter 1: Introduction $\quad 1$

1.1 A brief history of marine natural products 1

1.2 Microtubule-targeting agents and paclitaxel 2

1.3 (-)-Zampanolide and (+)-dactylolide $\quad 7$

$\begin{array}{ll}\text { 1.4 Published total synthesis of zampanolide } & 10\end{array}$

1.4.1 Synthetic methods for formation of the pyran fragment 12

1.4.2 Synthetic methods of macrocyclization $\quad 15$

1.4.3 Synthesis of $N$-acyl hemiaminal linkage $\quad 16$

$\begin{array}{ll}\text { 1.5 Published total synthesis of dactylolide } & 18\end{array}$

1.5.1 Synthetic methods for formation of the pyran fragment 19

1.5.2 Other methods for the formation of dactylolide macrocycle 21

$\begin{array}{ll}1.6 \text { Analogue studies } & 23\end{array}$

1.7 Efficiency of total synthesis: linchpin synthesis 26

$\begin{array}{ll}1.8 \text { References } & 32\end{array}$

Chapter 2: Aim and preliminary work $\quad 37$

2.1 Aim 37

$\begin{array}{ll}\text { 2.2 Preliminary work } & 38\end{array}$ 
4.3 Scope of the Bestmann ylide cascade in the synthesis of $\alpha, \beta, \gamma, \delta$-unsaturated esters 
5.3 Asymmetric alkynylation of aldehydes for C15-C16 connection

5.4 Summary

5.5 Experimental data

5.6 References 


\section{Abbreviations}

(S)-TRIP (S)-3,3'-Bis(2,4,6-triisopropylphenyl)-1,1'-binaphthyl-2,2'-diyl

Ac hydrogenphosphate

Ad

Acetic

aq.

Adamantyl

Asn

Aqueous

ATR

Asparagine

BAIB 1,1-Diacetateiodobenzene

BINOL 1,1'-Bi-2-naphthol

$\mathrm{Bn} \quad$ Benzyl

$\mathrm{Boc}_{2} \mathrm{O} \quad$ Di-tert-butyl dicarbonate

BSA

$\mathrm{N}, \mathrm{O}$-Bis(trimethylsilyl)acetamide

$\mathrm{Bz} \quad$ Bezoyl

CIGAR Constant time inverse-detection gradient accordion rescaled

COSY Correlation spectroscopy

Cp 1,3-Cyclopentadiene

CSA Camphorsulphonic acid

DBU 1,8-Diazabicycloundec-7-ene

DCE 1,2-Dichloroethane

DCM Dichloromethane

DDQ 2,3-Dichloro-5,6-dicyano-1,4-benzoquinone

DIBAL-H Di-iso-butylaluminum hydride

DIP-chloride Chlorodiisopinocampheylborane

DMAP 4-( $N, N$-Dimethylamino)pyridine

DME 1,2-dimethoxyethane

DMF Dimethylformamide

DMP Dess-Martin periodinane

DMSO Dimethyl sulfoxide

EDCI $N$-(3-Dimethylaminopropyl)- $N$ '-ethylcarbodiimide hydrochloride

ee

Enantiomeric excess

Et Ethyl

FCC Flash column chromatogrphy

FT-IR Fourier transform infrared spectroscopy

GI Growth inhibition concentration

Grubbs II Grubbs 2nd generation catalyst

HBTU $O$-(Benzotriazol-1-yl)- $N, N, N^{\prime}, N^{\prime}$-tetramethyluronium hexafluorophosphate

His

HMBC Heteronuclear multiple-bond correlation

HRMS High resolution mass spectrometry

HSQC Heteronuclear single quantum coherence spectroscopy 


\begin{tabular}{|c|c|}
\hline HWE & Horner-Wadsworth-Emmons \\
\hline IBX & 2-Iodoxybenzoic acid \\
\hline $\mathrm{IC}_{50}$ & Half maximal inhibitory concentration \\
\hline Imid. & Imidazole \\
\hline LiHMDS & Lithium bis(trimethylsilyl)amide \\
\hline MDA & Microtubule-destabilizing agents \\
\hline Me & Methyl \\
\hline MIDA & $N$-Methyliminodiacetic acid \\
\hline MOM & Methoxymethyl \\
\hline MRP & Multidrug resistance-associated proteins \\
\hline MS & Molecular sieve \\
\hline MSA & Microtubule-stabilizing agents \\
\hline MTA & Microtubule-targeting agent \\
\hline MTPA & $\alpha$-Methoxy- $\alpha$-trifluoromethylphenylacetic acid \\
\hline MTT & 3-(4,5-Dimethylthiazol-2-yl)-2,5-diphenyltetrazolium bromide \\
\hline NaHMDS & Sodium bis(trimethylsilyl)amide \\
\hline NHC & $N$-Heterocyclic carbene \\
\hline NMR & Nuclear magnetic resonance \\
\hline NOESY & Nuclear Overhauser effect spectroscopy \\
\hline ox. & Oxidation \\
\hline PCC & Pyridinium chlorochromate \\
\hline PG & Protecting group \\
\hline Piv & Pivaloyl \\
\hline PMB & para-Methoxybenzyl \\
\hline PMP & para-Methoxyphenyl \\
\hline PPTS & Pyridinium $p$-toluenesulfonate \\
\hline ProPhenol & 2,6-Bis[2-(hydroxydiphenylmethyl)-1-pyrrolidinyl-methyl]-4-methylphenol \\
\hline Py & Pyridine \\
\hline r.t. & Room temperature \\
\hline $\mathrm{RCM}$ & Ring-closing metathesis \\
\hline ROESY & Rotating frame Overhauser effect spectroscopy \\
\hline SAR & Structure-activity relationship \\
\hline TBAF & Tetra- $n$-butylammonium fluoride \\
\hline TBAI & Tetra- $n$-butylammonium iodide \\
\hline TBDPS & tert-Butyldiphenylsilyl \\
\hline TBHP & tert-Butyl hydroperoxide \\
\hline TBS & tert-Butyldimethylsilyl \\
\hline TCBC & 2,4,6-Trichlorobenzoylchloride \\
\hline TEMPO & $2,2,6,6$-Tetramethyl-1-piperidinyloxy free radical \\
\hline TEOC & Trimethylsilylethylcarboxy \\
\hline TES & Triethylsilyl \\
\hline Tf & triflate \\
\hline TFA & Trifluoroacetic acid \\
\hline TfO & Triflic \\
\hline
\end{tabular}


THF Tetrahydrofuran

TLC Thin layer chromatography

TMEDA Tetramethylethylenediamine

TMS Trimethylsilyl

TPPO Triphenylphosphine oxide

XTT

2,3-Bis-(2-methoxy-4-nitro-5-sulfophenyl)-2H-tetrazolium-5-carboxanilide 


\section{Chapter 1: Introduction}

\subsection{A brief history of marine natural products}

Historically, natural products have played an important role in drug development. From the herbal medicines used in ancient times and traditional medicines to industrially produced pharmaceuticals in modern days, nature has provided us with a rich mine of potential drugs with enormous diversity in structure and biochemical activities. The boom of marine natural product chemistry came with the invention of SCUBA. Prior to SCUBA, only shallow water species had been accessible. Isolation of natural products from marine organisms has proven to be a great source of pharmaceuticals. The first isolated marine products were the nucleosides spongothymidine (1) and spongouridine (2), discovered in 1951 (Figure 1.1). ${ }^{1}$ Since then, the field of marine natural products has attracted increasing attention, resulting in the discovery of a vast number of marine products, that could be used in fighting numerous diverse illnesses, for example fungal infections, tumour growth, cancer and Alzheimer's disease.

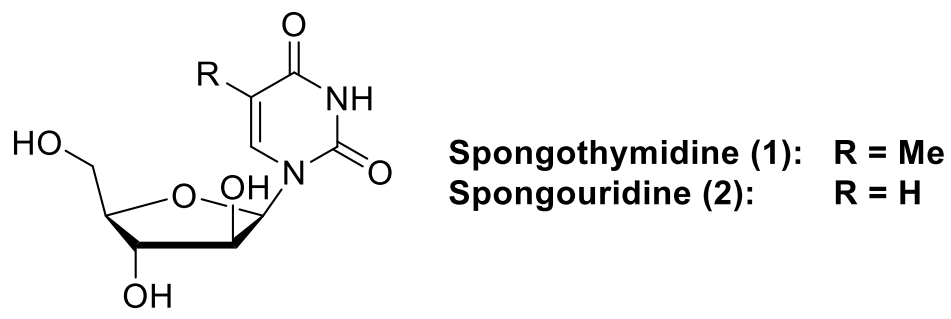

Figure 1.1: Structure of spongothymidine (1) and spongouridine (2).

Marine natural products are commonly secondary metabolites, which evolved for the natural defence of the organisms. Unlike vertebrates, marine sponges, corals and algae are sessile, meaning they don't have mobility; they also generally don't have external fighting facilities to defend themselves. Their defence is totally chemical and thus dependent on these secondary metabolites. The nature of their defence system determines that these metabolites have to be potent in order to be effective because, once released, they are diluted instantly by sea water. One example of current medicines that are derived from marine organisms is the breast cancer drug eribulin (3) (Figure 1.2). It is the simplified and 
optimized analogue of halichondrin B (4), which was isolated from the marine sponge, Halichondria okadai. $^{2}$

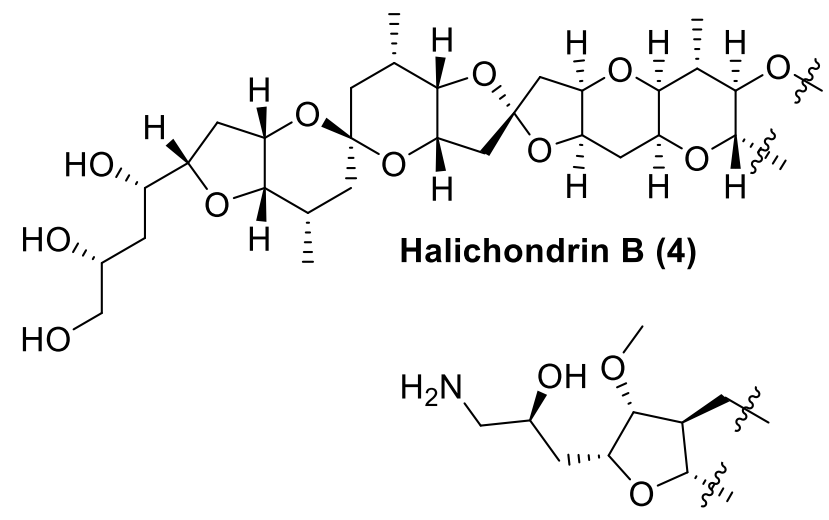

Eribulin (3)

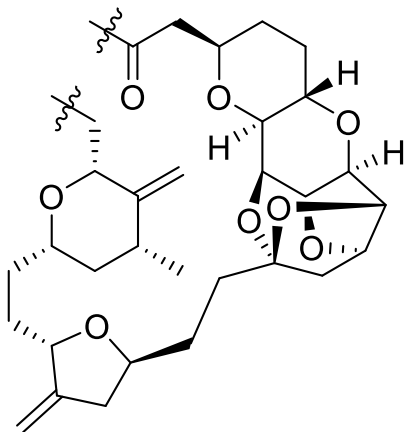

Figure 1.2: Structures of eribulin (3) and halichondrin B (4).

\subsection{Microtubule-targeting agents and paclitaxel}

Eribulin (3) is an example of the microtubule-targeting agents (MTAs), a group of largely nature-derived drugs or candidates that affect cell function by influencing the microtubules. They have been identified as good candidates for cancer treatment, and a number of such anticancer drugs are already in regular clinical use, such as vinorelbine (5), estramustine (6) and ixabepilone (7) (Figure 1.3). ${ }^{3}$ This success can be attributed to the important roles that microtubules play in cells, especially in proliferation and growth regulation. The first MTAs discovered were the vinca alkaloids. ${ }^{4}$ Their effect on microtubules was observed as the development of honeycomb-shaped crystals under the electron microscope, which were identified as abnormally large tubules resulting from the binding of vinca alkaloids. Since then a large number of such natural products have been reported, and enormous effort has been put towards better understanding of these compounds and their effects on microtubules.
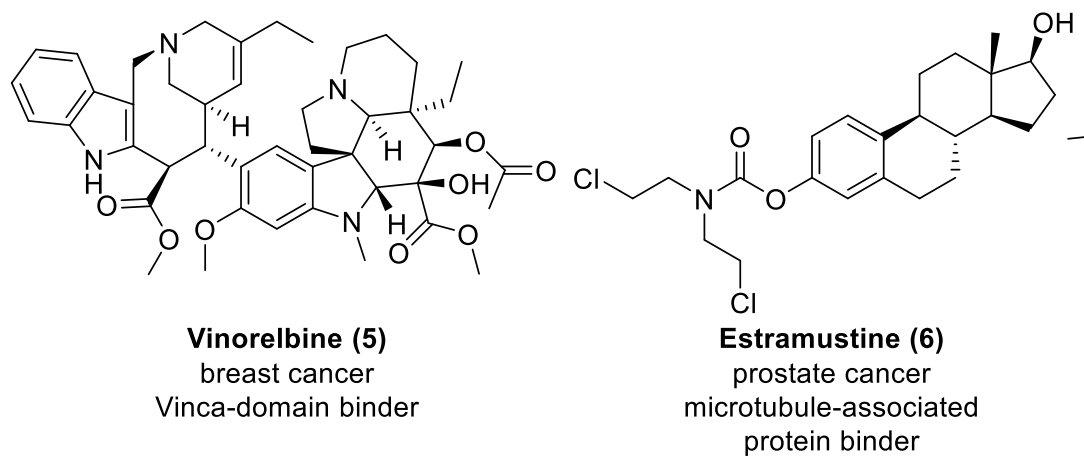

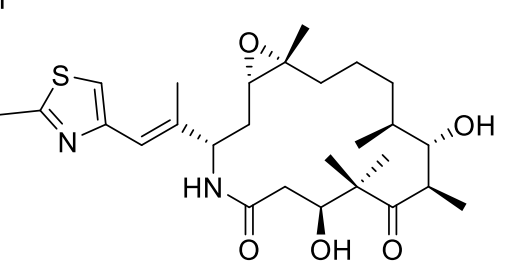
breast cancer
Vinca-domain binder

Figure 1.3: Examples of approved microtubule-targeting drugs. 
Microtubule-targeting agents can affect microtubules through different mechanisms. Microtubule formation is a dynamic process, such that both assembly and disassembly of tubule monomers occur simultaneously. By maintaining a healthy equilibrium, normal function of microtubules, such as cell division and proliferation, can be carried out. Interruption of either end of the equilibrium can be disruptive or lethal for cells. Most MTAs disturb this dynamic by binding directly to microtubules, but some were also found to bind to microtubuleassociated proteins, whose function is to regulate microtubule dynamics. ${ }^{5}$ Generally, MTAs are classified into two categories according to their outcomes: microtubule-destabilizing agents (MDAs) and microtubule-stabilizing agents (MSAs). Compounds that bind to the vinca domain (at the end of microtubules) or colchicine domain (soluble tubulin dimers) are MDAs. This type of binding disrupts polymerization of microtubules, and as a result the microfibers essential to pull cells apart cannot be formed, thus cell proliferation is halted. Vinca-domain binders include drugs such as eribulin (3), vinorelbine (5), vinblastine and romidepsin. Colchicine-domain binders are a smaller group, and contain the potential drugs fosbretabulin, verubulin and ombrabulin that are currently in clinical trials. On the other hand, those that bind to the paclitaxel domain (inner surface of microtubules) are MSAs. In this case, microtubule disassembly is interrupted and multiple asters are often formed, resulting in cell lysis. Although MSAs were discovered later, they have become a more active area of research than the MDAs.

The most well-known example of a microtubule-stablizing drug is paclitaxel (8), trade-marked as Taxol. It is one of the most successful anti-cancer drugs on the market. Discovered in the late 1960 's ${ }^{6-7}$ paclitaxel's biological activity was extensively studied during the following decade ${ }^{8}$ and it was finally approved for treatment of ovarian and breast cancer in 1992 and 1994, respectively. Because the natural source of paclitaxel (8), the Pacific yew tree (Taxus brevifolia), is highly scarce, isolation alone cannot meet the demand of the clinic. During the 1990s, the structure of paclitaxel (8) attracted around 30 groups worldwide towards its total synthesis, ${ }^{9}$ which contains a core 6-8-6 tricyclic ring system with appended hydroxyls, esters and a fused oxetane (Scheme 1.1). In addition to the tricyclic ring system, the existence of multiple quaternary and stereocenters makes the synthesis of $\mathbf{8}$ very challenging. In 1994, two of these total syntheses were published. Holton's synthesis utilized an epoxide-alcohol rearrangement strategy for the core synthesis (Scheme 1.1), ${ }^{10,11}$ which was developed by their group in 1988 to synthesize a similar taxane, taxusin. ${ }^{12}$ The saturated six-membered ring in 9 was formed via Dieckmann cyclization and the side-arm was sourced from Ojima's $\beta$-lactam (10). Holton's synthesis also included a route starting from baccatin III (11), which was also 
isolated from the Pacific yew tree. Although this could increase the production of paclitaxel (8), it is still far from meeting the market demand.
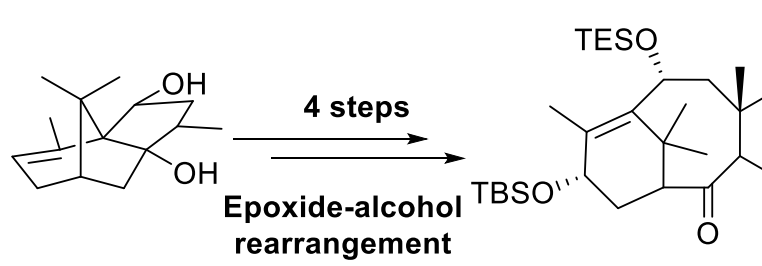

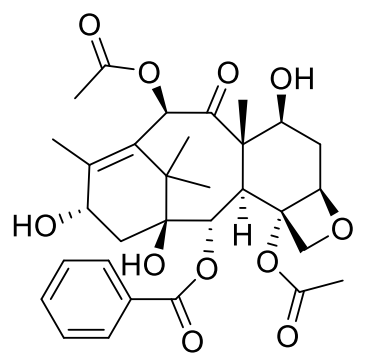

Baccatin III (11)

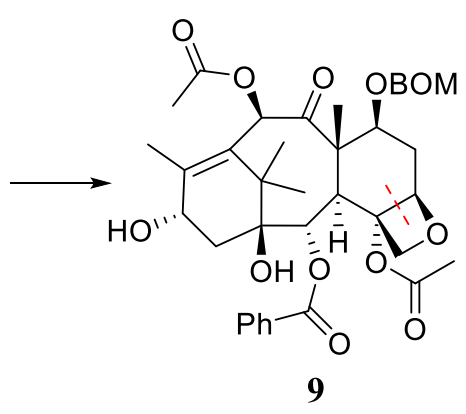

14 steps

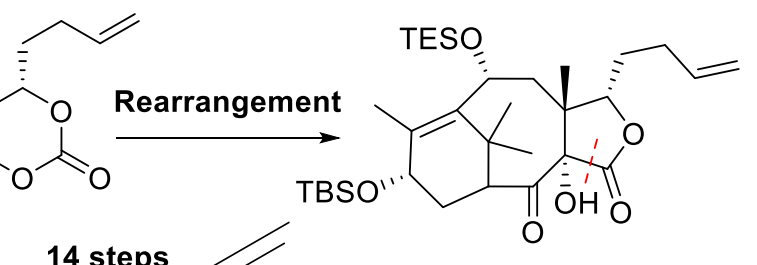

Dieckmann

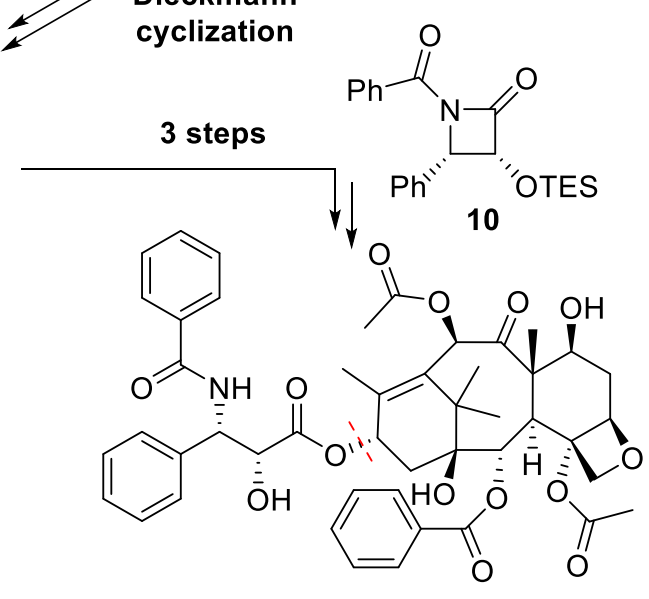

Paclitaxel (8)

Scheme 1.1: Holton's synthesis of paclitaxel (8).

Nicolaou's synthesis used the same $\beta$-lactam 10 for the side-arm, but the core structure was constructed around the central 8-membered ring, via Shapiro and McMurry coupling reactions (Scheme 1.2). ${ }^{13}$ Due to the complexity of the structure, a total synthesis approach would be too expensive for industry-scale production. Nevertheless, Holton and Nicolaou's research was a valuable development in synthetic methodology, and researchers continued to find more methods and reliable sources for mass production of paclitaxel $(\mathbf{8})$.

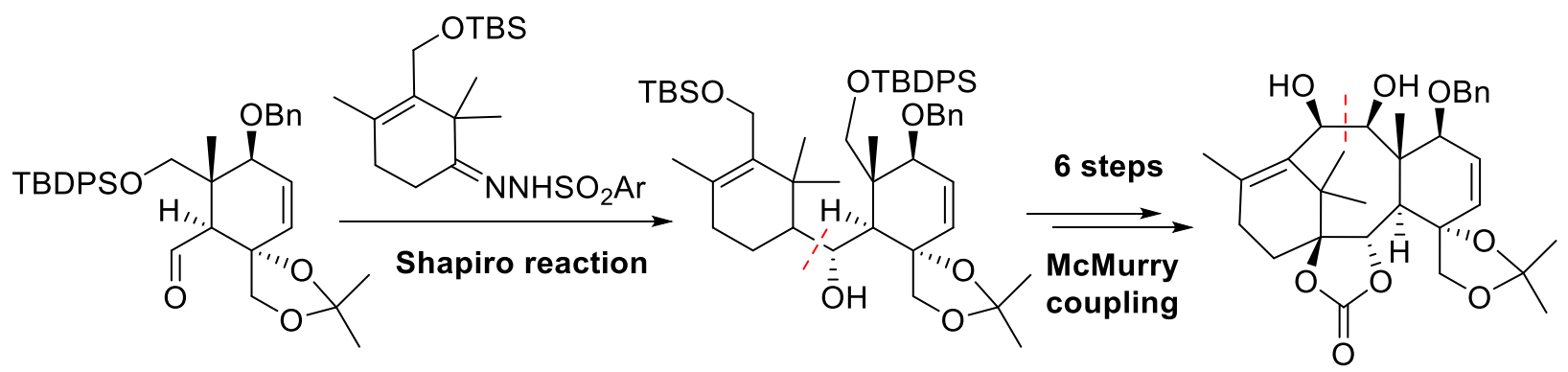

Scheme 1.2: Key steps of Nicolaou's synthesis of paclitaxel (8).

The source problem was resolved by Bristol-Myers Squibb. They re-discovered paclitaxel from the leaves of ornamental yew tree in a mixture with related taxanes (12) that differ at the amide 
on the side-arm (Scheme 1.3). Compared to the 100-200 years growth cycle needed to harvest paclitaxel from the bark of the Pacific yew trees, the leaves of ornamental yew trees only need 3-4 years to regenerate. ${ }^{14}$ A sequence was developed to convert the mixture of taxanes (12) to 8 in two simple steps, owing to a previously reported method of imine synthesis with Schwartz's reagent ${ }^{15,16}$ (Scheme 1.3). The amide on the side-arm was converted to an amine (13) via hydridozirconation to produce imine (14), followed by hydrolysis. The subsequent esterification afforded taxol (8). This method of production allows industry-scale manufacture

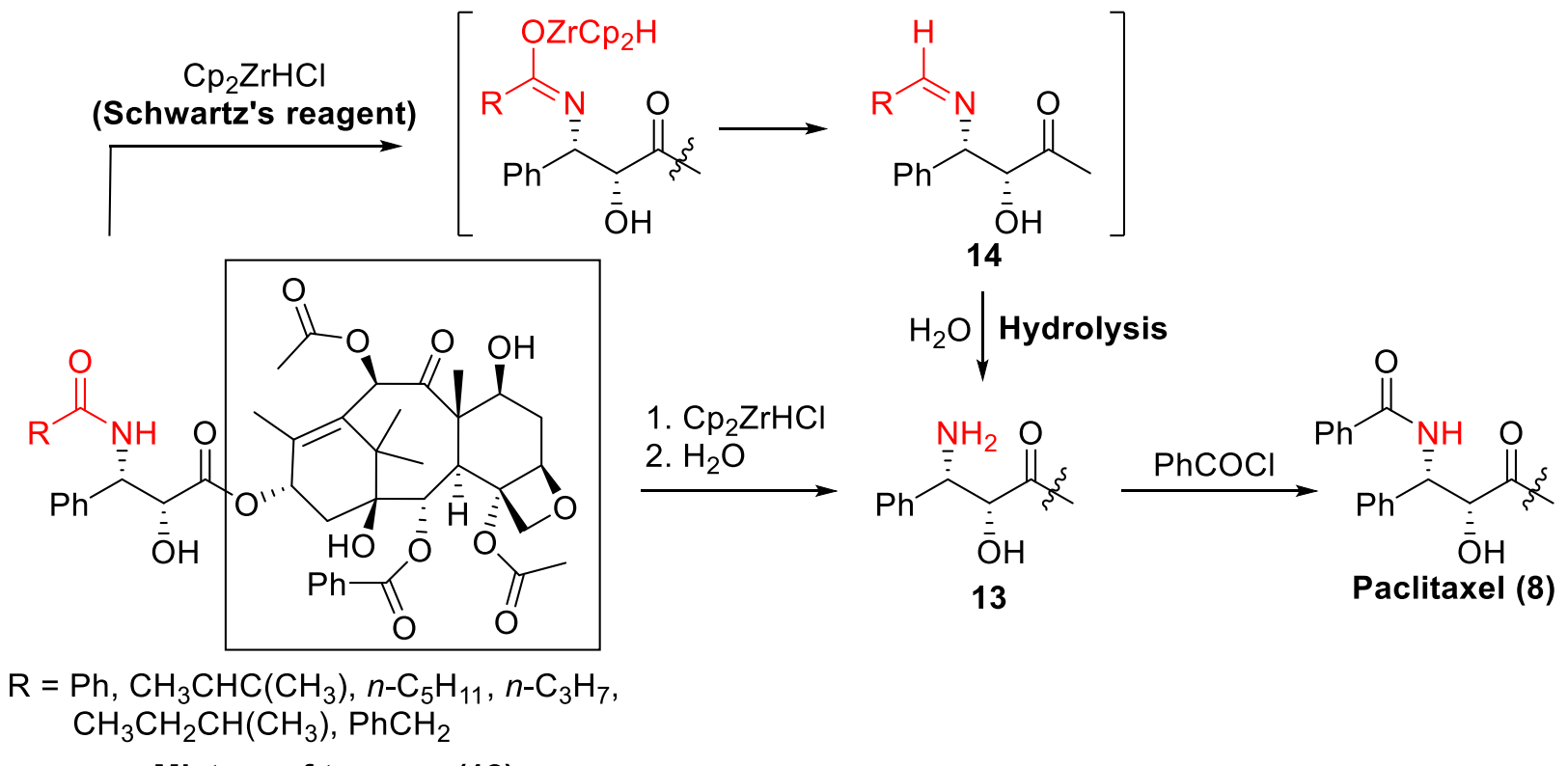

Mixture of taxanes (12)

Scheme 1.3: Bristol-Myers Squibb's synthesis of paclitaxel (8).

of paclitaxel (8) for commercialization, which also enables derivatives of paclitaxel (8) to be accessed readily and studied. Fruitfully, a few related drugs have since been developed and approved by FDA for various types of cancer, for example docetaxel (15), cabazitaxel (16) (Figure 1.4) and nanoparticle albumin-bound paclitaxel (nab-paclitaxel). The derivatization of paclitaxel (8) is still a very active area of study. ${ }^{17}$

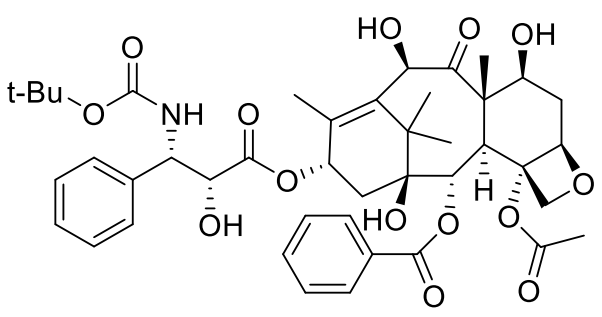

Docetaxel (15)

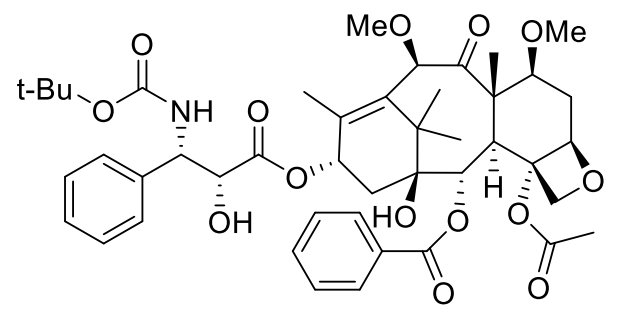

Cabazitaxel (16)

Figure 1.4: Structure of docetaxel (15) and cabazitaxel (16). 
During the clinical application of those drugs, some patients were found to be developing resistance. The first cause for this resistance was identified as an overexpression of Pglycoprotein efflux pumps. ${ }^{18-21}$ This mechanism is part of the energy-dependant transport of small molecules through the cell membrane, and provides the cell's natural defence against toxins. It has the ability to remove toxins, in this case drugs, from the cell, resulting in ineffective chemotherapy. ${ }^{22}$ Elevated P-glycoprotein level is the most common cause of drugresistance amongst many cell lines, and against various small-molecule drugs. ${ }^{18}$ Later, another resistance pathway was observed, involving multidrug resistance-associated proteins (MRP). The first MRP was isolated from drug-resistant lung cancer cells with normal P-glycoprotein levels, ${ }^{23}$ and six more members of the MRP family were subsequently discovered. ${ }^{24}$ Both Pglycoprotein and MRP are validated targets for overcoming the problem of drug resistance. Research targeting these mechanisms include suppression of these small-molecule efflux pumps by inhibitors and reducing the toxicity of drugs to allow higher application dose. ${ }^{20}$ There is also a potential solution offered by microtubule-stabilizing agents that bind covalently to microtubules. In 2005, Hamel's study on the previously isolated natural product cyclostreptin (17), also known as FR182877 (Figure 1.5), ${ }^{25-27}$ produced a puzzling outcome: ${ }^{28}$ although cyclostreptin (17) was 7- and 12-fold less potent than paclitaxel (8) against cell lines MCF-7 (breast cancer) and 1A9 (ovarian cancer) respectively, its cytotoxicity was less affected by paclitaxel-resistant cell lines (1A9PTX10, 1A9PTX22). While the effectiveness of paclitaxel was reduced by 33/34-fold against its resistant strains, that of cyclostreptin (17) was only reduced 2-fold. A follow-on study ascribed the cause of this observation to covalent binding between 17 and microtubules. ${ }^{29}$ This finding shed light on the problem of drug-resistance through small-molecule transporter channels: if the drug binds to microtubules irreversibly, the cell can no longer "pump" it out. In 2008, another group of natural products, taccalonolides, ${ }^{30-}$ 37 was confirmed to covalently bind to microtubules. ${ }^{38,39}$ Six members of this family of compounds demonstrated cytotoxicity, with taccalonolide AJ (18) leading the chart (Figure 1.5). ${ }^{40}$ However, all of taccalonolides and cyclostreptin (17) have relatively weak cytotoxicity, with their $\mathrm{IC}_{50}$ values only at $\mu \mathrm{M}$-scale. ${ }^{28,38}$ Even against the paclitaxel-resistant strains, they are less or only marginally more potent than paclitaxel (8). It wasn't until the discovery of another two marine natural products, (-)-zampanolide (19) and (+)-dactylolide (20), which are covalently binding microtubule-stabilizing agents, that new hope was found for this potential solution to drug-resistance. 


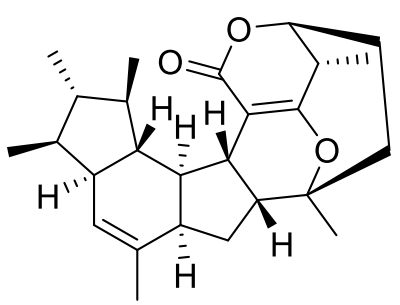

Cyclostreptin (17)

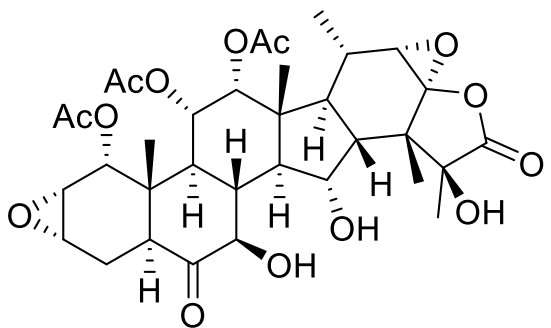

Taccalonolide AJ (18)

Figure 1.5: Structure of cyclostreptin (17) and taccalonolide AJ (18).

\section{$1.3 \quad(-)$-Zampanolide and (+)-dactylolide}

(-)-Zampanolide (19) was first isolated in 1996 from a marine sponge called Fasciospongia rimosa, which was discovered at Cape Zampa in Japan (Figure 1.6). ${ }^{41}$ Its unique structure consists of an 18-membered macrolactone with an unusual $\mathrm{N}$-acyl hemiaminal substituent at C19. The macrolide core is highly unsaturated and bears an embedded pyran with an exomethylene motif. The stereochemistry at C20 was not defined in the isolation paper and was later determined through the total synthesis by Smith, Safonov and Corbett. ${ }^{42}$

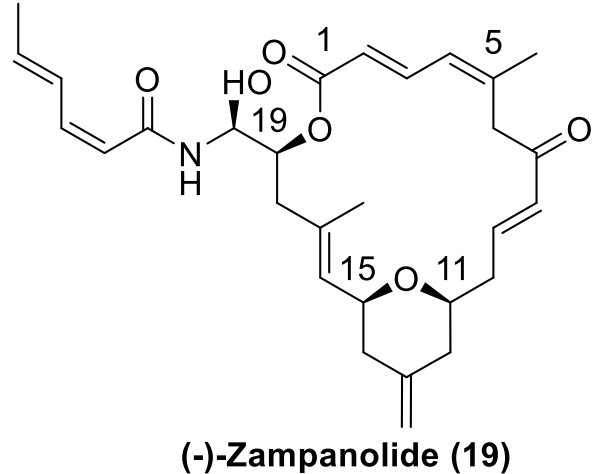

Figure 1.6: The structure of (-)-zampanolide (19).

(-)-Zampanolide (19) was found to exhibit potent anticancer activity comparable with the widely used cancer chemotherapy drug paclitaxel (8) (see Figure 1.4). ${ }^{43}$ It also displays a similar biochemical mode of action to paclitaxel (8), both being microtubule stabilizing agents. ${ }^{44}$ A detailed mechanistic study of (-)-zampanolide (19) has been reported by researchers at Victoria University of Wellington. ${ }^{43}$ The cytotoxicity was determined as a half maximal inhibitory concentration $\left(\mathrm{IC}_{50}\right)$, which is the concentration required to inhibit normal function of $50 \%$ of the cells in the assay. In this case, the inhibited cells can be evaluated by an MTT 
dye reduction assay. The $\mathrm{IC}_{50}$ values of (-)-zampanolide (19) were $4.3 \pm 1.1 \mathrm{nM}$ and $14.3 \pm 2.4$ nM against HL-60 (human promyelocytic leukemia) and 1A9 (human ovarian carcinoma) cells respectively. More remarkably, the cytotoxicity of (-)-zampanolide (19) was similar against the parental strain A2780 or the paclitaxel-resistant human ovarian cancer cell line A2780AD, with an $\mathrm{IC}_{50}$ value of $7.5 \pm 0.6 \mathrm{nM}$ against $\mathrm{A} 2780 \mathrm{AD}$, which is over 50 -fold more potent than paclitaxel (8). ${ }^{43}$ Studies have found that (-)-zampanolide (19) causes the stabilization of microtubule bundles at interphase and multiple asters during mitosis; as a result, the cell is divided unevenly into three or more non-viable daughter cells. ${ }^{43}$

In 2001, a similar natural product dactylolide (20) was isolated and identified by Cutignano (Figure 1.7).${ }^{45}$ Uenishi's thermolysis and degradation study of(-)-zampanolide (19) found that, although (+)-20 could be produced by thermolysis of (+)-19, no (-)-20 was observed subjecting (-)-19 to Riccio's isolation conditions. Therefore dactylolide (20) was thought not to be the decomposition product of (-)-zampanolide (19) from the isolation process, but a distinct natural product. $^{46}$ Surprisingly, the core macrocyclic structure of dactylolide (20) was initially proposed to have the same structure, but opposite configuration to (-)-zampanolide (19) based on optical rotation data of isolated and synthetic samples. ${ }^{45}$ However, evidence has since accumulated from the optical rotation values of synthetic dactylolide (20) to suggest that the opposite sign of optical rotation of isolated dactylolide is merely due to contamination of the natural sample by a highly absorbing species with a positive rotatory effect on plane polarised light (Figure 1.7). ${ }^{47}$ The structural similarity of zampanolide and dactylolide indicates that they are likely to be synthesized by the same biosynthetic pathways, yet they were isolated from different sponges. It would be unusual for the configuration of a metabolite to be inverted at a late stage of a biosynthesis. However, the hypothesis of contamination has not been proved yet. Like (-)-zampanolide (19), dactylolide (20) is a microtubule stabilizing agent, but has much lower potency. The cytotoxicity of $\mathbf{2 0}$ was reported together with the isolation. The inhibition percentages of dactylolide (20) at $3.2 \mu \mathrm{g} / \mathrm{mL}$ were $63 \%$ for the $\mathrm{L} 1210$ cell line (lymphatic leukaemia of mice) and $40 \%$ for SK-OV-3 (carcinoma of the ovaries). ${ }^{45}$ 
<smiles>C=C1C[C@H](C=O)O[C@@H](/C=C(\C)C[C@H](C=O)OC(=O)/C=C/C=C(/C)CC(=O)/C=C/C)C1</smiles>

Isolated: $\quad \alpha_{D}=+30(c=1.0, \mathrm{MeOH})$

(-)-Synthetic: $\alpha_{D}=-128$ to $-258(c=0.11$

to $1.2, \mathrm{MeOH}$ )

(+)-Synthetic: $\alpha_{D}=-128$ to $-258(c=0.07$

to $0.52, \mathrm{MeOH}$ )

(+)-Dactylolide (20)

Figure 1.7: The structure and optical rotation data of dactylolide (20).

More insight into the protein binding sites of (-)-zampanolide (19) was provided by a report in July 2012, which included (-)-dactylolide (20) for comparison. ${ }^{44}$ High resolution mass spectrometry (HRMS) and nuclear magnetic resonance (NMR) data indicated that both compounds bind to the luminal site on $\beta$-tubulin, adjacent to the paclitaxel-binding site, and thus disrupt the function of microtubule. More excitingly, the binding is covalent and irreversible, and the binding of (-)-zampanolide (19) is at least 8 times faster than the binding of (-)-dactylolide (20). The irreversible binding could mean low drug dosage and application frequency if (-)-zampanolide (19) were eventually commercialised. The HRMS study showed that the covalent binding is either between an Asn amide and C3, or a His and C9 of the zampanolide ring (Figure 1.8), which are the result of conjugate additions of the nucleophilic side-arms on the amino acids to the electrophilic $\alpha, \beta$-unsaturated carbonyl moieties. For (-)zampanolide (19), significant hydrogen bonding interaction was also seen between tubulin and the $\mathrm{N}$-acyl hemiaminal linkage. In addition, hydrogen bonding from tubulin to the carbonyl at C7 also occurs, and the exocyclic methylene group at C13 interacts hydrophobically with its resident protein pocket. Interestingly, modelling study indicated that the orientation of (-)dactylolide (20) in the binding site is reversed relative to $\mathbf{1 9}$, yet the covalent bonds form at the same positions. The ester and aldehyde provide the major hydrogen bonding in (-)-20, and the eastern side of (-)-dactylolide (20) occupies the pocket where the side-arm of (-)-19 resides. A hydrophobic interaction of the methylene still occurs, but with a hydrophobic pocket adjacent to the one involved in the (-)-zampanolide (19) binding. ${ }^{44}$ 


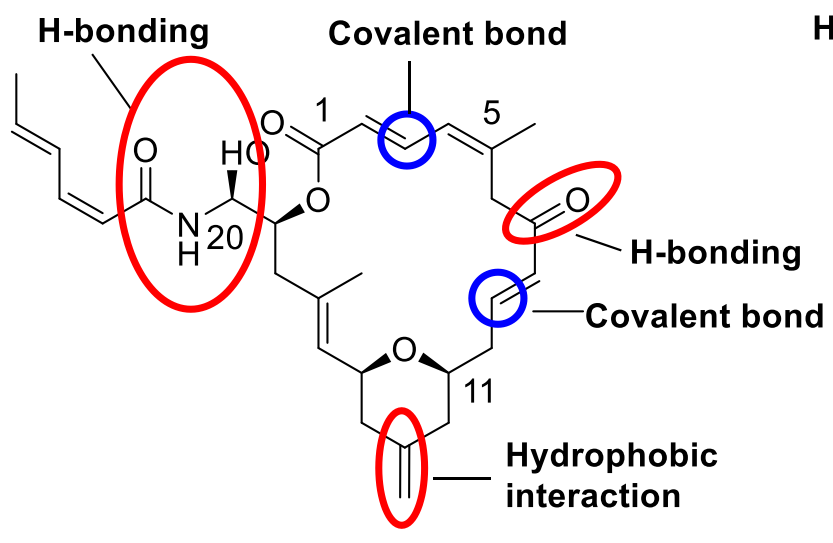

(-)-zampanolide (19)

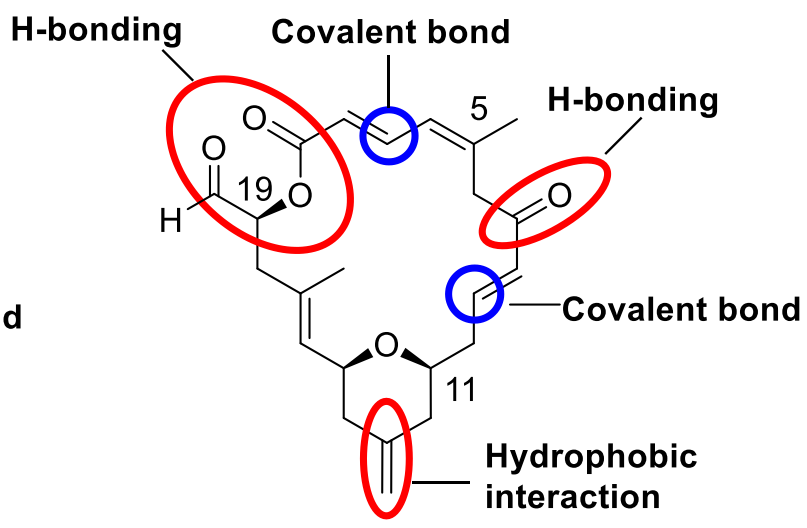

(-)-dactylolide (20)

Figure 1.8: Binding of (-)-zampanolide (19) and (-)-dactylolide (20).

In 2013, the high resolution X-ray crystallography of zampanolide (19) complexed with $\alpha \beta$ tubulin was published, ${ }^{48}$ which agreed with most of the findings from the HRMS study, and the covalent binding between His and C9 was confirmed. The most recently published study on zampanolide (19) binding resorted to computational methods, using molecular docking and dynamics stimulation to calculate the orientation and binding of zampanolide (19) in the taxane pocket. ${ }^{49}$ It concluded that the C3 binding should be major, because of the short distance between $\mathrm{C} 3$ and the His nitrogen (3.667 $⿱$ ) ) leading to the preferred nucleophilic attack. Although the major site for covalent binding interaction is still debatable, it is certain that the covalent binding between 19 and the taxane binding pocket enhances the cytotoxicity of zampanolide (19) and makes it a good anti-cancer drug candidate.

\subsection{Published total syntheses of zampanolide}

The potential for zampanolide (19) to become an effective anti-cancer drug has motivated research groups around the globe to target its total synthesis and obtain a better understanding of its mode of action. ${ }^{47}$ A number of total syntheses of zampanolide (19) have been published since 2001 (Table 1.1), as well as the total syntheses of dactylolide (20) and formal synthesis of 19, which will be described in section 1.5. A few analogues of $\mathbf{1 9}$ were also generated, which provided some structure-activity relationships. However, more insightful information on the tubulin binding of $\mathbf{1 9}$ was obtained from the mode of action studies. ${ }^{43,44,48,49}$ The structural complexity of the compound sets many challenges for its synthesis, especially the pyran ring synthesis, the macrocyclization step and formation of the $N$-hemiaminal linkage. 
Table 1.1: Timeline of published zampanolide (19) syntheses and mode of action studies.

\begin{tabular}{|c|c|c|}
\hline Year & Authors & Major finding \\
\hline 2001 & Smith, A. B.; Safonov, I. G.; Corbett, R. M. ${ }^{42,50}$ & Synthesis of $(+)-19$ \\
\hline 2003 & Hoye, T. R.; Hu, M. ${ }^{51}$ & Synthesis of (-)-19 \\
\hline 2009 & $\begin{array}{l}\text { Field, J. J.; Singh, A. J.; Kanakkanthara, A.; } \\
\text { Halafihi, T.; Northcote, P. T.; Miller, J. H. }{ }^{43}\end{array}$ & $\begin{array}{l}19 \text { identified as a microtubule- } \\
\text { stabilizing agent }\end{array}$ \\
\hline 2009 & Uenishi, J.; Iwamoto, T.; Tanaka, J. ${ }^{46}$ & Synthesis of (-)-19 \\
\hline 2012 & $\begin{array}{l}\text { Field, J. J.; Pera, B.; Calvo, E.; Canales, a.; } \\
\text { Zurwerra, D.; Trigili, C.; Rodriguez-Salarichs, } \\
\text { J.; Matesanz, R.; Kanakkanthara, A.; Wakefield, } \\
\text { J.; Singh, J.; Jimenez-Barbero, J.; Northcote, P.; } \\
\text { Miller, J. H.; Lopez, J. A.; Hamel, E.; Barasoain, } \\
\text { I.; Altmann, K-H.; Diaz, J. F. }{ }^{44}\end{array}$ & $\begin{array}{l}\text { Binding site of } \mathbf{1 9} \text { to tubulin } \\
\text { determined }\end{array}$ \\
\hline 2012 & Ghosh, A. K.; Cheng, X.; Bai, R.; Hamel, E. ${ }^{52}$ & Synthesis of (-)-19 \\
\hline 2012 & $\begin{array}{l}\text { Zurwerra, D.; Glaus, F.; Betschart, L.; Schuster, } \\
\text { J.; Gertsch, J.; Ganci, W.; Altmann, K-H. }{ }^{53}\end{array}$ & Synthesis of (-)-19 \\
\hline 2013 & $\begin{array}{l}\text { Prota, A. E.; Bargsten, K.; Zurwerra, D.; Field, } \\
\text { J. J.; Diaz, J. F.; Altmann, K. H.; Steinmetz, M. } \\
\text { O. }^{48}\end{array}$ & $\begin{array}{l}\text { X-ray crystallography structure } \\
\text { of zampanolide-tubulin complex }\end{array}$ \\
\hline 2014 & $\begin{array}{l}\text { Liao, S. Y.; Mo, G. Q.; Chen, J. C.; Zheng, K. } \\
\text { C. } 49\end{array}$ & $\begin{array}{l}\text { Computational study of } \mathbf{1 9} \\
\text { binding mode on tubulin. }\end{array}$ \\
\hline
\end{tabular}

The disconnections dictating the retrosynthetic strategies of the previous total syntheses are summarised in Figure 1.9. Although each total synthesis has its unique features, there are a few retrosynthetic disconnections that are popular strategies: in the forward direction, all of the total syntheses of zampanolide (19) have the formation of the $N$-acyl hemiaminal group as the last step; a majority adopt esterification or macrolactonization at $\mathrm{C} 1$, with either Mitsunobu or Yamaguchi condition; alkenes are generally chosen as major disconnection points, due to the 
abundance of well-established olefination methods, such as the Horner-Wadsworth-Emmons reaction (HWE), Wittig reaction, ring-closing metathesis (RCM) with Grubbs' catalyst and Julia-Kocienski olefination. On the other hand, the synthetic methods diverge with respect to the pyran motif.

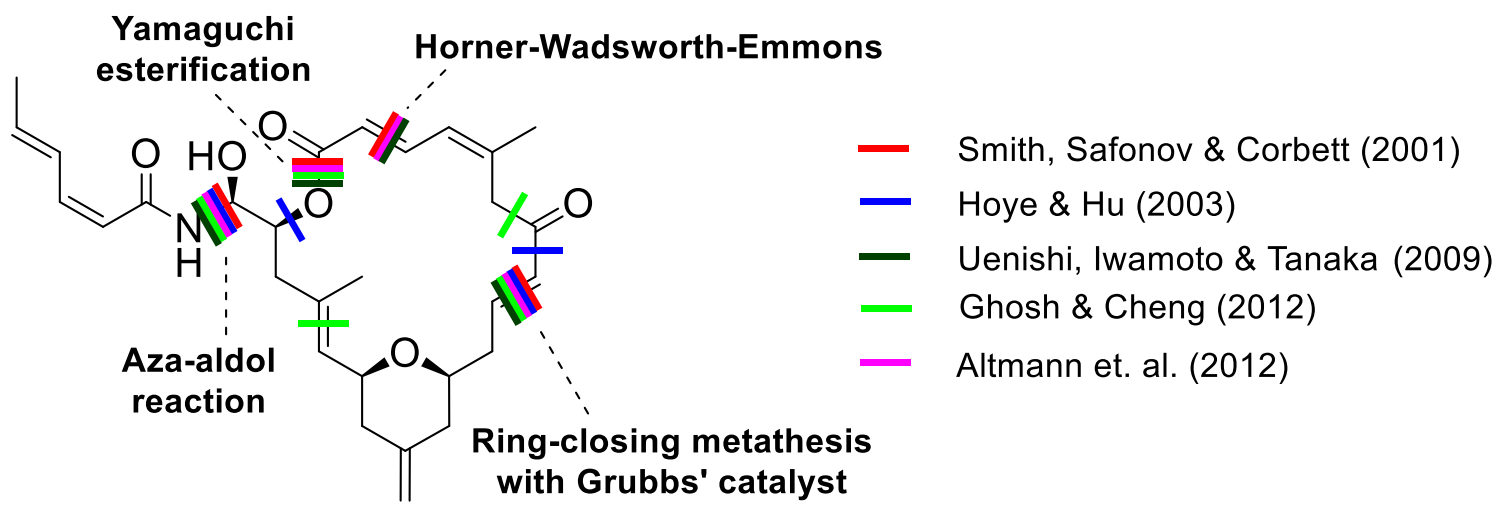

Figure 1.9: Reported major disconnections for (-)-zampanolide (19).

\subsubsection{Synthetic methods for formation of the pyran fragment}

In Smith's seminal total synthesis of the unnatural enantiomer, (+)-19, the C9-C17 pyran fragment was constructed by dioxanone formation, followed by a Petasis-Ferrier rearrangement (Scheme 1.4). ${ }^{42,50}$ This acid-promoted cyclization of trimethylsilyl (TMS) ester 21 with (E)-3-bromo-but-2-enal (22) can be carried out with triflic acid generated in situ from trimethylsilyl triflate (TMSOTf), but the addition of a catalytic amount of triflic acid (5 to 10 mol\%) was essential in scaled-up reactions to initiate the reaction. The subsequent PetasisFerrier reaction sequence involves methylenation of the dioxanone 23 by $\mathrm{Cp}_{2} \mathrm{TiMe}_{2}$ to produce 24, which then transformed to an aluminum enolate and rearranged in Ferrier-fashion. The pyran 25 was produced with the correct cis-configuration, which agrees with the prediction based on the substituent pattern. ${ }^{54}$ 


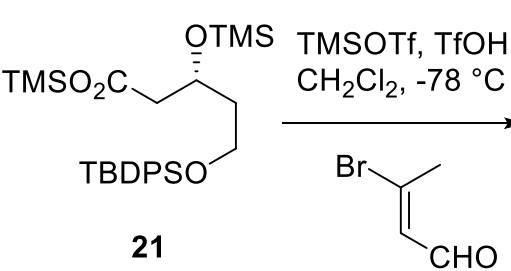

22

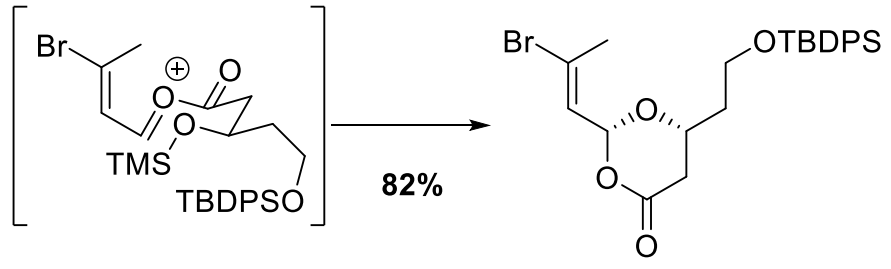

23

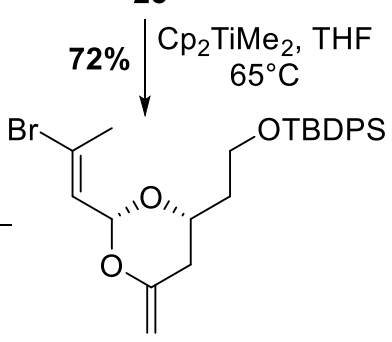

24

Scheme 1.4: Smith's Petasis-Ferrier rearrangement.

Although Smith's method produced the pyran with the correct stereochemistry in a satisfying yield, some other syntheses have chosen to use one-step methods for the pyran synthesis. Hoye and Ghosh both used an acid-catalyzed Sakurai-type reaction to produce the pyran with an exomethylene in one step (Scheme 1.5) ${ }^{51,52}$ This reaction is driven by the $\beta$-silicon effect. ${ }^{55}$ The electron deficient carbocation that forms at the $\beta$-position to the silyl is stabilized by the molecular orbitals of the trimethylsilyl group, which promotes the nucleophilic addition to the oxonium intermediate. Hoye used camphorsulfonic acid (CSA) to catalyze the union of the two fragments $\mathbf{2 6}$ and $\mathbf{2 7}$, and the product $\mathbf{2 8}$ was obtained with a good yield (78\%) and exclusively

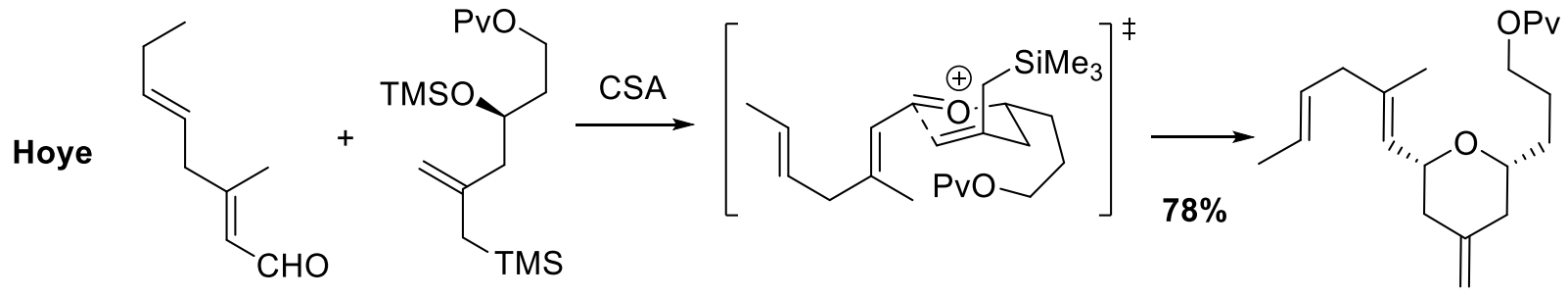
26 27 28<smiles>C=C(CC(C)C)C[C@H](CCO[SbH](=O)[O-])OC/C=C/c1ccccc1</smiles>

Scheme 1.5: Hoye and Ghosh's Sakurai-type reactions. 
in the desired configuration. ${ }^{51}$ Ghosh achieved the pyran cyclization of 29 via an oxidative and intramolecular Sakurai-type reaction. An oxocarbenium intermediate (30) was generated by 2,3-dichloro-5,6-dicyano-1,4-benzoquinone (DDQ) in the presence of a weak Lewis acid (PPTS) that enhances the oxidative ability of DDQ (Scheme 1.5). ${ }^{52}$

Uenishi also used a Sakurai-type reaction in the pyran synthesis, in conjunction with an $O$ Michael cyclization, producing the pyran fragment C9-C20 (Scheme 1.6). ${ }^{46}$ No stereoselectivity was observed for this Hosomi-Sakurai reaction, and a mixture of $R$ - and $S$-32 was obtained. Fortunately, the two isomers were separable, and the undesired $R$-isomer was converted to the $S$-isomer in $65 \%$ yield over a two-step process involving Mitsunobu reaction and methanolysis. This inversion of the configuration at $\mathrm{C} 15$ proceeded mechanistically through a $\mathrm{S}_{\mathrm{N}} 2$-type nucleophilic substitution of the activated alcohol followed by deacetylation to afford the inverted alcohol. After establishing a conjugated unsaturated methyl ester at C11, an intramolecular $O$-Michael addition was performed to complete the pyran (33) formation.

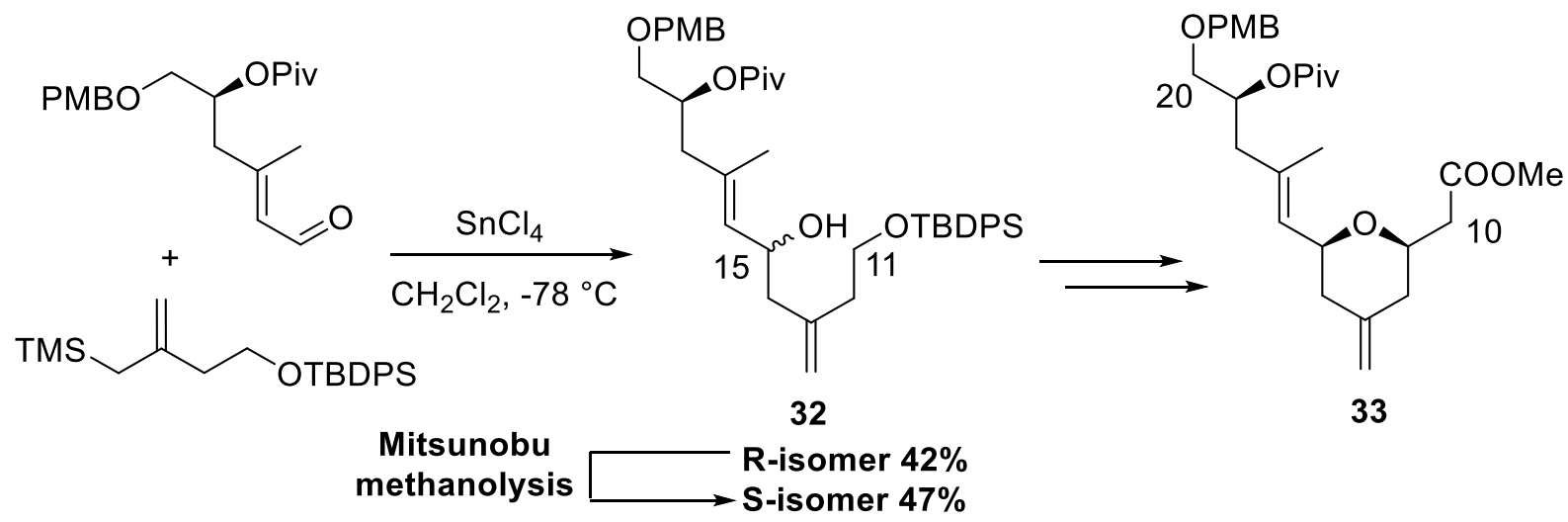

Scheme 1.6: Hosomi-Sakurai reaction and $O$-Michael addition in Uenishi's synthesis.

In Altmann's synthesis, a Prins cyclization was used to construct the pyran. The starting material 34 proceeded through a six-membered transition state $\mathbf{3 5}$ similar to Ghosh's Sakuraitype transition state to produce the pyran 36 with an appending iodide (Scheme 1.7). The iodide was transformed to a methylene via substitution by acetate, saponification, oxidation and Wittig reaction. 


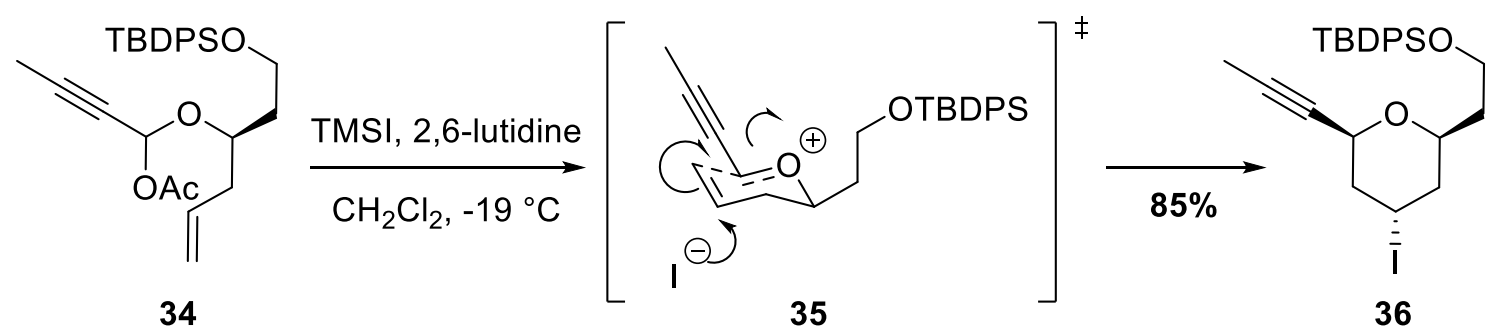

Scheme 1.7: Prins cyclization in Altmann's synthesis.

\subsubsection{Synthetic methods of macrocyclization}

Most of the total syntheses of $\mathbf{1 9}$ used well-established chemistry for macrocyclization. The most common ones are Yamaguchi esterification at $\mathrm{C} 1,{ }^{56}$ Horner-Wadsworth-Emmon reaction to form alkene $\mathrm{C} 2-\mathrm{C} 3^{50}$ and ring-closing metathesis to link $\mathrm{C} 8$ to $\mathrm{C} 9^{51,52,57}$ (Figure 1.10).

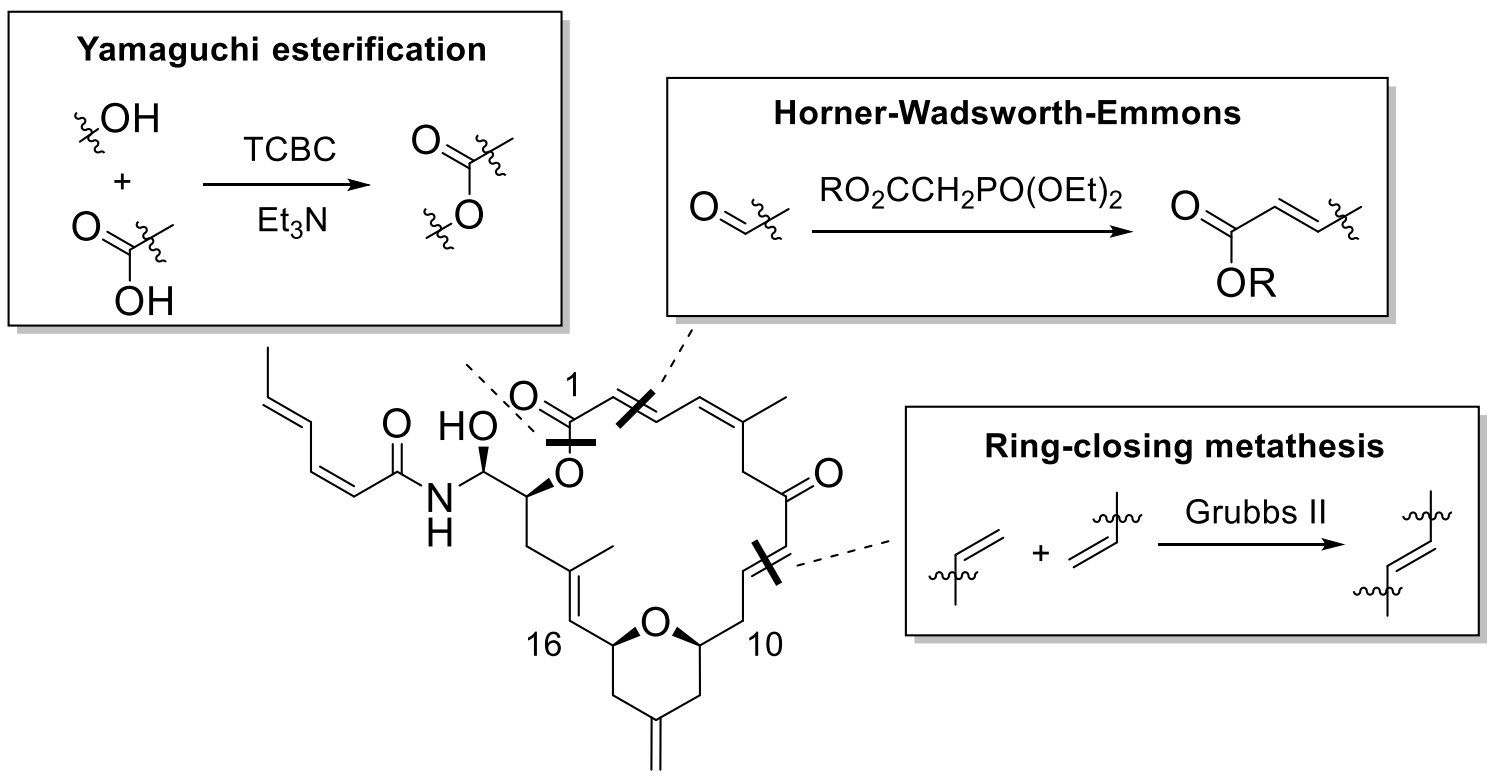

Figure 1.10: Common macrocyclization methods.

Hoye's synthesis planned to use a unique epoxide opening as their final macrolactonization step. ${ }^{51}$ However, the reaction had poor regioselectivity and lactonization at C20 became a problem. Therefore, this strategy was revised, and ring-closing metathesis was chosen as the final macrocyclization, after intermolecular epoxide opening (Scheme 1.8). The tetra(tertbutoxy)titanium-catalyzed epoxide opening of $\mathbf{3 7}$ by carboxylic acid $\mathbf{3 8}$ created the desired 
stereochemistry at $\mathrm{C} 19$, and the product was subjected to RCM to macrocycle $\mathbf{3 9}$, which proceeded through to produce (-)-dactylolide (20) and zampanolide (19) (Scheme 1.8).
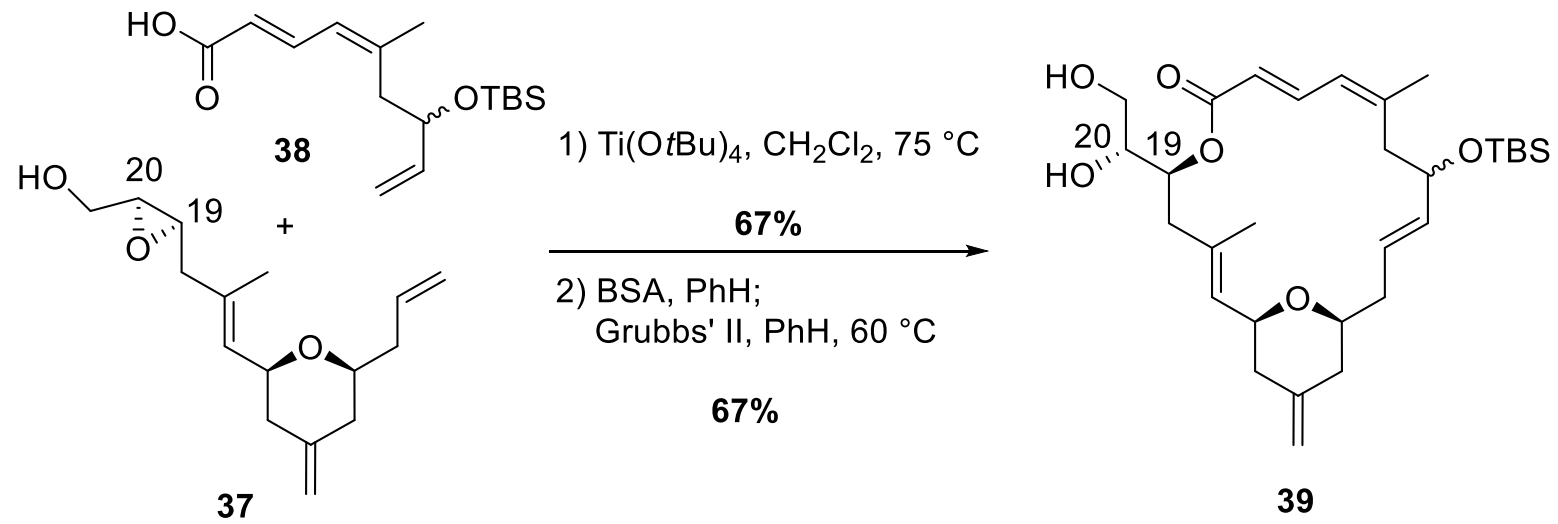

Scheme 1.8: Hoye's tetra(tert-butyoxy)titanium-catalyzed epoxide opening.

\subsubsection{Synthesis of $N$-acyl hemiaminal linkage}

The $N$-acyl hemiaminal functionality is more common within ring structures, and scarcely found in the linear form within natural products, thus little research has previously been done on the construction of groups such as that in the zampanolide side-arm. Smith's connection of the $N$-acyl hemiaminal side-arm to the core was achieved with Curtius rearrangement of $\mathbf{4 0}$ and acylation in good yield (Scheme 1.9). ${ }^{42}$ The Curtius rearrangement begins with a rearrangement of the acyl azide intermediate (41) to produce an isocyanate (42), which then

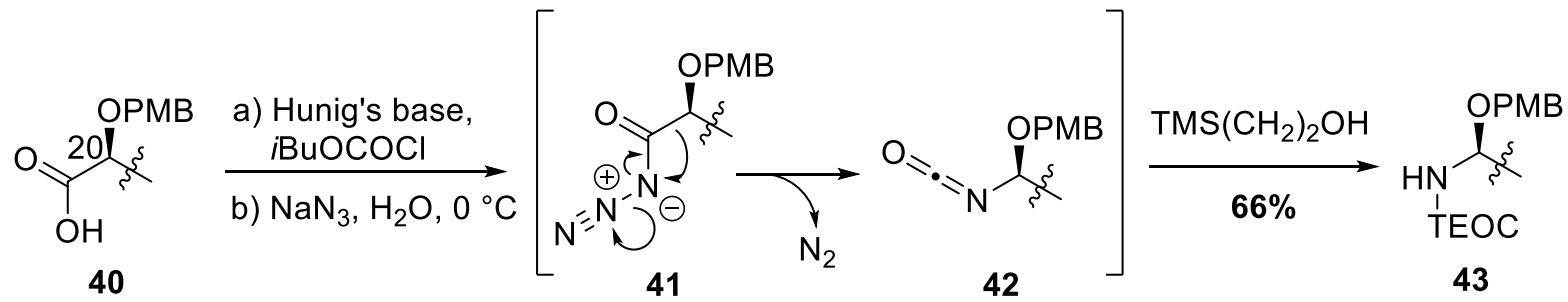

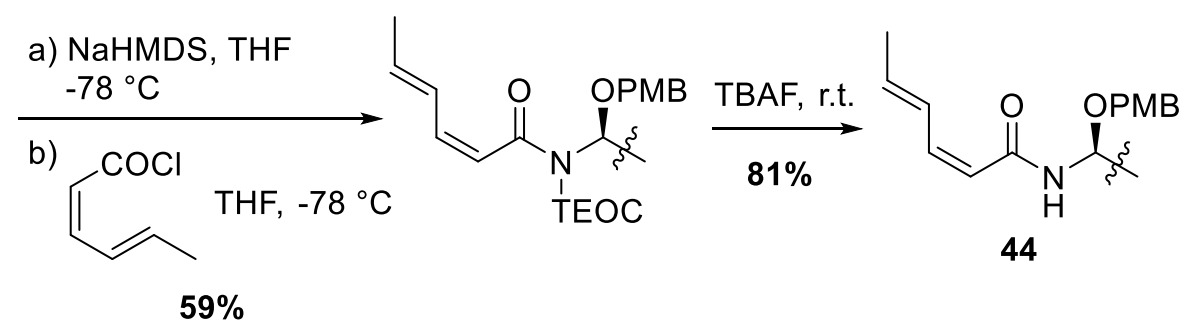

Scheme 1.9: Smith's $N$-acyl hemiaminal formation by Curtius rearrangement. 
reacts with trimethylsilylethyl alcohol to afford the trimethylsilylethyl carboxy (TEOC)protected amine (43). Upon coupling with an acyl chloride and deprotection, the desired $\mathrm{N}$ acyl hemiaminal (44) structure was formed.

Hoye and Uenishi chose to attach the side-arm with aza-aldol reactions, which were promoted by di-i-butylaluminum hydride (DIBAL-H) and camphorsulfonic acid (CSA), respectively (Scheme 1.10). ${ }^{51}$ In both cases the desired product was formed from (-)-20 and Z,E-hex-2,4dienamide (45), but no stereoselectivity was observed. Hoye's 1:1 mixture of the two C20epimers (46) was not separated, and no yield was reported. Uenishi only achieved a poor yield of $12 \%$ (Scheme 1.8). ${ }^{46}$ The low yield of zampanolide (19) was attributed primarily to incompletion of the reaction (35\% recovery of (-)-20), disubstitution by the amide $\mathbf{4 5}$ to form $47(16 \%)$ and the lack of stereoselectivity (12\% of C20-epimer (48)).
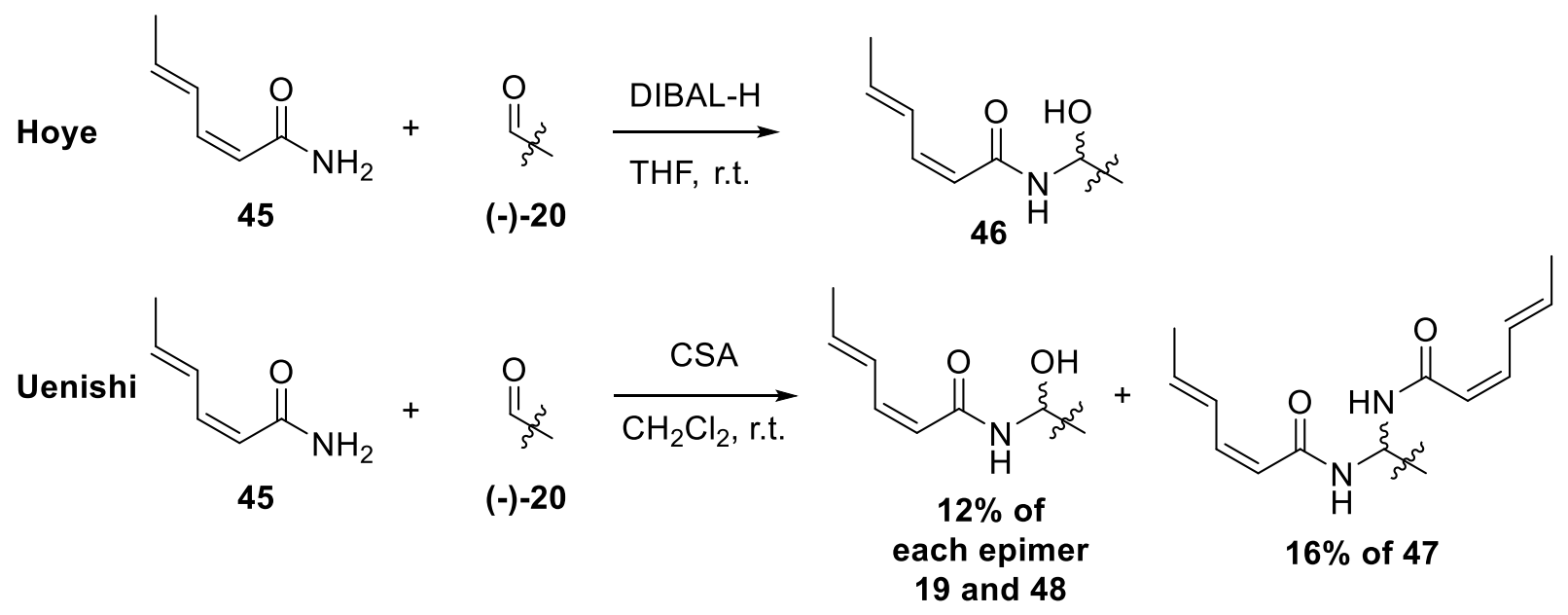

Scheme 1.10: Hoye and Uenishi's aza-aldol reactions for connection of the side-arm.

The most efficient method so far reported is the amidation employed in Ghosh's total synthesis. ${ }^{52}$ This amidation was catalyzed by a chiral Brønsted acid, $(S)$-TRIP (Scheme 1.11). This catalyst is one of the chiral cyclic phosphoric acids derived from BINOL, which have found use in asymmetric catalysis only within the last ten years. They have succeeded in catalyzing a number of processes, such as Mannich-type, Pictet-Spengler, Friedel-Crafts-type and aza-Diels-Alder reactions. ${ }^{58}$ The phosphoric acid motif in the promoter is bifunctional, containing both Lewis basic and Brønsted acidic parts. In this reaction, both aldehyde and amide substrates are thought to be activated by hydrogen bonding with the phosphoric acid. 
Dictated by the BINOL scaffold, the hydrogen bonding also brings the two substrates into close proximity. The stereoselectivity was provided by the relative positions of the two 2,4,6-tri $(i$ propyl)phenyl groups. This reaction totally eliminated the formation of the disubstituted product 47, and the desired product 19 and its $\mathrm{C} 20$ epimer (48) were produced in a 3:1 ratio.<smiles>C/C=C\C=C/C(N)=O</smiles>

45

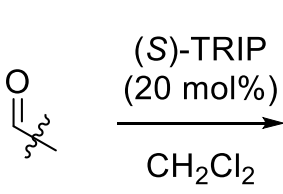

$(-)-21$<smiles>C/C=C\C=C/C(=O)NC(C)(C)O</smiles>

19: $51 \%$ 48: $18 \%$

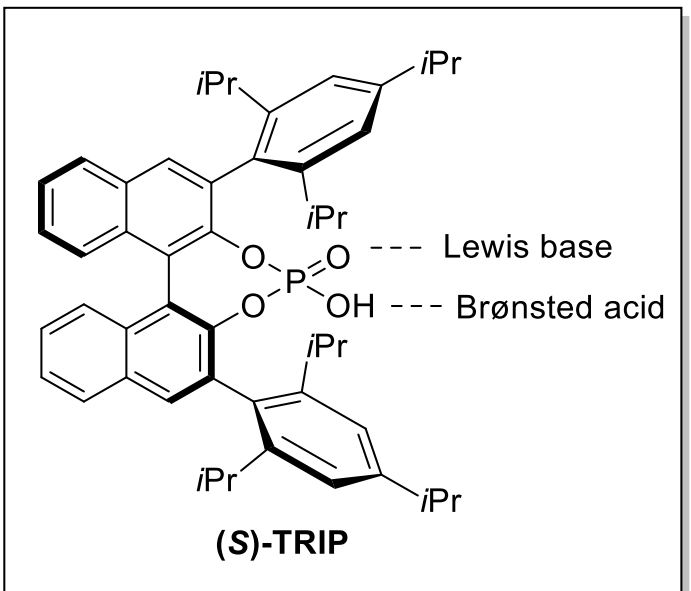

Scheme 1.11: Ghosh's $N$-acyl hemiaminal connection.

\subsection{Published total syntheses of dactylolide}

Due to the high structural similarity of dactylolide (20) and zampanolide (19), examination of the total syntheses of dactylolide (20) can provide good guidance to the macrolide core synthesis. In fact, all (-)-zampanolide (19) syntheses go via (-)-dactylolide (20) as an intermediate. A number of total syntheses of both (+)-20 and (-)-20 have been published (Table 1.2), including Smith et. al. and Altmann et. al. who also used their strategy to complete the total synthesis of (-)-zampanolide (19)..$^{53,56,59-62}$ 
Table 1.2: Timeline of published dactylolide (20) syntheses.

\begin{tabular}{|c|c|}
\hline Year & Authors \\
\hline 2002 & Smith, A. B.; Safonov, I. G. ${ }^{59}$ \\
\hline 2005 & Aubele, D. L.; Wan, S. Y.; Floreancig, P. E. ${ }^{56}$ \\
\hline 2005 & Sanchez, C. C.; Keck, G. E. ${ }^{60}$ \\
\hline 2006 & Louis, I.; Hungerford, N. L.; Humphries, E. J.; McLeod, M. D. ${ }^{61}$ \\
\hline 2008 & Ding, F.; Jennings, M. P. ${ }^{63}$ \\
\hline 2010 & Yun, S. Y.; Hansen, E. C.; Volchkov, I.; Cho, E. J.; Lo, W. Y.; Lee, D. ${ }^{64}$ \\
\hline 2010 & Zurwerra, D.; Gertsch, J.; Altmann, K. H. ${ }^{62}$ \\
\hline 2012 & Lee, K.; Kim, H.; Hong, J. Y. ${ }^{65}$ \\
\hline
\end{tabular}

\subsubsection{Synthetic methods for formation of the pyran fragment}

The strategies for the major disconnections in total syntheses of dactylolide (20) are similar to those of zampanolide (19), with Horner-Wadsworth-Emmon reaction followed by esterification to construct the dienoate and ring closing metathesis between C8 and C9 commonly used. As in the zampanolide (19) syntheses, the methodology for formation of the pyran in dactylolide (20) is diversified, and some very good methods with high yields and stereoselectivities were found. Floreancig's pyran synthesis from 49 used excess trimethylsilylmethylmagnesium chloride and cerium(III) chloride to form the substrate for Peterson olefination and Prins cyclization in situ, which smoothly produced $\mathbf{5 0}$ in a multi-step, one-pot reaction (Scheme 1.12). ${ }^{56}$ 


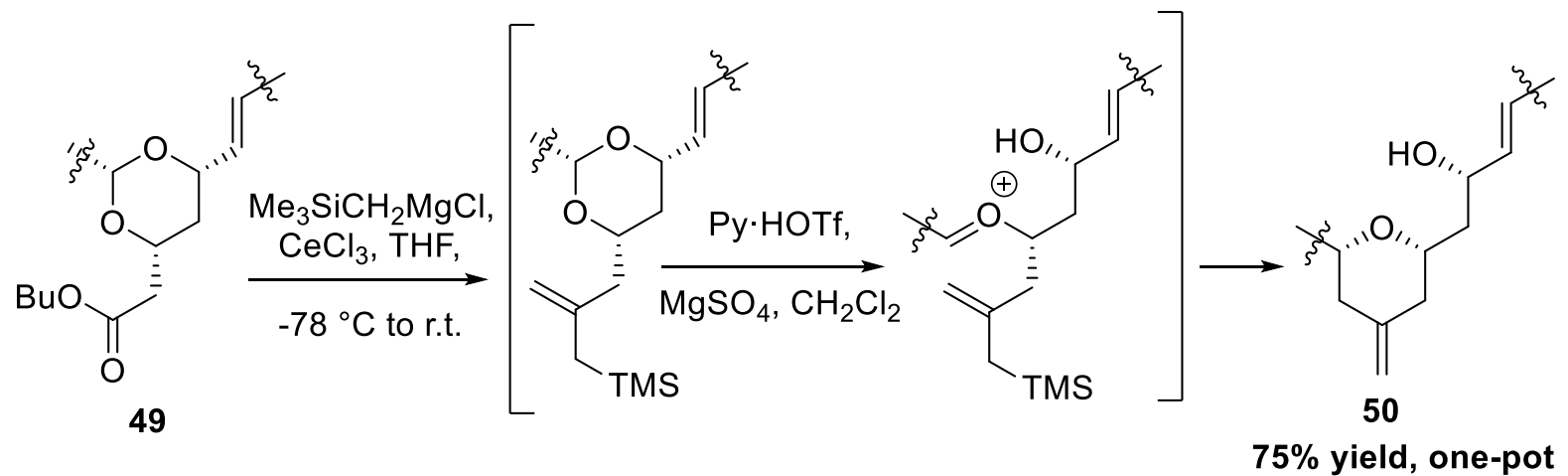

Scheme 1.12: Floreancig's pyran synthesis.

McLeod used a hetero-Diels-Alder reaction catalyzed by a chiral Lewis acid to construct the pyran motif. Upon desilylation, the pyranone $\mathbf{5 1}$ was produced with excellent yield and ee (Scheme 1.13). ${ }^{61}$ The Lewis acid catalyst was Jacobsen's chiral tridentate chromium(III) Schiff's base complex, containing an adamantyl (Ad) group for steric shielding, and was made conveniently in three steps. It provided excellent regio- and stereoselectivity in the formation of $\mathbf{5 1} .^{66}$
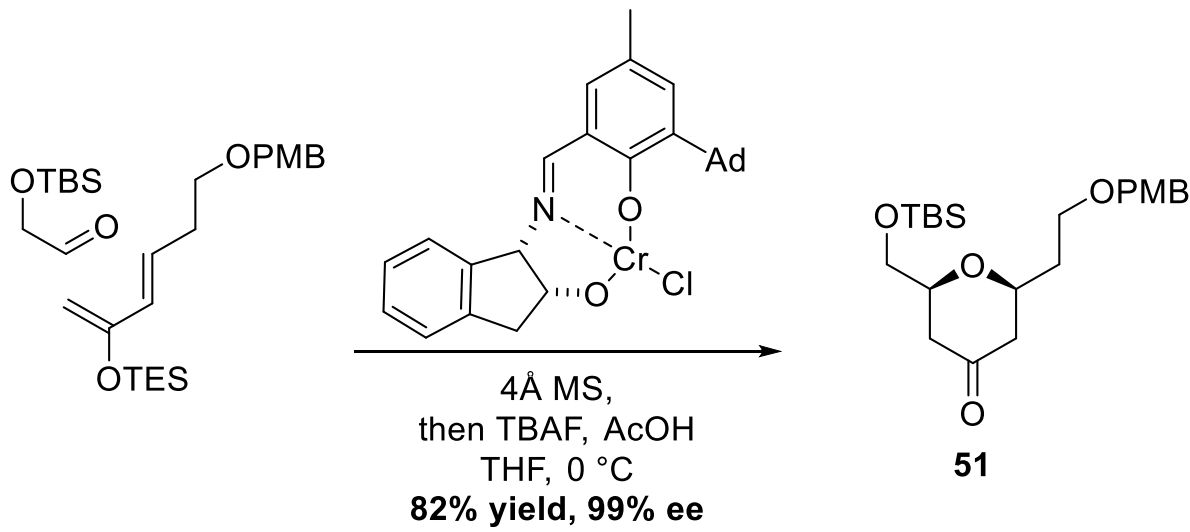

Scheme 1.13: McLeod's hetero-Diels-Alder reaction in pyran synthesis.

Hong employed an $O$-Michael addition with a chiral proline-derived catalyst (Scheme 1.14) ${ }^{64}$ This type of reactions usually proceed through an iminium intermediate resulted from the aldehyde. Although the chiral directing groups on the catalyst are further away from the reacting carbon in this 1,6-conjugate addition, excellent yield and diastereoselectivity were still obtained. Deprotection of the dithiane to a ketone sets up for the subsequent Wittig reaction to produce the exo-cyclic methylene. 

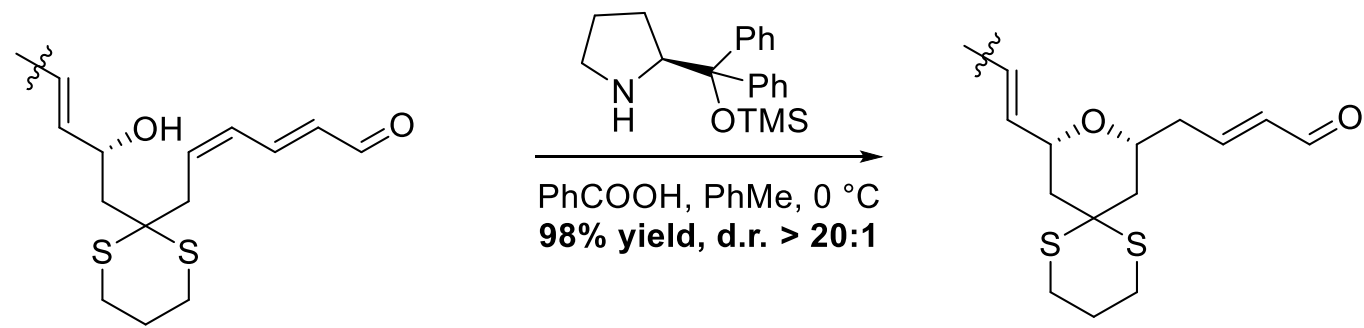

Scheme 1.14: Hong's $O$-conjugate addition in pyran synthesis.

Jennings' method proceeds via an $\alpha, \beta$-unsaturated lactone (52) (Scheme 1.15). ${ }^{63}$ A diastereoselective epoxidation controlled by the configuration of the substrate $\mathbf{5 2}$ followed by epoxide ring-opening afforded the $\beta$-hydroxy lactone (53) as a single diastereoisomer. Allyl addition to the carbonyl and deoxygenation then established the terminal alkene (54) for macrocyclic RCM.

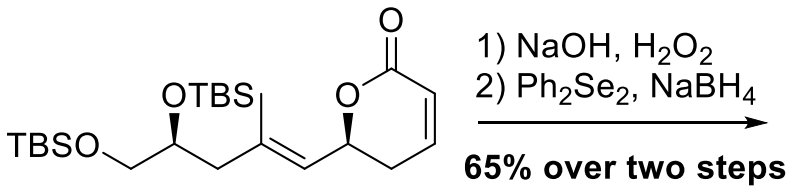

52

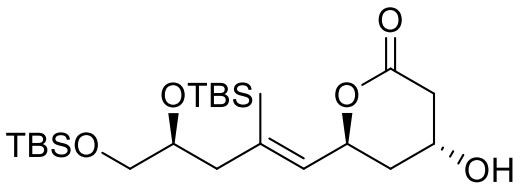

53

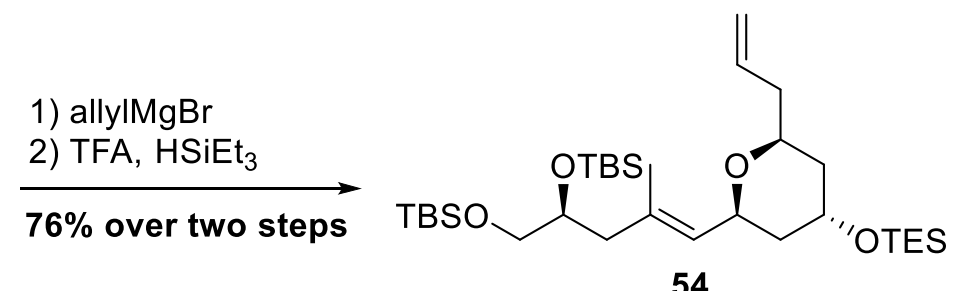

Scheme 1.15: Jenning's lactone method.

\subsubsection{Other methods for the formation of dactylolide macrocycle}

While the conjugated diene moiety is commonly made by Horner-Wadsworth-Emmons or Wittig reactions, in Yun's synthesis a Suzuki cross-coupling reaction was used (Scheme 1.16). ${ }^{64}$ Formation of a cyclic boronic acid 55 from boronate 56 was achieved by $[1,3]$ transposition of the allylic oxygen. ${ }^{67}$ The cyclic boronic acid $\mathbf{5 5}$ then underwent a Pd-mediated Suzuki reaction to provide the precursor for macrocyclization by RCM, viz. 57. Despite the 
complexity of functional groups in the structure, the two steps proceeded with a satisfactory combined yield of $51 \%$.<smiles>C=CC1CC(=C)CC(CC(/C=C/C/C(C)=C\B2OC(C)(C)C(C)(C)O2)O[Na])O1</smiles>

56

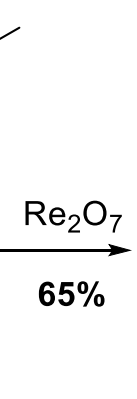<smiles>C=CC1CC(=C)CC(C/C=C/C2CC(C)=CB(O)O2)O1</smiles>

55
$\left[\mathrm{Pd}\left(\mathrm{PPh}_{3}\right)_{4}\right], \mathrm{TIOEt}$ $\mathrm{THF} / \mathrm{H}_{2} \mathrm{O}$<smiles>C=C(C)CC(COC(C)(C)C)OC(=O)/C=C/I</smiles><smiles>C=CC1CC(=C)CC(C/C=C/[C@H](O)C/C(C)=C\C=C\C(=O)OC(COC(C)(C)C)CC(=O)O)O1</smiles>

57

Scheme 1.16: Yun's Suzuki reaction.

Hong's $N$-heterocyclic carbene (NHC)-catalyzed oxidative macrolactonization is also quite unique (Scheme 1.17). ${ }^{65}$ In this interesting redox process, the aldehyde in $\mathbf{5 8}$ is activated by nucleophilic addition of the NHC formed by deprotonation of triazonium, and then oxidized to acyl azolium ion (59) by 3,3',5,5'-tetra-tert-butyl-diphenoquinone (inset box). It was observed that, without $N, N$-dimethylaminopyridine (DMAP), a very low yield was obtained for this reaction, thus activation of the carbonyl by DMAP may be required for the addition of NHC.

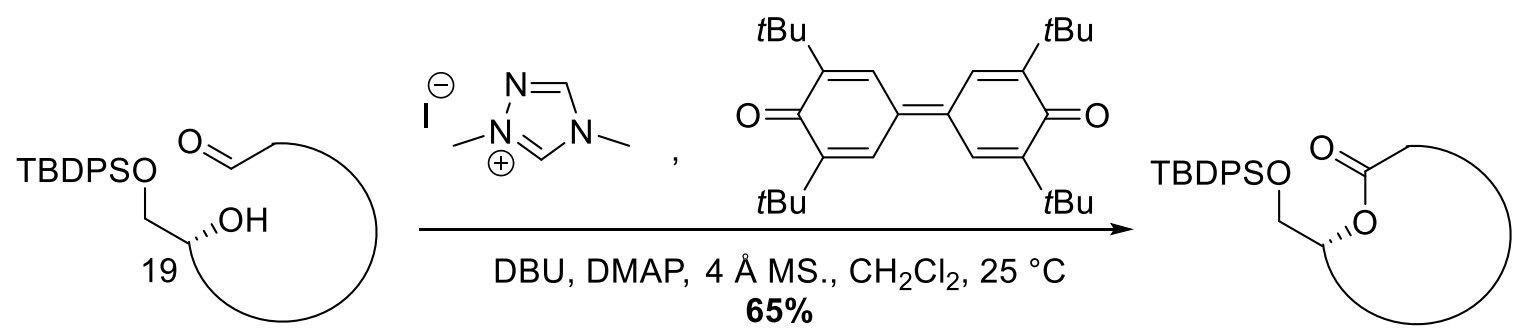

58

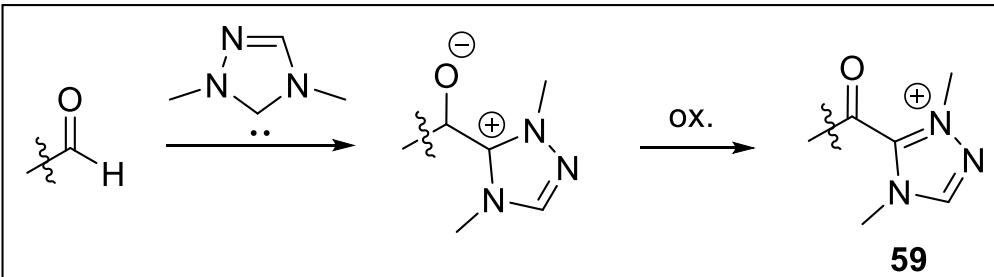

Scheme 1.17: Hong's macrolactonization. 
Hong's synthesis included the protection of C7 ketone with TBS-cyanide (Scheme 1.18). ${ }^{65}$ The TBS-protected cyanohydrin 60, upon deprotonation at the geminally substituted carbon, serves as an acyl anion equivalent to achieve $\alpha$-alkylation with the C1-C6 fragment. An excellent yield of $86 \%$ was obtained over two steps to produce $\mathbf{6 1}$. Conveniently, the protected cyanohydrin was inert to several subsequent transformations, and was later deprotected to afford the ketone after macrocyclization in a good yield $(75 \%)$.

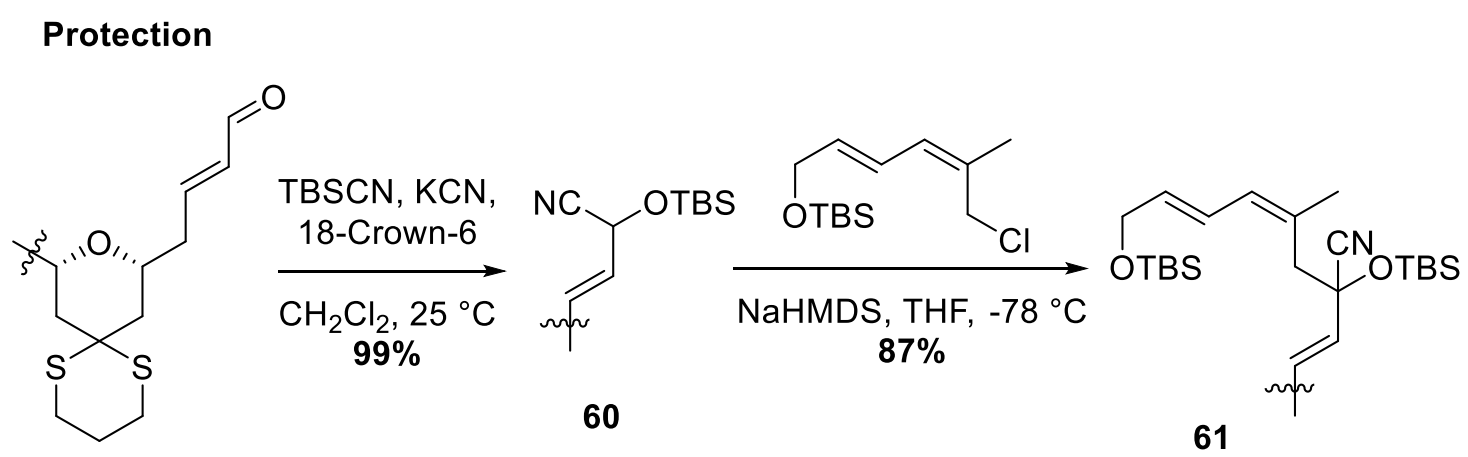

\section{Deprotection}
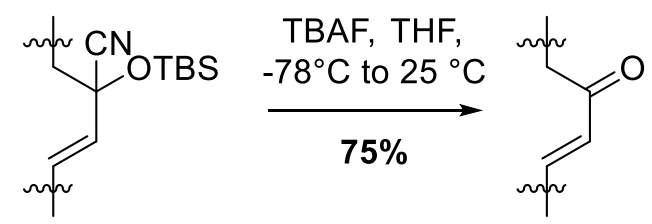

Scheme 1.18: Lee's TBSCN protection and deprotection.

\subsection{Analogue studies}

Although the total syntheses of zampanolide (19) and dactylolide (20) have been hotly contested, not many analogues have been reported. All of the analogues were reported before the publication of Field's paper that describes the covalent binding of (-)-zampanolide (19) and (-)-20 to $\beta$-tublin, ${ }^{44}$ and the main purpose for analogue formation was to perform structureactivity relationship (SAR) studies by determining the regions in the molecule that are important for its cytotoxicity. The structural similarity of $\mathbf{1 9}$ and $\mathbf{2 0}$ means that they can be considered as analogues of each other, and the fact that (-)-19 is about one thousand-fold more potent than 20 suggests that both the $N$-acyl hemiaminal side-arm and the configuration of the macrolide are crucial to its activity. 
The first unnatural analogue was published by Ding and Jennings, and they concentrated on altering the absolute configuration of the macrolide. Their synthesized (-)-20 displayed slightly more potent cytotoxicity than (+)-20, ${ }^{63}$ but it is still not comparable with (-)-zampanolide (19) (Table 1.3). This result confirmed the importance of the side-arm for the cytotoxicity of zampanolide (19).

Table 1.3: $\mathrm{IC}_{50}$ and GI values of (-)-zampanolide (19), (-)- and (+)-dactylolide (20). ${ }^{41,43,45,63}$

\begin{tabular}{|l|ccc|}
\hline Cell line & (-)-zampanolide (19) & (-)-dactylolide (20) & (+)-dactylolide (20) $^{\mathbf{c}}$ \\
A549 (lung) & $3.2 \mathrm{nM}^{\mathrm{a}}$ & $301 \mathrm{nM}^{\mathrm{a}}$ & \\
HCT116 (colon) & $7.2 \mathrm{nM}^{\mathrm{a}}$ & $0.133 \mu \mathrm{g} / \mathrm{mL}\left(\mathrm{GI}_{50}\right)^{\mathrm{b}}$ & \\
MCF-7 (breast) & $6.5 \mathrm{nM}^{\mathrm{a}}$ & $0.076 \mu \mathrm{g} / \mathrm{mL}\left(\mathrm{GI}_{50}\right)^{\mathrm{b}}$ & \\
SK-OV-3 (ovary) & & $1.8 \mu \mathrm{g} / \mathrm{mL}\left(\mathrm{GI}_{50}\right)^{\mathrm{b}}$ & $3.2 \mu \mathrm{g} / \mathrm{mL}\left(\mathrm{GI}_{50}\right)^{\mathrm{c}}$ \\
L1210 (leukemia) & & & $3.2 \mu \mathrm{g} / \mathrm{mL}\left(\mathrm{GI}_{40}\right)^{\mathrm{c}}$ \\
\end{tabular}

${ }^{\mathrm{a}}$ Methylene blue staining, $\mathrm{IC}_{50}$ value; ${ }^{\mathrm{b}} \mathrm{MTT}$ assay, $\mathrm{GI}_{50}$ value; ${ }^{\mathrm{c}} \mathrm{XTT}$ assay, and GI value with inhibition percentage indicated.

The next two analogues were side products obtained from the CSA-catalyzed aza-aldol reaction in Uenishi's total synthesis of (-)-zampanolide (19). ${ }^{46}$ One of them is the C20 epimer of (-)zampanolide (48), which is 10-fold less active than (-)-zampanolide (19) (Table 1.4). The other one is the disubstitution product (47), which is 500-fold less active. These two analogues provided some information about the importance of the side-arm. It was suggested that the stereochemistry at C20 has some significance in the cytotoxicity, and a bulkier group at C20 was not favorable. 
Table 1.4: $\mathrm{IC}_{50}$ values $^{\mathrm{a}}(\mathrm{nM})$ of Uenishi's analogues.

\begin{tabular}{|c|c|c|c|}
\hline Cell line & (-)-zampanolide & C20 epimer & Disubstitution product \\
\hline SKM-1 (leukemia) & 1.1 & 10 & 490 \\
\hline U937 (lymphoma) & 2.9 & 27 & 950 \\
\hline
\end{tabular}

\footnotetext{
${ }^{\mathrm{a}}$ MTT assay.
}

Another study of analogues used (-)-dactylolide (20) as a model, in order to study the requirement of both the carbonyl at C20 and the methylene substituent on the tetrahydrofuran ring. ${ }^{62}$ Four analogues were produced and studied by Altmann et al. (Table 1.5). By comparing the $\mathrm{IC}_{50}$ values of compounds $\mathbf{2 0}$ and $\mathbf{6 3}$, it can be seen that removal of the methylene at $\mathrm{C} 13$ from 20 has little effect on the inhibition concentration, if anything, enhancing it by 0.5 to 1.5 fold. The effect of a hydroxyl group at C20 is not clear. While $\mathbf{6 2}$ displayed a lower inhibitory concentration against cell lines A549 and MCF-7, the cytotoxicity against HCLT116 was slightly increased. In comparison, analogue 64, having both no exo-cyclic methylene and a hydroxyl group improved on the cytotoxicity of $\mathbf{2 0}$. 
Table 1.5: $\mathrm{IC}_{50}$ values $^{\mathrm{a}}(\mathrm{nM})$ of compounds 20 to 64.

\begin{tabular}{|c|c|c|c|c|}
\hline Cell line & $\begin{array}{c}\mathbf{2 0} \\
\mathrm{R}=\mathrm{CHO}\end{array}$ & $\begin{array}{c}62 \\
\mathrm{R}=\mathrm{CH}_{2} \mathrm{OH}\end{array}$ & $\begin{array}{c}63 \\
\mathrm{R}=\mathrm{CHO}\end{array}$ & $\begin{array}{c}64 \\
\mathrm{R}=\mathrm{CH}_{2} \mathrm{OH}\end{array}$ \\
\hline A549 (lung) & 301.5 & 149.0 & 127.5 & 189.0 \\
\hline MCF-7 (breast) & 247.6 & 68.0 & 106.0 & 114.4 \\
\hline HCLT116 (colon) & 210.4 & 249.5 & 155.8 & 74.1 \\
\hline
\end{tabular}

${ }^{a}$ MTT assay.

\subsection{Efficiency of total synthesis: linchpin synthesis}

In recent years, chemists have placed increasing importance on chemical efficiency and the "greenness" of a chemical process. Many renowned chemists have published accounts on different aspects of this matter, ${ }^{68-73}$ which Anastas and Eghbali summarized as the 12 principles of green chemistry. Poliakoff et. al. further concentrated the 12 principles as the acronym "PRODUCTIVELY" (Figure 1.11). ${ }^{74-76}$ Synthetic chemists have also envisaged better chemical efficiency in total synthesis. Trost developed the concept of atom economy in $1995,{ }^{69}$ and Nicolaou published an account, "Tandem reactions, cascade sequences and biomimetic strategies in total synthesis" in 2003, which illustrated the use of these methods to reduce the number of synthetic steps, increase yields and minimize the amount of waste. ${ }^{70}$ In 2008 , Wender introduced the function-oriented synthesis, where simplified analogues of complex natural products were designed to retain the functionalities important for bioactivity, while 
reducing the synthetic effort and increasing efficiency. ${ }^{77}$ Following these concepts, many syntheses of natural products with excellent efficiency have been developed. ${ }^{78}$

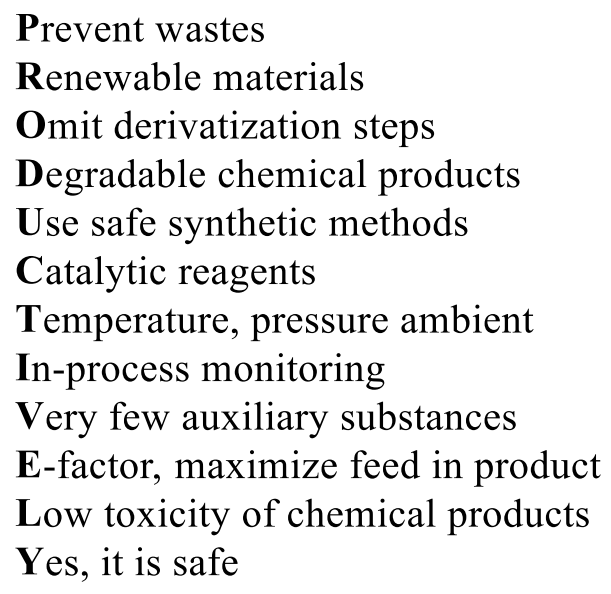

Figure 1.11: 12 principles of green chemistry.

One of the most frequently considered aspects of multistep syntheses is the convergence of the sequence. While in a linear synthesis, small building blocks are assembled in sequential order, a convergent synthesis builds larger fragments from the building blocks, and joins the fragments at a later stage. Linear synthesis has its own advantages, especially for highly repetitive molecules with well-established and reliable chemistry, in which case the synthesis can be automated. Examples are the routinely used peptide ${ }^{79-84}$ and oligonucleotide ${ }^{85-87}$ synthesizers, and the recent development of a small molecules synthesizer by Burke. Burke's initial study claimed that, with an iterative Suzuki-Miyaura reaction and 12 alkene-based building blocks, most of the polyene natural products can be made by an automated or semiautomated synthesis. ${ }^{88}$ The potential of expanding this process to more areas of natural product synthesis was then explored. This library of building blocks, now known as $\mathrm{N}$ methyliminodiacetic acid (MIDA) boronates, has been extended to include aryl, alkyl, alkynyl, and cyclic functionalities and a list of over 160 MIDA boronates are commercially available. With these building blocks, Burke's group produced precursors that can be converted to structures such as polycyclic natural products in a few steps (Scheme 1.19). ${ }^{89}$ 


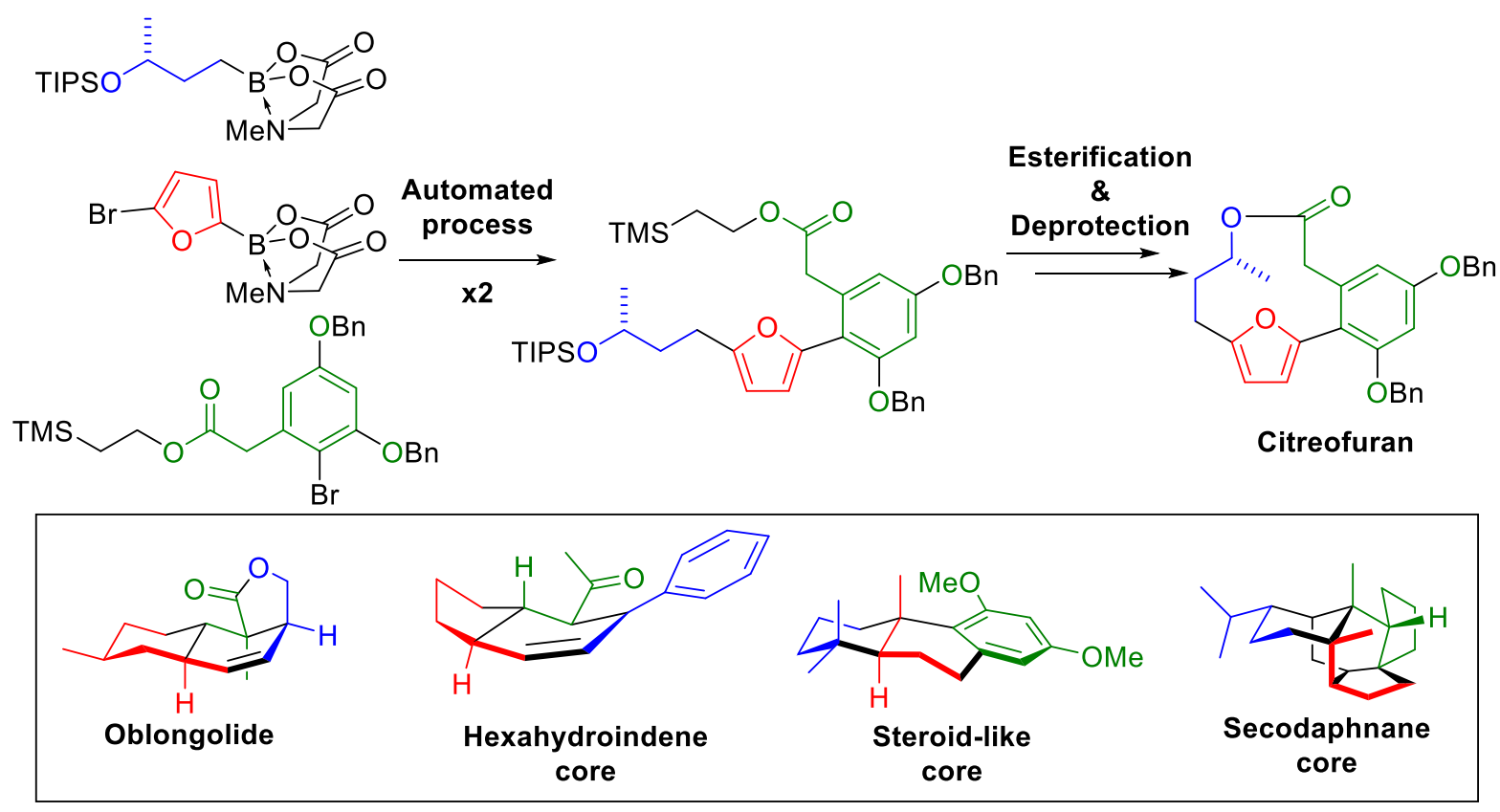

Scheme 1.19: Burke's semi-automated syntheses of natural products. ${ }^{89}$

For complex and diversified structures, convergent synthesis has more advantages: shortened longest linear sequence; comparably better yield; easier diversification. This strategy has been widely applied to the synthesis of dendrons and dendrimers, ${ }^{90,91}$ polycyclic ethers ${ }^{92}$ and alkaloid natural products ${ }^{93-99}$. One useful synthetic tool in convergent synthesis of natural product is the use of "linchpin". ${ }^{100-104}$ The term "linchpin" was first used for total synthesis in 1983, to describe the use of the dithiane (66) to link two 5-carbon units in the form of the allylic chloride 65, producing the 11-carbon precursor 67 of the spiroketal natural product 68 (Scheme 1.20). ${ }^{105}$

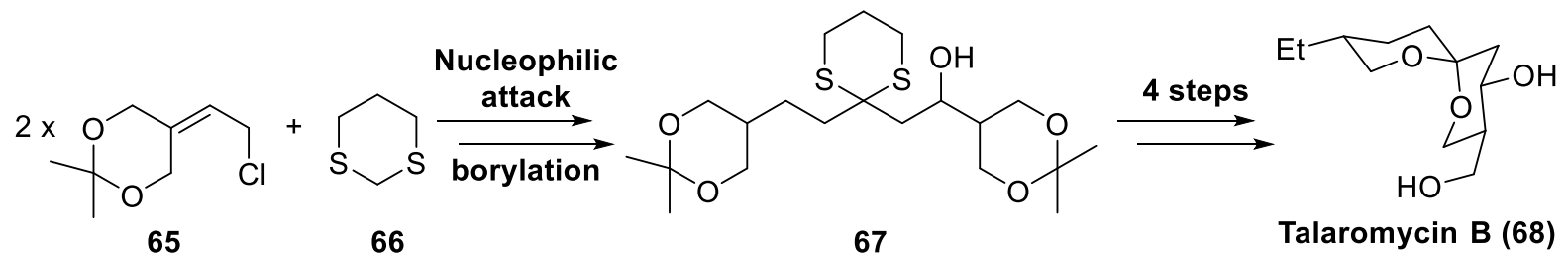

Scheme 1.20: Use of a dithiane linchpin in the total synthesis of talaromycin B (68).

This linchpin approach is a crafty strategy for total syntheses: linking two fragments with a small fragment is a good way to build up molecular weight fast. Chemists have developed various small fragments to serve as linchpins. Dithiane has been proven to be a valuable one- 
carbon linchpin. Not only does the acidic methylene facilitate nucleophilic addition, dithiane is often used as a protecting group for carbonyls, thereby providing easy access to carbonyls in the product; alternatively, it can be simply removed reductively by desulfurization. In Smith's synthesis of alkaloid (-)-205B (69), the dithiane linchpin was used to form the linear precursor of the di-cyclic product 70 (Scheme 1.21). At a late stage, the dithiane provided access to the tri-substituted alkene upon deprotection to a ketone, Wittig reaction and bond migration. ${ }^{106}$ Dithiane linchpin has also been used in the synthesis of small and macrocyclic lactones, for example (+)-cryptocarya diacetate (71) and 11- $\alpha$-methoxycurvularin (72). After assisting the construction of larger fragments, the dithiane was converted to an acetate in $\mathbf{7 1}$ and simply removed in $\mathbf{7 2 .}{ }^{107,108}$

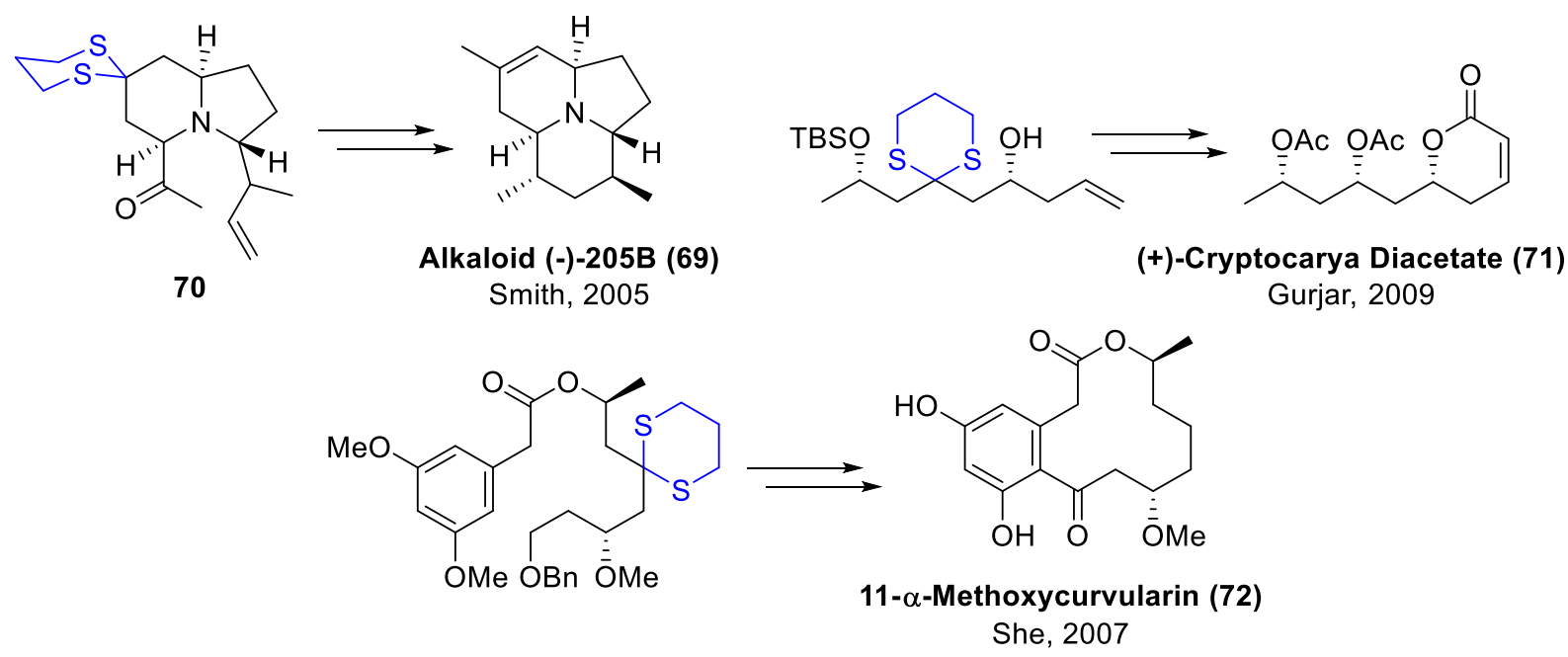

Scheme 1.21: Dithiane in natural product syntheses. ${ }^{106-108}$

Unlike dithiane, the majority of the linchpins are bifunctional small fragments. The design of linchpins is often tied with advancement of methodology. With the development of the $\mathrm{Zn}$ /Prophenol-catalyzed alkynylation of aldehyde by Trost, methyl propiolate (73) has become a useful linchpin (Scheme 1.22). ${ }^{109}$ Alkynylation is a powerful way to form C-C bonds, and the resulting propargylic alcohol is also highly versatile synthetically. The ester end can either be saponified to a carboxylic acid or reduced to an alcohol or aldehyde, all of which are wellestablished synthetic handles for further elaboration. Using this methodology, Trost's group has successfully synthesized several natural products including soraphen $A,{ }^{103}$ aspergillide $\mathrm{B}^{101}$ and asteriscunolide D. ${ }^{110}$ 


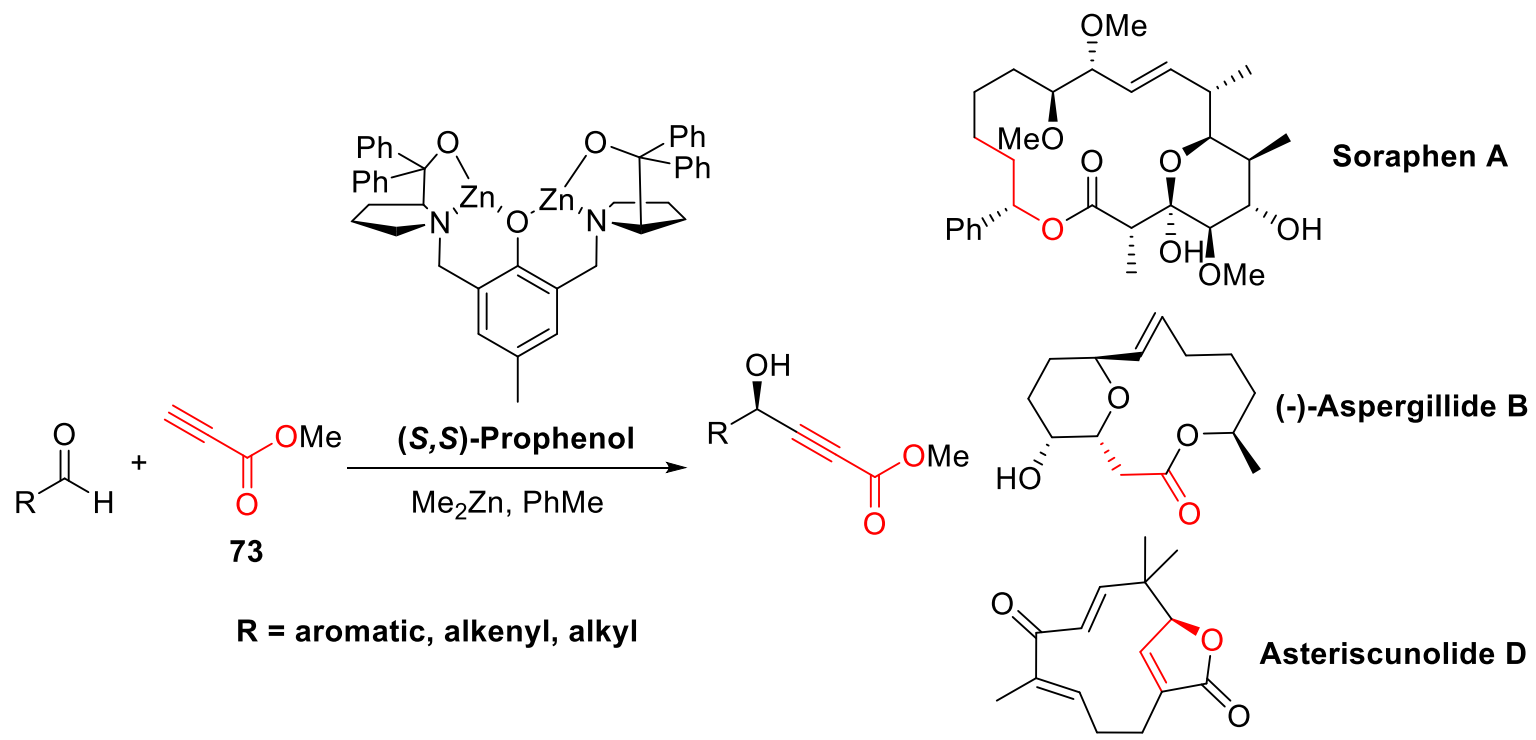

Scheme 1.22: Trost' asymmetric alkynylation and examples in natural product synthesis.

Another linchpin that relies on alkyne chemistry is a phosphonium salt connected to a silylated alkyne (74), where the phosphonium is set up for a Wittig reaction, and the silylated alkyne is readily deprotected for further connection through alkynylation (Figure 1.12). The potential of this linchpin hasn't been explored fully, however, it has been used to produce $E$,E-dienes upon reduction of alkyne, which further went through a Diels-Alder cyclization to produce the octahydronaphthalene structure in Marshall's kijanolide subunit (75) synthesis. ${ }^{111}$ Later, Rizzacasa's group used this linchpin $\mathbf{7 4}$ to produce the E,Z,E,E-tetraene motif in resolvin D2 (76). ${ }^{112}$

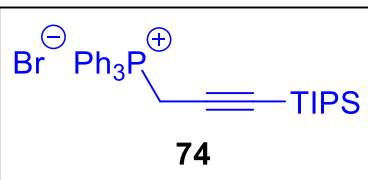

74

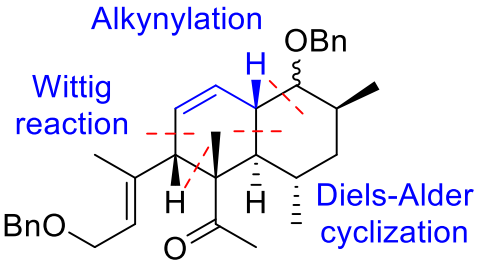

Kijanolide subunit (75) Marshall, 1990

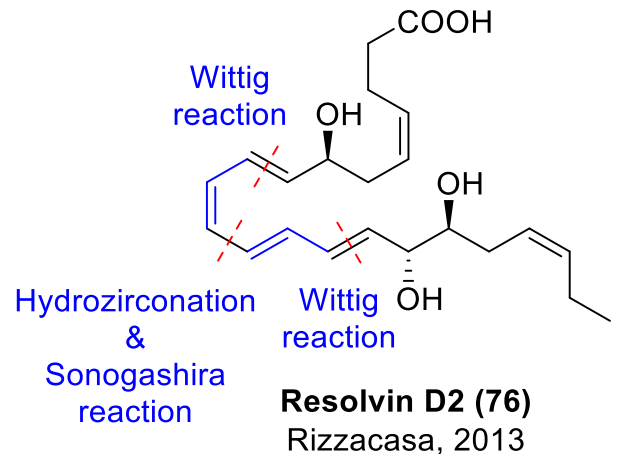

Rizzacasa, 2013

Figure 1.12: Phosphonium salt 74 in natural product synthesis. 
Although the term "linchpin" is not very often used in literature, linchpin-type strategies are well-established in natural product synthesis and relevant to this thesis, in macrolactone synthesis. Looking at several recently published syntheses of macrolactones, many of them contain linchpin-type fragments (Figure 1.13). ${ }^{113-116}$ However, the assembly of fragments with the aid of a linchpin often takes multiple steps, because protection, deprotection, and/or conversion of functional groups are often required. This does not utilize the full potential efficiency of the linchpin strategy and, arguably, is not truly a linchpin strategy. An efficient linchpin should be easy to prepare, have reasonable stability, and require mild reaction conditions that are compatible to various functional groups. Furthermore, it should ideally react with the fragments in a multi-component fashion in a single step, without additional manipulation between the reactions at each reacting site of the linchpin. In this project, a threecomponent linchpin method that meets the above criteria was explored and applied to the synthesis of a major portion of the (-)-zampanolide (19) and the (-)-dactylolide (20) macrocycle after difficulty with the first generation synthetic plan, which will be described in chapter two.

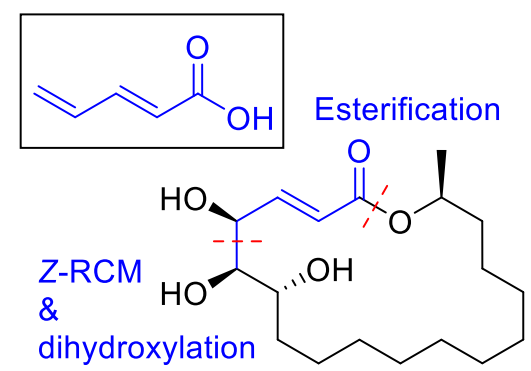

(+)-Aspicilin Hoveyda, 2014

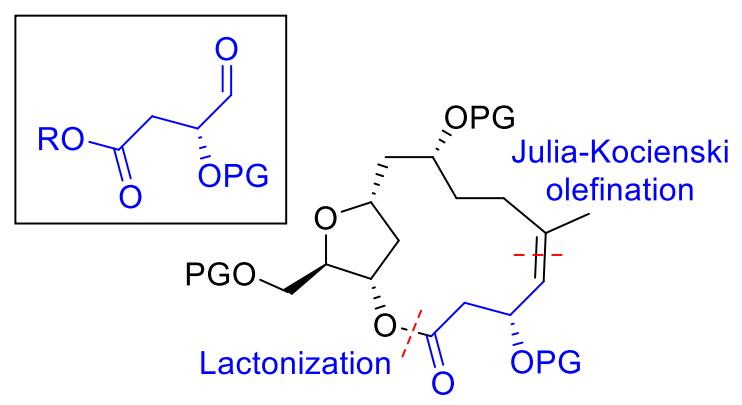

Phormidolide B,C core Alvarez, 2015

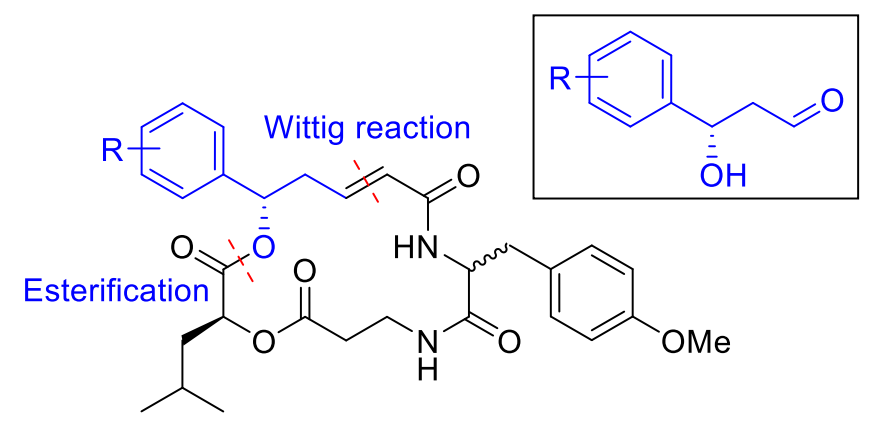

Cryptophycin analogue

Shah, 2015

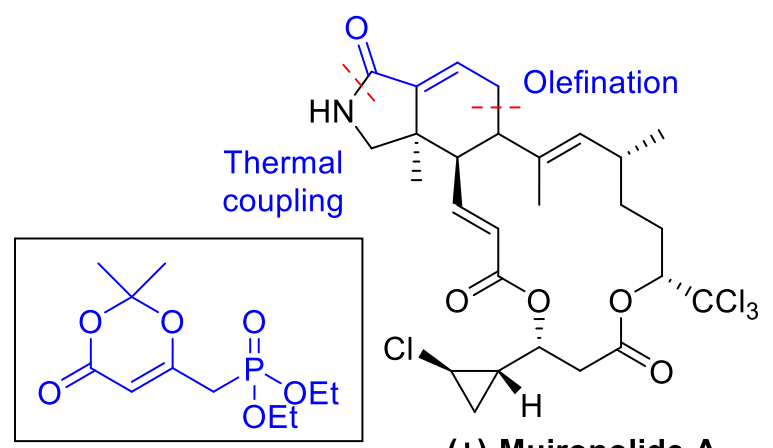

(+)-Muironolide A Zakarian, 2015

Figure 1.13: Recent examples of linchpins (in box) in total synthesis of macrolactones. 


\subsection{References}

(1) Bergmann, W.; Feeney, R. J. J. Org. Chem. 1951, 16, 981.

(2) Hirata, Y.; Uemura, D. Pure Appl. Chem. 1986, 58, 701.

(3) Dumontet, C.; Jordan, M. A. Nat. Rev. Drug Discov. 2010, 9, 587.

(4) Bensch, K. G.; Malawista, S. E. Nature 1968, 218, 1176.

(5) Stearns, M. E.; Wang, M.; Tew, K. D.; Binder, L. I. J. Cell Biol. 1988, 107, 2647.

(6) Wani, M. C.; Taylor, H. L.; Wall, M. E.; Coggon, P.; McPhail, A. T. J. Am. Chem. Soc. 1971, 93, 2325.

(7) Wani, M. C.; Horwitz, S. B. Anti-Cancer Drug 2014, 25, 482.

(8) Schiff, P. B.; Fant, J.; Horwitz, S. B. Nature 1979, 277, 665.

(9) Hall, N. Chem. Commun. 2003, 661.

(10) Holton, R. A.; Somoza, C.; Kim, H. B.; Liang, F.; Biediger, R. J.; Boatman, P. D.; Shindo, M.; Smith, C. C.; Kim, S.; Nadizadeh, H.; Suzuki, Y.; Tao, C.; Vu, P.; Tang, S.; Zhang, P.; Murthi, K. K.; Gentile, L. N.; Liu, J. H. J. Am. Chem. Soc. 1994, 116, 1597.

(11) Holton, R. A.; Somoza, C.; Kim, H. B.; Liang, F.; Biediger, R. J.; Boatman, P. D.; Shindo, M.; Smith, C. C.; Kim, S.; Nadizadeh, H.; Suzuki, Y.; Tao, C.; Vu, P.; Tang, S.; Zhang, P.; Murthi, K. K.; Gentile, L. N.; Liu, J. H. J. Am. Chem. Soc. 1994, 116, 1599.

(12) Holton, R. A.; Juo, R. R.; Kim, H. B.; Williams, A. D.; Harusawa, S.; Lowenthal, R. E.; Yogai, S. J. Am. Chem. Soc. 1988, $110,6558$.

(13) Nicolaou, K. C.; Yang, Z.; Liu, J. J.; Ueno, H.; Nantermet, P. G.; Guy, R. K.; Claiborne, C. F.; Renaud, J.; Couladouros, E. A.; Paulvannan, K.; Sorensen, E. J. Nature 1994, 367,630 .

(13) Ganem, B.; Franke, R. R. J. Org. Chem. 2007, 72, 3981.

(14) Schedler, D. J. A.; Godfrey, A. G.; Ganem, B. Tetrahedron Lett. 1993, 34, 5035.

(15) Schedler, D. J. A.; Li, J.; Ganem, B. J. Org. Chem. 1996, 61, 4115.

(17) Yared, J. A.; Tkaczuk, K. H. R. Drug Des. Dev. Ther. 2012, 6, 371.

(18) Juliano, R. L.; Ling, V. Biochim. Biophys. Acta 1976, 455, 152.

(19) Debenham, P. G.; Kartner, N.; Siminovitch, L.; Riordan, J. R.; Ling, V. Mol. Cell. Biol. 1982, 2,881 .

(20) Persidis, A. Nature Biotechnol. 1999, 17, 94. 
(21) Riordan, J. R.; Ling, V. J. Biol. Chem. 1979, 254, 2701.

(22) Sharom, F. J. J. Membr. Biol. 1997, 160, 161.

(23) Cole, S. P.; Bhardwaj, G.; Gerlach, J. H.; Mackie, J. E.; Grant, C. E.; Almquist, K. C.; Stewart, A. J.; Kurz, E. U.; Duncan, A. M.; Deeley, R. G. Science 1992, 258, 1650.

(24) Borst, P.; Evers, R.; Kool, M.; Wijnholds, J. Biochim. Biophys. Acta 1999, 1461, 347.

(25) Yoshimura, S.; Sato, B.; Kinoshita, T.; Takase, S.; Terano, H. J. Antibiot. 2000, 53, 615.

(26) Sato, B.; Nakajima, H.; Hori, Y.; Hino, M.; Hashimoto, S.; Terano, H. J. Antibiot. 2000, $53,204$.

(27) Sato, B.; Muramatsu, H.; Miyauchi, M.; Hori, Y.; Takase, S.; Hino, M.; Hashimoto, S.; Terano, H. J. Antibiot. 2000, 53, 123.

(28) Edler, M. C.; Buey, R. M.; Gussio, R.; Marcus, A. I.; Vanderwal, C. D.; Sorensen, E. J.; Diaz, J. F.; Giannakakou, P.; Hamel, E. Biochemistry 2005, 44, 11525.

(29) Buey, R. M.; Calvo, E.; Barasoain, I.; Pineda, O.; Edler, M. C.; Matesanz, R.; Cerezo, G.; Vanderwal, C. D.; Day, B. W.; Sorensen, E. J.; Lopez, J. A.; Andreu, J. M.; Hamel, E.; Diaz, J. F. Nature Chem. Biol. 2007, 3, 117.

(30) Chen, Z.-1.; Wang, B.-D.; Chen, M.-Q. Tetrahedron Lett. 1987, 28, 1673.

(31) Chen, Z.-L.; Wang, B.-D.; Shen, J.-H. Phytochemistry 1988, 27, 2999.

(32) Li, Z.; Upadhyay, V.; DeCamp, A. E.; DiMichele, L.; Reider, P. J. Synthesis 1999, 1453.

(33) Shen, J.; Chen, Z.; Gao, Y. Chin. J. Chem. 1991, 9, 92.

(34) Shen, J.; Chen, Z.; Gao, Y. Phytochemistry 1996, 42, 891.

(35) Yang, J.-Y.; Zhao, R.-H.; Chen, C.-X.; Ni, W.; Teng, F.; Hao, X.-J.; Liu, H.-Y. Helv. Chim. Acta 2008, 91, 1077.

(36) Mühlbauer, A.; Seip, S.; Nowak, A.; Tran, V. S. Helv. Chim. Acta 2003, 86, 2065.

(37) Huang, Y.; Liu, J.-K.; Mühlbauer, A.; Henkel, T. Helv. Chim. Acta 2002, 85, 2553.

(38) Risinger, A. L.; Jackson, E. M.; Polin, L. A.; Helms, G. L.; LeBoeuf, D. A.; Joe, P. A.; Hopper-Borge, E.; Luduena, R. F.; Kruh, G. D.; Mooberry, S. L. Cancer Res. 2008, 68, 8881.

(39) Tinley, T. L.; Randall-Hlubek, D. A.; Leal, R. M.; Jackson, E. M.; Cessac, J. W.; Quada, J. C., Jr.; Hemscheidt, T. K.; Mooberry, S. L. Cancer Res. 2003, 63, 3211.

(40) Risinger, A. L.; Riffle, S. M.; Lopus, M.; Jordan, M. A.; Wilson, L.; Mooberry, S. L. Molec. Cancer 2014, 13, 41.

(41) Tanaka, J.; Higa, T. Tetrahedron Lett. 1996, 37, 5535.

(42) Smith, A. B.; Safonov, I. G.; Corbett, R. M. J. Am. Chem. Soc. 2002, 124, 11102. 
(43) Field, J. J.; Singh, A. J.; Kanakkanthara, A.; Halafihi, T.; Northcote, P. T.; Miller, J. H. J. Med. Chem. 2009, 52, 7328.

(44) Field, J. J.; Pera, B.; Calvo, E.; Canales, A.; Zurwerra, D.; Trigili, C.; RodriguezSalarichs, J.; Matesanz, R.; Kanakkanthara, A.; Wakefield, J.; Singh, J.; JimenezBarbero, J.; Northcote, P.; Miller, J. H.; Lopez, J. A.; Hamel, E.; Barasoain, I.; Altmann, K.-H.; Diaz, J. F. Chem. Biol. 2012, 19, 686.

(45) Cutignano, A.; Bruno, I.; Bifulco, G.; Casapullo, A.; Debitus, C.; Gomez-Paloma, L.; Riccio, R. Eur. J. Org. Chem. 2001, 775.

(46) Uenishi, J.; Iwamoto, T.; Tanaka, J. Org. Lett. 2009, 11, 3262.

(47) Chen, Q. H.; Kingston, D. G. Nat. Prod. Rep. 2014, 31, 1202.

(48) Prota, A. E.; Bargsten, K.; Zurwerra, D.; Field, J. J.; Diaz, J. F.; Altmann, K. H.; Steinmetz, M. O. Science 2013, 339, 587.

(49) Liao, S. Y.; Mo, G. Q.; Chen, J. C.; Zheng, K. C. J. Mol. Model. 2014, 20, 2070.

(50) Smith, A. B.; Safonov, I. G.; Corbett, R. M. J. Am. Chem. Soc. 2001, 123, 12426.

(51) Hoye, T. R.; Hu, M. J. Am. Chem. Soc. 2003, 125, 9576.

(52) Ghosh, A. K.; Cheng, X. Org. Lett. 2011, 13, 4108.

(53) Zurwerra, D.; Glaus, F.; Betschart, L.; Schuster, J.; Gertsch, J.; Ganci, W.; Altmann, K. H. Chem.-Eur. J. 2012, 18, 16868.

(54) Petasis, N. A.; Lu, S. P. Tetrahedron Lett. 1996, 37, 141.

(55) Kelsi, P. S. Organic reactions and their mechanisms; 2nd ed.; Tunbridge Wells, UK: New Age Science, 1996.

(56) Aubele, D. L.; Wan, S. Y.; Floreancig, P. E. Angew. Chem. Int. Ed. 2005, 44, 3485.

(57) Ding, F.; Jennings, M. P. Org. Lett. 2005, 7, 2321.

(58) Akiyama, T. Chem. Rev. 2007, 107, 5744.

(59) Smith, A. B.; Safonov, I. G. Org. Lett. 2002, 4, 635.

(60) Sanchez, C. C.; Keck, G. E. Org. Lett. 2005, 7, 3053.

(61) Louis, I.; Hungerford, N. L.; Humphries, E. J.; McLeod, M. D. Org. Lett. 2006, 8, 1117.

(62) Zurwerra, D.; Gertsch, J.; Altmann, K. H. Org. Lett. 2010, 12, 2302.

(63) Ding, F.; Jennings, M. P. J. Org. Chem. 2008, 73, 5965.

(64) Yun, S. Y.; Hansen, E. C.; Volchkov, I.; Cho, E. J.; Lo, W. Y.; Lee, D. Angew. Chem. Int. Ed. 2010, 49, 4261.

(65) Lee, K.; Kim, H.; Hong, J. Y. Angew. Chem. Int. Ed. 2012, 51, 5735.

(66) Dossetter, A. G.; Jamison, T. F.; Jacobsen, E. N. Angew. Chem. Int. Ed. 1999, 38, 2398.

(67) Hansen, E. C.; Lee, D. S. J. Am. Chem. Soc. 2006, 128, 8142. 
(68) Sheldon, R. A. Chem. Commun. 2008, 3352.

(69) Trost, B. M. Angew. Chem. Int. Ed. 1995, 34, 259.

(70) Nicolaou, K. C.; Montagnon, T.; Snyder, S. A. Chem. Commun. 2003, 551.

(71) Mermolia, W.; Steinkam.J; Vogel, K. Nachrichtentech. Z. 1969, 22, 133.

(72) Curzons, A. D.; Constable, D. J. C.; Mortimer, D. N.; Cunningham, V. L. Green Chem. 2001, 3,1 .

(73) Sheldon, R. A. Pure Appl. Chem. 2000, 72, 1233.

(74) Kuntiyong, P.; Lee, T. H.; Kranemann, C. L.; White, J. D. Org. Biomol. Chem. 2012, 10,7884 .

(75) Tang, S. Y.; Bourne, R. A.; Poliakoff, M.; Smith, R. L. Green Chem. 2008, 10, 268.

(76) Tang, S. L. Y.; Smith, R. L.; Poliakoff, M. Green Chem. 2005, 7, 761.

(77) Wender, P. A.; Verma, V. A.; Paxton, T. J.; Pillow, T. H. Acco. Chem. Res. 2008, 41, 40 .

(78) Newhouse, T.; Baran, P. S.; Hoffmann, R. W. Chem. Soc. Rev. 2009, 38, 3010.

(79) Gauthier, M. A.; Klok, H. A. Chem. Commun. 2008, 2591.

(80) Hurevich, M.; Seeberger, P. H. Chem. Commun. 2014, 50, 1851.

(81) Lukas, T. J.; Prystowsky, M. B.; Erickson, B. W. Proc. Natl. Acad. Sci. USA 1981, 78, 2791.

(82) Merrifield, R. B. Science 1965, 150, 178.

(83) Merrifield, R. B.; Stewart, J. M. Nature 1965, 207, 522.

(84) Merrifield, R. B. Endeavour 1965, 24, 3.

(85) Joshi, R.; Jha, D.; Su, W.; Engelmann, J. J. Pept. Sci. 2010, 17, 8.

(86) Pfundheller, H. M.; Sorensen, A. M.; Lomholt, C.; Johansen, A. M.; Koch, T.; Wengel, J. Methods Mol. Biol. 2005, 288, 127.

(87) Caruthers, M. H. Science 1985, 230, 281.

(88) Woerly, E. M.; Roy, J.; Burke, M. D. Nat. Chem. 2014, 6, 484.

(89) Lang, R. W.; Hansen, H. J. Helv. Chim. Acta 1980, 63, 438.

(90) Konkolewicz, D.; Monteiro, M. J.; Perrier, S. Macromolecules 2011, 44, 7067.

(91) Grayson, S. M.; Frechet, J. M. J. Chem. Rev. 2001, 101, 3819.

(92) Fuwa, H.; Sasaki, M. Curr. Opin. Drug Discov. 2007, 10, 784.

(93) Reddy, B. V. S.; Babu, R. A.; Reddy, B. J. M.; Sridhar, B.; Murthy, T. R.; Pranathi, P.; Kalivendi, S. V.; Rao, T. P. RSC Adv. 2015, 5, 27476.

(94) Markad, S. B.; Argade, N. P. Org. Lett. 2014, 16, 5470. 
(95) Borrero, N. V.; DeRatt, L. G.; Ferreira Barbosa, L.; Abboud, K. A.; Aponick, A. Org. Lett. 2015, 17, 1754.

(96) Liu, X. Y.; Chen, D. Y. Angew. Chem. Int. Ed. 2014, 53, 924.

(97) Chen, R.; Liu, H.; Chen, X. J. Nat. Prod. 2013, 76, 1789.

(98) Bonazzi, S.; Cheng, B.; Wzorek, J. S.; Evans, D. A. J. Am. Chem. Soc. 2013, 135, 9338.

(99) Chiba, H.; Sakai, Y.; Ohara, A.; Oishi, S.; Fujii, N.; Ohno, H. Chemistry 2013, 19, 8875.

(100) Trost, B. M.; Michaelis, D. J.; Malhotra, S. Org. Lett. 2013, 15, 5274.

(101) Trost, B. M.; Bartlett, M. J. Org. Lett. 2012, 14, 1322.

(102) Trost, B. M.; Papillon, J. P. N. J. Am. Chem. Soc. 2004, 126, 13618.

(103) Trost, B. M.; Sieber, J. D.; Qian, W.; Dhawan, R.; Ball, Z. T. Angew. Chem. Int. Ed. 2009, $48,5478$.

(104) Trost, B. M.; Weiss, A. H. Adv. Synth. Catal. 2009, 351, 963.

(105) Evans, D. A.; Kim, A. S.; Metternich, R.; Novack, V. J. J. Am. Chem. Soc. 1998, 120, 5921.

(106) Smith, A. B., 3rd; Kim, D. S. Org. Lett. 2005, 7, 3247.

(107) Gurjar, M. K.; Raghupathi, N.; Chorghade, M. S. Heterocycles 2009, 77, 945.

(108) Liang, Q.; Sun, Y.; Yu, B.; She, X.; Pan, X. J. Org. Chem. 2007, 72, 9846.

(109) Trost, B. M.; Bartlett, M. J.; Weiss, A. H.; Jacobi von Wangelin, A.; Chan, V. S. Chem.Eur. J. 2012, 18, 16498.

(110) Gharpure, S. J.; Shelke, Y. G.; Reddy, S. R. B. RSC Adv. 2014, 4, 46962.

(111) Marshall, J. A.; Salovich, J. M.; Shearer, B. G. J. Org. Chem. 1990, 55, 2398.

(112) Fortier-McGill, B.; Toader, V.; Reven, L. Macromolecules 2011, 44, 2755.

(113) Zhang, H. M.; Yu, E. C.; Torker, S.; Schrock, R. R.; Hoveyda, A. H. J. Am. Chem. Soc. 2014, 136, 16493.

(114) Kumar, A.; Kumar, M.; Sharma, S.; Guru, S. K.; Shushan, S.; Shah, B. A. Eur. J. Med. Chem. 2015, 93, 55.

(115) Lorente, A.; Gil, A.; Fernandez, R.; Cuevas, C.; Albericio, F.; Alvarez, M. Chem.-Eur. J. 2015, 21, 150.

(116) Xiao, Q.; Young, K.; Zakarian, A. J. Am. Chem. Soc. 2015, 137, 5907. 


\section{Chapter 2: Aims and preliminary work}

\subsection{Aims}

The aim of this project is to advance towards the synthesis of (-)-zampanolide (19) and novel analogues to in order to undertake structure-activity relationship (SAR) studies. Guided by the protein binding studies of (-)-zampanolide $(\mathbf{1 9})^{1}$ and the thus-far published analogues, ${ }^{2-4}$ the design of the analogues has been focused on alterations of the side-arm, pendant methyl groups and the pyran motif (Figure 2.1). The importance of the side-arm for binding to tubulin has been suggested by the different cytotoxicities of $\mathbf{1 9}$ and (-)-dactylolide (20), and the interaction with protein was confirmed by HRMS and X-ray crystallography studies. A range of side-arm alterations was explored prior to this project, including the synthesis of aromatic, alkyl and alternative alkenyl amide moieties. The sequential removal of the methyl groups on the macrocycle is proposed in order to facilitate the synthesis, which might also reduce steric hindrance and improve the affinity of $\mathbf{1 9}$ for the microtubule binding site. As for the pyran modifications, previous analogue studies by Altmann have shown that the removal of the exomethylene has little effect on the cytotoxicity of (-)-20. ${ }^{4}$ Replacement of the exo-methylene with a carbonyl or hydroxyl group at this position might cause conformational change or

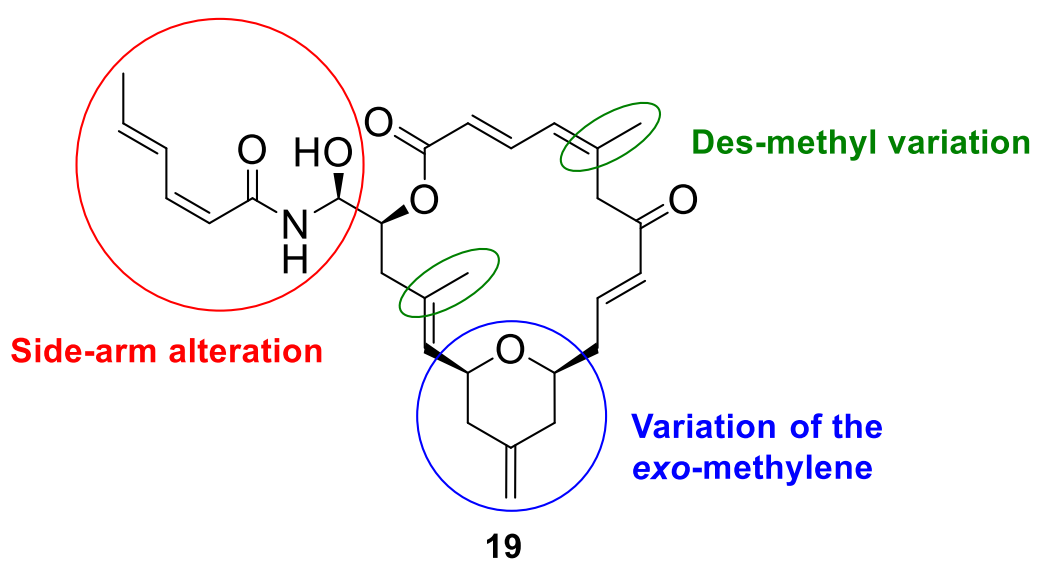

Figure 2.1: Proposed sites of modification.

encourage hydrogen bonding interactions, which could enhance the binding to the protein. In addition, monocyclic compounds lacking the pyran ring and with an hydroxy group in place of 
the pyran ether would certainly result in major conformational change. Nonetheless, if the microtubule activity can be sustained, a monocyclic analogue would significantly simplify the synthesis.

\subsection{Preliminary work}

The work of this thesis builds upon the preliminary work done by previous group members Samuel Ting and Claudia Gray. Ting's focus was on exploring synthetic routes to fragments making up the macrocyclic core, ${ }^{5}$ while Gray was working mostly on the synthesis of the analogue side-arms. ${ }^{6}$

\subsubsection{Preliminary work on side-arm variants}

A preliminary study on the synthesis of simple amides as models of the side-arm of zampanolide (19) was undertaken by Claudia Gray prior to the commencement of this project (Scheme 2.1). The one-pot amidation of primary alcohols via oxidation with iodine and in the presence of ammonia, was found to provide a reasonable yield of an aromatic amide 77, but the reaction of the saturated equivalent $\mathbf{7 8}$ was poor yielding (eq. 1). ${ }^{7}$ Therefore, a second method starting from carboxylic acids was explored, with di-t-butyl dicarbonate $\left(\mathrm{Boc}_{2} \mathrm{O}\right)$ activating the acid by anhydride formation, and ammonium carbonate as a nitrogen source. ${ }^{8}$ This method provided a better result for the synthesis of alkyl amide 79, and alkenyl amide $\mathbf{8 0}$ could also be prepared in a reasonable yield (eq. 2).

1)
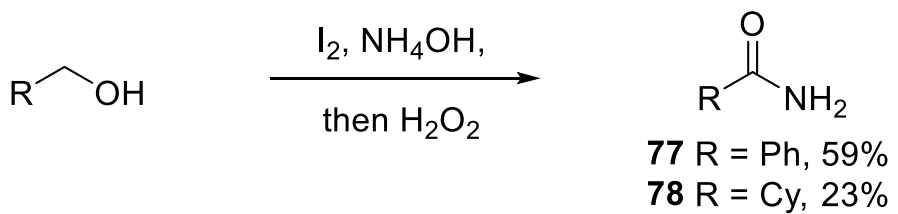

2)<smiles>[R]C(=O)O</smiles><smiles>CC(C)(C)OC(=O)COC(=O)OC(C)(C)C</smiles><smiles>[R]C(N)=O</smiles>
$79 \mathrm{R}=-\left(\mathrm{CH}_{2}\right)_{4} \mathrm{CH}_{3}, 75 \%$ $80 \mathrm{R}=-(\mathrm{CH})_{2}\left(\mathrm{CH}_{2}\right)_{2} \mathrm{CH}_{3}, 60 \%$

Scheme 2.1: Gray's synthesis of simple amides as models of the side-arm. 
Claudia Gray also explored the synthesis of $(Z, Z)-2,4$-hexadienylamide $(\mathbf{8 1})$ as side-arm from commercially available 82. First, a sequence involving amidation, Sonogashira coupling ${ }^{9}$ and Lindlar hydrogenation was explored (Scheme 2.2). However, the oxidative amidation of propargyl alcohol (82) failed to produce the amide 83. Reordering the sequence led to successful Sonogashira coupling of $\mathbf{8 2}$ and (Z)-1-bromopropene (84). The subsequent Lindlar hydrogenation of $\mathbf{8 5}$ caused some over-reduction, which was not prevented by the methods available, nor could the mixture of products be separated. Thus the subsequent amidation was not attempted.

\section{First attempt}

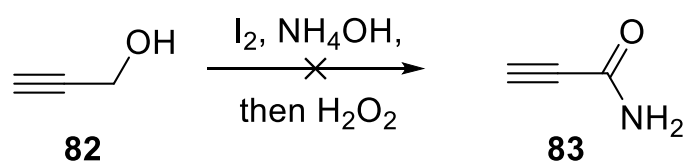

\section{Second attempt}
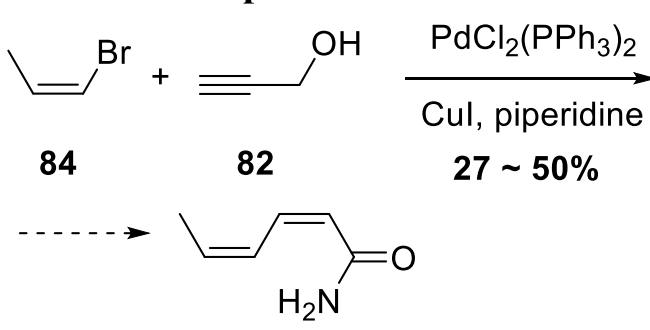

$27 \sim 50 \%$

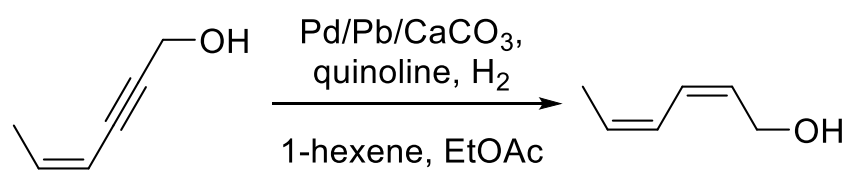

85

Scheme 2.2: Gray's attempts to synthesize (Z,Z)-2,4-hexadienylamide (81).

In the published total syntheses of zampanolide (19), reagents such as CSA, DIBAL-H, and the most successful $(S)$-TRIP have been used in aza-aldol reactions to construct $N$-acyl hemiaminal functionalities. ${ }^{2,10,11}$ Gray's attempt to reproduce the CSA-catalyzed aza-aldol reaction with sorbamide (86) as a model amide and $n$-pentanal (87) as a model aldehyde was successful (Scheme 2.3). ${ }^{6}$ The length of reaction was found to be crucial: a four-hour reaction produced the $N$-acyl hemiaminal $\mathbf{8 8}$ in $53 \%$ yield, while an overnight reaction only returned starting material in the crude reaction mixture. This was presumed to be due to the low stability of the product, as it could be sensitive to retro-aza-aldol hydrolysis. ${ }^{12}$<smiles>CC=CC=CC(N)=O</smiles>

86<smiles>CCCCCC=O</smiles>

87

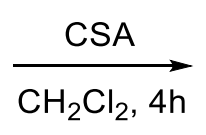

$53 \%$<smiles>C/C=C/C=C/C(=O)NC(O)CCCCC</smiles>

88

Scheme 2.3: Gray's $N$-acyl hemiaminal model reaction. 


\subsubsection{Preliminary work on fragment syntheses}

Prior to this project, Sam Ting had investigated the synthesis of fragments of the zampanolide macrolactone ring. Ting's original retrosynthetic strategy of (-)-dactylolide (20) incorporated the well-established esterification at $\mathrm{C} 1$ and ring-closing metathesis at $\mathrm{C} 8$. An $O$-Michael addition was planned to synthesize the pyran in $\mathbf{8 9}$, after a Nozaki-Hiyama-Kishi reaction to connect the western and southern fragments, 90 and 91 (Scheme 2.4). ${ }^{3,13,14}$

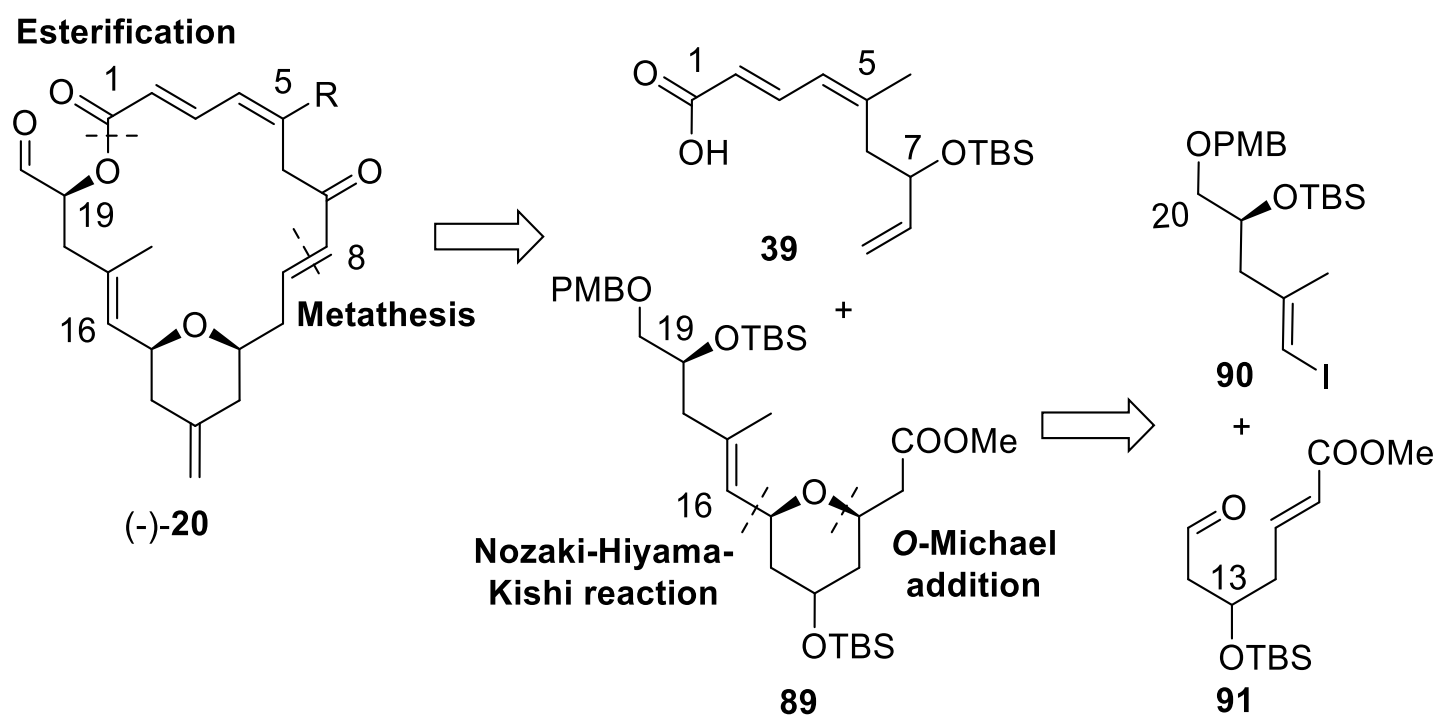

Scheme 2.4: Ting's retrosynthetic strategy.

The first synthetic route to build the northern fragment (39) proceeded by way of a Stille crosscoupling reaction (Scheme 2.5). Synthesis of the vinyl iodide 92, the Stille precursor, was first attempted using acrolein (93) as starting material; the Barbier reaction of acrolein (93) proceeded with a satisfying $62 \%$ yield of $\mathbf{9 4}$ obtained, after a series of optimization reactions to eliminate the homocoupling by-product 95 . However, the following carboalumination ${ }^{15}$ was found to be unfruitful. This was proposed to be due to the quality of available trimethylaluminum, but the addition of excess trimethylaluminum was deemed too risky because the active aluminum-zirconium species 96 could also react with the terminal alkene. 


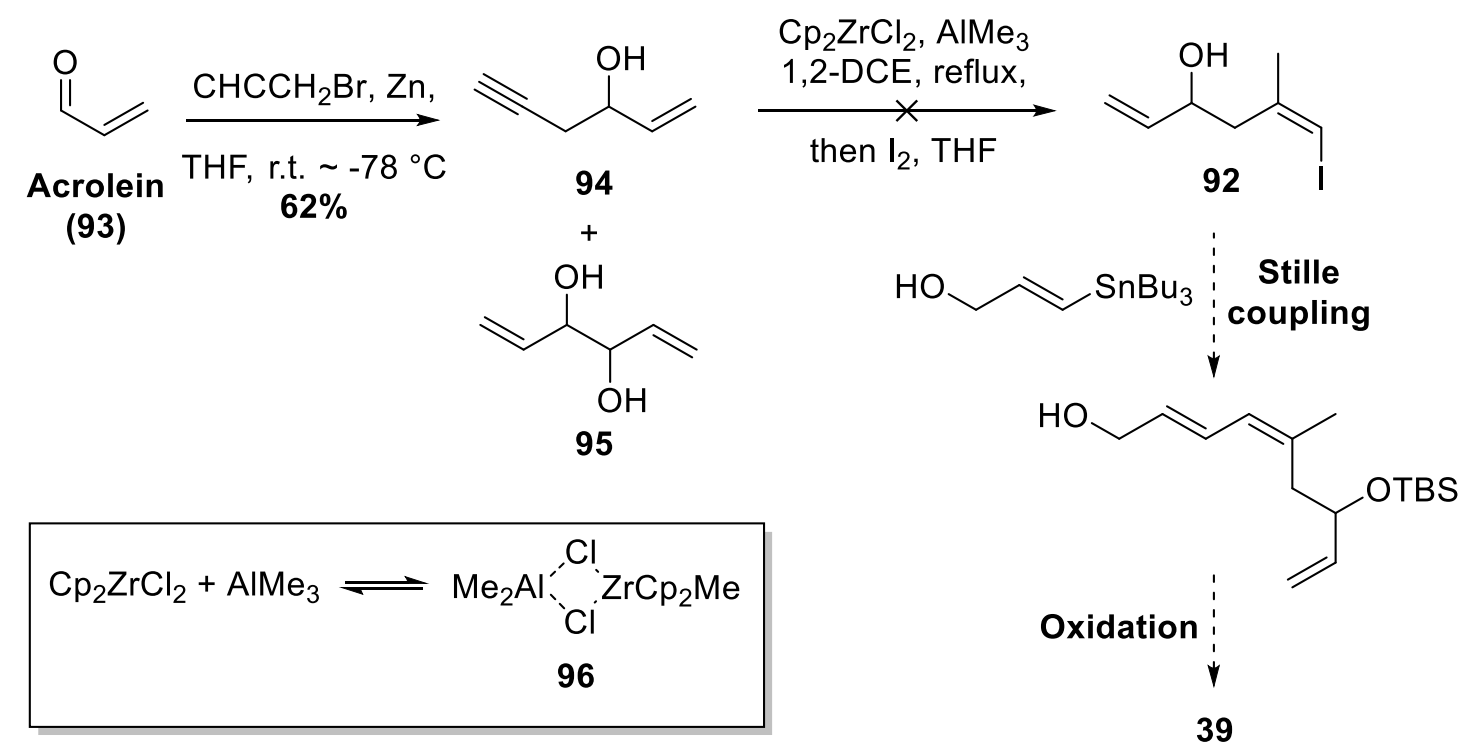

Scheme 2.5: Ting's first attempted synthesis of fragment 39.

Ting then tried to establish the iodoalkene functional group before installation of the terminal alkene. After protecting glycidol (97) as the triethylsilyl (TES) ether 98, the epoxide was opened by TMS-acetylene anion, and both of the silyl groups were then removed to produce diol 99 (Scheme 2.6). The ensuing carboalumination-iodination step progressed much more smoothly on this new substrate, leading to product 100. The terminal alkene in 92 was subsequently installed by a Corey-Chaykovsky reaction, where the tosylated primary alcohol derived from 99 was substituted by the ylide prepared from trimethylsulfonium iodide, and underwent elimination in the presence of a base to form alkene 92. However, when this vinyl iodide 92 was subjected to Stille coupling conditions, none of the desired diene 101 was formed. Instead, the product was a mixture of the unwanted Heck product 102, resulting from intramolecular reaction of the vinyl iodide with the terminal alkene and the oxidized stannane homocoupled product $\mathbf{1 0 3}$. 


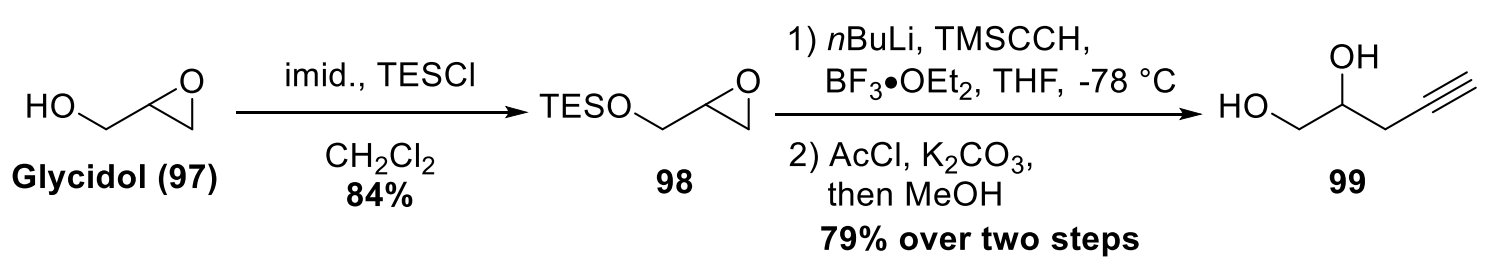<smiles>C/C(=C/I)CC(O)CO</smiles>

1) 1-(p-tosyl)imid., $\mathrm{NaH}$, $\mathrm{THF}, 0^{\circ} \mathrm{C}$

2) $n \mathrm{BuLi}, \mathrm{Me}_{3} \mathrm{~S}^{+} \mathrm{I}^{-}$, $\mathrm{THF},-10^{\circ} \mathrm{C}$ $59 \%$ over two steps

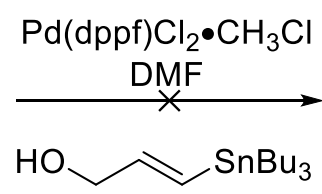<smiles>C=CC(O)C/C(C)=C\C=C/CO</smiles>
101

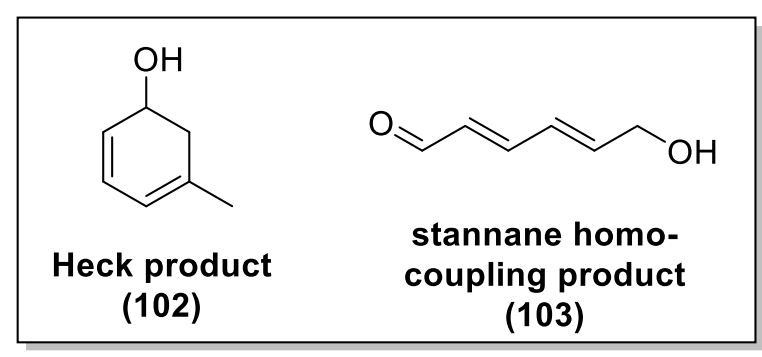

Scheme 2.6: Ting's second attempted synthesis of fragment 39.

A strategy was planned for the synthesis of the western fragment 90, using the existing configuration of diethyl tartrate $(\mathbf{1 0 4})$ to provide stereocontrol at the desired chiral centre. The plan was to carry out functional group transformations at both ends simultaneously and symmetrically, and then cleave the dimer towards the end of this sequence to produce two equivalents of the desired fragment 90 (Scheme 2.7). The acetal formation and the reduction of the two esters in $\mathbf{1 0 5}$ were successful. However, this route was quickly abandoned, after insufficient stereoselectivity was obtained in propargylzinc addition to $\mathbf{1 0 5}$ to produce $\mathbf{1 0 6}$. The best ratio of isomers was reported by Ting as 2:1, but he did not clarify the configuration of the isomers.<smiles>C#CC[C@H](O)[C@H]1OC(C)(C)O[C@H]1[C@H](O)CC#C</smiles>

Scheme 2.7: Ting's first attempt to synthesize fragment 90. 
Ting then resorted to using glycidol (97) as a precursor in the synthesis of fragment $\mathbf{9 0}$. The propargylic alcohol $\mathbf{1 0 7}$ was successfully made, but attempts to produce the vinyl iodide $\mathbf{1 0 8}$ following the same carboalumination/iodination procedure as before all failed (Scheme 2.8). Brief investigation into variations in temperature, solvent and order of addition did not promote the desired carboiodination.

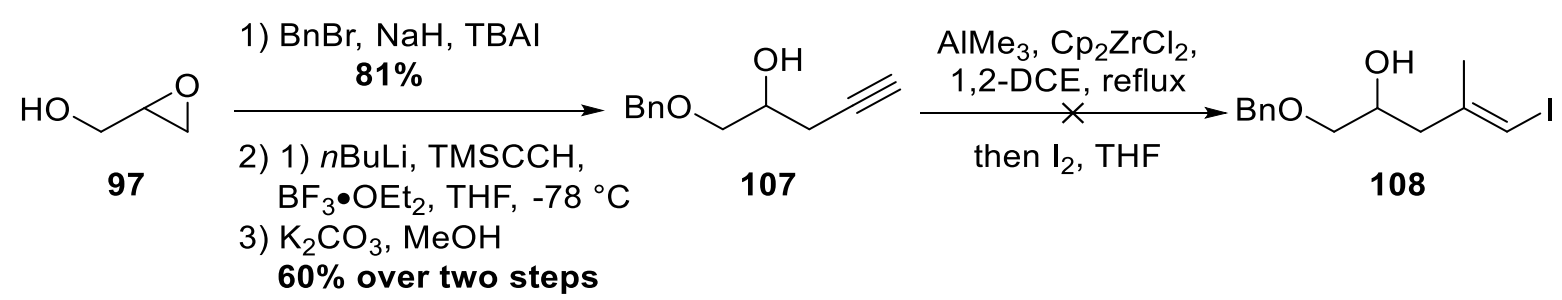

Scheme 2.8: Ting's attempt to synthesize fragment 108 from 97.

Because of the failed carboalumination-based synthesis of the northern fragment $\mathbf{3 9}$ and the difficulty in producing the NHK precursor 90, this synthetic plan was abandoned. Modification of the northern fragment synthesis to proceed from acrolein (93), and employing asymmetric alkynylation in place of the NHK reaction led to the first generation retrosynthesis described in this thesis.

\subsection{References}

(1) Zhao, M. Z.; King, A. O.; Larsen, R. D.; Verhoeven, T. R.; Reider, P. J. Tetrahedron Lett. 1997, 38, 2641.

(2) Uenishi, J.; Iwamoto, T.; Tanaka, J. Org. Lett. 2009, 11, 3262.

(3) Ding, F.; Jennings, M. P. Org. Lett. 2005, 7, 2321.

(4) Yun, S. Y.; Hansen, E. C.; Volchkov, I.; Cho, E. J.; Lo, W. Y.; Lee, D. Angew. Chem. Int. Ed. 2010, 49, 4261.

(5) Ting, S. Z. Y.; Harvey, J. E. Unpublished results, 2011.

(6) Gray, C. Synthesis of side chain variants for (-)-zampanolide analogues, Honours report, VUW 2011.

(7) Ohmura, R.; Takahata, M.; Togo, H. Tetrahedron Lett. 2010, 51, 4378.

(8) Patent WO 2008095058, TW 2008. 
(9) Egger, M.; Pellett, P.; Nickl, K.; Geiger, S.; Graetz, S.; Seifert, R.; Heilmann, J.; Konig, B. Chem.-Eur. J. 2008, 14, 10978.

(10) Ghosh, A. K.; Cheng, X. Org. Lett. 2011, 13, 4108.

(11) Hoye, T. R.; Hu, M. J. Am. Chem. Soc. 2003, 125, 9576.

(12) Gradillas, A.; Perez-Castells, J. Angew. Chem. Int. Ed. 2006, 45, 8086.

(13) Ghosh, A. K.; Cheng, X.; Bai, R.; Hamel, E. Eur. J. Org. Chem. 2012, 4130.

(14) Zurwerra, D.; Glaus, F.; Betschart, L.; Schuster, J.; Gertsch, J.; Ganci, W.; Altmann, K. H. Chem.-Eur. J. 2012, 18, 16868.

(15) Negishi, E.; Vanhorn, D. E.; Yoshida, T. J. Am. Chem. Soc. 1985, 107, 6639. 


\section{Chapter 3: First generation and fragment syntheses}

\subsection{Retrosynthetic analysis}

Target compounds of this thesis comprise the natural product (-)-zampanolide (19), the related compound (-)-20 and analogues described in chapter 2, which include modifications at the sidearm, pyran region and the appended methyl groups at $\mathrm{C} 5$ and $\mathrm{C} 17$ on the macrocycle. Both natural and modified synthetic fragments will be needed for the target compounds. Due to the structural similarity amongst these compounds, a synthetic plan was developed allowing the synthesis of the proposed analogues to be carried out in parallel with the total syntheses of 19 . A first-generation retrosynthetic analysis is shown in Scheme 3.1. Dactylolide (20) can be converted to 19 through an aza-aldol reaction with fragment 45 . The major retrosynthetic disconnections of the macrocycle are ring-closing metathesis at $\mathrm{C} 8-\mathrm{C} 9$ and esterification at $\mathrm{C} 1$, leading back to fragments 109 and 39, or the des-methyl analogue fragment $\mathbf{1 1 0 .}$

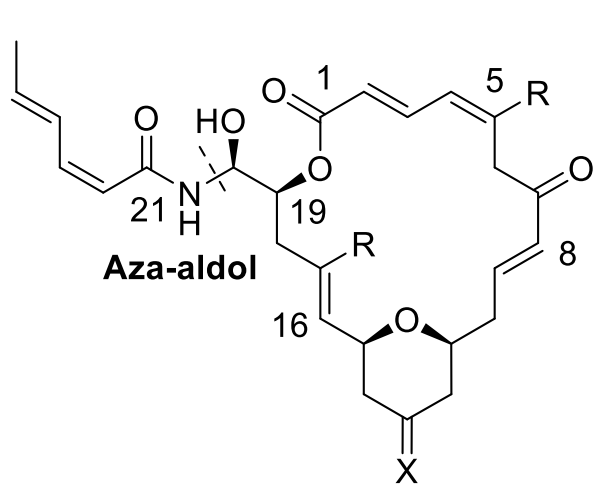

19 , analogues

$\mathrm{X}=\mathrm{CH}_{2}$, or $\mathrm{O}$, or $\mathrm{OH}, \mathrm{H}$

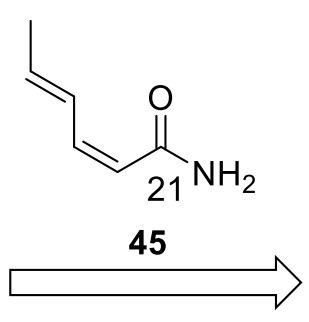

Esterification

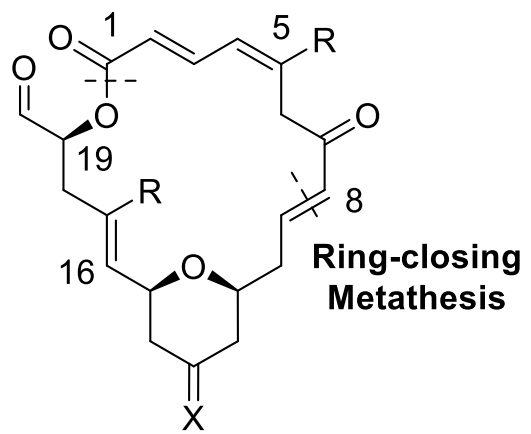

20, analogues

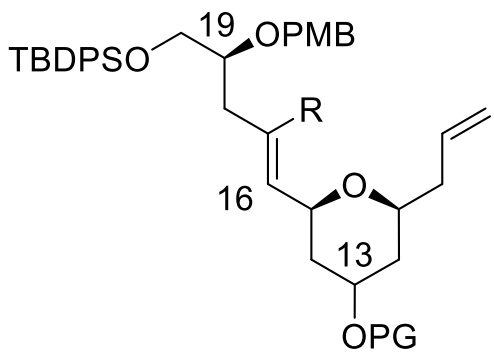

$109 \mathrm{PG}=\mathrm{TBS}$ or $\mathrm{MOM}$

$\mathrm{R}=\mathrm{Me}$ or $\mathrm{H}$
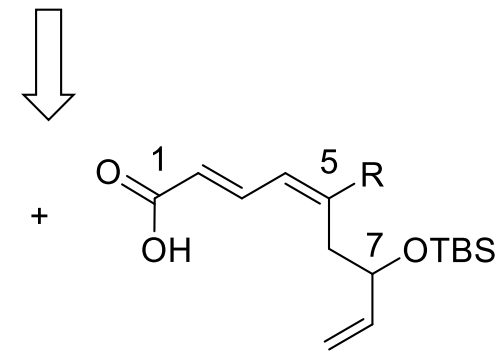

$39 \mathrm{R}=\mathrm{Me}$ $110 \mathrm{R}=\mathrm{H}$

Scheme 3.1: First generation retrosynthetic analysis. 
A protecting group strategy was developed to facilitate the synthesis, although it was realized that revisions might prove necessary. According to this synthetic plan, the hydroxyl group at C19 will be deprotected first in order to perform esterification. The hydroxyl groups at C7 and C13 can be deprotected and oxidized simultaneously to provide the C13 keto analogue and the natural product 19 in anticipation that the difference in electron deficiency at the two carbonyls will allow chemoselective Wittig olefination on the pyranone rather than the $\alpha, \beta$-unsaturated ketone at C7. Finally, the hydroxyl group at C20 can be deprotected and oxidized to produce the aldehyde of 20, and in preparation for the $N$-acyl hemiaminal synthesis to afford $\mathbf{1 9}$. However, for the analogue with a hydroxyl group on the pyran motif instead of the methylene, the protecting group plan will need to be changed so that the hydroxyl group at C13 is deprotected last. In case the chemoselective Wittig reaction alluded to above fails, this can also serve as a backup plan for the total synthesis. Therefore, the first hydroxyl protection strategy chosen to assist the planned synthesis involved TBS at O7, TBS or methoxymethyl (MOM) at O13, para-methoxybenzyl (PMB) at O19 and TBDPS at O20 (Scheme 3.1).

Fragment 109 contains a tetrahydropyran moity, which is a privileged scaffold in natural products. ${ }^{1-5}$ Extensive studies have been done to construct tetrahydropyrans, and the most commonly used methods are Prins-type cyclization, ${ }^{6,7}$ iodoetherification, ${ }^{8} O$-Michael conjugate addition ${ }^{5,9-12}$ and metal-catalyzed heterocyclization. ${ }^{13-15}$ To achieve the tetrahydropyran with the required substituents in 109, $O$-Michael addition, iodoetherification or palladium-catalyzed cyclization could be suitable for the current strategy, which leads to two related variations of the cyclization precursor, 111 and 112 (Scheme 3.2). Both

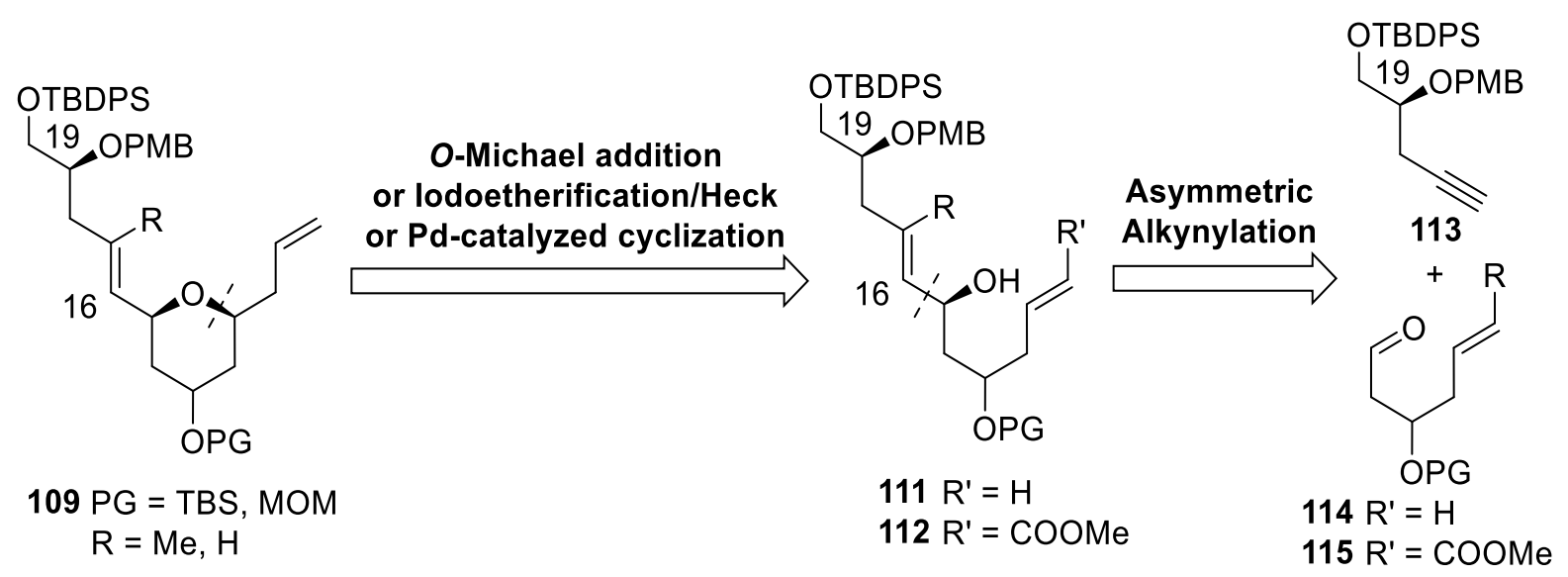

Scheme 3.2: Retrosynthetic analysis of the pyran fragment 109. 
tetrahydropyran precursors 111 and 112 can be synthesized via an asymmetric alkyne addition of $\mathbf{1 1 3}$ to aldehydes $\mathbf{1 1 4}$ or $\mathbf{1 1 5}$, followed by either alkyne reduction or reductive methylation to afford natural or analogue fragments.

The iodoetherification would need to be accompanied by a two-carbon homologation, such as by a Heck reaction in order to establish the terminal alkene required for ring-closing metathesis. Such Heck reactions involve the activation of a $\mathrm{sp}^{3}$ carbon by palladium (0), which is known to give an unstable intermediate prone to elimination and very few examples of related process have been published. ${ }^{16,17}$ A palladium-catalyzed cyclization could be coupled with a carbonylation step, producing intermediate 116 (Scheme 3.3). Upon treatment with methanol, 116 could be converted to an ester in $\mathbf{1 1 7}$, and the ester functionality can be transformed to an alkene in two or three steps. ${ }^{18-20}$ Palladium-catalyzed reactions are very sensitive to the choice of ligands and the catalyst loading, and lengthy optimization may be required. Therefore, the more reliable $O$-Michael addition of $\mathbf{1 1 2}$ will be attempted first. If this route proves unsuccessful, iodoetherification and palladium-catalyzed cyclization will be explored using the precursor 111.

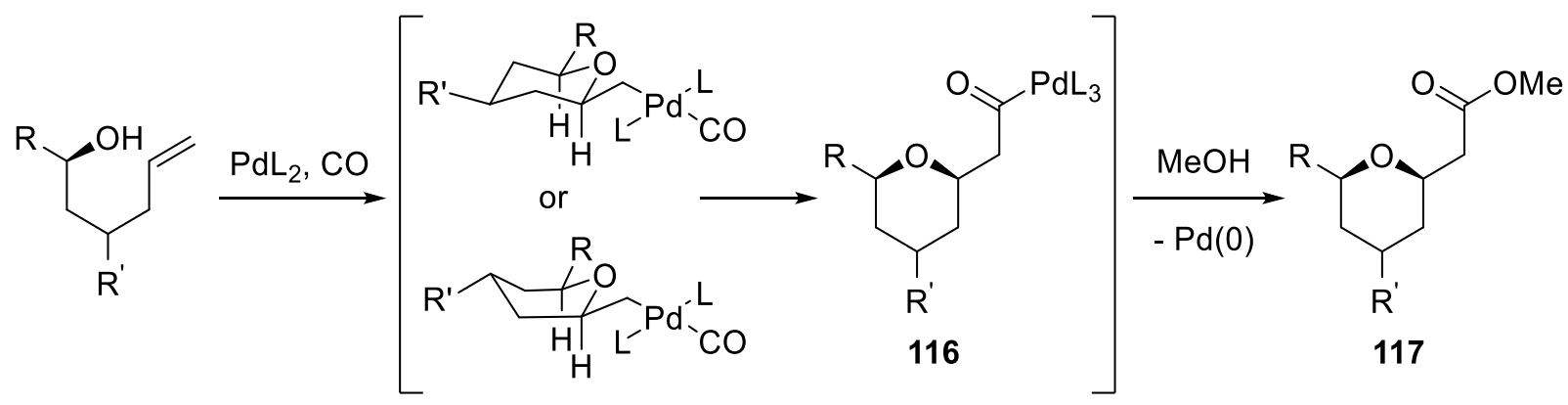

Scheme 3.3: Mechanism of the palladium-catalyzed cyclization-carbonylation cascade.

\subsection{Proposed synthesis of C1-C8 fragment}

Synthesis of the natural and modified variants of the C1-C8 fragment (viz. 39 and 110) was proposed to start from acrolein (93) and pass through a Barbier reaction followed by TBSprotection to provide enyne 118, and the subsequent alkyne substitution with methyl chloroformate forming ynoate 119 (Scheme 3.4). From this point, the fragment 39 will be achieved by reductive methylation, ester reduction, Wittig olefination and saponification. In 
the synthesis of the analogue fragment 110, the reductive methylation step will divert to a $Z$ selective reduction of alkyne in $\mathbf{1 1 9}$, which will be attempted using the Lindlar hydrogenation.

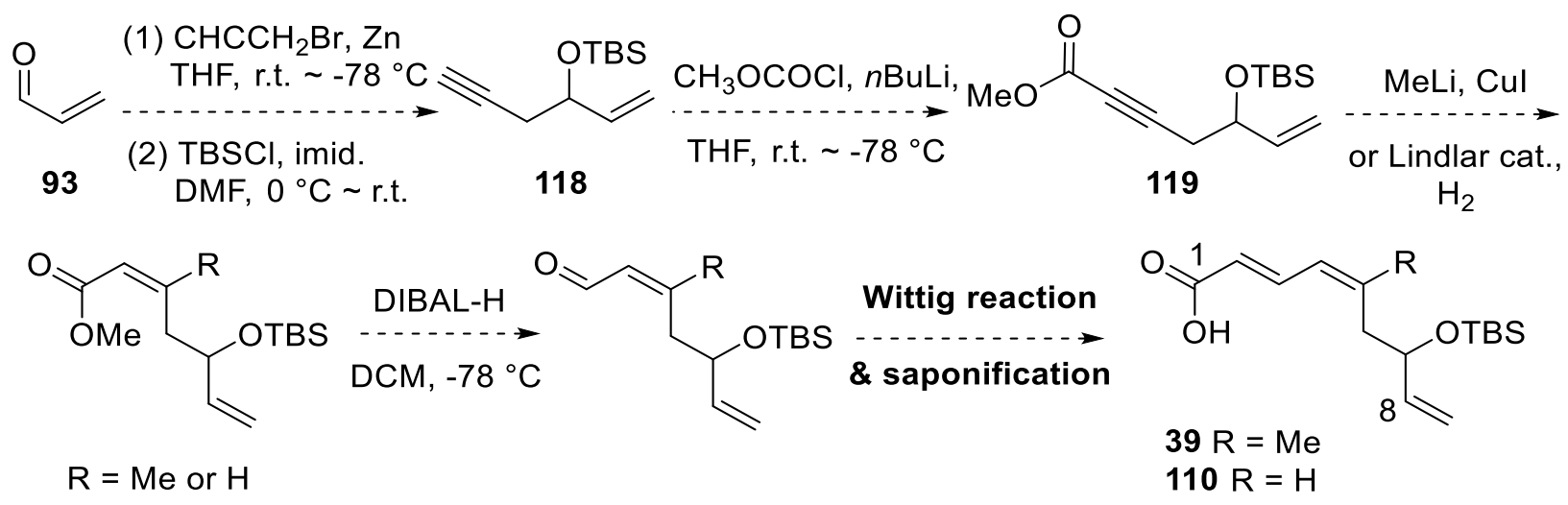

Scheme 3.4: Plan for fragments C1-C8 (39 and 110) synthesis.

\subsubsection{Synthesis of the natural C1-C8 fragment}

The Barbier reaction is often compared to the Grignard reaction, but it offers more advantages including wider substrate scope, more reliable preparation, more stable intermediate and milder reaction condition. ${ }^{21,22}$ Initial trials were carried out using commercially available zinc powder without activation. Following the reported procedure, in addition to the two equivalents each of propargyl bromide and zinc dust employed at the outset of the reaction to react with propargyl bromide, another 1 equivalent of zinc dust was added immediately before the addition of acrolein. ${ }^{21}$ The first attempt at the Barbier reaction did not achieve a satisfying result and a large amount of diol 120 (46\%) was obtained alongside the desired product 94 (22\% yield) (Scheme 3.5). A plausible mechanism was proposed to explain the formation of 120. The excess zinc or an impurity present in the reaction mixture may have activated the terminal alkyne in the zinc alkoxide salt of the intermediate $\mathbf{1 2 1}$ to allow deprotonation by the excess propargylzinc bromide, or by proton transfer from alkyne to alkoxide. The resulting acetylenic anion 122 could then perform a nucleophilic attack on another molecule of acrolein (93), upon protonation of $\mathbf{1 2 3}$ producing the observed diol 120. Due to the fact that acrolein (93) was the limiting reagent, the deprotonation of the terminal alkyne must be favored kinetically over the desired Barbier pathway. A trial with no additional equivalent of zinc dust at later stage of the reaction gave a poor yield (30\%) of the product 94 and no by-product 120. This result was attributed to incomplete reaction, because activation of the carbonyl by the third 
equivalent of zinc powder was absent. However, the highly volatile acrolein (93, b.p. $\left.51-53{ }^{\circ} \mathrm{C}\right)$ cannot be recovered to support this claim. The Barbier product 94 was also found to be volatile, so that exposure to a vacuum, such as by prolonged time on rotary evaporator, can cause loss of product.
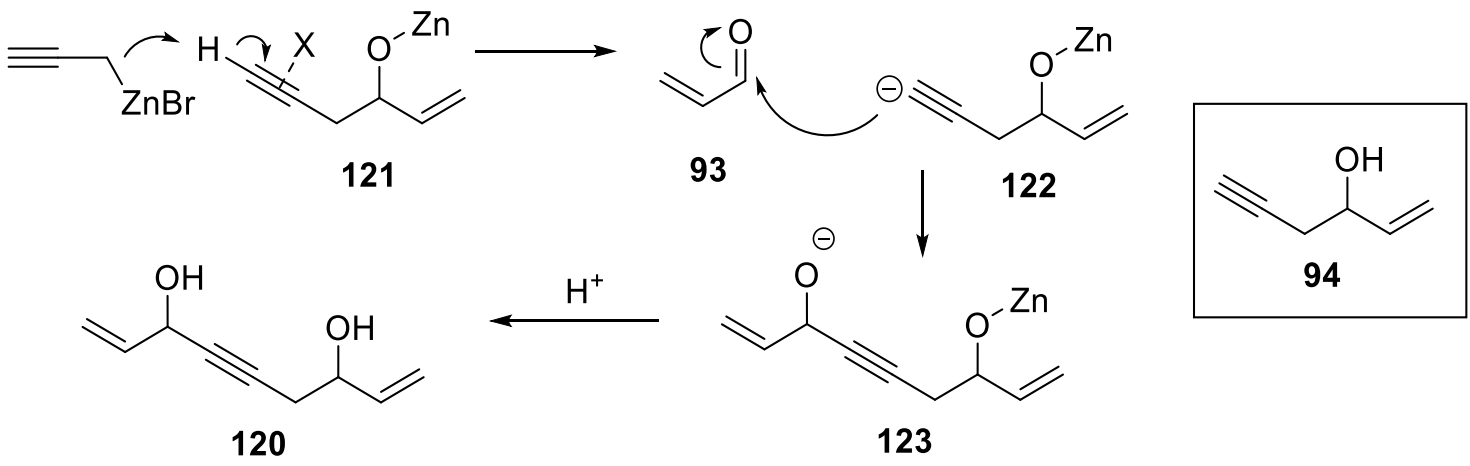<smiles>C=CC(O)C#CCC(O)C=C</smiles>

120

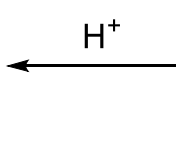

$X=$ unknown activating species

Scheme 3.5: Proposed mechanism for the formation of $\mathbf{1 2 0}$ in Barbier reaction.

Attention was turned to combining the Barbier reaction with TBS-protection of the resulting alcohol 94. Activated zinc powder was also used. An initial attempt at subjecting the crude Barbier product to silyl protection did not succeed. Without purifying the alcohol 94, no TBSprotection can occur. Next, the product of the Barbier reaction 94 was purified by a short silica plug. The elute was not reduced to dryness to avoid loss of $\mathbf{9 4}$, which was then subjected to TBS-protection. With 2 equivalents of activated zinc dust, a reproducible 61 68\% yield of 118 was obtained over the two-steps. The best yield, $81 \%$, was obtained using a third equivalent of activated zinc dust and newly purchased propargyl bromide without purification. The byproduct 120 was not observed, which suggested that the formation of the diol $\mathbf{1 2 0}$ was likely to be promoted by impurities present in the commercial zinc dust or propargyl bromide.

The carbonyl necessary for olefination was then established by a nucleophilic substitution of methyl chloroformate with alkyne 118, and a reductive methylation using Gilman reagent was used to produce the tri-substituted alkene 124 (Scheme 3.6). The use of Gilman reagent in 1,4addition to $\alpha, \beta$-unsaturated carbonyls is well-precedented. ${ }^{23,24}$ The Gilman reagent was preformed by treating copper (I) iodide with two equivalents of methyllithium at $0{ }^{\circ} \mathrm{C}$. A deep red colour, indicative of methylcopper (I), gradually developed during the addition of the first 
equivalent of methyllithium, which then disappeared slowly during the addition of the second equivalent, resulting in a colourless solution of the Gilman reagent, $\mathrm{Me}_{2} \mathrm{CuLi}$. The mechanism describing the regio-selectivity of the Gilman reagent is postulated to go through a bicyclic transition state 125, where the lithium interacts with both the carbonyl oxygen and one of the methyl groups on $\mathrm{Cu}$ to direct the methyl addition to the $\gamma$-position; the following $\mathrm{Cu}-\mathrm{H}$ exchange allowed the cis-selectivity (Scheme 3.6). The cis-configuration in product 124 was confirmed by a strong nuclear Overhauser effect spectroscopy (NOESY) correlation between the methyl protons $\mathrm{H}^{\mathrm{b}}$ and the alpha proton $\mathrm{H}^{\mathrm{a}}$, which indicates a through-space interaction between these nuclei and their proximity. The alkyne substitution of 118 with methyl chloroformate and the subsequent reductive methylation of $\mathbf{1 1 9}$ both proceeded smoothly when good quality $n$-butyllithium, methyllithium and purified copper (I) iodide ${ }^{25}$ were used, and high yields over the two steps were achieved.

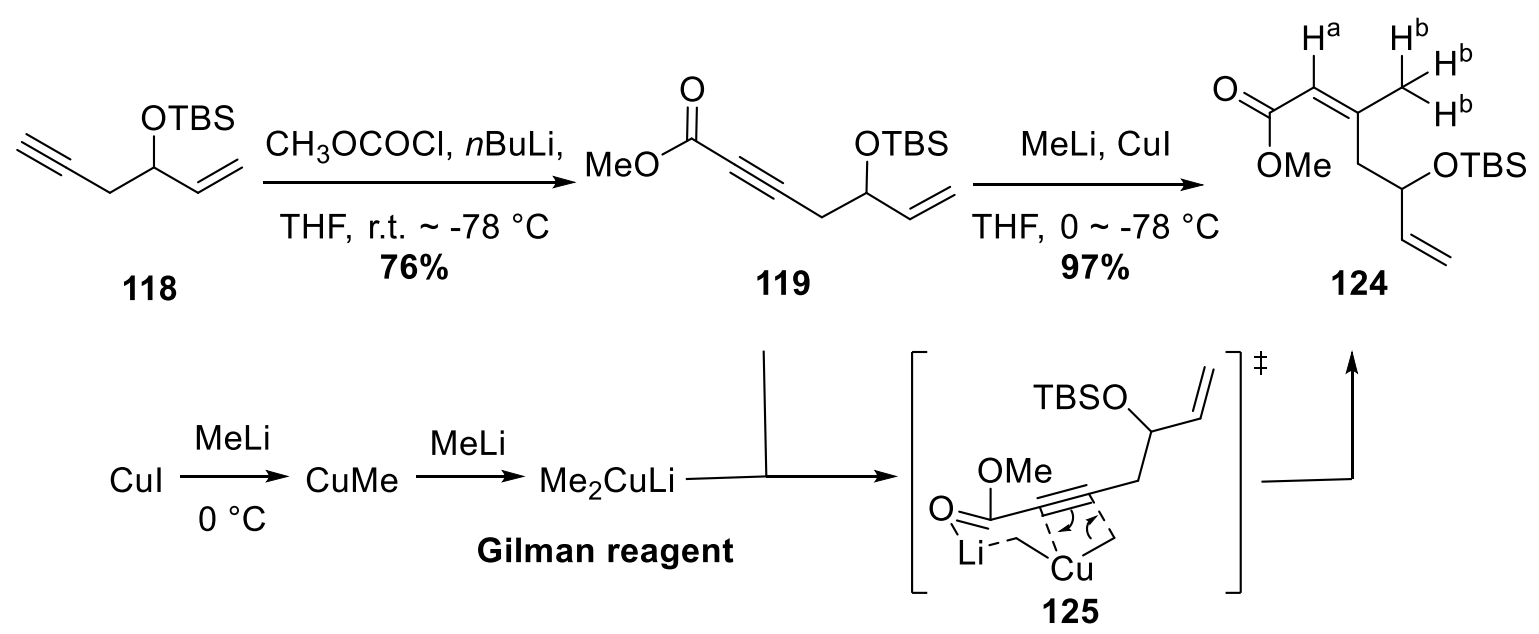

Scheme 3.6: Alkyne homologation and subsequent reductive methylation.

Attempts to reduce the ester $\mathbf{1 2 4}$ to the aldehyde $\mathbf{1 2 6}$ with DIBAL-H were unsuccessful. This is always a challenging reaction, as it is very sensitive to temperature and the stability of the intermediate (127 in this case) (Scheme 3.7). During the addition of DIBAL-H, the higher temperature of the droplets introduced to the cold reaction mixture can result in over-reduction. This is especially problematic for $\alpha, \beta$-unsaturated esters. ${ }^{26}$ To avoid over-reduction, 1.05 equivalent of DIBAL-H was added to a solution of ester 124 at $-78^{\circ} \mathrm{C}$ slowly against the inner wall of the reaction vessel, but only starting material was recovered. The fact that no aldehyde or alcohol was observed at any stage of the reaction suggests that the DIBAL-H was of poor 
quality. Staged addition of DIBAL-H was then carried out, and the reaction was monitored by TLC analysis. No reaction was observed with 1.1 and 2.2 equivalents of DIBAL-H, but when 3.4 equivalents was added, the over-reduced product 128 was produced exclusively and isolated in good yield (85\%). The amount of DIBAL-H necessary for reaction was later optimized to 2.8 equivalents. Therefore, a two-step reduction-oxidation process was undertaken to afford aldehyde $\mathbf{1 2 6 .}$

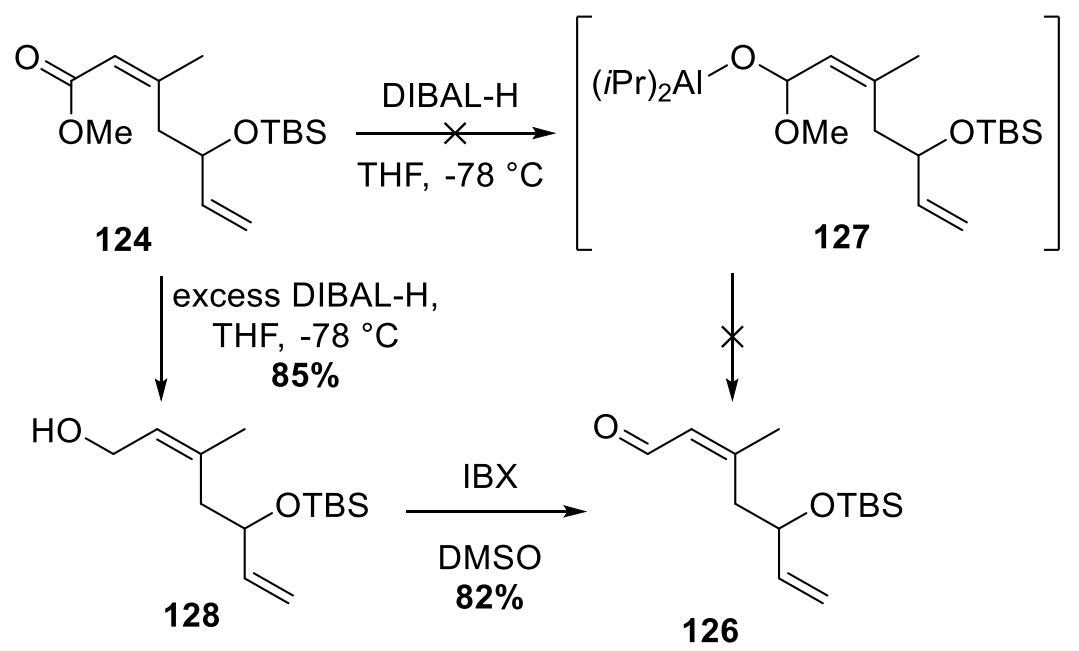

Scheme 3.7: Two-step reduction-oxidation process to aldehyde $\mathbf{1 2 6 .}$

Three oxidation methods were scanned for converting alcohol 128 to aldehyde 126: Swern oxidation was observed to produce reasonable yields, about $50 \%$ with recovered starting material, but it was not very reliable; Parikh-Doering oxidation only gave a poor yield of $18 \%$; employment of freshly prepared 2-iodoxybenzoic acid (IBX) ${ }^{27}$ gave the best result. Frigerio reported that the purities of IBX prepared from iodobenzoic acid using 1.3 and 3.0 equivalents of oxone are $\geq 95 \%$ and $\geq 99 \%$ respectively. ${ }^{27}$ It was found that the slight difference in the quality of IBX produced in these ways provided very different outcomes in the present work. The IBX prepared using 1.3 equivalents of oxone only provided up to $27 \%$ yield of $\mathbf{1 2 6}$, while the sample made using 3.0 equivalents of oxone resulted in an excellent $82 \%$ yield of $\mathbf{1 2 6}$ (Scheme 3.7). The aldehyde 126 was then subjected to a Wittig reaction with ethyl (triphenylphosphoranylidene)acetate to produce dienoate 129 (Scheme 3.8). However, the Wittig reaction did not go to completion after 22 hours. The product 129 was contaminated by aliphatic compounds and starting material, which gave an estimated yield of $\mathbf{1 2 9}$ about $70 \%$. 
No further purification was carried out, and the Wittig reaction was not optimized, as a better route that bypasses this step was found, which will be discussed in chapter four.

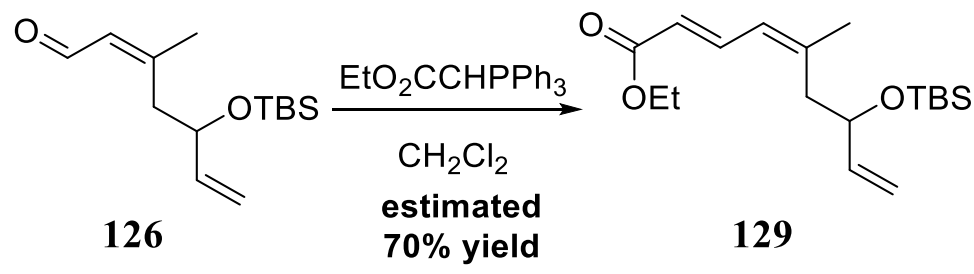

Scheme 3.8: Wittig reaction in the synthesis of the C1-C8 fragment 129.

\subsubsection{Synthesis of the des-methyl C1-C8 analogue fragment}

According to the planned synthetic route, preparation of the des-methyl analogue fragment $\mathbf{1 1 0}$ was initiated by reducing 119 using hydrogen gas in the presence of Lindlar's catalyst (see Scheme 3.4). A sacrificial alkene, 2-methylbut-2-ene, was used to avoid over-reduction of the alkenes in 130. However, this reaction did not reach completion, and significant amounts of over-reduction ccurred at the terminal alkene (Scheme 3.9). The over-reduced product 131 (present as $10 \%$ of the product mixture) was not separable from the desired product $\mathbf{1 3 0}$ by standard column chromatographic methods. Addition of extra portion of the sacrificial alkene did not make an improvement, and attempts to continue the reaction to completion resulted in 20 to $50 \%$ of over-reduction at the terminal alkene.<smiles>C=CC([O+])CC#CC(=O)OC</smiles>

119

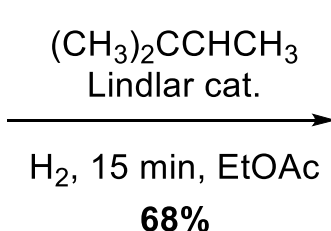

$68 \%$<smiles>C=CC(C/C=C\C(=O)OC)[O+][Sn]</smiles>

130<smiles>CCC(C/C=C\C(=O)OC)[O+]SC</smiles>

131

\section{9:1 mixture}

Scheme 3.9: Lindlar reduction of ynoate 119.

This mixture of $\mathbf{1 3 0}$ and $\mathbf{1 3 1}$ was first observed as obscured minor and major multiplets with the same splitting pattern at 6.38 and $6.33 \mathrm{ppm}$ in the ${ }^{1} \mathrm{H}$ nuclear magnetic resonance (NMR) spectrum, which correspond to $\beta$-protons. Only one set of the terminal alkene proton signals 
(5.81, 5.20, $5.07 \mathrm{ppm}$ ) was observed (Figure 3.1). In addition, two sets of carbon signals were found for the ester and di-substituted alkene, while only one set of the terminal alkene signals was present. A close examination of the ${ }^{1} \mathrm{H}$ NMR spectrum with the assistance of correlation spectroscopy (COSY) found that both $\beta$-protons correlate to a complex multiplet between 2.76 and $2.94 \mathrm{ppm}$, which then correlates to the oxymethine proton signal at $4.29 \mathrm{ppm}$, as expected, as well as an obscured upfield multiplet at about $3.73 \mathrm{ppm}$ (minor). The two corresponding oxymethine carbon signals were observed at 72.7 and $72.5 \mathrm{ppm}$ in the ${ }^{13} \mathrm{C}$ NMR spectrum, respectively. The significant up-field shift of the oxymethine proton in the minor compound indicates that the allylic effect is not present. The structure of the over-reduction product $\mathbf{1 3 1}$ would agree with this observation. Moreover, the oxymethine proton with chemical shift around $3.73 \mathrm{ppm}$ also correlates to an alkyl signal at $1.47 \mathrm{ppm}$, which accounts for two protons of the minor compound. In the ${ }^{13} \mathrm{C}$ NMR spectrum, two distinctive alkyl carbons signals of the over-reduced product $\mathbf{1 3 1}$ were found at 29.9 and $9.7 \mathrm{ppm}$.

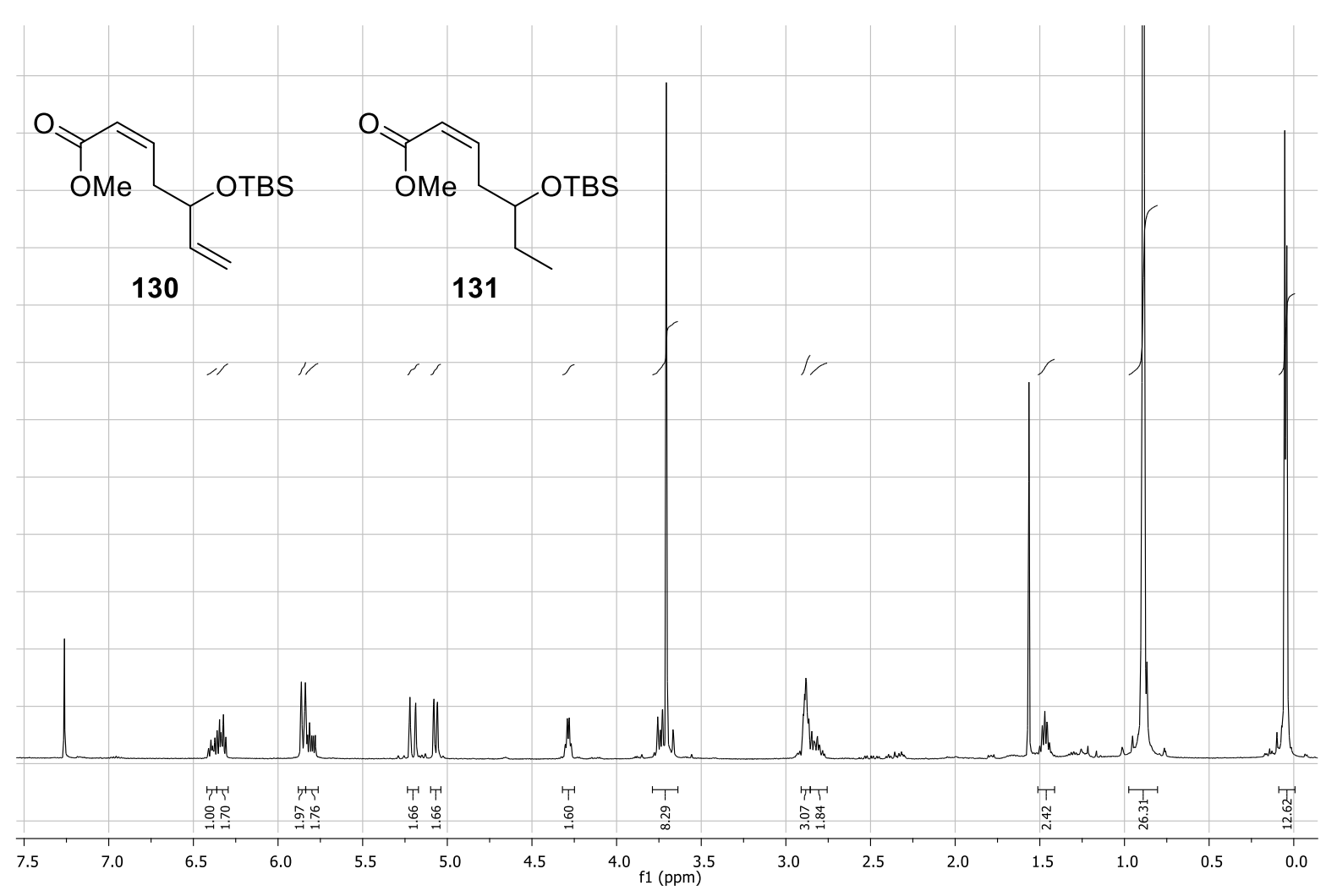

Figure 3.1: ${ }^{1} \mathrm{H}$ NMR spectrum of the mixture containing 130 and the over-reduced 131.

The presence of the over-reduced product $\mathbf{1 3 1}$ and its lack of separation from the desired product 130 invoked a need to optimize the Lindlar process. In the hope that the propargylic 
alcohol would be more electron rich than the conjugated ynoate, thus react significantly faster than alkene, the ester 119 was reduced to propargylic alcohol 132 by DIBAL-H prior to Lindlar reduction (Scheme 3.10, equation a). This reduction provided 132 in a moderate $50 \%$ yield. The initial attempt at the Lindlar reaction of $\mathbf{1 3 2}$ found that over-reduction occurred. It was thought that the sacrificial alkene 2-methylbut-2-ene could be too volatile (b.p. $36 \sim 40{ }^{\circ} \mathrm{C}$ ) to last for the entire four hours reaction, therefore, an additional equivalent must be added during the reaction. This approach indeed solved the problem, with $75 \%$ yield of $\mathbf{1 3 3}$ obtained and no over-reduction (equation a). Experiments to shorten the sequence by installing the alcohol functional group directly to alkyne $\mathbf{1 1 8}$ and thus avoiding the ester-reduction step were also attempted. The addition of the anion of $\mathbf{1 1 8}$ to paraformaldehyde produced a reasonable $68 \%$ yield of propargylic alcohol 132 (equation b). Attempts to to shorten the sequence even further by formylation of alkyne 118 using dimethylformamide (DMF) only achieved a low 28\% yield of $\mathbf{1 3 4}$ (equation c). In the hope that the yield could be optimized later, $\mathbf{1 3 4}$ was tested in Lindlar reduction, but this resulted in a complex mixture of the desired product, the isomerized $E$ alkene, over-reduced product at either one of the two alkenes, as well as doubly over-reduced product. In an effort to avoid the reduction-oxidation steps in the sequence leading to the natural fragment 126, reductive methylation on $\mathbf{1 3 4}$ was attempted, but only starting material was recovered.

(a)

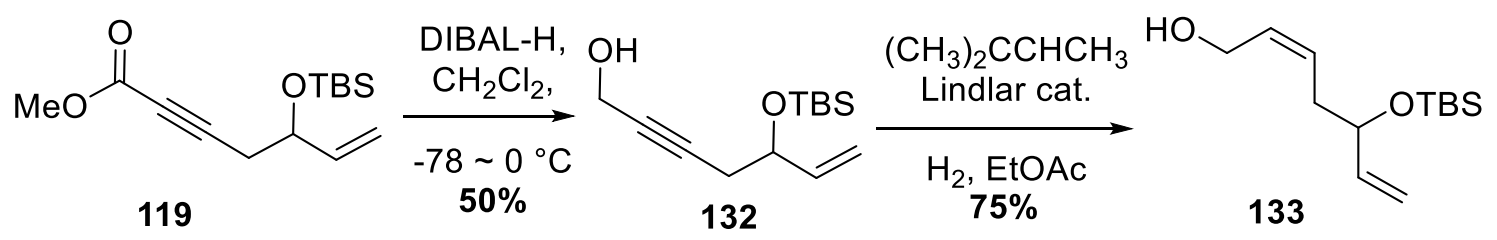

(b)

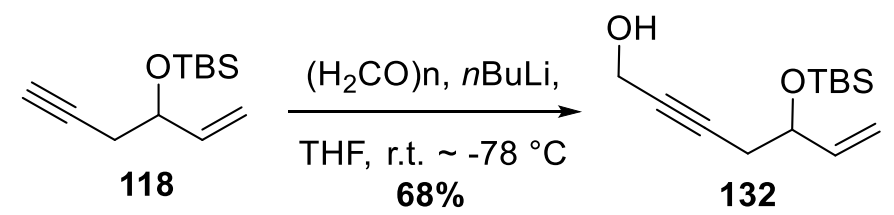

(c)
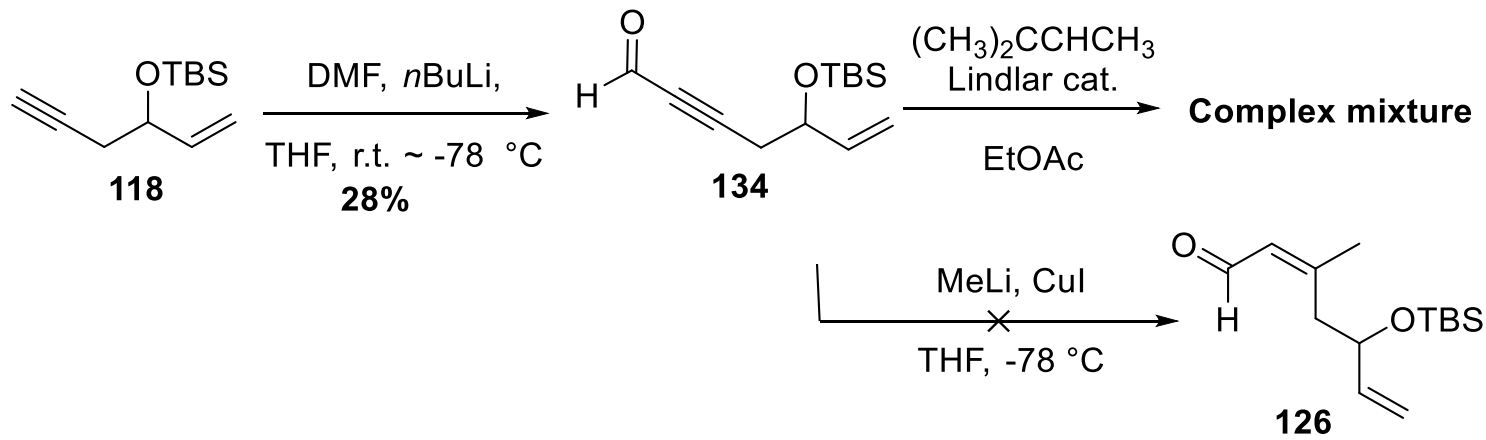

Scheme 3.10: Lindlar reduction of alkyne substrates $\mathbf{1 3 2}$ and $\mathbf{1 3 4}$. 
With the allylic alcohol 133 in hand, its oxidation to aldehyde 135 was performed. Thermal isomerization of $Z$-alkenes to the less strained $E$-configuration can readily occur for 1,2disubstituted alkenes at room temperature, catalyzed by the presence of acid. Hence, low temperature, basic oxidation methods like Swern reaction are often used to oxidize $Z$-allylic alcohols. Therefore, Swern oxidation was attempted first in order to minimize the formation of 136, but no reaction was observed (Table 3.1, entry 1). To facilitate this reaction, freshly distilled reagents and additional equivalents of dimethylsulfoxide (DMSO) and oxalyl chloride were used, but still no reaction occured. A step-wise elevation of temperature up to room temperature resulted in a 1:1 mixture of starting material and decomposed products (entry 2). A trace amount of the desired aldehyde $\mathbf{1 3 5}$ was also observed, which was too insignificant for isolation and purification. The decomposed products were not characterized, but it is well known that the standard sulfonium intermediate can go through an alternative pathway to a thioacetal 137 at high temperature, instead of the normal oxidation process.

Table 3.1: Results for the oxidation of $\mathbf{1 3 3 .}$

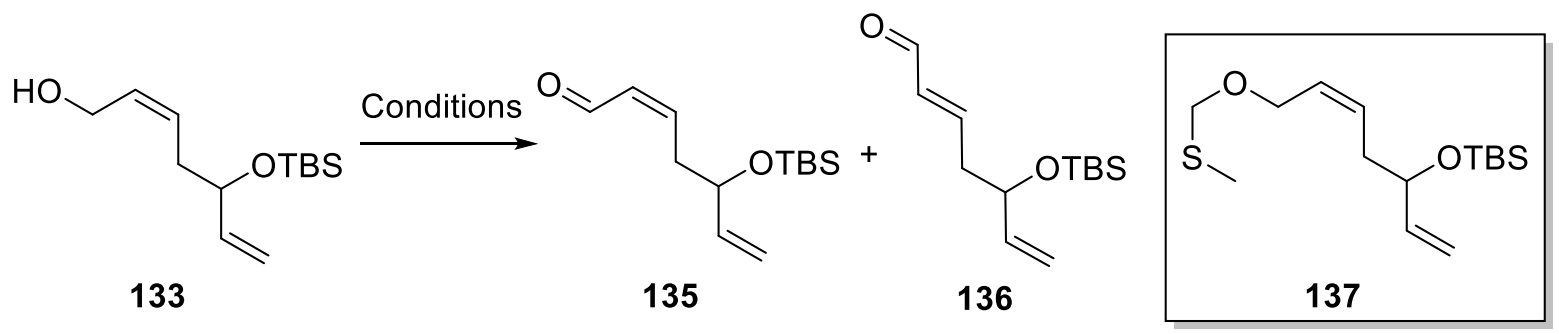

\begin{tabular}{|l|l|c|c|c|c|}
\hline \multirow{2}{*}{ Entry } & \multirow{2}{*}{ Conditions } & \multicolumn{3}{|c|}{ Obtained ratios of starting material and products } \\
\cline { 3 - 6 } & & $\mathbf{1 3 3}$ & $\mathbf{1 3 5}$ & $\mathbf{1 3 6}$ & Decomposition \\
\hline $\mathbf{1}$ & $\begin{array}{l}\text { DMSO, }(\mathrm{COCl})_{2}, \\
\mathrm{NEt}_{3},-78{ }^{\circ} \mathrm{C}\end{array}$ & 1 & - & - & - \\
\hline $\mathbf{2}$ & $\begin{array}{l}\text { DMSO, }(\mathrm{COCl})_{2}, \\
\mathrm{NEt}_{3},-78{ }^{\circ} \mathrm{C} \text { to r.t. }\end{array}$ & 1 & - & - & 1 \\
\hline $\mathbf{3}$ & $\begin{array}{l}\text { Commercially } \\
\text { available } \mathrm{MnO}_{2}, \text { r.t. }\end{array}$ & 1 & - & - & - \\
\hline $\mathbf{4}$ & $\begin{array}{l}\text { Prepared } \mathrm{MnO}_{2}, \\
\text { r.t., } 3 \mathrm{~h}^{\mathrm{a}}\end{array}$ & 3 & & & - \\
\hline $\mathbf{5}$ & $\begin{array}{l}\text { Prepared } \mathrm{MnO}_{2}, \\
\text { r.t., } 5 \mathrm{~h}^{\mathrm{b}}\end{array}$ & & & & - \\
\hline
\end{tabular}

${ }^{\mathrm{a}}$ The reaction was carried out in air; ${ }^{\mathrm{b}}$ The starting material was a 3:2 mixture of $\mathbf{1 3 3}$ and $\mathbf{1 3 5}$. 
Manganese dioxide provides an oxidation method that is selective for $\alpha, \beta$-unsaturated alcohols and is known to facilitate oxidation of $Z$-allylic alcohols without isomerization. ${ }^{28,29} \mathrm{~A}$ sample of commercial manganese dioxide did not promote any reaction, even after it was activated by heating at $130{ }^{\circ} \mathrm{C}$ for 18 hours (Table 3.1, entry 3). Freshly prepared manganese dioxide ${ }^{30}(10$ equivalents) was then used. As Gritter and Wallace reported that no difference in oxidation facility was observed whether under air or nitrogen atmosphere, ${ }^{31}$ the first trial with manganese dioxide was carried out without an inert atmosphere. This reaction converted about $40 \%$ of the alcohol 133 to aldehyde 135 after 3 hours, before the $\mathrm{MnO}_{2}$ became appearantly inactivated (entry 4). Future reactions involving $\mathrm{MnO}_{2}$ were carried out under an atmosphere of nitrogen to prevent inactivation. Encouragingly, the aldehyde product from the above $\mathrm{MnO}_{2}$ oxidation exclusively retained the $Z$-configuration of the precursor alcohol 133. This unpurified mixture of 3:2 alcohol:aldehyde was treated with another 10 equivalents of $\mathrm{MnO}_{2}$ and an additional 10 equivalents were added half-way through the reaction. After 5 hours, all starting material was consumed, but the product was obtained as a 7:3 mixture of Z:E-alkenes $\mathbf{1 3 5}$ and $\mathbf{1 3 6}$ (entry 5). In the ${ }^{1} \mathrm{H}$ NMR spectrum of the inseperable mixture, the signals for the internal alkene protons

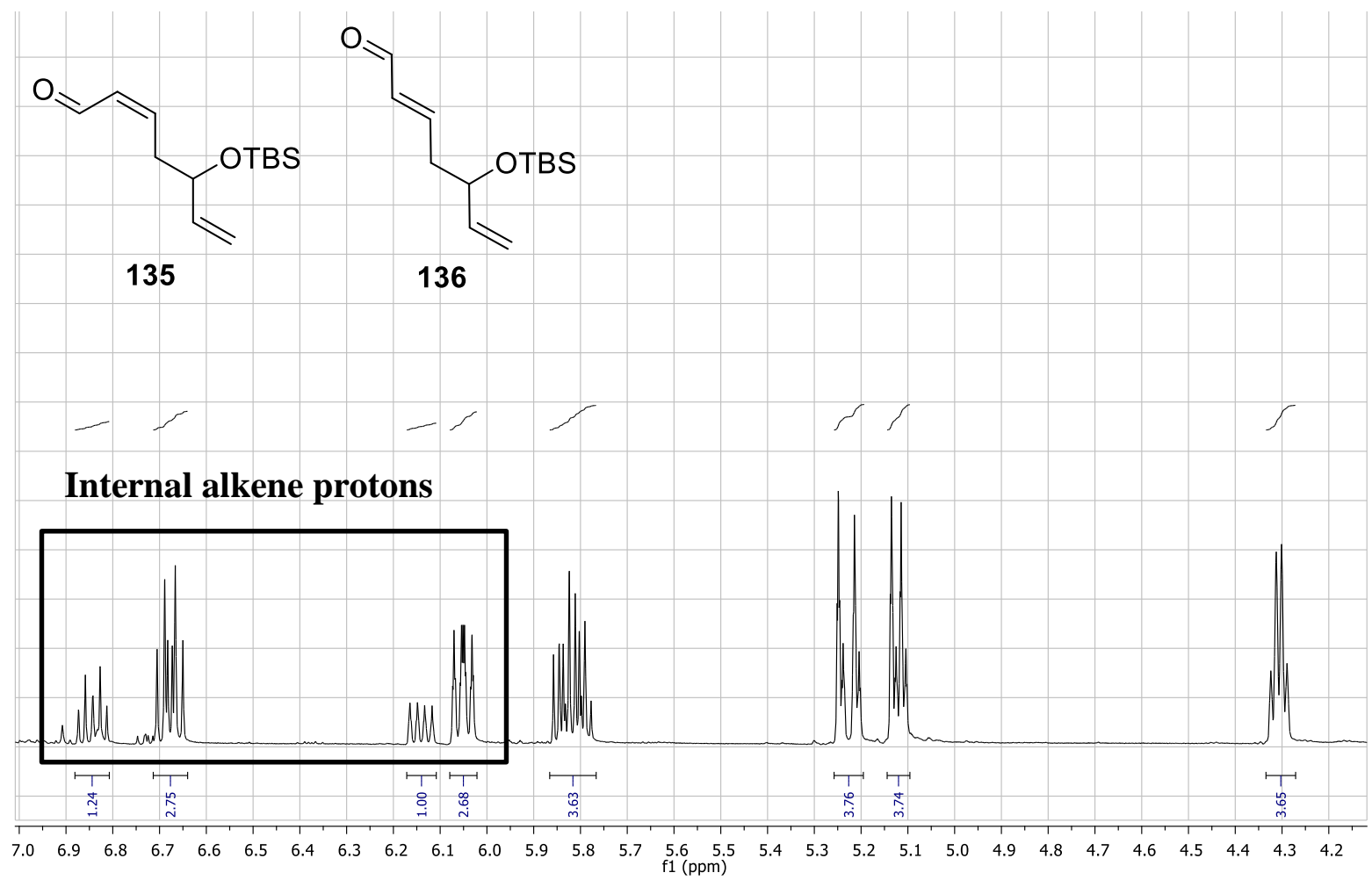

Figure 3.2: The alkene region of the ${ }^{1} \mathrm{H}$ NMR for the mixture of $\mathbf{1 3 5}$ and $\mathbf{1 3 6 .}$

are well-defined, and the vicinal coupling constants were measured as 11.1 and $15.5 \mathrm{~Hz}$ for the major and minor isomers, respectively, which are the typical values for $Z$ - and $E$-alkenes 
(Figure 3.2). Interestingly, although the oxymethine signal at $4.31 \mathrm{ppm}$ is not differentiated for the two compounds, the terminal alkene proton signals at 5.82, 5.23 and 5.12 ppm all had slight upfield shifts in the minor $E$-isomer 136. Thus, weak cross-talk must occur between the two alkenes in each compound. ${ }^{13} \mathrm{C}$ and $2 \mathrm{D}$ NMR experiments were conducted to assist the assignment of $\mathbf{1 3 5}$ and $\mathbf{1 3 5}$. The prolonged reaction time was seen to provide a chance for the alkene to isomerize. There was literature precedent that the addition of sodium carbonate to neutralize any acid and lowering the reaction temperature to $0{ }^{\circ} \mathrm{C}$ can avoid the problem of isomerization, ${ }^{32}$ which can be investigated in future.

Parikh-Doering oxidation has not been a commonly used method for the oxidation of $Z$-allylic alcohols, because it is typically carried out at room temperature, which is prone to cause thermal isomerization. However, this method was still tested on a mixture of the alcohols $\mathbf{1 3 3}$ and $\mathbf{1 3 8}$ produced from DIBAL-H reduction of a 1:1 mixture of $\mathbf{1 3 0}$ and $\mathbf{1 3 1}$ (Scheme 3.11). To decrease the chance of isomerization, the reaction was quenched before it reached completion. Encouragingly, the product consisted of a 1:1 mixture of the two Z-products, 135 and 139, and no isomerization was observed. Full NMR data were collected for characterization. Due to time constraints, Parikh-Doering oxidation on pure Z-allylic alcohol 133 was not performed.

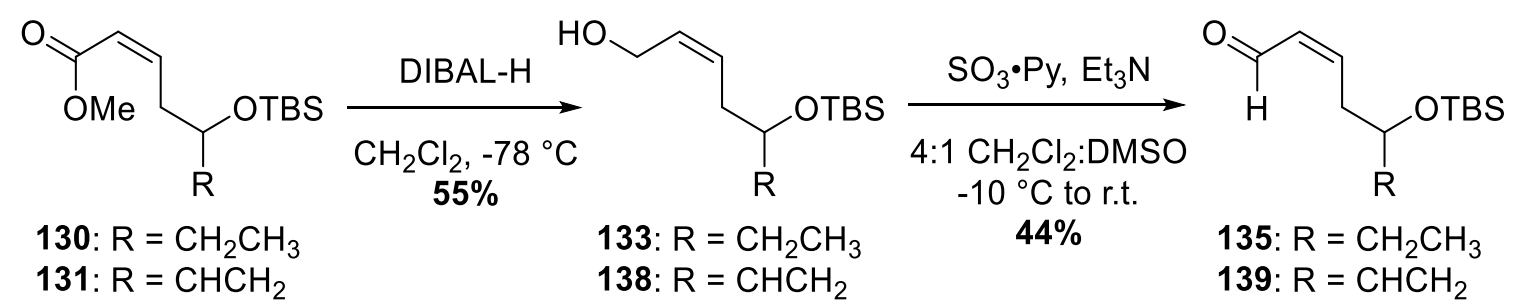

Scheme 3.11: Reduction and oxidation sequence on a 1:1 mixture of $\mathbf{1 3 0}$ and $\mathbf{1 3 1 .}$

\subsection{Synthesis of C16-C20 fragment}

According to the synthetic plan, the protection of the hydroxyl groups was sought with a TBDPS ether at C20 (see Scheme 2.2), and glycidol (97) was used as the starting material to synthesize the $\mathrm{C} 16-\mathrm{C} 20$ fragment $\mathbf{1 1 3}$. To this end, the protection of $\mathbf{9 7}$ to afford $\mathbf{1 4 0}$ proceeded 
in a consistently good yield (80 84\%), as did the epoxide ring-opening with TMS-acetylide to afford 141 (70 87\% yield) (Scheme 3.12). However, the acetylenic silyl deprotection produced an inseparable mixture of too products in a 5:2 ratio. While the TMS signal had disappeared, two sets of signals were observed in the oxygenated and propargylic regions of the ${ }^{1} \mathrm{H}$ NMR spectrum, and both closely resembled signals expected for the desired product 142. This mixture was proposed to consist of a 5:2 mixture of desired $\mathbf{1 4 2}$ and its regioisomer 143. To avoid silyl migration, this sequence was adjusted, such that removal of the acetynlenic TMS protecting group could be accomplished after protection of the secondary alcohol in $\mathbf{1 4 1}$, ideally as a para-methoxybenzyl (PMB) ether. Despite much effort, protection of the secondary alcohol with PMB was futile: both the well-established method using PMBtrichloroacetimidate ${ }^{33}$ and a recent acid-catalyzed protection method using PMB-alcohol and Amberlyst- $15^{34}$ only returned starting material. The most common method involving deprotonation of alcohol 141 with $\mathrm{NaH}$ followed by substitution of $\mathrm{PMBCl}$ was also attempted but, not surprisingly, silyl-migration occurred under the basic conditions. The NMR evidence from the crude reaction mixture suggested that the product was mostly starting material $\mathbf{1 4 1}$ and the silyl-migrated material 144, together with a small amount of C19-silyl,C20-PMBprotected product (145). Although this outcome is not desirable, it raised awareness that even

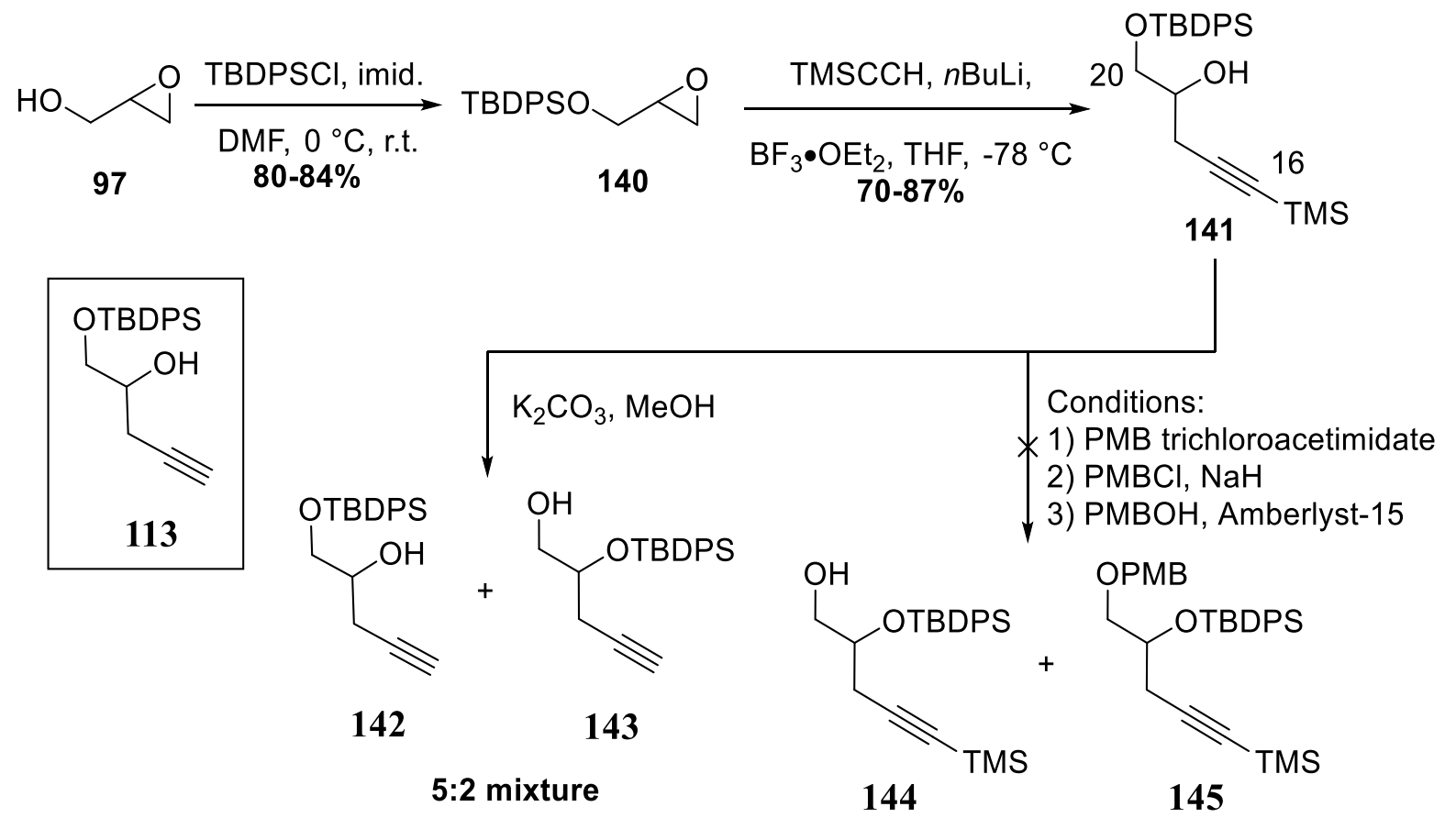

Scheme 3.12: The first attempt to synthesize C16-C20 fragment 113.

with a bulky protecting group such as TBDPS on C19, protection of the primary alcohol at C20 is still possible. In contrast, protection of the secondary hydroxyl group in the presence of a 
bulky C20 protecting group was deemed difficult, because of the higher steric hindrance around C19.

The previous findings evoked a new approach to this dual-protecting problem: a so-called "stepping stone" approach (Scheme 3.13). From the C20-PMB-protected fragment 146, transfer of the PMB group on C20 to C19 via a para-methoxyphenyl (PMP) acetal 147 could allow the less hindered primary $\mathrm{C} 20$ alcohol in $\mathbf{1 4 8}$ to be protected with a silyl group, and thus achieves the sought differential protection. A lot of work has previously been done on the regioselective opening of benzylidene acetals. ${ }^{35}$ The most commonly used DIBAL-H reduction method is expected to give the primary alcohol, because aluminum prefers to coordinate with the less hindered oxygen of the acetal, which then hydrolyzes during work-up to produce the primary alcohol. ${ }^{36-39}$ There are exceptions to the regioselectivity involving DIBAL-H, mainly due to unwanted additional chelation with other groups in those substrates, which should not occur with acetal 147.40,41 To test this strategy, fragment 146 was required, which could be prepared from glycidol (97) following a similar strategy as for the C20-TBDPS-protected fragment 141.

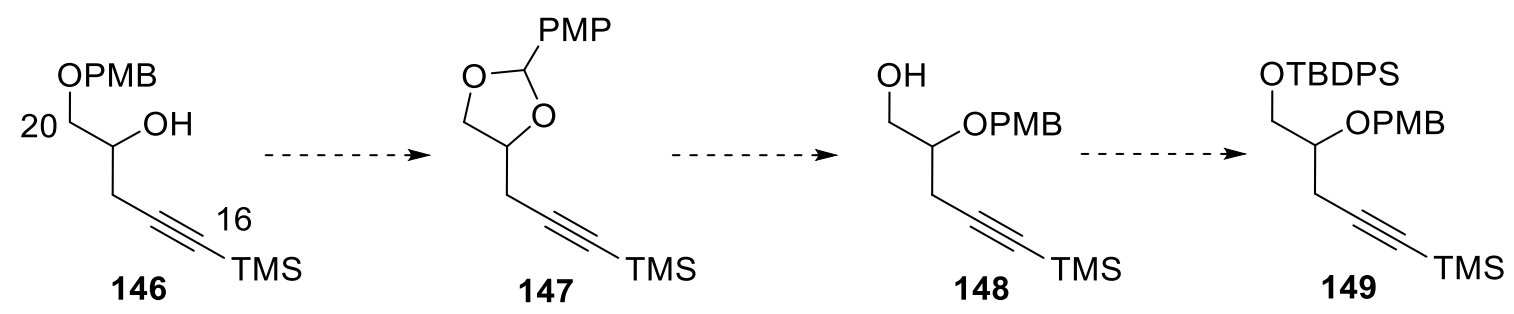

Scheme 3.13: "Stepping stone" approach to C16-C20 fragment 149.

The first attempt to protect glycidol (97) with commercially available p-methoxybenzyl chloride $(\mathrm{PMBCl})$ did not provide any reaction, presumed due to the quality of $\mathrm{PMBCl}$. $\mathrm{PMBCl}$ can be freshly made from $p$-methoxybenzyl alcohol, following Luzzio and Chen's sonication method. ${ }^{42}$ They reported that the quality of the prepared $\mathrm{PMBCl}$ was sufficient for use in reactions, after a simple separation of the aqueous layer, washing with water and drying with calcium chloride. However, the $\mathrm{PMBCl}$ prepared in that way also did not promote the desired protection, and mixtures of multiple degradation products were obtained, which were accompanied by disappearance of the epoxide signals in the ${ }^{1} \mathrm{H}$ NMR spectrum. The degradation could be resulted from the residual hydrochloric acid present in the prepared 
$\mathrm{PMBCl}$. An attempt to neutralize the PMBCl by washing it with an aqueous solution of sodium bicarbonate resulted in a mixture of about $1: 1 \mathrm{PMBCl}$ and $\mathrm{PMBOH}$. The $\mathrm{PMBCl}$ was then purified by dilution with diethyl ether, washing thoroughly with large amounts of water, drying over calcium chloride and purging under high vacuum. The quality of this prepared PMBCl was proved sufficient to be used for protection, with a satisfying $76 \%$ yield of the PMB ether 150 achieved (Scheme 3.14, equation 1). Synthesis of the required PMB ether 149 was also attempted by substitution of epichlorohydrin (151) with $p$-methoxybenzyloxide, or by reaction of glycidol (97) with freshly prepared PMB-trichloroacetimidate, but neither reaction provided satisfying results and insufficient conversions were obtained (equations 2 and 3).

1)

2)

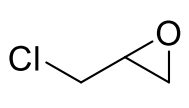

151

3)

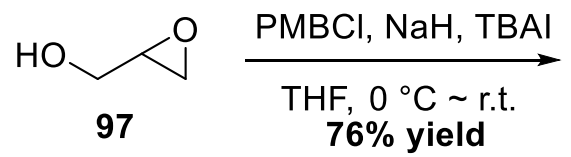

$\underset{\substack{\mathrm{THF}, 0{ }^{\circ} \mathrm{C} \sim \text { r.t. } \\ \mathbf{2 0} \% \text { yield }}}{\stackrel{\mathrm{PMBOH}, \mathrm{NaH}, \mathrm{TBAI}}{\longrightarrow}}$

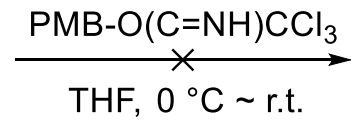

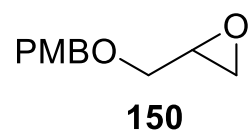
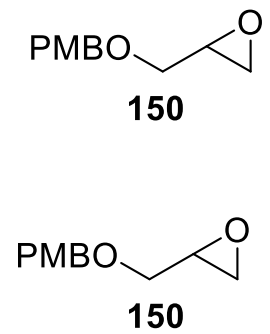

Scheme 3.14: Synthesis of PMB glycidyl ether $\mathbf{1 5 0 .}$

The epoxide opening of $\mathbf{1 5 0}$ by trimethylsilylacetylene was promoted by boron trifluoride diethyl etherate $\left(\mathrm{BF}_{3} \cdot \mathrm{OEt}_{2}\right)$. During the early trials, the available $\mathrm{BF}_{3} \cdot \mathrm{OEt}_{2}$ had been stored under atmospheric condition for over ten years, and it was distilled over calcium hydride prior to the reaction. However, the majority of the product obtained using this $\mathrm{BF}_{3} \cdot \mathrm{OEt}_{2}$ was the PMB-deprotected product 151, which could be due to the presence of a strong acid. It is well known that $\mathrm{BF}_{3} \cdot \mathrm{OEt}_{2}$ decomposes to a strong acid, tetrafluoroboric acid $\left(\mathrm{BF}_{4} \mathrm{H}\right)$ in the presence of water, and it may not be removed fully by distillation. ${ }^{43}$ With newly purchased $\mathrm{BF}_{3} \cdot \mathrm{OEt}_{2}$, this reaction went smoothly without any deprotection (73 89\% yield of 146), even on a gram scale (Scheme 3.15, equation a). The following acetylenic trimethylsilyl (TMS) deprotection with potassium carbonate and methanol produced $\mathbf{1 5 2}$ in a good yield. The synthesis of the enantiomerically pure fragments $(S)-146$ and $(S)$-152 from $(R)$-glycidol was carried out in the same manner and proceeded cleanly with good yields (equation $b$ ). 
(a)
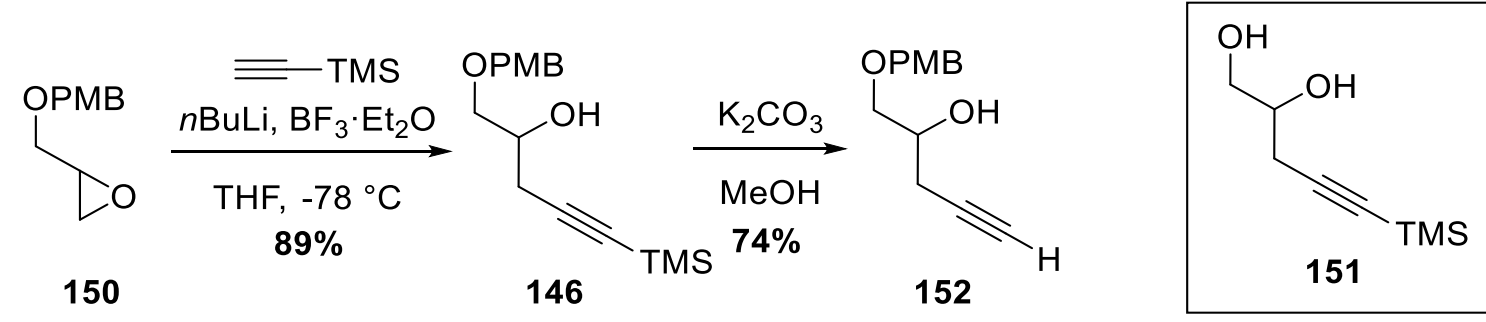

(b)

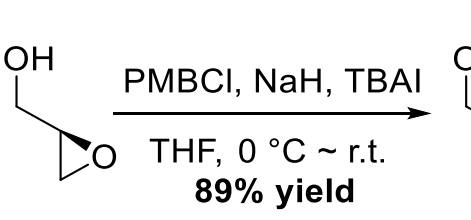

$(R)-97$

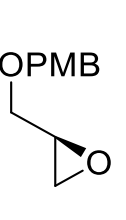

$(R)-150$

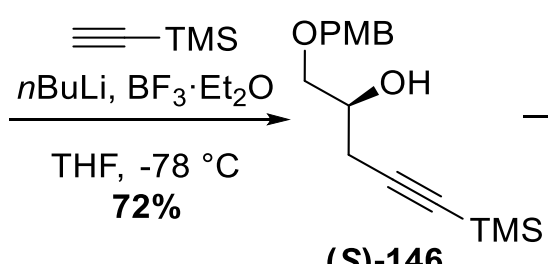

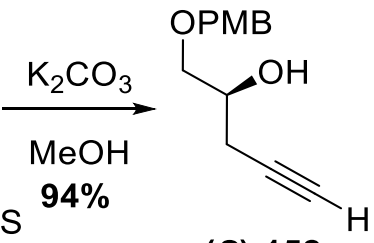

$(S)-152$

Scheme 3.15: Synthesis of the precursor to C16-C20 fragment 146 and 152.

Protection of the secondary alcohol in $\mathbf{1 5 2}$ with TBS was attempted. Not only is TBS less bulky than TBDPS and similarly orthogonal to the primary PMB protection at the $\mathrm{C} 20$ hydroxyl, the resulting product 153 would also offer an alternative route to the $\mathrm{C} 1-\mathrm{C} 8$ fragment 129 (Scheme 3.16). Although the synthesis of the $\mathrm{C} 1-\mathrm{C} 8$ fragment (129) is efficient and high yielding, the starting material acrolein (93) possesses many environmental and safety hazards, and can be fatal through inhalation, contact and swallowing. In addition, most chemical suppliers have discontinued supply of acrolein (93) because of its toxicity and difficulty to transport. Therefore, there may be no long-term, reliable supply of acrolein (93). Once the dual-protected C16-C20 fragment $\mathbf{1 5 3}$ is made, it could be adapted for the C3-C8 fragment (129) in the following way: the PMB group on C20 could be selectively deprotected, oxidized and olefinated via a Wittig reaction to produce enyne 119, a precursor to the $\mathrm{C} 1-\mathrm{C} 8$ fragment 129 as established earlier (see Scheme 3.4). However, the silyl protection did not proceed, even after 5 hours at $100{ }^{\circ} \mathrm{C}$. The search for an alternative route to fragment 129 continues.

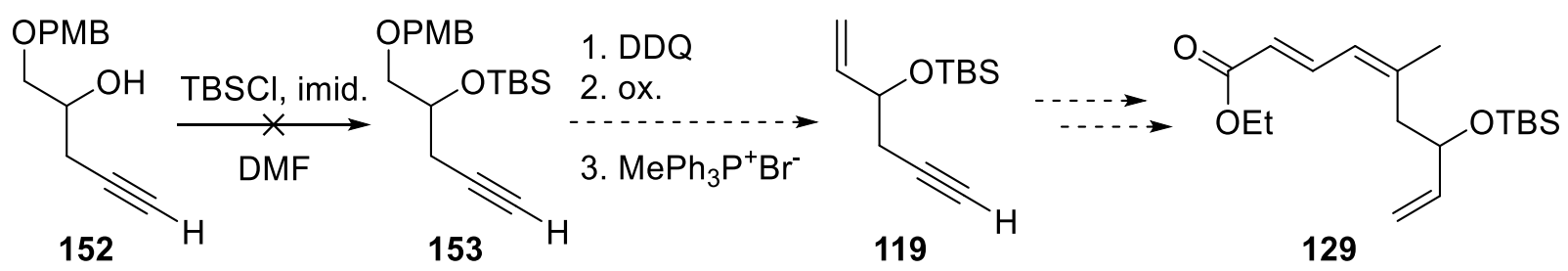

Scheme 3.16: Alternative synthetic plan for the C1-C8 fragment 129. 
The "stepping-stone' strategy for O19 protection was explored using 146 (Scheme 3.17). After a $14 \mathrm{~h}$ reaction with DDQ at $0{ }^{\circ} \mathrm{C}$, the oxidative acetal formation did not reach completion, and the crude reaction mixture consisted of a 2:2:3 ratio of diastereomers of 147: anisaldehyde: starting material 146. The presence of anisaldehyde indicates that this reaction had not been kept thoroughly dry, so more care in drying the reagents and glassware was required in future. A sample of $\mathbf{1 4 7}$ was isolated as a mixture of disterereomers, as expected, but was contaminated with $10 \mathrm{~mol} \%$ of anisaldehyde.
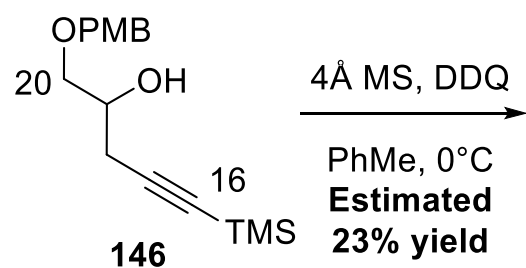
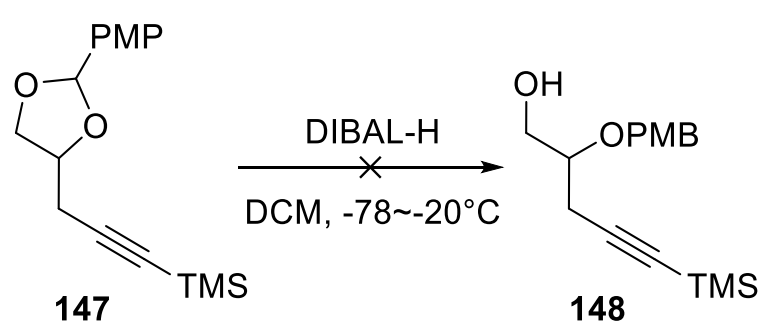

Scheme 3.17: Attempt to PMB-group transfer from O20 to O19.

The ${ }^{1} \mathrm{H}$ NMR spectrum of the mixture containing 147 diastereomers showed two sets of welldifferentiated peaks for the methine $\mathrm{H}^{\mathrm{a}}$ and the oxymethylene protons, $\mathrm{H}^{\mathrm{b}}$ in 147 (Figure 3.3). Two singlets at 5.91 and $5.76 \mathrm{ppm}$ were observed for the $\mathrm{H}^{\mathrm{a}}$ acetal protons of the diastereomers

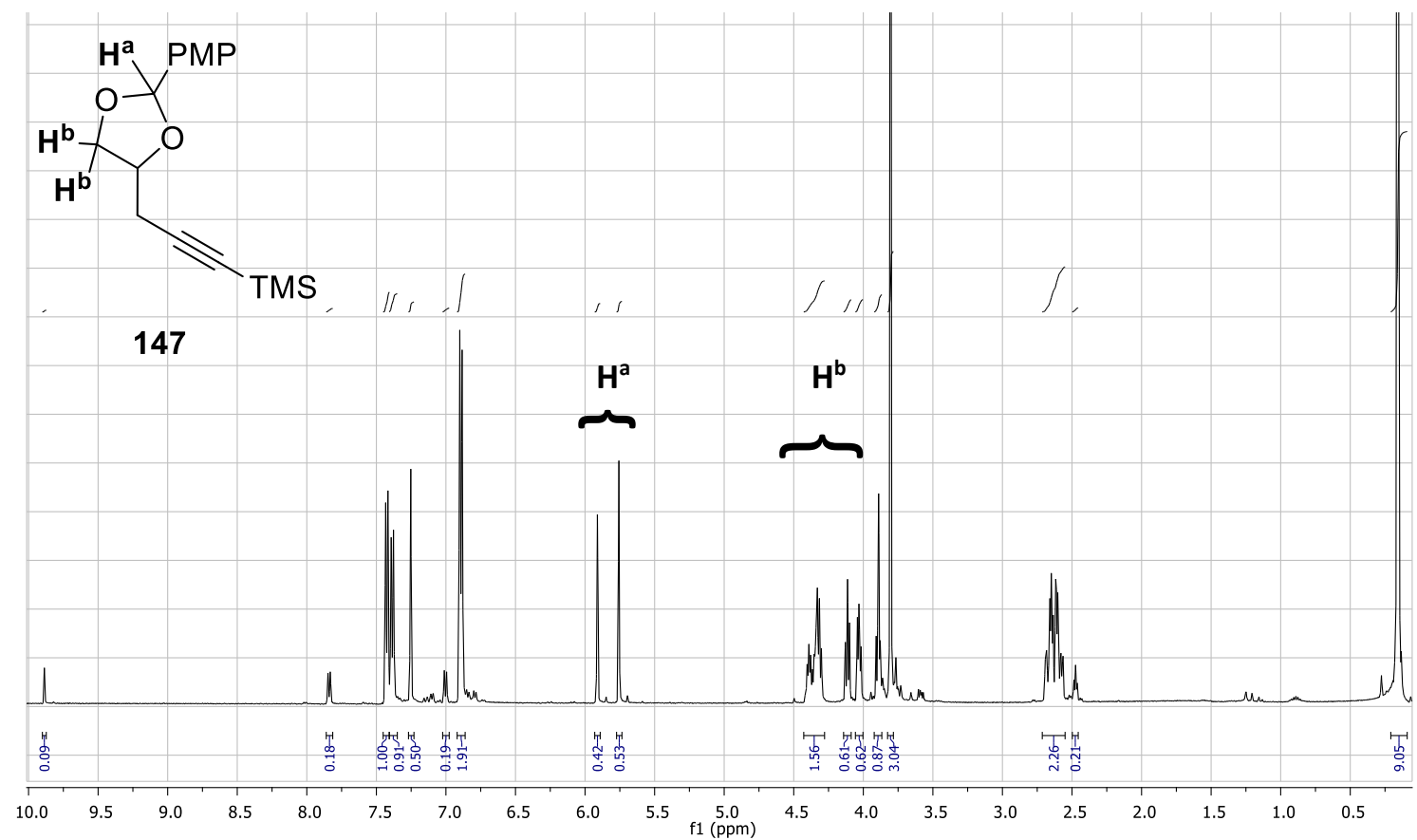

Figure 3.3: The ${ }^{1} \mathrm{H}$ NMR spectrum of the mixture containing diasteriomeric 147. 
of 147, while the oxymethylene protons $\mathrm{H}^{\mathrm{b}}$ were in an $\mathrm{ABM}$ sysem with the oxymethine protons, thus vicinal coupling was observed, and the signals appeared as two pairs. One pair of signals have higher chemical shifts at 4.34 and $4.39 \mathrm{ppm}$, and the other pair was found at 3.90 and $3.88 \mathrm{ppm}$.

The mixture containing acetal 147 was subjected to treatment with DIBAL-H to test the regioselectivity of the reductive ring-opening (Scheme 3.17). An excess of DIBAL-H (2.5 equivalents) was used to compensate for the presence of anisaldehyde. After an overnight reaction at $-19{ }^{\circ} \mathrm{C}$, only the acetal starting material 147 was observed by TLC analysis and ${ }^{1} \mathrm{H}$ NMR spectroscopy. Other acetal-opening methods are available for future exploration, for example, the lithium aluminum hydride/ trichloroaluminum combination, ${ }^{44}$ procedures involving borane $\mathrm{e}^{40,45}$ and other boron-containing reagents ${ }^{46,47}$. However, a more efficient approach that required the C19-hydroxyl to be unprotected was found, and thus effort was diverted to the new approach.

\subsection{Proposed synthesis of C9-C15 fragment}

Synthesis of the two variations of the C9-C15 subunit 115 and 116 (see Scheme 3.2) starts from (S)-aspartic acid (154) (Scheme 3.18). Firstly, the epoxide 155 can be formed stereoselectively via bromine substitution, reduction, epoxidation formation by intramolecular bromohydrin substitution and silyl protection. The preference for the oxirane over oxetane dictates exclusive formation of the desired epoxide 155. The epoxide 155 can then be opened by the vinyl Grignard reagent, and the resulting alcohol would be protected to afford 156. After the initial exploration of this method, a similar sequence was described in Altmann's publication of the total synthesis of (-)-zampanolide for production of the TBDPS equivalent of 155, which became the C9-C14 fragment upon construction of the pyran through a Prins reaction. ${ }^{48}$ In the present work, the secondary alcohol in 156 was protected with TBS or MOM groups for natural and analogue fragments. After selective deprotection of the silyl ether on the primary alcohol and oxidation, the substrate for pyran cyclization via iodoetherification or Pdmediated cyclization (114) can be produced. Alternatively, the alkene in $\mathbf{1 5 6}$ can be ozonized followed by a Horner-Wadsworth-Emmons reaction to establish the $\alpha, \beta$-unsaturated ester 
required for the $O$-Michael cyclisation, upon deprotection and oxidation producing fragment 115. Simplified fragments will also be synthesized to be used in model studies and to produce truncated analogues.

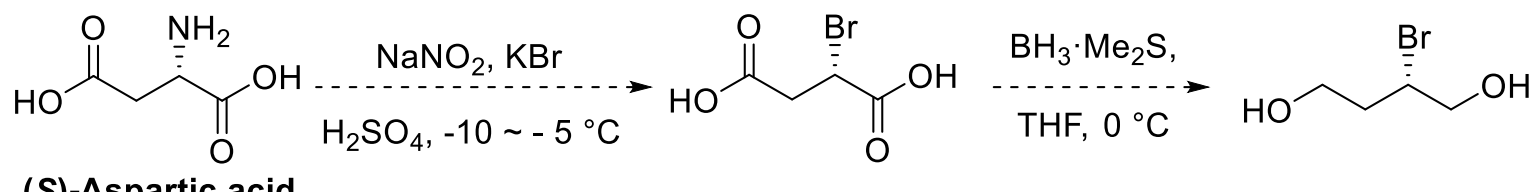

(S)-Aspartic acid

(154)

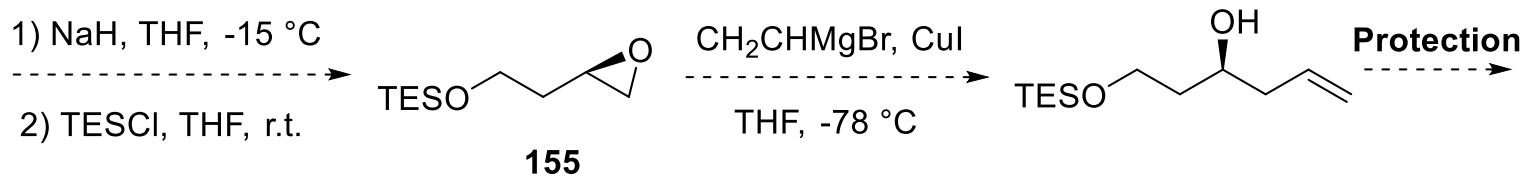

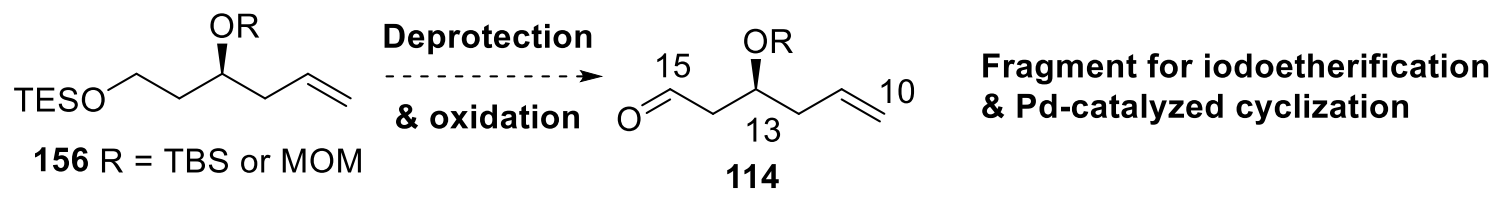

\section{Ozonolysis}

\& HWE

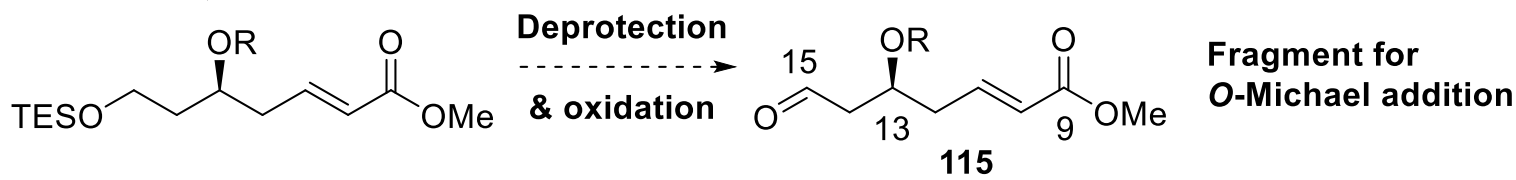

Scheme 3.18: Proposed synthesis of C9-C15 fragments 114 and $\mathbf{1 1 5 .}$

\subsubsection{Synthesis of the natural C9-C15 fragment}

This route had been explored by former colleague Sam Ting, although different protecting groups were planned to accommodate the current synthetic strategy. It proceeded with reasonable ease. The bromination to produce 157 is carried out via a Sandmeyer-type reaction, ${ }^{49}$ wherein the amine in $\mathbf{1 5 4}$ is converted to diazonium salt $\mathbf{1 5 8}$ upon treatment with acidic sodium nitrite solution. Neighbouring group participation by the carboxylic acid facilitates the dissociation of diazonium in a $\mathrm{S}_{\mathrm{N}} 2$-type fashion, forming an intermediate lactone 
159. Subsequent ring-opening by the bromide occurs, resulting in the double inversion, thus the stereochemistry at C17 is retained (Scheme 3.19).

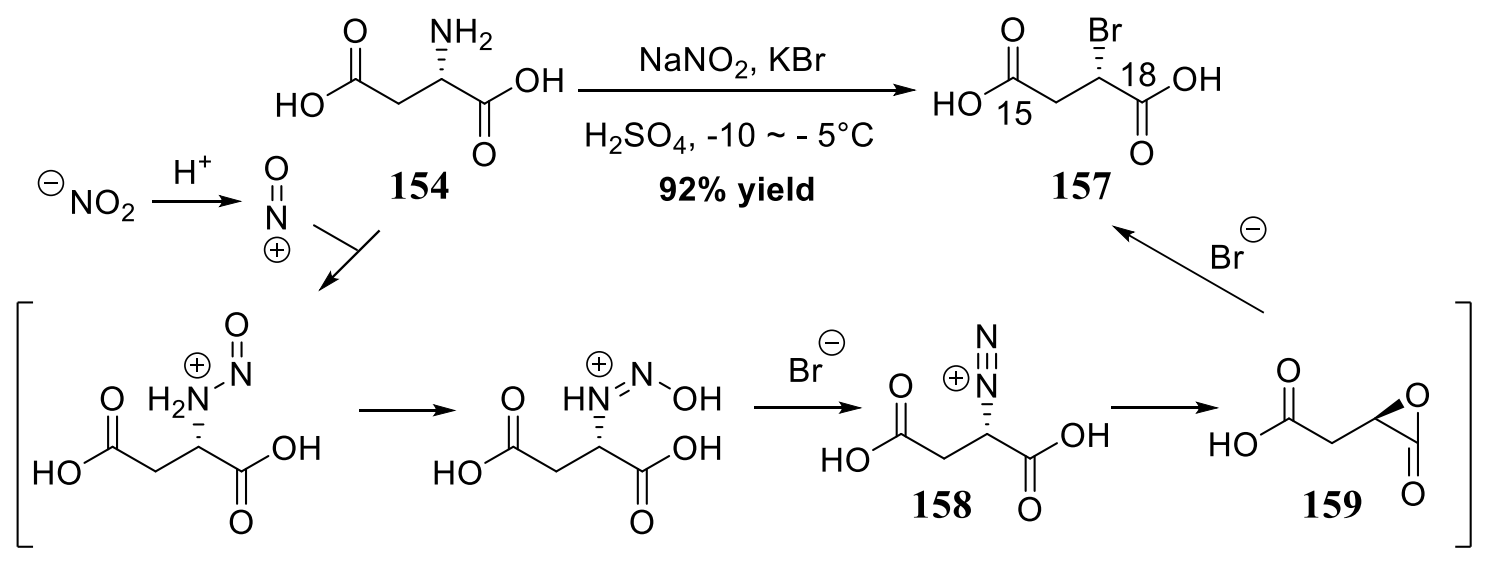

Scheme 3.19: Bromination of $\mathbf{1 5 4}$ via Sandmeyer reaction.

This reaction should be maintained below $-5{ }^{\circ} \mathrm{C}$, because diazonium salts are very unstable. Aromatic diazonium salts have been reported to dissociate to produce the corresponding phenol in the presence of acid and $\mathrm{H}_{2} \mathrm{O}$ if temperature arises. ${ }^{50,51} \mathrm{~A}$ related problem was encountered when scaling up the reaction from $10 \mathrm{~g}$ of $S$-aspartic acid to $20 \mathrm{~g}$ : an unknown by-product was formed. Its presence was first noticed as a yield of over 100\%. A closer examination revealed two peaks at 5.31 and $2.08 \mathrm{ppm}$ in the ${ }^{1} \mathrm{H}$ NMR spectrum, which are typical chemical shifts for an oxymethine proton in an ester and hydroxyl group, respectively (Figure 3.4), or alternatively dichloromethane and acetone. Neither of these solvents was used during the reaction or work-up, but, regardless, the product was further purged under high vacuum. The two signals at 5.31 and $2.08 \mathrm{ppm}$ did not disappear, consistent with them not being due to dichloromethane and acetone. The two peaks may suggest the formation of an alcohol byproduct and esterification with the carboxylic acid. However, the mass spectrum showed a second major negative molecular ion at $414.8474 \mathrm{~m} / \mathrm{z}$ as well as the product, and the isotope pattern indicated that it contains two bromines, which suggests instead that dimerization of the brominated product 157 or polymerization had occured. However, no obvious polymerization products with the above characteristics match the molecular weight. Even though it seems a minor impurity, its presence interferes with the subsequent reduction reaction, resulting in reduced yields and product contaminated by inseparable impurities. A small amount of the contaminated sample of $\mathbf{1 5 7}$ was recrystallized from water to produce non-transparent crystals, but this did not make an improvement in subsequent reactivity. 


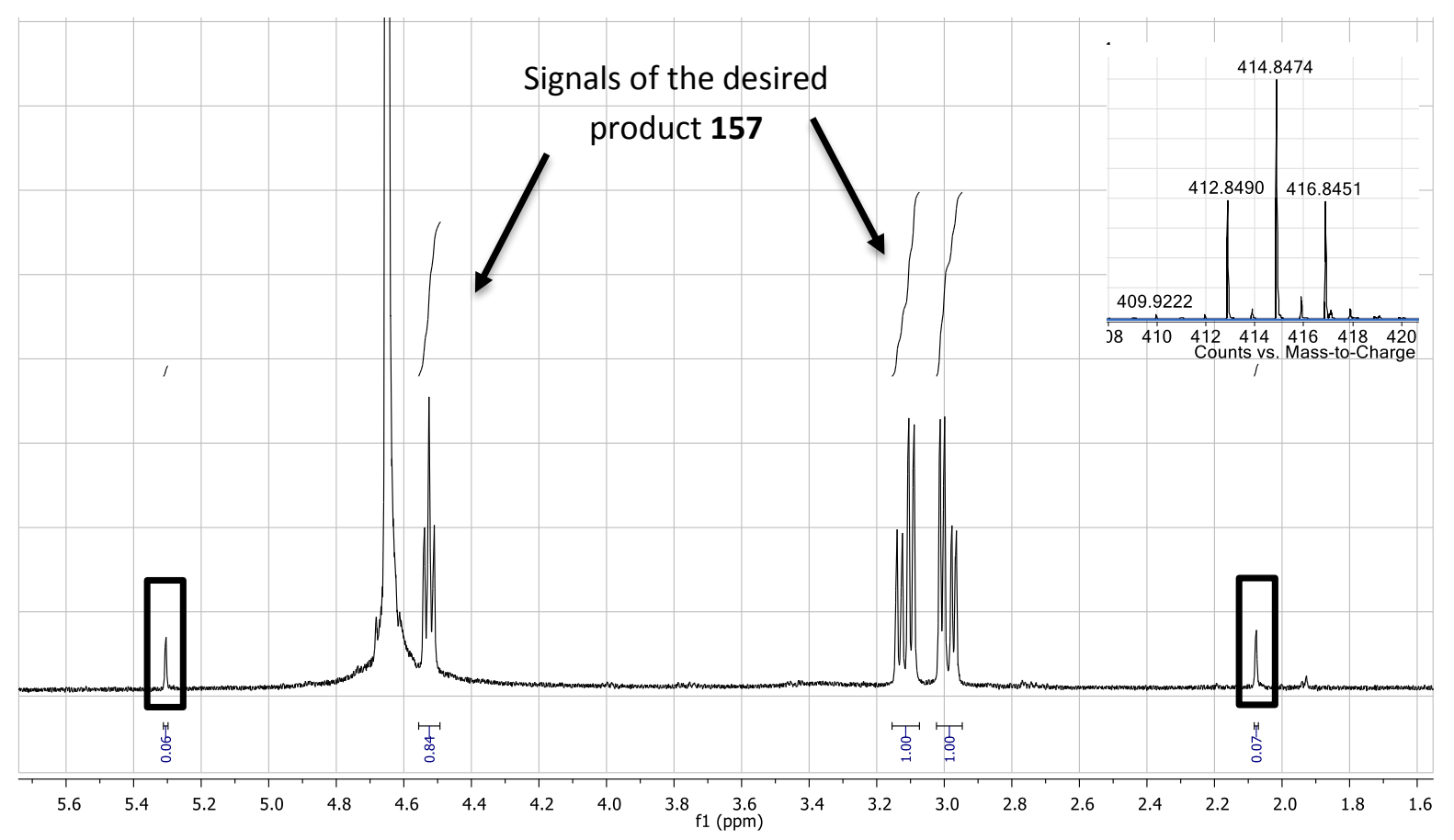

Figure 3.4: ${ }^{1} \mathrm{H}$ NMR and mass spectra of the unknown by-product from large-scale bromination.

The borane reduction of $\mathbf{1 5 7}$ to afford $\mathbf{1 6 0}$ was initially difficult to handle. Following the literature work-up, ${ }^{52}$ the reaction mixture turned into a hard gel upon warming to room temperature, even after quenching. This may have resulted from a borane-THF complexation or THF polymerization, but neither could be confirmed. Initially the reaction produced unsatisfyingly low yields. An attempt to switch the solvent from THF to toluene totally quenched the reactivity of borane and starting material was recovered. After more experiments the best yield (75\%) was achieved with a Rochelle salt quench at $0{ }^{\circ} \mathrm{C}$, slowly warming up to room temperature over an hour and vigorous stirring for a prolonged time (Scheme 3.20). The following one-pot epoxide formation and silyl protection to $\mathbf{1 5 5}$ is a very reliable reaction, and the epoxide opening with vinylmagnesium bromide also reached good yields when purified $\mathrm{CuI}$ and newly purchased Grignard reagent were used. According to the current protecting group strategy, this secondary alcohol in $\mathbf{1 5 6}$ was protected with TBS to afford bis-silylated product 161 with a $72 \%$ yield. 
<smiles>C[As](C)(=O)OCCC1CO1</smiles>

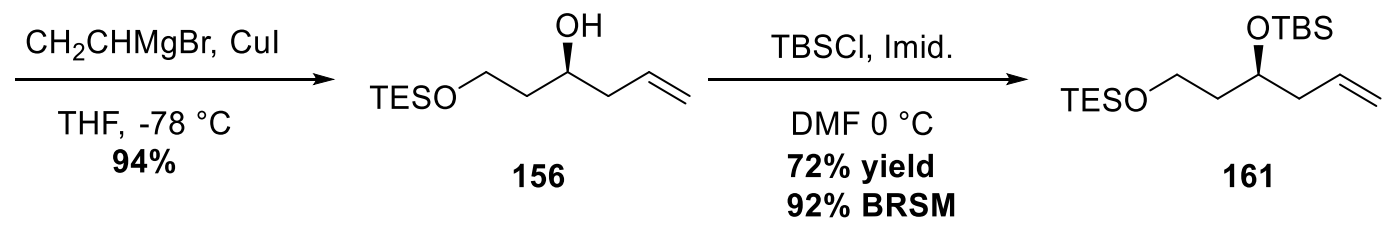

Scheme 3.20: Synthesis of C9-C15 fragment precursor 161.

Deprotection of the TES ether in $\mathbf{1 6 1}$ with HF $P$ Py to 162 was initially quite low yielding despite running the reaction overnight (Scheme 3.21). It was speculated that the prolonged reaction time promoted double deprotection to the diol $\mathbf{1 6 3}$, and that shorter reaction times could avoid all or the majority of TES-deprotection. It was also found that the dryness of acetonitrile is essential. When analytical grade acetonitrile was used, both silyl groups were fully deprotected and either or both of the alcohols were found to be acetylated, producing inseparable mixtures of 164, 165 and 166 in a ratio of 7:2:1, respectively. No direct acetylation source had been present.
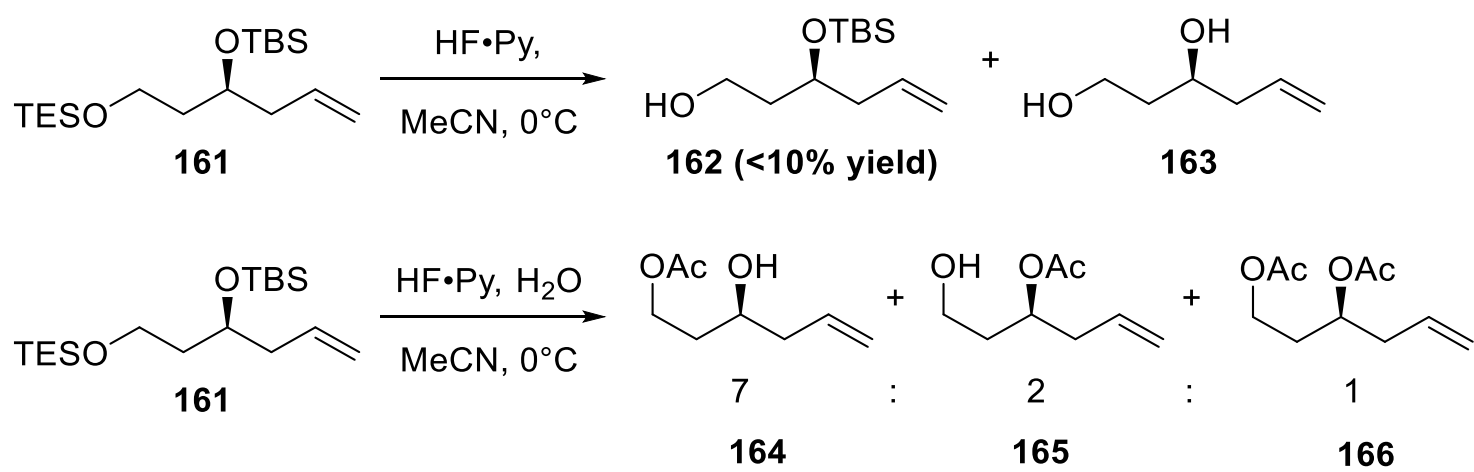

Scheme 3.21: Deprotection of TES ether in $\mathbf{1 6 1}$ with HF·Py.

This puzzling phenomenon could be explained by an attack of the alcohol functionalities in doubly deprotected $\mathbf{1 6 3}$ on acetonitrile to produce an imine, which is then hydrolyzed in the presence of water to produce the acetates 164, 165 and 166 (Scheme 3.22, mechanism I). This is only possible if the acetonitrile was protonated by $\mathrm{HF}$ in the presence of $\mathrm{H}_{2} \mathrm{O}$ to become a better electrophile. Another possible mechanism was considered based on an observation 
reported in 1970 by J. R. Norell. In that work, it was shown that hydrogen fluoride can fluorinate terminal alkenes at ambient temperatures $\left(25 \sim 40^{\circ} \mathrm{C}\right)$, and the resulting fluoride reacts with acetonitrile in the presence of water to produce $N$-alkyl acetamides. ${ }^{53}$ With this information, the acetyl may be sourced from the amide in 167 (Mechanism II). However, even though acetyl transfer to the secondary alcohol via a six-membered transition state is possible, the acetyl transfer to the primary alcohol via an eight-membered ring could be very difficult. In addition, to restore the terminal alkene, amine elimination must occur, which is highly unlikely under the reaction conditions.

\section{Mechanism I}

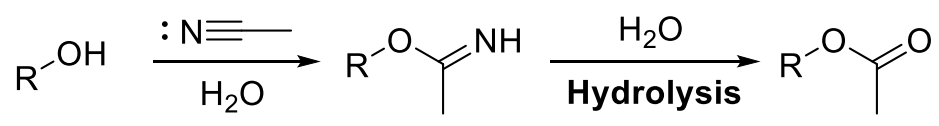

\section{Mechanism II}<smiles>C=CC[C@@H](O)CCO</smiles><smiles>C=CC[C@@H](O)CCOC(C)=O</smiles>

Scheme 3.22: Possible mechanisms for acetylation.

Current PhD student Sophie Geyrhofer confirmed the double deprotection of 161 to afford 163 occurs in overnight reactions, and successfully produced the TES-deprotected product 162 with a $61 \%$ yield after a $3 \mathrm{~h}$ reaction at $0{ }^{\circ} \mathrm{C}$. Even with the short reaction time, $20 \%$ of the doubly deprotected diol 163 was also isolated, thus further optimization of this reaction is required. However, the synthetic strategy has been altered, and the TES protection was retained until a later stage.

\subsubsection{Synthesis of C9-C15 analogue fragments}

One aim of this project is to find simplified analogues of zampanolide (19) that can be synthesized by shorter sequences than for the natural product. As removal of the exo-methylene was found to be beneficial to retain the cytotoxicity, ${ }^{48,54}$ the use of 5-hexenal (168) as an 
analogue fragment of $\mathrm{C} 9-\mathrm{C} 16$ was proposed, which avoids the lengthy process required to synthesize C9-C15 fragment (115). A good number of literature sources reported that 168 would be easily accessed by oxidation of the cheap and readily available 5-hexenol (169), and various oxidation methods could be used (Scheme 3.23). ${ }^{55-58}$

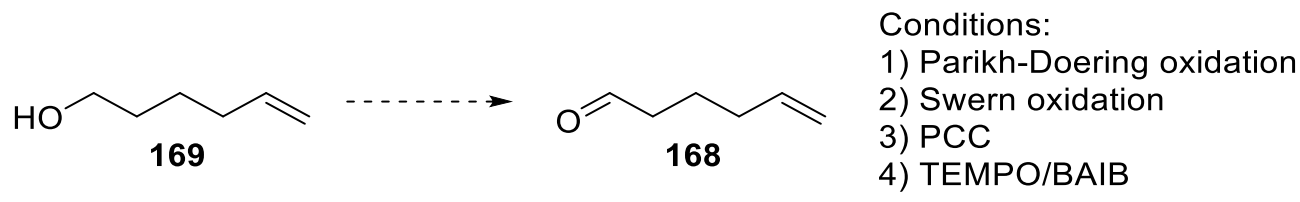

Scheme 3.23: Planned preparation of 5-hexenal (168) via oxidation.

Parikh-Doering oxidation was first attempted. By ${ }^{1} \mathrm{H}$ NMR spectroscopy, the crude mixture contained almost exclusively the desired aldehyde $\mathbf{1 6 8}$ and pyridinium compound. However, during column chromatography, the purified product decomposed. The ${ }^{1} \mathrm{H}$ NMR spectrum showed that nearly all aldehyde signals vanished and a new oxymethine signal appeared, which suggested that the aldehyde $\mathbf{1 6 8}$ might have polymerized. No effort was put towards the characterization of this product. Some fractions containing 168 was collected, but it was always contaminated by impurities. Preparation of 5-hexenal (168) was then attempted by using pyridinium chlorochromate (PCC). Attempts to purify the crude product with a Celite plug resulted in unsatisfying purification, and a silica plug again decomposed the desired $\mathbf{1 6 8}$. However, the aldehyde functionality was conserved this time. This product was characterized, and identified as the dimerized product 170. It is commonly known that aldehydes can dimerize via aldol reactions (Scheme 3.24), where the enol formation can be promoted by the presence of acid or base.

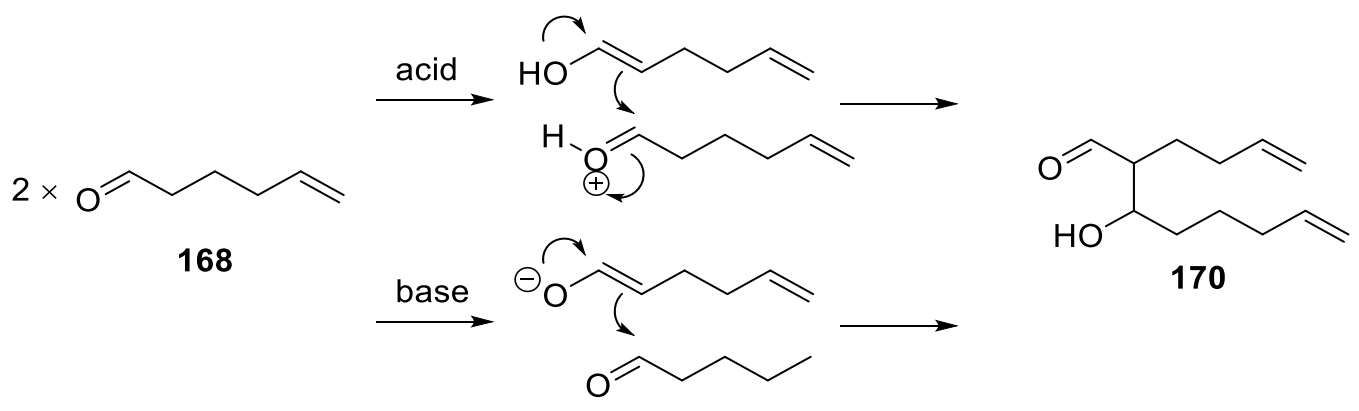

Scheme 3.24: Dimerization of 5-hexenal (168) via aldol reaction. 
The dimerized product 170 was never obtained in pure form, but NMR, HRMS and IR evidence all support the assignment of the dimer structure. Interestingly the ${ }^{1} \mathrm{H}$ NMR spectrum of $\mathbf{1 7 0}$ shows the signals at 2.45 and $4.07 \mathrm{ppm}$ as triplets (Figure 3.5), which are the protons $\alpha$ - and $\beta$ - to the aldehyde $\left(\mathrm{H}^{2}, \mathrm{H}^{3}\right)$ respectively. The coupling constants indicate that there is no vicinal coupling between aldehyde and $\alpha$-protons or $\alpha$ - and $\beta$-protons. According to the Karplus equation, vicinal coupling constant is proportional to $\cos ^{2} \theta$, where $\theta$ is the dihedral angel. Thus, it can be assumed that free rotation is hindered and the $\alpha$-proton must be approximately perpendicularly oriented to both aldehyde proton and $\beta$-proton.

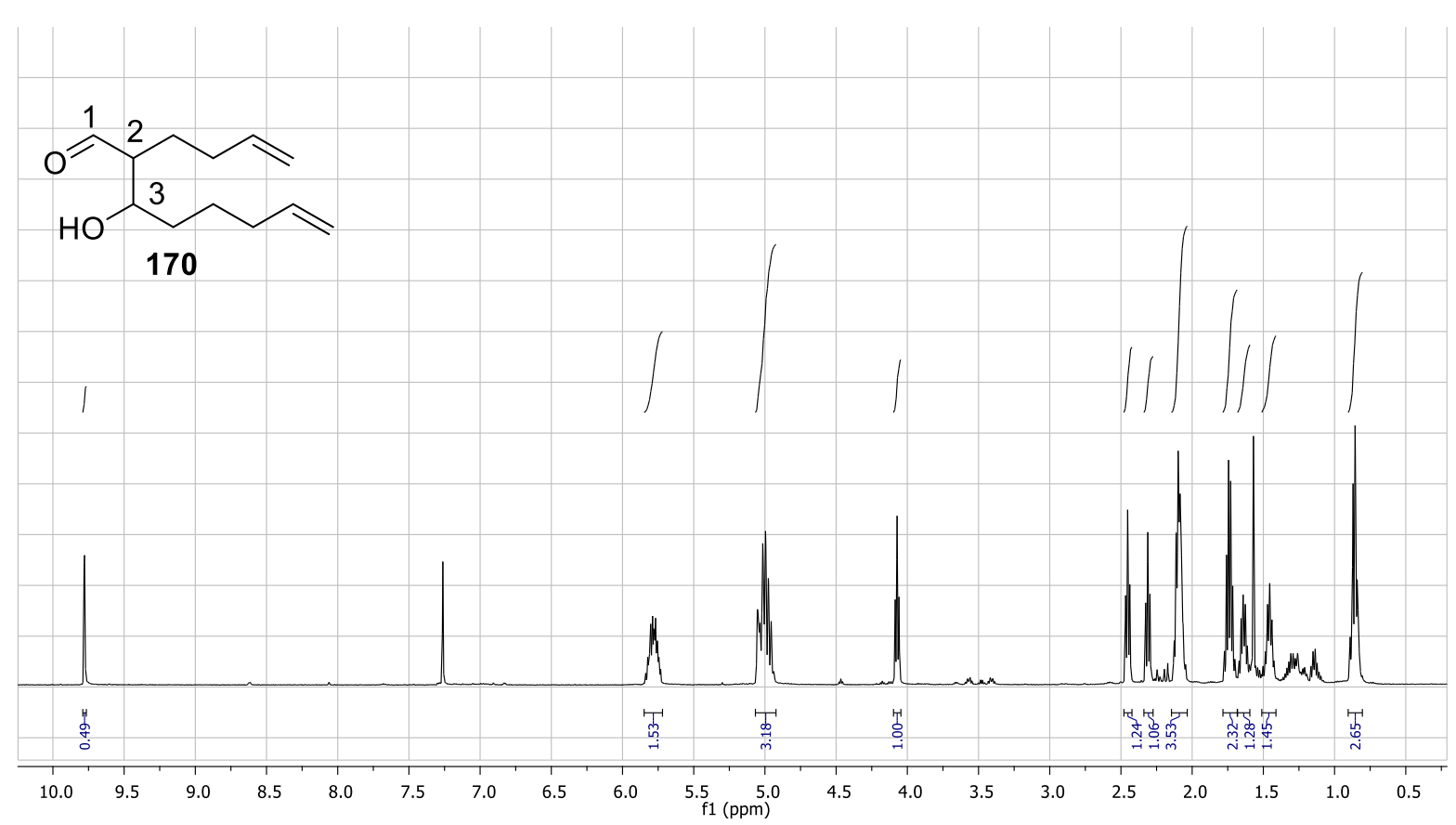

Figure 3.5: ${ }^{1} \mathrm{H}$ NMR spectrum of the dimerized aldehyde product $\mathbf{1 7 0}$.

To have such geometry, hydrogen bonding between the hydroxy and aldehyde together with the steric hindrance of the long chains may be constraining $\mathbf{1 7 0}$ in a rigid six-membered ring such that there are $c a .90^{\circ}$ angles between $\mathrm{H}^{1}, \mathrm{H}^{2}$ and $\mathrm{H}^{3}$. The Newman projection of $(2 R, 3 S)$ $\mathbf{1 7 0}$ is shown in Figure 3.6 for demonstration. 


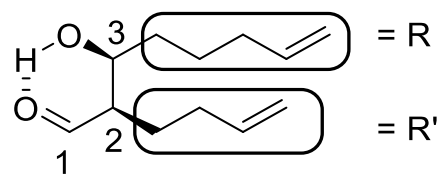

$(2 R, 3 S)-170$

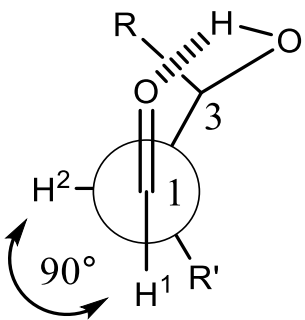

View along C1-C2 bond

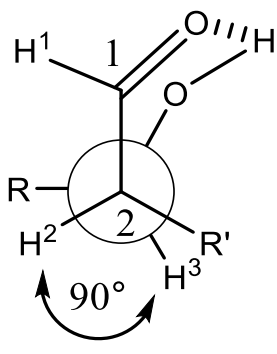

View along C2-C3 bond

Figure 3.6: Proposed conformation of the dimerized product 170 based on proton coupling.

It was hypothesized that aldehyde 168 could be unstable in contact with the acidic silica or upon concentration. Swern oxidation of 5-hexenol (169) produced the cleanest sample of crude product 168, which was hoped would allow purification without silica. After washing the reaction mixture thoroughly with water, the only contaminant left was triethylamine $\left(\mathrm{Et}_{3} \mathrm{~N}\right)$. However, the further attempt to remove $\mathrm{Et}_{3} \mathrm{~N}$ by washing with aqueous potassium bisulfate $\left(\mathrm{KHSO}_{4}\right)$ solution caused decomposition, and the aldehyde signal vanished on ${ }^{1} \mathrm{H}$ NMR spectrum. TEMPO/BAIB oxidation was also attempted. Theoretically, upon full conversion, the reaction mixture would contain mostly high boiling point species, and the relatively lower boiling point compounds would be the desired product $168\left(128 \sim 129{ }^{\circ} \mathrm{C}\right)^{59}$ and a low boiling solvent such as dichloromethane. Therefore, purification would be possible by distilling the reaction mixture to yield a solution of 5-hexenal (168) in dichloromethane. Vacuum distillation was initially investigated and yielded a dichloromethane solution of $\mathbf{1 6 8}$ enriched with iodobenzene. Atmospheric pressure distillation after dissolving the crude reaction mixture in diethyl ether indeed removed iodobenzene, but dimerization still occurred in the solution. Therefore, it is concluded that 5-hexenal (168) spontaneously dimerizes in pure form. A commercial source was also considered, but $\mathbf{1 6 8}$ is only available via custom synthesis, which is too expensive for this project. A careful review of the literature found that this aldehyde product 168 was often used without purification, ${ }^{60-63}$ but this is not an option for this project. The intended use of $\mathbf{1 6 8}$ is in a metal-promoted alkynylation reaction and such reactions are often very sensitive to impurities. Therefore, this model substrate was abandoned. Similar experiments to carry the C9-C15 fragment 162 to the aldehyde 114 were done by current $\mathrm{PhD}$ student Sophie Geyrhofer (Scheme 3.25). She found that the oxidation of TES-deprotected product $\mathbf{1 6 2}$ does not stop at the aldehyde, but demonstrated a high propensity to carry on to 
the acid 171. Various oxidation conditions were tested, including Dess-Martin periodinane, IBX, Swern, and TEMPO/BAIB oxidations.
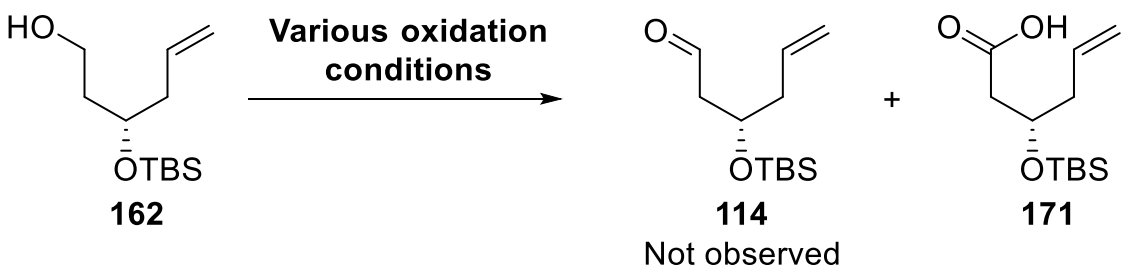

Scheme 3.25: Geyrhofer's oxidation of alcohol 162.

From the findings of both the model and real fragments, it was hypothesized that the terminal alkene might be interfering with the oxidation, thus the aldehyde should be formed in the absence of a terminal alkene. As described before, the fragment required for $O$-Michael addition (115) contains an $\alpha, \beta$-unsaturated ester instead of the terminal alkene, thus the synthesis of fragment 115 could be explored (see Scheme 3.18). Alternatively, the alkene in 161 can be ozonized to produce the aldehyde 172, and the C11 silyl ether can be cleaved after asymmetric alkynylation and protection of the resulting propargylic alcohol (Scheme 3.26). The primary alcohol is then revealed ready for oxidation to produce aldehyde 173. A TESprotection can be used for the propargylic alcohol, as the primary TES ether can be deprotected selectively over the secondary, and TES is partially orthogonal to TBS for later transformations. The 173 can be transformed via a Horner-Wadsworth-Emmons reaction to afford the $\alpha, \beta$ unsaturated methyl ester 174, set up for $O$-Michael addition, or via a Wittig reaction to produce the precursor 175 for iodoetherification or Pd-catalyzed cyclization. The terminal alkene 175 could alternatively be subjected to cross metathesis with methyl acrylate to afford 174 or RCM to form 176, precursor to a truncated monocyclic analogue. 

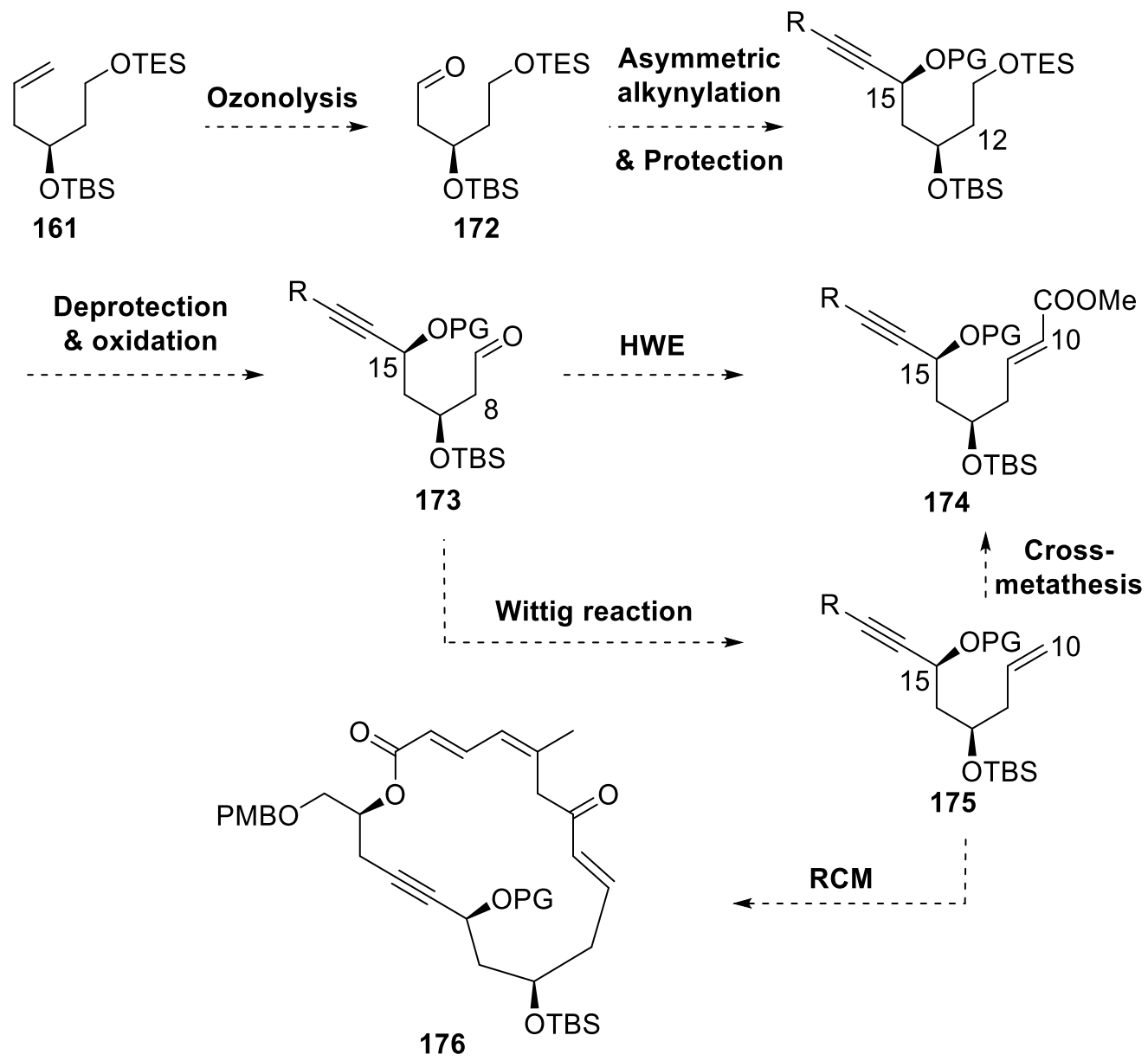

Scheme 3.26: Alternative synthetic strategy for pyran fragment $\mathbf{1 7 4}$ and $\mathbf{1 7 5}$.

A simple model aldehyde 177 was prepared in two steps via silyl protection of 5-hexenol (169) followed by ozonolysis. With only an aqueous work-up after the protection step, a good 95\% yield of $\mathbf{1 7 7}$ was obtained over the two steps.

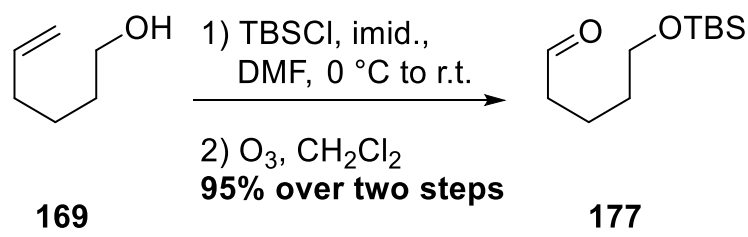

Scheme 3.27: Synthesis of model fragment 117. 


\subsection{Experimental data}

\section{General experimental information}

Unless otherwise stated, all reactions were carried out in oven-dried glassware under a positive pressure of nitrogen, delivered via a manifold, or argon from a balloon. Dry tetrahydrofuran, dichloromethane and toluene were obtained from a PureSolv MD 5 solvent purification system (Innovative Technology). Dry dimethylformamide was purchased from Acros and used without further purification. DMSO, triethylamine and oxalyl chloride were purified by distillation with calcium hydride as drying agent. Analytical grade solvents were used for aqueous work-up and column chromatography (petroleum ether, ethyl acetate, diethyl ether, dichloromethane and methanol). Column chromatography was performed on silica gel $60 \AA$ (Pure Science, 40-63 micron) with the eluent mixtures as stated in the corresponding procedures. Thin-layer chromatography was performed on silica-coated plastic plates (Macherey-Nagel, POLYGRAM ${ }^{\circledR}$ Sil G/UV 254 ). UV-active compounds were detected under UV irradiation $(\lambda=254 \mathrm{~nm})$, while non-UV-active compounds were visualised with anisaldehyde or potassium permanganate staining solutions.

$\mathrm{PMBCl}$ was prepared freshly using the previously reported method. ${ }^{42}$ All other chemicals were purchased from Pure Science, Sigma-Aldrich, AK Scientific, Acros, Merck, British Drug House, Burkes Research, Thermo Fisher Scientific, Avocado, Panreac Riedel-de Haën and Apollo. Infra-red (IR) spectra were collected from liquid films on a Perkin Elmer Spectrum One FT-IR spectrometer or neat sample on an ALPHA FT-IR spectrometer (Bruker) fitted with attenuated total reflectance (ATR). The intensities of signals are defined as: $b r=$ broad, $\mathrm{s}=$ strong, $\mathrm{m}=$ medium, $\mathrm{w}=$ weak. Mass spectra were collected on an Agilent 6530 AccurateMass Q-TOF LC/MS high-resolution mass spectrometer (HRMS). The specific rotations were collected on an AUTOPOL II automatic polarimeter (Rudolph Research Analytical), and the reported values are an average of 10 measurements and concentrations are reported in $\mathrm{g} / 100$ $\mathrm{mL}$.

Nuclear magnetic resonance (NMR) spectra were obtained in deuterated chloroform $\left(\mathrm{CDCl}_{3}\right)$ or deuterium oxide $\left(\mathrm{D}_{2} \mathrm{O}\right)$ using Varian Inova instruments operating at 300 or $500 \mathrm{MHz}$ for proton and 75 or $125 \mathrm{MHz}$ for carbon. Proton and carbon chemical shifts are reported in parts per million (ppm) relative to residual $\mathrm{CHCl}_{3}\left[\delta\left({ }^{1} \mathrm{H}\right)=7.26 \mathrm{ppm}\right], \mathrm{H}_{2} \mathrm{O}\left[\delta\left({ }^{1} \mathrm{H}\right)=4.66 \mathrm{ppm}\right]$, and $\mathrm{CDCl}_{3}\left[\delta\left({ }^{13} \mathrm{C}\right)=77.0 \mathrm{ppm}\right]$, respectively. Signals are defined as: $\mathrm{s}=$ singlet, $\mathrm{d}=$ doublet, $\mathrm{t}=$ triplet, $\mathrm{q}=$ quartet, quin $=$ quintet, $\mathrm{m}=$ multiplet, app. $=$ apparent, obs. $=$ obscured peak, br. $=$ 
broad. Coupling constants $(J)$ are reported in Hertz $(\mathrm{Hz})$. Assignments were determined by two-dimensional NMR experiments (COSY, NOESY, HSQC and HMBC).

\section{CuI purification:}

To a boiling aqueous solution of $\mathrm{NaI}(7.0 \mathrm{~g}, 47 \mathrm{mmol})$ in $\mathrm{H}_{2} \mathrm{O}(5 \mathrm{~mL}, 9 \mathrm{M})$, CuI (1.00 g, 5.26 mmol) was added portionwise over $45 \mathrm{~min}$. The solution progressively turned red with each addition. The solution was cooled down to r.t., and then $0{ }^{\circ} \mathrm{C} . \mathrm{H}_{2} \mathrm{O}$ was added to precipitate out $\mathrm{CuI}$. The precipitate was filtered, washed with $\mathrm{H}_{2} \mathrm{O}$, ethanol, EtOAc, $\mathrm{Et}_{2} \mathrm{O}$ and petroleum ether successively. The solid was further dried under high vacuum to yield $\mathrm{CuI}$ as a pale-pink powder (811 mg).

\section{Activation of zinc powder:}

To a suspension of zinc powder $(3.1 \mathrm{~g}, 47 \mathrm{mmol})$ in $\mathrm{H}_{2} \mathrm{O}(10 \mathrm{~mL})$, an aqueous $\mathrm{HCl}$ solution $(0.3 \mathrm{~mL}, 4 \mathrm{M})$ was added dropwise with shaking until the release of small gas bubbles was observed. The activated zinc powder was filtered, washed sequentially with $\mathrm{H}_{2} \mathrm{O}, \mathrm{MeOH}$, EtOAc, $\mathrm{Et}_{2} \mathrm{O}$ and petroleum ether, and dried under high vacuum to yield a pale grey powder $(3.0 \mathrm{~g})$.

\section{Synthesis of C3-C8 fragment}

\section{(Hex-1-en-5-yn-3-yloxy)tert-butyldimethylsilane (118)}

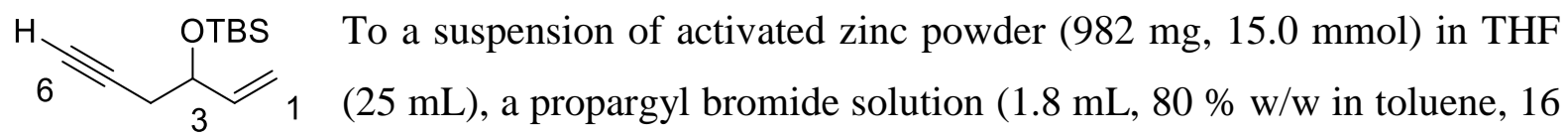
mmol) was added dropwise. The reaction mixture was stirred at r.t. for $1 \mathrm{~h} 30 \mathrm{~min}$. After the addition of further equivalent of activated zinc powder (410 mg, $6.27 \mathrm{mmol})$, the reaction was cooled down to $-78{ }^{\circ} \mathrm{C}$. A solution of acrolein $(\mathbf{9 3})(0.50 \mathrm{~mL}, 7.5 \mathrm{mmol})$ in THF $(4.2 \mathrm{~mL})$ was added dropwise at $-78^{\circ} \mathrm{C}$. The reaction mixture was stirred at $-78{ }^{\circ} \mathrm{C}$ for $1 \mathrm{~h}$ and at r.t. for $2 \mathrm{~h}$. The reaction was quenched with sat. aq. $\mathrm{NH}_{4} \mathrm{Cl}(20 \mathrm{~mL})$ and filtered through a Celite pad. The filtrate was extracted with $\mathrm{Et}_{2} \mathrm{O}(3 \times 50 \mathrm{~mL})$. The organic layers were combined, dried over $\mathrm{MgSO}_{4}$, filtered and concentrated under reduced pressure. The yellow oil obtained was purified by column chromatography (silica, 3:1 Pet. ether/EtOAc, $R_{f}=0.27$ ). The relevant fractions were partially concentrated to yield a solution of the desired intermediate alcohol in EtOAc. This mixture was combined with imidazole $(620 \mathrm{mg}, 9.11 \mathrm{mmol})$ and dissolved in DMF (9.0 
$\mathrm{mL})$. After cooling down to $0{ }^{\circ} \mathrm{C}$, a solution of TBSCl $(1.32 \mathrm{~g}, 6.27 \mathrm{mmol})$ in DMF $(9.0 \mathrm{~mL})$ was added dropwise. The reaction was stirred at r.t. for $14 \mathrm{~h}$, then diluted with $\mathrm{Et}_{2} \mathrm{O}(50 \mathrm{~mL})$, washed with $\mathrm{H}_{2} \mathrm{O}(3 \times 50 \mathrm{~mL})$ and brine $(50 \mathrm{~mL})$, dried over $\mathrm{MgSO}_{4}$, filtered and concentrated under reduced pressure. This crude product was purified by column chromatography (silica, 10:1 Pet. ether/EtOAc, $\left.R_{\mathrm{f}}=0.80\right)$ to yield 118 as a colourless oil $(1.28 \mathrm{~g}, 81 \%$ yield $)$.

${ }^{1} \mathbf{H}$ NMR $\left(500 \mathrm{MHz}, \mathrm{CDCl}_{3}\right): \delta 5.92(\mathrm{ddd}, J=16.8,10.8,5.6 \mathrm{~Hz}, 1 \mathrm{H}, 2-\mathrm{CH}), 5.26(\mathrm{~d}, J=17.1$ $\mathrm{Hz}, 1 \mathrm{H}$, one of 1- $\left.\mathrm{CH}_{2}\right), 5.12\left(\mathrm{~d}, J=10.5 \mathrm{~Hz}, 1 \mathrm{H}\right.$, one of $\left.1-\mathrm{CH}_{2}\right), 4.27$ (app. q, $J=5.6 \mathrm{~Hz}, 1 \mathrm{H}$, 3-CH), 2.42 (ddd, $J=16.6,6.1,2.9 \mathrm{~Hz}, 1 \mathrm{H}$, one of 4-CH ), 2.33 (ddd, $J=16.6,7.1,2.4 \mathrm{~Hz}$, $1 \mathrm{H}$, one of 4- $\mathrm{CH}_{2}$ ), 1.99 ( $\left.\mathrm{t}, J=2.6 \mathrm{~Hz}, 1 \mathrm{H}, 6-\mathrm{CH}\right), 0.91$ (s, 9H, $\left.t \mathrm{Bu}, \mathrm{TBS}\right), 0.10$ (s, 3H, Me, TBS), 0.07 (s, 3H, Me, TBS).

${ }^{13}$ C NMR (125 MHz, $\left.\mathrm{CDCl}_{3}\right): \delta 139.9(\mathrm{CH}, \mathrm{C} 2), 114.7\left(\mathrm{CH}_{2}, \mathrm{C} 1\right), 81.3(\mathrm{C}, \mathrm{C} 5), 72.2(\mathrm{CH}$, C3), 69.9 (CH, C6), $28.3\left(\mathrm{CH}_{2}, \mathrm{C} 4\right), 25.8\left(\mathrm{CH}_{3}, t \mathrm{Bu}, \mathrm{TBS}\right), 18.2(\mathrm{C}, t \mathrm{Bu}, \mathrm{TBS}),-4.6\left(\mathrm{CH}_{3}, \mathrm{Me}\right.$, TBS), $-4.9\left(\mathrm{CH}_{3}, \mathrm{Me}, \mathrm{TBS}\right)$.

These data were consistent with those reported previously. ${ }^{64}$

\section{Methyl 5-tert-butyldimethylsilyloxy-6-hepten-2-ynoate (119)}

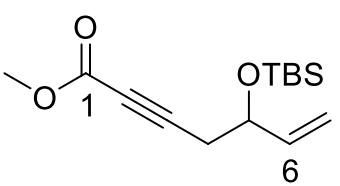

To a solution of terminal alkyne 118 (905 mg, $4.30 \mathrm{mmol})$ in THF (43

$\mathrm{mL})$ at $-78^{\circ} \mathrm{C}, n \mathrm{BuLi}(2.6 \mathrm{~mL}, 1.8 \mathrm{M}$ in cyclohexane, $4.68 \mathrm{mmol})$ was added dropwise. The reaction was stirred at $-78{ }^{\circ} \mathrm{C}$ for $40 \mathrm{~min}$. Methyl chloroformate $(8.60 \mathrm{mmol}, 0.66 \mathrm{~mL})$ was added dropwise. After stirring for $2 \mathrm{~h} 30 \mathrm{~min}$ at $78^{\circ} \mathrm{C}$, the reaction was quenched with sat. aq. $\mathrm{NH}_{4} \mathrm{Cl}(30 \mathrm{~mL})$ and warmed up to r.t. The aqueous layer was separated and extracted with $\mathrm{Et}_{2} \mathrm{O}(3 \times 30 \mathrm{~mL})$. The organic layers were combined, dried over $\mathrm{MgSO}_{4}$, filtered and concentrated under reduced pressure. This crude product was purified by column chromatography (silica, 30:1 Pet. ether/EtOAc, $R_{f}=0.16$ ) to yield the title compound $\mathbf{1 1 9}$ as a pale oil $(875 \mathrm{mg}, 76 \%)$.

${ }^{1} \mathbf{H}$ NMR $\left(500 \mathrm{MHz}, \mathrm{CDCl}_{3}\right): \delta 5.87(\mathrm{ddd}, J=16.7,10.7,5.9 \mathrm{~Hz}, 1 \mathrm{H}, 6-\mathrm{CH}), 5.27(\mathrm{~d}, J=17.1$ $\mathrm{Hz}, 1 \mathrm{H}$, one of 7-CH$)_{2}, 5.14\left(\mathrm{~d}, J=10.5 \mathrm{~Hz}, 1 \mathrm{H}\right.$, one of 7- $\left.\mathrm{CH}_{2}\right), 4.32$ (app. q, $J=6.3 \mathrm{~Hz}, 1 \mathrm{H}$, 5-CH), 3.76 (s, 3H, $\mathrm{CH}_{3}, \mathrm{OMe}$ ), 2.55 (dd, $J=16.9,6.3 \mathrm{~Hz}, 1 \mathrm{H}$, one of 4- $\mathrm{CH}_{2}$ ), 2.47 (dd, $J=$ 16.9, $6.3 \mathrm{~Hz}, 1 \mathrm{H}$, one of 4- $\mathrm{CH}_{2}$ ), 0.90 (s, 9H, $\left.t \mathrm{Bu}, \mathrm{TBS}\right), 0.10$ (s, 3H, Me, TBS), 0.06 (s, 3H, Me, TBS). 
${ }^{13} \mathrm{C}$ NMR (125 MHz, $\left.\mathrm{CDCl}_{3}\right): \delta 154.1(\mathrm{C}, \mathrm{C} 1), 139.4(\mathrm{CH}, \mathrm{C} 6), 115.4\left(\mathrm{CH}_{2}, \mathrm{C} 7\right), 110.0(\mathrm{C}$, C3), 86.5 (C, C2), $71.5(\mathrm{CH}, \mathrm{C} 5), 52.6\left(\mathrm{CH}_{3}, \mathrm{OMe}\right), 28.6\left(\mathrm{CH}_{2}, \mathrm{C} 4\right), 25.7\left(\mathrm{CH}_{3}, t \mathrm{Bu}, \mathrm{TBS}\right)$, $18.2(\mathrm{C}, t \mathrm{Bu}, \mathrm{TBS}),-4.6\left(\mathrm{CH}_{3}, \mathrm{Me}, \mathrm{TBS}\right),-5.0\left(\mathrm{CH}_{3}, \mathrm{Me}, \mathrm{TBS}\right)$.

IR (neat) cm $\mathrm{cm}^{-1}: 2954(\mathrm{~m}, \mathrm{C}-\mathrm{H}), 2930(\mathrm{~m}, \mathrm{C}-\mathrm{H}), 2857$ (m, C-H), $2241(\mathrm{~m}, \mathrm{C} \equiv \mathrm{C}), 1716$ (s, C=O), 1248 (s, C-O), 1073 (s, C-H), 930 (s, C-Si), 836 (s, C-Si), 777 (s, C-Si).

HRMS (ESI) $m / z$ : found 286.1837, calcd for $\mathrm{C}_{14} \mathrm{H}_{28} \mathrm{O}_{3} \mathrm{SiN}\left[\mathrm{M}+\mathrm{NH}_{4}\right]^{+} 286.1833(\Delta=2.1 \mathrm{ppm})$.

\section{(2Z)-Methyl 5-(tert-butyldimethylsilyloxy)-3-methyl-2,6-heptadienoate (125)}

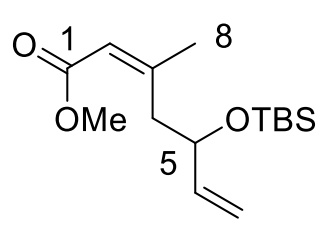

To a suspension of $\mathrm{CuI}(641 \mathrm{mg}, 3.37 \mathrm{mmol})$ in $\mathrm{THF}(14 \mathrm{~mL})$ at $0{ }^{\circ} \mathrm{C}$, MeLi was added dropwise (2.4 mL, 2.8 $\mathrm{M}$ in $\left.\mathrm{Et}_{2} \mathrm{O}, 8.4 \mathrm{mmol}\right)$. After stirring at $0{ }^{\circ} \mathrm{C}$ for $45 \mathrm{~min}$, a solution of the ynoate $120(600 \mathrm{mg}, 2.24$ $\mathrm{mmol})$ in THF $(3.2 \mathrm{~mL})$ was added dropwise at $-78{ }^{\circ} \mathrm{C}$. The reaction mixture was stirred at $-78{ }^{\circ} \mathrm{C}$ for $3 \mathrm{~h}$. The reaction was quenched with sat. aq. $\mathrm{NH}_{4} \mathrm{Cl}(30 \mathrm{~mL})$ and warmed up to r.t. The aqueous layer was separated and extracted with $\mathrm{Et}_{2} \mathrm{O}(3 \times 50 \mathrm{~mL})$. The organic layers were combined, dried over $\mathrm{MgSO}_{4}$, filtered and concentrated concentrated under reduced pressure. This crude product was purified by column chromatography (silica, 36:1 Pet. ether/ $\left.\mathrm{Et}_{2} \mathrm{O}, \mathrm{R}_{\mathrm{f}}=0.22\right)$ to yield $\mathbf{1 2 5}$ as a yellow oil $(620 \mathrm{mg}, 97 \%$ yield $)$.

${ }^{1} \mathbf{H}$ NMR (500 MHz, $\mathrm{CDCl}_{3}$ ): $\delta 5.86$ (ddd, $\left.J=16.4,10.5,5.9 \mathrm{~Hz}, 1 \mathrm{H}, 6-\mathrm{CH}\right), 5.73$ (s, 1H, 2$\mathrm{CH}), 5.20(\mathrm{~d}, J=17.1 \mathrm{~Hz}, 1 \mathrm{H}$, one of 7-CH$), 5.03(\mathrm{~d}, J=10.3 \mathrm{~Hz}, 1 \mathrm{H}$, one of 7-CH 2$), 4.42$ (m, 1H, 5-CH), 3.68 (s, 3H, $\left.\mathrm{CH}_{3}, \mathrm{OMe}\right), 2.88\left(\mathrm{dd}, J=12.2,4.6 \mathrm{~Hz}, 1 \mathrm{H}\right.$, one of 4-CH $\mathrm{CH}_{2}, 2.71$ $\left(\mathrm{dd}, J=12.6,7.9 \mathrm{~Hz}, 1 \mathrm{H}\right.$, one of $\left.4-\mathrm{CH}_{2}\right), 1.95\left(\mathrm{~s}, 3 \mathrm{H}, 8-\mathrm{CH}_{3}\right), 0.88(\mathrm{~s}, 9 \mathrm{H}, t \mathrm{Bu}, \mathrm{TBS}), 0.01$ (s, $6 \mathrm{H}, \mathrm{Me}, \mathrm{TBS})$.

${ }^{13} \mathrm{C}$ NMR (125 MHz, $\left.\mathrm{CDCl}_{3}\right)$ : $\delta 166.7$ (C, C1), 158.4 (C, C3), $141.3(\mathrm{CH}, \mathrm{C} 6), 116.9$ (CH, C2), $113.7\left(\mathrm{CH}_{2}, \mathrm{C} 7\right), 73.6(\mathrm{CH}, \mathrm{C} 5), 50.8\left(\mathrm{CH}_{3}, \mathrm{OMe}\right), 41.9\left(\mathrm{CH}_{2}, \mathrm{C} 4\right), 27.5\left(\mathrm{CH}_{3}, \mathrm{C} 8\right), 25.9\left(\mathrm{CH}_{3}\right.$, $t \mathrm{Bu}, \mathrm{TBS}), 18.1$ (C, $t \mathrm{Bu}, \mathrm{TBS}),-4.5\left(\mathrm{CH}_{3}, \mathrm{Me}, \mathrm{TBS}\right),-4.9\left(\mathrm{CH}_{3}, \mathrm{Me}, \mathrm{TBS}\right)$.

IR (neat) cm $\mathrm{cm}^{-1}: 2952(\mathrm{~m}, \mathrm{C}-\mathrm{H}), 2929(\mathrm{~m}, \mathrm{C}-\mathrm{H}), 2857$ (m, C-H), 1718 (s, C=O), 1645 (m, C=C), 1251 (s, C-O), 1196 (s, C-H), 1027 (s, C-H), 834 (s, C-Si), 775 (s, C-Si).

HRMS (ESI) $m / z$ : found 285.1869, calcd for $\mathrm{C}_{15} \mathrm{H}_{32} \mathrm{O}_{3} \mathrm{SiN}\left[\mathrm{M}+\mathrm{NH}_{4}\right]^{+} 285.1880(\Delta=3.9 \mathrm{ppm})$. 
<smiles></smiles>

To a solution of the ester 125 (306 mg, $1.08 \mathrm{mmol})$ in $\mathrm{CH}_{2} \mathrm{Cl}_{2}(10.5 \mathrm{~mL}$, $0.10 \mathrm{M})$ at $-78^{\circ} \mathrm{C}$, a solution of DIBAl-H (3.5 mL, 1.0 M in THF, 3.5 mmol) was added dropwise. The reaction was stirred at $-78{ }^{\circ} \mathrm{C}$ for 30 min, followed by $0{ }^{\circ} \mathrm{C}$ for $30 \mathrm{~min}$ and r.t. for $30 \mathrm{~min}$. It was then quenched with a sat. aq. solution of Rochelle's salt $(15 \mathrm{~mL})$ and stirred vigorously for $1 \mathrm{~h}$. The mixture was extracted with $\mathrm{CH}_{2} \mathrm{Cl}_{2}(3 \times 15 \mathrm{~mL})$. The organic layers were combined and dried over $\mathrm{MgSO}_{4}$ and concentrated under reduced pressure. This crude product was purified by column chromatography ( ilica, 5:1 Pet. ether/EtOAc, $\mathrm{R}_{\mathrm{f}}=0.41$ ) to yield the product $\mathbf{1 2 8}$ as a yellow oil (229 mg, $85 \%$ yield).

${ }^{1} \mathbf{H}$ NMR (500 MHz, $\mathrm{CDCl}_{3}$ ): $\delta 5.83(\mathrm{ddd}, J=17.0,10.5,6.6 \mathrm{~Hz}, 1 \mathrm{H}, 6-\mathrm{CH}), 5.65$ (t, $J=7.1$ $\mathrm{Hz}, 1 \mathrm{H}, 2-\mathrm{CH}), 5.17\left(\mathrm{dd}, J=17.3,1.2 \mathrm{~Hz}, 1 \mathrm{H}\right.$, one of 7-CH $\mathrm{CH}_{2}, 5.06(\mathrm{dd}, J=10.3,1.0 \mathrm{~Hz}, 1 \mathrm{H}$, one of 7- $\left.\mathrm{CH}_{2}\right), 4.25(\mathrm{~m}, 1 \mathrm{H}, 5-\mathrm{CH}), 4.19\left(\mathrm{~m}, 1 \mathrm{H}\right.$, one of 1- $\left.\mathrm{CH}_{2}\right), 4.00$ (app. dt, $J=12.1,6.5$ $\mathrm{Hz}, 1 \mathrm{H}$, one of $\left.1-\mathrm{CH}_{2}\right), 2.51\left(\mathrm{dd}, J=13.3,8.7 \mathrm{~Hz}, 1 \mathrm{H}\right.$, one of $\left.4-\mathrm{CH}_{2}\right), 2.10(\mathrm{dd}, J=13.4,4.6$ $\mathrm{Hz}, 1 \mathrm{H}$, one of $\left.4-\mathrm{CH}_{2}\right), 1.96(\mathrm{t}, J=5.4 \mathrm{~Hz}, 1 \mathrm{H}, \mathrm{OH}), 1.78\left(\mathrm{~s}, 3 \mathrm{H}, 8-\mathrm{CH}_{3}\right), 0.89(\mathrm{~s}, 9 \mathrm{H}, t \mathrm{Bu})$, 0.05 (s, 3H, Me), 0.05 (s, 3H, Me).

${ }^{13} \mathrm{C}$ NMR (125 MHz, $\left.\mathrm{CDCl}_{3}\right): \delta 141.4$ (CH, C6), 136.8 (C, C3), 127.1 (CH, C2), $114.1\left(\mathrm{CH}_{2}\right.$, C7), $72.1(\mathrm{CH}, \mathrm{C} 5), 58.6\left(\mathrm{CH}_{2}, \mathrm{C} 1\right), 41.0\left(\mathrm{CH}_{2}, \mathrm{C} 4\right), 25.9\left(\mathrm{CH}_{3}, t \mathrm{Bu}\right), 23.9\left(\mathrm{CH}_{3}, \mathrm{C} 8\right), 18.3(\mathrm{C}$, $t \mathrm{Bu}),-4.5\left(\mathrm{CH}_{3}, \mathrm{Me}\right),-4.7\left(\mathrm{CH}_{3}, \mathrm{Me}\right)$.

IR (film from $\mathrm{CH}_{2} \mathrm{Cl}_{2}$ ) cm cm $^{-1} 3410$ (br, O-H), 2956 (s, C-H), 2930 (s, C-H), 2886 (s, C-H), 2857 (s, C-H), 1678 (s, C=C), 1472 (m, C-H), 1253 (s, C-O), 937 (s, C-H), 8345 (s, C-Si), $776(\mathrm{~s}, \mathrm{C}-\mathrm{Si})$.

HRMS (ESI) $m / z$ : found 279.1756, calcd for $\mathrm{C}_{14} \mathrm{H}_{28} \mathrm{O}_{2} \mathrm{SiNa}[\mathrm{M}+\mathrm{Na}]^{+} 279.1756(\Delta=0.0 \mathrm{ppm})$.

NOESY(600 MHz, $\left.\mathrm{CDCl}_{3}\right)$ :<smiles>C=CC(C/C(=C\CC)CO)O[Sb]</smiles> 
<smiles></smiles>

To a solution of the alcohol $128(374 \mathrm{mg}, 1.46 \mathrm{mmol})$ in DMSO $(2.5 \mathrm{~mL}$, $0.58 \mathrm{M})$ at r.t., a solution of IBX $(1.23 \mathrm{~g}, 4.37 \mathrm{mmol})$ in DMSO $(18.8 \mathrm{~mL})$ was added dropwise. After stirring at r.t. for $17 \mathrm{~h}$, EtOAc $(20 \mathrm{~mL})$ was added to the reaction mixture to precipitate out IBX. The mixture was filtered through Celite, and the filtrate was concentrated under reduced pressure. This crude product was purified by column chromatography (silica, 20:1 Pet. ether/ EtOAc, $R_{f}=0.38$ ) to yield the aldehyde $\mathbf{1 2 6}$ as a colourless oil (306 mg, 82\% yield).

${ }^{1} \mathbf{H}$ NMR $\left(500 \mathrm{MHz}, \mathrm{CDCl}_{3}\right): \delta 9.90(\mathrm{~d}, J=8.1 \mathrm{~Hz}, 1 \mathrm{H}, 1-\mathrm{CH}), 5.96(\mathrm{~d}, J=7.7 \mathrm{~Hz}, 1 \mathrm{H}, 2-\mathrm{CH})$, 5.83 (dddd, $J=17.9,10.3,6.4,2.1 \mathrm{~Hz}, 1 \mathrm{H}, 6-\mathrm{CH}), 5.22$ (d, $J=17.3 \mathrm{~Hz}, 1 \mathrm{H}$, one of 7- $\mathrm{CH}_{2}$ ), $5.11\left(\mathrm{~d}, J=10.5 \mathrm{~Hz}, 1 \mathrm{H}\right.$, one of 7- $\left.\mathrm{CH}_{2}\right), 4.32(\mathrm{~m}, 1 \mathrm{H}, 5-\mathrm{CH}), 2.91(\mathrm{ddd}, J=13.0,8.2,1.5 \mathrm{~Hz}$, $1 \mathrm{H}$, one of $\left.4-\mathrm{CH}_{2}\right), 2.54\left(\mathrm{ddd}, J=13.1,4.3,1.3 \mathrm{~Hz}, 1 \mathrm{H}\right.$, one of $\left.4-\mathrm{CH}_{2}\right), 2.02\left(\mathrm{~s}, 3 \mathrm{H}, 8-\mathrm{CH}_{3}\right)$, 0.86 (s, 9H, $t \mathrm{Bu}), 0.02$ (s, 3H, Me), 0.01 (s, 3H, Me).

${ }^{13}$ C NMR (125 MHz, $\left.\mathrm{CDCl}_{3}\right): \delta 191.5$ (CH, C1), 159.8 (C, C3), 140.6 (CH, C6), 130.4 (CH, C2), $114.9\left(\mathrm{CH}_{2}, \mathrm{C} 7\right), 72.6(\mathrm{CH}, \mathrm{C} 5), 41.5\left(\mathrm{CH}_{2}, \mathrm{C} 4\right), 26.1\left(\mathrm{CH}_{3}, \mathrm{C} 8\right), 25.8\left(\mathrm{CH}_{3}, t \mathrm{Bu}\right), 18.1$ $(\mathrm{C}, t \mathrm{Bu}),-4.5\left(\mathrm{CH}_{3}, \mathrm{Me}\right),-4.9\left(\mathrm{CH}_{3}, \mathrm{Me}\right)$.

IR (neat) $\mathrm{cm}^{-1}: 2956$ (m, C-H), $2930(\mathrm{~m}, \mathrm{C}-\mathrm{H}), 2857$ (m, C-H), 1676 (s, C=O), 1631 (w, C=C), 1609 (w, C=C), 1073 (s, C-O), 835 (s, C-Si), 775 (s, C-Si).

HRMS (ESI) $m / z$ : found 255.1776, calcd for $\mathrm{C}_{14} \mathrm{H}_{27} \mathrm{O}_{2} \mathrm{Si}[\mathrm{M}+\mathrm{H}]^{+} 255.1775(\Delta=0.4 \mathrm{ppm})$.

NOESY $\left(600 \mathrm{MHz}, \mathrm{CDCl}_{3}\right)$ :<smiles>C=CC(C/C(=C/C=O)CNC)O[Sn]</smiles> 
Mixture of (2Z)-methyl 5-(tert-butyldimethylsilyloxy)-2,6-heptadienoate (130) and (2Z)methyl 5-(tert-butyldimethylsilyloxy)-2-heptenoate (131) (3:2)

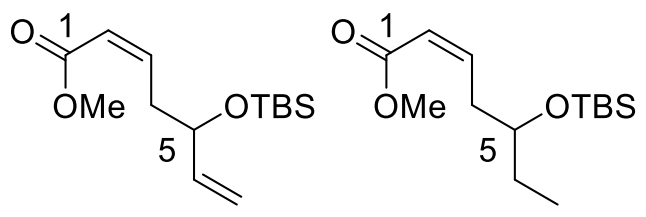

To a solution of $119(50 \mathrm{mg}, 0.186 \mathrm{mmol})$ and Lindlar's catalyst $(10 \mathrm{mg})$ in EtOAc $(1.3 \mathrm{~mL}, 0.14 \mathrm{M})$, was added 2-methylbutene $(0.13 \mathrm{~mL}) . \mathrm{H}_{2}$ gas was bubbled through the solution for $2 \mathrm{~h}$. The reaction mixture was filtered through a Celite pad, and rinsed with $\mathrm{CH}_{2} \mathrm{Cl}_{2}$. The filtrate was concentrated under reduced pressure. This crude product was purified by column chromatography (silica, 95:5 Pet. ether/EtOAc, $R_{f}=0.55$ ) to yield $\mathbf{1 3 0}$ in a mixture with $40 \%$ of $\mathbf{1 3 1}$ (34 mg, 68\% combined yield).

${ }^{1} \mathbf{H}$ NMR $\left(500 \mathrm{MHz}, \mathrm{CDCl}_{3}\right) \delta 6.39(\mathrm{dt}, J=11.4,7.2 \mathrm{~Hz}, 0.4 \mathrm{H}, 3-\mathrm{CH}-131), 6.33$ (dt, $J=11.6$, 7.2 Hz, 0.6H, 3-CH-130), 5.85 (d, $J=11.7 \mathrm{~Hz}, 1 \mathrm{H}, 2-\mathrm{CH}), 5.80$ (ddd, $J=11.7,10.5,5.6 \mathrm{~Hz}$, 0.6H, 6-CH-130), 5.21 (dd, $J=17.1,1.4 \mathrm{~Hz}, 0.6 \mathrm{H}$, one of 7- $\left.\mathrm{CH}_{2}-\mathbf{1 3 0}\right), 5.07$ (dd, $J=10.4,1.3$ $\mathrm{Hz}, 0.6 \mathrm{H}$, one of 7-CH $\mathrm{CH}_{2}-130$ ), 4.29 (app. q, $J=5.6 \mathrm{~Hz}, 0.6 \mathrm{H}, 5-\mathrm{CH}-130$ ), 3.79-3.64 (obs. m, 0.4H, 5-CH-131), 3.71 (s, 3H, $\mathrm{CH}_{3}, \mathrm{OMe}$ ), 2.95-2.76 (complex m, 2H, 4-CH $\mathrm{CH}_{2}$ ), 1.47 (app. quin, $J=7.3 \mathrm{~Hz}, 0.8 \mathrm{H}, 6-\mathrm{CH}_{2}-\mathbf{1 3 1}$ ), 0.91-0.86 (complex m, 10.2H, $\mathrm{CH}_{3}, t \mathrm{Bu}-\mathrm{TBS}$ and 7-CH -131 ), 0.05 (s, 2.4H, $\mathrm{CH}_{3}, \mathrm{Me}$, TBS-131), 0.043 (obs. s, 1.8H, $\mathrm{CH}_{3}, \mathrm{Me}$, TBS-130), 0.041 (obs. s, $1.8 \mathrm{H}, \mathrm{CH}_{3}, \mathrm{Me}$, TBS-130).

${ }^{13}$ C NMR (126 MHz, $\left.\mathrm{CDCl}_{3}\right) \delta 166.7$ (C, C1), $147.3(\mathrm{CH}, \mathrm{C} 3-131), 146.4(\mathrm{CH}, \mathrm{C} 3-130), 140.7$ (CH, C6-130), 120.5 (CH, C2-130), 120.2 (CH, C2-131), $114.2\left(\mathrm{CH}_{2}, \mathrm{C} 7-130\right), 72.7$ (CH, C5131), 72.5 (CH, C5-130), $67.9\left(\mathrm{CH}_{3}, \mathrm{OMe}\right), 51.98(), 51.95(), 37.1\left(\mathrm{CH}_{2}, \mathrm{C} 4-130\right), 35.9\left(\mathrm{CH}_{2}\right.$, C4-131), $29.9\left(\mathrm{CH}_{2}, \mathrm{C6}-131\right), 25.83\left(\mathrm{CH}_{3}, t \mathrm{Bu}, \mathrm{TBS}\right), 25.77\left(\mathrm{CH}_{3}, t \mathrm{Bu}, \mathrm{TBS}\right), 18.2(\mathrm{C}, t \mathrm{Bu}$, TBS), 18.1 (C, $t \mathrm{Bu}, \mathrm{TBS}), 9.7\left(\mathrm{CH}_{3}, \mathrm{C} 7-131\right),-4.54\left(\mathrm{CH}_{3}, \mathrm{Me}, \mathrm{TBS}\right),-4.56\left(\mathrm{CH}_{3}, \mathrm{Me}, \mathrm{TBS}\right),-$ $4.6\left(\mathrm{CH}_{3}, \mathrm{Me}, \mathrm{TBS}\right),-4.9\left(\mathrm{CH}_{3}, \mathrm{Me}, \mathrm{TBS}\right)$.

\section{5-(tert-Butyldimethylsilyloxy)-6-hepten-2-yn-1-ol (132)}

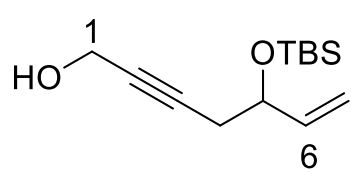

To a solution of ester 119 (100 mg, $0.475 \mathrm{mmol})$ in THF (1.0 mL, 0.5 M) at $-78^{\circ} \mathrm{C}, n \mathrm{BuLi}(0.36 \mathrm{~mL}, 2.0 \mathrm{M}$ in THF, $0.71 \mathrm{mmol})$ was added dropwise. After stirring at $-78^{\circ} \mathrm{C}$ for $35 \mathrm{~min}$, paraformaldehyde $(29 \mathrm{mg}$, $0.95 \mathrm{mmol}$ ) was added, and the mixture was warmed to r.t. and stirred for $20 \mathrm{~h}$. The reaction was quenched with sat. aq. $\mathrm{NH}_{4} \mathrm{Cl}$ solution $(10 \mathrm{~mL})$, and extracted with $\mathrm{Et}_{2} \mathrm{O}(2 \times 10 \mathrm{~mL})$. The 
organic layers were combined, dried over $\mathrm{MgSO}_{4}$ and concentrated under reduced pressure. This crude product was purified by column chromatography (silica, 5:1 Pet. ether/EtOAc, $R_{\mathrm{f}}=$ 0.35 ) to yield $\mathbf{1 3 2}$ as a colourless oil (77 $\mathrm{mg}, 68 \%$ yield).

${ }^{1} \mathbf{H}$ NMR $\left(500 \mathrm{MHz}, \mathrm{CDCl}_{3}\right): \delta 5.91(\mathrm{ddd}, J=16.3,10.4,5.5 \mathrm{~Hz}, 1 \mathrm{H}, 6-\mathrm{CH}), 5.25(\mathrm{~d}, J=17.1$ $\mathrm{Hz}, 1 \mathrm{H}$, one of 7-CH$), 5.11\left(\mathrm{~d}, J=10.4 \mathrm{~Hz}, 1 \mathrm{H}\right.$, one of 7- $\left.\mathrm{CH}_{2}\right), 4.28-4.22$ (complex m, 3H, $1-\mathrm{CH}_{2}$ and 5-CH), $2.45\left(\mathrm{dd}, J=16.5,6.3 \mathrm{~Hz}, 1 \mathrm{H}\right.$, one of $\left.4-\mathrm{CH}_{2}\right), 2.36(\mathrm{dd}, J=16.5,6.7 \mathrm{~Hz}$, $1 \mathrm{H}$, one of 4- $\mathrm{CH}_{2}$ ), 1.54 (t, $\left.J=5.5 \mathrm{~Hz}, 1 \mathrm{H}, \mathrm{OH}\right), 0.91$ (s, 9H, $\left.t \mathrm{Bu}, \mathrm{TBS}\right), 0.09$ (s, 3H, CH $3, \mathrm{Me}$, TBS), 0.07 (s, 3H, $\mathrm{CH}_{3}, \mathrm{Me}, \mathrm{TBS}$ ).

${ }^{13}$ C NMR (125 MHz, $\left.\mathrm{CDCl}_{3}\right) \delta 140.0$ (CH, C6), 114.6 (C, C7), 83.3 (C, C3), 80.0 (C, C2), $72.3(\mathrm{CH}, \mathrm{C} 5), 51.4\left(\mathrm{CH}_{2}, \mathrm{C} 1\right), 28.6\left(\mathrm{CH}_{2}, \mathrm{C} 4\right), 25.8\left(\mathrm{CH}_{3}, t \mathrm{Bu}, \mathrm{TBS}\right), 18.3(\mathrm{C}, t \mathrm{Bu}),-4.6\left(\mathrm{CH}_{3}\right.$, $\mathrm{Me}),-4.9\left(\mathrm{CH}_{3}, \mathrm{Me}\right)$.

HRMS (ESI) $m / z$ : found 258.1884, calcd for $\mathrm{C}_{13} \mathrm{H}_{28} \mathrm{O}_{2} \mathrm{SiN}\left[\mathrm{M}+\mathrm{NH}_{4}\right]^{+} 258.1884(\Delta=0.0 \mathrm{ppm})$.

\section{E-5-(tert-Butyldimethylsilyloxy)hepta-2,6-dien-1-ol (133)}

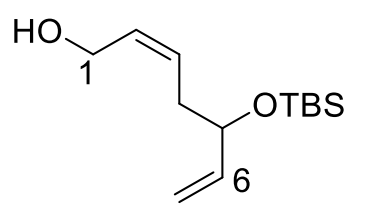

To a solution of $132(24 \mathrm{mg}, 0.099 \mathrm{mmol})$ and Lindlar's catalyst $(6 \mathrm{mg})$ in EtOAc (0.9 mL, 0.11 M), was added 2-methylbutene (0.08 mL). $\mathrm{H}_{2}$ gas was bubbled through the solution for $6 \mathrm{~h}$, with another portion of 2methylbutene $(0.08 \mathrm{~mL})$ added at $2 \mathrm{~h}$. The reaction mixture was filtered through a Celite pad, and rinsed with $\mathrm{CH}_{2} \mathrm{Cl}_{2}$. The filtrate was concentrated under reduced pressure to yield $\mathbf{1 3 3}$ as a colourless oil (18 $\mathrm{mg}, 75 \%$ yield).

${ }^{1} \mathbf{H}$ NMR $\left(500 \mathrm{MHz}, \mathrm{CDCl}_{3}\right): \delta 5.82$ (partially obs. ddd, $\left.J=16.9,10.5,6.1 \mathrm{~Hz}, 1 \mathrm{H}, 6-\mathrm{CH}\right)$, 5.77 (partially obs. dt, $J=11.4,6.9 \mathrm{~Hz}, 1 \mathrm{H}, 2-\mathrm{CH}$ ), 5.59 (dt, $J=11.0,7.5 \mathrm{~Hz}, 1 \mathrm{H}, 3-\mathrm{CH}$ ), 5.17 $\left(\mathrm{d}, J=17.1 \mathrm{~Hz}, 1 \mathrm{H}\right.$, one of 7- $\left.\mathrm{CH}_{2}\right), 5.07(\mathrm{~d}, J=10.3 \mathrm{~Hz}, 1 \mathrm{H}$, one of 7-CH 2$), 4.21-4.07$ (complex $\left.\mathrm{m}, 3 \mathrm{H}, 1-\mathrm{CH}_{2} \& 5-\mathrm{CH}\right), 2.37\left(\mathrm{dt}, J=13.9,7.8 \mathrm{~Hz}, 1 \mathrm{H}\right.$, one of 4-CH $\mathrm{CH}_{2}, 2.27(\mathrm{~m}, 1 \mathrm{H}$, one of 4$\mathrm{CH}_{2}$ ), 1.62 (t, $\left.J=5.6 \mathrm{~Hz}, 1 \mathrm{H}, \mathrm{OH}\right), 0.90$ (s, 9H, $\left.\mathrm{CH}_{3}, t \mathrm{Bu}, \mathrm{TBS}\right), 0.06$ (s, 3H, $\mathrm{CH}_{3}, \mathrm{Me}, \mathrm{TBS}$ ), 0.05 (s, 3H, $\left.\mathrm{CH}_{3}, \mathrm{Me}, \mathrm{TBS}\right)$.

${ }^{13} \mathrm{C} \mathrm{NMR}\left(125 \mathrm{MHz}, \mathrm{CDCl}_{3}\right): \delta 141.0(\mathrm{CH}, \mathrm{C} 6), 130.7$ (CH, C2), $128.8(\mathrm{CH}, \mathrm{C} 3), 114.2\left(\mathrm{CH}_{2}\right.$, C7), 73.2 (CH, C5), $58.5\left(\mathrm{CH}_{2}, \mathrm{C} 1\right), 36.3\left(\mathrm{CH}_{2}, \mathrm{C} 4\right), 25.9\left(\mathrm{CH}_{3}, t \mathrm{Bu}, \mathrm{TBS}\right), 18.3(\mathrm{C}, t \mathrm{Bu}, \mathrm{TBS})$, $-4.5\left(\mathrm{CH}_{3}, \mathrm{Me}, \mathrm{TBS}\right),-4.7\left(\mathrm{CH}_{3}, \mathrm{Me}, \mathrm{TBS}\right)$. 
IR (ATR) cm c $^{-1} 3355$ (br, O-H), 2931 (m, C-H), 2858 (m, C-H), 1462 (w, C-H), 1252 (m, CO), 1026 (s, C-O), 834 (s, C-Si), 775 (s, C-Si).

HRMS (ESI) $m / z$ : found 243.1777, calcd for $\mathrm{C}_{13} \mathrm{H}_{27} \mathrm{O}_{2} \mathrm{Si}[\mathrm{M}+\mathrm{H}]^{+} 243.1775(\Delta=0.8 \mathrm{ppm})$.

Mixture of (2Z)-5-(tert-butyldimethylsilyloxy)hepta-2,6-dienal (135) and (2E) 5-(tertbutyldimethylsilyloxy)hepta-2,6-dienal (136) (7:3)

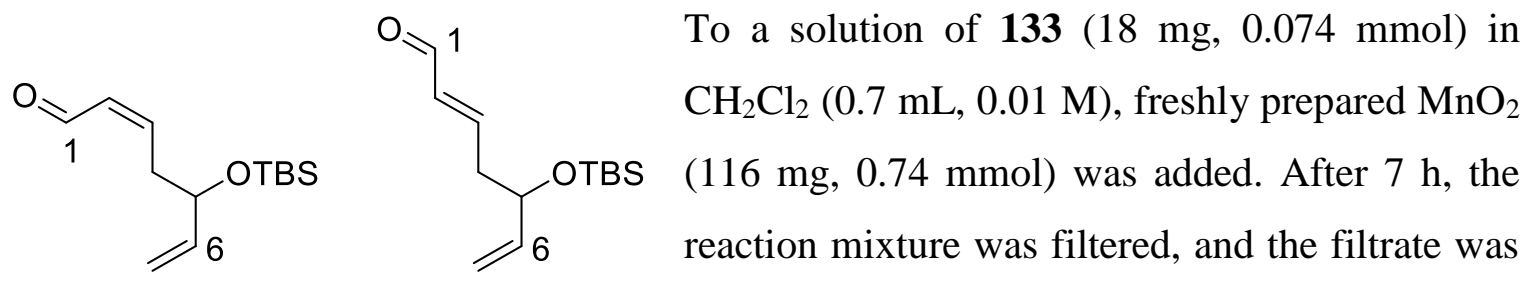

concentrated to yield a mixture of 3:2 s.m.:desired Z-product. This mixture was dissolved in $\mathrm{CH}_{2} \mathrm{Cl}_{2}(0.5 \mathrm{~mL})$, and $\mathrm{MnO}_{2}(147 \mathrm{mg}, 0.93 \mathrm{mmol})$ was added. After $3 \mathrm{~h}$, additional $\mathrm{MnO}_{2}(102$ $\mathrm{mg}, 0.65 \mathrm{mmol}$ ) was added, and the reaction was stirred for a further $2 \mathrm{~h} 30 \mathrm{~min}$. The reaction mixture was filtered, and the filtrate was concentrated to yield a colorless oil. This crude product was purified by column chromatography (silica, 10:1 Pet. ether/EtOAc, $R_{f}=0.39$ ) to yield a mixture of 7:3 135:136 as a colourless oil ( $9 \mathrm{mg}, 50 \%$ combined yield).

${ }^{1} \mathbf{H}$ NMR $\left(500 \mathrm{MHz}, \mathrm{CDCl}_{3}\right) \delta 10.03(\mathrm{~d}, J=8.0 \mathrm{~Hz}, 0.7 \mathrm{H}, 1-\mathrm{CH}-\mathbf{1 3 5}), 9.50(\mathrm{~d}, J=7.9 \mathrm{~Hz}$, $0.3 \mathrm{H}, 1-\mathrm{CH}-136), 6.84(\mathrm{dt}, J=15.8,7.6 \mathrm{~Hz}, 0.3 \mathrm{H}, 3-\mathrm{CH}-136), 6.68(\mathrm{dt}, J=11.3,8.1 \mathrm{~Hz}, 0.7 \mathrm{H}$, 3-CH-135), 6.14 (dd, $J=15.7,7.9 \mathrm{~Hz}, 0.3 \mathrm{H}, 2-\mathrm{CH}-136), 6.05$ (ddt, $J=11.0,8.1,1.4 \mathrm{~Hz}, 0.7 \mathrm{H}$, 2-CH-135), 5.82 (dd, $J=17.0,10.4,6.1 \mathrm{~Hz}, 0.7 \mathrm{H}, 6-\mathrm{CH}-135$ ), 5.85-5.77 (obs. m, 0.3H, 6-CH136), $5.24\left(\mathrm{dt}, J=17.1,1.3 \mathrm{~Hz}, 0.7 \mathrm{H}\right.$, one of $\left.7-\mathrm{CH}_{2}-135\right), 5.23(\mathrm{dt}, J=17.1,1.3 \mathrm{~Hz}, 0.3 \mathrm{H}$, one of 7-CH $2-136), 5.12\left(\mathrm{dt}, J=10.3,1.2 \mathrm{~Hz}, 0.7 \mathrm{H}\right.$, one of 7-CH$\left.-\mathrm{CH}_{2}-\mathbf{1 3 5}\right), 5.11$ (dt, $J=10.4,1.2 \mathrm{~Hz}$, $0.3 \mathrm{H}$, one of 7-CH $\mathrm{CH}_{2}-136$ ), 4.31 (app. q, $J=5.9 \mathrm{~Hz}, 1 \mathrm{H}, 5-\mathrm{CH}$ ), 2.88-2.73 (complex m, 1.4H, 4- $\mathrm{CH}_{2}$-135), 2.54 (app. ddt, $J=7.2,5.7,1.4 \mathrm{~Hz}, 0.6 \mathrm{H}, 4-\mathrm{CH}_{2}-136$ ), 0.89 (s, 2.7H, $\mathrm{CH}_{3}, t \mathrm{Bu}$, TBS-136), 0.89 (s, 6.3H, $\left.\mathrm{CH}_{3}, t \mathrm{Bu}, \mathrm{TBS}-135\right), 0.06$ (s, 0.9H, $\left.\mathrm{CH}_{3}, \mathrm{Me}, \mathrm{TBS}-136\right), 0.05(\mathrm{~s}, 2.1 \mathrm{H}$, $\mathrm{CH}_{3}, \mathrm{Me}$, TBS-135), 0.04 (s, 3H, $\mathrm{CH}_{3}, \mathrm{Me}, \mathrm{TBS}-\mathbf{1 3 5}$ and TBS-136).

${ }^{13}$ C NMR (126 MHz, $\left.\mathrm{CDCl}_{3}\right) \delta 193.9$ (C, C1-136), 191.2 (C, C1-135), $154.6(\mathrm{CH}, \mathrm{C} 3-136)$, 148.7 (CH, C3-135), 140.14 (CH, C6-136), 140.09 (CH, C6-135), 134.9 (CH, C2-136), 131.7 (CH, C2-135), 131.50, $115.1\left(\mathrm{CH}_{2}, \mathrm{C} 7-\mathbf{1 3 5}\right), 115.0\left(\mathrm{CH}_{2}, \mathrm{C} 7-\mathbf{1 3 6}\right), 72.4(\mathrm{CH}, \mathrm{C} 5-135), 72.3$ (CH, C5-136), $41.3\left(\mathrm{CH}_{2}, \mathrm{C} 4-136\right), 36.4\left(\mathrm{CH}_{2}, \mathrm{C} 4-135\right), 25.77\left(\mathrm{CH}_{3}, t \mathrm{Bu}, \mathrm{TBS}\right), 25.76\left(\mathrm{CH}_{3}\right.$, 
$t \mathrm{Bu}, \mathrm{TBS}), 18.2(\mathrm{C}, t \mathrm{Bu}, \mathrm{TBS}),-4.4\left(\mathrm{CH}_{3}, \mathrm{Me}, \mathrm{TBS}\right),-4.5\left(\mathrm{CH}_{3}, \mathrm{Me}, \mathrm{TBS}\right),-4.87\left(\mathrm{CH}_{3}, \mathrm{Me}\right.$, TBS), $-4.91\left(\mathrm{CH}_{3}, \mathrm{Me}, \mathrm{TBS}\right)$.

\section{Synthesis of C16-C20 fragment}

\section{2-(tert-Butyldiphenylsilyloxy)methyloxirane (140)}

OTBDPS To a solution of glycidol $(97,116 \mathrm{mg}, 1.56 \mathrm{mmol})$ and imidazole (138 $\mathrm{mg}, 2.03$ 1 $\mathrm{mmol})$ in DMF $(2.2 \mathrm{~mL}, 0.71 \mathrm{M})$ at $0{ }^{\circ} \mathrm{C}$, TBDPSCl $(0.47 \mathrm{~mL}, 1.8 \mathrm{mmol})$ was added dropwise. After stirring at r.t. for $3 \mathrm{~h} 30 \mathrm{~min}$, the reaction mixture was quenched with $\mathrm{H}_{2} \mathrm{O}(10 \mathrm{~mL})$ and diluted with $\mathrm{Et}_{2} \mathrm{O}(15 \mathrm{~mL})$. The organic layer was separated and washed sequentially with saturated aqueous $\mathrm{NaHCO}_{3}$ solution $(2 \times 15 \mathrm{~mL}), \mathrm{H}_{2} \mathrm{O}(15 \mathrm{~mL})$, brine $(15 \mathrm{~mL})$, and then dried over $\mathrm{MgSO}_{4}$, filtered and concentrated under reduced pressure. This crude product was purified by column chromatography (silica, 50:1 Pet. ether/EtOAc, $\mathrm{R}_{\mathrm{f}}$ $=0.18)$ to yield 140 as a colourless oil (396 mg, 84\%).

${ }^{1} \mathbf{H}$ NMR $\left(500 \mathrm{MHz}, \mathrm{CDCl}_{3}\right.$ ): $\delta$ 7.71-7.67 (complex m, 4H, CH, Ph, TBDPS), 7.46-7.37 (complex m, 6H, CH, Ph, TBDPS), $3.85\left(\mathrm{dd}, J=11.7,3.2 \mathrm{~Hz}, 1 \mathrm{H}\right.$, one of 1- $\left.\mathrm{CH}_{2}\right), 3.71(\mathrm{dd}, J$ $=11.8,4.8 \mathrm{~Hz}, 1 \mathrm{H}$, one of 1- $\left.\mathrm{CH}_{2}\right), 3.14(\mathrm{~m}, 1 \mathrm{H}, 2-\mathrm{CH}), 2.75\left(\mathrm{t}, J=4.6 \mathrm{~Hz}, 1 \mathrm{H}\right.$, one of $\left.3-\mathrm{CH}_{2}\right)$, $2.62\left(\mathrm{dd}, J=5.1,2.7 \mathrm{~Hz}, 1 \mathrm{H}\right.$, one of $\left.3-\mathrm{CH}_{2}\right), 1.06\left(\mathrm{~s}, 9 \mathrm{H}, \mathrm{CH}_{3}, t \mathrm{Bu}, \mathrm{TBDPS}\right)$.

${ }^{13} \mathrm{C}$ NMR (126 MHz, $\left.\mathrm{CDCl}_{3}\right): \delta=135.61(\mathrm{CH}, \mathrm{Ph}), 135.55(\mathrm{CH}, \mathrm{Ph}), 133.26(\mathrm{C}, \mathrm{Ph}), 133.24$ (C, Ph), $129.74(\mathrm{CH}, \mathrm{Ph}), 129.73(\mathrm{CH}, \mathrm{Ph}), 127.72(\mathrm{CH}, \mathrm{Ph}), 127.71(\mathrm{CH}, \mathrm{Ph}), 64.3\left(\mathrm{CH}_{2}, \mathrm{C} 1\right)$, $52.3(\mathrm{CH}, \mathrm{C} 2), 44.5\left(\mathrm{CH}_{2}, \mathrm{C} 3\right), 26.7\left(\mathrm{CH}_{3}, t \mathrm{Bu}\right), 19.2(\mathrm{C}, t \mathrm{Bu})$.

These data matched those reported previously. ${ }^{65}$ 


\section{1-(tert-Butyldiphenylsilyloxy)-5-trimethylsilyl-4-pentyn-2-ol (141)}

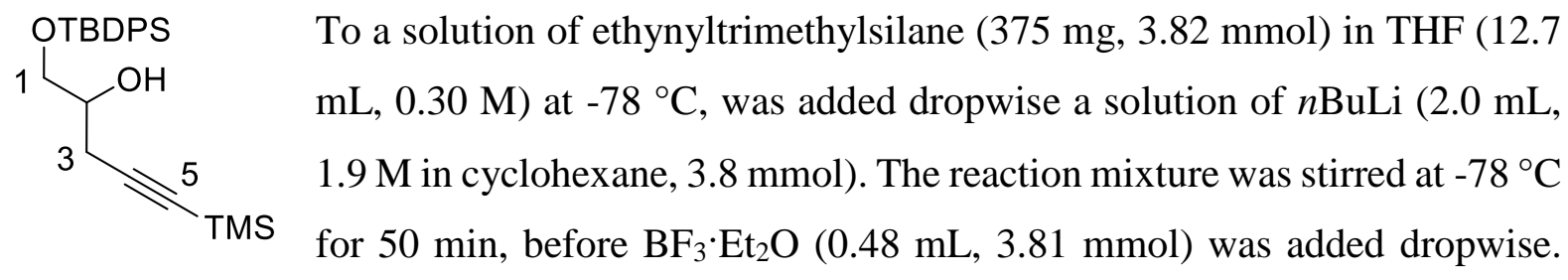

After $10 \mathrm{~min}$ stirring, a solution of epoxide 140 (991 mg, $3.17 \mathrm{mmol})$ in THF (4.0 mL, 0.79 M) was added dropwise. The reaction was stirred at $-78^{\circ} \mathrm{C}$ for $2 \mathrm{~h} 40 \mathrm{~min}$, and then quenched with saturated aqueous $\mathrm{NH}_{4} \mathrm{Cl}(15 \mathrm{~mL})$, and extracted with $\mathrm{Et}_{2} \mathrm{O}(3 \times 40 \mathrm{~mL})$. The organic layers were combined, dried over $\mathrm{MgSO}_{4}$, filtered and concentrated under reduced pressure. This crude product was purified by column chromatography (silica, 20:1 Pet. ether/EtOAc, $R_{\mathrm{f}}=$ $0.23)$ to yield 141 a pale yellow oil $(1.18 \mathrm{~g}, 91 \%)$.

${ }^{1}$ H NMR (500 MHz, $\mathrm{CDCl}_{3}$ ): $\delta$ 7.71-7.67 (complex m, 4H, CH, Ph, TBDPS), 7.44 (t, $J=7.2$ $\mathrm{Hz}, 2 \mathrm{H}, \mathrm{CH}, \mathrm{Ph}, \mathrm{TBDPS}), 7.41$ (t, $J=7.2 \mathrm{~Hz}, 4 \mathrm{H}, \mathrm{CH}, \mathrm{Ph}$, TBDPS), 3.88 (m, 1H, 2-CH), 3.76 $\left(\mathrm{dd}, J=10.1,4.3 \mathrm{~Hz}, 1 \mathrm{H}\right.$, one of 1- $\left.\mathrm{CH}_{2}\right), 3.69\left(\mathrm{dd}, J=10.0,5.9 \mathrm{~Hz}, 1 \mathrm{H}\right.$, one of 1- $\left.\mathrm{CH}_{2}\right), 2.54$ $\left(\mathrm{dd}, J=16.9,6.3 \mathrm{~Hz}, 1 \mathrm{H}\right.$, one of $\left.3-\mathrm{CH}_{2}\right), 2.51\left(\mathrm{dd}, J=17.3,6.7 \mathrm{~Hz}, 1 \mathrm{H}\right.$, one of $\left.3-\mathrm{CH}_{2}\right), 1.07$ (s, 9H, $\left.\mathrm{CH}_{3}, t \mathrm{Bu}, \mathrm{TBDPS}\right), 0.11$ (s, 9H, $\mathrm{CH}_{3}, \mathrm{TMS}$ ).

${ }^{13}$ C NMR (125 MHz, $\mathrm{CDCl}_{3}$ ): $\delta 135.52$ (CH, Ph, TBDPS), 135.51 (CH, Ph, TBDPS), 133.05 (C, Ph, TBDPS), 133.03 (C, Ph, TBDPS), 129.84 (CH, Ph, TBDPS), 129.83 (CH, Ph, TBDPS), 127.8 (CH, Ph, TBDPS), 102.6 (C, C4), 87.1 (C, C5), $70.2\left(\mathrm{CH}_{2}, \mathrm{C} 1\right), 66.4(\mathrm{CH}, \mathrm{C} 2), 26.9$ $\left(\mathrm{CH}_{3}, t \mathrm{Bu}, \mathrm{TBDPS}\right), 24.7\left(\mathrm{CH}_{2}, \mathrm{C} 3\right), 19.3$ (C, $\left.t \mathrm{Bu}, \mathrm{TBDPS}\right), 0.03\left(\mathrm{CH}_{3}, \mathrm{TMS}\right)$.

These data matched those reported previously. ${ }^{66}$

\section{(S)-2-(para-Methoxybenzyl)methyloxirane (150)}

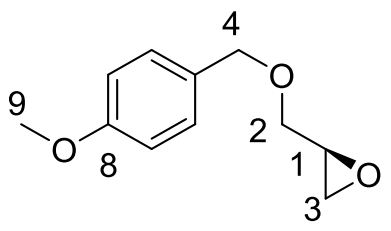

To a suspension of $\mathrm{NaH}(725 \mathrm{mg}, 60 \% \mathrm{w} / \mathrm{w}$ in mineral oil, $18.1 \mathrm{mmol})$ in DMF $(11.0 \mathrm{~mL}, 1.6 \mathrm{M})$ at $-70{ }^{\circ} \mathrm{C}$, a solution of $(S)$-glycidol $(\mathbf{9 7}$, $1.0 \mathrm{~mL}, 1.11 \mathrm{~g}, 14.8 \mathrm{mmol})$ in $\mathrm{DMF}(5.5 \mathrm{~mL}, 2.7 \mathrm{M})$ was added dropwise. The mixture was stirred for $30 \mathrm{~min}$. $\mathrm{PMBCl}(2.87 \mathrm{~g}, 18.3$

mmol, freshly prepared from PMBOH) was added dropwise, followed by TBAI (6 mg, 0.02 $\mathrm{mmol}$ ). The reaction was stirred for $25 \mathrm{~min}$ at $-70{ }^{\circ} \mathrm{C}$ before warming to r.t., and stirred for $5 \mathrm{~h}$ 25 min. Reaction was quenched with $\mathrm{H}_{2} \mathrm{O}(40 \mathrm{~mL})$, and then extracted with $\mathrm{Et}_{2} \mathrm{O}(3 \times 50 \mathrm{~mL})$. 
The organic layers were combined, dried over $\mathrm{MgSO}_{4}$ and concentrated under reduced pressure. The crude product was purified by column chromatography (silica, 10:1 Pet. ether/EtOAc, $\mathrm{R}_{\mathrm{f}}$ $=0.14)$ to yield $\mathbf{1 5 0}$ as a colourless oil $(2.60 \mathrm{~g}, 89 \%)$.

${ }^{1} \mathbf{H}$ NMR $\left(500 \mathrm{MHz}, \mathrm{CDCl}_{3}\right): \delta 7.28(\mathrm{~d}, J=9.3 \mathrm{~Hz}, 2 \mathrm{H}, 6-\mathrm{CH}), 6.89(\mathrm{~d}, J=8.5 \mathrm{~Hz}, 2 \mathrm{H}, 7-\mathrm{CH})$, $4.55\left(\mathrm{~d}, J=11.5 \mathrm{~Hz}, 1 \mathrm{H}\right.$, one of $\left.\mathrm{CH}_{2}, 4-\mathrm{CH}_{2}\right), 4.49(\mathrm{~d}, J=11.5 \mathrm{~Hz}, 1 \mathrm{H}$, one of 4-CH$), 3.81$ (s, $\left.3 \mathrm{H}, 9-\mathrm{CH}_{3}\right), 3.73\left(\mathrm{dd}, J=11.4,3.1 \mathrm{~Hz}, 1 \mathrm{H}\right.$, one of $\left.2-\mathrm{CH}_{2}\right), 3.42(\mathrm{dd}, J=11.5,5.9 \mathrm{~Hz}, 1 \mathrm{H}$, one of 2- $\mathrm{CH}_{2}$ ), 3.18 (ddt, $\left.J=5.9,4.1,2.9 \mathrm{~Hz}, 1 \mathrm{H}, 1-\mathrm{CH}\right), 2.80(\mathrm{dd}, J=5.0,4.3 \mathrm{~Hz}, 1 \mathrm{H}$, one of 3$\left.\mathrm{CH}_{2}\right), 2.61\left(\mathrm{dd}, J=5.1,2.7 \mathrm{~Hz}, 1 \mathrm{H}\right.$, one of $\left.3-\mathrm{CH}_{2}\right)$.

${ }^{13}$ C NMR (125 MHz, $\left.\mathrm{CDCl}_{3}\right): \delta 159.3$ (C, C8), 129.9 (C, C5), 129.4 (CH, C6), 113.8 (CH, C7), $73.0\left(\mathrm{CH}_{2}, \mathrm{C} 4\right), 70.5\left(\mathrm{CH}_{2}, \mathrm{C} 1\right), 55.3\left(\mathrm{CH}_{3}, \mathrm{C} 9\right), 50.9(\mathrm{CH}, \mathrm{C} 2), 44.4\left(\mathrm{CH}_{2}, \mathrm{C} 3\right)$.

Specific rotation: $[a]_{D}{ }^{25}=-1.04\left(c=1.34, \mathrm{CH}_{2} \mathrm{Cl}_{2}\right)$. Lit.: $[a]_{D}{ }^{24}=-5.98\left(c=0.98, \mathrm{CHCl}_{3}\right){ }^{54}$ These NMR data matched those reported previously. ${ }^{54}$

\section{(S)-1-(para-Methoxybenzyl)oxy-5-trimethylsilyl-4-pentyn-2-ol (146)}

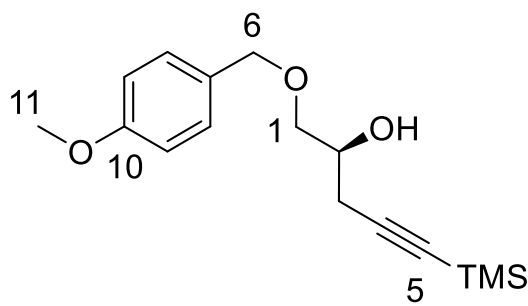

To a solution of ethynyltrimethylsilane $(0.87 \mathrm{~mL}, 609 \mathrm{mg}$, $6.20 \mathrm{mmol})$ in THF $(20.0 \mathrm{~mL}, 0.31 \mathrm{M})$ at $-78^{\circ} \mathrm{C}, n \operatorname{BuLi}(3.2$ $\mathrm{mL}, 1.9 \mathrm{M}$ in cyclohexane, $6.18 \mathrm{mmol}$ ) was added dropwise.

This solution was stirred for $50 \mathrm{~min} . \mathrm{BF}_{3} \cdot \mathrm{Et}_{2} \mathrm{O}(0.78 \mathrm{~mL}$,

$6.18 \mathrm{mmol}$ ) was added dropwise. After $10 \mathrm{~min}$, a solution of $151(1.01 \mathrm{~g}, 5.20 \mathrm{mmol})$ in THF $(5.0 \mathrm{~mL}, 1.0 \mathrm{M})$ was added dropwise. The reaction was stirred for $3 \mathrm{~h} 15 \mathrm{~min}$ at $-78{ }^{\circ} \mathrm{C}$. The reaction was quenched with sat. aq. $\mathrm{NH}_{4} \mathrm{Cl}$ solution, and then extracted with EtOAc $(3 \times 30 \mathrm{~mL})$. The organic layers were combined, dried over $\mathrm{MgSO}_{4}$ and concentrated under reduced pressure. The crude product was purified by column chromatography (silica, 5:1 Pet. ether/EtOAc, $\left.R_{\mathrm{f}}=0.38\right)$ to yield 146 as a pale yellow oil (1.08 g, $72 \%)$.

${ }^{1} \mathbf{H}$ NMR (500 MHz, $\left.\mathrm{CDCl}_{3}\right): \delta 7.27(\mathrm{~d}, J=8.7 \mathrm{~Hz}, 2 \mathrm{H}, 8-\mathrm{CH}), 6.89(\mathrm{~d}, J=8.8 \mathrm{~Hz}, 2 \mathrm{H}, 9-\mathrm{CH})$, 4.51 (s, 2H, 6- $\left.\mathrm{CH}_{2}\right), 3.98-3.91(\mathrm{~m}, 1 \mathrm{H}, 2-\mathrm{CH}), 3.81$ (s, 3H, 11- $\left.\mathrm{CH}_{3}\right), 3.58(\mathrm{dd}, J=9.6,3.9 \mathrm{~Hz}$, $1 \mathrm{H}$, one of $\left.1-\mathrm{CH}_{2}\right), 3.47\left(\mathrm{dd}, J=9.8,6.5 \mathrm{~Hz}, 1 \mathrm{H}\right.$, one of $\left.1-\mathrm{CH}_{2}\right), 2.51(\mathrm{dd}, J=16.8,6.0 \mathrm{~Hz}, 1 \mathrm{H}$, one of $\left.3-\mathrm{CH}_{2}\right), 2.46\left(\mathrm{dd}, J=16.8,6.8 \mathrm{~Hz}, 1 \mathrm{H}\right.$, one of $\left.3-\mathrm{CH}_{2}\right), 2.42(\mathrm{~d}, J=4.1 \mathrm{~Hz}, 1 \mathrm{H}, \mathrm{OH})$, 0.14 (s, 9H, $\left.\mathrm{CH}_{3}, \mathrm{TMS}\right)$. 
${ }^{13}$ C NMR (125 MHz, $\left.\mathrm{CDCl}_{3}\right): \delta 159.3$ (C, C10), 129.9 (C, C7), $129.4(\mathrm{CH}, \mathrm{C} 8), 113.8(\mathrm{CH}$, C9), 102.5 (C, C4), 87.3 (C, C5), $73.1\left(\mathrm{CH}_{2}, \mathrm{C} 6\right), 72.4\left(\mathrm{CH}_{2}, \mathrm{C} 1\right), 68.8(\mathrm{CH}, \mathrm{C} 2), 55.3\left(\mathrm{CH}_{3}\right.$, C11), $25.0\left(\mathrm{CH}_{2}, \mathrm{C} 3\right), 0.03\left(\mathrm{CH}_{3}, \mathrm{TMS}\right)$.

IR (neat) cm $\mathrm{cm}^{-1}: 3433$ (br, OH), 2956 (m, C-H), 2921 (m, C-H), 2836 (m, C-H), $2179(\mathrm{~m}, \mathrm{C} \equiv \mathrm{C})$, 1612 (m, Ar C-C), 1247 (s, C-O), 1073 (br, C-O), 1033 (s, C-O), 839 (s, C-Si), 739 (m, C$\mathrm{H})$.

HRMS (ESI) $m / z$ : found 293.1571, calcd for $\mathrm{C}_{16} \mathrm{H}_{25} \mathrm{O}_{3} \mathrm{Si}[\mathrm{M}+\mathrm{H}]^{+} 293.1567$ ( $\left.\Delta=1.4 \mathrm{ppm}\right)$.

Specific rotation: $[a]_{D}^{22}=+13.9\left(c=1.14, \mathrm{CH}_{2} \mathrm{Cl}_{2}\right)$.

Only ${ }^{1} \mathrm{H}$ NMR data was reported previously, and the above ${ }^{1} \mathrm{H}$ NMR data matched those reported previously. ${ }^{67}$

(S)-1-(para-Methoxybenzyl)oxy-4-pentyn-2-ol (152)

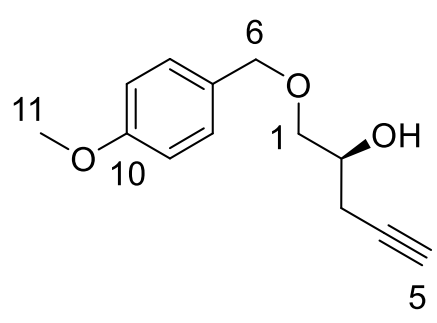

To a solution of $146(114 \mathrm{mg}, 0.390 \mathrm{mmol})$ in $\mathrm{MeOH}(2.6 \mathrm{~mL}$, $0.15 \mathrm{M})$ at r.t., $\mathrm{K}_{2} \mathrm{CO}_{3}(26 \mathrm{mg}, 1.95 \mathrm{mmol})$ was added. After $4 \mathrm{~h}$ 30 min of stirring, reaction was diluted with $\mathrm{H}_{2} \mathrm{O}$ and extracted with $\mathrm{Et}_{2} \mathrm{O}(3 \times 40 \mathrm{~mL})$. The organic layers were combined, dried

5 over $\mathrm{MgSO}_{4}$ and concentrated under reduced pressure. The crude product was purified by column chromatography (silica, 5:1 Pet. ether/EtOAc, followed by 1:1 Pet. ether/EtOAc, $R_{f}=0.10$ in 5:1 Pet. ether/EtOAc) to yield 152 as a colourless oil $(64 \mathrm{mg}$, $74 \%)$.

${ }^{1} \mathbf{H}$ NMR $\left(500 \mathrm{MHz}, \mathrm{CDCl}_{3}\right): \delta 7.27(\mathrm{~d}, J=8.1 \mathrm{~Hz}, 2 \mathrm{H}, 8-\mathrm{CH}), 6.89(\mathrm{~d}, J=8.3 \mathrm{~Hz}, 2 \mathrm{H}, 9-\mathrm{CH})$, $4.51\left(\mathrm{~s}, 2 \mathrm{H}, 6-\mathrm{CH}_{2}\right), 3.97(\mathrm{~m}, 1 \mathrm{H}, 2-\mathrm{CH}), 3.81\left(\mathrm{~s}, 3 \mathrm{H}, 11-\mathrm{CH}_{3}\right), 3.59$ (dd, $J=9.5,3.7 \mathrm{~Hz}, 1 \mathrm{H}$, one of 1- $\left.\mathrm{CH}_{2}\right), 3.48\left(\mathrm{dd}, J=9.4,6.7 \mathrm{~Hz}, 1 \mathrm{H}\right.$, one of $\left.1-\mathrm{CH}_{2}\right), 2.51$ (br. d, $J=6.2 \mathrm{~Hz}, 2 \mathrm{H}, 3-$ $\mathrm{CH}_{2}$ ), 2.47 (d, J=4.9 Hz, 1H, OH), 2.03 (br. s, 1H, 5-CH).

${ }^{13}$ C NMR (125 MHz, $\left.\mathrm{CDCl}_{3}\right): \delta 159.3$ (C, C10), 129.9 (C, C7), $129.4(\mathrm{CH}, \mathrm{C} 8), 113.9(\mathrm{CH}$, C9), 80.2 (C, C4), $73.1\left(\mathrm{CH}_{2}, \mathrm{C} 6\right), 72.5\left(\mathrm{CH}_{2}, \mathrm{C} 1\right), 70.6(\mathrm{CH}, \mathrm{C} 5), 68.7(\mathrm{CH}, \mathrm{C} 2), 55.3\left(\mathrm{CH}_{3}\right.$, C11), $23.5\left(\mathrm{CH}_{2}, \mathrm{C} 3\right)$. 


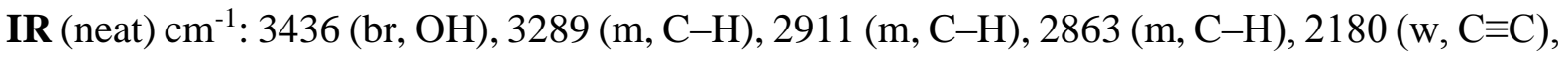
1612 (m, Ar C-C), 1245 (s, C-O), 1078 (m, C-O), 1031 (s, C-O), 817 (m, C-H), 638 (m, C$\mathrm{H})$.

HRMS (ESI) $m / z$ : found 243.1000, calcd for $\mathrm{C}_{13} \mathrm{H}_{16} \mathrm{O}_{3} \mathrm{Na}[\mathrm{M}+\mathrm{Na}]^{+} 243.0992(\Delta=3.3 \mathrm{ppm})$.

Specific rotation: $[a]_{D}{ }^{23}=+6.32\left(c=0.64, \mathrm{CH}_{2} \mathrm{Cl}_{2}\right)$.

\section{Fragment C9-C15}

\section{(S)-Bromosuccinic acid (157)}<smiles>O=C(O)CC(Br)C(=O)O</smiles>

A solution of $(S)$-sspartic acid $(\mathbf{1 5 4}, 10.0 \mathrm{~g}, 75.1 \mathrm{mmol})$ and potassium bromide (40.7 g, $342 \mathrm{mmol}$ ) in sulfuric acid (195 mL, $2.5 \mathrm{M}$ in $\mathrm{H}_{2} \mathrm{O}$ ) was cooled down to $-10{ }^{\circ} \mathrm{C}$. A solution of sodium nitrite $(9.25 \mathrm{~g}, 134 \mathrm{mmol})$ in water $(17.8 \mathrm{~mL}, 7.54 \mathrm{M})$ was added slowly over $50 \mathrm{~min}$, at such a rate to keep the temperature between -10 and $-5{ }^{\circ} \mathrm{C}$. The fumes generated in the reaction were neutralized in a gas trap containing $\mathrm{NaOH}$ aqueous solution before releasing in the fumehood. The reaction was stirred at $-10{ }^{\circ} \mathrm{C}$ for $2 \mathrm{~h}$, and white precipitate was observed. The reaction mixture was warmed to r.t. and extracted with EtOAc $(3 \times 100 \mathrm{~mL})$. The organic layers were combined, dried over $\mathrm{MgSO}_{4}$ and concentrated under reduced pressure. The product obtained was further dried under high vacuum to yield 157 as a white powder (12.5 g, 84\% yield).

${ }^{1} \mathrm{H}$ NMR $\left(500 \mathrm{MHz}, \mathrm{D}_{2} \mathrm{O}\right): \delta 4.53(\mathrm{dd}, J=7.9,6.5 \mathrm{~Hz}, 1 \mathrm{H}, 2-\mathrm{CH}), 3.11(\mathrm{dd}, J=17.5,7.8 \mathrm{~Hz}$, $1 \mathrm{H}$, one of 3- $\left.\mathrm{CH}_{2}\right), 2.99\left(\mathrm{dd}, J=17.5,6.5 \mathrm{~Hz}, 1 \mathrm{H}\right.$, one of $\left.3-\mathrm{CH}_{2}\right)$.

${ }^{13} \mathrm{C}$ NMR $\left(125 \mathrm{MHz}, \mathrm{D}_{2} \mathrm{O}\right): \delta 173.8(\mathrm{C}, \mathrm{C} 4), 172.9(\mathrm{C}, \mathrm{C} 1), 39.3\left(\mathrm{CH}_{2}, \mathrm{C} 3\right), 39.0(\mathrm{CH}, \mathrm{C} 2)$.

IR (neat): 3009 (br, O-H), 2646 (br, C-H), 1702 (s, C=O), 1420 (s, C-H), 1306 (m, C-H), 1185 (s, C-O), 934 (s, O-H), 648 (s, C-Br) cm ${ }^{-1}$.

HRMS (ESI) $m / z$ : found 194.9292, calcd for $\mathrm{C}_{4} \mathrm{H}_{4} \mathrm{O}_{4} \mathrm{Br}^{79}[\mathrm{M}-\mathrm{H}]^{-} 194.9298(\Delta=3.1 \mathrm{ppm})$.

M.p.: $169.4-170.8^{\circ} \mathrm{C}\left(\right.$ Lit. $\left.166-167^{\circ} \mathrm{C}\right)$.

Specific rotation: $[a]_{D}{ }^{27}=-41.8\left(c=1.11, \mathrm{H}_{2} \mathrm{O}\right)$. 
These NMR data are consistent with those reported in $\mathrm{MeOH}-\mathrm{d}_{4}$, and the IR and m.p. matched those reported previously. ${ }^{68}$

\section{(S)-2-Bromobutane-1,4-diol (160)}

$\underbrace{\stackrel{\mathrm{Br}}{=} \mathrm{OH}}_{1} \begin{aligned} & \text { To a solution of }(S) \text {-bromosuccinic acid }(\mathbf{1 5 7}, 3.83 \mathrm{~g}, 19.4 \mathrm{mmol}) \text { in } \mathrm{THF} \\ & (23.0 \mathrm{~mL}, 0.84 \mathrm{M}) \text { at } 0{ }^{\circ} \mathrm{C}, \mathrm{BH}_{3} \cdot \mathrm{Me}_{2} \mathrm{~S}(29.1 \mathrm{~mL}, 2.0 \mathrm{M} \text { in THF, 58.2 mmol })\end{aligned}$ was added drop-wise over $1 \mathrm{~h} 15 \mathrm{~min}$. This reaction was stirred at $0{ }^{\circ} \mathrm{C}$ for $1 \mathrm{~h}$, and then slowly warmed to r.t. over $20 \mathrm{~min}$. A saturated aqueous solution of $\mathrm{K}_{2} \mathrm{CO}_{3}(10$ $\mathrm{mL}$ ) was added dropwise, at a rate that allowed the vigorous gas release to settle after each addition. This mixture was filtered through Celite and the filtrate was concentrated. The crude product was purified by column chromatography (silica, 50:1 EtOAc: $\mathrm{MeOH}, \mathrm{R}_{\mathrm{f}}=0.44$ ) to yield 160 as a colourless clear oil $(2.47 \mathrm{~g}, 75 \%$ yield $)$.

${ }^{1} \mathbf{H}$ NMR $\left(500 \mathrm{MHz}, \mathrm{CDCl}_{3}\right.$ ): $\delta 4.37$ (app. dt, $\left.J=12.9,5.6 \mathrm{~Hz}, 1 \mathrm{H}, 2-\mathrm{CH}\right), 3.95-3.80$ (complex m, 4H, 1- $\mathrm{CH}_{2} \& 4-\mathrm{CH}_{2}$ ), 2.68 (br., 2H, OH), 2.21-2.07 (m, 2H, 3- $\mathrm{CH}_{2}$ ).

${ }^{13} \mathrm{C}$ NMR $\left(125 \mathrm{MHz}, \mathrm{CDCl}_{3}\right): \delta 67.1\left(\mathrm{CH}_{2}, \mathrm{C} 4\right), 60.1\left(\mathrm{CH}_{2}, \mathrm{C} 1\right), 55.2(\mathrm{CH}, \mathrm{C} 2), 37.7\left(\mathrm{CH}_{2}\right.$, C3).

IR (neat) cm $\mathrm{cm}^{-1}: 3315$ (br, O-H), 2932 (w, C-H), 2885 (w, C-H), 1420 (m, C-H), 1377 (w, CH), 1051 (s, C-O), 1022 (s, C-O), 639 (m, C-Br), 533 (m, C-Br).

Specific rotation: $[a]_{D}{ }^{25}=-32.8\left(c=1.00, \mathrm{CH}_{2} \mathrm{Cl}_{2}\right)$.

These data matched those reported previously. ${ }^{54,52}$

\section{(R)-Triethyl-3-(oxiranyl)ethoxysilane (155)}

TESO $\overbrace{4}^{1} \begin{aligned} & \text { ThF }(20 \mathrm{~mL}) \text { at }-15{ }^{\circ} \mathrm{C} \text { under } \mathrm{N}_{2} \text { atm., a solution of }(S) \text {-2-bromobutane- } \\ & \mathrm{TH}\end{aligned}$ 1,4-diol (160, $2.47 \mathrm{~g}, 14.6 \mathrm{mmol})$ in THF (20 mL, 0.71 M) was added dropwise over $45 \mathrm{~min}$. After stirring at temperatures between -9 and $-15^{\circ} \mathrm{C}$ for $30 \mathrm{~min}$, chlorotriethylsilane $(2.25 \mathrm{~mL}$, $17.5 \mathrm{mmol}$ ) was added dropwise via a syringe, and THF $(1.0 \mathrm{~mL})$ was used to rinse the syringe. The reaction mixture was allowed to warm to r.t. over $10 \mathrm{~min}$. After stirring at r.t. for $1 \mathrm{~h}$, the 
reaction was slowly quenched with sat. aq. $\mathrm{NH}_{4} \mathrm{Cl}$ solution $(30 \mathrm{~mL})$, and a minimum amount of $\mathrm{H}_{2} \mathrm{O}$ was added to dissolve any precipitate. The mixture was extracted with EtOAc $(3 \times 50$ $\mathrm{mL}$ ). The organic layers were combined, dried over $\mathrm{MgSO}_{4}$ and concentrated under reduced pressure. The crude product was purified by column chromatography (silica, 5:1 Pet. ether:EtOAc, $\left.\mathrm{R}_{\mathrm{f}}=0.69\right)$ to yield $\mathbf{1 5 5}$ as a colourless clear oil $(2.08 \mathrm{~g}, 70 \%$ yield $)$.

${ }^{1} \mathbf{H}$ NMR $\left(500 \mathrm{MHz}, \mathrm{CDCl}_{3}\right): \delta 3.78$ (t, $J=6.0 \mathrm{~Hz}, 2 \mathrm{H}, 1-\mathrm{CH}_{2}$ ), 3.06 (m, 1H, 3-CH), 2.79 (app. $\mathrm{t}, J=4.6 \mathrm{~Hz}, 1 \mathrm{H}$, one of 4- $\left.\mathrm{CH}_{2}\right), 2.52\left(\mathrm{dd}, J=5.1,2.7 \mathrm{~Hz}, 1 \mathrm{H}\right.$, one of 4- $\left.\mathrm{CH}_{2}\right), 1.81(\mathrm{dtd}, J=$ $13.9,7.0,5.0 \mathrm{~Hz}, 1 \mathrm{H}$, one of 2- $\mathrm{CH}_{2}$ ), 1.71 (app. dq, $J=13.9,5.9 \mathrm{~Hz}, 1 \mathrm{H}$, one of 2- $\mathrm{CH}_{2}$ ), 0.97 (t, $\left.J=8.1 \mathrm{~Hz}, 9 \mathrm{H}, \mathrm{CH}_{3}, \mathrm{TES}\right), 0.61$ (q, $J=8.1 \mathrm{~Hz}, 6 \mathrm{H}, \mathrm{CH}_{2}$, TES).

${ }^{13} \mathrm{C}$ NMR $\left(125 \mathrm{MHz}, \mathrm{CDCl}_{3}\right): \delta 59.7\left(\mathrm{CH}_{2}, \mathrm{C} 1\right), 50.0(\mathrm{CH}, \mathrm{C} 3), 47.2\left(\mathrm{CH}_{2}, \mathrm{C} 4\right), 35.9\left(\mathrm{CH}_{2}\right.$, $\mathrm{C} 2), 6.7\left(\mathrm{CH}_{3}, \mathrm{TES}\right), 4.4\left(\mathrm{CH}_{2}, \mathrm{TES}\right)$.

IR (neat) cm $\mathrm{cm}^{-1}: 2954$ (m, C-H), 2913 (m, C-H), 2876 (m, C-H), 1459 (m, C-H), 1414 (m, CH), 1238 (m, epoxide), 1096 (s, C-O), 1039 (s, C-O), 765 (m, epoxide), 727 (s, O-Si).

HRMS (ESI) $m / z$ : found 241.1025, calcd for $\mathrm{C}_{10} \mathrm{H}_{22} \mathrm{O}_{2} \mathrm{SiK}[\mathrm{M}+\mathrm{K}]^{+} 241.1021(\Delta=1.7 \mathrm{ppm})$.

Specific rotation: $[a]_{D}{ }^{25}=+1.35\left(c=1.06, \mathrm{CH}_{2} \mathrm{Cl}_{2}\right)$.

\section{(S)-Triethyl-(3-hydroxy)hex-5-enoxysilane (156)}

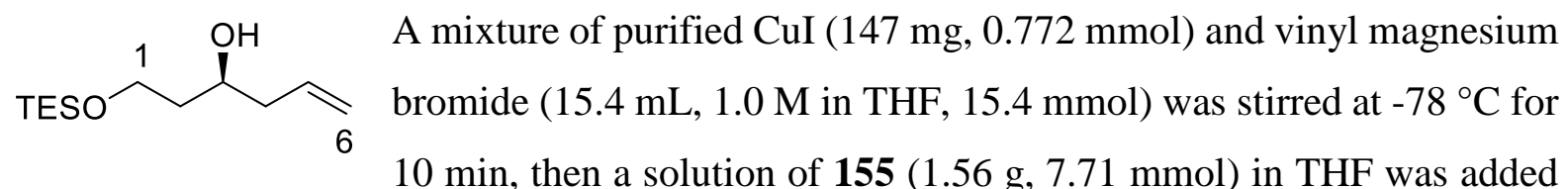
dropwise. This reaction was stirred for $2 \mathrm{~h}$, and slowly warmed to $-50{ }^{\circ} \mathrm{C}$. A sat. aq. $\mathrm{NH}_{4} \mathrm{Cl}$ solution $(30 \mathrm{~mL})$ was added to quench the reaction, followed by $\mathrm{H}_{2} \mathrm{O}(10 \mathrm{~mL})$ and aqueous ammonia solution $(5 \mathrm{~mL}, 35 \% \mathrm{w} / \mathrm{w})$, and the mixture was stirred at r.t. for a further $10 \mathrm{~min}$. The mixture was extracted with EtOAc $(2 \times 30 \mathrm{~mL})$. The organic layers were combined, dried over $\mathrm{MgSO}_{4}$ and concentrated under reduced pressure. This crude product was purified by column chromatography $\left(\mathrm{SiO}_{2}, 2: 1\right.$ Pet. ether:EtOAc, $\left.\mathrm{R}_{\mathrm{f}}=0.66\right)$ to yield 156 as a clear oil $(1.67$ g, $94 \%$ yield).

${ }^{1} \mathbf{H}$ NMR $\left(500 \mathrm{MHz}, \mathrm{CDCl}_{3}\right): \delta 5.85(\mathrm{ddt}, J=15.6,8.8,8.5 \mathrm{~Hz}, 1 \mathrm{H}, 5-\mathrm{CH}), 5.11(\mathrm{~d}, J=15.6$ $\mathrm{Hz}, 1 \mathrm{H}$, one of 6- $\left.\mathrm{CH}_{2}\right), 5.08\left(\mathrm{~d}, J=9.4 \mathrm{~Hz}, 1 \mathrm{H}\right.$, one of 6- $\mathrm{CH}_{2}$ ), 3.94-3.87 (complex m, 2H, 3- 
$\mathrm{CH}$ and one of 1- $\left.\mathrm{CH}_{2}\right), 3.87-3.78\left(\mathrm{~m}, 1 \mathrm{H}\right.$, one of $\left.1-\mathrm{CH}_{2}\right), 3.47(\mathrm{~d}, J=1.7 \mathrm{~Hz}, \mathrm{OH}), 2.33-2.18$ (m, 2H, 4- $\mathrm{CH}_{2}$ ), 1.68 (app. q, $J=5.4 \mathrm{~Hz}, 2 \mathrm{H}, 2-\mathrm{CH}_{2}$ ), 0.96 (t, $\left.J=7.9 \mathrm{~Hz}, 9 \mathrm{H}, \mathrm{CH}_{3}, \mathrm{TES}\right), 0.62$ (q, $J=7.9 \mathrm{~Hz}, 6 \mathrm{H}, \mathrm{CH}_{2}$, TES).

${ }^{13} \mathrm{C}$ NMR (125 MHz, $\left.\mathrm{CDCl}_{3}\right): \delta 135.0(\mathrm{CH}, \mathrm{C} 5), 117.3\left(\mathrm{CH}_{2}, \mathrm{C} 6\right), 71.3(\mathrm{CH}, \mathrm{C} 1), 62.3\left(\mathrm{CH}_{2}\right.$, $\mathrm{C} 3), 42.0\left(\mathrm{CH}_{2}, \mathrm{C} 4\right), 37.7\left(\mathrm{CH}_{2}, \mathrm{C} 2\right), 6.7\left(\mathrm{CH}_{3}, \mathrm{TES}\right), 4.2\left(\mathrm{CH}_{2}, \mathrm{TES}\right)$.

IR (neat) cm $\mathrm{cm}^{-1}: 3440$ (br, O-H), 3077 (w, C-H), 2954 (s, C-H), 2912 (s, C-H), 2876 (s, C-H), 1641 (w, C=C), 1414 (m, C-H), 1239 (m, C-H), 1085 (s, C-O), 743 (s, O-Si).

HRMS (ESI) $m / z$ : found 231.1770, calcd for $\mathrm{C}_{12} \mathrm{H}_{27} \mathrm{O}_{2} \mathrm{Si}[\mathrm{M}+\mathrm{H}]^{+} 231.1775$ ( $\Delta=2.2 \mathrm{ppm}$ ).

Specific rotation: $[a]_{D}{ }^{20}=-9.03\left(c=1.20, \mathrm{CH}_{2} \mathrm{Cl}_{2}\right)$.

\section{(S)-1-Triethylsilyloxy-3-(t-butyldimethylsilyloxy)hex-5-ene (161)}

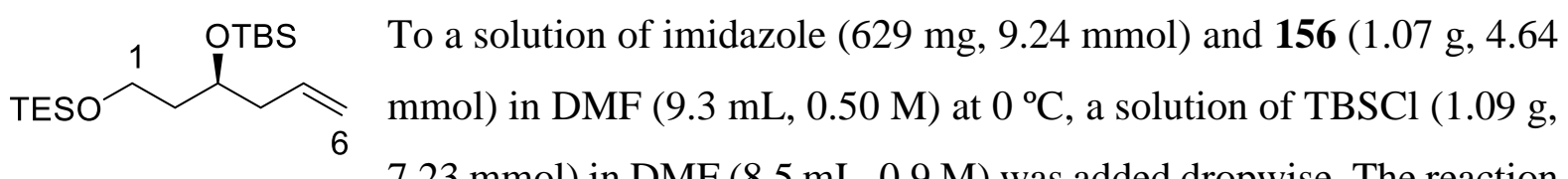
temperature was brought up to r.t. and stirred for $21 \mathrm{~h}$. The reaction mixture was then diluted with EtOAc $(30 \mathrm{~mL})$ and washed with $\mathrm{H}_{2} \mathrm{O}(30 \mathrm{~mL})$. The aqueous layer was extracted with EtOAc $(2 \times 30 \mathrm{~mL})$. The organic layers were combined, washed with $\mathrm{H}_{2} \mathrm{O}(30 \mathrm{~mL})$ and brine $(2 \times 30 \mathrm{~mL})$, dried over $\mathrm{MgSO}_{4}$ and concentrated under reduced pressure. The crude product was purified by column chromatography $\left(\mathrm{SiO}_{2}, 20: 1\right.$ Pet. ether:EtOAc, $\left.\mathrm{R}_{\mathrm{f}}=0.56\right)$ to yield 161 as a clear oil (1.16 $\mathrm{g}, 72 \%$ yield).

${ }^{1} \mathbf{H}$ NMR $\left(500 \mathrm{MHz}, \mathrm{CDCl}_{3}\right): \delta 5.88-5.76(\mathrm{~m}, 1 \mathrm{H}, 5-\mathrm{CH}), 5.04(\mathrm{~d}, J=16.6 \mathrm{~Hz}, 1 \mathrm{H}$, one of 6$\left.\mathrm{CH}_{2}\right), 5.03\left(\mathrm{~d}, J=11.0 \mathrm{~Hz}, 1 \mathrm{H}\right.$, one of $\left.6-\mathrm{CH}_{2}\right), 3.87(\mathrm{tt}, J=12.5,6.4 \mathrm{~Hz}, 1 \mathrm{H}, 3-\mathrm{CH}), 3.72-3.61$ (m, 2H, 1- $\left.\mathrm{CH}_{2}\right), 2.32-2.15\left(\mathrm{~m}, 2 \mathrm{H}, 4-\mathrm{CH}_{2}\right), 1.73-1.60\left(\mathrm{~m}, 2 \mathrm{H}, 2-\mathrm{CH}_{2}\right), 0.96(\mathrm{t}, J=7.9 \mathrm{~Hz}, 9 \mathrm{H}$, $\mathrm{CH}_{3}, \mathrm{TES}$ ), 0.89 (s, 9H, $\mathrm{CH}_{3}, \mathrm{TBS}$ ), 0.60 (q, $J=7.8 \mathrm{~Hz}, 6 \mathrm{H}, \mathrm{CH}_{3}, \mathrm{TES}$ ), 0.05 (s, 3H, $\mathrm{CH}_{3}$, TBS), 0.04 (s, 3H, $\mathrm{CH}_{3}$, TBS).

${ }^{13} \mathrm{C}$ NMR (125 MHz, $\left.\mathrm{CDCl}_{3}\right): \delta 135.1(\mathrm{CH}, \mathrm{C} 5), 116.8\left(\mathrm{CH}_{2}, \mathrm{C} 6\right), 69.0(\mathrm{CH}, \mathrm{C} 3), 59.6\left(\mathrm{CH}_{2}\right.$, C1), $42.2\left(\mathrm{CH}_{2}, \mathrm{C} 4\right), 39.8\left(\mathrm{CH}_{2}, \mathrm{C} 2\right), 25.9\left(\mathrm{CH}_{3}, t \mathrm{Bu}, \mathrm{TBS}\right), 18.1(\mathrm{C}, t \mathrm{Bu}, \mathrm{TBS}), 6.8\left(\mathrm{CH}_{3}\right.$, TES), 4.4 ( $\mathrm{CH}_{2}$, TES $),-4.7\left(\mathrm{CH}_{3}, \mathrm{Me}, \mathrm{TBS}\right),-5.3\left(\mathrm{CH}_{3}, \mathrm{Me}, \mathrm{TBS}\right)$. 
IR (neat) cm $\mathrm{cm}^{-1}: 3077$ (w, C-H), 2954 (s, C-H), 2877 (s, C-H), 1641 (w, C=C), 1471 (m, C-H), 1415 (m, C-H), 1253 (m, C-H), 1089 (s, C-O), 834 (s, O-Si), 773 (s, O-Si), 725 (s, O-Si).

HRMS (ESI) $m / z$ : found 345.2643, calcd for $\mathrm{C}_{18} \mathrm{H}_{41} \mathrm{O}_{2} \mathrm{Si}_{2}[\mathrm{M}+\mathrm{H}]^{+} 345.2640(\Delta=0.9 \mathrm{ppm})$.

Specific rotation: $[a]_{D}^{22}=+12.0\left(c=0.87, \mathrm{CH}_{2} \mathrm{Cl}_{2}\right)$.

2-(But-3'-enyl)-3-hydroxyoct-7-enal (170, Characterized from a mixture with unidentified by-product)<smiles>C=CCCCC(O)C(CC)C(C)=O</smiles>

${ }^{1} \mathbf{H}$ NMR $\left(500 \mathrm{MHz}, \mathrm{CDCl}_{3}\right): \delta 9.78(\mathrm{~d}, J=1.2 \mathrm{~Hz}, 1 \mathrm{H}, 1-\mathrm{CH}), 5.85-5.72$ (complex m, 2H, 7$\mathrm{CH} \& 3 '-\mathrm{CH}$ ), 5.07-4.92 (complex m, 4H, 8- $\left.\mathrm{CH}_{2} \& 4^{\prime}-\mathrm{CH}_{2}\right), 4.07$ (t, $\left.J=6.6 \mathrm{~Hz}, 1 \mathrm{H}, 3-\mathrm{CH}\right)$, $2.45\left(\mathrm{t}, J=7.3 \mathrm{~Hz}, 1 \mathrm{H}, 2-\mathrm{CH}\right.$ ), 2.14-2.04 (complex m, 4H, 6- $\mathrm{CH}_{2} \& 2^{\prime}-\mathrm{CH}_{2}$ ), 1.74 (partially obs. dt, $J=7.3,7.0 \mathrm{~Hz}, 2 \mathrm{H}, 1^{\prime}-\mathrm{CH}_{2}$ ), 1.64 (app. quin, $J=7.2 \mathrm{~Hz}, 2 \mathrm{H}, 4-\mathrm{CH}_{2}$ ), 1.64 (app. quin, $\left.J=7.6 \mathrm{~Hz}, 2 \mathrm{H}, 5-\mathrm{CH}_{2}\right)$.

${ }^{13} \mathrm{C}$ NMR (125 MHz, $\left.\mathrm{CDCl}_{3}\right): \delta 202.5(\mathrm{CH}, \mathrm{C} 1), 138.3$ (C, C7), $137.5\left(\mathrm{C}, \mathrm{C} 3\right.$ '), $115.6\left(\mathrm{CH}_{2}\right.$, C8), $114.8\left(\mathrm{CH}_{2}, \mathrm{C}^{\prime}\right), 64.2(\mathrm{CH}, \mathrm{C} 3), 43.1(\mathrm{CH}, \mathrm{C} 2), 33.06\left(\mathrm{CH}_{2}, \mathrm{C} 6\right), 33.00\left(\mathrm{CH}_{2}, \mathrm{C} 2{ }^{\prime}\right), 28.1$ $\left(\mathrm{CH}_{2}, \mathrm{C} 4\right), 25.2\left(\mathrm{CH}_{2}, \mathrm{C} 5\right), 21.2\left(\mathrm{CH}_{2}, \mathrm{Cl}^{\prime}\right)$.

IR (neat) cm $\mathrm{cm}^{-1}: 3437$ (br, O-H), 3077 (w, C-H), 2933 (s, C-H), 2862 (m, C-H), 1735 (s, C=O), 1440 (s, C-H), 1244 (s, C-O), 1170 (s, C-O), 909 (s, C-H).

HRMS (ESI) $m / z$ : found 197.1536, calcd for $\mathrm{C}_{12} \mathrm{H}_{21} \mathrm{O}_{2}[\mathrm{M}+\mathrm{H}]^{+} 197.1536(\Delta=0.0 \mathrm{ppm})$.

\section{5-(t-Butyldimethylsilyloxy)pentanal (177)}

$1=0$ OTBS To a solution of 5-hexenol $(\mathbf{1 6 9}, 508 \mathrm{mg}, 5.08 \mathrm{mmol})$ and imidazole $(419 \mathrm{mg}$,
$6.16 \mathrm{mmol})$ in $\operatorname{DMF}(5.0 \mathrm{~mL}, 1.0 \mathrm{M})$ at $0{ }^{\circ} \mathrm{C}$, a solution of TBSCl $(937 \mathrm{mg}$, $6.22 \mathrm{mmol})$ in DMF (5.0 mL, 1.2 M) was added dropwise. The reaction was stirred at $0{ }^{\circ} \mathrm{C}$ for $10 \mathrm{~min}$, then warmed to r.t. and stirred for $16 \mathrm{~h}$. The reaction mixture was diluted with EtOAc (30 mL) and washed with $\mathrm{H}_{2} \mathrm{O}(30 \mathrm{~mL})$. The aqueous layer was extracted with EtOAc $(2 \times 30$ 
$\mathrm{mL}$ ). The organic layers were combined, dried over $\mathrm{MgSO}_{4}$ and concentrated under reduced pressure. The crude mixture was filtered through a silica plug (5:1 Pet. Ether:EtOAc). The filtrate was concentrated to yield the TBS ether. The product was dissolved in $\mathrm{CH}_{2} \mathrm{Cl}_{2}(25 \mathrm{~mL})$, and cooled down to $-78^{\circ} \mathrm{C}$. Ozone gas was passed through the reaction until the solution turned pale blue. Triphenylphosphine (1.56 g, $5.74 \mathrm{mmol})$ was added, and the blue colour disappeared. The reaction was allowed to warm to room temperature and stirred overnight. The solvent was removed and the oil obtained was purified by column chromatography $\left(\mathrm{SiO}_{2}, 10: 1\right.$ Pet. ether:EtOAc, $\left.\mathrm{R}_{\mathrm{f}}=0.38\right)$ to yield $\mathbf{1 7 7}$ a clear colourless oil (1.05 g, 95\% yield).

${ }^{1} \mathbf{H}$ NMR $\left(500 \mathrm{MHz}, \mathrm{CDCl}_{3}\right): \delta 9.76(\mathrm{t}, J=1.6 \mathrm{~Hz}, 1 \mathrm{H}, 1-\mathrm{CH}), 3.62\left(\mathrm{t}, J=6.2 \mathrm{~Hz}, 2 \mathrm{H}, 5-\mathrm{CH}_{2}\right)$, $2.45\left(\mathrm{td}, J=7.3,1.6 \mathrm{~Hz}, 2 \mathrm{H}, 2-\mathrm{CH}_{2}\right.$ ), 1.69 (quin, $J=7.5 \mathrm{~Hz}, 2 \mathrm{H}, 3-\mathrm{CH}_{2}$ ), 1.61-1.49 (m, 2H, 4$\mathrm{CH}_{2}$ ), 0.88 (s, 9H, $\left.\mathrm{CH}_{3}, t \mathrm{Bu}, \mathrm{TBS}\right), 0.04$ (s, 6H, $\left.t \mathrm{Bu}, \mathrm{TBS}\right)$.

${ }^{13} \mathrm{C}$ NMR $\left(126 \mathrm{MHz}, \mathrm{CDCl}_{3}\right): \delta 202.7(\mathrm{CH}, \mathrm{C} 1), 62.6\left(\mathrm{CH}_{2}, \mathrm{C} 5\right), 43.6\left(\mathrm{CH}_{2}, \mathrm{C} 2\right), 32.1\left(\mathrm{CH}_{2}\right.$, C4), $25.9\left(\mathrm{CH}_{3}, t \mathrm{Bu}, \mathrm{TBS}\right), 18.6(\mathrm{C}, t \mathrm{Bu}, \mathrm{TBS}), 18.3\left(\mathrm{CH}_{2}, \mathrm{C} 3\right),-5.4\left(\mathrm{CH}_{3}, \mathrm{Me}, \mathrm{TBS}\right)$.

These data matched those reported previously. ${ }^{69}$

\subsection{References}

(1) Lu, S.; Kurtan, T.; Yang, G. J.; Sun, P.; Mandi, A.; Krohn, K.; Draeger, S.; Schulz, B.; Yi, Y. H.; Li, L.; Zhang, W. Eur. J. Org. Chem. 2011, 5452.

(2) Kito, K.; Ookura, R.; Yoshida, S.; Namikoshi, M.; Ooi, T.; Kusumi, T. Org. Lett. 2008, $10,225$.

(3) Wright, A. E.; Botelho, J. C.; Guzman, E.; Harmody, D.; Linley, P.; McCarthy, P. J.; Pitts, T. P.; Pomponi, S. A.; Reed, J. K. J. Nat. Prod. 2007, 70, 412.

(4) Williams, D. E.; Roberge, M.; Van Soest, R.; Andersen, R. J. J. Am. Chem. Soc. 2003, 125, 5296 .

(5) Fuwa, H. Heterocycles 2012, 85, 1255.

(6) Olier, C.; Kaafarani, M.; Gastaldi, S.; Bertrand, M. P. Tetrahedron 2010, 66, 413.

(7) Xu, Y. J.; Yin, Z. P.; Lin, X. L.; Gan, Z. B.; He, Y. Y.; Gao, L.; Song, Z. L. Org. Lett. 2015, 17, 1846.

(8) Minami, T.; Moriyama, A.; Hanaoka, M. Synlett 1995, 663. 
(9) Fuwa, H.; Noguchi, T.; Noto, K.; Sasaki, M. Org. Biomol. Chem. 2012, 10, 8108.

(10) Bates, R. W.; Song, P. Synthesis 2010, 2935.

(11) Banwell, M. G.; Bissett, B. D.; Bui, C. T.; Pham, H. T. T.; Simpson, G. W. Aust. J. Chem. 1998, 51, 9 .

(12) Gharpure, S. J.; Prasad, J. V. K.; Bera, K. Eur J. Org. Chem. 2014, 3570.

(13) Qian, H.; Han, X. Q.; Widenhoefer, R. A. J. Am. Chem. Soc. 2004, 126, 9536.

(14) Sutivisedsak, N.; Dawadi, S.; Spilling, C. D. Tetrahedron Lett. 2015, 56, 3534.

(15) Tietze, L. F.; Zinngrebe, J.; Spiegl, D. A.; Stecker, F. Heterocycles 2007, 74, 473.

(16) Gharpure, S. J.; Shelke, Y. G.; Reddy, S. R. B. RSC Adv. 2014, 4, 46962.

(17) Mao, J. G.; Zhang, S. Q.; Shi, B. F.; Bao, W. L. Chem. Commun. 2014, 50, 3692.

(18) Semmelhack, M. F.; Bodurow, C. Abstr. of Pap. Am. Chem. Soc. 1983, 186, 87.

(19) White, J. D.; Hong, J.; Robarge, L. A. Tetrahedron Lett. 1999, 40, 1463.

(20) Kuntiyong, P.; Lee, T. H.; Kranemann, C. L.; White, J. D. Org. Biomol. Chem. 2012, 10,7884 .

(21) Bohlmann, F.; Herbst, P. Chem. Ber.-Recl. 1959, 92, 1319.

(22) Molle, G.; Bauer, P. J. Am. Chem. Soc. 1982, 104, 3481.

(23) Gilman, H.; Jones, R. G.; Woods, L. A. J. Org. Chem. 1952, 17, 1630.

(24) Normant, J. F. Synth. Int. J. Methods 1972, 63.

(25) Dieter, R. K.; Silks, L. A.; Fishpaugh, J. R.; Kastner, M. E. J. Am. Chem. Soc. 1985, 107,4679 .

(26) Zakharkin, L. I.; Khorlina, I. M. B. Acad. Sci. USSR Chem. 1963, 12, 316.

(27) Frigerio, M.; Santagostino, M.; Sputore, S. J. Org. Chem. 1999, 64, 4537.

(28) Wei, X. D.; Taylor, R. J. K. J. Org. Chem. 2000, 65, 616.

(29) Aoyama, T.; Sonoda, N.; Yamauchi, M.; Toriyama, K.; Anzai, M.; Ando, A.; Shioiri, T. Synlett 1998, 35.

(30) Carpino, L. A. J. Org. Chem. 1970, 35, 3971.

(31) Gritter, R. J.; Wallace, T. J. J. Org. Chem. 1959, 24, 1051.

(32) Xiao, X. Y.; Prestwich, G. D. Synth. Commun. 1990, 20, 3125.

(33) Reddy, K. K.; Saady, M.; Falck, J. R.; Whited, G. J. Org. Chem. 1995, 60, 3385.

(34) Chavan, S. P.; Harale, K. R. Tetrahedron Lett. 2012, 53, 4683.

(35) Wuts, P. G. M.; Greene, T. W. Greene's protective groups in organic synthesis, 4th ed.; Wiley-Interscience Hoboken, N.J, 2007.

(36) Munakata, R.; Katakai, H.; Ueki, T.; Kurosaka, J.; Takao, K.; Tadano, K. J. Am. Chem. Soc. 2004, 126, 11254. 
(37) Fürstner, A.; Nagano, T.; Müller, C.; Seidel, G.; Müller, O. Chemistry 2007, 13, 1452.

(38) Gille, A.; Hiersemann, M. Org. Lett. 2010, 12, 5258.

(39) Bejjanki, N. K.; Venkatesham, A.; Balraju, K.; Nagaiah, K. Helv. Chim. Acta 2013, 96, 1571.

(40) Tsuri, T.; Kamata, S. Tetrahedron Lett. 1985, 26, 5195.

(41) Mulzer, J.; Mantoulidis, A.; Ohler, E. J. Org. Chem. 2000, 65, 7456.

(42) Luzzio, F. A.; Chen, J. J. Org. Chem. 2008, 73, 5621.

(43) Wamser, C. A. J. Am. Chem. Soc. 1951, 73, 409.

(44) Sato, I.; Akahori, Y.; Iida, K.; Hirama, M. Tetrahedron Lett. 1996, 37, 5135.

(45) Hernandez-Torres, J. M.; Achkar, J.; Wei, A. J. Org. Chem. 2004, 69, 7206.

(46) Evans, D. A.; Kim, A. S.; Metternich, R.; Novack, V. J. J. Am. Chem. Soc. 1998, 120, 5921.

(47) Dilhas, A.; Bonnaffe, D. Tetrahedron Lett. 2004, 45, 3643.

(48) Zurwerra, D.; Glaus, F.; Betschart, L.; Schuster, J.; Gertsch, J.; Ganci, W.; Altmann, K. H. Chem.-Eur. J. 2012, 18, 16868.

(49) Li, J. J., Name reactions for homologation, Part 1. John Wiley \& Sons: Hoboken, NJ, 2009; $\mathrm{p} 685$.

(50) Hoffman, R. V. Org. Synth. 1981, 60, 121.

(51) Pavia, D.; Kriz, G.; Lampman, G.; Engel, R. A Small Scale Approach to Organic Laboratory Techniques, 4th ed.; Cengage Learning: Boston, MA, 2015.

(52) Frick, J. A.; Klassen, J. B.; Bathe, A.; Abramson, J. M.; Rapoport, H. Synthesis 1992, 621.

(53) Norell, J. R. J. Org. Chem. 1970, 35, 1611.

(54) Zurwerra, D.; Gertsch, J.; Altmann, K. H. Org. Lett. 2010, 12, 2302.

(55) Margrey, K. A.; Chinn, A. J.; Laws, S. W.; Pike, R. D.; Scheerer, J. R. Org. Lett. 2012, $14,2458$.

(56) Petrignet, J.; Boudhar, A.; Blond, G.; Suffert, J. Angew. Chem. Int. Ed. 2011, 50, 3285.

(57) Uenishi, J.; Ohmi, M.; Ueda, A. Tetrahedron Asymm. 2005, 16, 1299.

(58) Paczkowski, R.; Maichle-Mossmer, C.; Maier, M. E. Org. Lett. 2000, 2, 3967.

(59) House, H. O.; Lee, L. F. J. Org. Chem. 1976, 41, 863.

(60) Lagisetti, C.; Yermolina, M. V.; Sharma, L. K.; Palacios, G.; Prigaro, B. J.; Webb, T. R. Acs. Chem. Biol. 2014, 9, 643.

(61) Fukahori, Y.; Takayama, Y.; Imaoka, T.; Iwamoto, O.; Nagasawa, K. Chem.-Asian J. 2013, 8, 244. 
(62) Fox, R. J.; Lalic, G.; Bergman, R. G. J. Am. Chem. Soc. 2007, 129, 14144.

(63) Spino, C.; Barriault, N. J. Org. Chem. 1999, 64, 5292.

(64) Roulland, E.; Monneret, C.; Florent, J. C.; Bennejean, C.; Renard, P.; Leonce, S. J. Org. Chem. 2002, 67, 4399.

(65) Liu, J.; He, X. F.; Wang, G. H.; Merino, E. F.; Yang, S. P.; Zhu, R. X.; Gan, L. S.; Zhang, H.; Cassera, M. B.; Wang, H. Y.; Kingston, D. G. I.; Yue, J. M. J. Org. Chem. 2014, 79, 599.

(66) Trost, B. M.; Machacek, M. R.; Faulk, B. D. J. Am. Chem. Soc. 2006, 128, 6745.

(67) Kiyotsuka, Y.; Kobayashi, Y. J. Org. Chem. 2009, 74, 7489.

(68) Wullschleger, C. W.; Gertsch, J.; Altmann, K. H. Org. Lett. 2010, 12, 1120.

(69) Frankowski, K. J.; Golden, J. E.; Zeng, Y. B.; Lei, Y.; Aubé, J. J. Am. Chem. Soc. 2008, 130,6018 . 


\section{Chapter 4: Second generation synthesis and Bestmann ylide linchpin}

\subsection{Second generation retrosynthetic analysis}

The difficulty with protecting C19 in the C16-C20 fragment $(\mathbf{1 4 1}, \mathbf{1 4 6})$, and the problem of oxidizing the hydroxy group at $\mathrm{C} 15$ to an aldehyde led to the development of a new reaction plan. The second generation strategy relied on a linchpin strategy to construct the dienoate, which involves the use of Bestmann ylide. ${ }^{1}$ The fragments to be used in the linchpin reaction, C3-C8 aldehyde (126) and the C16-C20 alcohol (viz. 141 and 146) were already prepared (Scheme 4.1). The strategy for side-arm attachment, ring-closing and pyran formation stayed the same, namely aza-aldol reaction, metathesis and alkynylation followed by $O$-Michael reaction. In previous zampanolide (19) and dactylolide (20) syntheses, the dienoate moiety is commonly synthesized by a sequence of a Wittig-type reaction to construct the C2-C3 alkene and esterification between a carboxylic acid at $\mathrm{C} 1$ and an alcohol at $\mathrm{C} 19 .^{2-6}$ The proposed linchpin approach is more efficient, as it not only reduces the number of steps, but also

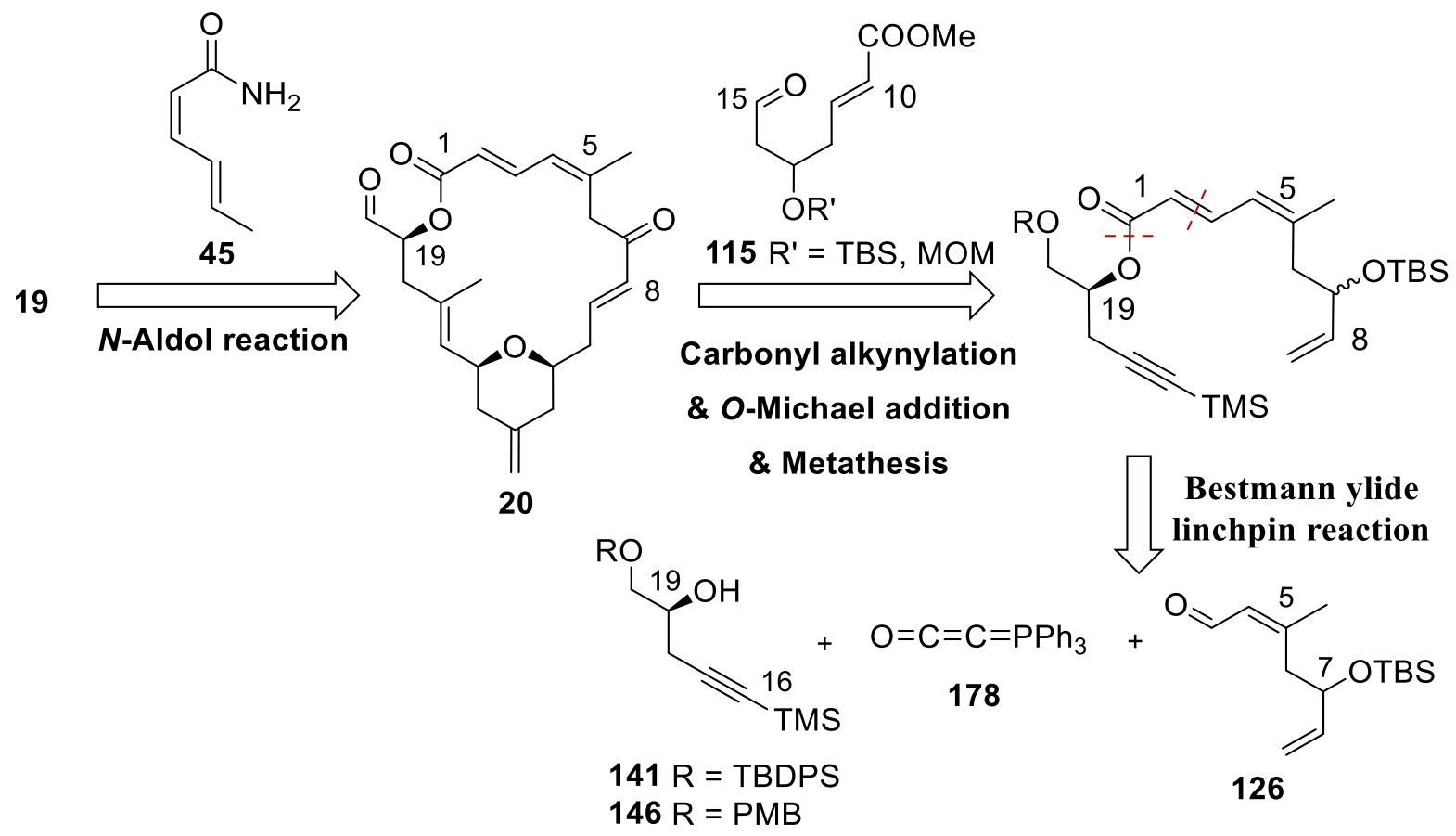

Scheme 4.1: Second generation retrosynthetic analysis. 
removes the need for protection at $\mathrm{C} 19$. The scope of this three-component Bestmann ylide reaction more generally in the synthesis of $\alpha, \beta, \gamma, \delta$-unsaturated esters was also studied.

\subsection{Bestmann ylide}

(Triphenylphosphoranylidene)ketene, $\mathrm{Ph}_{3} \mathrm{P}=\mathrm{C}=\mathrm{C}=\mathrm{O}$, also known as Bestmann ylide (178) is capable of, inter alia, three-component reactions to form $\alpha, \beta$-unsaturated esters from alcohols and aldehydes. ${ }^{1}$ First reported in 1966, it initially attracted attention due to its unique structure, namely the $145.5^{\circ}$ angle of the $\mathrm{C}=\mathrm{C}=\mathrm{P}$ moiety and the unusually short $\mathrm{C}=\mathrm{C}$ bond $(1.210 \AA)$. Bestmann ylide (178) has surprising stability, and can be stored under inert atmosphere at room temperature for months. This stability is attributed to resonance stabilization (Figure 4.1). Two zwitterionic resonance structures of the uncharged phosphorane (I) exist. The phosphonium ylide (II) can have bent conformatioin which better represents the Wittig-type reactivity and is the source of the $145.5^{\circ}$ angle of the $\mathrm{C}=\mathrm{C}=\mathrm{P}$ moiety (insert, Figure 4.1), while the chargesegregated alkyne (III) can explain the unusually short $\mathrm{C}=\mathrm{C}$ bond.

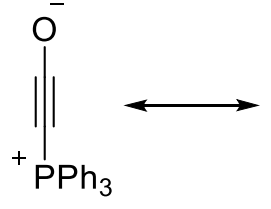

III

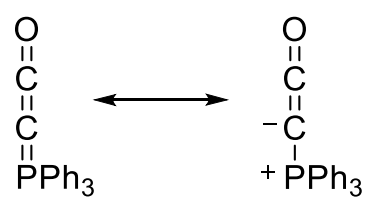

II

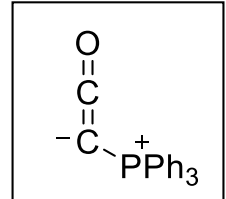

Figure 4.1: Resonance structures of Bestmann ylide (178).

Its utility was subsequently explored with pioneering work by Bestmann and co-workers, ${ }^{9-11}$ lending the name Bestmann ylide to this versatile and readily obtainable reagent. ${ }^{1,12,13}$ Studies revealed that the ylide can react with alcohols, amines and thiols to form $\alpha$-phosphoranylidene esters, amides and thioesters, providing diverse isolable Wittig reagents that can be used in subsequent transformations (Scheme 4.2, equation 1). ${ }^{9-12}$ The use of a $\beta$-ketoamide in this type of reaction has also been explored (equation 2). ${ }^{14}$ Furthermore, if the $\alpha$-phosphoranylidene ester or amide is formed in the presence of an aldehyde, ketone or ester, an additional in situ Wittig reaction step can occur. ${ }^{15-21}$ In a similar way, intramolecular couplings with Bestmann ylide (178) have enabled direct lactone (equation 3$)^{22}$ and lactam synthesis, ${ }^{16-18}$ including the 
preparation of macrolactones. ${ }^{19,21}$ Such Bestmann ylide cascade reactions can allow good compatibility with other reaction conditions, forming longer cascades. An extension of this methodology by the Taylor group to $\gamma$-hydroxyenone substrates allows preparation of $\alpha$ alkylidene- $\gamma$-butyrolactones through tandem acylation and Michael addition, followed by a Wittig reaction (equation 4). ${ }^{23,24}$ Burke and Risi performed a one-pot hydroformylationmacrocyclization cascade, where the aldehyde resulting from enantioselective hydroformylation reacted with Bestmann ylide (178) to complete this macrolactone ring (equation 5). The intermolecular Bestmann ylide cascade leads to amides, esters and thioesters through three-component couplings. ${ }^{17,19}$ In the examples above, the $\mathbf{1 7 8}$ is a bifunctional twocarbon linchpin containing two sites: one for nucleophilic attack and the other for subsequent

1)

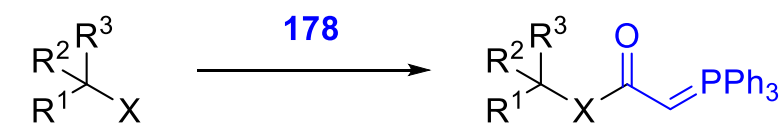

$X=\mathrm{O}, \mathrm{NH}, \mathrm{S}$

2)<smiles>CC(C)(C)ON1CC(=O)CC1=O</smiles><smiles>O=C1CN(C(=O)O)C(=O)C1=C(O)C=P</smiles>

3)

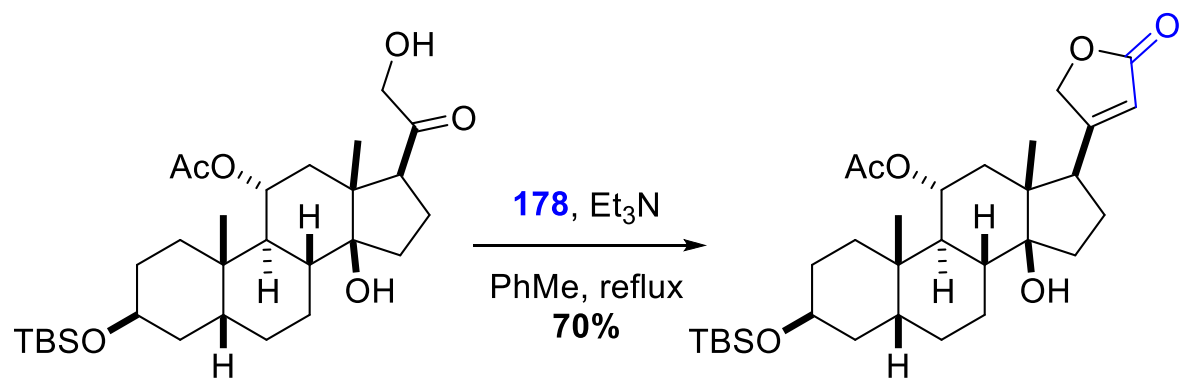

4)<smiles>CCC(CCC1(C)CC(O)C=CC1=O)OS(C)(C)C</smiles>

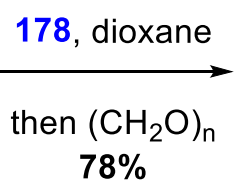<smiles>C=C1C(=O)O[C@H]2CC(C)(CCC(CC)OS(C)(C)C)C(=O)C[C@H]12</smiles>

5)<smiles>CC(=O)O/C=C\CCCCC[C@H](C)O</smiles>

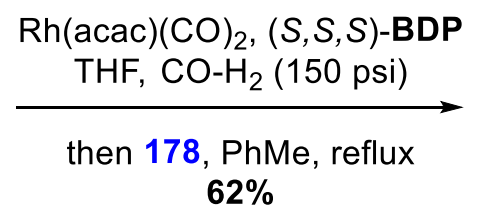

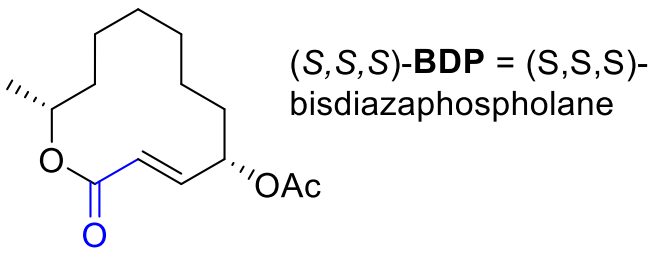

Scheme 4.2: Examples of the Bestmann ylide (178) in synthesis. 
Wittig reaction. Unlike the linchpins discussed in section 1.7, Bestmann ylide (178) partakes in cascades that proceed in a one-pot manner, which optimizes the efficiency of the synthetic linchpin. Although the utility of Bestmann ylide (178) in the synthesis of acyclic $\alpha, \beta$ unsaturated esters and dienamides has already been reported, ${ }^{16,19,25}$ its application to the synthesis of $\alpha, \beta, \gamma, \delta$-unsaturated esters (i.e. dienoates) remains uncharted. Because Wittig reactions are known to readily occur with $\alpha, \beta$-unsaturated aldehydes, this Bestmann ylide cascade should proceed with ease.

As reported by Schobert, Bestmann ylide (178) can be prepared by deprotonation of methyl (triphenylphosphoranylidene)acetate (179) with the strong non-nucleophilic base sodium bis(trimethylsilyl)amide (NaHMDS). ${ }^{13}$ The phosphorane 179 is commercially available, but can also be prepared following a sequence starting from bromoacetic acid (180) (Scheme 4.3). ${ }^{26}$ The acid 180 was methylated to methyl bromoacetate (181) after activation with oxylyl chloride, which can readily convert to the desired 179 via a phosphonium bromide salt. The four steps only reached a combined yield of 33\%, while the substitution and ylidene formation steps have an good yield of 87 88\%. Both bromoacetic acid (180) and methyl bromoacetate (181) are commercially available; the small cost difference between them encouraged the preparation of 179 from 181 . The phosphorane 179 was subjected to deprotonation by NaHMDS. Schobert prepared NaHMDS from sodium amide and bis(trimethylsilyl)amine in situ prior to the addition of $\mathbf{1 7 9}$. However, because of the toxicity and potentially explosive nature of sodium amide, NaHMDS solution was purchased from a commercial source (SigmaAldrich). Schobert reported Bestmann ylide (178) as a "very pale yellow, flaky powder", but with careful recrystallization, creamy white needle-shaped crystals were obtained. The better
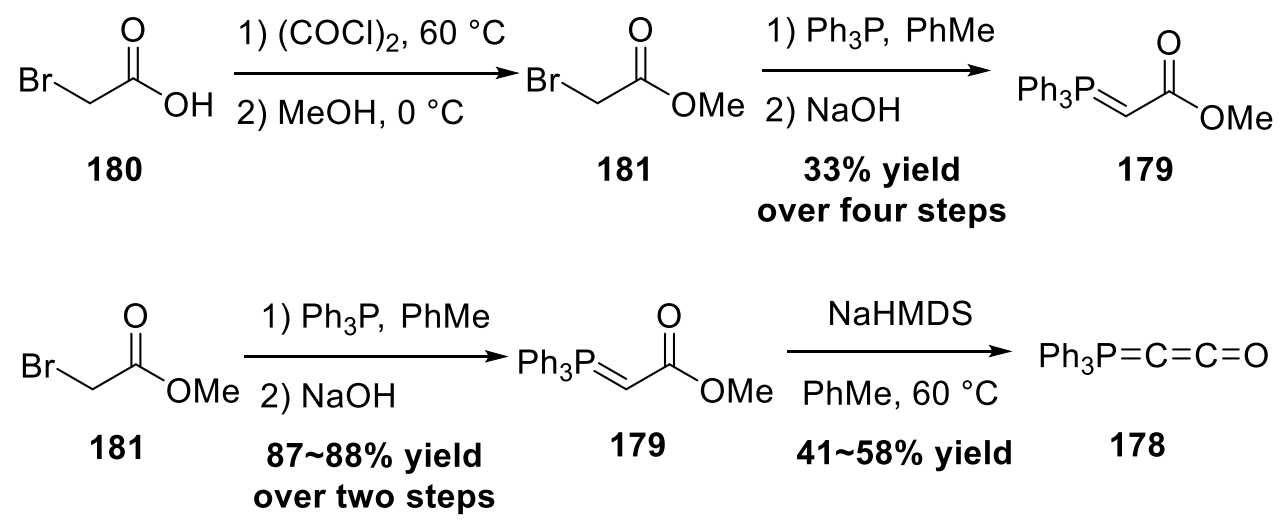

Scheme 4.3: Preparation of Bestmann ylide (178). 
crystal quality was compensated by the yields of 41 to $58 \%$ of $\mathbf{1 7 8}$ obtained, which are lower than Schobert's yield (Scheme 4.3). Interestingly, an attempt to prepare $\mathbf{1 7 8}$ from ethyl (triphenylphosphoranylidene)acetate under the same reaction conditions only returned starting material. This could be a result of the extra steric hindrance from the ethyl group, or reduced acidity of the ylidene proton.

The different appearance may explain the slightly lower melting point measured in this work, 164 169 ${ }^{\circ} \mathrm{C}$, compared to the quoted value $173{ }^{\circ} \mathrm{C},{ }^{13}$ although it could also be merely the discrepancy between melting point apparatus. This sample of Bestmann ylide (178) obtained was also characterized by IR, ${ }^{31} \mathrm{P}$ NMR and ${ }^{13} \mathrm{C}$ NMR spectroscopy, and showed broad agreement with literature (Table 4.1). ${ }^{1} \mathrm{H}$ NMR spectroscopy cannot provide useful information on the identification of $\mathbf{1 7 8}$ due to the paucity of characteristic hydrogens in the molecule, and the ESI-HRMS technique only decomposed the compound. The ${ }^{13} \mathrm{C}$ NMR data obtained did not completely match those reported: the $\alpha$ and $\beta$-carbon signals, assigned by Schobert at $-10.5 \mathrm{ppm}(J=185.4 \mathrm{~Hz})$ and $145.6 \mathrm{ppm}(J=43.0 \mathrm{~Hz})$, respectively, were not observed, while excess aromatic signals were displayed. The absence of the $\alpha$ and $\beta$-carbon signals could be a result of weak peak intensities for those carbonyl and ylide carbons. The excess aromatic signals could be from residue ylidene starting material 179. However, the overall agreement of the data suggested that $\mathbf{1 7 8}$ was made.

Table 4.1: Comparison of the measured Bestmann ylide (178) data with literature.

\begin{tabular}{|c|c|c|}
\hline $\begin{array}{c}\text { Spectroscopic } \\
\text { method }\end{array}$ & Prepared & Lit. $^{13}$ \\
\hline IR $(C=P)$ & $2097 \mathrm{~cm}^{-1}$ & $2090 \mathrm{~cm}^{-1}$ \\
\hline 31P NMR & $5.5 \mathrm{ppm}$ & $6.0 \mathrm{ppm}$ \\
\hline m.p. & $164 \sim 169{ }^{\circ} \mathrm{C}$ & $173^{\circ} \mathrm{C}$ \\
\hline${ }^{13} \mathrm{C}$ NMR & $\begin{array}{c}134.99(\mathrm{~d}, J=3.3 \mathrm{~Hz}), 133.31(\mathrm{~d}, \\
J=10.8 \mathrm{~Hz}), 132.07(\mathrm{~d}, J=10.0 \\
\mathrm{Hz}), 130.39(\mathrm{~d}, J=13.0 \mathrm{~Hz}), \\
128.48(\mathrm{~d}, J=12.2 \mathrm{~Hz}), 119.3(\mathrm{~d}, \\
\quad J=88.1 \mathrm{~Hz}) .\end{array}$ & $\begin{array}{l}145.6(\mathrm{~d}, J=43.0 \mathrm{~Hz}), 132.3(\mathrm{~s}), \\
132.2(\mathrm{~s}), 129.6(\mathrm{~d}, J=98.5 \mathrm{~Hz}), \\
128.8(\mathrm{~d}, J=12.9 \mathrm{~Hz}),-10.5(\mathrm{~d}, J \\
=185.4 \mathrm{~Hz})\end{array}$ \\
\hline
\end{tabular}


As discussed in Schobert's paper, $\mathbf{1 7 8}$ can be stored for a few months under inert atmosphere. This was corroborated in this work. No change in the quality of $\mathbf{1 7 8}$ was observed for up to six months after preparation. However, longer storage led to gradual decrease in the reactivity. Althought no visible change of appearance, IR of the partially decomposed product showed reduced intensity of the characteristic band at $2097 \mathrm{~cm}^{-1}$.

\subsection{Scope of the Bestmann ylide cascade in the synthesis of $\alpha, \beta, \gamma, \delta$-unsaturated esters}

The study of the reactions between Bestmann ylide, alcohols and $\alpha, \beta$-unsaturated aldehydes began with investigation of the coupling between the linchpin 178, $E$-hex-2-en-1-ol (182) and E-cinnamaldehyde (183) (Table 4.2, entry 1). Typically, Bestmann ylide reactions are performed at elevated temperature in either high boiling or ether solvents, such as toluene, 1,4dioxane or THF. ${ }^{17-20,23-25}$ To investigate the necessity for high temperature, the first reaction in this study was initiated at room temperature $\left(19{ }^{\circ} \mathrm{C}\right)$ in toluene and then progressively warmed to reflux $\left(110^{\circ} \mathrm{C}\right)$ while monitoring progress by TLC. It was noted that the Bestmann ylide reagent (178) was insoluble up to $80^{\circ} \mathrm{C}$ and no reaction was observed until the reaction mixture was heated at reflux. Under these conditions, incomplete consumption of both starting materials was seen after $18 \mathrm{~h}$ and the poor conversion was attributed to the instability of Bestmann ylide (178) over long periods at elevated temperatures and in the presence of any adventitious nucleophilic source. In response to these observations, the reaction was attempted in THF, a solvent in which the Bestmann ylide readily dissolved, even at room temperature. Upon heating at reflux, this reaction provided better conversion, although the isolated yield of 184 was only marginally improved (entry 2). The poor yields could be due to excessive handling to monitor the reaction. Gratifyingly, the reaction of oct-2-en-1-ol (185) with cinnamaldehyde (183) was efficient and high yielding, and after a reaction time of just 1.5 hours in high yield (93\%) of $\mathbf{1 8 6}$ was obtained (entry 3). Reaction of Z-allylic alcohol $\mathbf{1 8 7}$ was run in parallel (entry 4), and likewise produced full conversion and excellent amounts of the product $\mathbf{1 8 8}$ (91\% yield), although a longer reaction time was required to achieve this. The Zgeometry of the allylic alcohol was retained in 187, as expected. After this, the secondary allylic alcohol 189 was investigated and a reasonable yield of the product was obtained when the reaction was carried out in THF (entry 5). A comparative reaction in toluene was also performed and found to a deliver a better yield of the product $\mathbf{1 9 0}$ after the same length of time 
Table 4.2: Coupling reactions of model alcohols and aldehydes with Bestmann ylide $(\mathbf{1 7 8})^{\mathrm{a}}$

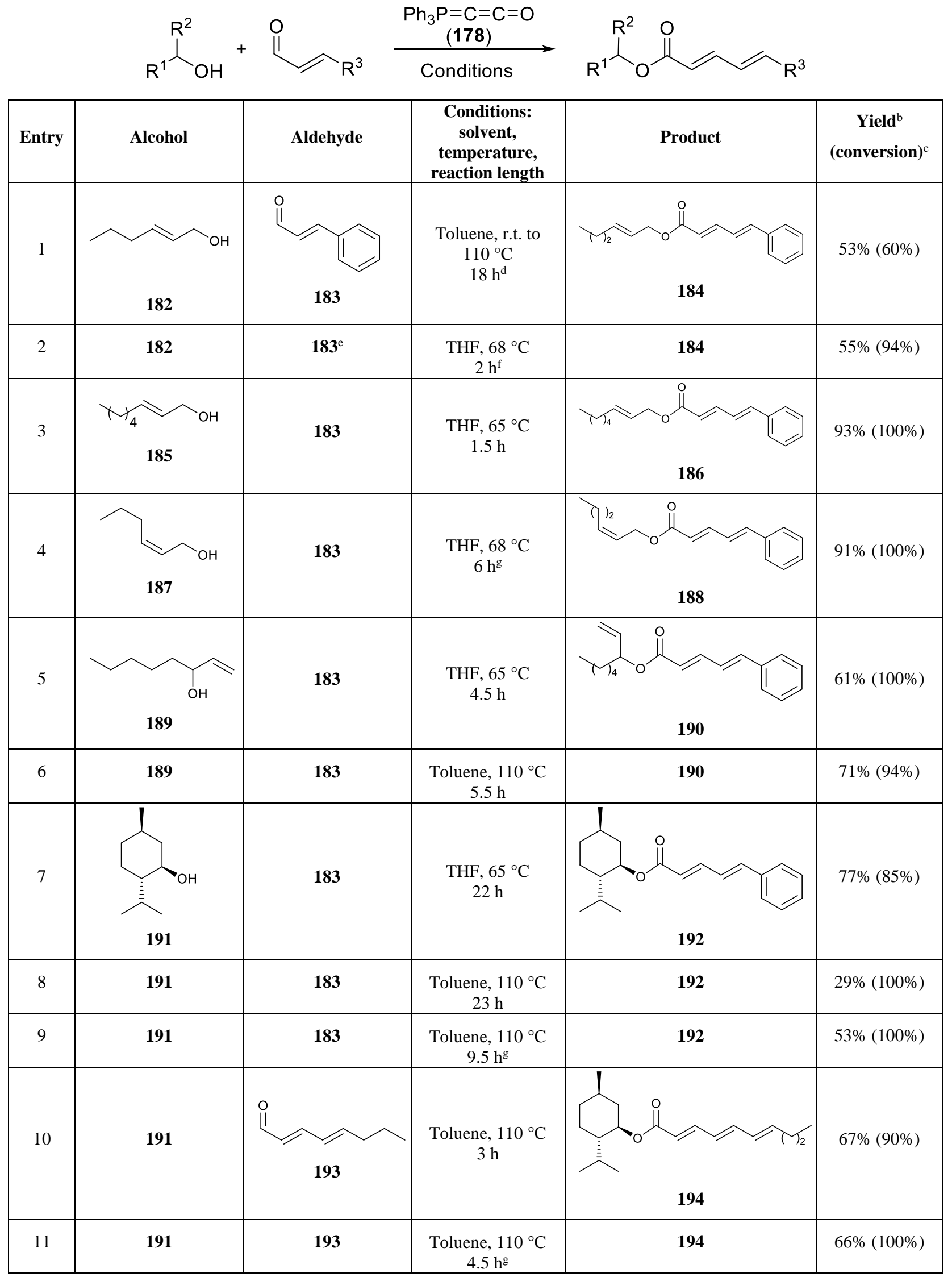


${ }^{\text {a }}$ Unless otherwise stated, reactions were performed on a $0.1 \mathrm{mmol}$ scale using approximately 1:1:1 ratio of alcohol/Bestmann ylide/aldehyde. ${ }^{\mathrm{b}}$ Isolated yields. ${ }^{\mathrm{c}}$ Conversion was calculated based on comparison of peak integrations for the limiting reagent (aldehyde) and product in ${ }^{1} \mathrm{H}$ NMR spectra of the crude product mixture after workup. ${ }^{\mathrm{d}}$ Reaction was carried out on $0.8 \mathrm{mmol}$ scale. ${ }^{\mathrm{e}} 0.57$ equiv. of aldehyde 145 were used. ${ }^{\mathrm{f}}$ Reaction was carried out on $0.2 \mathrm{mmol}$ scale. ${ }^{\mathrm{g}}$ Reaction was carried out on $0.3 \mathrm{mmol}$ scale.

(entry 6). The saturated secondary alcohol menthol (191), with additional steric encumbrance and stereogenic centres, provided a good yield of the product 192 in THF, despite incomplete conversion after $22 \mathrm{~h}$ (entry 7). Disappointingly, full conversion but a poor isolated yield of the product was achieved in toluene after reaction for 23 hours (entry 8). Decreasing the reaction time provided better results (entry 9), indicating that the product may decompose upon prolonged periods at the elevated reflux temperature of toluene. It should be noted that this latter reaction was performed on a larger scale $(0.3 \mathrm{mmol}$ rather than $0.1 \mathrm{mmol})$. The Bestmann ylide reaction with menthol (191) and octa-2,4-dienal (193) delivered the trienoate product 194 in good yields at both 0.1 and $0.3 \mathrm{mmol}$ scales (entry 10 and 11). Taken together, these results indicate that primary alcohol substrates react effectively in THF, while more hindered secondary alcohols require either longer reaction time or the higher temperature available with toluene. There is also a need for balancing conversion rate and decomposition by adjusting reaction time.

The ${ }^{1} \mathrm{H}$ NMR spectra of the products all showed characteristic signals for the dienoate $\beta$-proton with chemical shift between 7.4 and 7.5 ppm (Figure 4.2). Most of them overlap with phenyl signals, apart from in the trienoate 194, where the $\beta$-proton was observed as a doublet of doublets with coupling constants of 15.4 and $11.2 \mathrm{~Hz}$. For all the dienoate products, the transconfiguration was confirmed by the coupling constant of the $\alpha$-protons at about $6.0 \mathrm{ppm}(J=$ 14.9 15.6 Hz). The $\alpha$-protons are always well resolved, thus these signals were used to quantify the conversion rates by comparison with the singlet due to the aldehyde proton of the starting material. The $\gamma$ - and $\delta$-protons of the dienoates formed from cinnamaldehyde (183) are expected to provide signals with doublet of doublets and doublet respectively, but the multiplet observed are heavily distorted. The $\gamma$ - and $\delta$-protons are in a ABM spin system (Pople's notion), such that the very small difference in their chemical shifts in relation to the coupling constants can result in second order spin couplings, which significantly diverts the intensities of the multiplets from Pascal's triangle. ${ }^{27}$ The assignments of $\gamma$ - and $\delta$-protons were confirmed by 2D NMR. 


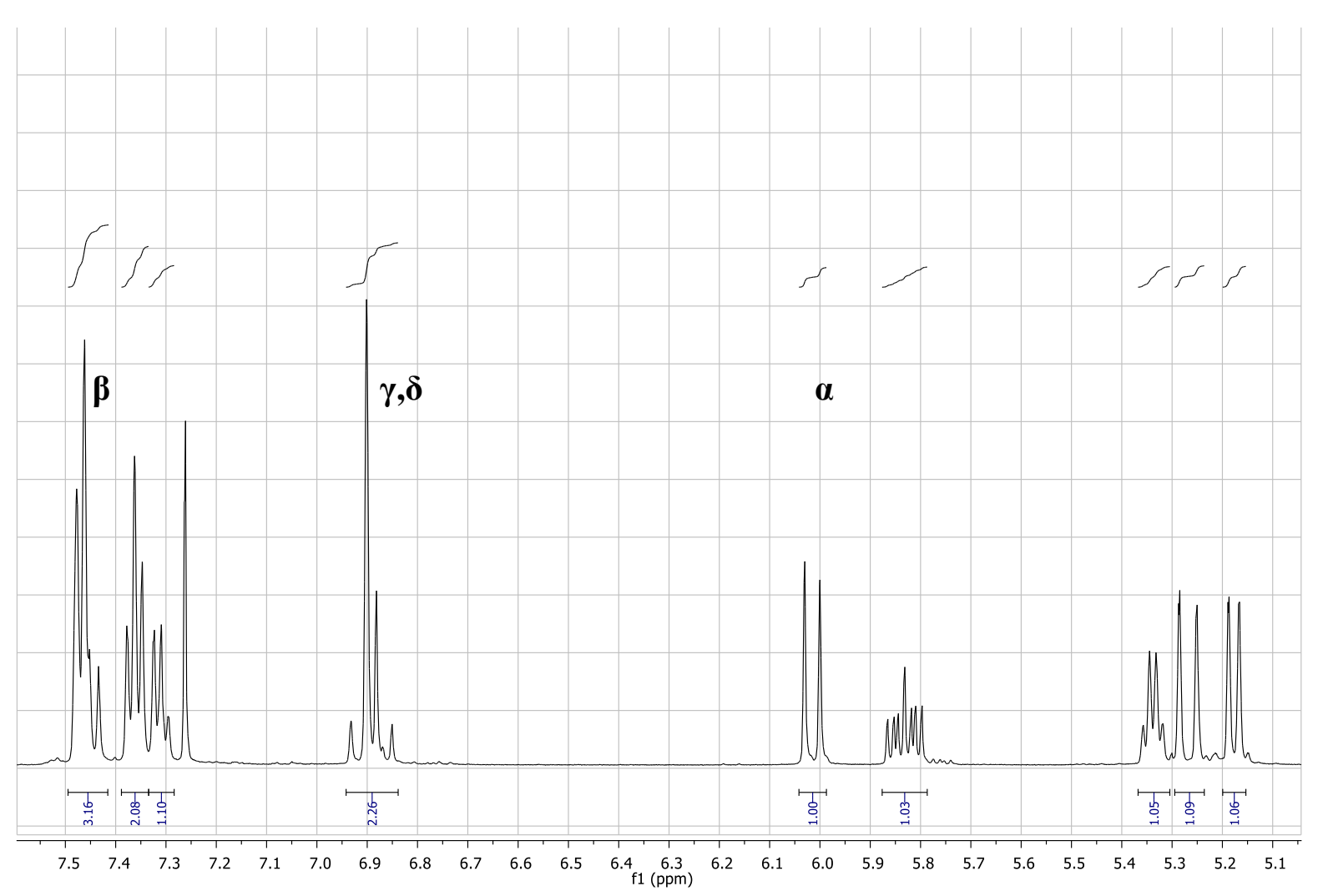

Figure 4.2: Typical multiplets seen for $\alpha-, \beta-, \gamma$ - and $\delta$-protons (for 190 as an example).

In the ${ }^{1} \mathrm{H}$ NMR spectra of products generated from primary alcohols (viz. products 184, 186, 188), a small signal at $8.15 \mathrm{ppm}(\mathrm{dd}, J=11 \sim 12$ and $15 \sim 16 \mathrm{~Hz})$ was always observed, which integrated up to $10 \%$ of the major product (Figure 4.3). Product 184 obtained after much handling had the highest percentage of this by-product. This multiplet was also observed in the ${ }^{1} \mathrm{H}$ NMR spectra of products formed from secondary alcohols, but was barely above the noise level. Analyzing the correlation spectroscopy (COSY) NMR spectrum of 184, this signal has a correlation to signal at $6.75 \mathrm{ppm}(\mathrm{td}, J=11.5,1.5 \mathrm{~Hz})$, which also correlates to a doublet at $5.74 \mathrm{ppm}$ with a $J$-value of $11.0 \mathrm{~Hz}$. This system is very similar to the major product, but the $11.0 \mathrm{~Hz}$ coupling constant of the doublet at $5.74 \mathrm{ppm}$ is much lower than the $15 \sim 16 \mathrm{~Hz}$ observed for the major $E, E$-products. Weak signals at alkene, aromatic and oxymethine regions were also observed in the ${ }^{13} \mathrm{C}$ NMR, and showed appropriate HSQC correlations to minor ${ }^{1} \mathrm{H}$ NMR signals. This minor species could be the $Z, E$-isomer of the desired (major) $E, E$-dienoate. Attempts to separate the two structural isomers by column chromatography were unfruitful and insufficient data was collected for full characterization. Due to the low occurrence of the minor isomer in products generated from secondary alcohols, as required for zampanolide (19) synthesis, further separation was not attempted. 


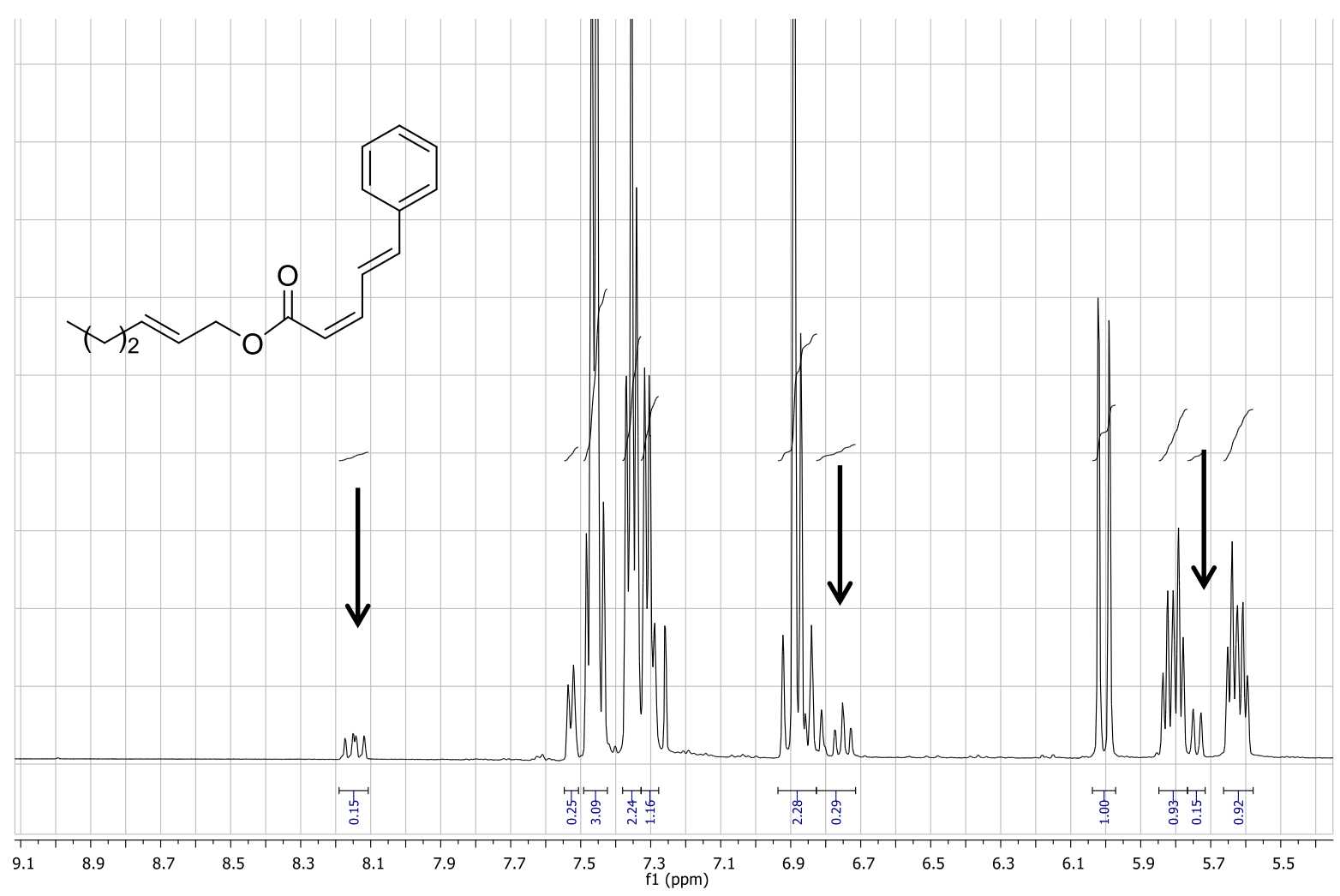

Figure 4.3: Partial ${ }^{1} \mathrm{H}$ NMR spectrum of $E, E$-dienoate 184 with signals attributed to $Z, E$ isomer indicated.

A singlet peak at $3.78 \mathrm{ppm}$ was also noticed, and the compound was isolated and identified as the methoxy protons of the corresponding methyl ester 195 (Scheme 4.4). This could be due to the presence of methyl phosphoranylidene 179 in the Bestmann ylide (178) prepared, and its Wittig reaction with the aldehydes. However, the varying quantity obtained from different reactions indicated that it could instead be a decomposition product resulting from contact of the desired dienoate products with a source of methanol, and transesterification. The source of methanol was unknown at the time, but residual methanol after the preparation of Bestmann ylide (178) was suspected. Thus, the $\mathbf{1 7 8}$ prepared was left under high vacuum for prolonged time.<smiles>[R]OC(=O)/C=C/C=C/c1ccccc1</smiles>

Scheme 4.4: Decomposition of the desired dienoate in the presence of methanol. 


\subsection{Applying the Bestmann ylide linchpin to macrocycle fragments}

After the promising results with simple alcohols, the racemic TBDPS-protected C16-C20 fragment of zampanolide, 141, ${ }^{28,29}$ was subjected to the Bestmann ylide linchpin reaction with cinnamaldehyde (183) in THF and toluene (Table 4.3, entries 1 and 2). In an effort to avoid degradation, the reactions were terminated prior to full conversion, leading to the dienoate product 196 in modest yields and with good recovery of starting material. Unfortunately, it was found that the product was not pure. Apart from the already identified methyl ester degradation product 195, the purified product contains the desired 196 and a by-product in a ratio between 3:2 and 5:2. Similarly, the reaction of alcohol 141 with hept-2-enal (197) afforded the dienoate 198 in equally poor yield and purity (Table 4.3, entries 3).

Table 4.3: Coupling reactions of C16-C20 alcohol fragment 141 and model aldehydes with Bestmann ylide $(\mathbf{1 7 8})^{\mathrm{a}}$

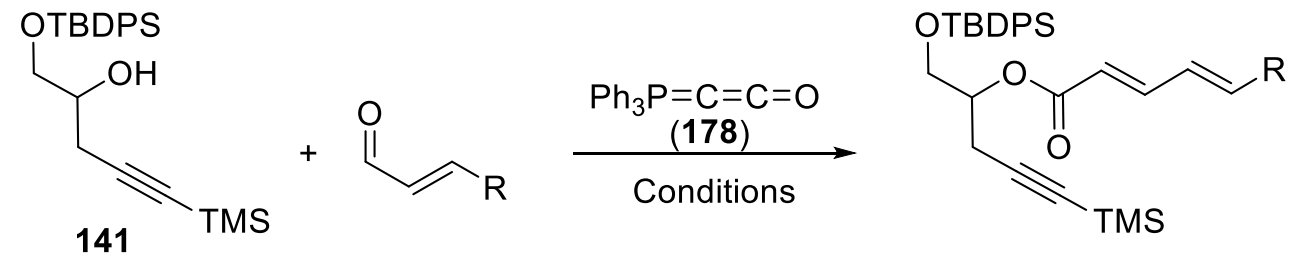

\begin{tabular}{|c|c|c|c|c|}
\hline Entry & aldehyde & $\begin{array}{c}\text { Conditions: solvent, } \\
\text { temperature, } \\
\text { reaction length }\end{array}$ & Product & $\begin{array}{c}\text { Yield }^{\mathrm{b}} \\
\text { (conversion) }^{\mathrm{c}}\end{array}$ \\
\hline 1 & 183 & $\begin{array}{c}\mathrm{THF}, 68^{\circ} \mathrm{C} \\
3.5 \mathrm{~h}\end{array}$ & OTMS & $<36 \%(43 \%)$ \\
\hline 2 & 183 & $\begin{array}{c}\text { Toluene, } 110^{\circ} \mathrm{C} \\
2 \mathrm{~h}\end{array}$ & 196 & $<49 \%(73 \%)$ \\
\hline 3 & $\stackrel{0}{11}$ & $\begin{array}{c}\text { Toluene, } 110^{\circ} \mathrm{C} \\
1 \mathrm{~h}\end{array}$ & OTBDPS & $<41 \%(50 \%)$ \\
\hline
\end{tabular}

a Reactions were performed on a $0.1 \mathrm{mmol}$ scale using approximately 1:1:1 ratio of alcohol/Bestmann ylide/aldehyde. ${ }^{\mathrm{b}}$ Isolated yields. ${ }^{\mathrm{c}}$ Conversion was calculated based on comparison of peak integrations for the limiting reagent (aldehyde) and product in ${ }^{1} \mathrm{H}$ NMR spectra of the crude product mixture after workup. 
Comparing the ${ }^{1} \mathrm{H}$ NMR spectra obtained from the crude reaction mixture and the post-column purification species of 196, the methyl ester decomposition product 195 was only present after purification, which suggested post-reaction decomposition. The source of this decomposition was identified as methanol used to dissolve the product prior to TLC analysis, thus it was switched to dichloromethane, and the situation improved. Separation of the methyl ester 195 from the desired product 196 was not achieved with EtOAc/petroleum ether or $\mathrm{Et}_{2} \mathrm{O}$ /petroleum ether elution, but use of $\mathrm{CH}_{2} \mathrm{Cl}_{2}$ /petroleum ether as eluent afforded satisfactory separation. However, the product was still a mixture of two compounds. Examination of the ${ }^{1} \mathrm{H}$ NMR spectrum revealed great structural similarity between the two products, wherein, apart from the non-resolvable phenyl region, each of the protons in the major compound have a corresponding minor signal with similar peak shape and chemical shift (Figure 4.4). Assisted by 2D NMR data, the oxymethine protons were identified as the apparent quintet signals at 5.16 and 4.10 ppm for the major and minor compounds, respectively. The chemical shift of $5.16 \mathrm{ppm}$ is within the expected range of the ester oxymethine in the desired product 196, while the chemical shift of $4.10 \mathrm{ppm}$ would indicate the absence of the ester functionality. The

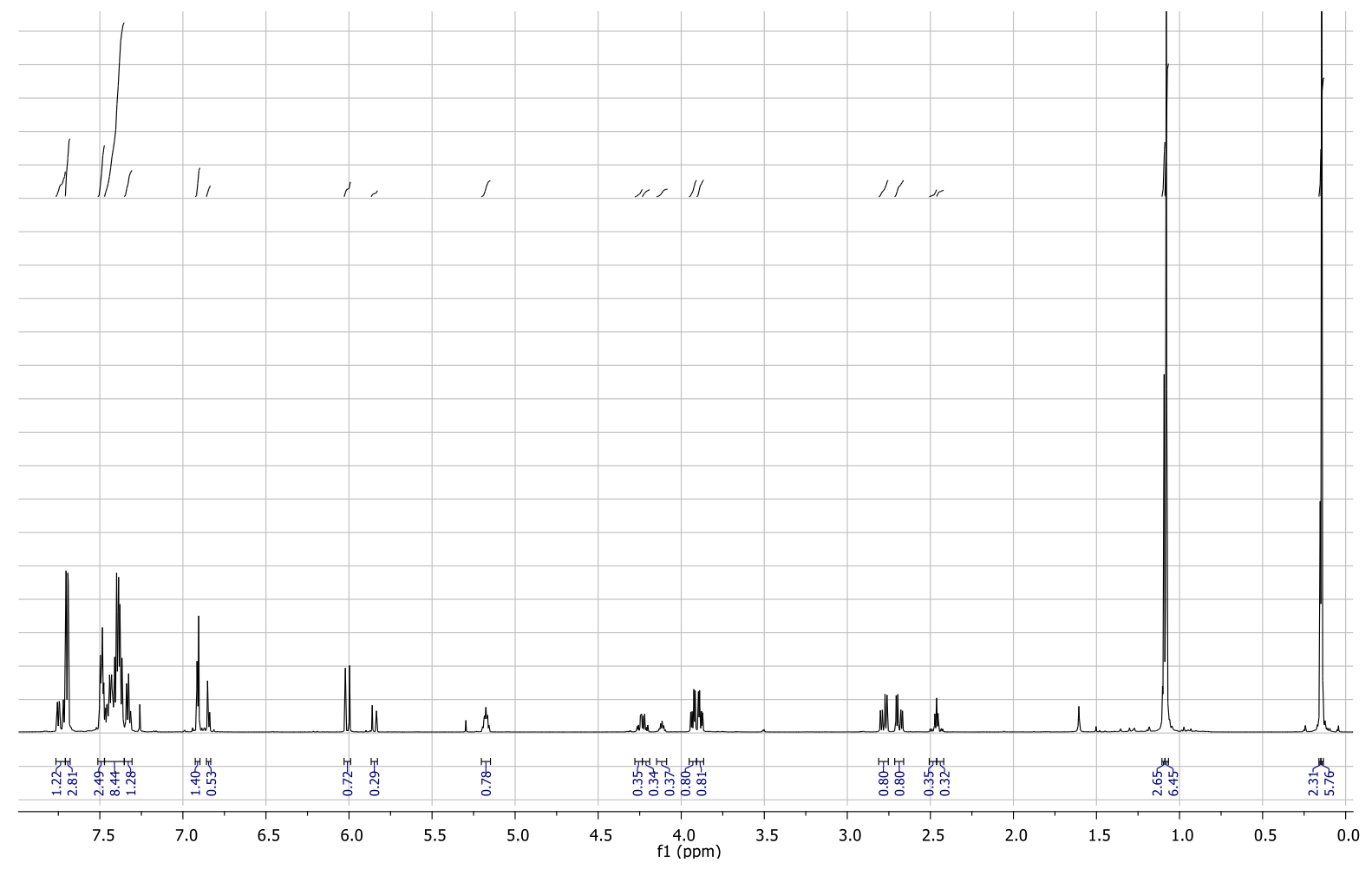

Figure 4.4: ${ }^{1} \mathrm{H}$ NMR spectrum of the mixture containing 196.

oxymethylene protons in the minor compound (4.24 and $4.20 \mathrm{ppm}$ ) exhibited higher chemical shifts than the equivalent ones in the major compound (3.91 and $3.82 \mathrm{ppm}$ ), showing a pair of 
signals at, which suggested that the stronger electron withdrawing group was connected to the methylene in the minor compound.

Based on these observations, the mixture might consist of the desired product 196 and its silylmigrated isomer 199 (Figure 4.5). To confirm this, correlation between $\mathrm{H} 2^{\prime}$ and $\mathrm{C} 1$ in the major and $\mathrm{H}^{\prime}$ and $\mathrm{C} 1$ in the minor product is needed. However, normal heteronuclear multiplebond correlation (HMBC) spectroscopy did not detect this three-bond correlation. The classic HMBC is set to detect correlations optimized at about $8 \mathrm{~Hz}$, but three- or four-bond coupling constants can range between 2 and $25 \mathrm{~Hz}^{30}$ A carbon-proton coupling across an ester functionality (typically $3 \sim 4 \mathrm{~Hz}$ ) can be beyond the detection limit due to incomplete relaxation. Ideally, an HMBC spectrum would show minimal signals from both one-bond carbon-proton and multiple-bond proton-proton correlations, and be able to detect up to five-bond carbonproton correlations. ${ }^{30,31}$ Great effort has been put into the improvement of HMBC techniques, and several advancements have been reported. ${ }^{32-35}$ A modified HMBC experiment, namely, constant time inverse-detection gradient accordion rescaled (CIGAR) HMBC spectroscopy ${ }^{36}$ is one of the most recent development, where the dual-stage low-pass $J$-filter removes a broad range of one-bond proton-carbon couplings, and the complete suppression of proton-proton coupling detection maximises the resolution of the desired multi-bond proton-carbon correlations. ${ }^{36}$ This CIGAR-HMBC method was applied to the mixture and allowed detection of the three-bond correlations between $\mathrm{H}_{2}^{\prime}$ and $\mathrm{C} 1$ in $\mathbf{1 9 6}$ and $\mathrm{H} 1^{\prime}$ and $\mathrm{C} 1$ in 199.
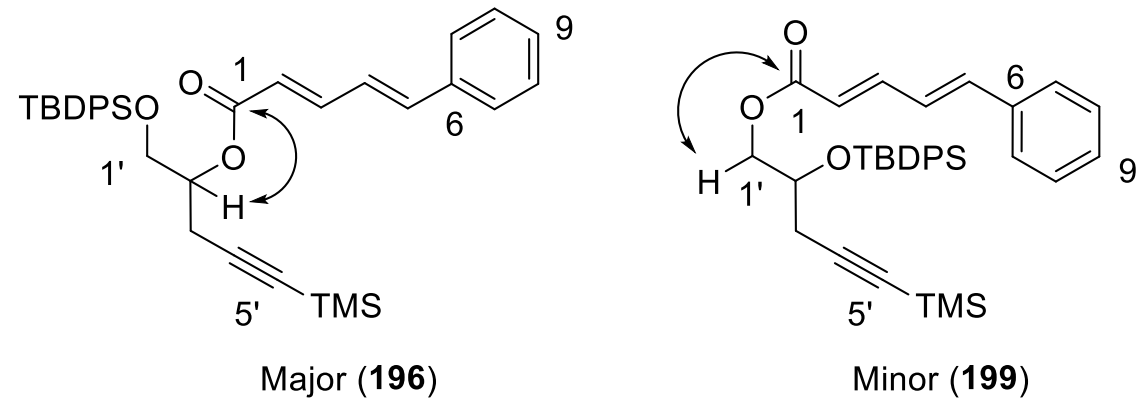

Figure 4.5: CIGAR-HMBC correlations used to confirm the position of the ester functionality in product 196 and 199.

Silyl groups are known to migrate under basic conditions, and lack of an exogenous base in the simple composition of the reaction mixture suggested that the ylide was serving as the base. 
This level of basicity is not expected for Bestmann ylide (178) itself, but the migration could also be facilitated by various basic intermediates generated in the cascade. The three component cascade reaction involving $\mathbf{1 7 8}$ is thought to proceed via the phosphoranylidene intermediate 200 (Scheme 4.5), ${ }^{4,5,9-12}$ which is isolable in reactions lacking the aldehyde component. There are two possible pathways to form the intermediate 200: Pathway I shows the case where the hydroxyl would perform the nucleophilic attack directly at the electrophilic

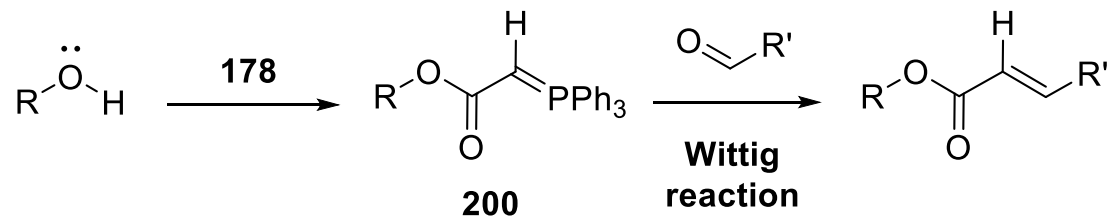

Pathway I

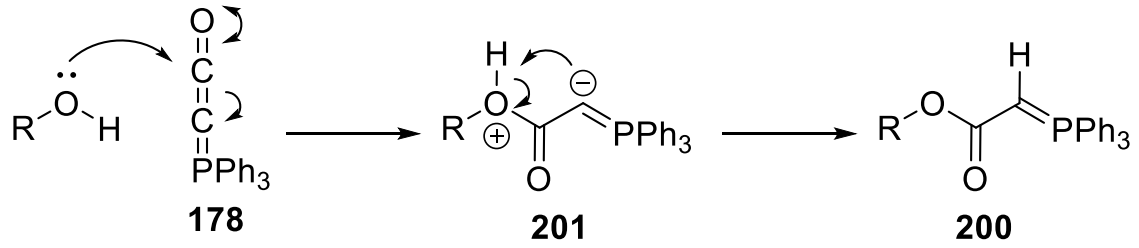

Pathway II

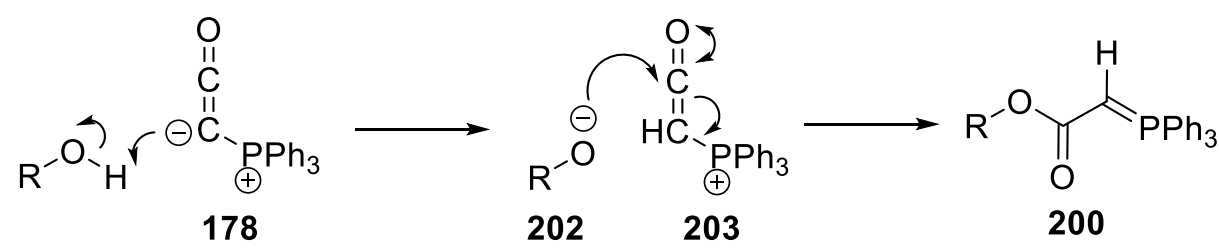

Scheme 4.5: Proposed mechanistic pathways of the ylide-alcohol coupling.

carbon of Bestmann ylide (178) to produce 201, followed by proton transfer, either inter- or intramolecularly, to afford phosphoranylidene 200; Pathway II involves the deprotonation of the secondary alcohol by $\mathbf{1 7 8}$ first, which produces a stronger alkoxide nucleophile $\mathbf{2 0 2}$ and a better carbonyl electrophile $\mathbf{2 0 3}$ for the subsequent nucleophilic attack. The generation of alkoxide 202 in Pathway II could facilitate the observed silyl migration, and the intermediate 201 in pathway I is potentially basic enough to deprotonate the alcohol starting material to allow the silyl protecting group to migrate. Hydroxyls are not very acidic, with pKa typically around 30 in DMSO. Strong bases such as hydrides, alkaline metals and alkoxides are usually required to deprotonate an alcohol. However, the elevated reaction temperature could have encouraged the deprotonation, and full deprotonation of the alcohol may not be necessary for the silyl to migrate. 
With C3-C8 fragment 126 in hand, a reaction with 178 was performed in toluene using the TBDPS-protected alcohol 141. A mixture of four isomeric compounds was observed by ${ }^{1} \mathrm{H}$ and ${ }^{13} \mathrm{C}$ NMR spectroscopy, two diastereomers of 204 and two diastereomers of the silyl migrated product 205 (Scheme 4.6). The diastereomers were not differentiable by ${ }^{1} \mathrm{H}$ NMR spectroscopy, but four sets of signals were observed in the ${ }^{13} \mathrm{C}$ NMR spectrum. The assignment was supported by the obtained 2D NMR data including CIGAR-HMBC. With the problem of silyl migration seen in all reaction of alcohol 141, an alternative protection group was required.

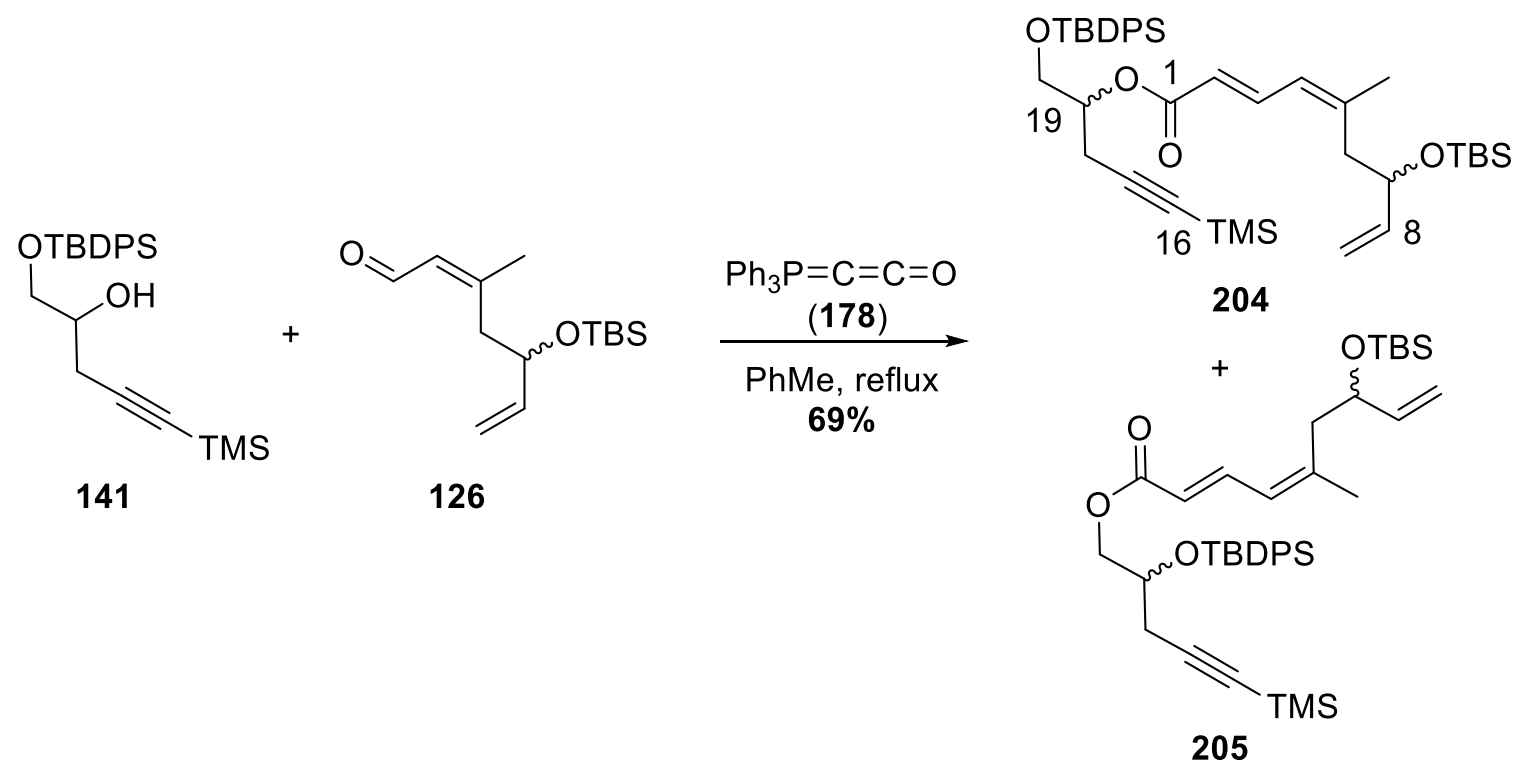

Scheme 4.6: Coupling of macrocycle fragments 141 with 126.

A three-component reaction with the PMB-protected variant 146 was then attempted with cinnamaldehyde 183. The trial performed in THF did not reach completion after $8 \mathrm{~h}$, and a moderate $42 \%$ yield of $\mathbf{2 0 6}$ was achieved, while using toluene as the solvent produced a good 70\% yield after 4 h. (Scheme 4.7). The product 206 was obtained with good purity. Employing the alcohol 146 in the reaction with macrocycle fragment 126 led to gratifying yields of products 207, as a mixture of diastereomers. While the reaction of 146 with aldehyde 126 in THF took $11 \mathrm{~h}$ to go to completion (62\% isolated yield of 207), the equivalent reaction in toluene required only $5 \mathrm{~h}$ (68\% yield). Alcohol 152 was used to test the compatibility of an unprotected alkyne in this linchpin reaction for synthetic ease. To our delight, reaction of aldehyde 126 with alcohol 152 in toluene provided the desired product 208 in a comparable yield $(66 \%)$ after $5 \mathrm{~h}$. The coupling of enantiopure fragment $\boldsymbol{S - 1 5 2}$ with $\mathbf{1 2 6}$ was later carried 
out, but only $26 \%$ of $\mathbf{1 9 S - 2 0 8}$ was obtained with recovered starting material (33\%). This is thought to be due to decomposition of the Bestmann ylide (178) after months in storage.

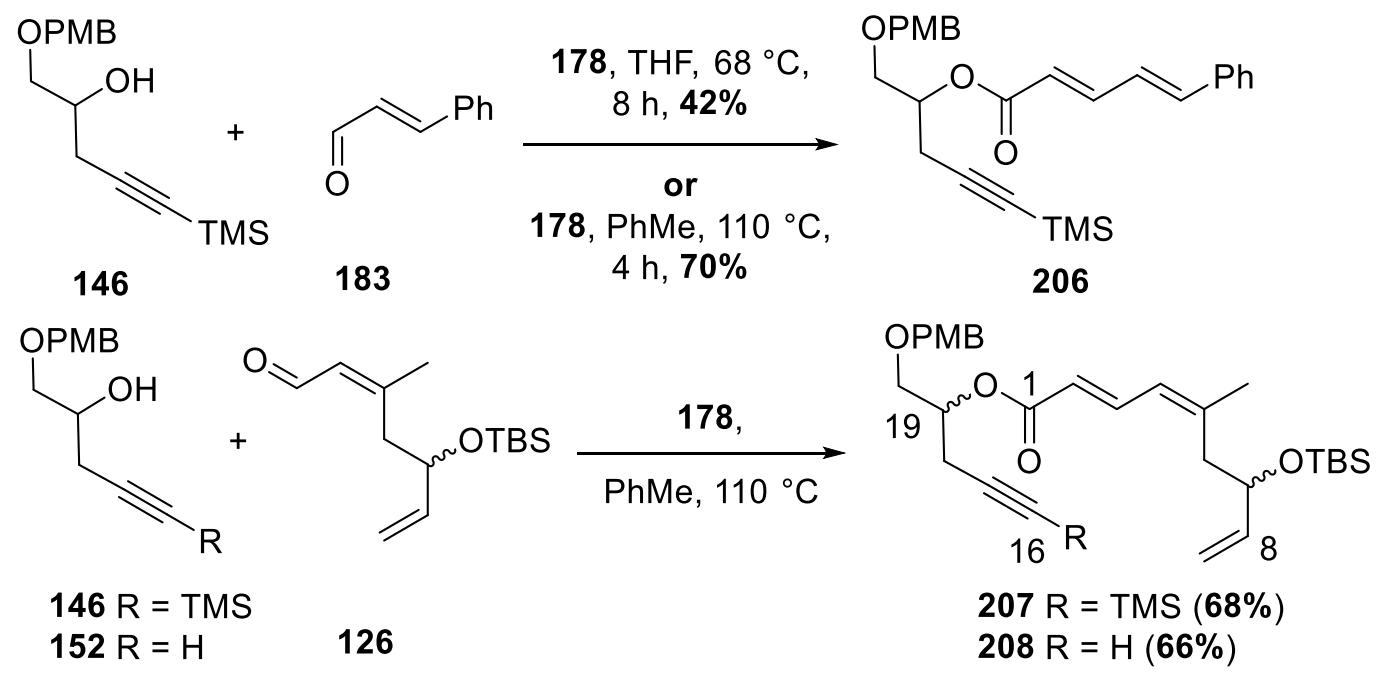

Scheme 4.7: Coupling of $\mathbf{1 4 6}$ or $\mathbf{1 5 2}$ with model $\mathbf{1 8 3}$ and macrocycle fragments $\mathbf{1 2 6}$.

The E-configuration of C2-C3 alkene in the E,Z-dienoates 207 and $\mathbf{2 0 8}$ was confirmed by the coupling constant of around $15 \mathrm{~Hz}$ between the $\alpha$ - and $\beta$-protons, as well as the strong throughspace correlation of the $\alpha$-proton to the $\gamma$-proton observed by rotating frame Overhauser effect spectroscopy (ROESY) (Figure 4.5). Very weak ROESY correlation between $\alpha$ - and $\beta$-protons was observed, which is more likely to be due to noise from through-bond interaction. The $Z$ configuration of the $\gamma, \delta$-alkene was retained as expected, based on strong ROESY correlation of the $\gamma$-proton with the singlet attributed to the allylic methyl protons. Correlations between the $\beta$-proton and the allylic methylene protons were also clearly seen. The pairs of diastereomers are differentiable in the ${ }^{13} \mathrm{C}$ NMR spectra, with doubled signals between 1.0 and 4.8 Hz apart. The differentiated diastereomeric signals are from carbons around the two stereocentres, C19 and C7, with more differentiation around the C7 centre. The two peaks attributed to $\mathrm{C} 7$ in the diastereomers differ by $4.8 \mathrm{~Hz}$, and signals for C6 and C8 are also differentiated. On the other hand, the two signals for C19 only differ by $1.9 \mathrm{~Hz}$ and only one peak each was observed for C18 and C20. 


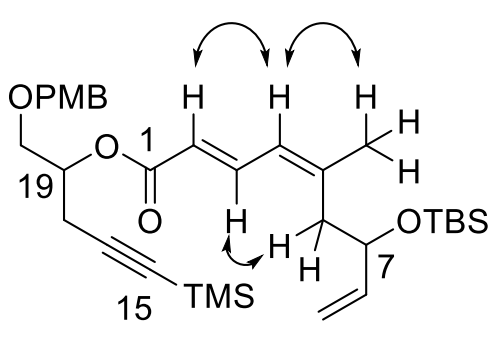

207

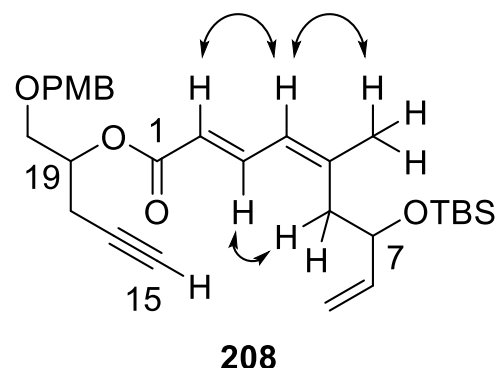

208

Figure 4.5: ROESY correlations of the diene region in 207 and 208.

In summary, the scope of the efficient three-component reaction between Bestmann ylide (178), an alcohol and an unsaturated aldehyde to deliver $\alpha, \beta, \gamma, \delta$-unsaturated esters was studied for simple alcohols and aldehydes. This methodology enabled the facile synthesis of $E, Z$-dienoate products $\mathbf{2 0 7}$ and $\mathbf{2 0 8}$, which represent two-thirds of the dactylolide/zampanolide macrocycle. Terminal alkene $\mathbf{2 0 8}$ is poised to undergo alkynylation at C16 and metathesis at C8.

\subsection{Experimental data}

\section{General experimental information}

Unless otherwise stated, all reactions were carried out in oven-dried glassware under a positive pressure of nitrogen, delivered via a manifold. Dry tetrahydrofuran and toluene were obtained from a PureSolv MD 5 solvent purification system (Innovative Technology). Analytical grade solvents were used for aqueous work-up and column chromatography (petroleum ether, $n$ hexane, diethyl ether and dichloromethane). Column chromatography was performed on silica gel $60 \AA$ (Pure Science, 40-63 micron) with the eluent mixtures as stated in the corresponding procedures. Thin-layer chromatography was performed on silica-coated plastic plates (Macherey-Nagel, POLYGRAM ${ }^{\circledR}$ Sil G/UV 254 ). UV-active compounds were detected under UV irradiation $(\lambda=254 \mathrm{~nm})$, while non-UV-active compounds were visualised with anisaldehyde or potassium permanganate staining solutions.

All other chemicals were purchased from Pure Science, Sigma-Aldrich, Panreac and Bedoukian Research. Infra-red (IR) spectra were collected on an ALPHA FT-IR spectrometer (Bruker) fitted with attenuated total reflectance (ATR). The intensities of signals are defined as: $\mathrm{br}=$ broad, $\mathrm{s}=$ strong, $\mathrm{m}=$ medium, $\mathrm{w}=$ weak. Mass spectra were collected on an Agilent 
6530 Accurate-Mass Q-TOF LC/MS high-resolution mass spectrometer (HRMS). The specific rotations were collected on an AUTOPOL II automatic polarimeter (Rudolph Research Analytical), and the reported values are an average of 10 measurements and concentrations are reported in $\mathrm{g} / 100 \mathrm{~mL}$.

Nuclear magnetic resonance (NMR) spectra were obtained in deuterated chloroform $\left(\mathrm{CDCl}_{3}\right)$ using Varian Inova instruments operating at 500 or $600 \mathrm{MHz}$ for proton, 125 or $150 \mathrm{MHz}$ for carbon, and $120 \mathrm{MHz}$ for phosphorus. Proton and carbon chemical shifts are reported in parts per million (ppm) relative to residual $\mathrm{CHCl}_{3}\left[\delta\left({ }^{1} \mathrm{H}\right)=7.26 \mathrm{ppm}\right]$ and $\mathrm{CDCl}_{3}\left[\delta\left({ }^{13} \mathrm{C}\right)=77.0\right.$ ppm], respectively. Signals are defined as: $\mathrm{s}=$ singlet, $\mathrm{d}=$ doublet, $\mathrm{t}=$ triplet, $\mathrm{q}=$ quartet, quin $=$ quintet, sext $=$ sextet, sept $=$ septet, $\mathrm{m}=$ multiplet, app. $=$ apparent, obs. $=$ obscured peak . Coupling constants $(J)$ are reported in Hertz $(\mathrm{Hz})$. Assignments were determined by twodimensional NMR experiments (COSY, HSQC, HMBC, ROESY and CIGAR-HMBC).

\section{Methyl (triphenylphosphoranylidene)acetate (179)}<smiles>COC(=O)C=P(c1ccccc1)(c1ccccc1)c1ccccc1</smiles>

To a solution of triphenylphosphine $(7.08 \mathrm{~g}, 27.0 \mathrm{mmol})$ in toluene (40 $\mathrm{mL}, 0.67 \mathrm{M})$, a solution of methyl bromoacetate $(\mathbf{1 8 1}, 4.04 \mathrm{~g}, 26.4$ $\mathrm{mmol})$ in toluene $(8.0 \mathrm{~mL}, 3.3 \mathrm{M})$ was added. The reaction turned cloudy upon the addition, and was stirred at r.t. for $19 \mathrm{~h}$. The solid was collected by filtration to yield a white powder. The powder was dissolved in $\mathrm{CH}_{2} \mathrm{Cl}_{2}(100 \mathrm{~mL})$, and an aqueous $\mathrm{NaOH}$ solution $(60 \mathrm{~mL}, 0.43 \mathrm{M})$ was added. The mixture was shook vigorously for $1 \mathrm{~min}$, and the aqueous layer was separated and extracted with $\mathrm{CH}_{2} \mathrm{Cl}_{2}(3 \times 50 \mathrm{~mL})$. The organic layers were combined and dried over $\mathrm{MgSO}_{4}$, and the solvent was removed under reduced pressure to yield the phosphoranylidene $\mathbf{1 7 9}$ as a white powder (7.59 g, 87\%).

${ }^{1} \mathbf{H}$ NMR $\left(500 \mathrm{MHz}, \mathrm{CDCl}_{3}\right): \delta 7.66(\mathrm{dt}, J=16.9,8.7 \mathrm{~Hz}, 6 \mathrm{H}, 5-\mathrm{CH}), 7.59-7.51(\mathrm{~m}, 3 \mathrm{H}, 6-$ $\mathrm{CH}), 7.50-7.41(\mathrm{~m}, 6 \mathrm{H}, 4-\mathrm{CH}), 3.52$ (s, 3H, $\left.\mathrm{CH}_{3}, \mathrm{Me}\right), 2.90$ (s, 1H, 2-CH).

${ }^{13} \mathrm{C}$ NMR (125 MHz, $\left.\mathrm{CDCl}_{3}\right): \delta 133.0$ (d, J=10.0 Hz, CH, Ph), 131.9 (d, J = 2.8 Hz, CH, $\mathrm{Ph}), 128.7$ (d, $J=12.7 \mathrm{~Hz}, \mathrm{CH}, \mathrm{Ph}), 50.0$ (d, $\left.J=4.9 \mathrm{~Hz}, \mathrm{CH}_{3}, \mathrm{Me}\right), 29.7$ (d, $J=131.6 \mathrm{~Hz}$, $\mathrm{CH}, \mathrm{C} 2)$.

${ }^{31} \mathbf{P}$ NMR $\left(120 \mathrm{MHz}, \mathrm{CDCl}_{3}\right): \delta$ 17.6.

M.p.: $163.6-164.8^{\circ} \mathrm{C}\left(\right.$ Lit. $\left.162-163{ }^{\circ} \mathrm{C}\right) .{ }^{37}$ 
The signals for $\mathrm{C} 1$ and $\mathrm{C} 3$ were missing from the ${ }^{13} \mathrm{C}$ NMR data, but ${ }^{31} \mathrm{P}$ NMR and m.p. data agree with those reported previously. ${ }^{37}$

\section{(Triphenylphosphoranylidene)ketene (178)}

$\begin{array}{cl}2 & \text { To a solution of methyl (triphenylphosphoranylidene)acetate }(179,3.00 \mathrm{~g}, \\ \mathrm{Ph}_{3} \mathrm{P}=\mathrm{C}=\mathrm{C}=\mathrm{O} & \begin{array}{c}\text { 8.97 mmol) in toluene }(30 \mathrm{~mL}, 0.30 \mathrm{M}) \text {, a solution of NaHMDS }(17 \mathrm{~mL}, 0.6 \\ 1\end{array} \\ \text { M in toluene, } 10 \mathrm{mmol}) \text { was added. The reaction was heated at } 65^{\circ} \mathrm{C} \text { for } 20 \mathrm{~h} .\end{array}$ While still hot, the reaction mixture was filtered through a thin pad of Celite, and the filtrate was concentrated under reduced pressure until white precipitate started to form. After the precipitate was re-dissolved with heating, the solution was cooled down to $4{ }^{\circ} \mathrm{C}$ and left to recrystallize overnight. The precipitate was collected by filtration to yield the ylide $\mathbf{1 7 8}$ as cream white needle-shaped crystals $(1.43 \mathrm{~g}, 53 \%)$.

${ }^{13}$ C NMR (125 MHz, $\left.\mathrm{CDCl}_{3}\right): \delta 135.0(\mathrm{~d}, J=3.3 \mathrm{~Hz}), 133.3(\mathrm{~d}, J=10.8 \mathrm{~Hz}), 132.1(\mathrm{~d}, J=$ $10.0 \mathrm{~Hz}), 130.4(\mathrm{~d}, J=13.0 \mathrm{~Hz}), 128.5(\mathrm{~d}, J=12.2 \mathrm{~Hz}), 119.3(\mathrm{~d}, J=88.1 \mathrm{~Hz})$.

${ }^{31} \mathbf{P}$ NMR $\left(120 \mathrm{MHz}, \mathrm{CDCl}_{3}\right): \delta 5.5$.

IR (ATR): 2910 (w, C-H), 2093 (s, C=P), 1620 (s, C=O), 1435 (s, C-H), 1347 (s, C-H), 1104 (s, C-O), 743 (s, C-P), 717 (s, C-P), 514 (s, C-H).

M.p.: $163.7-168.6^{\circ} \mathrm{C}\left(\right.$ Lit. $\left.173{ }^{\circ} \mathrm{C}\right)$.

The signals for $\mathrm{C} 1$ and $\mathrm{C} 2$ were missing from the ${ }^{13} \mathrm{C}$ NMR data, but ${ }^{31} \mathrm{P}$ NMR, IR and m.p. data broadly agree with those reported previously. ${ }^{13}$

\section{General procedure for Bestmann ylide linchpin reaction:}

To a mixture of alcohol (1 eq., 0.1-0.3 M) and Bestmann ylide (1 eq.) in solvent (toluene or tetrahydrofuran) heated at reflux, a solution of aldehyde (1 eq., 1.0 M) was added. The reaction was heated at reflux until full consumption of starting material aldehyde was observed by TLC. After cooling to r.t., the reaction was concentrated and purified by silica column chromatography to afford the product as a colourless or pale yellow oil. 
Formed in 53\% yield, $76 \%$ BRSM. No detection of $\left(2^{\prime} E, 2 Z, 4 E\right)$-isomer when reaction was carried out to completion with minimum handling.

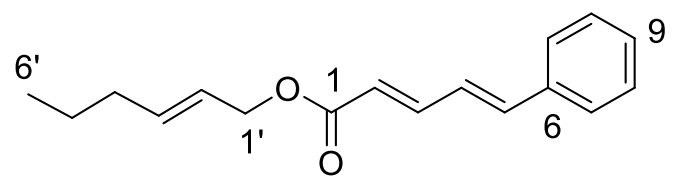

TLC: $R_{\mathrm{f}}=0.23\left(20: 1\right.$ Pet. ether: $\left.\mathrm{Et}_{2} \mathrm{O}\right)$.

${ }^{1} \mathbf{H}$ NMR (500 MHz, $\mathrm{CDCl}_{3}$ ): $\delta$ 7.48-7.43 (complex m, 3H, 3-CH \& 7-CH), 7.36 (app. t, $J=$ 7.6 Hz, 2H, 8-CH), 7.30 (t, J=6.9 Hz, 1H, 9-CH), 6.82-6.93 (complex m, 2H, 4-CH \& 5-CH), $6.01(\mathrm{~d}, J=15.6 \mathrm{~Hz}, 1 \mathrm{H}, 2-\mathrm{CH}), 5.81\left(\mathrm{dt}, J=15.4,6.6 \mathrm{~Hz}, 1 \mathrm{H}, 3^{\prime}-\mathrm{CH}\right), 5.62(\mathrm{dt}, J=15.4,6.2$ $\left.\mathrm{Hz}, 1 \mathrm{H}, 2^{\prime}-\mathrm{CH}\right), 4.63\left(\mathrm{~d}, J=6.6 \mathrm{~Hz}, 2 \mathrm{H}, 1^{\prime}-\mathrm{CH}_{2}\right), 2.14$ (app. q, $\left.J=7.1 \mathrm{~Hz}, 2 \mathrm{H}, 4^{\prime}-\mathrm{CH}_{2}\right), 1.43$ (app. sext, $J=7.4 \mathrm{~Hz}, 2 \mathrm{H}, 5^{\prime}-\mathrm{CH}_{2}$ ), 0.92 (t, $J=7.3 \mathrm{~Hz}, 3 \mathrm{H}, 6^{\prime}-\mathrm{CH}_{3}$ ).

${ }^{13} \mathrm{C}$ NMR (125 MHz, $\left.\mathrm{CDCl}_{3}\right): \delta 166.8(\mathrm{C}, \mathrm{C}=\mathrm{O}), 144.7(\mathrm{CH}, \mathrm{C} 3), 140.4(\mathrm{CH}, \mathrm{C} 5), 136.3(\mathrm{CH}$, C3'), 136.0 (C, C6), 129.0 (CH, C9), 128.8 (CH, C8), 127.2 (CH, C7), 126.2 (CH, C4), 124.0 $\left(\mathrm{CH}, \mathrm{C} 2^{\prime}\right), 121.2(\mathrm{CH}, \mathrm{C} 2), 65.2\left(\mathrm{CH}_{2}, \mathrm{C}^{\prime}\right), 34.3\left(\mathrm{CH}_{2}, \mathrm{C} 4{ }^{\prime}\right), 22.0\left(\mathrm{CH}_{2}, \mathrm{C}^{\prime}\right), 13.6\left(\mathrm{CH}_{3}, \mathrm{C}^{\prime}\right)$. IR (neat) cm $\mathrm{cm}^{-1}: 2958$ (m, C-H), 2929 (m, C-H), 1706 (s, C=O), 1625 (s, C=C), 1449 (m, CH), 1236 (s, C-O), 1172 (s, C-O), 997 (m, C-H), 689 (m, C-H).

HRMS (ESI) $m / z$ : found 257.1529, calcd for $\mathrm{C}_{17} \mathrm{H}_{21} \mathrm{O}_{2}[\mathrm{M}+\mathrm{H}]^{+} 257.1536(\Delta=2.7 \mathrm{ppm})$.

\section{$(2 ' E, 2 E, 4 E)$-Oct-2'-enyl 5-phenylpenta-2,4-dienoate (186)}

Formed in $93 \%$ yield, contains $1 \%$ of the $\left(2^{\prime} E, 2 Z, 4 E\right)$-isomer as determined by integration of the post-chromatography ${ }^{1} \mathrm{H}$ NMR spectrum. Key spectral resonances were used to determine the ratio of minor to major isomers as 1:99: 6.01 (d, $J=15.4 \mathrm{~Hz}, 0.99 \mathrm{H}, 2-\mathrm{CH}$-major), 8.14 (dd, $J=15.5,12.0 \mathrm{~Hz}, 0.01 \mathrm{H}, 3-\mathrm{CH}$-minor). NMR data are of the major isomer signals obtained from the spectrum of the purified mixture.<smiles>[B]CCCC/C=C/COC(=O)/C=C/C=C/c1ccccc1</smiles> 
TLC: $R_{\mathrm{f}}=0.08$ (40:1 Pet. ether: $\left.\mathrm{Et}_{2} \mathrm{O}\right)$.

${ }^{1} \mathbf{H}$ NMR (500 MHz, $\mathrm{CDCl}_{3}$ ): $\delta$ 7.57-7.50 (complex m, 3H, 3-CH \& 7-CH), 7.35 (t, $J=7.3 \mathrm{~Hz}$, 2H, 8-CH), 7.31 (t, $J=7.3 \mathrm{~Hz}, 1 \mathrm{H}, 9-\mathrm{CH}), 6.93-6.82$ (complex m, 2H, 4-CH \& 5-CH), 6.01 (d, $J=15.4 \mathrm{~Hz}, 1 \mathrm{H}, 2-\mathrm{CH}), 5.81\left(\mathrm{dt}, J=15.0,7.0 \mathrm{~Hz}, 1 \mathrm{H}, 3^{\prime}-\mathrm{CH}\right), 5.62(\mathrm{dt}, J=15.1,6.6 \mathrm{~Hz}$, $1 \mathrm{H}, 2^{\prime}-\mathrm{CH}$ ), 4.62 (d, $J=6.3 \mathrm{~Hz}, 2 \mathrm{H}, 1^{\prime}-\mathrm{CH}_{2}$ ), 2.07 (app. q, $J=7.1 \mathrm{~Hz}, 2 \mathrm{H}, 4^{\prime}-\mathrm{CH}_{2}$ ), 1.40 (app. quin $\left.J=7.3 \mathrm{~Hz}, 2 \mathrm{H}, 5^{\prime}-\mathrm{CH}_{2}\right), 1.34-1.24$ (complex m, 4H, 6'- $\left.\mathrm{CH}_{2} \& 7^{\prime}-\mathrm{CH}_{2}\right), 0.90(\mathrm{t}, J=6.8$ $\left.\mathrm{Hz}, 3 \mathrm{H}, 8^{\prime}-\mathrm{CH}_{3}\right)$.

${ }^{13} \mathrm{C}$ NMR (125 MHz, $\left.\mathrm{CDCl}_{3}\right): \delta 166.8$ (C, C1), 144.7 (CH, C3), 140.4 (CH, C4 or C5), 136.6 (CH, C3'), 136.0 (C, C6), 129.0 (CH, C9), 128.8 (CH, C8), 127.2 (CH, C7), 126.2 (CH, C4 or C5), $123.8\left(\mathrm{CH}, \mathrm{C} 2^{\prime}\right), 121.2(\mathrm{CH}, \mathrm{C} 2), 65.3\left(\mathrm{CH}_{2}, \mathrm{C} 1^{\prime}\right), 32.3\left(\mathrm{CH}_{2}, \mathrm{C}^{\prime}\right), 31.4\left(\mathrm{CH}_{2}, \mathrm{C}^{\prime}\right), 28.6$ $\left(\mathrm{CH}_{2}, \mathrm{C}^{\prime}\right), 22.5\left(\mathrm{CH}_{2}, \mathrm{C}^{\prime}\right), 14.0\left(\mathrm{CH}_{3}, \mathrm{C} 8^{\prime}\right)$.

IR (neat) cm $\mathrm{cm}^{-1}: 2956$ (m, C-H), 2955 (m, C-H), 1709 (s, br, C=O), 1625 (s, C=C), 1235 (s, CO), 1129 (s, C-O), 969 (s, C-H), 691 (m, C-H).

HRMS (ESI) $m / z$ : found 307.1666, calcd for $\mathrm{C}_{19} \mathrm{H}_{24} \mathrm{O}_{2} \mathrm{Na}[\mathrm{M}+\mathrm{Na}]^{+} 307.1669(\Delta=0.9 \mathrm{ppm})$.

\section{(2'Z,2E,4E)-Hex-2'-enyl 5-phenylpenta-2,4-dienoate (188)}

Formed in $91 \%$ yield, contains $7 \%$ of the $\left(2^{\prime} E, 2 Z, 4 E\right)$-isomer as determined by integration of the post-chromatography ${ }^{1} \mathrm{H}$ NMR spectrum. Key spectral resonances were used to determine the ratio of major and minor isomers as 93:7: $6.03(\mathrm{~d}, J=14.9 \mathrm{~Hz}, 0.93 \mathrm{H}, 2-\mathrm{CH}$-major), 8.15 (dd, $J=15.7,11.4 \mathrm{~Hz}, 0.07 \mathrm{H}, 3-\mathrm{CH}$-minor). NMR data are of the major isomer signals obtained from the spectrum of the purified mixture.

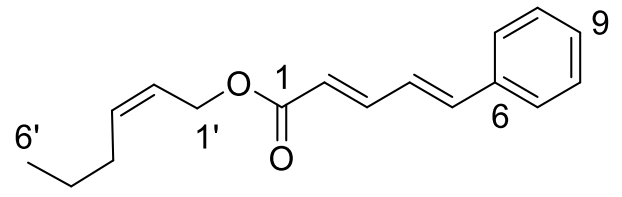

TLC: $R_{\mathrm{f}}=0.25$ (20:1 Pet. ether: $\left.\mathrm{Et}_{2} \mathrm{O}\right)$.

${ }^{1}$ H NMR (500 MHz, $\mathrm{CDCl}_{3}$ ): $\delta$ 7.49-7.44 (complex m, 3H, 3-CH \& 7-CH), 7.36 (app. t, $J=$ 7.6 Hz, 2H, 8-CH), 7.30 (t, $J=6.9 \mathrm{~Hz}, 1 \mathrm{H}, 9-\mathrm{CH}), 6.98-6.83$ (complex m, 2H, 4-CH \& 5-CH), $6.03(\mathrm{~d}, J=14.9 \mathrm{~Hz}, 1 \mathrm{H}, 2-\mathrm{CH}), 5.69\left(\mathrm{dt}, J=11.0,7.5 \mathrm{~Hz}, 1 \mathrm{H}, 2^{\prime}-\mathrm{CH}\right), 5.63(\mathrm{dt}, J=11.8,6.4$ 
$\left.\mathrm{Hz}, 1 \mathrm{H}, 3^{\prime}-\mathrm{CH}\right), 4.76$ (d, $\left.J=7.2 \mathrm{~Hz}, 2 \mathrm{H}, 1^{\prime}-\mathrm{CH}\right), 2.14$ (app. q, $J=7.2 \mathrm{~Hz}, 2 \mathrm{H}, 4^{\prime}-\mathrm{CH}$ ), 1.45 (app. sext, $\left.J=7.2 \mathrm{~Hz}, 2 \mathrm{H}, 5^{\prime}-\mathrm{CH}\right), 0.95$ (t, $J=7.3 \mathrm{~Hz}, 3 \mathrm{H}, 6^{\prime}-\mathrm{CH}$ ).

${ }^{13} \mathrm{C}$ NMR (125 MHz, $\left.\mathrm{CDCl}_{3}\right): \delta 167.0$ (C, C1), 144.7 (CH, C3), 140.5 (CH, C4 or C5), 136.0 (C, C6), $135.2(\mathrm{CH}, \mathrm{C2}$ '), $129.0(\mathrm{CH}, \mathrm{C} 9), 128.8$ (CH, C8), $127.2(\mathrm{CH}, \mathrm{C} 7), 126.2$ (CH, C4 or C5), $123.6\left(\mathrm{CH}, \mathrm{C}^{\prime}\right), 121.1(\mathrm{CH}, \mathrm{C} 2), 60.4\left(\mathrm{CH}_{2}, \mathrm{C} 1^{\prime}\right), 29.6\left(\mathrm{CH}_{2}, \mathrm{C}^{\prime}\right), 22.6\left(\mathrm{CH}_{2}, \mathrm{C}^{\prime}\right), 13.7$ $\left(\mathrm{CH}_{3}, \mathrm{C}^{\prime}\right)$.

IR (neat) cm $\mathrm{cm}^{-1}: 2959(\mathrm{~m}, \mathrm{C}-\mathrm{H}), 2930(\mathrm{~m}, \mathrm{C}-\mathrm{H}), 1707$ (s, C=O), $1624(\mathrm{~s}, \mathrm{C}=\mathrm{C}), 1449$ (m, CH), 1234 (s, C-O), 997 (s, C-H), 690 (m, C-H).

HRMS (ESI) $m / z$ : found 257.1527, calcd for $\mathrm{C}_{17} \mathrm{H}_{21} \mathrm{O}_{2}[\mathrm{M}+\mathrm{H}]^{+} 257.1536(\Delta=3.5 \mathrm{ppm})$.

\section{(2E,4E)-Oct-1'-en-3'-yl 5-phenylpenta-2,4-dienoate (190)}

Formed in $61 \%$ yield in THF or $71 \%$ in toluene, contains $3 \%$ of the $\left(2^{\prime} E, 2 Z, 4 E\right)$-isomer as determined by integration of the post-chromatography ${ }^{1} \mathrm{H}$ NMR spectrum. Key spectral resonances were used to determine the ratio of major and minor as 97:3: 6.02 (d, $J=14.9 \mathrm{~Hz}$, 0.H, 2-CH-major), 8.17 (dd, $J=15.6,11.4 \mathrm{~Hz}, 0.03 \mathrm{H}, 3-\mathrm{CH}$-minor). NMR data are of the major isomer signals obtained from the spectrum of the purified mixture.

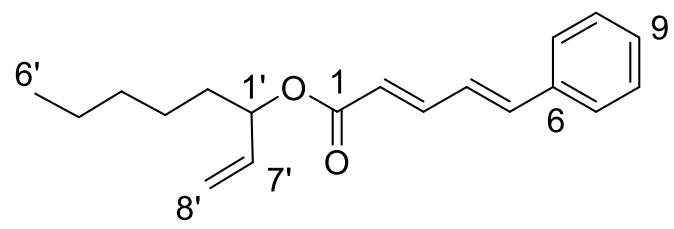

TLC: $R_{\mathrm{f}}=0.16\left(40: 1\right.$ Pet. ether: $\left.\mathrm{Et}_{2} \mathrm{O}\right)$.

${ }^{1} \mathbf{H}$ NMR $\left(500 \mathrm{MHz}, \mathrm{CDCl}_{3}\right): \delta 7.47(\mathrm{~d}, J=7.8 \mathrm{~Hz}, 2 \mathrm{H}, 7-\mathrm{CH}), 7.46(\mathrm{dd}, J=14.9,8.8 \mathrm{~Hz}, 1 \mathrm{H}$, 3-CH), 7.36 (app. t, $J=7.6 \mathrm{~Hz}, 2 \mathrm{H}, 8-\mathrm{CH}), 7.31$ (t, $J=7.2 \mathrm{~Hz}, 1 \mathrm{H}, 9-\mathrm{CH}), 6.95-6.84$ (complex m, 2H, 4-CH \& 5-CH), 6.02 (d, $J=14.9 \mathrm{~Hz}, 1 \mathrm{H}, 2-\mathrm{CH}), 5.83$ (ddd, $J=17.1,10.6,6.2 \mathrm{~Hz}, 1 \mathrm{H}$, 7'-CH), 5.34 (app. q, $\left.J=6.6 \mathrm{~Hz}, 1 \mathrm{H}, 1^{\prime}-\mathrm{CH}\right), 5.27$ (dd, $J=17.3,1.2 \mathrm{~Hz}, 1 \mathrm{H}$, one of $8^{\prime}-\mathrm{CH}_{2}$ ), $5.18\left(\mathrm{dd}, J=10.5,1.0 \mathrm{~Hz}, 1 \mathrm{H}\right.$, one of 8'- $\left.\mathrm{CH}_{2}\right), 1.74-1.59$ (complex m, 2H, 2'-CH $\left.\mathrm{CH}_{2}\right), 1.39-1.26$ (complex m, 6H, 3'- $\mathrm{CH}_{2} \& 4^{\prime}-\mathrm{CH}_{2} \& 5^{\prime}-\mathrm{CH}_{2}$ ), 0.89 (t, $J=6.1 \mathrm{~Hz}, 3 \mathrm{H}, 6^{\prime}-\mathrm{CH}_{3}$ ).

${ }^{13}$ C NMR (125 MHz, $\left.\mathrm{CDCl}_{3}\right): \delta 166.3$ (C, C1), $144.6(\mathrm{CH}, \mathrm{C} 3), 140.4$ (CH, C4 or C5), 136.7 $\left(\mathrm{CH}, \mathrm{C}^{\prime}\right), 136.0(\mathrm{C}, \mathrm{C} 6), 129.0(\mathrm{CH}, \mathrm{C} 9), 128.8$ (CH, C8), $127.2(\mathrm{CH}, \mathrm{C} 7), 126.2(\mathrm{CH}, \mathrm{C} 4$ or 
C5), $121.5(\mathrm{CH}, \mathrm{C} 2), 116.4\left(\mathrm{CH}_{2}, \mathrm{C} 8{ }^{\prime}\right), 74.7(\mathrm{CH}, \mathrm{C} 1 '), 34.3\left(\mathrm{CH}_{2}, \mathrm{C} 2{ }^{\prime}\right), 31.6$ and 24.8 and $22.5\left(\mathrm{CH}_{2}, \mathrm{C}^{\prime}\right.$ and $\mathrm{C}^{\prime}$ and $\left.\mathrm{C}^{\prime}\right), 14.0\left(\mathrm{CH}_{3}, \mathrm{C}^{\prime}\right)$.

IR (neat) cm $\mathrm{cm}^{-1}: 2930$ (m, C-H), 2859 (m, C-H), 1706 (s, C=O), 1625 (s, C=C), 1235 (s, C-O), 1130 (s, C-O), 996 (s, C-H), 688 (m, C-H).

HRMS (ESI) $m / z$ : found 307.1667, calcd for $\mathrm{C}_{19} \mathrm{H}_{24} \mathrm{O}_{2} \mathrm{Na}[\mathrm{M}+\mathrm{Na}]^{+} 307.1669(\Delta=0.65 \mathrm{ppm})$.

\section{$\left(1^{\prime} R, 2^{\prime} S, 5^{\prime} R, 2 E, 4 E\right)-2^{\prime}$-iso-Propyl-5'-methylcyclohex-1'-yl 5-phenylpenta-2,4-dienoate} (192)

Formed in $77 \%$ yield in THF or $53 \%$ in toluene. No detection of $\left(2^{\prime} E, 2 Z, 4 E\right)$-isomer.

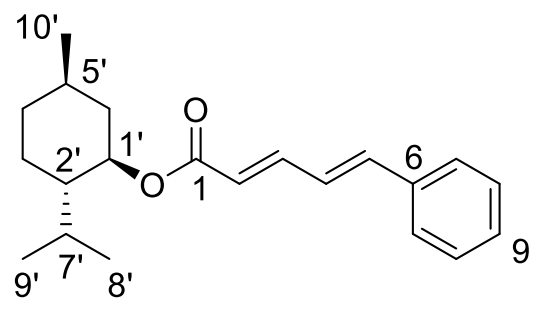

TLC: $R_{\mathrm{f}}=0.14$ (40:1 Pet. ether: $\left.\mathrm{Et}_{2} \mathrm{O}\right)$.

${ }^{1}$ H NMR $\left(500 \mathrm{MHz}, \mathrm{CDCl}_{3}\right): \delta 7.46(\mathrm{~d}, J=7.8 \mathrm{~Hz}, 2 \mathrm{H}, 7-\mathrm{CH}), 7.43$ (partially obs. ddd, $J=$ $15.3,9.2,1.0 \mathrm{~Hz}, 1 \mathrm{H}, 3-\mathrm{CH}$ ), 7.36 (app. t, $J=7.6 \mathrm{~Hz}, 2 \mathrm{H}, 8-\mathrm{CH}$ ), 7.30 (tt, $J=7.3,2.4 \mathrm{~Hz}, 1 \mathrm{H}$, 9-CH), 6.93-6.83 (complex m, 2H, 4-CH \& 5-CH), 5.99 (d, J=15.4 Hz, 1H, 2-CH), 4.79 (td, $\left.J=10.9,4.4 \mathrm{~Hz}, 1 \mathrm{H}, 1^{\prime}-\mathrm{CH}\right), 2.05\left(\mathrm{dddd}, J=11.9,4.4,3.0,2.0 \mathrm{~Hz}, 1 \mathrm{H}\right.$, one of $\left.6^{\prime}-\mathrm{CH}_{2}\right), 1.91$ (septd, $J=7.0,2.7 \mathrm{~Hz}, 1 \mathrm{H}, 7^{\prime}-\mathrm{CH}$ ), 1.74-1.66 (complex m, 2H, one of 3'- $\mathrm{CH}_{2} \&$ one of 4'$\mathrm{CH}_{2}$ ), 1.53 (m, 1H, 5'-CH), 1.43 (tt, $J=11.7,2.9 \mathrm{~Hz}, 1 \mathrm{H}, 2^{\prime}-\mathrm{CH}$ ), 1.09 (qd, $J=13.2,3.3 \mathrm{~Hz}$, $1 \mathrm{H}$, one of 4'- $\left.\mathrm{CH}_{2}\right), 1.02\left(\mathrm{q}, J=11.5 \mathrm{~Hz}, 1 \mathrm{H}\right.$, one of $\left.6^{\prime}-\mathrm{CH}_{2}\right), 0.92\left(\mathrm{~d}, J=6.6 \mathrm{~Hz}, 3 \mathrm{H}, 10^{\prime}-\mathrm{CH}_{3}\right)$, $0.91\left(\mathrm{~d}, J=7.1 \mathrm{~Hz}, 3 \mathrm{H}, 8^{\prime}-\mathrm{CH}_{3}\right), 0.94-0.84$ (partially obs. $\mathrm{m}, 1 \mathrm{H}$, one of $\left.3^{\prime}-\mathrm{CH}_{2}\right), 0.78(\mathrm{~d}, J=$ $\left.7.1 \mathrm{~Hz}, 3 \mathrm{H}, 9^{\prime}-\mathrm{CH}_{3}\right)$.

${ }^{13}$ C NMR (125 MHz, $\left.\mathrm{CDCl}_{3}\right): \delta 166.6$ (C, C1), 144.3 (CH, C3), 140.2 (CH, C4 or C5), 136.1 (C, C6), $129.0(\mathrm{CH}, \mathrm{C} 9), 128.8(\mathrm{CH}, \mathrm{C} 8), 127.1(\mathrm{CH}, \mathrm{C} 7), 126.3(\mathrm{CH}, \mathrm{C} 4$ or $\mathrm{C} 5), 121.9(\mathrm{CH}$, C2), $74.1\left(\mathrm{CH}, \mathrm{C}^{\prime}\right), 47.2\left(\mathrm{CH}, \mathrm{C} 2^{\prime}\right), 41.0\left(\mathrm{CH}_{2}, \mathrm{C}^{\prime}\right), 34.3\left(\mathrm{CH}_{2}, \mathrm{C} 3^{\prime}\right), 31.4\left(\mathrm{CH}, \mathrm{C} 5^{\prime}\right), 26.3$ $\left(\mathrm{CH}, \mathrm{C}^{\prime}\right), 23.6\left(\mathrm{CH}_{2}, \mathrm{C}^{\prime}\right), 22.0\left(\mathrm{CH}_{3}, \mathrm{Cl}^{\prime}\right), 20.8\left(\mathrm{CH}_{3}, \mathrm{C} 8^{\prime}\right), 16.5\left(\mathrm{CH}_{3}, \mathrm{C}^{\prime}\right)$. 
IR (neat) cm $\mathrm{cm}^{-1}: 2953$ (m, C-H), $2925(\mathrm{~m}, \mathrm{C}-\mathrm{H}), 2868(\mathrm{~m}, \mathrm{C}-\mathrm{H}), 1702$ (s, C=O), 1625 (s, C=C), 1237 (s, C-Si), 1131 (s, C-O), 995 (s, C-H), 754 (s, C-Si), 689 (s, C-Si).

HRMS (ESI) $m / z$ : found 335.1969, calcd for $\mathrm{C}_{21} \mathrm{H}_{28} \mathrm{O}_{2} \mathrm{Na}[\mathrm{M}+\mathrm{Na}]^{+} 335.1982(\Delta=3.9 \mathrm{ppm})$.

Specific rotation: $[\alpha]_{\mathrm{D}}^{22}=-60\left(c=0.40, \mathrm{CH}_{2} \mathrm{Cl}_{2}\right)$.

This compound has been reported previously. ${ }^{38}$ There is close correlation between the IR and ${ }^{13} \mathrm{C}$ NMR data entered above and those in the earlier report. However, the ${ }^{1} \mathrm{H}$ NMR data quoted previously do not match those obtained. The identity of the sample prepared in this work was supported by NMR and HRMS data, and all NMR assignments were made on the basis of thorough 2D NMR experiments (COSY and HSQC). Therefore, it was suspected that the 90 $\mathrm{MHz}$ instrument used in the earlier work did not allow accurate identification of the ${ }^{1} \mathrm{H}$ NMR signals, and the earlier report does not indicate either HRMS or elemental analytical results.

$\left(1^{\prime} R, 2^{\prime} S, 5^{\prime} R, 2 E, 4 E, 6 E\right)-2^{\prime}$-iso-Propyl-5'-methylcyclohex-1'-yl deca-2,4,6-trienoate (194)

Formed in $67 \%$ yield. No detection of $\left(2^{\prime} E, 2 Z, 4 E\right)$-isomer.

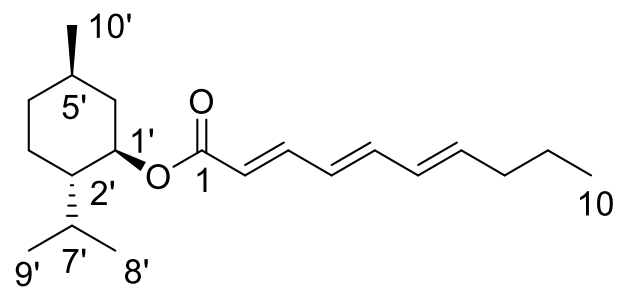

TLC: $R_{\mathrm{f}}=0.14$ (40:1 Pet. ether: $\left.\mathrm{Et}_{2} \mathrm{O}\right)$.

${ }^{1} \mathbf{H}$ NMR $\left(500 \mathrm{MHz}, \mathrm{CDCl}_{3}\right): \delta 7.28(\mathrm{dd}, J=15.4,11.2 \mathrm{~Hz}, 1 \mathrm{H}, 3-\mathrm{CH}), 6.53(\mathrm{dd}, J=14.9$, $10.7 \mathrm{~Hz}, 1 \mathrm{H}, 5-\mathrm{CH}), 6.21$ (dd, $J=14.9,11.2 \mathrm{~Hz}, 1 \mathrm{H}, 4-\mathrm{CH}), 6.13$ (dd, $J=15.1,10.7 \mathrm{~Hz}, 1 \mathrm{H}$, 6-CH), 5.92 (dt, $J=14.9,7.2 \mathrm{~Hz}, 1 \mathrm{H}, 7-\mathrm{CH}), 5.83$ (d, $J=15.4 \mathrm{~Hz}, 1 \mathrm{H}, 2-\mathrm{CH}$ ), 4.75 (app. td, $J=10.9,4.4 \mathrm{~Hz}, 1 \mathrm{H}, 1^{\prime}-\mathrm{CH}$ ), 2.12 (app. q, $J=7.3 \mathrm{~Hz}, 2 \mathrm{H}, 8-\mathrm{CH}_{2}$ ), 2.02 (br d, $J=12.2 \mathrm{~Hz}$, $1 \mathrm{H}$, one of $\left.6^{\prime}-\mathrm{CH}_{2}\right), 1.88$ (septd, $\left.J=6.8,2.3 \mathrm{~Hz}, 1 \mathrm{H}, 7^{\prime}-\mathrm{CH}\right), 1.65-1.71$ (complex m, 2H, one of $3^{\prime}-\mathrm{CH}_{2} \&$ one of $\left.4^{\prime}-\mathrm{CH}\right), 1.50$ (partially obs. m, $\left.1 \mathrm{H}, 5^{\prime}-\mathrm{CH}_{2}\right), 1.44\left(\mathrm{~m}, 2 \mathrm{H}, 9-\mathrm{CH}_{2}\right), 1.40$ (partially obs. m, 1H, 2'-CH), 1.07 (app. qd, $J=12.9,2.9 \mathrm{~Hz}, 1 \mathrm{H}$, one of 4'-CH2), 0.99 (app. q, $J=11.5 \mathrm{~Hz}, 1 \mathrm{H}$, one of $\left.6^{\prime}-\mathrm{CH}_{2}\right), 0.91\left(\mathrm{t}, J=7.3 \mathrm{~Hz}, 3 \mathrm{H}, 10-\mathrm{CH}_{3}\right), 0.90(\mathrm{~d}, J=6.1 \mathrm{~Hz}, 3 \mathrm{H}$, 
$\left.10^{\prime}-\mathrm{CH}_{3}\right), 0.89\left(\mathrm{~d}, J=6.8 \mathrm{~Hz}, 3 \mathrm{H}, 8^{\prime}-\mathrm{CH}_{3}\right), 0.87$ (partially obs. m, $1 \mathrm{H}$, one of 3'- $\mathrm{CH}_{2}$ ), 0.76 $\left(\mathrm{d}, J=7.1 \mathrm{~Hz}, 3 \mathrm{H}, 9^{\prime}-\mathrm{CH}_{3}\right)$.

${ }^{13} \mathrm{C}$ NMR (125 MHz, $\left.\mathrm{CDCl}_{3}\right): \delta 166.8$ (C, C1), 144.6 (CH, C3), $141.0(\mathrm{CH}, \mathrm{C} 5), 140.2(\mathrm{CH}$, C7), 130.0 (CH, C6), 127.8 (CH, C4), 120.5 (CH, C2), 73.9 (CH, C1'), $47.2\left(\mathrm{CH}, \mathrm{C} 2{ }^{\prime}\right), 41.0$ $\left(\mathrm{CH}_{2}, \mathrm{C}^{\prime}\right), 35.0\left(\mathrm{CH}_{2}, \mathrm{C} 8\right), 34.3\left(\mathrm{CH}_{2}, \mathrm{C}^{\prime}\right), 31.4\left(\mathrm{CH}, \mathrm{C}^{\prime}\right), 26.3\left(\mathrm{CH}, \mathrm{C}^{\prime}\right), 23.6\left(\mathrm{CH}_{2}, \mathrm{C}^{\prime}\right)$, $22.2\left(\mathrm{CH}_{2}, \mathrm{C} 9\right), 22.0\left(\mathrm{CH}_{3}, \mathrm{C} 10^{\prime}\right), 20.7\left(\mathrm{CH}_{3}, \mathrm{C} 8^{\prime}\right), 16.4\left(\mathrm{CH}_{2}, \mathrm{C}^{\prime}\right), 13.7\left(\mathrm{CH}_{3}, \mathrm{C} 10\right)$.

IR (neat) cm $\mathrm{cm}^{-1}: 2955$ (s, C-H), 2930 (s, C-H), 2869 (s, C-H), 1694 (s, C=O), 1615 (s, C=C), 1456 (m, C-H), 1342 (m, C-H), 1133 (s, C-O), 1007 (s, C-H).

HRMS (ESI) $m / z$ : found 305.2486, caled for $\mathrm{C}_{20} \mathrm{H}_{33} \mathrm{O}_{2}[\mathrm{M}+\mathrm{H}]^{+} 305.2475(\Delta=3.6 \mathrm{ppm})$.

Specific rotation: $[\alpha]_{\mathrm{D}}^{22}=-26\left(c=0.42, \mathrm{CH}_{2} \mathrm{Cl}_{2}\right)$.

Mixture of $(2 E, 4 E)-\left[1^{\prime}\right.$-(tert-butyldiphenylsilyloxy)-5'-trimethylsilyl]pent-4'-yn-2'-yl 5phenylpenta-2,4-dienoate (196) and the silyl migrated product $(2 E, 4 E)$-[2'-(tertbutyldiphenylsilyloxy)-5'-trimethylsilyl]pent-4'-yn-1'-yl 5-phenylpenta-2,4-dienoate (199) $(3: 2)$

The isomers were formed in a combined $36 \%$ yield in THF or $49 \%$ in toluene.

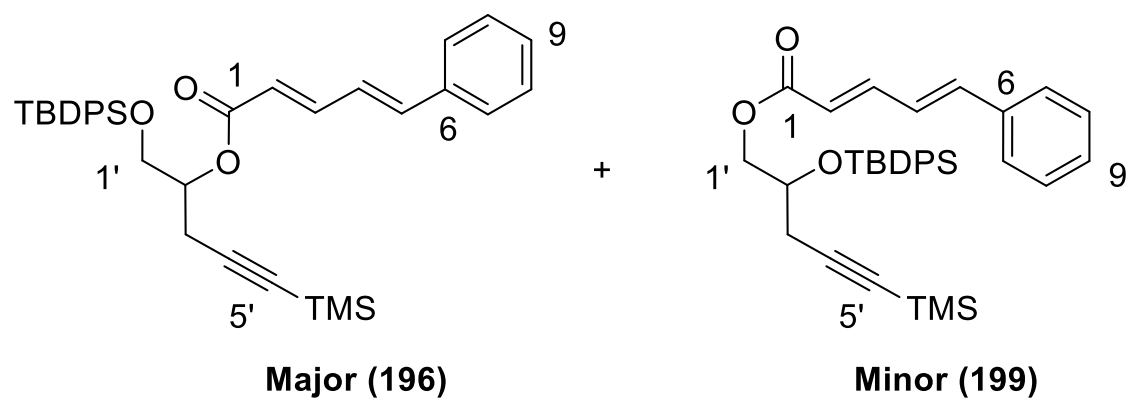

TLC: $R_{\mathrm{f}}=0.14\left(36: 1\right.$ Pet. ether: $\left.\mathrm{Et}_{2} \mathrm{O}\right)$.

${ }^{1} \mathbf{H}$ NMR (500 MHz, $\mathrm{CDCl}_{3}$ ): $\delta$ 7.75-7.67 (complex m, 4H, CH, Ph), 7.55-7.30 (complex m, 11H, CH, Ph), 7.47 (obs. m, 0.6H, 3-CH-196), 7.32 (obs. m, 0.4H, 3-CH-199), 6.94-6.79 (complex m, 2H, 4-CH \& 5-CH), 5.99 (d, $J=15.3 \mathrm{~Hz}, 0.6 \mathrm{H}, 2-\mathrm{CH}-196), 5.83$ (d, $J=15.6 \mathrm{~Hz}$, 0.4H, 2-CH-199), 5.16 (app. quin, $\left.J=5.6 \mathrm{~Hz}, 0.6 \mathrm{H}, 2^{\prime}-\mathrm{CH}-196\right), 4.23$ (dd, $J=11.4,4.4 \mathrm{~Hz}$, $0.4 \mathrm{H}$, one of 1'- $\left.\mathrm{CH}_{2}-199\right), 4.20\left(\mathrm{dd}, J=11.2,5.9 \mathrm{~Hz}, 0.4 \mathrm{H}\right.$, one of 1'- $\left.\mathrm{CH}_{2}-199\right), 4.10$ (app. quin, $\left.J=5.3 \mathrm{~Hz}, 0.4 \mathrm{H}, 2^{\prime}-\mathrm{CH}-199\right), 3.91\left(\mathrm{dd}, J=11.2,5.0 \mathrm{~Hz}, 0.6 \mathrm{H}\right.$, one of 1'- $\left.\mathrm{CH}_{2}-196\right), 3.86$ (dd, 
$J=10.9,4.1 \mathrm{~Hz}, 0.6 \mathrm{H}$, one of 1'- $\left.\mathrm{CH}_{2}-196\right), 2.77\left(\mathrm{dd}, J=16.7,7.0 \mathrm{~Hz}, 0.6 \mathrm{H}\right.$, one of 3'- $\mathrm{CH}_{2-}$ 196), 2.67 (dd, $J=16.7,5.9 \mathrm{~Hz}, 0.6 \mathrm{H}$, one of $\left.3^{\prime}-\mathrm{CH}_{2}-196\right), 2.47$ (dd, $J=17.0,6.5 \mathrm{~Hz}, 0.4 \mathrm{H}$, one of 3'- $\left.\mathrm{CH}_{2}-199\right), 2.43$ (dd, $J=17.0,5.1 \mathrm{~Hz}, 0.4 \mathrm{H}$, one of $\left.3^{\prime}-\mathrm{CH}_{2}-199\right), 1.08\left(\mathrm{~s}, 2.7 \mathrm{H}, \mathrm{CH}_{3}\right.$, $t \mathrm{Bu}-199), 1.06$ (s, 5.4H, $\left.\mathrm{CH}_{3}, t \mathrm{Bu}-196\right), 0.14\left(\mathrm{~s}, 2.7 \mathrm{H}, \mathrm{CH}_{3}, \mathrm{Me}-199\right), 0.13$ (s, 5.4H, $\mathrm{CH}_{3}, \mathrm{Me}-$ 196).

${ }^{13} \mathrm{C}$ NMR (125 MHz, $\left.\mathrm{CDCl}_{3}\right): \delta 166.6$ (C, C1-199), 166.1 (C, C1-196), 145.0 (CH, C3-196), 144.8 (CH, C3-199), 140.6 (CH, C5/4-196), 140.5 (CH, C5/4-199), 136.0 (CH, Ph), 135.9 (CH, C6), 135.8 (CH, Ph), 135.54 (CH, Ph), 135.52 (CH, Ph), 133.7 (C, Ph), 133.5 (C, Ph), 133.3 (C, Ph), 129.8 (CH, Ph), 129.7 (CH, Ph), 129.08 (CH, C7-196), 129.06 (CH, C7-199), 128.8 (CH, C9), 127.70 (CH, Ph), 127.68 (CH, Ph), 127.65 (CH, Ph), 127.59 (CH, Ph), 127.21 (CH, C8-196), 127.18 (CH, C8-199), 126.22 (CH, C4/5-196), 126.18 (CH, C4/5-199), 121.1 (CH, C2-196), 120.8 (CH, C2-199), 102.6 (C, C4'-199), 102.1 (C, C4'-196), 87.2 (C, C5'-199), 86.9 (C, C5'-196), 72.1 (CH, C2'-196), 69.6 (CH, C2'-199), 66.9 ( $\mathrm{CH}_{2}, \mathrm{C}^{\prime}$ '-199), $63.7\left(\mathrm{CH}_{2}, \mathrm{Cl}^{\prime}\right.$ 196), $26.9\left(\mathrm{CH}_{3}, t \mathrm{Bu}-199\right), 26.7\left(\mathrm{CH}_{3}, t \mathrm{Bu}-196\right), 25.8\left(\mathrm{CH}_{2}, \mathrm{C}^{\prime}{ }^{\prime}-199\right), 21.9\left(\mathrm{CH}_{2}, \mathrm{C}^{\prime}{ }^{\prime}-196\right)$, 19.4 (C, $t \mathrm{Bu}-199), 19.3$ (C, $t \mathrm{Bu}-199),-0.01\left(\mathrm{CH}_{3}, \mathrm{Me}\right)$.

IR (neat) $\mathrm{cm}^{-1}: 3071(\mathrm{w}, \mathrm{C}-\mathrm{H}), 2958(\mathrm{~m}, \mathrm{C}-\mathrm{H}), 2857(\mathrm{~m}, \mathrm{C}-\mathrm{H}), 2178(\mathrm{~m}, \mathrm{C} \equiv \mathrm{C}), 1710$ (s, C=O), 1625 (s, C=C), 1235 (s, Si-C), 1112 (s, C-O), 997 (s, C-H), 840 (s, Si-C), 700 (s, SiC), $504(\mathrm{~s}, \mathrm{Si}-\mathrm{C})$.

HRMS (ESI) $m / z$ : found 605.2314, calcd for $\mathrm{C}_{35} \mathrm{H}_{42} \mathrm{O}_{3} \mathrm{Si}_{2} \mathrm{~K}[\mathrm{M}+\mathrm{K}]^{+} 605.2304(\Delta=1.7 \mathrm{ppm})$.

The three-bond $\mathrm{C}-\mathrm{H}$ correlations across the esters in both compounds were confirmed by CIGAR-HMBC NMR.

Mixture of $(2 E, 4 E)-\left[1^{\prime}\right.$-(tert-butyldiphenylsilyloxy)-5'-trimethylsilyl]pent-4'-yn-2'-yl nona-2,4-dienoate (198) and the silyl migrated product, $(2 E, 4 E)-[2$ '-(tertbutyldiphenylsilyloxy)-5' -trimethylsilyl]pent-4'-yn-1'-yl nona-2,4-dienoate (2:1)

The isomers were formed in a combined $41 \%$ yield. 


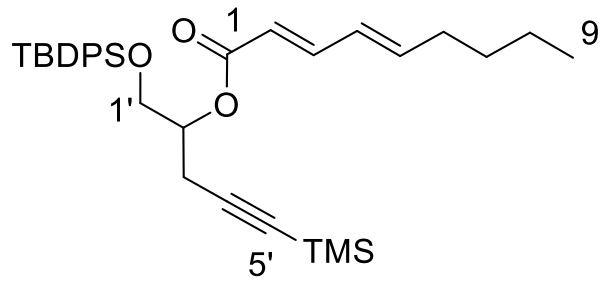

Major (198)

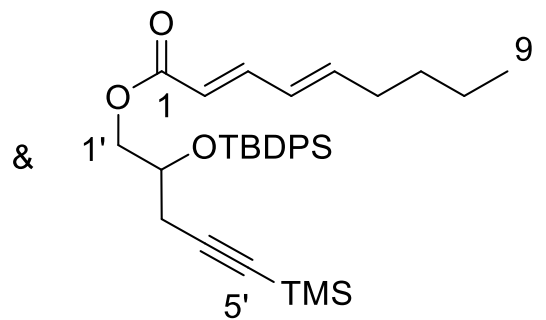

Minor

TLC: $R_{\mathrm{f}}=0.12\left(36: 1\right.$ Pet. ether: $\left.\mathrm{Et}_{2} \mathrm{O}\right)$.

${ }^{1} \mathbf{H}$ NMR (500 MHz, $\mathrm{CDCl}_{3}$ ): $\delta$ 7.74-7.61 (complex m, 4H, CH, Ph), 7.47-7.32 (complex m, 6H, CH, Ph), 7.28 (dd, $J=14.7,10.5 \mathrm{~Hz}, 0.67 \mathrm{H}, 3-\mathrm{CH}-198), 7.15$ (dd, $J=15.4,9.8 \mathrm{~Hz}, 0.33 \mathrm{H}$, 3-CH-minor), 6.23-6.06 (complex m, 2H, 4-CH \& 5-CH), 5.78 (d, J = 15.4 Hz, 0.67H, 2-CH198), 5.64 (d, $J=15.1,0.33 \mathrm{H}, 2-\mathrm{CH}$-minor), 5.12 (app. quin, $J=5.6 \mathrm{~Hz}, 0.67 \mathrm{H}, 2^{\prime}-\mathrm{CH}-198$ ), $4.19\left(\mathrm{dd}, J=10.0,4.2 \mathrm{~Hz}, 0.33 \mathrm{H}\right.$, one of $1^{\prime}-\mathrm{CH}_{2}$-minor), $4.19(\mathrm{dd}, J=10.9,4.8 \mathrm{~Hz}, 0.33 \mathrm{H}$, one of 1'- $\mathrm{CH}_{2}$-minor), 4.07 (app. dt, $J=10.7,5.4 \mathrm{~Hz}, 0.33 \mathrm{H}, 2^{\prime}-\mathrm{CH}$-minor), 3.89 (dd, $J=11.0$, $4.8 \mathrm{~Hz}, 0.67 \mathrm{H}$, one of $\left.1^{\prime}-\mathrm{CH}_{2}-198\right), 3.84\left(\mathrm{dd}, J=10.5,4.2 \mathrm{~Hz}, 0.67 \mathrm{H}\right.$, one of 1'- $\left.\mathrm{CH}_{2}-198\right), 2.74$ $\left(\mathrm{dd}, J=16.6,7.3 \mathrm{~Hz}, 0.67 \mathrm{H}\right.$, one of $\left.3^{\prime}-\mathrm{CH}_{2}-198\right), 2.64(\mathrm{dd}, J=16.9,6.7 \mathrm{~Hz}, 0.67 \mathrm{H}$, one of 3'$\mathrm{CH}_{2}$-198), 2.47 - 2.37 (complex m, 0.66H, 3'- $\mathrm{CH}_{2}$-minor), 2.18 (dt, J=13.4, $6.8 \mathrm{~Hz}, 2 \mathrm{H}, 6$ $\mathrm{CH}_{2}$ ), 1.46-1.39 (complex m, 2H, 7- $\mathrm{CH}_{2}$ ), 1.06 (s, 2.97H, $\mathrm{CH}_{3}, t \mathrm{Bu}-$ minor), 1.05 (s, 6.03H, $\mathrm{CH}_{3}, t \mathrm{Bu}-198$ ), 0.95-0.89 (complex m, 2H, 8- $\mathrm{CH}_{2}$ ), 0.89-0.80 (complex m, 3H, 9- $\mathrm{CH}_{2}$ ), 0.13 (s, 2.97H, $\mathrm{CH}_{3}, \mathrm{Me}-$ minor), 1.03 (s, 6.03H, $\left.\mathrm{CH}_{3}, \mathrm{Me}-198\right)$.

${ }^{13} \mathrm{C}$ NMR (125 MHz, $\left.\mathrm{CDCl}_{3}\right): \delta 166.9$ (C, C1-minor), $166.4(\mathrm{C}, \mathrm{C} 1-198), 145.6(\mathrm{CH}, \mathrm{C} 3-198)$, 145.4 (CH, C3-minor), 145.0 (CH, C4-198), 144.9 (CH, C4-minor), $136.0(\mathrm{CH}, \mathrm{Ph}), 135.8$ (CH, C5), 135.61 (CH, Ph), $135.55(\mathrm{CH}, \mathrm{Ph}), 135.53$ (CH, Ph), 135.51 (CH, Ph), $133.3(\mathrm{C}, \mathrm{Ph})$, 129.8 (CH, Ph), 129.7 (CH, Ph), 128.8 (CH, C9), 127.70 (CH, Ph), $127.70(\mathrm{CH}, \mathrm{Ph}), 127.68$ (CH, Ph), 127.66 (CH, Ph), $127.62(\mathrm{CH}, \mathrm{CH}, \mathrm{C} 5), 127.58$ (CH, Ph), 118.9 (CH, C2-198), 118.7 (CH, C2-minor), 102.1 (C, C4'), 86.8 (C, C5'), 71.9 (CH, C2'-198), 69.6 (CH, C2'-minor), $66.8\left(\mathrm{CH}_{2}, \mathrm{C1}\right.$ '-minor), 63.7 ( $\left.\mathrm{CH}_{2}, \mathrm{Cl}^{\prime}-\mathbf{1 9 8}\right), 32.70\left(\mathrm{CH}_{2}, \mathrm{C} 6-198\right), 32.68\left(\mathrm{CH}_{2}, \mathrm{C} 6-\right.$ minor$)$, $30.94\left(\mathrm{CH}_{2}, \mathrm{C} 7\right.$-minor), $30.8\left(\mathrm{CH}_{2}, \mathrm{C} 7-198\right), 26.9\left(\mathrm{CH}_{3}, t \mathrm{Bu}\right.$-minor $), 26.7\left(\mathrm{CH}_{3}, t \mathrm{Bu}-198\right)$, $22.6\left(\mathrm{CH}_{2}, \mathrm{C} 8\right), 22.2\left(\mathrm{CH}_{2}, \mathrm{C}^{\prime}\right), 19.4(\mathrm{C}, t$ Bu-minor $), 19.3$ (C, $t$ Bu-minor), $13.9\left(\mathrm{CH}_{3}, \mathrm{C} 9\right)$, $0.02\left(\mathrm{CH}_{3}, \mathrm{TMS}-\right.$ minor $),-0.03\left(\mathrm{CH}_{3}, \mathrm{TMS}-198\right)$. 
IR (neat) cm $\mathrm{cm}^{-1}: 2957$ (m, C-H), 2928 (s, C-H), 2857 (m, C-H), 2179 (w, C $\left.\equiv \mathrm{C}\right), 1717$ (s, C=O), 1643 (m, C=C), 1249 (s, Si-C), 1137 (s, C-O), 999 (s, C-H), 842 (s, Si-C), 702 (s, Si-C), 506 (s, $\mathrm{Si}-\mathrm{C})$.

HRMS (ESI) $m / z$ : found 547.3033, calcd for $\mathrm{C}_{33} \mathrm{H}_{47} \mathrm{O}_{3} \mathrm{Si}_{2}[\mathrm{M}+\mathrm{H}]^{+} 547.3058(\Delta=4.6 \mathrm{ppm})$.

Mixture of $(2 E, 4 Z)-1^{\prime}$-(tert-butyldiphenylsilyloxy)-5'-(trimethylsilyl)pent-4'-yn-2'-yl 7(tert-butyldimethylsilyloxy)-5-methylnona-2,4,8-trienoate (204) and the silyl migrated product, $(2 E, 4 Z)-2$ '-(tert-butyldiphenylsilyloxy)-5' -(trimethylsilyl)pent-4' -yn-1'-yl 7-(tertbutyldimethylsilyloxy)-5-methylnona-2,4,8-trienoate (205) (2:1)

The isomers were formed in a combined $69 \%$ yield.

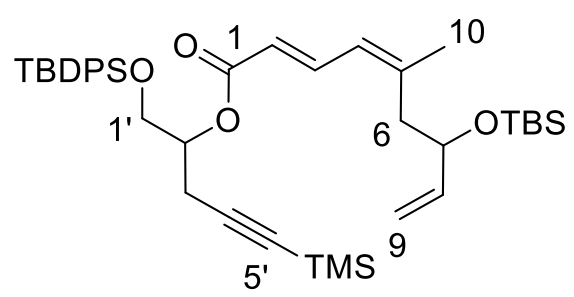

Major (204)

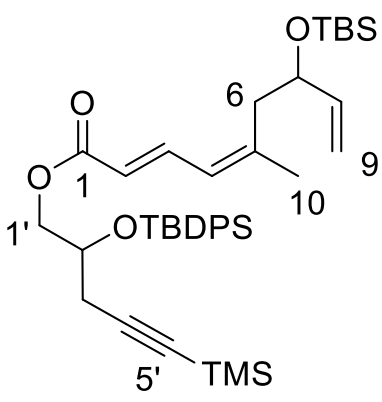

Minor (205)

TLC: $R_{\mathrm{f}}=0.21\left(40: 1\right.$ Pet. ether: $\left.\mathrm{Et}_{2} \mathrm{O}\right)$.

${ }^{1} \mathbf{H}$ NMR (500 MHz, $\mathrm{CDCl}_{3}$ ): $\delta$ 7.75-7.64 (complex m, 4H, CH, Ph), 7.57 (partially obs. ddd, $J=15.3,11.6,3.9 \mathrm{~Hz}, 0.67 \mathrm{H}, 3-\mathrm{CH}-204$ ), 7.51 (partially obs. ddd, $J=15.4,11.7,3.9 \mathrm{~Hz}, 0.33 \mathrm{H}$, 3-CH-205), 7.46-7.34 (complex m, 6H, CH, Ph), 6.09 (d, J = 11.7 Hz, 0.67H, 4-CH-204), 6.04 (d, $J=11.7 \mathrm{~Hz}, 0.33 \mathrm{H}, 4-\mathrm{CH}-205$ ), 5.85-5.74 (complex m, 1.67H, 8-CH \& 2-CH-204), 5.64 (d, $J=15.1 \mathrm{~Hz}, 0.33 \mathrm{H}, 2-\mathrm{CH}-205$ ), 5.22-5.10 (complex m, 1.67H, 2'-CH-204 \& one of 9- $\mathrm{CH}_{2}$ ), 5.07-5.00 (complex m, 1H, one of 9- $\mathrm{CH}_{2}$ ), 4.25 (dt, $\left.J=6.6,5.9 \mathrm{~Hz}, 1 \mathrm{H}, 7-\mathrm{CH}\right), 4.18$ (dd, $J=$ 5.1, $1.5 \mathrm{~Hz}, 0.66 \mathrm{H}, 1^{\prime}-\mathrm{CH}_{2}-205$ ), 4.09-4.04 (complex m, 0.33H, 2'-CH), 3.89 (ddd, $J=11.0$, 4.6, 2.4 Hz, 0.67H, one of 1'- $\left.\mathrm{CH}_{2}-\mathbf{2 0 4}\right), 3.84$ (ddd, $J=11.0,4.4,1.7 \mathrm{~Hz}, 0.67 \mathrm{H}$, one of 1'- $\mathrm{CH}_{2}-$ 204), 2.75 (ddd, $J=16.9,7.1,1.5 \mathrm{~Hz}, 0.67 \mathrm{H}$, one of $\left.3^{\prime}-\mathrm{CH}_{2}-204\right), 2.64$ (obs. ddd, $J=16.9,5.9$, $4.2 \mathrm{~Hz}, 0.67 \mathrm{H}$, one of $3^{\prime}-\mathrm{CH}_{2}-\mathbf{2 0 4}$ ), 2.60-2.52 (complex m, $1 \mathrm{H}$, one of 6- $\mathrm{CH}_{2}$ ), 2.44-2.39 (complex m, 0.66H, 3'- $\left.\mathrm{CH}_{2}-\mathbf{2 0 5}\right), 2.36\left(\mathrm{dd}, J=13.4,5.4 \mathrm{~Hz}, 1 \mathrm{H}\right.$, one of 6- $\left.\mathrm{CH}_{2}\right), 1.93(\mathrm{~s}, 2.0 \mathrm{H}$, 
10- $\mathrm{CH}_{3}$-204), 1.92 (s, 1.0H, 10- $\mathrm{CH}_{3}$-205), 1.07 (s, 3.0H, $\mathrm{CH}_{3}, t \mathrm{Bu}$, TBDPS-205), 1.05 (s, 6.0H, $\mathrm{CH}_{3}, t \mathrm{Bu}$, TBDPS-204), 0.86 (s, 3.0H, $\left.\mathrm{CH}_{3}, t \mathrm{Bu}, \mathrm{TBS}-205\right), 0.86$ (s, 6.0H, $\left.\mathrm{CH}_{3}, t \mathrm{Bu}, \mathrm{TBS}-204\right)$, 0.13 (s, 3.0H, $\left.\mathrm{CH}_{3}, \mathrm{TMS}-205\right), 0.12$ (s, 6.0H, $\left.\mathrm{CH}_{3}, \mathrm{TMS}-204\right), 0.01$ (s, 6H, $\mathrm{CH}_{3}, \mathrm{Me}$ ).

${ }^{13} \mathrm{C}$ NMR (125 MHz, $\left.\mathrm{CDCl}_{3}\right): \delta 167.15$ and $167.14(\mathrm{C}, \mathrm{C} 1-205), 166.68$ and $166.65(\mathrm{C}, \mathrm{C} 1-$ 204), 146.54 and 146.51 and 146.46 (C, C5), 141.50 and 141.48 (CH, C3-204), 141.30 and 141.29 (CH, C3-205), 140.90 and 140.88 and 140.84 (CH, C8), $135.9(\mathrm{CH}, \mathrm{Ph}), 135.82(\mathrm{CH}$, $\mathrm{Ph}$ ), 135.81 (CH, Ph), 135.61 (CH, Ph), 135.58 (CH, Ph), 135.54 (CH, Ph), 135.52 (CH, Ph), 135.51 (CH, Ph), 135.50 (CH, Ph), 133.62 (C, Ph), 133.57 (C, Ph), 133.4 (C, Ph), 133.3 (C, Ph), 129.8 (CH, Ph), 129.68 (CH, Ph), 129.66 (CH, Ph), 129.65 (CH, Ph), 129.59 (CH, Ph), 129.32 (CH, Ph), 127.69 (CH, Ph), 127.67 (CH, Ph), 127.64 (CH, Ph), 127.62 (CH, Ph), 127.58 $(\mathrm{CH}, \mathrm{Ph}), 126.11$ and 126.06 and $126.04(\mathrm{CH}, \mathrm{C} 4), 119.02$ and $118.96(\mathrm{CH}, \mathrm{C} 2-204), 118.76$ and $118.75(\mathrm{CH}, \mathrm{C} 2-\mathbf{2 0 5}), 114.2\left(\mathrm{CH}_{2}, \mathrm{C} 9\right), 102.74$ and $102.72\left(\mathrm{C}, \mathrm{C} 4^{\prime}-\mathbf{2 0 5}\right), 102.23$ and 102.21 (C, C4'-204), 87.01 (C, C5'-205), 86.77 and 86.76 (C, C5'-204), 72.86 (CH, C7-205), 72.84 (CH, C7-204), 71.87 and 71.83 (CH, C2'-204), 69.53 (CH, C2'-205), 66.58 and 66.54 $\left(\mathrm{CH}_{2}, \mathrm{C} 1^{\prime}-205\right), 63.72$ and $63.69\left(\mathrm{CH}_{2}, \mathrm{C} 1^{\prime}-204\right), 41.7\left(\mathrm{CH}_{2}, \mathrm{C} 6\right), 26.9\left(\mathrm{CH}_{3}, t \mathrm{Bu}\right), 26.74\left(\mathrm{CH}_{3}\right.$, $t \mathrm{Bu}), 26.72\left(\mathrm{CH}_{3}, t \mathrm{Bu}\right), 25.82\left(\mathrm{CH}_{3}, \mathrm{C} 10-\mathbf{2 0 4}\right), 25.68\left(\mathrm{CH}_{3}, \mathrm{C} 10-205\right), 25.66$ and $25.65\left(\mathrm{CH}_{2}\right.$, C3'-205), $21.9\left(\mathrm{CH}_{2}, \mathrm{C}^{\prime}\right.$ '-204), $19.4(\mathrm{C}, t \mathrm{Bu}), 19.3(\mathrm{C}, t \mathrm{Bu}), 18.1(\mathrm{C}, t \mathrm{Bu}), 1.02\left(\mathrm{CH}_{3}, \mathrm{Me}\right)$, $0.01\left(\mathrm{CH}_{3}, \mathrm{Me}\right), 0.00\left(\mathrm{CH}_{3}, \mathrm{Me}\right),-0.03\left(\mathrm{CH}_{3}, \mathrm{Me}\right)$.

IR (Et ${ }_{2} \mathrm{O}$ film) $\mathrm{cm}^{-1}: 3072(\mathrm{w}, \mathrm{C}-\mathrm{H}), 2959(\mathrm{~s}, \mathrm{C}-\mathrm{H}), 2858(\mathrm{~s}, \mathrm{C}-\mathrm{H}), 2179(\mathrm{~m}, \mathrm{C} \equiv \mathrm{C}), 1716$ (m, C=O), 1637 (m, C=C), 1251 (m, C-Si), 1114 (s, Si-O), 776 (m, Si-Me), 702 (s, Si-C).

HRMS (ESI) $m / z$ : found 689.3838, calcd for $\mathrm{C}_{40} \mathrm{H}_{62} \mathrm{O}_{4} \mathrm{Si}_{3}[\mathrm{M}+\mathrm{H}]^{+} 689.3872(\Delta=4.8 \mathrm{ppm})$.

The three-bond $\mathrm{C}-\mathrm{H}$ correlations across the esters in both compounds were confirmed by CIGAR-HMBC NMR.

$(2 E, 4 E)$-[1'-(para-Methoxybenzyloxy)-5'-trimethylsilyl]pent-4'-yn-2'-yl 5-phenylpenta2,4-dienoate (206)

Formed in $42 \%$ yield in THF or $70 \%$ in toluene. 
<smiles>CC#CCC(OC(=O)/C=C/C=C/c1ccccc1)C(I)O[Tl]</smiles>

TLC: $R_{\mathrm{f}}=0.28\left(80 \% \mathrm{CH}_{2} \mathrm{Cl}_{2}\right.$ in $n$-hexane $)$.

${ }^{1} \mathbf{H}$ NMR (500 MHz, $\mathrm{CDCl}_{3}$ ): $\delta$ 7.51-7.44 (complex m, 3H, 3-CH \& 8-CH), 7.37 (app. t, $J=$ 7.1 Hz, 2H, 7-CH), 7.33 (m, 1H, 9-CH), 7.28 (br d, $J=8.8$ Hz, 2H, 9'-CH), 6.95-6.84 (complex m, 4H, 8'-CH \& 4-CH \& 5-CH), 6.02 (d, $J=15.4 \mathrm{~Hz}, 1 \mathrm{H}, 2-\mathrm{CH}$ ), 5.20 (app. dt, $J=10.5,5.7$ $\left.\mathrm{Hz}, 1 \mathrm{H}, 2^{\prime}-\mathrm{CH}\right), 4.55\left(\mathrm{~d}, J=11.5 \mathrm{~Hz}, 1 \mathrm{H}\right.$, one of $\left.11^{\prime}-\mathrm{CH}_{2}\right), 4.50(\mathrm{~d}, J=11.7 \mathrm{~Hz}, 1 \mathrm{H}$, one of $\left.11^{\prime}-\mathrm{CH}_{2}\right), 3.80\left(\mathrm{~s}, 3 \mathrm{H}, 6^{\prime}-\mathrm{CH}_{3}\right), 3.72-3.67\left(\mathrm{~m}, 2 \mathrm{H}, 1^{\prime}-\mathrm{CH}_{2}\right), 2.68(\mathrm{dd}, J=17.1,7.1 \mathrm{~Hz}, 1 \mathrm{H}$, one of $\left.3^{\prime}-\mathrm{CH}_{2}\right), 2.63\left(\mathrm{dd}, J=16.9,5.9 \mathrm{~Hz}, 1 \mathrm{H}\right.$, one of $\left.3^{\prime}-\mathrm{CH}_{2}\right), 0.14\left(\mathrm{~s}, 9 \mathrm{H}, \mathrm{CH}_{3}, \mathrm{TMS}\right)$.

${ }^{13} \mathrm{C}$ NMR (125 MHz, $\left.\mathrm{CDCl}_{3}\right): \delta 166.2(\mathrm{C}, \mathrm{C} 1), 159.2(\mathrm{C}, \mathrm{C} 7$ '), $145.2(\mathrm{CH}, \mathrm{C} 3), 140.7(\mathrm{CH}$, C5), 136.0 (C, C6), 130.1 (C, C10'), 129.3 (CH, C9'), 129.1 (CH, C7), 128.8 (CH, C9), 127.2 (CH, C8), 126.2 (CH, C4), 121.0 (CH, C2), 113.8 (CH, C8'), 101.9 (C, C4'), 87.1 (C, C5'), 73.0 $\left(\mathrm{CH}_{2}, \mathrm{C} 11^{\prime}\right), 70.7\left(\mathrm{CH}, \mathrm{C} 2^{\prime}\right), 69.4\left(\mathrm{CH}_{2}, \mathrm{C}^{\prime}\right), 55.2\left(\mathrm{CH}_{3}, \mathrm{C}^{\prime}\right), 22.3\left(\mathrm{CH}_{2}, \mathrm{C} 3^{\prime}\right), 0.00\left(\mathrm{CH}_{3}\right.$, TMS).

IR (neat) $\mathrm{cm}^{-1}: 3028(\mathrm{w}, \mathrm{C}-\mathrm{H}), 2957(\mathrm{~m}, \mathrm{C}-\mathrm{H}), 2901(\mathrm{~m}, \mathrm{C}-\mathrm{H}), 2178(\mathrm{~m}, \mathrm{C} \equiv \mathrm{C}), 1709$ (s, $\mathrm{C}=\mathrm{O}), 1625$ (s, C=C), 1512 (m, C-O), 1245 (s, C-O), 1128 (s, C-O), 840 (s, C-Si), 757 (s, C$\mathrm{Si})$.

HRMS (ESI) $m / z$ : found 449.2146, calcd for $\mathrm{C}_{27} \mathrm{H}_{33} \mathrm{O}_{4} \mathrm{Si}[\mathrm{M}+\mathrm{H}]^{+} 449.2143(\Delta=0.67 \mathrm{ppm})$.

\section{(2E,4Z)-1'-(para-Methoxybenzyloxy)-5' -(trimethylsilyloxy)pent-4'-yn-2'-yl 7-(tert-}

\section{butyldimethylsilyloxy)-5-methylnona-2,4,8-trienoate (207)}

Formed in $68 \%$ yield as a single regioisomer, and with 1:1 d.r. based on composition of racemic starting materials. 


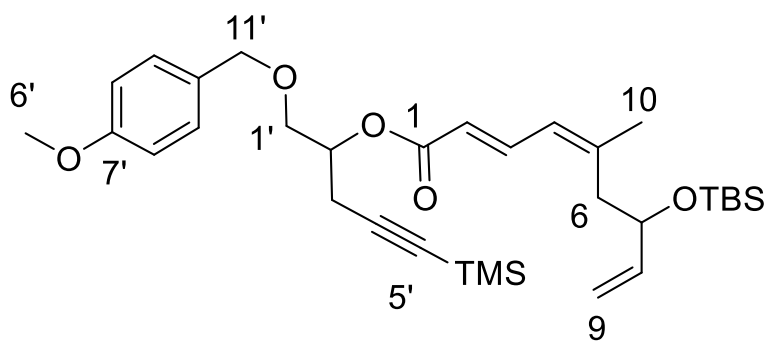

TLC: $R_{\mathrm{f}}=0.30\left(80 \% \mathrm{CH}_{2} \mathrm{Cl}_{2}\right.$ in $n$-hexane $)$.

${ }^{1} \mathbf{H}$ NMR (500 MHz, $\left.\mathrm{CDCl}_{3}\right): \delta 7.57(\mathrm{dd}, J=14.9,11.8 \mathrm{~Hz}, 1 \mathrm{H}, 3-\mathrm{CH}), 7.26(\mathrm{~d}, J=8.3 \mathrm{~Hz}$, $\left.2 \mathrm{H}, 9^{\prime}-\mathrm{CH}\right), 6.87$ (d, $\left.J=8.3 \mathrm{~Hz}, 2 \mathrm{H}, 8^{\prime}-\mathrm{CH}\right), 6.07$ (d, $\left.J=11.5 \mathrm{~Hz}, 1 \mathrm{H}, 4-\mathrm{CH}\right), 5.80$ (obs. ddd, $J=16.8,10.6,5.7 \mathrm{~Hz}, 1 \mathrm{H}, 8-\mathrm{CH}$ ), 5.80 (obs. d, $J=15.2 \mathrm{~Hz}, 1 \mathrm{H}, 2-\mathrm{CH}$ ), 5.23-5.11 (obs. m, $1 \mathrm{H}, 2^{\prime}-\mathrm{CH}$ ), 5.18 (obs. d, $J=17.2 \mathrm{~Hz}, 1 \mathrm{H}$, one of 9- $\mathrm{CH}_{2}$ ), 5.05 (d, $J=10.3 \mathrm{~Hz}, 1 \mathrm{H}$, one of 9$\left.\mathrm{CH}_{2}\right), 4.53\left(\mathrm{~d}, J=11.5 \mathrm{~Hz}, 1 \mathrm{H}\right.$, one of $\left.11^{\prime}-\mathrm{CH}_{2}\right), 4.48\left(\mathrm{~d}, J=11.5 \mathrm{~Hz}, 1 \mathrm{H}\right.$, one of $\left.11^{\prime}-\mathrm{CH}_{2}\right)$, 4.25 (app. q, $J=6.2 \mathrm{~Hz}, 1 \mathrm{H}, 7-\mathrm{CH}$ ), 3.80 (s, 3H, 6'-CH3), 3.67 (app. d, $J=4.9 \mathrm{~Hz}, 2 \mathrm{H}, 1^{\prime}-\mathrm{CH}_{2}$ ), 2.69-2.54 (complex m, 3H, 3'- $\mathrm{CH}_{2} \&$ one of 6- $\mathrm{CH}_{2}$ ), 2.36 (ddd, $J=13.0,6.5,5.5 \mathrm{~Hz}, 1 \mathrm{H}$, one of 6- $\left.\mathrm{CH}_{2}\right), 1.92\left(\mathrm{~s}, 3 \mathrm{H}, 10-\mathrm{CH}_{3}\right), 0.87$ (s, 9H, $\left.\mathrm{CH}_{3}, t \mathrm{Bu}\right), 0.13$ (s, 9H, $\left.\mathrm{CH}_{3}, \mathrm{TMS}\right), 0.01$ (s, 6H, $\left.\mathrm{CH}_{3}, \mathrm{Me}\right)$.

${ }^{13} \mathrm{C} \mathrm{NMR}\left(125 \mathrm{MHz}, \mathrm{CDCl}_{3}\right): \delta 166.71$ and 166.69 (C, C1), $159.2(\mathrm{C}, \mathrm{C} 7$ '), 146.58 and 146.56 (C, C5), 141.70 and 141.67 (CH, C3), 140.9 (CH, C8), 130.1 (C, C10'), 129.3 (CH, C9'), 126.09 and $129.07(\mathrm{CH}, \mathrm{C} 4), 118.89$ and $118.87(\mathrm{CH}, \mathrm{C} 2), 114.2\left(\mathrm{CH}_{2}, \mathrm{C} 9\right), 113.8\left(\mathrm{CH}, \mathrm{C} 8^{\prime}\right), 102.0$ (C, $\left.4^{\prime}\right), 86.92$ and 86.90 (C, C5'), 73.00 and $72.99\left(\mathrm{CH}_{2}, \mathrm{C} 11^{\prime}\right), 72.86$ and 72.82 (CH, C7), 70.48 and $70.47\left(\mathrm{CH}, \mathrm{C} 2^{\prime}\right), 69.45$ and $69.41\left(\mathrm{CH}_{2}, \mathrm{C} 1^{\prime}\right), 55.2\left(\mathrm{CH}_{3}, \mathrm{C}^{\prime}\right), 41.7\left(\mathrm{CH}_{2}, \mathrm{C} 6\right), 25.83$ and $25.82\left(\mathrm{CH}_{3}, t \mathrm{Bu}\right), 25.64$ and $25.62\left(\mathrm{CH}_{3}, \mathrm{C} 10\right), 22.32$ and $22.29\left(\mathrm{CH}_{2}, \mathrm{C}^{\prime}\right), 18.1(\mathrm{C}, t \mathrm{Bu})$, 0.00 and $-0.01\left(\mathrm{CH}_{3}, \mathrm{TMS}\right),-4.54$ and $-4.88\left(\mathrm{CH}_{3}, \mathrm{TBS}\right)$.

IR (neat) $\mathrm{cm}^{-1}: 2956(\mathrm{~s}, \mathrm{C}-\mathrm{H}), 2857(\mathrm{~m}, \mathrm{C}-\mathrm{H}), 2180(\mathrm{w}, \mathrm{C} \equiv \mathrm{C}), 1714(\mathrm{~s}, \mathrm{C}=\mathrm{O}), 1636(\mathrm{~m}, \mathrm{C}=\mathrm{C})$, 1513 (m, C=C), 1249 (s, C-O), 1033 (m, C-H), 837 (s, C-Si), 775 (m, C-Si), 760 (m, C-Si).

HRMS (ESI) $m / z$ : found 571.3276, calcd for $\mathrm{C}_{32} \mathrm{H}_{51} \mathrm{O}_{5} \mathrm{Si}_{2}[\mathrm{M}+\mathrm{H}]^{+} 571.3270(\Delta=1.1 \mathrm{ppm})$.

(2E,4Z)-1'-(para-Methoxybenzyloxy)pent-4'-yn-2'-yl 7-(tert-butyldimethylsilyloxy)-5methylnona-2,4,8-trienoate (208) 
Formed in $66 \%$ yield as a single regioisomer, and with 1:1 d.r. based on composition of racemic starting materials.

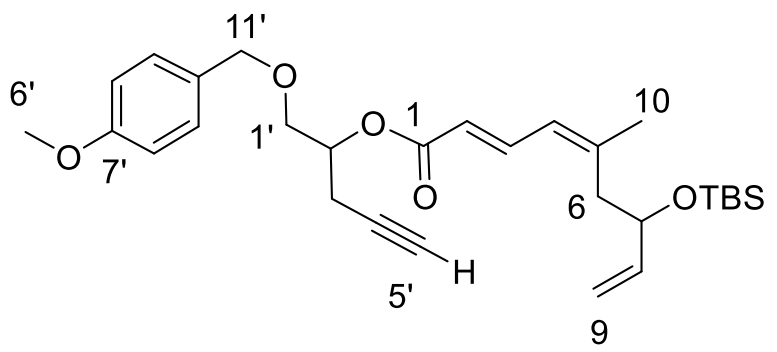

TLC: $R_{\mathrm{f}}=0.32\left(80 \% \mathrm{CH}_{2} \mathrm{Cl}_{2}\right.$ in $n$-hexane $)$.

${ }^{1}$ H NMR (500 MHz, $\left.\mathrm{CDCl}_{3}\right): \delta 7.58(\mathrm{dd}, J=14.9,11.7 \mathrm{~Hz}, 1 \mathrm{H}, 3-\mathrm{CH}), 7.26(\mathrm{~d}, J=8.6 \mathrm{~Hz}$, 2H, 9'-CH), 6.87 (d, $\left.J=8.6 \mathrm{~Hz}, 2 \mathrm{H}, 8^{\prime}-\mathrm{CH}\right), 6.07$ (d, $\left.J=11.5 \mathrm{~Hz}, 1 \mathrm{H}, 4-\mathrm{CH}\right), 5.80$ (obs. ddd, $J=17.1,10.5,5.9 \mathrm{~Hz}, 1 \mathrm{H}, 8-\mathrm{CH}$ ), 5.80 (obs. d, $J=14.9 \mathrm{~Hz}, 1 \mathrm{H}, 2-\mathrm{CH}$ ), 5.23-5.14 (obs. m, $1 \mathrm{H}, 2^{\prime}-\mathrm{CH}$ ), 5.18 (obs. d, $J=16.9 \mathrm{~Hz}, 1 \mathrm{H}$, one of 9- $\mathrm{CH}_{2}$ ), 5.05 (d, $J=10.3 \mathrm{~Hz}, 1 \mathrm{H}$, one of 9$\left.\mathrm{CH}_{2}\right), 4.53\left(\mathrm{~d}, J=11.5 \mathrm{~Hz}, 1 \mathrm{H}\right.$, one of 11'- $\left.\mathrm{CH}_{2}\right), 4.48\left(\mathrm{~d}, J=11.5 \mathrm{~Hz}, 1 \mathrm{H}\right.$, one of 11'- $\left.\mathrm{CH}_{2}\right)$, 4.25 (app. q, $J=5.6 \mathrm{~Hz}, 1 \mathrm{H}, 7-\mathrm{CH}), 3.80$ (s, 3H, 6'- $\mathrm{CH}_{3}$ ), 3.71-3.62 (m, 2H, 1'- $\mathrm{CH}_{2}$ ), 2.65 (ddd, $J=16.9,6.6,2.7 \mathrm{~Hz}, 1 \mathrm{H}$, one of 3'- $\left.\mathrm{CH}_{2}\right), 2.58(\mathrm{ddd}, J=16.9,5.4,2.5 \mathrm{~Hz}, 1 \mathrm{H}$, one of 3'$\mathrm{CH}_{2}$ ), 2.61-2.54 (obs. m, 1H, one of 6- $\mathrm{CH}_{2}$ ), 2.36 (app. dt, $J=13.1,4.9 \mathrm{~Hz}, 1 \mathrm{H}$, one of 6- $\mathrm{CH}_{2}$ ), $1.97\left(\mathrm{~m}, 1 \mathrm{H}, 5^{\prime}-\mathrm{CH}\right), 1.92$ (s, 3H, 10- $\left.\mathrm{CH}_{3}\right), 0.86$ (s, 9H, $\left.\mathrm{CH}_{3}, t \mathrm{Bu}\right), 0.01$ (s, 3H, $\left.\mathrm{CH}_{3}, \mathrm{Me}\right), 0.00$ (s, $\left.3 \mathrm{H}, \mathrm{CH}_{3}, \mathrm{Me}\right)$.

${ }^{13} \mathrm{C}$ NMR (125 MHz, $\mathrm{CDCl}_{3}$ ): $\delta 166.7$ (C, C1), 159.2 (C, C7'), 146.81 and 146.78 (C, C5), 141.92 and 141.89 (CH, C3), 140.95 and 140.93 (CH, C8), 130.1 (C, C10'), 129.31 and 129.30 $\left(\mathrm{CH}, \mathrm{C}^{\prime}\right), 126.07$ and $126.05(\mathrm{CH}, \mathrm{C} 4), 118.71$ and $118.68(\mathrm{CH}, \mathrm{C} 2), 114.2\left(\mathrm{CH}_{2}, \mathrm{C} 9\right), 113.8$ $\left(\mathrm{CH}, \mathrm{C} 8^{\prime}\right), 79.6\left(\mathrm{C}, \mathrm{C}^{\prime}\right), 73.0\left(\mathrm{CH}_{2}, \mathrm{C} 11^{\prime}\right), 72.81$ and $72.77(\mathrm{CH}, \mathrm{C} 7), 70.33$ and $70.30(\mathrm{CH}$, C5'), 70.18 and $70.13\left(\mathrm{CH}, \mathrm{C}^{\prime}\right), 69.3\left(\mathrm{CH}_{2}, \mathrm{C1}^{\prime}\right), 55.2\left(\mathrm{CH}_{3}, \mathrm{C6}^{\prime}\right), 41.8\left(\mathrm{CH}_{2}, \mathrm{C} 6\right), 25.8\left(\mathrm{CH}_{3}\right.$, $t \mathrm{Bu}), 25.66$ and $25.65\left(\mathrm{CH}_{3}, \mathrm{C} 10\right), 20.97$ and $20.95\left(\mathrm{CH}_{2}, \mathrm{C}^{\prime}\right), 18.1(\mathrm{C}, t \mathrm{Bu}),-4.54$ and -4.88 $\left(\mathrm{CH}_{3}, \mathrm{TBS}\right)$.

IR (neat) $\mathrm{cm}^{-1}: 3308$ (w, C-H), $2930(\mathrm{~m}, \mathrm{C}-\mathrm{H}), 2857$ (s, C-H), 2214 (w, C $\left.\equiv \mathrm{C}\right), 1712$ (s, C=O), 1635 (m, C=C), 1612 (m, C=C), 1514 (s, C-H), 1248 (s, C-O), 1033 (m, C-O), 836 (s, C-Si), 776 (s, C-Si).

HRMS (ESI) $m / z$ : found 499.2868, calcd for $\mathrm{C}_{29} \mathrm{H}_{43} \mathrm{O}_{5} \mathrm{Si}[\mathrm{M}+\mathrm{H}]^{+} 499.2874(\Delta=1.2 \mathrm{ppm})$. 
$\left(2 E, 4 Z, 2^{\prime} S\right)-1$ '-(para-Methoxybenzyloxy)pent-4'-yn-2'-yl 7-(tert-butyldimethylsilyloxy)-5methylnona-2,4,8-trienoate $(2 ' S-208)$

Formed in $26 \%$ yield as a single regioisomer, and with 1:1 d.r. based on composition of starting materials.

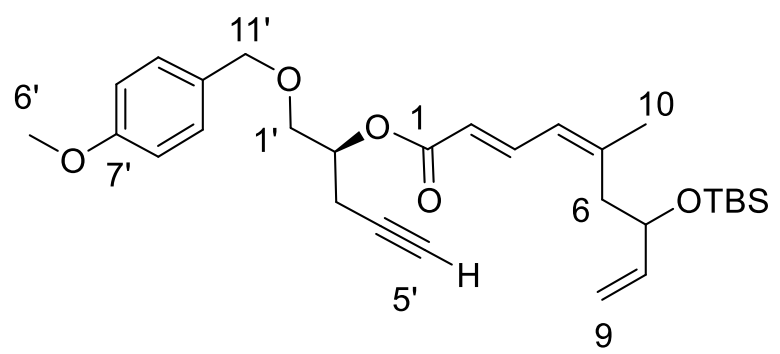

All spectroscopic data matched those of the racemate $\mathbf{2 0 8}$.

Specific rotation: $[a]_{D}{ }^{21}=-2.11\left(c=0.18, \mathrm{CH}_{2} \mathrm{Cl}_{2}\right)$.

\subsection{References}

(1) Bartlett, M. Synlett 2013, 24, 773.

(2) Smith, A. B.; Safonov, I. G.; Corbett, R. M. J. Am. Chem. Soc. 2001, 123, 12426.

(3) Ding, F.; Jennings, M. P. J. Org. Chem. 2008, 73, 5965.

(4) Uenishi, J.; Iwamoto, T.; Tanaka, J. Org. Lett. 2009, 11, 3262.

(5) Ghosh, A. K.; Cheng, X. Org. Lett. 2011, 13, 4108.

(6) Zurwerra, D.; Glaus, F.; Betschart, L.; Schuster, J.; Gertsch, J.; Ganci, W.; Altmann, K. H. Chem.-Eur. J. 2012, 18, 16868.

(7) Daly, B. J. J.; Wheatley, P. J. Inorg. Phys. Theor. 1966, 1703.

(8) Matthews, C. N.; Birum, G. H. Tetrahedron Lett. 1966, 7, 5707.

(9) Bestmann, H. J.; Sandmeier, D. Chem. Ber.-Recl. 1980, 113, 274.

(10) Bestmann, H. J.; Schobert, R. Synthesis 1989, 419.

(11) Bestmann, H. J.; Kellermann, W. Synthesis 1994, 1257.

(12) Bestmann, H. J. Angew. Chem. Int. Ed. 1977, 16, 349.

(13) Schobert, R. Org. Synth. 2005, 82, 140. 
(14) Schlenk, A.; Diestel, R.; Sasse, F.; Schobert, R. Chem.-Eur. J. 2010, 16, 2599.

(15) Jung, M. E.; Yoo, D. Org. Lett. 2011, 13, 3766.

(16) Westman, J.; Orrling, K. Comb. Chem. High T. Scr. 2002, 5, 571.

(17) Fedoseyenko, D.; Raghuraman, A.; Ko, E.; Burgess, K. Org. Biomol. Chem. 2012, 10, 921.

(18) Raghuraman, A.; Ko, E.; Perez, L. M.; Ioerger, T. R.; Burgess, K. J. Am. Chem. Soc. 2011, 133, 12350 .

(19) Schobert, R.; Siegfried, S.; Gordon, G. J. J. Chem. Soc. Perk. T. 1 2001, 2393.

(20) Risi, R. M.; Burke, S. D. Org. Lett. 2012, 14, 1180.

(21) Bestmann, H. J.; Kellermann, W.; Pecher, B. Synthesis 1993, 149.

(22) Jung, M. E.; Yoo, D. Org. Lett. 2011, 13, 2698.

(23) Kitson, R. R. A.; Taylor, R. J. K.; Wood, J. L. Org. Lett. 2009, 11, 5338.

(24) Kitson, R. R. A.; McAllister, G. D.; Taylor, R. J. K. Tetrahedron Lett. 2011, 52, 561.

(25) Pachali, S.; Hofmann, C.; Rapp, G.; Schobert, R.; Baro, A.; Frey, W.; Laschat, S. Eur. J. Org. Chem. 2009, 2828.

(26) Werkhoven, T. M.; van Nispen, R.; Lugtenburg, J. Eur. J. Org. Chem. 1999, 2909.

(27) Bernstein, H. J.; Pople, J. A.; Schneider, W. G. Can. J. Chem. 1957, 35, 67.

(28) Trost, B. M.; Machacek, M. R.; Faulk, B. D. J. Am. Chem. Soc. 2006, 128, 6745.

(29) Kuntiyong, P.; Lee, T. H.; Kranemann, C. L.; White, J. D. Org. Biomol. Chem. 2012, 10,7884 .

(30) Furrer, J. Concept. Magnetic Res. A 2012, 40A, 101.

(31) Furrer, J. Concept. Magnetic Res. A 2012, 40A, 146.

(32) Wagner, R.; Berger, S. Magn. Reson. Chem. 1998, 36, S44.

(33) Hadden, C. E.; Martin, G. E.; Krishnamurthy, V. V. J. Magn. Reson. 1999, 140, 274.

(34) Hurd, R. E. J. Magn. Reson. 1990, 87, 422.

(35) Ruizcabello, J.; Vuister, G. W.; Moonen, C. T. W.; Vangelderen, P.; Cohen, J. S.; Van Zij1, P. C. M. J. Magn. Reson. 1992, 100, 282.

(36) Hadden, C. E.; Martin, G. E.; Krishnamurthy, V. V. Magn. Reson. Chem. 2000, 38, 143.

(37) Matveeva, E. D.; Podrugina, T. A.; Grishin, Y. K.; Pavlova, A. S.; Zefirov, N. S. Russ. J. Org. Chem. 2007, 43, 201.

(38) Larson, G. L.; Quiroz, F.; Suarez, J. Synth. Commun. 1983, 13, 833. 


\section{Chapter 5: Exploration of late-stage connections}

\subsection{Formation of $N$-acyl hemiaminal}

As discussed in section 1.4.3, linear $N$-acyl hemiaminal structures are rare in natural product. Apart from zampanolide (19), natural products in the pederin family are often used to demonstrate the occurrence of the $N$-acyl hemiaminal functionality (examples shown in Figure 5.1). However, construction of the $N$-acyl hemiaminal in members of the pederin family has been achieved primarily by amide synthesis from carboxylic acids and amines. ${ }^{1,2}$ In the total syntheses of 19, aza-aldol reactions have been more commonly used (see section 1.4.3). Since very few aza-aldol reactions conducted in this fashion were previously published, ${ }^{3,4,5}$ the total synthesis of 19 provided a good basis for exploration of the methodology to form $N$-acyl hemiaminal via aza-adol reaction, especially in complex natural product synthesis.

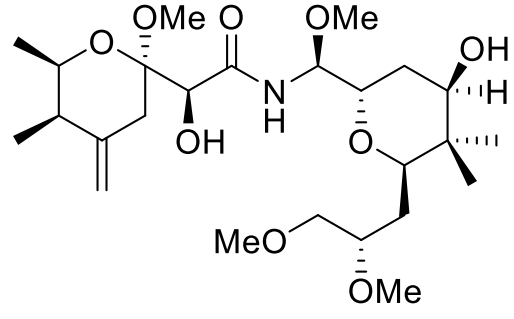

Pederin<smiles>C=C(C)C[C@H](OC)[C@@H](O)C(=O)N[C@H](OC)[C@@H]1C[C@@H](O)C(C)(C)[C@@H](C[C@H](O)[C@@H](C)[C@H]2Cc3c(C)c(O)cc(O)c3C(=O)O2)O1</smiles>

Irciniastatin A

Figure 5.1: Examples of the pederin family.

In the present study, the attachment of the amides to the macrocyclic core was attempted by a boron-catalyzed aza-aldol reaction. A non-stereoselective boron-catalyzed aza-aldol reaction for $\mathrm{N}$-acyl hemiaminal formation was reported by Kiren, Shangguan and William in $2007 .{ }^{6} \mathrm{In}$ their experiments, a number of chlorodicyclohexylborane $\left(\mathrm{Cy}_{2} \mathrm{BCl}\right)$-mediated direct additions of amides to aldehydes were conducted, and moderate to good yields were obtained after a 30 min reaction followed by quenching with a mixture of $\mathrm{MeOH}$, phosphate buffer $(\mathrm{pH}=7.40$ ) and $\mathrm{H}_{2} \mathrm{O}_{2}$ (Scheme 5.1). 


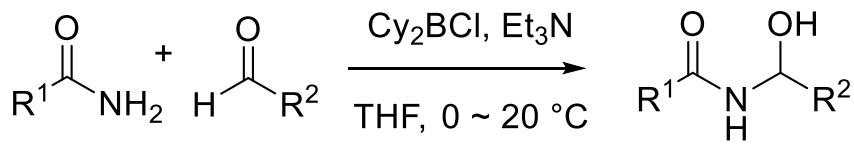

$39 \sim 88 \%$ yield

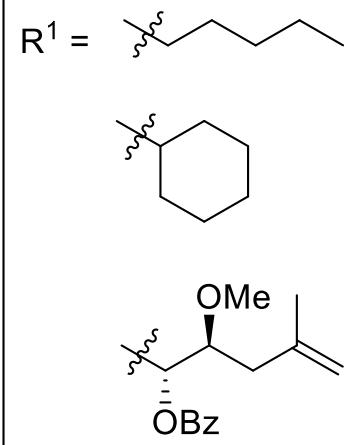

(d.r. 1:1)

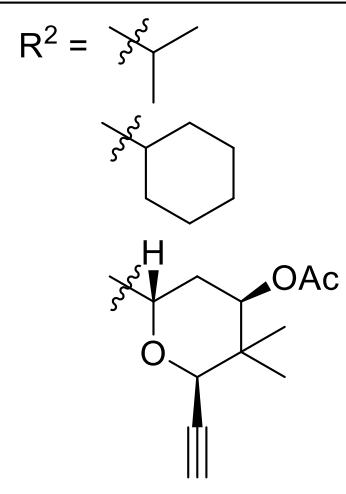

(d.r. $1: 1$ or $2: 1$ )

Scheme 5.1: Kiren's aza-aldol reactions. ${ }^{6}$

Adaption of this type of reaction to use a chiral boron reagent to achieve stereoselectivity was investigated, in particular chlorodiisopinocampheylborane (DIP-chloride). Although DIPchloride has never been used in aza-aldol reaction, it is well-established to mediate asymmetric adol reaction. ${ }^{7}$ Both (+)-DIP-chloride and (-)-DIP-chloride were to be tested. (-)-DIP-chloride was purchased, but the high cost encouraged us to also explore the synthesis of DIP-chloride. DIP-chloride can be prepared from the readily available starting material $\alpha$-pinene following a few well-precedented methods. ${ }^{8-10}$ Reider's convenient method was attempted first (Scheme 5.2). In this procedure, ${ }^{-} \mathrm{BHCl}_{3}$ and borane are proposed to form, generated from boron trichloride and excess borohydride in situ. The borane or a related entity then reacts with two equivalents of $\alpha$-pinene to produce the intermediate 209, which is chlorinated, probably by either ${ }^{-} \mathrm{BHCl}_{3}$ or $\mathrm{BCl}_{3}$, to produce DIP-chloride as a solution in 1,2-dimethoxyethane (DME). ${ }^{10}$

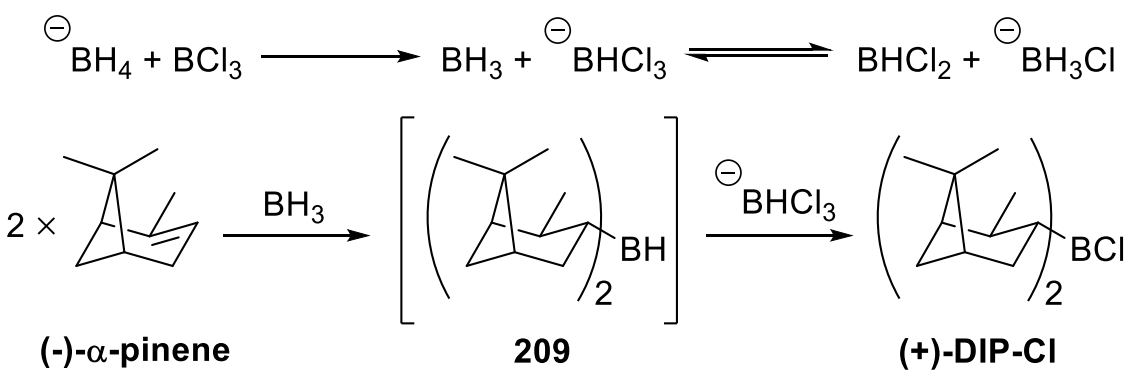

Scheme 5.2: Reider's preparation of (+)-DIP-Cl and proposed mechanism.

In this way, (+)-DIP-chloride was prepared from (-)- $\alpha$-pinene. The activity of the home-made (+)-DIP-chloride was tested in the reduction of acetophenone, and full conversion was achieved after 5 hours at $-23{ }^{\circ} \mathrm{C}$ followed by 1 hour at $0{ }^{\circ} \mathrm{C}$. However, the enantioselectivity of the 
reagent was not assessed at this time, and the presence of any remaining active borane species in the mixture could reduce the aldehyde starting material in the aza-adol reaction.

The planned DIP-chloride-promoted aza-aldol reaction was first tested in model studies involving simple aldehydes (Scheme 5.3), where DIP-chloride, amide and $\mathrm{Et}_{3} \mathrm{~N}$ were premixed prior to the addition of the aldehyde. With the amine models sorbamide (210) and cyclohexylamide (211) and aldehyde models 2-methylbutyraldehyde (212) and n-pentanal (213), various reaction conditions were modified, including temperature ( 0 to $\left.40{ }^{\circ} \mathrm{C}\right)$, time (30 min to overnight) and solvent (THF or DME).
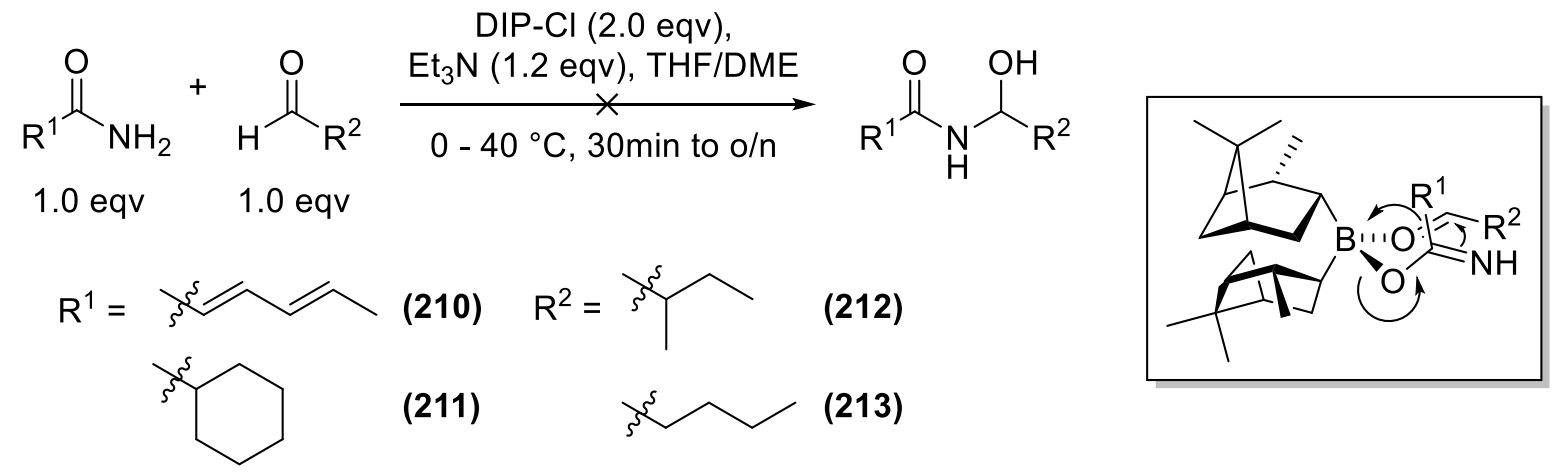

Scheme 5.3: Aza-aldol reaction with DIP-Cl to $N$-acyl hemiaminal.

Model reactions with sorbamide (210) and $n$-pentanal (213) were carried out in THF, but starting material remained after reacting for up to $60 \mathrm{~h}$ at toom temperature (Scheme 5.3). It was noted that sorbamide (210) has very low solubility in THF. Sonication, heating and changing the solvent to DME all failed to produce the required $N$-acyl hemiaminal. Attention was then turned to models similar to Kiren's, cyclohexanecarboxamide (211) and 2methylbutyraldehyde (212). In Kiren's procedure, a $30 \mathrm{~min}$ reaction at $0{ }^{\circ} \mathrm{C}$ was sufficient to carry most of the reactions to completion. ${ }^{6}$ However, in this study, TLC analysis at 30 min showed the presence of both starting materials, and in the ${ }^{1} \mathrm{H}$ NMR spectrum of the aliquot removed and quenched after $30 \mathrm{~min}$, the signature hemiaminal signal (doublet of doublets at around $5.0 \mathrm{ppm}$ ) was not observed. Furthermore, aliquots removed at $15 \mathrm{~min}$ intervals during the first hour and then hourly for 3 hours displayed no observable change from the reaction mixture at $\mathrm{t}=0 \mathrm{~min}$. With commercial (-)-DIP-Cl and an overnight reaction time, aldehyde signal nearly all disappeared and two interesting doublets at around $5.0 \mathrm{ppm}$ with coupling 
constants 4.2 and $5.1 \mathrm{~Hz}$ were observed (Figure 5.2). Unfortunately, this material was lost during column chromatography, and the eluent after flushing the column with ethyl acetate contains mostly isopinocampheol.

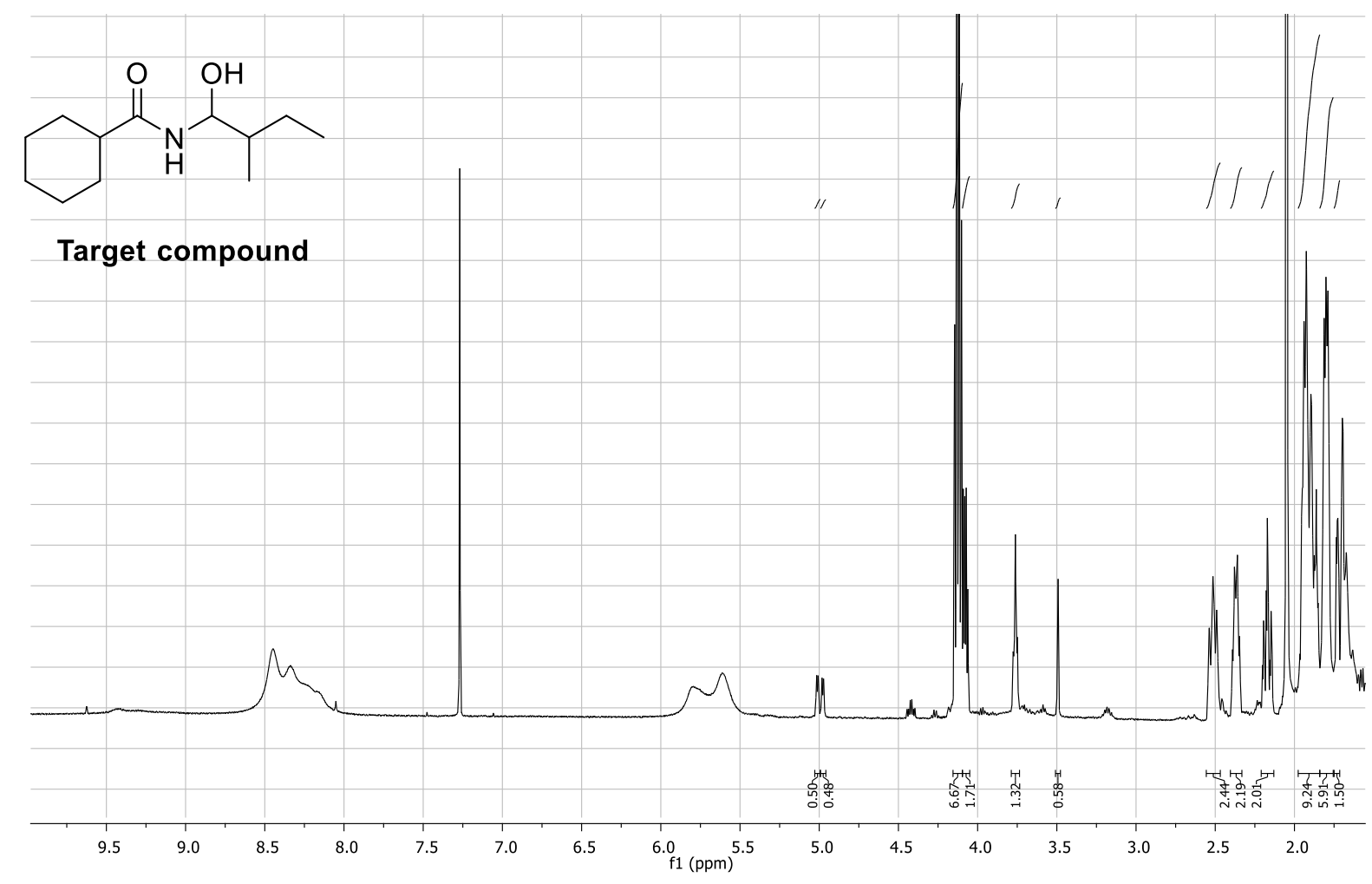

Figure 5.2: ${ }^{1} \mathrm{H}$ NMR spectrum $(500 \mathrm{MHz})$ of the crude mixture from a model aza-aldol reaction of 211 with 212.

Although the compound with interesting-looking ${ }^{1} \mathrm{H}$ NMR signals was lost during column chromatography, further exploration of this reaction was undertaken on substrates 211 and 212. Interestingly, conducting the work-up with distilled water produced a different result to that obtained with hydrogen peroxide and $\mathrm{pH} 7$ buffer. Theoretically, the purpose of hydrogen peroxide is only to facilitate the purification by oxidatively hydrolyzing the boronate ester intermediate to produce boric acid and isopinocampheol. While the result of the hydrogen peroxide work-up was not encouraging, with the water-only work-up, a dd at $5.18 \mathrm{ppm}$ in the ${ }^{1} \mathrm{H}$ NMR spectrum of the crude mixture with coupling constants of 6.2 and $6.8 \mathrm{~Hz}$ was observed. This signal is comparable with the oxymethine signal reported for 1-hydroxyl-1cyclohexylmethyl hexamide (dd at $5.06 \mathrm{ppm}, J=7.8,7.5 \mathrm{~Hz}$ ). ${ }^{6}$ After column chromatography, a small amount of a promising-looking product was obtained in impure form $(<5 \sim 9 \%$ yield $)$. The signal at $5.18 \mathrm{ppm}$ appeared as a triplet with $J$ value of $6.1 \mathrm{~Hz}$, and correlated to the signals 
at 6.01 and $3.56 \mathrm{ppm}$, which could be the amide proton and the hydrogen bonded alcohol, respectively (Figure 5.3). An aldehyde signal with identical chemical shift (9.74 ppm) to that of aldehyde 212 was observed, which was not present in the ${ }^{1} \mathrm{H}$ NMR spectrum of the crude reaction mixture before purification. This suggests decomposition of the product on silica, which contradicts Kiren's results. The minor signals near the multiplet at $3.56 \mathrm{ppm}$ could be resulted from other stereoisomers in the mixture. However, full characterization was never achieved, due to decomposition and the low quantity of material hampering efforts to purify it.

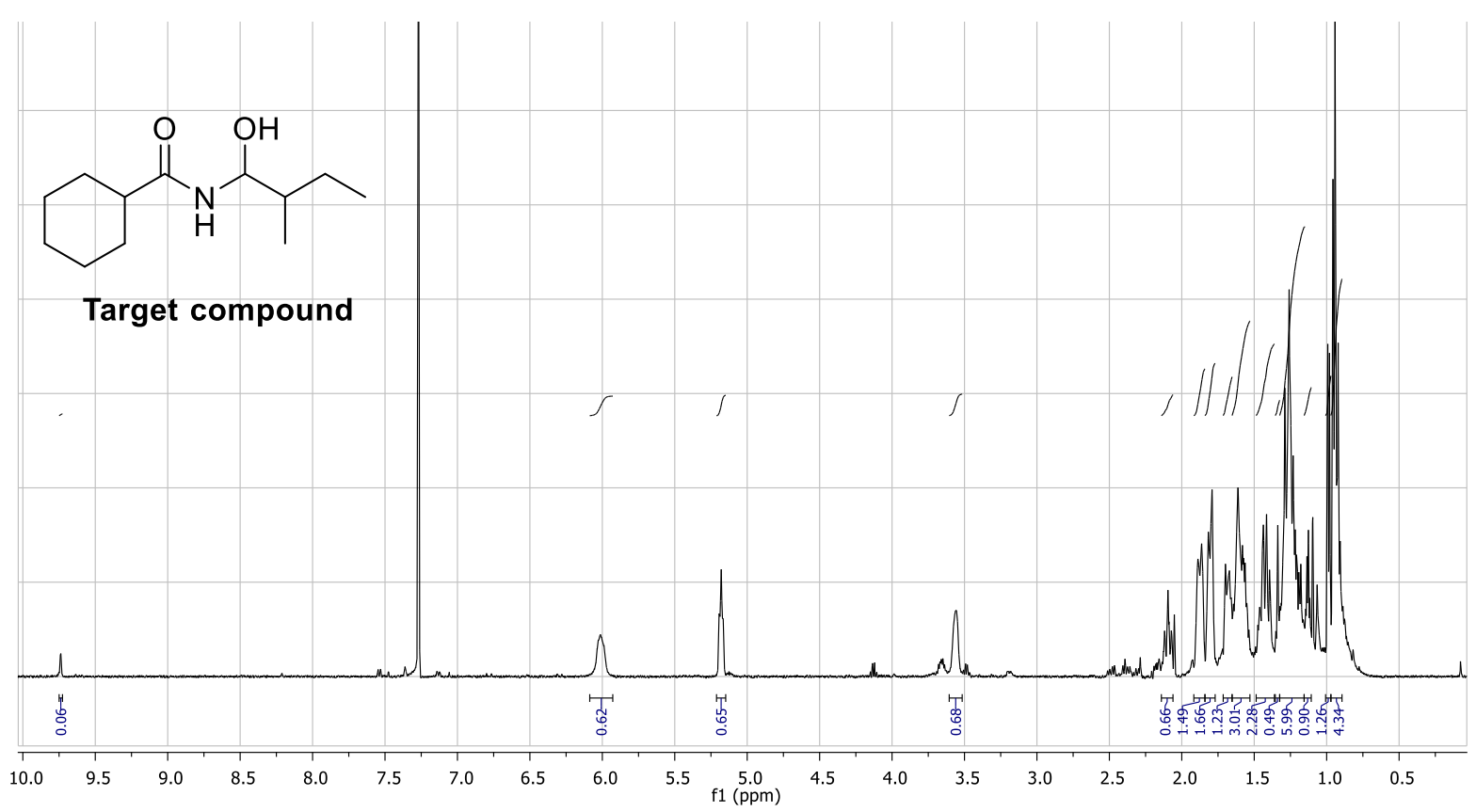

Figure 5.3: ${ }^{1} \mathrm{H}$ NMR spectrum $(500 \mathrm{MHz})$ of the promising product from model $N$-aldol reaction of 211 with 212.

A proposal of a hydrogen bonding network in oxygenated $\mathrm{N}$-acyl hemiaminals, including zampanolide (19) was reported by Porco and Troast (Figure 5.4). ${ }^{11}$ Based on their calculation, this system could contribute to the stability of zampanolide (19). ${ }^{11}$ Porco and Troast also reported that simple $N$-acyl hemiaminals decomposed on the acidic silica gel, and suggested using neutral aluminum oxide for chromatography as a substitute purification method. ${ }^{11}$ 


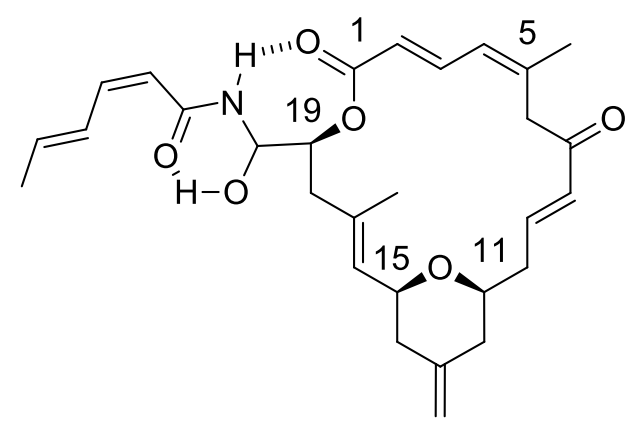

Figure 5.4: Porco's proposed hydrogen bonding network.

New model substrates were planned to better mimic the structure in (-)-zampanolide (19). A couple of aldehyde substrates were proposed that would enable the hydrogen bonding network in product. One is the $\alpha$-acetoxy aldehyde (214), which would lead to a similar $O$-acylated $\alpha$ hydroxy- $N$-acyl hemiaminal (215) system to that in zampanolide (19) (Scheme 5.4, eq. 1). However, aldehydes are often accessed by reduction of esters or oxidation of alcohols, so the

1)<smiles>[R]C([NH3+])=O</smiles><smiles>[R]C(=O)OC([R])C=O</smiles>
214

2)<smiles>[R]C([NH3+])=O</smiles><smiles>[R]C(O)C=O</smiles>

216<smiles>[R]C(=O)OC([R2])C(O)N1COCC1[R]</smiles><smiles></smiles><smiles></smiles>

Scheme 5.4: Model aldehydes $\mathbf{2 1 4}$ and 216 that enable double hydrogen bonding.

presence of the acetate group would require selective reduction, selective acetylation or other convoluted approaches. Another model is the $\alpha$-hydroxy aldehyde (216), which would produce $\alpha$-hydroxy- $N$-acyl hemiaminal 217 upon aza-aldol reaction (eq. 2). The $\alpha$-hydroxy aldehyde model 216 is easier to synthesize, and the product is also capable of forming a hydrogen bonding network, but it would produce a five-membered ring instead of the seven membered ring in the zampanolide system. Both the secondary amide $\mathrm{NH}$ and hydroxyl $\mathrm{OH}$ in 217 consist of hydrogen bonding donor and acceptor, so an equilibrium was expected, which could improve the stability. Thus, $\alpha$-hydroxy aldehyde $\mathbf{2 1 6}$ would be tested first. 
A suitable aldehyde substrate would ideally meet the following criteria: convenient to prepare; stable and easy to handle; easy to be detected by TLC analysis. (S)-2-Hydroxy-3phenylpropanal (218) was chosen for this purpose, which was expected to be stable, UV-active, and available through a three-step preparation from the cheap amino acid $(L)$-phenylalanine (219) (Scheme 5.5). The first two steps, hydroxylation and methylation proceeded smoothly with moderate yields. The Sandmeyer-type reaction used to convert the amine to an alcohol was related to that previously discussed during the synthesis of the C9-C15 natural fragment in chapter 3 , although that was carried out in the presence of bromine at below $-5^{\circ} \mathrm{C}$ to achieve bromination. In this case, the increased temperature $\left(0^{\circ} \mathrm{C}\right)$ led to the production of the hydroxylated product $\mathbf{2 2 0}$. The subsequent reduction of methyl ester $\mathbf{2 2 0}$ was incomplete and produced a mixture of inseparable compounds.

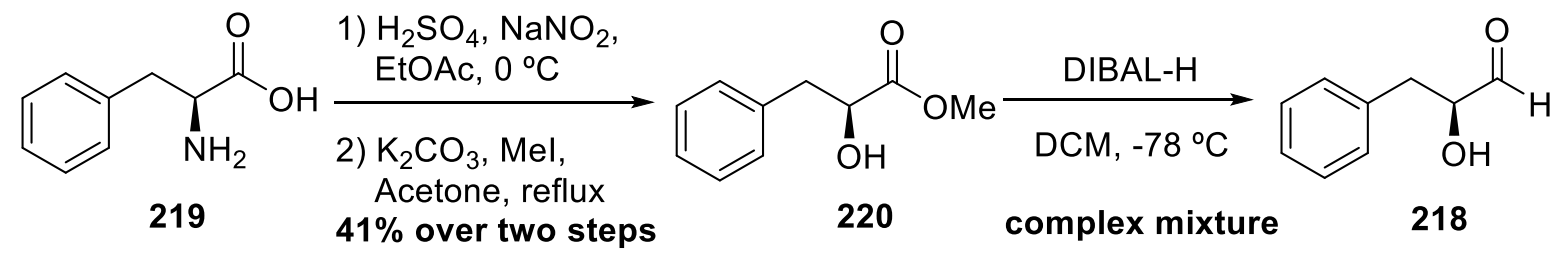

Scheme 5.5: Synthesis of the model aldehyde 218.

The ${ }^{1} \mathrm{H}$ NMR spectrum of the inseparable mixture showed a very complicated oxygenated $\mathrm{C}-$ $\mathrm{H}$ region between 3.5 and $5.5 \mathrm{ppm}$, with abundant signals. The desired aldehyde signal was also observed, but far weaker than the combined signals in the oxygenated region. This problem was believed to be the result of dimerization of $\mathbf{2 1 8}$ to afford various hemiacetals, which can proceed through two different pathways, resulting in both five- and six-membered heterocycles, 221 and 222, respectively (Scheme 5.6). The existence of multiple stereocenters in this mixture, together with different ring sizes, made the mixture impossible to purify and properly characterize, therefore another model substrate was explored. 


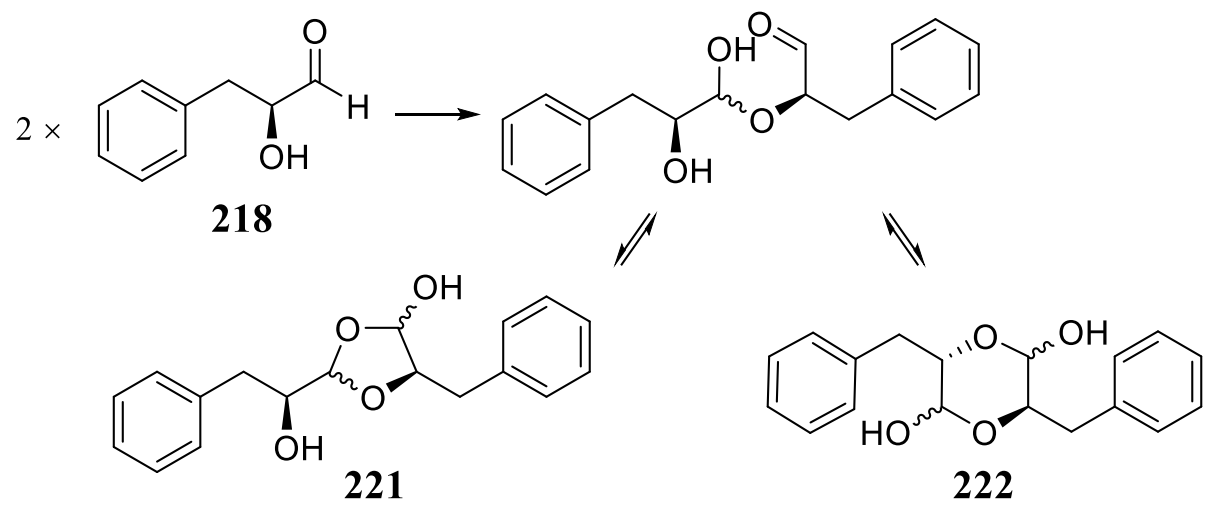

Scheme 5.6: Proposed dimerization of model aldehyde 218.

Protection of the $\alpha$-hydroxy group as either an ester or a carbonate was then proposed, as both could serve as a hydrogen bond acceptor in stabilisation of the $N$-acyl hemiaminal. Compared to acetyl protection, a carbonate would be more stable in the reduction of the substrate to afford the aldehyde, and can be easily accessed using the already synthesized intermediate $\mathbf{2 2 0}$. Therefore, tert-butyl carbonate (Boc)-protection was attempted on 220, and the corresponding aldehyde 223 was produced by DIBAL-H reduction of 224 (Scheme 5.7). The low yield (38\%) of this reduction is a result of incomplete reduction, which indicated poor quality of DIBALH. Only ${ }^{1} \mathrm{H}$ NMR and HRMS data were collected to support the characterization of 223.

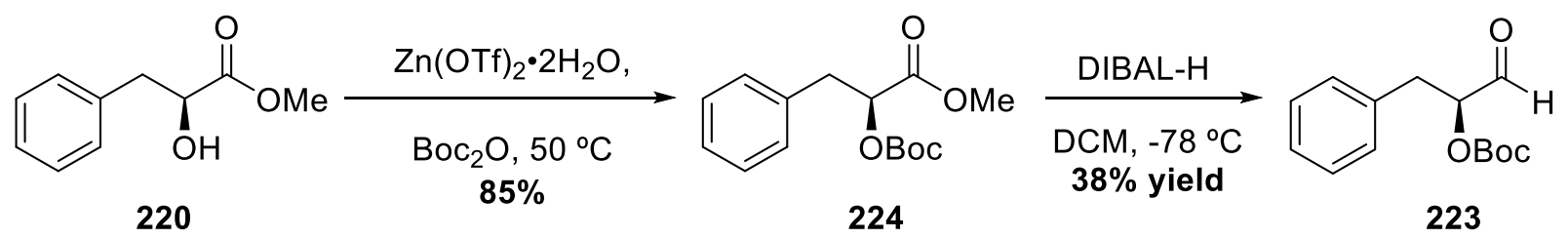

Scheme 5.7: Synthesis of model aldehyde 223.

A boron reagent-promoted aza-aldol reaction was then tested with substrates $\mathbf{2 2 3}$ and sorbamide (210) using commercial (-)-DIP-chloride. Dichloromethane was used as the solvent to achieve good solubility of the aldehyde and amide (Scheme 5.8). Unfortunately, this reaction failed to proceed. After monitoring the reaction for 60 hours, TLC analysis still indicated the presence of the aldehyde, and the crude product mixture contained only the starting materials and pinene-like compounds. This failure might be caused by the bulkiness of the Boc group, which could sterically hinder the reaction. 


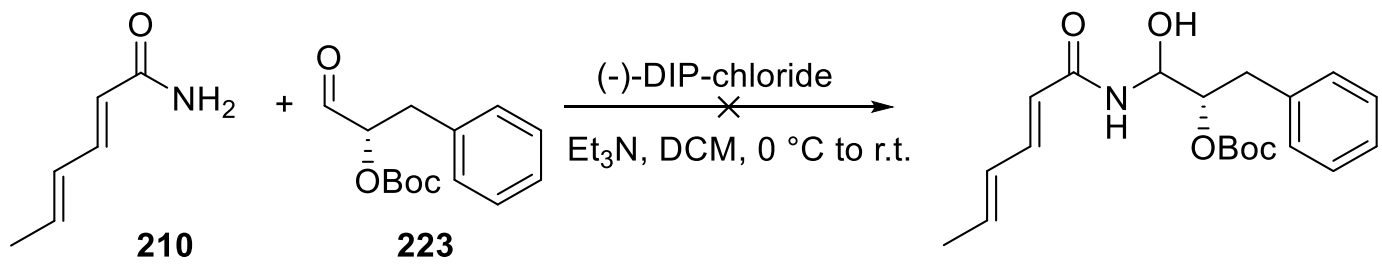

Scheme 5.8: Aza-aldol reaction of aldehyde 223 and sorbamide (210).

The synthesis of the $\alpha$-acetoxy aldehyde $\mathbf{2 2 4}$ was also investigated, as the relatively small size of the acetyl protecting group would hopefully not cause steric inhibition of the aza-aldol reaction. This acetylated substrate $\mathbf{2 2 4}$ cannot be synthesized via the same route as before, because of the difficulty in differentiating the acetoxy from the methyl ester to be reduced. An oxidative addition of acetic acid to 3-phenylpropanal (225) was reported to produce the desired $\alpha$-acetyloxy aldehyde 224 using tetrabutylammonium iodide (TBAI) and tert-butyl hydroperoxide (TBHP) (Scheme 5.9). ${ }^{12}$ The combination of TBAI and TBHP has been found to be useful in a variety of bond forming reactions. ${ }^{13}$ The mechanism of the reaction is believed to go through a radical intermediate, promoted by the active species hypoiodite $\left(\left[\mathrm{R}_{4} \mathrm{~N}\right]^{+}[\mathrm{IO}]^{-}\right)$ or iodite $\left(\left[\mathrm{R}_{4} \mathrm{~N}\right]^{+}\left[\mathrm{IO}_{2}\right]^{-}\right.$generated by oxidation of TBAI by TBHP. ${ }^{13}$ However, when this reaction was performed in this work, the product obtained was not the desired 224.

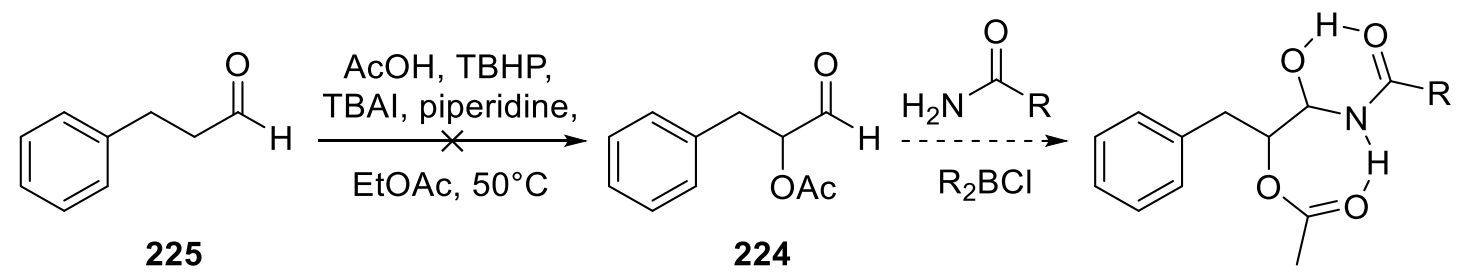

Scheme 5.9: Proposed substrate 224 for model study of aza-aldol reaction.

The ${ }^{1} \mathrm{H}$ NMR spectrum of the purified product obtained from this attempted $\alpha$-oxidation showed a 1:4:10 ratio between aldehyde, phenyl and benzylic signals, which suggested dimerization of starting material 225 (Figure 5.5). However, the signal at $3.59 \mathrm{ppm}$ was thought to be too high field to be the oxymethine signal in the dimerization product $\mathbf{2 2 6}$ via an aldol reaction. In addition, the peak at $3.59 \mathrm{ppm}$ correlated to a carbon signal at $34.4 \mathrm{ppm}$, and thus was not oxygenated. Due to time constraints, the assignment of the unknown by-product and the synthesis of model aldehyde $\mathbf{2 2 4}$ were not pursued further. However, further 
investigation of the reaction could be attempted and, if unsuccessful, other procedures for oxidative $\alpha$-acetoxylation of aldehydes are also available. ${ }^{14,15}$

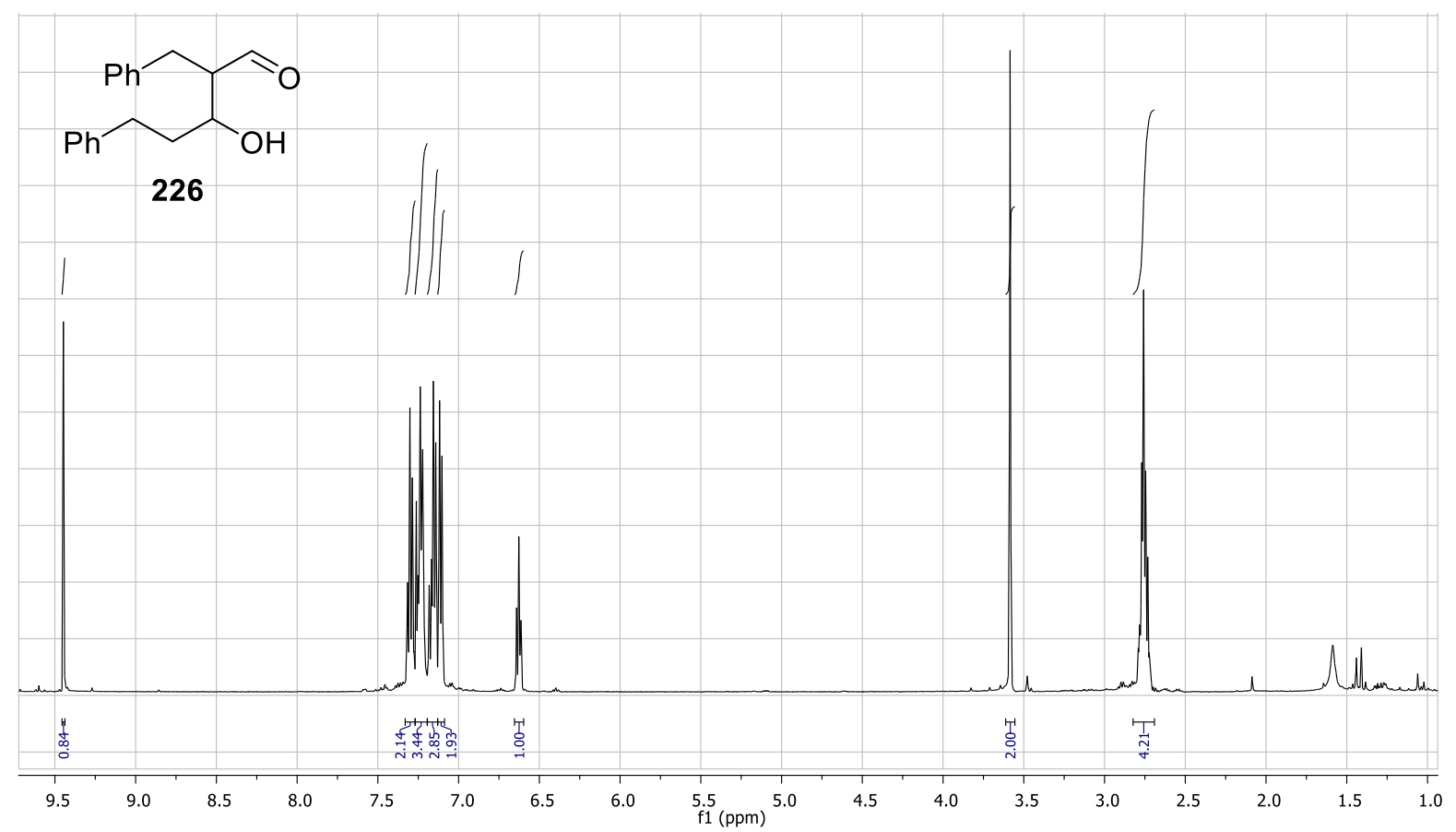

Figure 5.5: ${ }^{1} \mathrm{H}$ NMR spectrum of the product obtained from the attempted oxidative addition.

After the initial exploration, Ghosh's attempt to use boron reagent-promoted aza-aldol reaction in (-)-zampanolide (19) synthesis was published. ${ }^{16}$ In the reported work, achiral boron reagent, dicyclohexylboron chloride $\left(\mathrm{Cy}_{2} \mathrm{BCl}\right)$ was used. A couple of $\mathrm{Cy}_{2} \mathrm{BCl}$-promoted model reactions were successfully carried out (Scheme 5.10), but when applying this method to the addition of (Z,E)-hex-2,4-dienamide (45) to (-)-dactylolide (20), decomposition was observed. Thus, the viability of using $\mathrm{R}_{2} \mathrm{BCl}$ in the synthesis of the natural product and analogues is questionable.
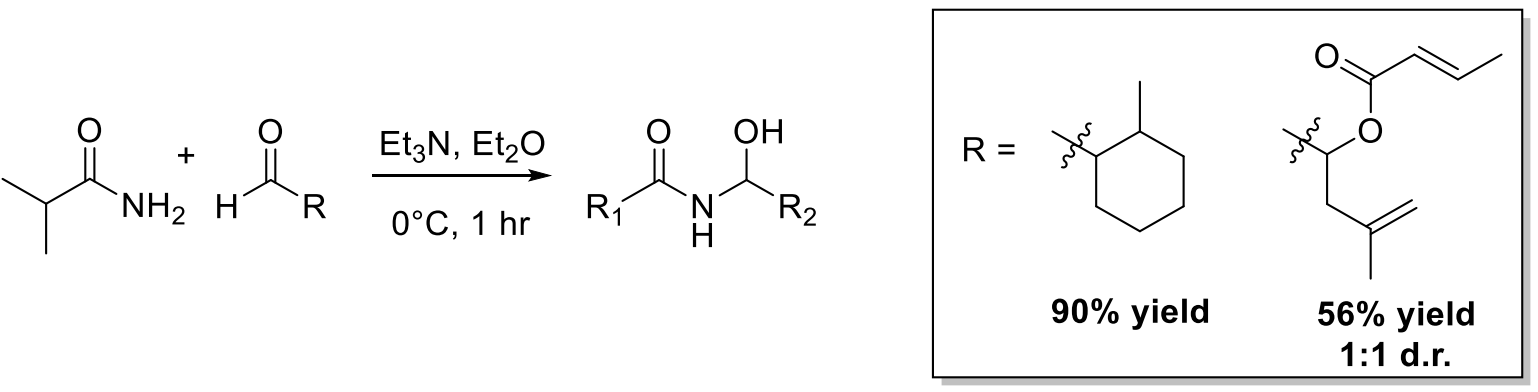

Scheme 5.10: Ghosh's $\mathrm{Cy}_{2} \mathrm{BCl}$-catalyzed aza-aldol model reactions. 


\subsection{Model study of C20 oxidation}

The conversion of the C20-hydroxyl to an aldehyde (228) was done exclusively with DessMartin periodinane (DMP) in past dactylolide (20) and zampanolide (19) syntheses. ${ }^{17-24}$ Product 206 from the model Bestmann ylide cascade was used to test this oxidation of alcohol at C20. The PMB group was deprotected selectively with the well-established oxidative deprotection method of DDQ and $\mathrm{H}_{2} \mathrm{O}$ (Scheme 5.11). ${ }^{25}$ The best yield of 227 (95\%) was achieved when the reaction mixture was directly subjected to column chromatography without aqueous work-up. The oxidation of $\mathbf{2 2 7}$ did not go smoothly, so a number of oxidation methods were tested. The precedented DMP and the related oxidant IBX resulted in complicated mixtures, which showed multiple signals in the aldehyde region of the ${ }^{1} \mathrm{H}$ NMR spectrum, and potentially also contained starting material and structurally similar compounds. At least eight multiplets with various intensities were observed in the oxymethine region (4.8 to $5.4 \mathrm{ppm}$ ). Attempts to separate the major aldehyde product by column chromatography failed. Apart from the similar polarity amongst the products, some components also streaked on the TLC plate, typical of carboxylic acids, but DMP and IBX are not known for over-oxidation of alcohols. Swern and Parikh-Doering methods did not promote any oxidation and starting material was recovered. The last method attempted was TEMPO/BAIB oxidation, which is quite different from all the above methods. It proceeds via a catalytic cycle, whereby TEMPO goes through a redox sequence assisted by BAIB in order to oxidize the alcohols to aldehydes. ${ }^{26}$ Unfortunately, TEMPO/BAIB oxidation produced the over-oxidized carboxylic acid 229 quantitatively. After column chromatography, significant line-broadening was observed by ${ }^{1} \mathrm{H}$ NMR spectroscopy of 229, which may be a sign of decomposition. Therefore, some characterization data for acid 229 were obtained using the crude product prior to purification. The desired molecular ion [M$\mathrm{H}]^{-}$was found in large abundance using mass spectrometry, and the broad hydroxy stretch was observed by IR spectroscopy with the carboxylic acid $\mathrm{C}=\mathrm{O}$ stretch at $1709 \mathrm{~cm}^{-1}$ also evident. In the ${ }^{1} \mathrm{H}$ NMR spectrum, apart from the disappearance of the oxymethylene signal, very little change was evident in chemical shift and multiplicity. Aldehyde-like compounds were never observed, either by NMR spectroscopy or by TLC analysis during the reaction. The results of these oxidation methods are not very well understood. The hydroxyl group in our substrate 227 may be participating in hydrogen bonding with the ester carbonyl. This interaction may be disturbed in the precursor of dactylolide by the steric hindrance of the ring, but strong enough in the model substrate to interfere with the oxidative reagents. Although the oxidation results 
are very discouraging, we are still confident of this late-stage oxidation in the real system, because of the abundant precedence in the literature.

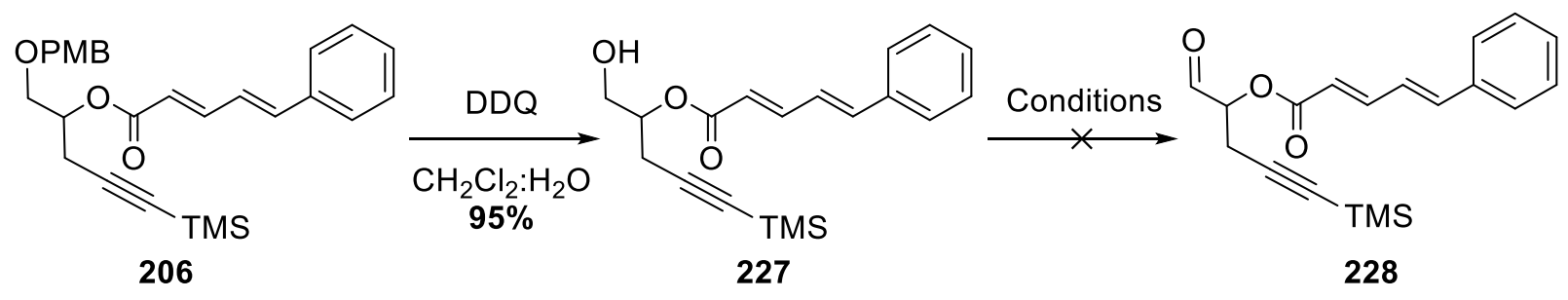

\section{Conditions: \\ 1) Swern oxidation \\ 2) Parikh-Doering oxidation \\ 3) Dess-Martin periodinane \\ 4) IBX \\ 5) TEMPO/BAIB}

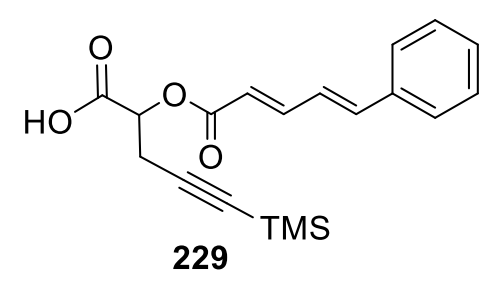

229

Scheme 5.11: Model oxidation of alcohol at C20.

\subsection{Asymmetric alkynylation of aldehydes for C15-C16 connection}

Alkynylation of carbonyls has often been used in total syntheses to construct the versatile propargylic alcohol motif, for which metalated alkynylides are commonly used as the nucleophiles. Lithium and magnesium alkynylides are readily formed by treating terminal alkynes with BuLi and alkyl Grignard reagents, respectively, but they are harsh nucleophilic bases and have high reactivity towards a large variety of functional groups, thus are unsuited for reaction with complicated substrates. The formation of zinc alkynides by treating terminal alkynes with Et 2 Zn has been known since the mid-1960's, ${ }^{27}$ and the use of zinc alkynides in the addition to carbonyls was subsequently explored in the past few decades. Although these reactions are slow, the mild reaction conditions and compatibility with a range of functional groups are favored in organic synthesis. With the assistant of chiral catalysts, asymmetric alkynylations can be achieved. A number of methods involving dialkylzinc were developed, including Trost's ProPhenol/Me $2 \mathrm{Zn}$ and the BINOL/Ti(IV)/Et 2 Zn methods. ${ }^{28}$ 
As discussed in section 1.7, Trost's ProPhenol-catalyzed alkynylation can achieve excellent yields and ee's between propiolate, aromatic and the sensitive $\alpha, \beta$-unsaturated aldehydes (see Scheme 1.22). ${ }^{29}$ The success with propiolate was attributed to the interaction of the Lewis basic carbonyl with ProPhenol-bound zinc. The addition of triphenylphosphine oxide (TPPO) was found to compensate for the absence of a Lewis basic moiety in the alkyne substrates, which further expand the scope to aliphatic alkynes. However, with aliphatic alkynes and enolizable aldehydes such as $\mathbf{2 3 0}$ and 231, increased catalytic loading and prolonged pre-mixing before the addition of the aldehyde are required to achieve a moderate yield (69\%) and enantioselectivity (67\% ee) (Scheme 5.12). ${ }^{29,30}$

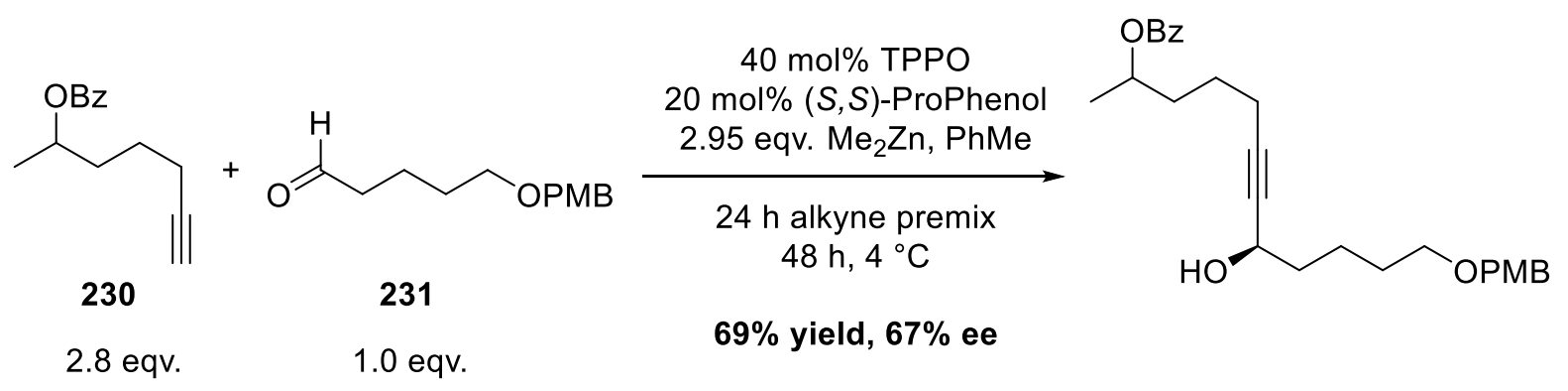

Scheme 5.12: Prophenol-catalysed alkynylation of aliphatic alkyne 230 and aldehyde 231.

In the $\mathrm{Et}_{2} \mathrm{Zn} / \mathrm{Ti}(\mathrm{IV}) / \mathrm{BINOL}$ system published by $\mathrm{Pu}$, the alkynylzinc was formed by heating alkyne and diethylzinc in toluene at reflux for 5 hours (Scheme 5.13) ${ }^{31}$ At the same time, a very similar procedure was published by Chan, whereby treating an alkyne with dimethylzinc at room temperature in THF for 18 hours afforded the alkynylzinc species. ${ }^{32}$ The Ti(IV)/BINOL-catalyzed alkyne addition to aldehydes achieved good yields and stereoselectivity in both cases. The reflux condition in Pu's method limits its compatibility with low boiling point and heat sensitive substrates, so Pu and You explored ways to carry out the alkynylzinc formation at room temperature while maintaining high stereoselectivity. Additives such as hexamethylphosphoramide, $N$-methylimidazole and dicyclohexylamine were found to be efficient, and the scope of this method was further extended to aliphatic alkynes and aldehydes at the same time. ${ }^{33-35}$ Although these above methods are efficient and enantioselective, the use of the highly pyrophoric dialkylzinc introduces environmental and safety hazards, and requires extravagant care to exclude any moisture. Therefore, the formation of $\mathrm{Et}_{2} \mathrm{Zn}$ in situ was explored by Pu's group. It was found that with the assistance of $\mathrm{Ti}(\mathrm{O} i \mathrm{Pr})_{4}$ and BINOL, the alkynylzinc complex can be formed from iodoethane, zinc powder and alkyne 
in THF at room temperature, which can then react with aromatic aldehydes in diethylether with high enantioselectivity (Scheme 5.13). ${ }^{36}$ Optimization of this facile alkynylation method by $\mathrm{Pu}$ led to conditions involving 4 equivalents of alkyne, 6 equivalents of zinc powder, 12 equivalents of iodoethane and stoichiometric amount of $\mathrm{Ti}(\mathrm{O} i \mathrm{Pr})_{4}$, thus it is not economical or environmentally friendly. With complex substrates such as those required for zampanolide (19) synthesis, further optimization to reduce the amount of reagents, especially the alkyne and $\operatorname{Ti}(\mathrm{O} i \mathrm{Pr})_{4}$ required, would be prudent.
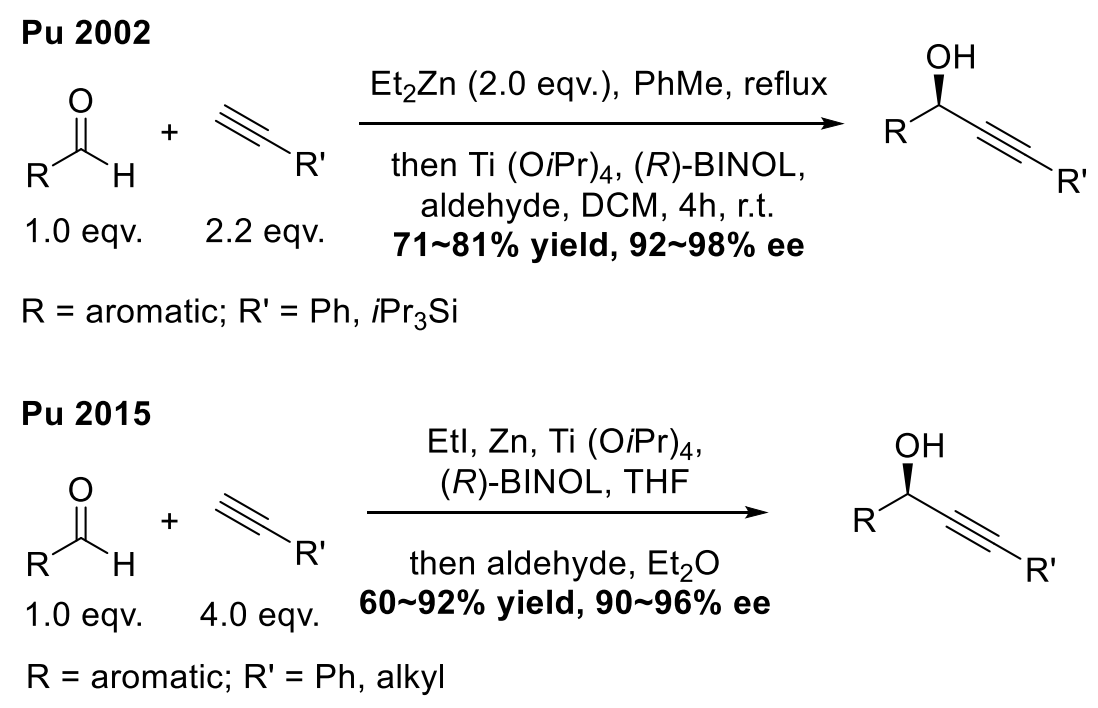

Scheme 5.13: Pu's development of Ti (IV)/BINOL-catalyzed asymmetric alkynylation.

Another efficient way to produce zinc alkynylides was discovered by Carreira. ${ }^{37}$ With a catalytic amount of zinc triflate and amine base, the zinc alkynylides can readily form from aliphatic, aromatic, mono-silylated and allylic alkynes. The nucleophilic attack of Zinc alkynylides was reported with nitrones, but examples of aldehyde, ketone and imine were also given. ${ }^{37}$ Further investigation established the use of $N$-methylephedrine as an effective director for asymmetric alkynylation to aldehydes, ${ }^{38}$ and that the inert atmosphere and exclusion of moisture is not necessary for this method. ${ }^{39}$ Differing from the methods above, aliphatic aldehydes provide better yields than aromatic aldehydes under Carreira's conditions, because Cannizaro reactions can occur with aromatic aldehydes ${ }^{38}$ Despite this, Carreira's $\mathrm{Zn}(\mathrm{OTf})_{2} / \mathrm{N}$ methylephedrine protocol has become the most commonly used asymmetric alkynylation method in natural product synthesis, and good yields and stereoselectivity are often achieved for complicated natural product fragments. ${ }^{40-43}$ For example, it was used for a late-stage connection in the synthesis of (+)-10-epi-latrunculol, whereby the product was prepared with 
the desired configuration in $95 \%$ yield (Scheme 5.14). ${ }^{43}$ It was noted during the optimization process that it is essential to thoroughly dry zinc triflate prior to use, which contradicts Carreira's finding that the presence of moisture and oxygen did not interfere with the alkynylation. ${ }^{39}$
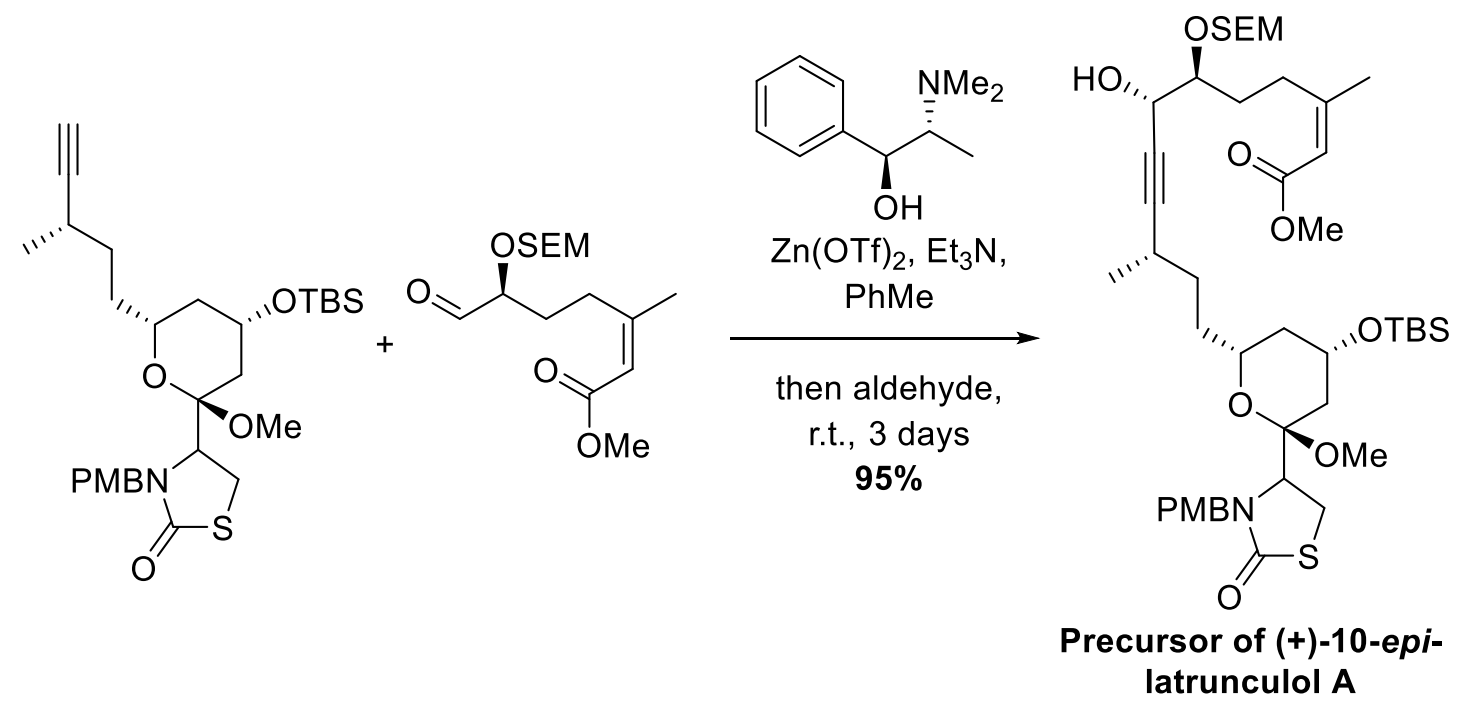

Scheme 5.14: Asymmetric alkynylation in the synthesis of (+)-10-epi-latrunculol A.

Unfortunately, ephedrine-derived compounds are strictly controlled substances in New Zealand and, even with a lengthy and costly application process, access is most likely not granted. ${ }^{44}$ An alternative method using zinc alkynylide generated by zinc triflate was reported by Xiong, which involves the use of a different chiral ligand $(1 S, 2 S)$-232 derived from $(1 S, 2 S)$ 2-amino-1-(4-nitrophenyl)-1,3-propanediol (233) (Scheme 5.15). Unlike ephedrinederivatives, the precursor (+) and (-)-233 are commercially accessible and available in New Zealand. Therefore, this method was tested in the present study. During the literature research, discrepancy was found with methods involving the use of zinc triflate. Apart from the dryness of zinc triflate as mentioned before, the particle size and surface morphology can also affect the outcome of this alkynylation, but insufficient studies have been conducted to fully understand this phenomenon. ${ }^{45}$ 


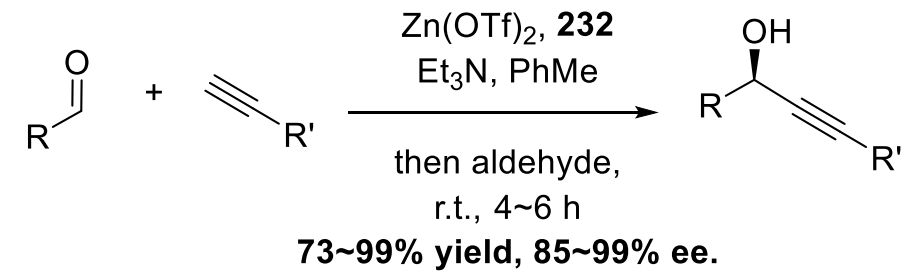

$\mathrm{R}=$ alkyl, phenyl; $\mathrm{R}^{\prime}=$ phenyl, alkyl, silyl

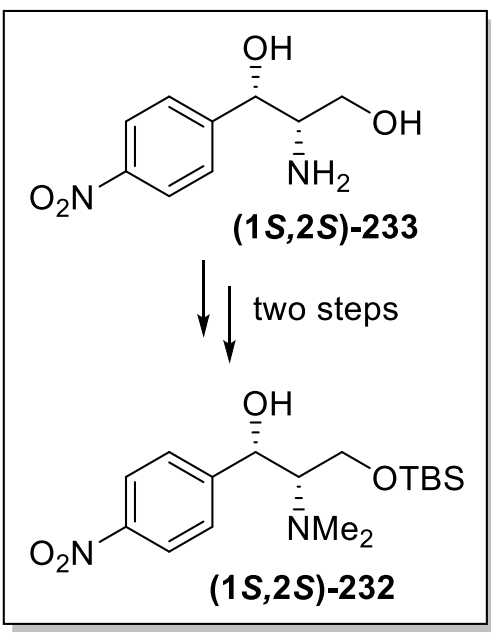

Scheme 5.15: Xiong's Zn(OTf $)_{2}$ method using chiral ligand 232.

Indium (III) has also been used successfully to facilitate asymmetric alkynylation, owing to its dual activating properties for aldehydes and alkynes. Shibasaki has developed a facile asymmetric alkynylation method involving In(III)/BINOL (Scheme 5.16). ${ }^{46}$ Good yields and selectivity are obtained, apart from the pairing of an enolizable aldehyde with an aliphatic alkyne. Shibasaki also tested the reaction of benzaldehyde and phenylacetylene in air and found no loss of yield or stereoselectivity.

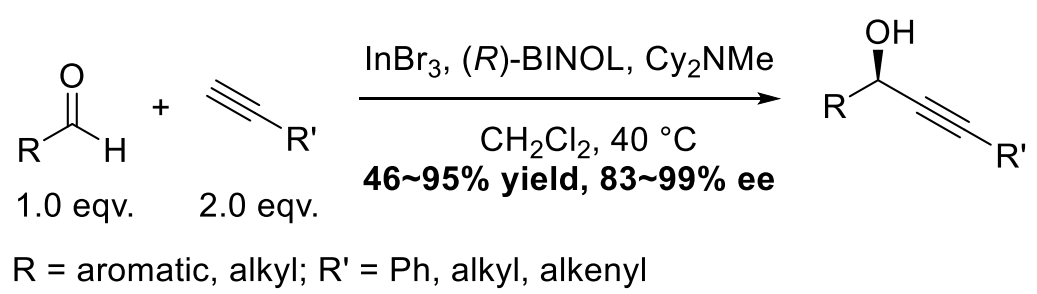

Scheme 5.16: Shibasaki's In(III)/BINOL alkynylation method.

In this study, the alkynylation was tested with model substrate $\mathbf{2 3 4}$ first, which was synthesized via Steglich esterification of alcohol 153 and cinnamic acid (Scheme 5.17). A few of the literature procedures for asymmetric aldehyde alkynylation were tested, including Carreira's non-stereoselective $\mathrm{Zn}(\mathrm{OTf})_{2} / \mathrm{EtNiPr}_{2}$ method $^{37}$ with either lab-made or commercial zinc triflate, Xiong's $\mathrm{Zn}(\mathrm{OTf})_{2}$ method with the accessible chiral ligand $\mathbf{2 3 2}^{47}$ and Trost's alkynylation using chiral ligand ProPhenol ${ }^{29}$. 


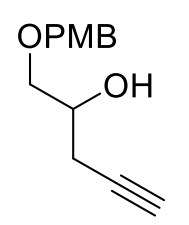

153

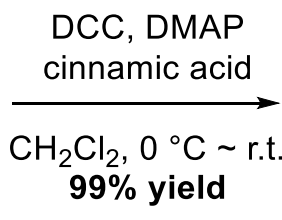

$\mathbf{9 9 \%}$ yield

Scheme 5.17: Synthesis of model substrate 234 for alkynylation.

Carreira's three articles describing the alkynylation methods contain three sets of reaction conditions. ${ }^{37-39}$ The non-stereoselective method was first reported for alkyne additions mainly to nitrones with one example of an aldehyde substrate. This method used a catalytic amount of $\mathrm{Zn}(\mathrm{OTf})_{2}(10 \mathrm{~mol} \%)$ and $i \operatorname{Pr}_{2} \mathrm{EtN}(25 \mathrm{~mol} \%)$ in dichloromethane. ${ }^{37}$ The subsequently developed asymmetric alkynylation to aldehydes also used catalytic amount of reagents (20 mol\% $\mathrm{Zn}(\mathrm{OTf})_{2}, 22 \mathrm{~mol} \%(+)-N$-methylephedrine, $\left.50 \mathrm{~mol} \% \mathrm{Et}_{3} \mathrm{~N}\right)$, but was carried out in toluene at $60^{\circ} \mathrm{C} .{ }^{38}$ Later, it was found that the reaction can be performed at room temperature in toluene, although its effectiveness was compromised by requiring stoichiometric amounts of $\mathrm{Zn}(\mathrm{OTf})_{2}$ (1.1 equiv.), (+)- $N$-methylephedrine (1.2 equiv.) and $\mathrm{Et}_{3} \mathrm{~N}$ (1.2 equiv.). ${ }^{39}$ Due to the poor availability of (+)- $\mathrm{N}$-methylephedrine, the non-stereoselective method was tested first, with catalytic and stoichiometric amounts of reagents on simple substrates phenylacetylene (235) and hexanal (236) as reported previously, using zinc triflate made by treating activated zinc powder with triflic acid (Scheme 5.18). ${ }^{48}$ No reaction was observed. Because discrepancies were present in reports of alkynylation reactions regarding the dryness and particle size of zinc triflate, the prepared zinc triflate was ground and dried under high vacuum at $140{ }^{\circ} \mathrm{C}$ overnight, but this did not make any improvement. ${ }^{39,45}$<smiles>C#Cc1ccccc1</smiles>

235

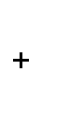

Conditions:

1) $\mathrm{Zn}(\mathrm{OTf})_{2}$ (10 mol\%, lab-made), EtNiPr 2 (20 mol\%), $\mathrm{CH}_{2} \mathrm{Cl}_{2}$, r.t., $20 \mathrm{~min}$, then aldehyde

2) $\mathrm{Zn}(\mathrm{OTf})_{2}$ (1.1 eqv, lab-made), $\mathrm{Et}_{3} \mathrm{~N}$ (1.2 eqv), PhMe, r.t., $20 \mathrm{~min}$, then aldehyde

Scheme 5.18: Non-stereoselective alkynylation reactions using lab-made $\mathrm{Zn}(\mathrm{OTf})_{2}$. 
Commercially available zinc triflate was then used in the alkynylation of 235 to 236 (Scheme 5.19). The initial experiment with a catalytic amount of zinc triflate and DIPEA in dichloromethane did not produce any product, only starting material was observed by TLC analysis and ${ }^{1} \mathrm{H}$ NMR spectroscopy after 6 hours at room temperature. Therefore, this mixture was concentrated, re-dissolved in toluene, and additional stoichiometric amounts of zinc triflate and triethylamine were added. After 15 hours at $60^{\circ} \mathrm{C}$, a small amount of the desired propargyl alcohol 237 was isolated (5\% yield). The propargylic functionality showed a characteristic proton signal at $4.6 \mathrm{ppm}$ and a carbon signal at $63.0 \mathrm{ppm}$, which are in agreement with literature values. The major products were the polymerized compounds derived from hexanal (236), which is likely to be caused by the concentration process to remove dichloromethane.

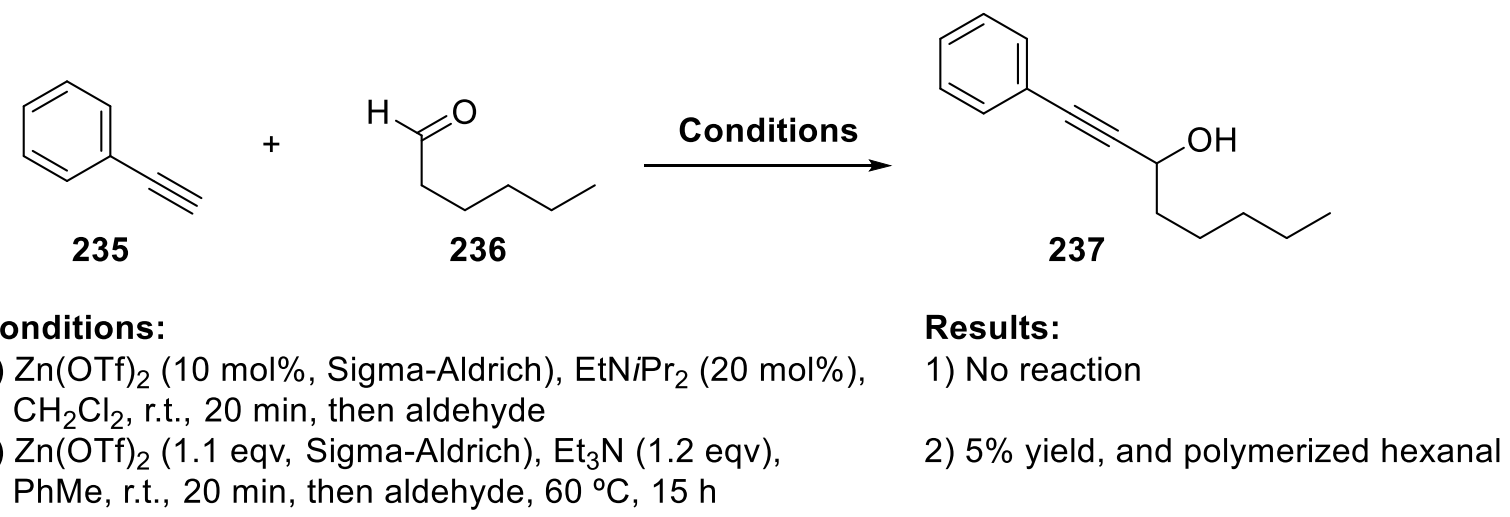

Scheme 5.19: Non-stereoselective alkynylation reactions using commercially available $\mathrm{Zn}(\mathrm{OTf})_{2}$.

At the same time, the chiral ligand $(1 R, 2 R)$-232 was prepared via two steps, $N$-methylation and silyl protection (Scheme 5.20). ${ }^{47}$ Because the required configuration in this project is opposite to that of Xiong's report using $(1 S, 2 S)$-232, $(1 R, 2 R)$-232 was prepared. The methylation of amines with aqueous formaldehyde and formic acid is a well-established method. ${ }^{49}$ During the reaction, the amine of $(1 R, 2 R)-\mathbf{2 3 3}$ was transformed to an imine or iminium with formaldehyde, which was then reduced by formic acid to form each of the two methyl groups, producing carbon dioxide as the by-product. ${ }^{50}$ This step produced the dimethylated amine $\mathbf{2 3 8}$ in an excellent $94 \%$ yield. The following selective mono-silyl protection only reached a moderate $61 \%$ yield of $(1 R, 2 R)-\mathbf{2 3 2}$. Only $3 \%$ of the diprotected product $\mathbf{2 3 9}$ was isolated, and the rest of the mass was thought to be unreacted starting material. A species with higher polarity was observed by TLC analysis, but was not recovered. 


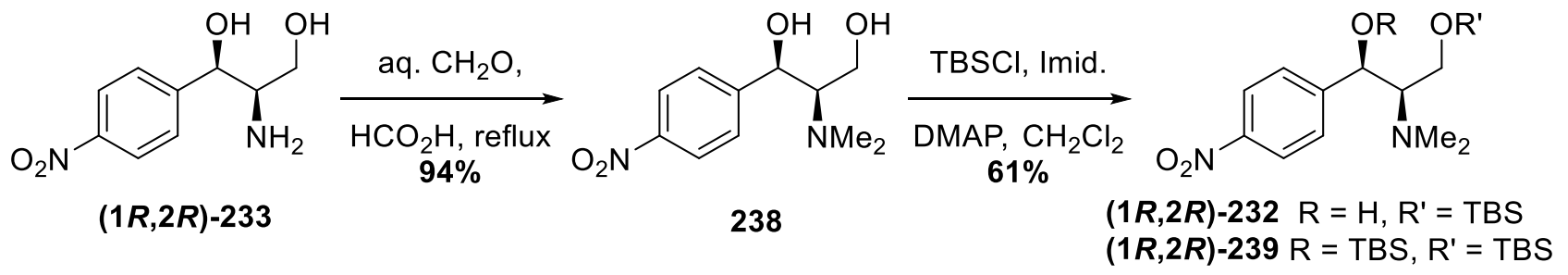

Scheme 5.20: Two-step preparation of chiral ligand $(1 R, 2 R)-\mathbf{2 3 2}$.

The asymmetric alkynylation using Xiong's chiral ligand $(1 R, 2 R)-\mathbf{2 3 2}$ was attempted on the model substrates 234 and 177 (Scheme 5.21), despite the poor result obtained with the nonstereoselective alkynylation performed with similar reagents. It has been report that the amino alcohol ligand $(1 R, 2 R)$-232 may be essential for the reactivity as well as the stereoselectivity. ${ }^{51}$ With stoichiometric amount of reagents, this reaction was first performed at room temperature. After $14 \mathrm{~h}$, no reaction was observed, thus the reaction mixture was heated up to $60{ }^{\circ} \mathrm{C}$. However, starting material remained after four days at $60{ }^{\circ} \mathrm{C}$. Further investigation is required.<smiles>C#CCC(CO[Na])OC(=O)/C=C/c1ccccc1</smiles>

234

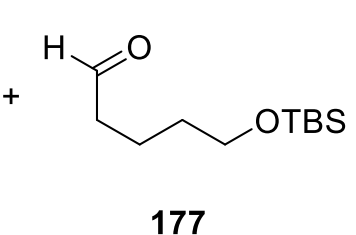

177

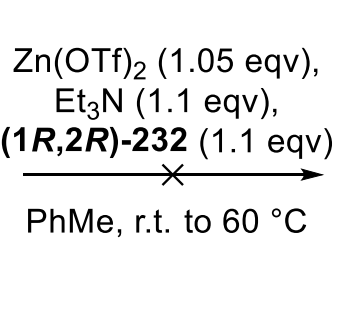

Scheme 5.21: Attempted Xiong's asymmetric alkynylation on model substrates 234 and 177.

Trost's alkynylation involving the use of ProPhenol was then attempted with substrates 234 and 177 (Scheme 5.22). Due to difficulty in obtaining dimethylzinc, diethylzinc was used instead. Longer premixing of alkyne with diethylzinc, TPPO and $(R, R)$-ProPhenol was applied to compensate for the potentially lower activity of diethylzinc. This air-sensitive reaction was initially carried out as a bench-top reaction under nitrogen atmosphere. All glassware was dried under high vacuum with heating, and the non-volatile reagents were dried under high vacuum. No reaction was observed, possibly due to the presence of adventitious water or air. Therefore, this reaction was next carried out in a glovebox. The alkyne 234 was premixed for $64 \mathrm{~h}$, and the resulting alkynylzinc was allowed to react with the aldehyde $\mathbf{1 7 7}$ for $24 \mathrm{~h}$. To our delight, 
the desired product $\mathbf{2 4 0}$ was obtained in high yield (76\%) after a single column chromatography operation.

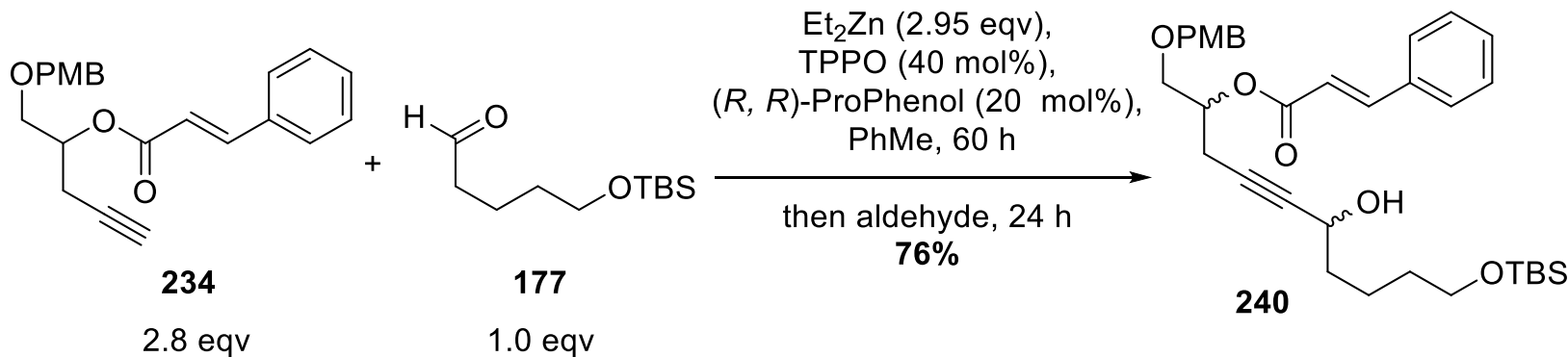

Scheme 5.22: Trost's alkynylation of substrates 234 and 177.

The product $\mathbf{2 4 0}$ was expected to exist as diastereomers. Kinetic resolution in the alkynylation could conceivably result in a single diastereomer, but the high isolated yield indicated that both stereoisomers of $\mathbf{2 3 4}$ have reacted, as is likely. The signals in the ${ }^{1} \mathrm{H}$ and ${ }^{13} \mathrm{C}$ NMR spectra showed no differentiation (Figure 5.6), and the configuration at the newly formed propargylic alcohol was yet to be determined.

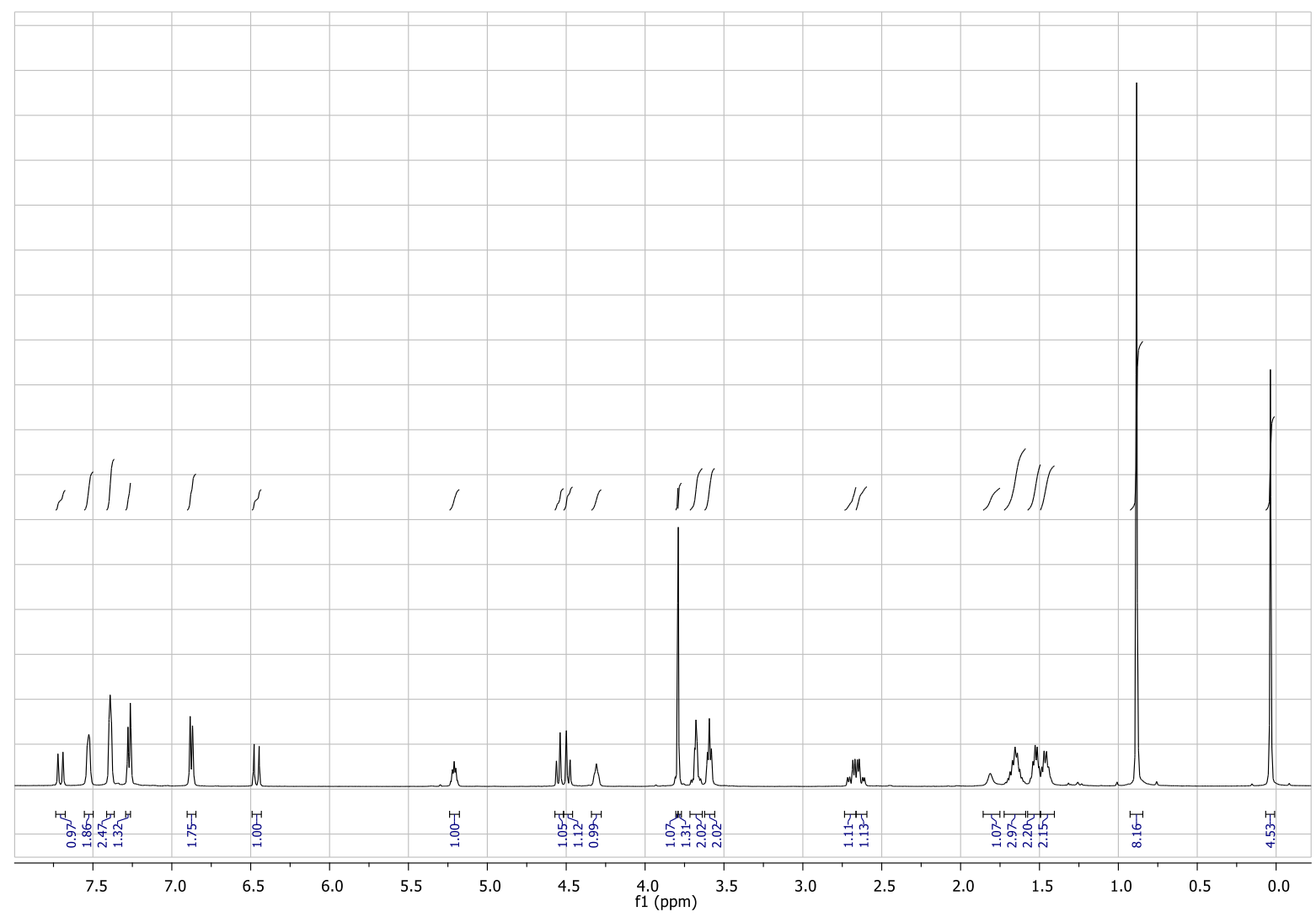

Figure 5.6: ${ }^{1} \mathrm{H}$ NMR spectrum of propargylic alcohol 240. 
Using chiral derivatizing agents is a convenient NMR-based method to determine the absolute configuration of alcohols. ${ }^{45}$ A commonly used chiral derivatizing agent is $\alpha$-methoxy- $\alpha$ trifluoromethylphenylacetic acid (MTPA), also known as Mosher's acid, which reacts with the alcohol to produce its corresponding trifluoromethylphenylmethoxyacetate via esterification. ${ }^{46,47}$ As the Mosher model describes, in the lowest energy conformation of the 241, the electronegative $\alpha-\mathrm{CF}_{3}$ would be positioned as shown in Figure 5.7 to avoid the antibonding orbitals of the ester carbonyl, and the $\mathrm{H}^{\mathrm{a}}$ would also be eclipsed with the ester carbonyl to minimise steric hindrance. Considering the two configurations of the propargylic alcohol, the $\mathrm{H}^{\mathrm{b}}$ protons on the substituent would experience a through-space deshielding or shielding effect from the methoxy or phenyl group on the same side, respectively (Figure 5.7).

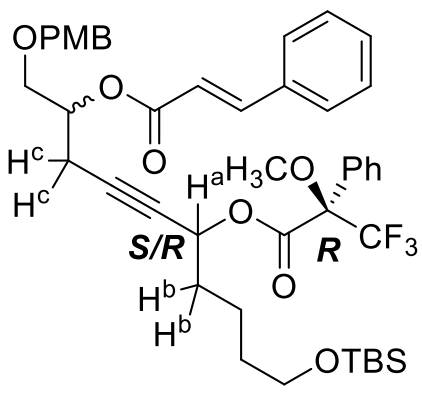

241
$S, R$-isomer:

$R, R$-isomer:
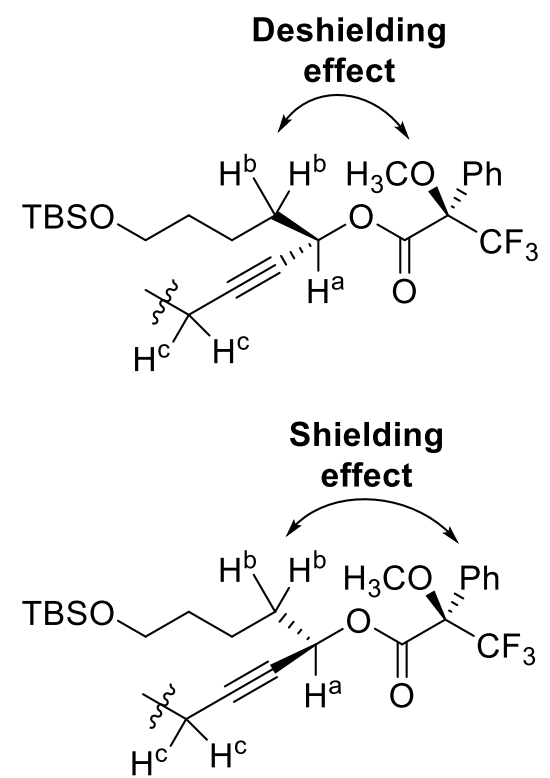

Figure 5.7: Using Mosher's ester method to determine the configuration at the new propargylic centre.

The propargylic protons $\mathrm{H}^{\mathrm{c}}$ may also be influenced in the opposite way, but the extended distance would mean a very weak effect. If the product $\mathbf{2 4 0}$ is present as a mixture of the two configurations at the new stereocentre, the ratio of the two isomers can be determined by comparing the integrals of the two pairs of chemical shifts after derivatization of the stereoisomers with either $R$ - or $S$-MTPA. However, this will be complicated by the fact that the starting material 234 is racemic. When $R$-MTPA was used, the compound with a shift of $\mathrm{H}^{\mathrm{b}}$ signal to lower field would bear the $S$-configuration at the newly formed propargylic centre, and the shift to higher field would indicate $R$-configuration. If the asymmetric alkynylation is entirely stereoselective, the configuration at the new propargylic centre will be determined by 
comparing the chemical shift of $\mathrm{H}^{\mathrm{b}}$ in the derivatization products from both $S$ - and $R$-MTPA ( $\delta_{S}$ and $\delta_{R}$, respectively). The $\Delta \delta^{S R}$ (defined as $\delta_{S}-\delta_{R}$ ) value will be calculated, and a positive value would suggest the $R$-configuration and a negative value the $S$-isomer.

To produce the desired Mosher ester 241, Steglich esterification with $R$-MTPA was attempted first, but only starting material $\mathbf{2 4 0}$ was observed by TLC analysis and ${ }^{1} \mathrm{H}$ NMR spectroscopy after 14 hours. Yamaguchi esterification was then attempted, but it did not reach completion after 20 hours. The ${ }^{1} \mathrm{H}$ NMR spectrum of crude product showed that $25 \%$ of the alcohol starting material remained.

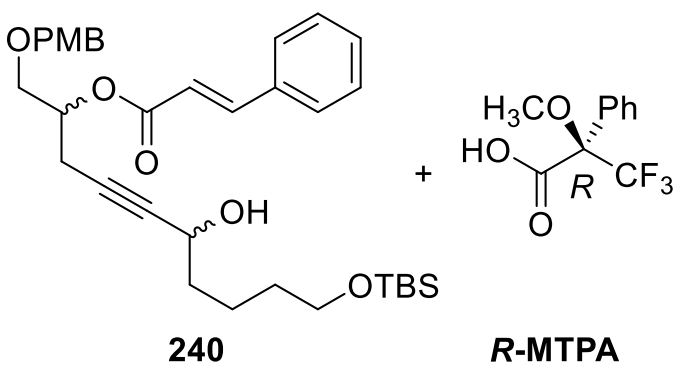

R-MTPA

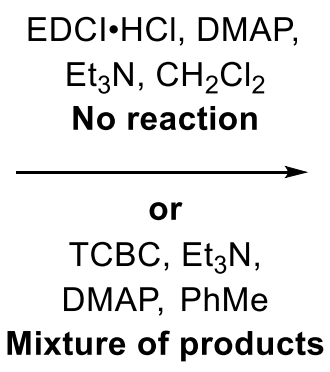

Mixture of products

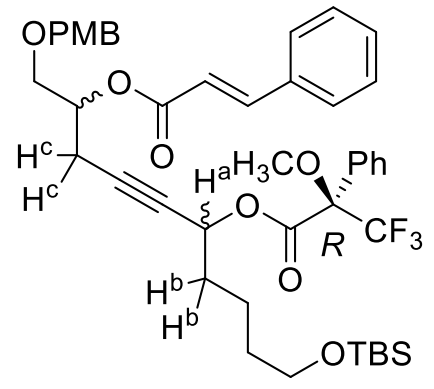

241

Scheme 5.23: Derivatization of $\mathbf{2 4 0}$ with $R$-MTPA.

Two overlapping spots with slightly different $R_{f}$ was observed on TLC plate, which were thought to be the stereoisomers. Therefore, the products was isolated from column chromatography as two mixtures at $11 \mathrm{mg}$ and $3 \mathrm{mg}$ in weight, and the later contains less of the compound with higher $R_{f}$. NMR data were obtained from a $600 \mathrm{MHz}$ machine equipped with an indirect detection cold probe to have sufficient resolution to differentiate all of the potential isomers. Six closely related compounds were identified in each mixture, which were sorted into three isomeric pairs according to their intensities, chemical shifts, multiplet pattern and through-bond correlations. The six compounds are likely to be the four stereoisomers of 241 and two by-products. The signals from the pair of by-products were differentiated from the desired stereoisomers of $\mathbf{2 4 1}$ with the assistance of COSY, HSQC and HMBC NMR spectroscopy. Observed in the ${ }^{1} \mathrm{H}$ and ${ }^{13} \mathrm{C}$ NMR spectra, significantly less by-product was present in the $3 \mathrm{mg}$ mixture than the $11 \mathrm{mg}$, thus the compound with higher $\mathrm{R}_{\mathrm{f}}$ was likely to the by-product. It was also found that the by-products are likely to be a pair of stereoisomers, 
and contain the same cinnamate and propargylic systems as the desired products, because most of the signals attributed to those systems overlap with the desired ones (Figure 5.8). However, the by-product displayed a distinctively higher chemical shift for the oxymethine proton at the newly formed ester, $5.59 \mathrm{ppm}$ compared to the 5.51 and $5.48 \mathrm{ppm}$ found for the desired products. The ${ }^{13} \mathrm{C}$ NMR signal of the oxymethine was found at $163.1 \mathrm{ppm}$, which showed HMBC correlation to two singlet peaks in the aromatic region. The two peaks have chemical shifts of 7.30 and $7.31 \mathrm{ppm}$, close to the aromatic signals reported for 2,4,6-trichlorobenzoyl functionality $(7.33 \mathrm{ppm}) .{ }^{55}$ Therefore, partial reaction of the alcohol $\mathbf{2 4 0}$ with TCBC, instead of MTPA was suspected. The presence of 2,4,6-trichlorobenzoate by-product 242 was confirmed by HRMS.

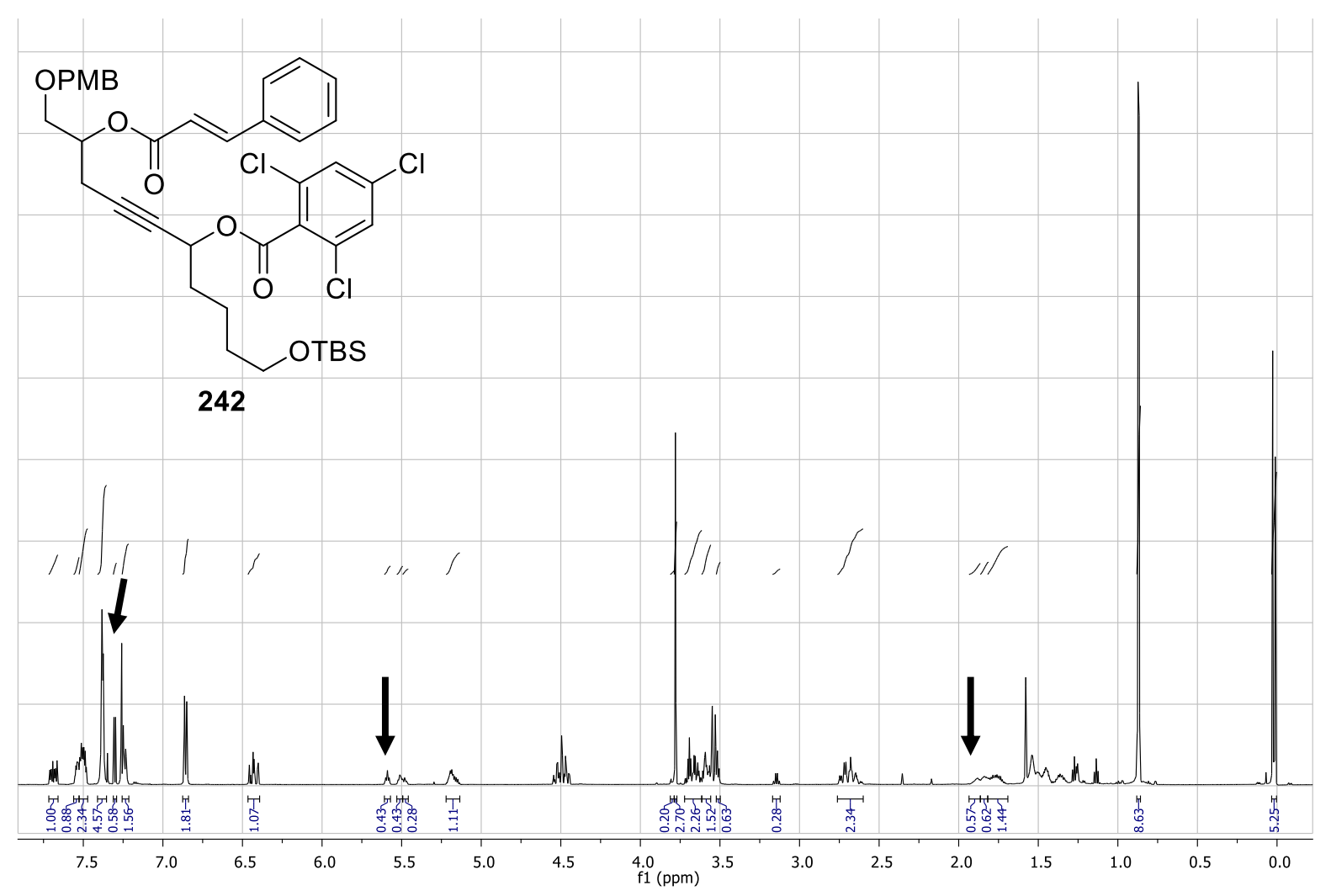

Figure 5.8: ${ }^{1} \mathrm{H}$ NMR spectrum of the mixture containing 241 and the proposed by-products, with distinctive signals attributed to the by-product $\mathbf{2 4 2}$ indicated.

The formation of $\mathbf{2 4 2}$ could be from direct reaction of alcohol $\mathbf{2 4 1}$ and TCBC. The TCBC was added in excess, and the direct esterification of alcohol and acyl chloride can occur in the presence of base, but high temperature is often required for sterically hindered substrates (Scheme 5.24, pathway I). ${ }^{56}$ The attack of $\mathbf{2 4 0}$ at the trichlorophenylcarbonyl in $\mathbf{2 4 3}$ to produce 
242 is also possible, because of the high steric hindrance at the MTPA-originated carbonyl (pathway II). Two heteroatom-linked ethyl groups were also identified: one involves a quartet at $3.15 \mathrm{ppm}$ and the triplet at $1.14 \mathrm{ppm}$; the other one has the distinctive triplet at $1.27 \mathrm{ppm}$ and an obscured multiplet at $3.60 \mathrm{ppm}$ (Figure 5.8). The source of the ethyl moieties was thought to be triethylamine, as the chemical shifts were similar to triethylamine hydrochloride $(3.16$ and $1.43 \mathrm{ppm}) .{ }^{57}$ However, due to the lack of additional information in a clean spectrum, no conclusion can be firmly drawn.

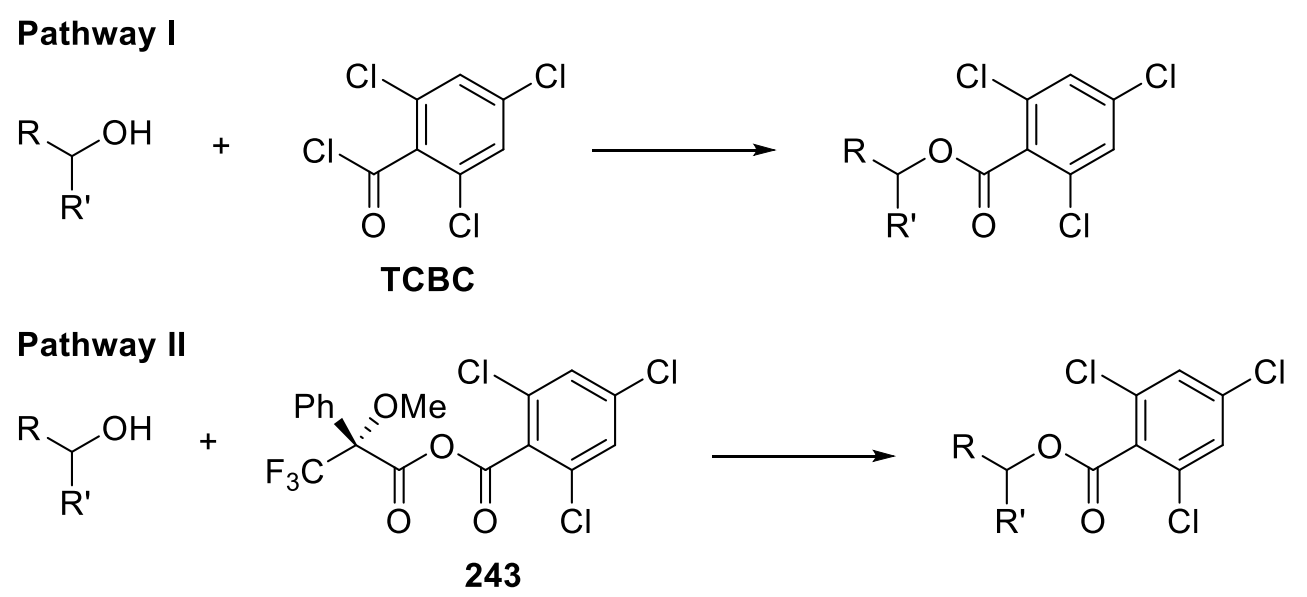

Scheme 5.24: Possible pathways for the formation of $\mathbf{2 4 2}$.

HRMS confirmed the presence of the desired Mosher ester 242. The observation of four sets of $\mathbf{2 4 2}$ signals in the NMR spectra suggested that both configurations of the propargylic alcohol were formed. Signals of $\mathrm{H}^{\mathrm{b}}$ are slightly differentiated for the two groups of stereoisomers (insert C, Figure 5.9), and the COSY and HSQC signals were used to define the boundary of multiplets. It is clear that the major pair of signals has a lower chemical shift than the minor pair. According to the discussion before, the major pair of stereoisomers would bear the desired $R$-configuration at the propargylic centre, while the minor pair of stereoisomers would have $S$ configuration. The ratio of the stereoisomers cannot be accurately determined based on the integrals of $\mathrm{H}^{\mathrm{b}}$ in the ${ }^{1} \mathrm{H}$ NMR spectrum, because of the overlapping of the two complex multiplets associated with the major and minor pair of stereoisomers (insert $\mathbf{C}$ ). Careful examination of the ${ }^{1} \mathrm{H}$ NMR spectrum led to the decision of using the multiplets at 5.53-5.47 ppm (insert B), and doublets at 6.46-6.39 ppm (insert A), which are the signals for the oxymethine protons next to the cinnamate ester and the $\alpha$-protons of the cinnamate group. The boundary of the major and minor multiplets at 5.53-5.47 ppm is reasonably defined, while the 
doublets at 6.46-6.39 ppm are all partially overlapping, but contain a few well-isolated single peaks which can provide representative ratios for the four constituent compounds. The integrals for both oxymethine and $\alpha$-protons agreed that the ratio of the major and minor products is consistent in both mixtures, and measured to be 3:2 R:S-configuration, which indicates poor stereoselectivity of the method. The ratio was also obtained from the ${ }^{1} \mathrm{H}$ NMR spectrum of the crude product to better representate the composition of the mixture formed in the reaction, which agreed with the ratio of $3: 2$, with the $R$-configuration as major. Further optimization of the stereoselectivity will be required.

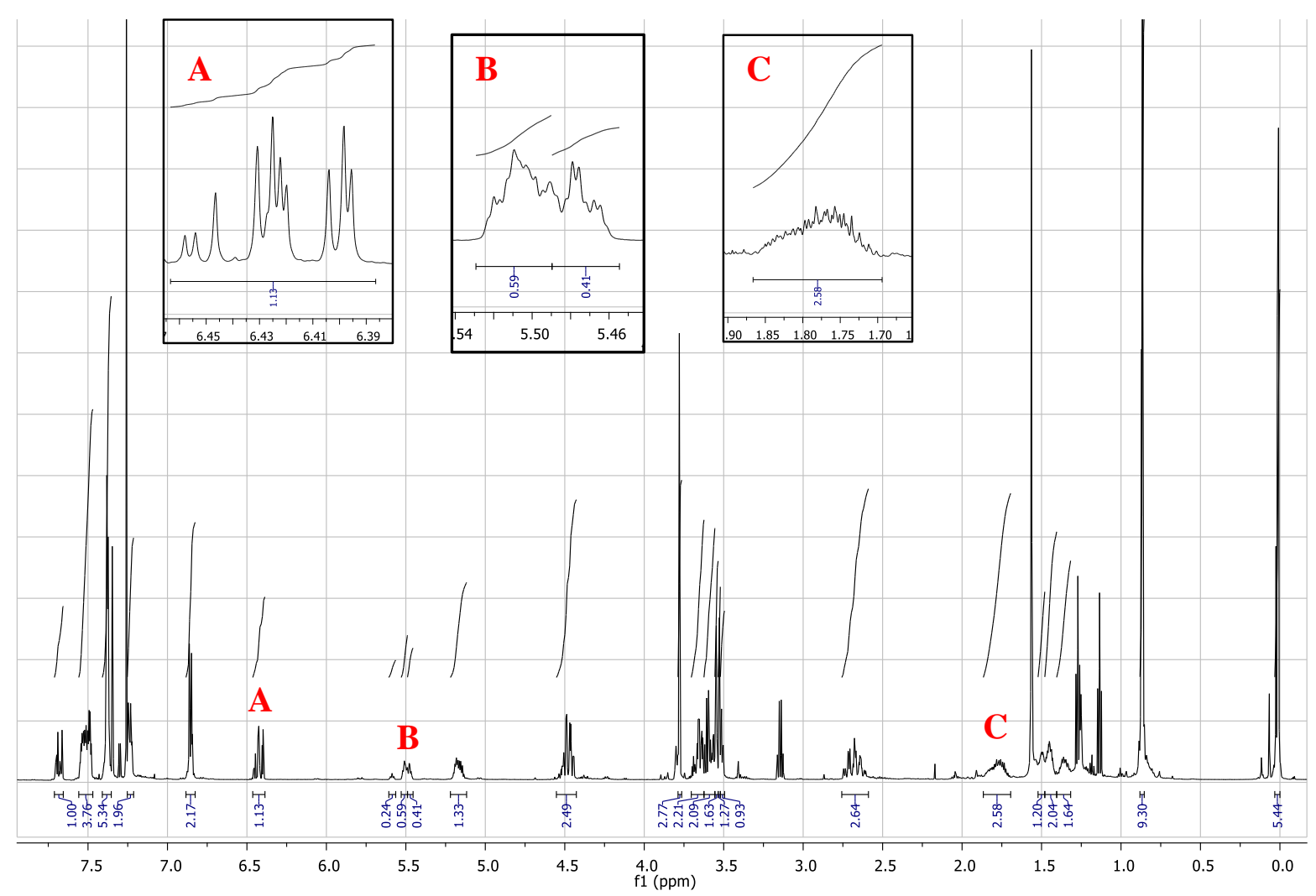

Figure 5.9: ${ }^{1} \mathrm{H}$ NMR spectrum of the mixture containing 242, with inserts $\mathbf{A}, \mathbf{B}$ and $\mathbf{C}$ showing expansion of the multiplets at $6.42,5.50$ and $1.80 \mathrm{ppm}$, respectively.

The viability of subjecting the advanced fragment $\mathbf{2 0 8}$ to Trost's asymmetric alkynylation with analogue aldehyde 177 was also tested, but only 4\% of the desired product 244 was obtained, alongside $17 \%$ of recovered starting material (Scheme 5.25). A substantial amount of the deesterified product 245 was obtained, which was not purified. The presence of 245 was confirmed by HRMS and comparing ${ }^{1} \mathrm{H}$ NMR signals with those of a purified and characterized 
sample of compound 245 provided by $\mathrm{PhD}$ student Geyrhofer. The absence of alkene signals and a signal at $3.96 \mathrm{ppm}$ corresponding to the de-esterified $\mathrm{H} 19$ were observed in the ${ }^{1} \mathrm{H}$ NMR spectrum. Using Pu's alkynylation method involving in situ generation of diethylzinc, Geyrhofer had previously isolated mostly the de-esterified product $\mathbf{2 4 5}$, even with model alkynes similar to 234. Although Trost's method provided a good yield for model alkyne 234, the dienoate in fragment $\mathbf{2 0 8}$ was too unstable under the reaction condition. The stereoselectivity of this reaction was expected to be similar as the model system, but substrate influence from the additional stereocenter and the larger substituent could also be a factor. Due to time constraints, Mosher's ester analysis was not performed on 244.
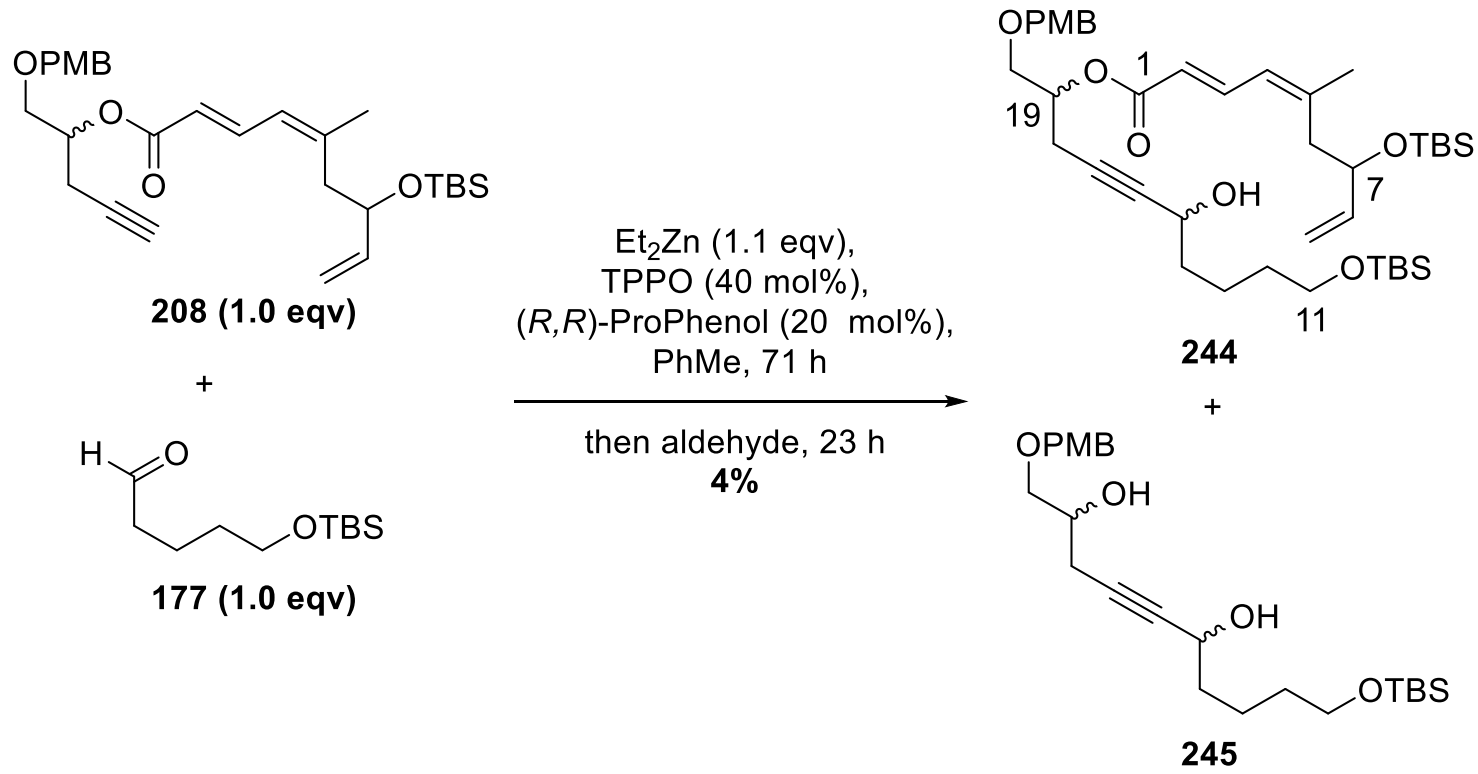

Scheme 5.25: Use of Trost's alkynylation method with substrates 208 and $\mathbf{1 7 7 .}$

\subsection{Summary}

In summary, the side arm attachment by a chiral boron reagent-promoted aza-aldol reaction failed to produce the desired product with a simple aldehyde model. However, model substrates that better account for the functionality of the zampanolide macrocycle should be tested in this reaction. If unsuccessful, reliable alternative methods for the aza-aldol reaction can be attempted next. The oxidation of the alcohol group at C20 was briefly tested on a model of zampanolide/dactylolide. Although the well-precedented DMP oxidation led to degradation, 
it could be a problem specific to the substrate used, thus substrates better represent dactylolide (21) could be investigated.

Alkynylation to form the $\mathrm{C} 15-\mathrm{C} 16$ bond was also investigated. While unsatisfying results were obtained from Carreira's non-stereoselective and Xiong's methods, alkynylation involving ProPhenol and diethylzinc produced an excellent yield with a model alkyne. Although the stereoselectivity of the $\mathrm{Et}_{2} \mathrm{Zn} / \mathrm{ProPhenol}$ alkynylation is yet to be optimized, it was also tested on the full zampanolide fragment generated from the Bestmann ylide reaction. A small amount of the desired product was isolated, alongside the de-esterified major product. Further optimization of this reaction and its stereoselectivity are underway.

\subsection{Experimental data}

\section{General experimental information}

Unless otherwise stated, all reactions were carried out in oven-dried glassware under a positive pressure of nitrogen, delivered via a manifold. Dry tetrahydrofuran, dichloromethane and toluene were obtained from a PureSolv MD 5 solvent purification system (Innovative Technology). Analytical grade solvents were used for aqueous work-up and column chromatography (petroleum ether, ethyl acetate, diethyl ether, methanol and dichloromethane). Column chromatography was performed on silica gel $60 \AA$ A (Pure Science, 40-63 micron) with the eluent mixtures as stated in the corresponding procedures. Thin-layer chromatography was performed on silica-coated plastic plates (Macherey-Nagel, POLYGRAM ${ }^{\circledR}$ Sil G/UV 254 ). All compounds were detected under UV irradiation $(\lambda=254 \mathrm{~nm})$, followed by visualization with anisaldehyde staining solutions.

All other chemicals were purchased from Pure Science, Sigma-Aldrich, Panreac, Merk and AK scientific. Infra-red (IR) spectra were collected on an ALPHA FT-IR spectrometer (Bruker) fitted with attenuated total reflectance (ATR). The intensities of signals are defined as: br = broad, $\mathrm{s}=$ strong, $\mathrm{m}=$ medium, $\mathrm{w}=$ weak. Mass spectra were collected on an Agilent 6530 Accurate-Mass Q-TOF LC/MS high-resolution mass spectrometer (HRMS). The specific rotations were collected on an AUTOPOL II automatic polarimeter (Rudolph Research Analytical), and the reported values are an average of 10 measurements and concentrations are reported in $\mathrm{g} / 100 \mathrm{~mL}$. 
Nuclear magnetic resonance (NMR) spectra were obtained in deuterated chloroform $\left(\mathrm{CDCl}_{3}\right)$ using Varian Inova instruments operating at 500 or $600 \mathrm{MHz}$ for proton and 125 or $150 \mathrm{MHz}$ for carbon. Proton and carbon chemical shifts are reported in parts per million (ppm) relative to residual $\mathrm{CHCl}_{3}\left[\delta\left({ }^{1} \mathrm{H}\right)=7.26 \mathrm{ppm}\right]$ and $\mathrm{CDCl}_{3}\left[\delta\left({ }^{13} \mathrm{C}\right)=77.0 \mathrm{ppm}\right]$, respectively. Signals are defined as: $\mathrm{s}=$ singlet, $\mathrm{d}=$ doublet, $\mathrm{t}=$ triplet, $\mathrm{q}=$ quartet, quin $=$ quintet, $\mathrm{m}=$ multiplet, app. $=$ apparent, obs. $=$ obscured peak. Coupling constants $(J)$ are reported in Hertz $(\mathrm{Hz})$. Assignments were determined by two-dimensional NMR experiments (COSY, HSQC, and HMBC).

\section{Methyl 2-hydroxy-3-phenylpropanoate (220)}<smiles>COC(=O)C(O)Cc1ccccc1</smiles>

To a solution of $(S)$-phenylalanine $(4.00 \mathrm{~g}, 24.2 \mathrm{mmol})$ in aqueous $\mathrm{H}_{2} \mathrm{SO}_{4}$ solution ( $36.0 \mathrm{~mL}, 3 \% \mathrm{~V} / \mathrm{V}$ in $\mathrm{H}_{2} \mathrm{O}, 4.66 \mathrm{mmol}$ ) at $0{ }^{\circ} \mathrm{C}$, a solution of $\mathrm{NaNO}_{2}(2.51 \mathrm{~g}, 36.4 \mathrm{mmol})$ in $\mathrm{H}_{2} \mathrm{O}(4.8 \mathrm{~mL}, 7.5 \mathrm{M})$ was added dropwise

over $1 \mathrm{~h}$. After the addition, the reaction was slowly warmed to r.t. and stirred for $16 \mathrm{~h}$. The reaction mixture was extracted with EtOAc $(3 \times 100 \mathrm{~mL})$, and the organic layers were combined, dried over $\mathrm{MgSO}_{4}$ and the solvent was removed under reduced pressure to produce 2-hydroxy-3-phenylpropanoic acid as a yellow crystalline material (2.29 g). This yellow solids and $\mathrm{K}_{2} \mathrm{CO}_{3}(2.30 \mathrm{~g}, 16.6 \mathrm{mmol})$ were dissolved in acetone $(81 \mathrm{~mL})$, and $\mathrm{MeI}(1.9 \mathrm{~mL}, 27.8$ mmol) was added. This reaction mixture was heated at $50^{\circ} \mathrm{C}$ for $4 \mathrm{~h}$. The reaction mixture was concentrated under reduced pressure and dissolved in $\mathrm{H}_{2} \mathrm{O}(30 \mathrm{~mL})$ and EtOAc $(30 \mathrm{~mL})$. The aqueous layer was separated and extracted with EtOAc $(3 \times 30 \mathrm{~mL})$. The organic layers were combined, dried over $\mathrm{MgSO}_{4}$ and under reduced pressure to yield 220 as a pale yellow solid (1.58 g, 44\% yield from $(S)$-phenylalanine).

${ }^{1} \mathbf{H}$ NMR (500 MHz, $\mathrm{CDCl}_{3}$ ): $\delta$ 7.34-7.29 (m, 2H, CH, Ph), 7.26-7.20 (m, 3H, CH, Ph), 4.47 (ddd, $J=6.7,5.6,4.2 \mathrm{~Hz}, 1 \mathrm{H}, 2-\mathrm{CH}), 3.79$ (s, 3H, $\mathrm{CH}_{3}, \mathrm{Me}$ ), 3.14 (dd, $J=13.9,4.4 \mathrm{~Hz}, 1 \mathrm{H}$, one of 3- $\left.\mathrm{CH}_{2}\right), 2.98\left(\mathrm{dd}, J=13.9,6.8 \mathrm{~Hz}, 1 \mathrm{H}\right.$, one of $\left.3-\mathrm{CH}_{2}\right), 2.70(\mathrm{~d}, J=6.1 \mathrm{~Hz}, 1 \mathrm{H}, \mathrm{OH})$.

${ }^{13} \mathrm{C}$ NMR (125 MHz, CDCl 3 ): $\delta 174.6$ (C, C1), 136.3 (C, Ph), 129.5 (CH, Ph), $128.4(\mathrm{CH}, \mathrm{Ph})$, $126.9(\mathrm{CH}, \mathrm{Ph}), 71.2(\mathrm{CH}, \mathrm{C} 2), 52.5\left(\mathrm{CH}_{3}, \mathrm{Me}\right), 40.6\left(\mathrm{CH}_{2}, \mathrm{C} 3\right)$.

The data agree with previously reported. ${ }^{58}$ 


\section{Methyl 2-(t-butylcarbonate)-3-phenylpropanoate (224)}<smiles>COC(=O)OC(Cc1ccccc1)C(=O)OC</smiles>

A mixture of 220 (304 mg, $1.69 \mathrm{mmol}), \mathrm{Zn}(\mathrm{OAc})_{2} \cdot 2 \mathrm{H}_{2} \mathrm{O}(37 \mathrm{mg}, 0169$ $\mathrm{mmol})$ and $\mathrm{Boc}_{2} \mathrm{O}(0.43 \mathrm{~mL}, 407 \mathrm{mg}, 1.86 \mathrm{mmol})$ were stirred at $50{ }^{\circ} \mathrm{C}$ for $4 \mathrm{~h}$. Upon cooling, the reaction mixture was diluted with $\mathrm{CH}_{2} \mathrm{Cl}_{2}(10$ $\mathrm{mL})$ and $\mathrm{H}_{2} \mathrm{O}(10 \mathrm{~mL})$. The aqueous layer was separated and extracted with $\mathrm{CH}_{2} \mathrm{Cl}_{2}(2 \times 10 \mathrm{~mL})$, the organic layers were combined, dried over $\mathrm{MgSO}_{4}$ and concentrated under reduced pressure. The crude product was purified by column chromatography (silica, 10:1 pet. ether:EtOAc, $R_{\mathrm{f}}=0.29$ ) to yield the product 224 as a pale yellow solid (397 mg, 85\% yield). Only ${ }^{1} \mathrm{H}$ NMR data was collected when 224 was first prepared. After over three years of storage, some decomposition occurred. The ${ }^{13} \mathrm{C} \mathrm{NMR,} \mathrm{IR}$ and HRMS data were collected on this partially decomposed product, and the desired carbon signals were identified in the mixture by $2 \mathrm{D}$ correlations.

${ }^{1} \mathbf{H}$ NMR (500 MHz, $\mathrm{CDCl}_{3}$ ): $\delta$ 7.34-7.28 (m, 2H, CH, Ph), 7.28-7.22 (m, 3H, CH, Ph), 5.10 $(\mathrm{dd}, J=8.3,4.4 \mathrm{~Hz}, 1 \mathrm{H}, 2-\mathrm{CH}), 3.74$ (s, 3H, $\left.\mathrm{CH}_{3}, \mathrm{Me}\right), 3.19$ (dd, $J=14.2,4.1 \mathrm{~Hz}, 1 \mathrm{H}$, one of $\left.3-\mathrm{CH}_{2}\right), 3.11\left(\mathrm{dd}, J=14.0,8.6 \mathrm{~Hz}, 1 \mathrm{H}\right.$, one of $\left.3-\mathrm{CH}_{2}\right), 1.45\left(\mathrm{~s}, 9 \mathrm{H}, \mathrm{CH}_{3}, t \mathrm{Bu}\right)$.

${ }^{13}$ C NMR (125 MHz, $\mathrm{CDCl}_{3}$ ): $\delta 170.3$ (C, C1), 152.8 (C, C4), 135.7 (C, Ph), $129.4(\mathrm{CH}, \mathrm{Ph})$, $128.5(\mathrm{CH}, \mathrm{Ph}), 127.0(\mathrm{CH}, \mathrm{Ph}), 83.2(\mathrm{C}, t \mathrm{Bu}), 75.2(\mathrm{CH}, \mathrm{C} 2), 52.4\left(\mathrm{CH}_{3}, \mathrm{OMe}\right), 37.5\left(\mathrm{CH}_{2}\right.$, C3), $27.6\left(\mathrm{CH}_{3}, t \mathrm{Bu}\right)$.

IR (neat) cm $\mathrm{cm}^{-1}: 3031$ (w, C-H), $2980(\mathrm{~m}, \mathrm{C}-\mathrm{H}), 1739$ (s, C=O), 1604 (w, C-H), 1278 (s, C-O), 1154 (s, C-O), 1103 (s, C-O), 792 (m, C-H), 698 (s, C-H).

HRMS (ESI) $m / z$ : found 298.1549, calcd for $\mathrm{C}_{15} \mathrm{H}_{24} \mathrm{O}_{5} \mathrm{~N} 298.1547\left[\mathrm{M}+\mathrm{NH}_{4}\right]^{+}(\Delta=0.7 \mathrm{ppm})$.

\section{2-(t-Butylcarbonate)-3-phenylpropanal (223)}<smiles>CC(Cc1ccccc1)OC(=O)C=O</smiles>

sat. aq. Rochelle salt $(1.0 \mathrm{~mL})$. The mixture was warmed to r.t.. After stirring vigorously for 2 $\mathrm{h}$, the reaction mixture was extracted with EtOAc $(3 \times 10 \mathrm{~mL})$. The organic layers were combined, dried over $\mathrm{MgSO}_{4}$ and concentrated under reduced pressure. The crude material was 
purified by column chromatography (silica, $10: 1$ pet. ether:EtOAc, $R_{f}=0.12$ ) to yield the product $\mathbf{2 2 3}$ as a pale yellow solid (21 $\mathrm{mg}, 38 \%$ yield) and a mixture of starting material and product (31 mg, 4:1 224:223). Only ${ }^{1} \mathrm{H}$ NMR and HRMS data were collected.

${ }^{1} \mathbf{H}$ NMR (500 MHz, $\left.\mathrm{CDCl}_{3}\right): \delta 9.61(\mathrm{~s}, 1 \mathrm{H}, 1-\mathrm{CH}), 7.35-7.29(\mathrm{~m}, 2 \mathrm{H}, \mathrm{CH}, \mathrm{Ph}), 7.29-7.20(\mathrm{~m}$, $3 \mathrm{H}, \mathrm{CH}, \mathrm{Ph}), 5.06(\mathrm{dd}, J=8.0,5.0 \mathrm{~Hz}, 1 \mathrm{H}, 2-\mathrm{CH}), 3.18(\mathrm{dd}, J=14.4,4.5 \mathrm{~Hz}, 1 \mathrm{H}$, one of 3$\left.\mathrm{CH}_{2}\right), 3.04\left(\mathrm{dd}, J=14.4,8.8 \mathrm{~Hz}, 1 \mathrm{H}\right.$, one of $\left.3-\mathrm{CH}_{2}\right), 1.46\left(\mathrm{~s}, 9 \mathrm{H}, \mathrm{CH}_{3}, t \mathrm{Bu}\right)$.

HRMS (ESI) $m / z$ : found 251.1300, calcd for $\mathrm{C}_{14} \mathrm{H}_{19} \mathrm{O}_{4}[\mathrm{M}+\mathrm{H}]^{+} 215.1278(\Delta=1.0 \mathrm{ppm})$.

\section{(5'-Trimethylsilyl)pent-4'-yn-2'-yl 5-phenylpenta-2,4-dienoate (227)}<smiles>CC#CCCC(CC)OC(=O)C=CC=Cc1ccccc1</smiles>

To a stirred solution of the PMB-ether 206 (131 mg, $0.292 \mathrm{mmol}$ ) in $\mathrm{CH}_{2} \mathrm{Cl}_{2}: \mathrm{H}_{2} \mathrm{O}(10: 1 \mathrm{~V} / \mathrm{V}, 3.9 \mathrm{~mL})$ at r.t., DDQ (79 mg, 0.348 mmol) was added. The reaction mixture was stirred at r.t. for $1 \mathrm{~h}$ $30 \mathrm{~min}$. The solvent was removed under reduced pressure. The crude product was purified by column chromatography (silica, 5:1 pet. ether:EtOAc, $R_{f}=0.15$ ) to yield the alcohol 227 as a yellow oil (91 $\mathrm{mg}$, 95\% yield).

${ }^{1} \mathbf{H}$ NMR $\left(500 \mathrm{MHz}, \mathrm{CDCl}_{3}\right) \delta 7.51(\mathrm{dd}, J=16.2,10.2 \mathrm{~Hz}, 1 \mathrm{H}, 2-\mathrm{CH}), 7.49-7.46(\mathrm{~m}, 2 \mathrm{H}, 7$ $\mathrm{CH}), 7.39-7.30(\mathrm{~m}, 3 \mathrm{H}, 8-\mathrm{CH}$ and 9-CH), $6.96-6.84(\mathrm{~m}, 2 \mathrm{H}, 4-\mathrm{CH}$ and 5-CH), 6.02 (d, $J=$ $\left.15.3 \mathrm{~Hz}, 1 \mathrm{H}, 2^{\prime}-\mathrm{CH}\right), 5.09$ (dtd, $\left.J=7.1,5.8,3.6 \mathrm{~Hz}, 1 \mathrm{H}, 2-\mathrm{CH}\right), 3.95-3.89$ (m, 1H, one of 1'$\left.\mathrm{CH}_{2}\right), 3.89-3.83\left(\mathrm{~m}, 1 \mathrm{H}\right.$, one of 1'- $\left.\mathrm{CH}_{2}\right), 2.67\left(\mathrm{dd}, J=14.9,4.0 \mathrm{~Hz}, 1 \mathrm{H}\right.$, one of $\left.3^{\prime}-\mathrm{CH}_{2}\right), 2.65$ $-2.60\left(\mathrm{~m}, 1 \mathrm{H}\right.$, one of $\left.3^{\prime}-\mathrm{CH}_{2}\right), 0.15\left(\mathrm{~s}, 9 \mathrm{H}, \mathrm{CH}_{3}, \mathrm{Me}\right)$.

${ }^{13} \mathrm{C}$ NMR $\left(125 \mathrm{MHz}, \mathrm{CDCl}_{3}\right) \delta 166.6$ (C, C1), 145.6 (CH, C3), 141.1 (CH, C5), 135.9 (C, C6), 129.2 (CH, C8), 128.8 (CH, C9), 127.3 (CH, C7), 126.0 (CH, C4), 120.5 (CH, C2), 101.4 (C, C4'), $87.6\left(\mathrm{C}, \mathrm{C}^{\prime}\right), 72.8\left(\mathrm{CH}, \mathrm{C} 2^{\prime}\right), 63.6\left(\mathrm{CH}_{2}, \mathrm{C}^{\prime}\right), 22.0\left(\mathrm{CH}_{2}, \mathrm{C}^{\prime}\right),-0.05\left(\mathrm{CH}_{3}, \mathrm{Me}\right)$.

HRMS (ESI) $m / z$ : found 329.1572, calcd for $\mathrm{C}_{19} \mathrm{H}_{25} \mathrm{O}_{3} \mathrm{Si}[\mathrm{M}+\mathrm{H}]^{+} 329.1567$ ( $\left.\Delta=1.4 \mathrm{ppm}\right)$. 
<smiles>O=C(/C=C/c1ccccc1)OC(I)CO[CH]c1ccc(O[Tl])cc1</smiles>

To a solution of alcohol $153(100 \mathrm{mg}, 0.454 \mathrm{mmol})$ in $\mathrm{CH}_{2} \mathrm{Cl}_{2}(1.0 \mathrm{~mL}, 0.15 \mathrm{M})$ at r.t., cinnamic acid (75 mg, $0.51 \mathrm{mmol})$ and DMAP (3 mg, $0.02 \mathrm{mmol})$ were added. This solution was stirred for $10 \mathrm{~min}$. Upon the addition of DCC (103 mg, $0.499 \mathrm{mmol})$,

the clear solution turned cloudy. The reaction was stirred for $4 \mathrm{~h}$ at r.t., filtered through Celite, and the filtrate was concentrated under reduced pressure. The crude product was purified by column chromatography (silica, 10:1 pet. ether:EtOAc, $R_{\mathrm{f}}=0.14$ ) to yield the ester 234 as a colourless oil (158 mg, 99\% yield).

${ }^{1} \mathbf{H}$ NMR (500 MHz, $\left.\mathrm{CDCl}_{3}\right): \delta 7.71(\mathrm{~d}, J=16.1 \mathrm{~Hz}, 1 \mathrm{H}, 3-\mathrm{CH}), 7.53(\mathrm{~d}, J=6.2 \mathrm{~Hz}, 2 \mathrm{H}, 5-$ $\mathrm{CH}$ ), 7.41-7.37 (complex m, 3H, 6-CH \& 7-CH), 7.27 (obs. d, $J=8.5 \mathrm{~Hz}, 2 \mathrm{H}, 8^{\prime}-\mathrm{CH}$ ), 6.88 (d, $J=8.5 \mathrm{~Hz}, 2 \mathrm{H}, 9^{\prime}-\mathrm{CH}$ ), 6.47 (d, $J=15.9 \mathrm{~Hz}, 1 \mathrm{H}, 2-\mathrm{CH}$ ), 5.23 (app. quin, $J=5.4 \mathrm{~Hz}, 1 \mathrm{H}, 2^{\prime}-$ $\mathrm{CH}), 4.55\left(\mathrm{~d}, J=11.7 \mathrm{~Hz}, 1 \mathrm{H}\right.$, one of $\left.6^{\prime}-\mathrm{CH}_{2}\right), 4.50\left(\mathrm{~d}, J=11.7 \mathrm{~Hz}, 1 \mathrm{H}\right.$, one of $\left.6^{\prime}-\mathrm{CH}_{2}\right), 3.79$ $\left(\mathrm{s}, 3 \mathrm{H}, 11^{\prime}-\mathrm{CH}_{3}\right), 3.72\left(\mathrm{dd}, J=10.5,5.1 \mathrm{~Hz}, 1 \mathrm{H}\right.$, one of $\left.1^{\prime}-\mathrm{CH}_{2}\right), 3.69(\mathrm{dd}, J=10.7,4.6 \mathrm{~Hz}, 1 \mathrm{H}$, one of 1'- $\mathrm{CH}_{2}$ ), 2.69 (ddd, $J=16.9,6.6,2.4 \mathrm{~Hz}, 1 \mathrm{H}$, one of $\left.3^{\prime}-\mathrm{CH}_{2}\right), 2.63$ (ddd, $J=16.9,5.9$, $2.7 \mathrm{~Hz}, 1 \mathrm{H}$, one of $\left.3^{\prime}-\mathrm{CH}_{2}\right), 2.00\left(\mathrm{t}, J=2.6 \mathrm{~Hz}, 1 \mathrm{H}, 5^{\prime}-\mathrm{CH}\right)$.

${ }^{13}$ C NMR (125 MHz, $\left.\mathrm{CDCl}_{3}\right)$ : $\delta 166.2(\mathrm{C}, \mathrm{C} 1), 159.3$ (C, C10'), $145.4(\mathrm{CH}, \mathrm{C} 3), 134.3$ (C, C4), 130.4 (CH, C7), 129.9 (C, C7'), 129.3 (CH, C8'), 128.9 (CH, C6), 128.1 (CH, C5), 117.8 (CH, C2), $113.8\left(\mathrm{CH}, \mathrm{C}^{\prime}\right), 79.4\left(\mathrm{C}, \mathrm{C}^{\prime}\right), 73.0\left(\mathrm{CH}_{2}, \mathrm{C}^{\prime}\right), 70.6\left(\mathrm{CH}, \mathrm{C}^{\prime} / \mathrm{C}^{\prime}\right), 70.5\left(\mathrm{CH}, \mathrm{C}^{\prime} / \mathrm{C}^{\prime}\right)$, $69.4\left(\mathrm{CH}_{2}, \mathrm{Cl}^{\prime}\right), 55.3\left(\mathrm{CH}_{3}, \mathrm{C} 11^{\prime}\right), 21.0\left(\mathrm{CH}_{2}, \mathrm{C}^{\prime}\right)$.

IR (neat) $\mathrm{cm}^{-1}: 3290$ (m, C-H), 2909 (m, C-H), 2863 (m, C-H), 2120 (w, C $\left.\equiv \mathrm{C}\right), 1709$ (s, C=O), 1636 (s, C=C), 1511 (s, C-O), 1245 (s, C-O), 1165 (s, C-O), 710 (s, C-Si).

HRMS (ESI) $m / z$ : found 368.1859, calcd for $\mathrm{C}_{22} \mathrm{H}_{26} \mathrm{O}_{4} \mathrm{~N}\left[\mathrm{M}+\mathrm{NH}_{4}\right]^{+} 368.1856(\Delta=0.8 \mathrm{ppm})$.

$(1 R, 2 R)-2-(N, N$-Dimethylamino)-1-(4'-nitrophenyl)propane-1,3-diol (238)<smiles>CN(C(CO)CO)[C@@H](O)c1ccc([N+](=O)[O-])cc1</smiles>

$(1 R, 2 R)$-2-amino-1-(4'-nitrophenyl)propane-1,3-diol (233, $1.00 \mathrm{~g}$, $5.98 \mathrm{mmol})$, aqueous formaldehyde solution $(1.5 \mathrm{~mL}, 37 \%)$ and formic acid $(2.0 \mathrm{~mL}, 98 \%)$ were mixed in a flask. The starting material 233 dissolved upon heating, and the solution was heated at 
$100{ }^{\circ} \mathrm{C}$ for $8 \mathrm{~h}$. After cooling to r.t., the yellow solution was neutralized with aqueous $\mathrm{NaOH}$ (1N) solution to $\mathrm{pH} 8$ to precipitate out the solid. The aqueous mixture was extracted with $\mathrm{CH}_{2} \mathrm{Cl}_{2}(5 \times 50 \mathrm{~mL})$, and the organic layers were combined, dried over $\mathrm{MgSO}_{4}$ and concentrated under reduced pressure. The yellow oil obtained was then purified by column chromatography $\left(\mathrm{SiO}_{2}, 10: 1 \mathrm{CH}_{2} \mathrm{Cl}_{2}: \mathrm{MeOH}\right)$ to yield the product 238 as yellow crystals $(1.06$ g, 94\%).

${ }^{1} \mathbf{H}$ NMR $\left(500 \mathrm{MHz}, \mathrm{CDCl}_{3}\right) \delta 8.20\left(\mathrm{~d}, J=8.7 \mathrm{~Hz}, 2 \mathrm{H}, 3^{\prime}-\mathrm{CH}\right), 7.60\left(\mathrm{~d}, J=8.7 \mathrm{~Hz}, 2 \mathrm{H}, 2^{\prime}-\right.$ $\mathrm{CH}), 4.59(\mathrm{~d}, J=9.7 \mathrm{~Hz}, 1 \mathrm{H}, 1-\mathrm{CH}), 3.61\left(\mathrm{~d}, J=4.7 \mathrm{~Hz}, 2 \mathrm{H}, 3-\mathrm{CH}_{2}\right), 2.59(\mathrm{dt}, J=10.4,5.2$ $\mathrm{Hz}, 1 \mathrm{H}, 2-\mathrm{CH}), 2.54$ (s, 6H, $\left.\mathrm{CH}_{3}, \mathrm{Me}\right)$.

${ }^{13} \mathrm{C}$ NMR (125 MHz, $\left.\mathrm{CDCl}_{3}\right): \delta 149.9\left(\mathrm{C}, \mathrm{C} 4{ }^{\prime}\right), 128.0\left(\mathrm{CH}, \mathrm{C2}{ }^{\prime}\right), 123.6\left(\mathrm{CH}, \mathrm{C} 3{ }^{\prime}\right), 71.3(\mathrm{CH}$, C2), $69.9(\mathrm{CH}, \mathrm{C} 1), 57.9\left(\mathrm{CH}_{2}, \mathrm{C} 3\right), 41.6\left(\mathrm{CH}_{3}, \mathrm{Me}\right)$.

IR (neat) cm $\mathrm{cm}^{-1}: 3359$ (br, C-O), 2981 (w, C-H). 2917 (m, C-H), 2796 (w, C-H), 1519 (s, CC), 1348 (s, N-C), 1244 (m, N-C), 1177 (m, N-C), 1059 (s, C-O).

HRMS (ESI) $m / z$ : found 241.1183, calcd for $\mathrm{C}_{11} \mathrm{H}_{17} \mathrm{~N}_{2} \mathrm{O}_{4}[\mathrm{M}+\mathrm{H}]^{+} 241.1183(\Delta=0.0 \mathrm{ppm})$. M.p.: $102.0-103.4^{\circ} \mathrm{C}$. (Lit. for $(1 S, 2 S)$-isomer: $\left.88.8-89.1^{\circ} \mathrm{C}.\right)^{47}$

Specific rotation: $[a]_{D}{ }^{21}=-15.4\left(c=0.532, \mathrm{CH}_{2} \mathrm{Cl}_{2}\right)$. (Lit. for $(1 S, 2 S)$-isomer: $+25.7(c=0.505$, $\left.\left.\mathrm{CH}_{3} \mathrm{OH}\right).\right)^{47}$

The carbon signal for $\mathrm{Cl}^{\prime}$ was missing, but the overall agreement of the NMR and IR data with those reported for the $(1 S, 2 S)$-isomer and the HRMS data suggest that $\mathbf{2 3 8}$ was successfully prepared. ${ }^{47}$ The optical rotation data obtained has opposite sign with the $(1 S, 2 S)$-isomer. ${ }^{47}$

$(1 R, 2 R)-3-(t$-Butyldimethylsilyloxy)-2-( $N, N$-dimethylamino)-1-(4'-nitrophenyl)propan-1ol (232)<smiles></smiles>

A solution of the diol $238(1.05 \mathrm{~g}, 4.37 \mathrm{mmol}), \mathrm{TBSCl}(676 \mathrm{mg}$, $4.49 \mathrm{mmol}$ ), imidazole (734 mg, $10.8 \mathrm{mmol}$ ) and DMAP (5 mg, $0.04 \mathrm{mmol})$ in $\mathrm{CH}_{2} \mathrm{Cl}_{2}(15 \mathrm{~mL})$ was stirred at r.t. for $15 \mathrm{~h}$. The reaction was diluted with $\mathrm{H}_{2} \mathrm{O}(10 \mathrm{~mL})$ and basified with aqueous $\mathrm{NaOH}(1 \mathrm{~N})$ to $\mathrm{pH}$ 9. The aqueous layer was separated and extracted with $\mathrm{CH}_{2} \mathrm{Cl}_{2}(2 \times 20 \mathrm{~mL})$. The organic layers were combined, dried over $\mathrm{MgSO}_{4}$ and concentrated under reduced pressure. The yellow oil 
obtained was then purified by column chromatography $\left(\mathrm{SiO}_{2}, 10: 1\right.$ pet. ether:EtOAc, $\left.\mathrm{R}_{\mathrm{f}}=0.35\right)$ to yield the product 232 as a yellow oil (946 $\mathrm{mg}, 61 \%)$.

${ }^{1} \mathbf{H}$ NMR $\left(500 \mathrm{MHz}, \mathrm{CDCl}_{3}\right) \delta 8.18\left(\mathrm{~d}, J=8.6 \mathrm{~Hz}, 2 \mathrm{H}, 3^{\prime}-\mathrm{CH}\right), 7.59\left(\mathrm{~d}, J=8.6 \mathrm{~Hz}, 2 \mathrm{H}, 2^{\prime}-\right.$ $\mathrm{CH}), 4.62(\mathrm{~d}, J=9.7 \mathrm{~Hz}, 1 \mathrm{H}, 1-\mathrm{CH}), 3.64(\mathrm{dd}, J=11.3,2.2 \mathrm{~Hz}, 1 \mathrm{H}$, one of 3-CH 2$), 3.46$ (dd,

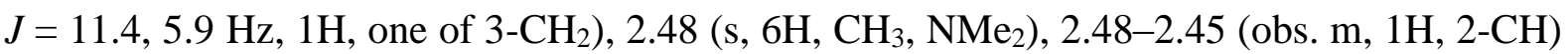
0.86 (s, 9H, $t \mathrm{Bu}, \mathrm{TBS}),-0.04$ (s, 3H, Me, TBS), -0.05 (s, 3H, Me, TBS).

${ }^{13} \mathrm{C}$ NMR $\left(125 \mathrm{MHz}, \mathrm{CDCl}_{3}\right) \delta 150.3\left(\mathrm{C}, \mathrm{C}^{\prime}\right), 147.4\left(\mathrm{C}, \mathrm{C} 1^{\prime}\right), 128.1\left(\mathrm{CH}, \mathrm{C} 2{ }^{\prime}\right), 123.4(\mathrm{CH}$, C3'), $71.4(\mathrm{CH}, \mathrm{C} 2), 69.1(\mathrm{CH}, \mathrm{C} 1), 57.1\left(\mathrm{CH}_{2}, \mathrm{C} 3\right), 41.7\left(\mathrm{CH}_{3}, \mathrm{Me}\right), 25.8\left(\mathrm{CH}_{3}, t \mathrm{Bu}, \mathrm{TBS}\right)$, $18.0(\mathrm{C}, t \mathrm{Bu}, \mathrm{TBS}),-5.8\left(\mathrm{CH}_{3}, \mathrm{Me}, \mathrm{TBS}\right),-5.8\left(\mathrm{CH}_{3}, \mathrm{Me}, \mathrm{TBS}\right)$.

IR (neat) cm cm $^{-1} 3333$ (br, O-H), 2929 (w, C-H). 2857 (m, C-H), 2795 (w, C-H), 1521 (s, CC), 1346 (s, N-C), 1253 (m, N-C), 1110 (s, C-O), 833 (s, C-H and Si-C), 775 (s, Si-C).

HRMS (ESI) $m / z$ : found 355.2054, calcd for $\mathrm{C}_{17} \mathrm{H}_{30} \mathrm{~N}_{2} \mathrm{O}_{4} \mathrm{Si}[\mathrm{M}+\mathrm{H}]^{+} 355.2048(\Delta=1.7 \mathrm{ppm})$.

Specific rotation: $[a]_{D}{ }^{23}=+12.6\left(c=0.400, \mathrm{CH}_{2} \mathrm{Cl}_{2}\right)$. (Lit. for $(1 S, 2 S)$-isomer: $-15.8(c=1.09$, $\left.\left.\mathrm{CHCl}_{3}\right).\right)^{47}$

The NMR and IR data matches those reported for the $(1 S, 2 S)$-isomer, and the optical rotation data obtained has opposite sign. ${ }^{47}$

\section{$(1 R, 2 R)-1,3-B i s-(t$-butyldimethylsilyloxy)-2- $N, N$-dimethylamino-1-(4'-nitrophenyl)} propane (239)

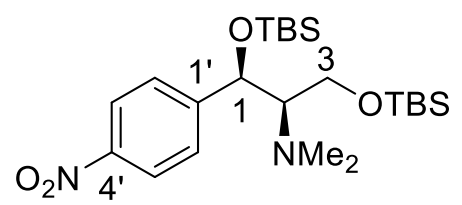
The di-TBS protected product $\mathbf{2 3 9}$ was a minor product in the TBS protection reaction and was obtained as a yellow oil $(62 \mathrm{mg}$, $3 \%) . R_{\mathrm{f}}(3: 1$ pet. Ether:EtOAc $)=0.55$.

${ }^{1} \mathbf{H}$ NMR $\left(500 \mathrm{MHz}, \mathrm{CDCl}_{3}\right) \delta 8.15\left(\mathrm{~d}, J=7.5 \mathrm{~Hz}, 2 \mathrm{H}, 3^{\prime}-\mathrm{CH}\right), 7.50\left(\mathrm{~d}, J=7.9 \mathrm{~Hz}, 2 \mathrm{H}, 2^{\prime}-\right.$ $\mathrm{CH}), 5.01(\mathrm{~d}, J=3.7 \mathrm{~Hz}, 1 \mathrm{H}, 1-\mathrm{CH}), 3.81\left(\mathrm{dd}, J=9.6,7.0 \mathrm{~Hz}, 1 \mathrm{H}\right.$, one of 3-CH $\left.\mathrm{CH}_{2}\right), 3.63(\mathrm{dd}, J$ $=9.7,6.4 \mathrm{~Hz}, 1 \mathrm{H}$, one of 3- $\left.\mathrm{CH}_{2}\right), 2.55$ (app. q, $\left.J=5.5 \mathrm{~Hz}, 1 \mathrm{H}, 2-\mathrm{CH}\right), 2.35\left(\mathrm{~s}, 6 \mathrm{H}, \mathrm{CH}_{3}, \mathrm{Me}\right)$, 0.91 (s, 18H, $\mathrm{CH}_{3}, t \mathrm{Bu}, \mathrm{TBS}$ ), 0.07 (s, 3H, $\mathrm{CH}_{3}, \mathrm{Me}, \mathrm{TBS}$ ), 0.05 (s, 3H, $\mathrm{CH}_{3}, \mathrm{Me}, \mathrm{TBS}$ ), 0.04 (s, 3H, $\mathrm{CH}_{3}, \mathrm{Me}$, TBS), -0.20 (s, 3H, $\mathrm{CH}_{3}, \mathrm{Me}, \mathrm{TBS}$ ). 
${ }^{13} \mathrm{C}$ NMR $\left(125 \mathrm{MHz}, \mathrm{CDCl}_{3}\right) \delta 151.9\left(\mathrm{C}, \mathrm{C}^{\prime}\right), 146.8\left(\mathrm{C}, \mathrm{C} 1{ }^{\prime}\right), 127.6\left(\mathrm{CH}, \mathrm{C} 2{ }^{\prime}\right), 122.8(\mathrm{CH}$, C3'), $74.3(\mathrm{CH}, \mathrm{C} 1), 71.0(\mathrm{CH}, \mathrm{C} 2), 59.3\left(\mathrm{CH}_{2}, \mathrm{C} 3\right), 43.5\left(\mathrm{CH}_{3}, \mathrm{Me}\right), 25.9\left(\mathrm{CH}_{3}, t \mathrm{Bu}, \mathrm{TBS}\right)$, $25.8\left(\mathrm{CH}_{3}, t \mathrm{Bu}, \mathrm{TBS}\right), 18.1$ (C, $\left.t \mathrm{Bu}, \mathrm{TBS}\right),-4.7$ ( $\left.\mathrm{CH}_{3}, \mathrm{Me}, \mathrm{TBS}\right),-5.1\left(\mathrm{CH}_{3}, \mathrm{Me}, \mathrm{TBS}\right),-5.38$ $\left(\mathrm{CH}_{3}, \mathrm{Me}, \mathrm{TBS}\right),-5.44\left(\mathrm{CH}_{3}, \mathrm{Me}, \mathrm{TBS}\right)$.

IR (neat) cm $\mathrm{cm}^{-1}: 2929$ (w, C-H). 2857 (m, C-H), 2795 (w, C-H), 1522 (s, C-C), 1388 (s, N-C), 1255 (m, N-C), 1094 (s, C-O), 833 (s, C-H and Si-C), 774 (s, Si-C).

HRMS (ESI) $m / z$ : found 469.2917, calcd for $\mathrm{C}_{23} \mathrm{H}_{45} \mathrm{~N}_{2} \mathrm{O}_{4} \mathrm{Si}_{2}[\mathrm{M}+\mathrm{H}]^{+} 469.2912(\Delta=1.1 \mathrm{ppm})$.

\section{1-Phenyloct-1-yn-3-ol (237)}

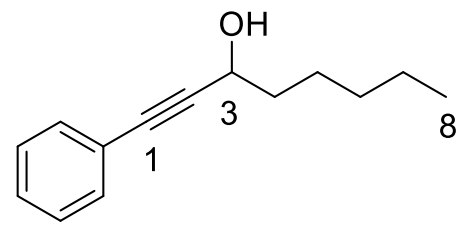

${ }^{1} \mathbf{H}$ NMR $\left(500 \mathrm{MHz}, \mathrm{CDCl}_{3}\right): \delta 7.45-7.40$ (m, 2H, Ph), 7.33-7.29 (m, 3H, Ph), 4.60 (app. q, $J$ $=6.2 \mathrm{~Hz}, 1 \mathrm{H}, 3-\mathrm{CH}), 1.88(\mathrm{~d}, J=5.8 \mathrm{~Hz}, 1 \mathrm{H}, \mathrm{OH}), 1.86-1.74\left(\mathrm{~m}, 2 \mathrm{H}, 4-\mathrm{CH}_{2}\right), 1.57-1.48(\mathrm{~m}$, 2H, 5- $\mathrm{CH}_{2}$ ), 1.40-1.31 (complex m, 4H, 6- $\mathrm{CH}_{2}$ and 7- $\mathrm{CH}_{2}$ ), 0.91 (t, $J=7.0 \mathrm{~Hz}, 3 \mathrm{H}, 8-\mathrm{CH}_{3}$ ).

${ }^{13} \mathrm{C}$ NMR (125 MHz, $\left.\mathrm{CDCl}_{3}\right): \delta 131.7(\mathrm{CH}, \mathrm{Ph}), 128.3(\mathrm{CH}, \mathrm{Ph}), 128.3(\mathrm{CH}, \mathrm{Ph}), 122.7(\mathrm{C}$, Ph), 90.2 (C, C2), 84.8 (C, C1), $63.0(\mathrm{CH}, \mathrm{C} 3), 37.9\left(\mathrm{CH}_{2}, \mathrm{C} 4\right), 31.5\left(\mathrm{CH}_{2}, \mathrm{C} 6 / \mathrm{C} 7\right), 24.9\left(\mathrm{CH}_{2}\right.$, C5), $22.6\left(\mathrm{CH}_{2}, \mathrm{C} 6 / \mathrm{C} 7\right), 14.0\left(\mathrm{CH}_{3}, \mathrm{C} 8\right)$.

These data were consistent with those reported previously. ${ }^{59}$

1'-(para-Methoxybenzyloxy)-6' -hydroxy-10' -( $t$-butyldimethylsilyloxy)dec-4' -yn-2' -yl 3phenylprop-2-enoate (240)

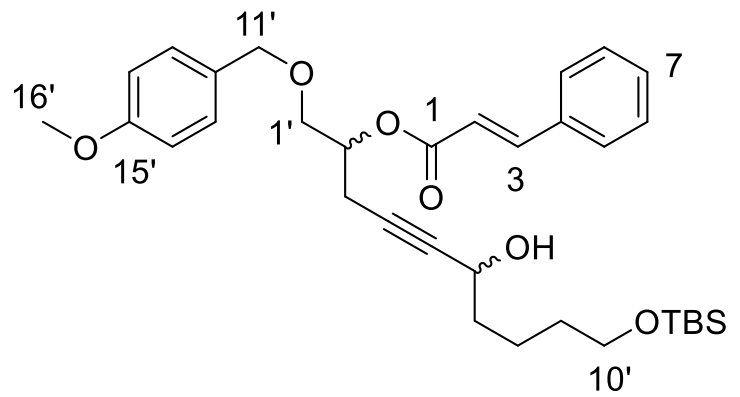

To a solution of alkyne 234 (98 $\mathrm{mg}, 0.28 \mathrm{mmol})$, $(R, R)$-ProPhenol (13 $\mathrm{mg}, 0.020 \mathrm{mmol})$ and triphenylphosphine oxide $(11 \mathrm{mg}, 0.040 \mathrm{mmol})$ in toluene $(0.3 \mathrm{~mL})$ at r.t., $\mathrm{Et}_{2} \mathrm{Zn}(0.30 \mathrm{~mL}, 1.0$ $\mathrm{M}$ in hexane, $0.30 \mathrm{mmol}$ ) was added dropwise. After the reaction was stirred at r.t. for $64 \mathrm{~h}$, a 
solution of aldehyde 177 (38 $\mathrm{mg}, 0.18 \mathrm{mmol})$ in toluene $(0.3 \mathrm{~mL})$ was added. The reaction was stirred at r.t. for an additional $24 \mathrm{~h}$, and then quenched with sat. aq. $\mathrm{NH}_{4} \mathrm{Cl}(15 \mathrm{~mL})$. The reaction mixture was extracted with $\mathrm{Et}_{2} \mathrm{O}(3 \times 20 \mathrm{~mL})$, and the organic layers were combined, dried over $\mathrm{MgSO}_{4}$ and concentrated under reduced pressure. The crude product was purified by column chromatography $\left(\mathrm{SiO}_{2}, 5: 1\right.$ Pet. ether:EtOAc) to yield the product $\mathbf{2 4 0}$ as a colourless, clear oil (76 mg, $76 \%$ yield).

${ }^{1} \mathbf{H}$ NMR (500 MHz, $\left.\mathrm{CDCl}_{3}\right): \delta 7.71(\mathrm{~d}, J=15.9 \mathrm{~Hz}, 1 \mathrm{H}, 3-\mathrm{CH}), 7.56-7.50(\mathrm{~m}, 2 \mathrm{H}, 5-\mathrm{CH})$, 7.41-7.36 (complex m, 3H, 6-CH \& 7-CH), 7.27 (obs. d, $J=7.1 \mathrm{~Hz}, 2 \mathrm{H}, 14$ '-CH), 6.88 (d, $J=$ $\left.7.5 \mathrm{~Hz}, 2 \mathrm{H}, 13^{\prime}-\mathrm{CH}\right), 6.46$ (d, $\left.J=16.0 \mathrm{~Hz}, 1 \mathrm{H}, 2-\mathrm{CH}\right), 5.21$ (app. quin, $J=5.2 \mathrm{~Hz}, 1 \mathrm{H}, 2^{\prime}-\mathrm{CH}$ ), $4.55\left(\mathrm{~d}, J=11.9 \mathrm{~Hz}, 1 \mathrm{H}\right.$, one of 11'- $\left.\mathrm{CH}_{2}\right), 4.49\left(\mathrm{~d}, J=11.7 \mathrm{~Hz}, 1 \mathrm{H}\right.$, one of $\left.11^{\prime}-\mathrm{CH}_{2}\right), 4.34-$ 4.27 (m, 1H, 6'-CH), 3.79 (s, 3H, $\left.\mathrm{CH}_{3}, \mathrm{C} 16^{\prime}\right), 3.72-3.63\left(\mathrm{~m}, 2 \mathrm{H}, 1^{\prime}-\mathrm{CH}_{2}\right), 3.59$ (t, $J=6.2 \mathrm{~Hz}$, $\left.2 \mathrm{H}, 10^{\prime}-\mathrm{CH}_{2}\right), 2.69\left(\mathrm{dd}, J=16.7,6.8 \mathrm{~Hz}, 1 \mathrm{H}\right.$, one of 3'- $\left.\mathrm{CH}_{2}\right), 2.63(\mathrm{dd}, J=16.8,5.9 \mathrm{~Hz}, 1 \mathrm{H}$, one of 3'- $\mathrm{CH}_{2}$ ), 1.81 (br. s, $1 \mathrm{H}, \mathrm{OH}$ ), 1.72-1.58 (m, 2H, 7'- $\mathrm{CH}_{2}$ ), 1.53 (app. quin, $J=6.3 \mathrm{~Hz}$, $2 \mathrm{H}, 9^{\prime}-\mathrm{CH}_{2}$ ), 1.46 (app. quin, $J=6.6 \mathrm{~Hz}, 2 \mathrm{H}, 8^{\prime}-\mathrm{CH}_{2}$ ), 0.88 (s, 9H, $\mathrm{CH}_{3}, t \mathrm{Bu}, \mathrm{TBS}$ ), 0.04 (s, $\left.6 \mathrm{H}, \mathrm{CH}_{3}, \mathrm{Me}, \mathrm{TBS}\right)$.

${ }^{13}$ C NMR (126 MHz, $\left.\mathrm{CDCl}_{3}\right): \delta 166.3$ (C, C1), 159.3 (C, C15'), 145.4 (CH, C3), 134.3 (C, C4), 130.4 (CH, C7), 129.9 (C, C12'), 129.4 (CH, C14'), 128.9 (CH, C6), 128.1 (CH, C5), 117.8 $(\mathrm{CH}, \mathrm{C} 2), 113.8\left(\mathrm{CH}, \mathrm{C} 13^{\prime}\right), 83.5$ (C, C5'), 80.3 (C, C4'), $73.0\left(\mathrm{CH}_{2}, \mathrm{C} 11^{\prime}\right), 70.9$ (CH, C2'), $\left.69.3\left(\mathrm{CH}_{2}, \mathrm{Cl}^{\prime}\right), 63.0\left(\mathrm{CH}_{2}, \mathrm{C} 10^{\prime}\right), 62.5(\mathrm{CH}, \mathrm{C6})^{\prime}\right), 55.3\left(\mathrm{CH}_{3}, \mathrm{PMB}\right), 37.7\left(\mathrm{CH}_{2}, \mathrm{C}^{\prime}\right), 32.4$ $\left(\mathrm{CH}_{2}, \mathrm{C}^{\prime}\right), 26.0\left(\mathrm{CH}_{3}, t \mathrm{Bu}, \mathrm{TBS}\right), 21.5\left(\mathrm{CH}_{2}, \mathrm{C} 8^{\prime}\right), 21.2\left(\mathrm{CH}_{2}, \mathrm{C}^{\prime}\right), 18.3(\mathrm{C}, t \mathrm{Bu}, \mathrm{TBS}),-5.3$ $\left(\mathrm{CH}_{3}, \mathrm{Me}, \mathrm{TBS}\right)$.

IR (neat) cm $\mathrm{cm}^{-1}: 3477$ (br, O-H), 3190 (w, C-H), 2933 (m, C-H). 2857 (m, C-H), 1712 (s, C=O), 1637 (m, C-C), 1513 (m, C-C), 1388 (m, C-H), 1280 (m, C-H), 1248 (s, C-O), 1171 (s, CO), 1095 (s, C-O), 1033 (s, C-O), 833 (s, C-Si), 767 (s, C-Si), 682 (C-H).

HRMS (ESI) $m / z$ : found 605.2698, calcd for $\mathrm{C}_{33} \mathrm{H}_{46} \mathrm{O}_{6} \mathrm{SiK}[\mathrm{M}+\mathrm{K}]^{+} 605.2695(\Delta=0.5 \mathrm{ppm})$.

Specific rotation: $[a]_{D}{ }^{21}=-0.51\left(c=1.36, \mathrm{CH}_{2} \mathrm{Cl}_{2}\right)$. 


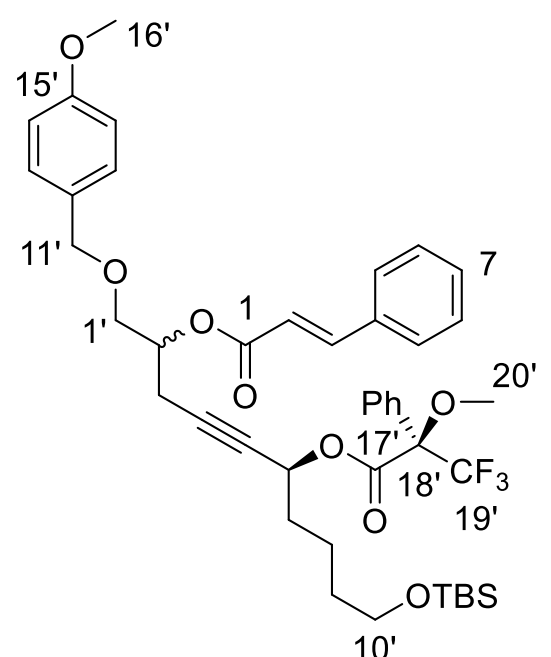

$\left(6^{\prime} R\right)-241$

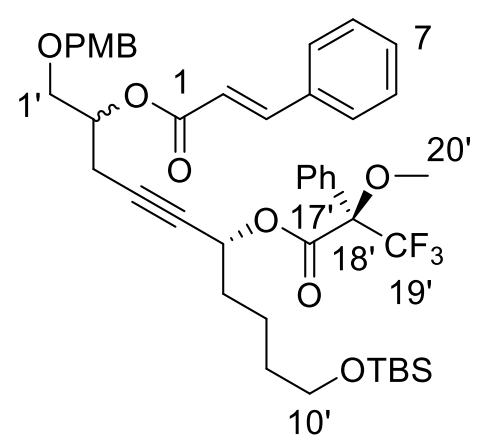

(6'S)-241

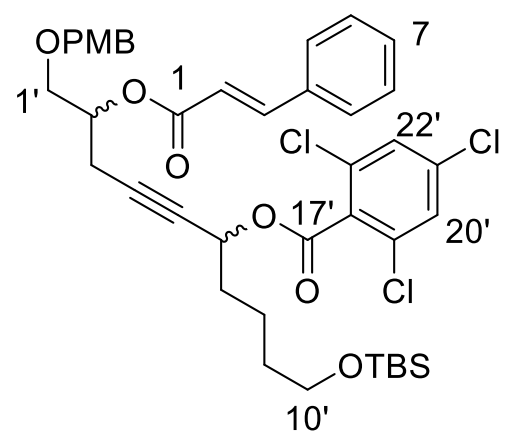

242

To a solution of $(R)$-methoxy- $\alpha$-(trifluoromethyl)phenylacetic acid $(11 \mathrm{mg}, 0.047 \mathrm{mmol})$ in toluene $(0.2 \mathrm{~mL}, 0.24 \mathrm{M})$ at r.t., $\mathrm{Et}_{3} \mathrm{~N}(147 \mu \mathrm{L}, 107 \mathrm{mg}, 1.06 \mathrm{mmol})$ and 2,4,6-trichlorobenzoyl chloride $(12 \mu \mathrm{L}, 19 \mathrm{mg}, 0.078 \mathrm{mmol})$ were added. After stirring at r.t. for $1 \mathrm{~h} 10 \mathrm{~min}$, a solution of alcohol 240 (17 mg, $0.030 \mathrm{mmol})$ and DMAP $(6 \mathrm{mg}, 0.05 \mathrm{mmol})$ in toluene $(0.2 \mathrm{~mL})$ was added dropwise. The reaction was stirred for $20 \mathrm{~h}$ at r.t.. The solvent was removed under reduced pressure, and the crude product was purified by column chromatography $\left(\mathrm{SiO}_{2}, 5: 1\right.$ Pet. ether:EtOAc, $\mathrm{R}_{\mathrm{f}}=0.33$ ) to yield two fractions consisting of mixtures of isomeric products $\mathbf{2 4 1}$ and by-product $\mathbf{2 4 2}$ as colourless oils (The $11 \mathrm{mg}$ sample contains more by-product $\mathbf{2 4 2}$, and $3 \mathrm{mg}$ with less 242).

Table 5.1: Molar ratios of $6^{\prime} R$-241, $6^{\prime} S-\mathbf{2 4 1}$ and 242 in the $11 \mathrm{mg}$ and $3 \mathrm{mg}$ samples, calculated based on the ${ }^{1} \mathrm{H}$ NMR integrals of $2^{\prime}-\mathrm{CH}$.

\begin{tabular}{|c|c|c|c|}
\hline \multirow{2}{*}{} & \multicolumn{3}{|c|}{ Molar ratios of isomeric products 241 and by-product $\mathbf{2 4 2}$} \\
\cline { 2 - 4 } & $\left(6^{\prime} R\right)-\mathbf{2 4 1}$ & $\left(6^{\prime} S\right)-\mathbf{2 4 1}$ & $\mathbf{2 4 2}$ \\
\hline $11 \mathrm{mg}$ sample & 3 & 2 & 3 \\
\hline $3 \mathrm{mg}$ sample & 3 & 2 & 1 \\
\hline
\end{tabular}

${ }^{1} \mathbf{H}$ NMR of the $3 \mathrm{mg}$ sample $\left(600 \mathrm{MHz}, \mathrm{CDCl}_{3}\right): \delta 7.695$ and $7.686(2 \times \mathrm{d}, J=16.1 \mathrm{~Hz}, 0.17 \mathrm{H}$, 3-CH-242), 7.690 and $7.677\left(2 \times \mathrm{d}, J=16.1 \mathrm{~Hz}, 0.33 \mathrm{H}, 3-\mathrm{CH}-\left(6^{\prime} S\right)-241\right), 7.683$ and 7.677 (2 $\left.\times \mathrm{d}, J=16.1 \mathrm{~Hz}, 0.50 \mathrm{H}, 3-\mathrm{CH}-\left(6^{\prime} R\right)-241\right), 7.56-7.50(\mathrm{~m}, 1 \mathrm{H}, \mathrm{CH}, \mathrm{Ph}), 7.52-7.47(\mathrm{~m}, 2 \mathrm{H}, \mathrm{CH}$, $\mathrm{Ph}), 7.31$ (s, 0.17H, 20'/22'-CH-242), 7.30 (s, 0.17H, 20'/22'-CH-242), 7.41-7.35 (m, 5H, CH, 
$\mathrm{Ph}), 7.27-7.22$ 2H (m, 1H, CH, Ph), 6.86 (d, $\left.J=8.6 \mathrm{~Hz}, 2 \mathrm{H}, 13^{\prime}-\mathrm{CH}\right), 6.445$ and $6.441(2 \times \mathrm{d}$, $J=16.0 \mathrm{~Hz}, 0.17 \mathrm{H}, 2-\mathrm{CH}-242), 6.435$ and $6.408\left(2 \times \mathrm{d}, J=16.0 \mathrm{~Hz}, 0.33 \mathrm{H}, 2-\mathrm{CH}-\left(6^{\prime} S\right)-241\right)$, 6.415 and $6.410\left(2 \times \mathrm{d}, J=16.0 \mathrm{~Hz}, 0.50 \mathrm{H}, 2-\mathrm{CH}-\left(6^{\prime} R\right)-241\right), 5.59\left(\mathrm{t}, J=6.9 \mathrm{~Hz}, 0.17 \mathrm{H}, 6^{\prime}-\right.$ CH-242), 5.53-5.49 (m, 0.50H, 6'-CH-(6'R)-241), 5.49-5.46 (m, 0.33H, 6'-CH-(6'S)-241), 5.22-5.13 (m, 1H, 2'-CH), 4.55-4.43 (m, 2H, 11'- $\left.\mathrm{CH}_{2}\right), 3.78\left(\mathrm{~s}, 3 \mathrm{H}, 16^{\prime}-\mathrm{CH}_{3}\right), 3.55(\mathrm{~s}, 1.5 \mathrm{H}$, $\left.20^{\prime}-\mathrm{CH}_{3}-\left(6^{\prime} R\right)-241\right), 2.53$ (s, 1.0H, 20'- $\left.\mathrm{CH}_{3}-\left(6^{\prime} S\right)-241\right), 3.72-3.61$ (m, 2H, 1'- $\left.\mathrm{CH}_{2}\right), 3.61-3.50$ (m, 2H, 10'- $\mathrm{CH}_{2}$ ), 2.76-2.60 (m, 2H, 3'- $\left.\mathrm{CH}_{2}\right), 1.93-1.87$ (m, 0.34H, 9'- $\left.\mathrm{CH}_{2}-242\right), 1.87-1.82$ (m, 0.66H, 9'- $\left.\mathrm{CH}_{2}-\left(6^{\prime} S\right)-241\right), 1.82-1.69$ (m, 1.0H, 9'- $\left.\mathrm{CH}_{2}-\left(6^{\prime} R\right)-241\right), 1.57-1.47$ (m, 0.34H, 7'- $\mathrm{CH}_{2}-242$ and 8'- $\left.\mathrm{CH}_{2}-242\right), 1.48-1.40\left(\mathrm{~m}, 3.32 \mathrm{H}, 7^{\prime}-\mathrm{CH}_{2}-\left(6^{\prime} R\right)\right.$ and $\left(6^{\prime} S\right)-241$ and $8^{\prime}-\mathrm{CH}_{2}-$ $\left(6^{\prime} R\right)$ and $\left.\left(6^{\prime} S\right)-241\right), 0.873$ and 0.869 and $0.866(\mathrm{~s}, 9 \mathrm{H}, t \mathrm{Bu}, \mathrm{TBS}), 0.027$ and 0.018 and 0.011 (s, 6H, Me, TBS)

${ }^{13} \mathrm{C}$ NMR $\left(150 \mathrm{MHz}, \mathrm{CDCl}_{3}\right) \delta 166.16$ and $166.14(\mathrm{C}, \mathrm{C} 1), 165.71$ and 165.70 and 165.64 and $165.63\left(\mathrm{C}, \mathrm{C} 17^{\prime}\right), 163.7\left(\mathrm{CH}, \mathrm{C} 6^{\prime}\right), 159.24$ and $159.22\left(\mathrm{C}, \mathrm{C} 15^{\prime}\right), 145.43$ and 145.42 and 145.38 $\left(\mathrm{CH}, \mathrm{C} 3-\left(6^{\prime} R\right)\right.$ and $\left.\left(6^{\prime} S\right)-241\right), 145.33$ and $145.31(\mathrm{CH}, \mathrm{C} 3-242), 135.04$ and $134.40(\mathrm{C}$, C18'/C19'/21'-242), 134.30 and 134.29 (C, C4-242), 134.26 and 134.25 and 134.23 and 134.21 (C, C4-(6'R) and (6'S)-241), 132.68 (C, C18'/19'/21'-242), 132.42 (C, Ph), 132.32 (C, Ph),

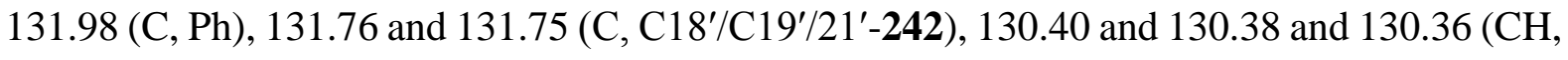
$\mathrm{Ph}), 129.93$ and 129.89 and 129.87 and 129.85 and 129.84 (C, C12'), $129.60(\mathrm{CH}, \mathrm{Ph}), 129.30$ $(\mathrm{CH}, \mathrm{Ph}), 128.86(\mathrm{CH}, \mathrm{Ph}), 128.37$ and 128.35 and $128.34(\mathrm{CH}, \mathrm{Ph}), 128.18$ and 128.13 and $128.12(\mathrm{CH}, \mathrm{Ph}), 127.98$ and $127.97\left(\mathrm{CH}, \mathrm{C} 20^{\prime}-242\right), 127.44$ and $127.30(\mathrm{CH}, \mathrm{Ph}), 117.81$ and 117.80 and 117.72 and 117.71 and 117.68 and $117.65(\mathrm{CH}, \mathrm{C} 2), 113.77$ and 113.77 and 113.76 $\left(\mathrm{CH}, \mathrm{C} 13^{\prime}\right), 82.39$ and 82.38 (C, C4'-(6'R)-241), 82.24 and 82.23 (C, C4'-(6'S)-241), 82.21(C, C4'-242), 78.73 and 78.72 (C, C5'-242), 78.62 and 78.60 (C, C5'-(6'R)-241), 78.44 and 78.43 (C, C5'-(6'S)-241), 73.04 and $73.02\left(\mathrm{CH}_{2}, \mathrm{C}^{\prime} 1^{\prime}\right), 70.61$ and 70.59 and 70.51 and 70.49 and $70.48\left(\mathrm{CH}, \mathrm{C} 2{ }^{\prime}\right), 69.31$ and 69.22 and 69.21 and 69.17 and $69.15\left(\mathrm{CH}_{2}, \mathrm{C} 1^{\prime}\right), 66.7\left(\mathrm{CH}, \mathrm{C6}^{\prime}-\right.$ $\left(6^{\prime} R\right)$ and (6'S)-241), 66.37 and $66.34\left(\mathrm{CH}, \mathrm{C}^{\prime}{ }^{\prime}-\mathbf{2 4 2}\right), 62.79$ and $62.73\left(\mathrm{CH}_{2}, \mathrm{C} 10^{\prime}\right), 55.49$ and $55.44\left(\mathrm{CH}_{3}, \mathrm{C}^{2} 0^{\prime}-\left(6^{\prime} R\right)\right.$ and $\left.\left(6^{\prime} S\right)-241\right), 55.2\left(\mathrm{CH}_{3}, \mathrm{C}^{\prime} 6^{\prime}\right), 34.58$ and 34.41 and $34.39\left(\mathrm{CH}_{2}, \mathrm{C}^{\prime}\right)$, 32.15 and 32.10 and $32.02\left(\mathrm{CH}_{2}, \mathrm{C}^{\prime}\right), 25.94$ and $25.92\left(\mathrm{CH}_{3}, t \mathrm{Bu}, \mathrm{TBS}\right), 21.55$ and 21.45 and 21.26 and $21.20\left(\mathrm{CH}_{2}, \mathrm{C}^{\prime}\right), 21.14$ and 21.13 and 21.09 and $21.06\left(\mathrm{CH}_{2}, \mathrm{C}^{\prime}\right), 18.32$ and 18.30 (C, $t \mathrm{Bu}, \mathrm{TBS}),-5.31$ and $-5.34\left(\mathrm{CH}_{3}, \mathrm{Me}, \mathrm{TBS}\right)$.

HRMS (ESI) $m / z$ : 241 found 800.3815, calcd for $\mathrm{C}_{43} \mathrm{H}_{57} \mathrm{~F}_{3} \mathrm{O}_{8} \mathrm{SiN}\left[\mathrm{M}+\mathrm{NH}_{4}\right]^{+} 800.3800(\Delta=$ 1.9); 242 found 811.1802, calcd for $\mathrm{C}_{40} \mathrm{H}_{57}{ }^{35} \mathrm{Cl}_{3} \mathrm{O}_{7} \mathrm{SiK}[\mathrm{M}+\mathrm{K}]^{+} 811.1788$ ( $\Delta=1.8 \mathrm{ppm}$ ). 
1'-(para-Methoxybenzyloxy)-6' -hydroxy-10' -( $t$-butyldimethylsilyloxy)dec-4' -yn-2' -yl 5methyl-7-( $t$-butyldimethylsilyloxy)non-2,4,8-trienoate (244)

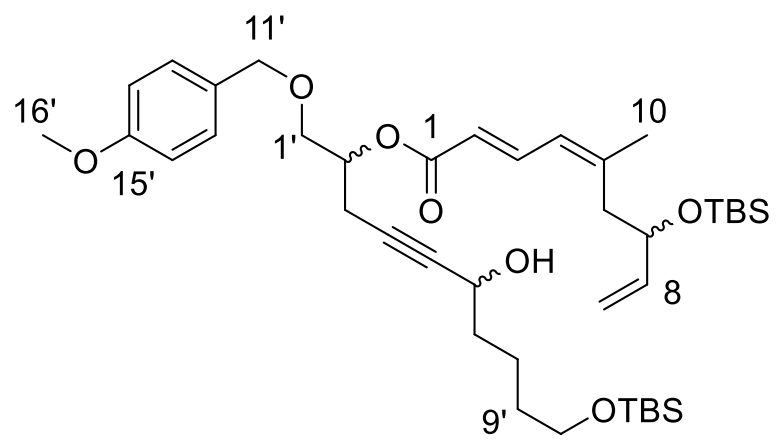

To a solution of 208 (48 $\mathrm{mg}, 0.096 \mathrm{mmol})$, $(R, R)$-ProPhenol (12 mg, $0.019 \mathrm{mmol})$ and TPPO (11 mg, $0.038 \mathrm{mmol})$ in toluene $(0.25$ $\mathrm{mL})$ at r.t., a solution of $\mathrm{Et}_{2} \mathrm{Zn}(0.11 \mathrm{~mL}, 1.0$ $\mathrm{M}$ in cyclohexane, $0.11 \mathrm{mmol})$ was added dropwise. The reaction was stirred for $71 \mathrm{~h}$, and a solution of aldehyde 177 (26 mg, 0.120

$\mathrm{mmol})$ in toluene $(0.1 \mathrm{~mL})$ was added dropwise. After stirring for $23 \mathrm{~h}$ at r.t., the reaction was quenched with sat. aq. $\mathrm{NH}_{4} \mathrm{Cl}(10 \mathrm{~mL})$, and extracted with $\mathrm{CH}_{2} \mathrm{Cl}_{2}(3 \times 20 \mathrm{~mL})$. The organic layers were combined, dried over $\mathrm{MgSO}_{4}$ and concentrated under reduced pressure. The crude product was purified by column chromatography $\left(\mathrm{SiO}_{2}\right.$, gradient elution: 20:1 then 10:1 then 5:1 Pet. ether:EtOAc, then $100 \%$ EtOAc, $\mathrm{R}_{\mathrm{f}}=0.15$ in 5:1 Pet. ether:EtOAc). Unsatisfactory separation was achieved, and the mixture containing the majority of the desired product isomers $(11 \mathrm{mg})$ were further purified by column chromatography $\left(\mathrm{SiO}_{2}, 100 \% \mathrm{CH}_{2} \mathrm{Cl}_{2}, \mathrm{R}_{\mathrm{f}}=\right.$ 0.06) to yield the product as a colourless, clear oil ( $3 \mathrm{mg}, 4 \%$ yield). Evidence of a trace amount of the 2Z-isomer of $\mathbf{2 4 4}$ was observed. Due to the complexity of the mixture and the weak signals from the minor compounds, only the signals of the major compound were quoted below.

${ }^{1} \mathbf{H}$ NMR $\left(600 \mathrm{MHz}, \mathrm{CDCl}_{3}\right): \delta 7.57(\mathrm{dd}, J=15.0,11.5 \mathrm{~Hz}, 1 \mathrm{H}, 3-\mathrm{CH}), 7.25(\mathrm{~d}, J=7.5 \mathrm{~Hz}$, 2H, 14'-CH), 6.87 (d, J=7.2 Hz, 2H, 13'-CH), 6.06 (d, J = 11.6 Hz, 1H, 4-CH), 5.86-5.73 (m, $1 \mathrm{H}, 8-\mathrm{CH}), 5.79(\mathrm{~d}, J=15.0 \mathrm{~Hz}, 1 \mathrm{H}, 2-\mathrm{CH}), 5.17\left(\mathrm{~d}, J=17.4 \mathrm{~Hz}, 1 \mathrm{H}\right.$, one of 9- $\left.\mathrm{CH}_{2}\right), 5.22-$ $5.10\left(\mathrm{~m}, 1 \mathrm{H}, 2^{\prime}-\mathrm{CH}\right), 5.04\left(\mathrm{~d}, J=10.3 \mathrm{~Hz}, 1 \mathrm{H}\right.$, one of 9- $\left.\mathrm{CH}_{2}\right), 4.53(\mathrm{~d}, J=11.9 \mathrm{~Hz}, 1 \mathrm{H}$, one of $\left.11^{\prime}-\mathrm{CH}_{2}\right), 4.47$ (d, $J=11.5 \mathrm{~Hz}, 1 \mathrm{H}$, one of $11^{\prime}-\mathrm{CH}_{2}$ ), 4.29 (app. q, $\left.J=5.7 \mathrm{~Hz}, 1 \mathrm{H}, 6^{\prime}-\mathrm{CH}\right), 4.24$ (app. q, $J=6.7 \mathrm{~Hz}, 1 \mathrm{H}, 7-\mathrm{CH}), 3.80$ (s, 3H, 16'- $\mathrm{CH}_{3}$ ), 3.69-3.54 (complex m, 4H, 1'- $\mathrm{CH}_{2}$ and $10^{\prime}-\mathrm{CH}_{2}$ ), 2.69-2.52 (complex m, 3H, 6- $\mathrm{CH}_{2}$ and one of 3'- $\left.\mathrm{CH}_{2}\right), 2.40-2.30$ (m, 1H, one of 3'$\mathrm{CH}_{2}$ ), 1.91 (s, 3H, 10- $\mathrm{CH}_{3}$ ), 1.80-1.29 (complex m, 6H, 7'- $\mathrm{CH}_{2}, 8^{\prime}-\mathrm{CH}_{2}$ and 9'- $\mathrm{CH}_{2}$ ), 0.94$0.81(\mathrm{~m}, 18 \mathrm{H}, \mathrm{TBS}), 0.08--0.02(\mathrm{~m}, 12 \mathrm{H}, \mathrm{TBS})$.

${ }^{13}$ C NMR (150 MHz, $\left.\mathrm{CDCl}_{3}\right): \delta 166.8(\mathrm{C}, \mathrm{C} 1), 159.2\left(\mathrm{C}, \mathrm{C} 15^{\prime}\right), 146.8$ (C, C5), 141.9 (CH, C3), 140.89 and 140.87 and 140.85 (CH, C8), 130.0 (C, C12'), 129.3 (CH, C13'), 126.1 (CH, C4), $118.7(\mathrm{CH}, \mathrm{C} 2), 114.2\left(\mathrm{CH}_{2}, \mathrm{C} 9\right), 113.7\left(\mathrm{CH}, \mathrm{C} 14^{\prime}\right), 83.3\left(\mathrm{C}, \mathrm{C} 5^{\prime}\right), 80.46$ and $80.45\left(\mathrm{C}, \mathrm{C}^{\prime}\right)$, $72.9\left(\mathrm{CH}_{2}, \mathrm{C} 11^{\prime}\right), 72.79$ and $72.77(\mathrm{CH}, \mathrm{C} 7), 70.45$ and $70.43\left(\mathrm{CH}, \mathrm{C}^{\prime}\right), 69.31$ and $69.27\left(\mathrm{CH}_{2}\right.$, 
$\left.\mathrm{Cl}^{\prime}\right), 63.0\left(\mathrm{CH}_{2}, \mathrm{C} 10^{\prime}\right), 62.5\left(\mathrm{CH}, \mathrm{C}^{\prime}\right), 55.3\left(\mathrm{CH}_{3}, \mathrm{Cl}^{\prime}\right), 41.7\left(\mathrm{CH}_{2}, \mathrm{C} 6\right), 37.7\left(\mathrm{CH}_{2}, \mathrm{C}^{\prime}\right), 32.4$

$\left(\mathrm{CH}_{2}, \mathrm{C}^{\prime}\right), 26.0$ and $25.8\left(\mathrm{CH}_{3}, t \mathrm{Bu}, \mathrm{TBS}\right), 25.6$ and $25.5\left(\mathrm{CH}_{3}, \mathrm{C} 10\right), 21.5\left(\mathrm{CH}_{2}, \mathrm{C} 8^{\prime}\right), 21.2$ $\left(\mathrm{CH}_{2}, \mathrm{C}^{\prime}\right), 18.4$, and $18.3(\mathrm{C}, t \mathrm{Bu}, \mathrm{TBS}),-4.6$ and -4.9 and -5.27 and $-5.33\left(\mathrm{CH}_{3}, \mathrm{Me}, \mathrm{TBS}\right)$.

HRMS (ESI) $m / z$ : found 715.4453, calcd for $\mathrm{C}_{40} \mathrm{H}_{67} \mathrm{O}_{7} \mathrm{Si}_{2}[\mathrm{M}+\mathrm{H}]^{+} 715.4420(\Delta=4.6 \mathrm{ppm})$.

\subsection{References}

(1) Mosey, R. A.; Floreancig, P. E. Nat. Prod. Rep. 2012, 29, 980.

(2) Bielitza, M.; Pietruszka, J. Angew. Chem. Int. Ed. 2013, 52, 10960.

(3) Halli, J.; Hofman, K.; Beisel, T.; Manolikakes, G. Eur. J. Org. Chem. 2015, 4624.

(4) Zhang, Y.; Dai, Y.; Li, G.; Cheng, X. Synlett 2014, 25, 2644.

(5) Bayer, A.; Maier M. E. Tetrahedron 2004, 60, 6665.

(6) Kiren, S.; Shangguan, N.; Williams, L. J. Tetrahedron Lett. 2007, 48, 7456.

(7) Cergol, K. M.; Coster, M. J. Nature Protocols 2007, 2, 2568.

(8) Brown, H. C.; Ayyangar, N. R.; Zweifel, G. J. Am. Chem. Soc. 1964, 86, 1071.

(9) Chandrasekharan, J.; Ramachandran, P. V.; Brown, H. C. J. Org. Chem. 1985, 50, 5446.

(10) Zhao, M. Z.; King, A. O.; Larsen, R. D.; Verhoeven, T. R.; Reider, P. J. Tetrahedron Lett. 1997, 38, 2641.

(11) Troast, D. M.; Porco, J. A. Org. Lett. 2002, 4, 991.

(12) Uyanik, M.; Suzuki, D.; Yasui, T.; Ishihara, K. Angew. Chem. Int. Ed. 2011, 50, 5331.

(13) Wu, X. F.; Gong, J. L.; Qi, X. X. Org. Biomol. Chem. 2014, 12, 5807.

(14) Kano, T.; Mii, H.; Maruoka, K. J. Am. Chem. Soc. 2009, 131, 3450.

(15) Gotoh, H.; Hayashi, Y. Chem. Commun. 2009, 3083.

(16) Ghosh, A. K.; Cheng, X.; Bai, R.; Hamel, E. Eur. J. Org. Chem. 2012, 4130.

(17) Ding, F.; Jennings, M. P. Org. Lett. 2005, 7, 2321.

(18) Uenishi, J.; Iwamoto, T.; Tanaka, J. Org. Lett. 2009, 11, 3262.

(19) Zurwerra, D.; Gertsch, J.; Altmann, K. H. Org. Lett. 2010, 12, 2302.

(20) Ghosh, A. K.; Cheng, X. Org. Lett. 2011, 13, 4108.

(21) Zurwerra, D.; Glaus, F.; Betschart, L.; Schuster, J.; Gertsch, J.; Ganci, W.; Altmann, K. H. Chem.-Eur. J. 2012, 18, 16868. 
(22) Sanchez, C. C.; Keck, G. E. Org. Lett. 2005, 7, 3053.

(23) Louis, I.; Hungerford, N. L.; Humphries, E. J.; McLeod, M. D. Org. Lett. 2006, 8, 1117.

(24) Yun, S. Y.; Hansen, E. C.; Volchkov, I.; Cho, E. J.; Lo, W. Y.; Lee, D. Angew. Chem. Int. Ed. 2010, 49, 4261.

(25) Nakajima, N.; Abe, R.; Yonemitsu, O. Chem. Pharm. Bull. 1988, 36, 4244.

(26) A. E. J. Nooy, A. C. Besemer, H. van Bekkum, Synthesis 1996, 10, 1153.

(27) Okhlobys.O. Y.; Zakharki.L. I. J. Organomet. Chem. 1965, 3, 257.

(28) Trost, B. M.; Weiss, A. H. Adv. Synth. Catal. 2009, 351, 963.

(29) Trost, B. M.; Bartlett, M. J.; Weiss, A. H.; von Wangelin, A. J.; Chan, V. S. Chem.Eur. J. 2012, 18, 16498.

(30) Trost, B. M.; Michaelis, D. J.; Malhotra, S. Org. Lett. 2013, 15, 5274.

(31) Moore, D.; Pu, L. Org. Lett. 2002, 4, 1855.

(32) Lu, G.; Li, X. S.; Chan, W. L.; Chan, A. S. C. Chem. Commun. 2002, 172.

(33) Gao, G.; Xie, R. G.; Pu, L. P. Natl. Acad. Sci. USA 2004, 101, 5417.

(34) Yang, F.; Xi, P. H.; Yang, L.; Lan, J. B.; Xie, R. G.; You, J. S. J. Org. Chem. 2007, $72,5457$.

(35) Du, Y. H.; Turlington, M.; Zhou, X. A.; Pu, L. Tetrahedron Lett. 2010, 51, 5024.

(36) Chen, S. Y.; Liu, W. N.; Wu, X. D.; Ying, J.; Yu, X. Q.; Pu, L. Chem. Commun. 2015, 51,358 .

(37) Frantz, D. E.; Fassler, R.; Carreira, E. M. J. Am. Chem. Soc. 1999, 121, 11245.

(38) Anand, N. K.; Carreira, E. M. J. Am. Chem. Soc. 2001, 123, 9687.

(39) Boyall, D.; Frantz, D. E.; Carreira, E. M. Org. Lett. 2002, 4, 2605.

(40) Archambaud, S.; Legrand, F.; Aphecetche-Julienne, K.; Collet, S.; Guingant, A.; Evain, M. Eur. J. Org. Chem. 2010, 1364.

(41) Sabitha, G.; Bhikshapathi, M.; Ranjith, N.; Ashwini, N.; Yadav, J. S. Synthesis 2011, 821.

(42) Mahapatra, S.; Carter, R. G. J. Am. Chem. Soc. 2013, 135, 10792.

(43) Williams, B. D.; Smith, A. B. J. Org. Chem. 2014, 79, 9284.

(44) Blundell, D.; New Zealand ministry of health, Ed.; Parliamentary counsel office: 1977.

(45) Kirkham, J. E. D.; Courtney, T. D. L.; Lee, V.; Baldwin, J. E. Tetrahedron 2005, 61, 7219. 
(46) Takita, R.; Yakura, K.; Ohshima, T.; Shibasaki, M. J. Am. Chem. Soc. 2005, 127, 13760.

(47) Jiang, B.; Chen, Z. L.; Xiong, W. N. Chem. Commun. 2002, 1524.

(48) Lombard, J.; Romain, S.; Dumas, S.; Chauvin, J.; Collomb, M. N.; Daveloose, D.; Deronzier, A.; Lepretre, J. C. Eur. J. Inorg. Chem. 2005, 3320.

(49) Pine, S. H.; Sanchez, B. L. J. Org. Chem. 1971, 36, 829.

(50) Gibson, H. W. Chem. Rev. 1969, 69, 673.

(51) Li, Z.; Upadhyay, V.; DeCamp, A. E.; DiMichele, L.; Reider, P. J. Synthesis 1999, 1453.

(52) Seco, J. M.; Quinoa, E.; Riguera, R. Chem. Rev. 2004, 104, 17.

(53) Dale, J. A.; Dull, D. L.; Mosher, H. S. J. Org. Chem. 1969, 34, 2543.

(54) Hoye, T. R.; Jeffrey, C. S.; Shao, F. Nat. Protoc. 2007, 2, 2451.

(55) Tran, H. A.; Kitov, P. I.; Paszkiewicz, E.; Sadowska, J. M.; Bundle, D. R. Org. Biomol. Chem. 2011, 9, 3658.

(56) Otera, J.; Nishikido, J. Esterification: Methods, Reactions, and Applications; John Wiley \& Sons: Weinheim, Germany, 2010.

(57) Sigma-Aldrich compound data for triethylamine hydrochloride, \#90350.

(58) Fanning, K. N.; Jamieson, A. G.; Sutherland, A. Org. Biomol. Chem. 2005, 3, 3749.

(59) Pacheco, M. C.; V, Gouverneur. Org. Lett. 2005, 7, 1267. 


\section{Chapter 6: Summary and Future work}

In this project, progress was made towards the synthesis of zampanolide (19) and its analogues. According to the first-generation synthetic plan, precursors to fragments $\mathrm{C} 1-\mathrm{C} 8, \mathrm{C} 9-\mathrm{C} 15, \mathrm{C} 16-$ C20 and a des-methyl analogue of the C1-C8 fragment were successfully synthesized. However, some difficulties were encountered in advancing the precursors to the desired fragments, namely in protection at the $\mathrm{O} 19$ position, incomplete of Wittig reaction to construct the $\mathrm{C} 2-\mathrm{C} 3$ alkene and oxidation at $\mathrm{C} 15$ of the $\mathrm{C} 9-\mathrm{C} 15$ precursor to aldehyde. The synthesis was then revised, and a more efficient second-generation synthesis utilizing a linchpin approach was developed. This was made possible by the use of Bestmann ylide as a linchpin. This is an expanded application of Bestmann ylide, therefore the scope of the Bestmann ylide reaction to construct $\alpha, \beta, \gamma, \delta$-unsaturated esters (dienoates) was explored, and it was successfully applied to the coupling of the $\mathrm{C} 3-\mathrm{C} 8(\mathbf{1 2 7})$ and $\mathrm{C} 15-\mathrm{C} 20$ (147 and 153) fragments. Late stage strategies were also tested on model compounds, including the side-arm attachment via aza-aldol reaction with chiral boron reagents, oxidation of the C20 alcohol to an aldehyde and C15-C16 alkynylation of aldehydes. Although more research is required, an alkynylation method was found to produce a small amount of the desired product $\mathbf{2 4 4}$, which established 16 out of the 18 carbons of the macrocycle.

Research to optimize the asymmetric alkynylation is already underway, and the alkynylation product 244 will be transformed to an analogue macrocycle using the methods outlined in chapter 3, or a truncated simplified macrocycle in four steps. An alternative route to the C3-C8 fragment (127) is also necessary, due to the scarce supply of the starting material acrolein (93). 


\subsection{Alternatives to the acrolein-dependent C3-C8 fragment}

An alternative method for the synthesis of C3-C8 fragment is required, because of the environmental and safety hazards that acrolein (93) possesses, and the fact that its supply is now expensive and unreliable. Synthesis of 93 from allyl alcohol (246) was briefly attempted (Scheme 6.1, equation 1). To minimise handling of the highly volatile and toxic 93, oxidation of allyl alcohol (246) with $\mathrm{MnO}_{2}$ in THF was performed in the hope that, after a simple filtration, the acrolein (93) solution in THF could be used directly for reaction. However, only a small amount of the allyl alcohol was converted to acrolein (93), and an attempt to purify 93 by distillation did not provide satisfying separation from $\mathbf{2 4 6}$, while loss of product occurred even though the collection vessel was kept at $0{ }^{\circ} \mathrm{C}$.

1)

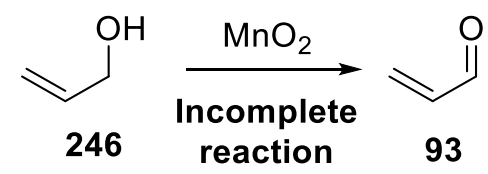

2)

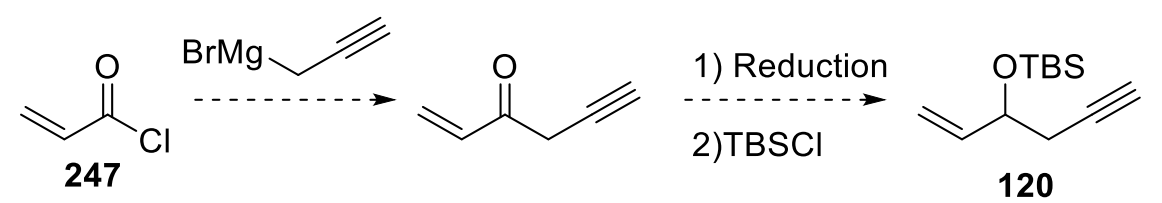

3)
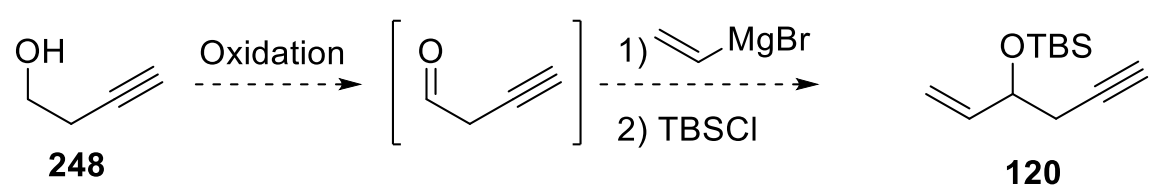

Scheme 6.1: Alternative synthesis of the C3-C8 fragment precursor 120.

Acryloyl chloride (247) was then considered as a starting material, where the chloride can be substituted by a propargyl group. Upon reduction of the ketone and silyl protection, the precursor to C3-C8 fragment, 120, would be produced (Scheme 6.1, equation 2). One foreseen problem in this sequence is that the reaction of the acyl halide is prone to disubstitution, and reaction conditions to minimise the disubstitution can be hard to find. In addition, no commercial supply and little literature precedence was found on the production of the propargyl Grignard reagent, so it could be hard to obtain. Preparation of 120 from but-3-yn-1-ol (248) via a one-pot oxidation and vinyl addition reaction followed by silyl protection was also planned (equation 3). Possible oxidation methods include Swern and TEMPO/BAIB oxidation. 


\subsection{A new strategy involving a dithiane at C15}

Introduced in Chapter 1, dithiane has long been a well-established linchpin, that can be converted to a carbonyl group upon oxidative cleavage. As a protecting group, dithiane allows umpolung-type reactions, where the electrophilic carbon of the carbonyl is converted into a nucleophile. As shown in Scheme 6.2, an approach using a dithiane for the C15 position, together with RCM and the Bestmann ylide linchpin, can lead retrosynthetically to fragments C3-C8 (127), C10-C14 (249) and C15-C20 (250). As discussed in section 3.1, a TBS or MOMprotecting group would be used in fragment 249. The MOM-protected variant of 249 has been previously reported, and the TBS-protected variant can be prepared via a similar strategy. ${ }^{1}$

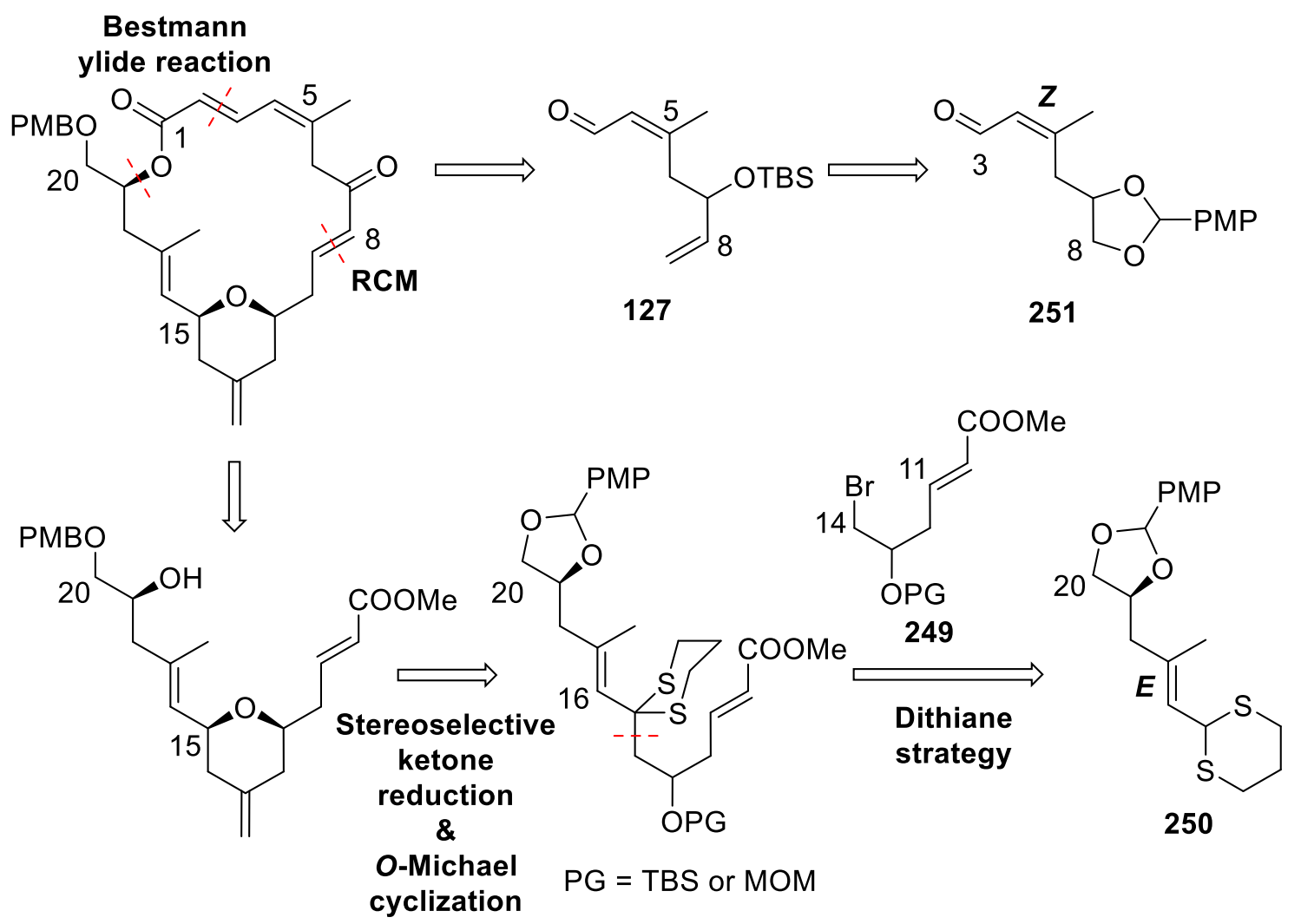

Scheme 6.2: Proposed dithiane approach in retrosynthetic analysis.

Interestingly, the above analysis revealed a symmetry in zampanolide macrocycle, where the C16-C20 fragment (250) is structurally similar to an alternative precursor of the C3-C8 fragment, 251. Therefore, the two fragments 127 and $\mathbf{2 5 0}$ could be synthesized via the same route with late stage modification. This convergent synthesis would improve the efficiency of 
the synthesis greatly. This strategy cannot be applied using the current precursors to the tetrahydropyran fragments. With the hope this would also lead to an alternative route to fragment C3-C8 (127), literature research on the fragment synthesis of this new synthetic plan was carried out.

A divergent synthesis of the $\mathrm{C} 3-\mathrm{C} 8$ and $\mathrm{C} 16-\mathrm{C} 20$ fragments from a common intermediate is theoretically possible. The synthesis can start with a cross-metathesis between the cheap and readily available 3-buten-2-one (252) and allyl alcohol (246) (Scheme 6.3). Grubbs' second generation catalyst can be used for this reaction, because it was reported to promote $E$-selective
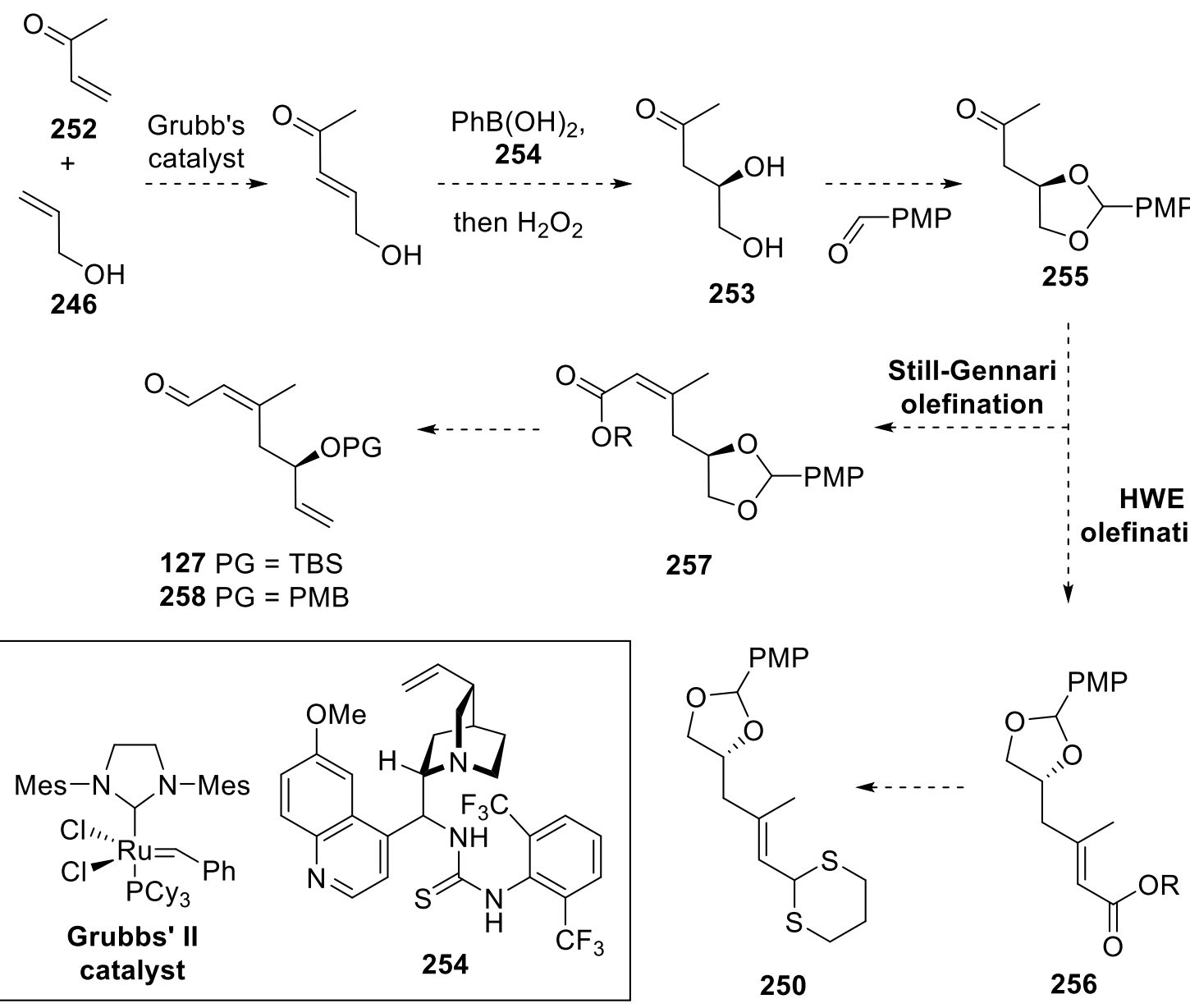

Scheme 6.3: Divergent synthesis of fragments $\mathbf{1 2 7}$ and $\mathbf{2 5 0 .}$

cross-metathesis in the presence of unprotected allyl alcohols. ${ }^{2}$ An asymmetric $O$-Michael reaction, achieved by treatment with phenylboronic acid and hydrogen peroxide, can then be carried out to produce diol 253. This process is facilitated and directed by interaction of the boron reagent with the allylic hydroxyl and chiral amine base $254 .{ }^{3}$ After protecting the diol 
253 as a PMP-acetal (255), ${ }^{4} E$ - and $Z$-selective olefination of the ketone 255 can be used to diverge the synthesis to intermediates $\mathbf{2 5 6}$ and $\mathbf{2 5 7}$. Olefination is a well-explored strategy with a lot of methods available, and can be stereoselective for $Z$ - or $E$-alkenes. ${ }^{5}$ The HornerWadsworth-Emmons (HWE) olefination is reliabe and employs readily available reagents. In general, this olefination favours the formation of $E$-alkenes, and the use of methylmagnesium bromide as the base was reported to improve the $E$-selectivity greatly. ${ }^{6}$ To achieve $Z$-selectivity, Still-Gennari's modification of the HWE olefination using bis(2,2,2-trifluoroethyl) phosphonates can be used. ${ }^{7}$ Both HWE olefination and Still-Gennari's method have been explored mostly on aldehyde substrates. In case that the ketone substrates in this study do not achieve the required stereoselectivity, chromatographic separation of the $E$ - and $Z$-products would be employed. The $E$-isomer $\mathbf{2 5 6}$ would need to be reduced to an aldehyde before the dithiane protection to produce the required fragment 250. The $Z$-isomer 257 can lead to fragment $\mathrm{C} 3-\mathrm{C} 8$ by regioselective acetal ring-opening, oxidation and a Wittig reaction to establish the terminal alkene, followed by conversion of the ester to an aldehyde. Changing the PMB group to a TBS ether would deliver the current C3-C8 fragment 127, although retaining the PMB group in $\mathbf{2 5 8}$ would also be compatible with the end-game strategy.

Following the procedure described, synthesis of both C3-C8 and C15-C20 fragments can be achieved from a common precursor. The nucleophilic substitution of the bromide 249 by a dithiane anion and the subsequent $O$-Michael addition leads to an alternative route to the pyran fragment. The Bestmann ylide linchpin reaction studied in this thesis and the well-established ring-closing metathesis provide an end-game strategy to complete the synthesis of the zampanolide macrocycle, which is compatible with both the current alkynylation and the proposed dithiane approaches.

\subsection{References}

(1) Lin, W. M.; Zercher, C. K. J. Org. Chem. 2007, 72, 4390.

(2) Engelhardt, F. C.; Schmitt, M. J.; Taylor, R. E. Org. Lett. 2001, 3, 2209.

(3) Li de, R.; Murugan, A.; Falck, J. R. J. Am. Chem. Soc. 2008, 130, 46. 
(4) Wuts, P. G. M.; Greene, T. W. Greene's protective groups in organic synthesis 4th ed.; Wiley-Interscience Hoboken, N.J, 2007.

(5) Takeda, T. Modern carbonyl olefination: methods and applications; WILEY-VCH Verlag GmbH \& Co. KGaA: Weinheim, 2004.

(6) Claridge, T. D. W.; Davies, S. G.; Lee, J. A.; Nicholson, R. L.; Roberts, P. M.; Russell, A. J.; Smith, A. D.; Toms, S. M. Org. Lett. 2008, 10, 5437.

(7) Still, W. C.; Gennari, C. Tetrahedron Lett. 1983, 24, 4405. 


\section{Appendix: NMR spectra}

(Hex-1-en-5-yn-3-yloxy)tert-butyldimethylsilane (118)

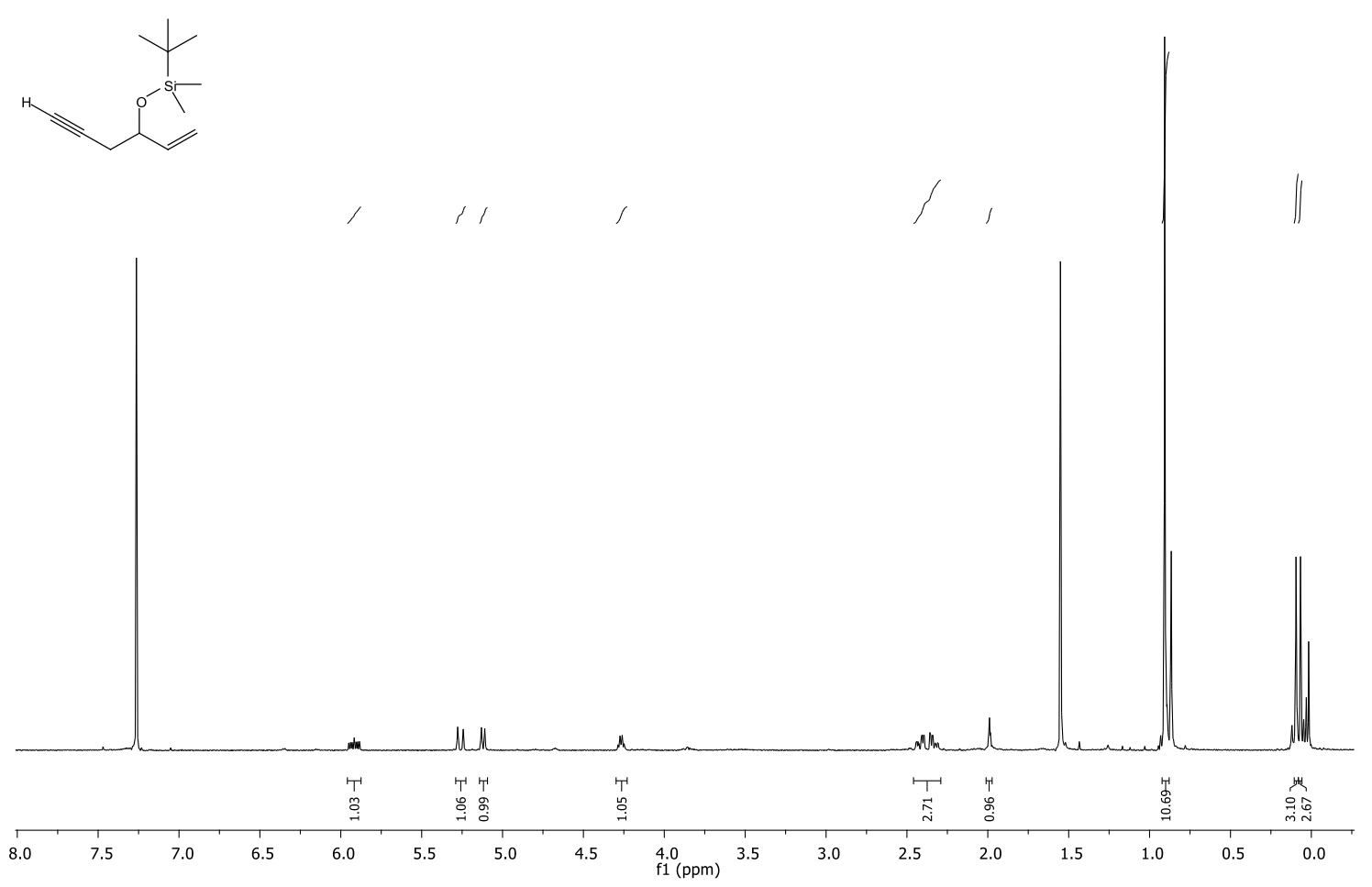

${ }^{1} \mathbf{H}$ NMR $\left(500 \mathrm{MHz}, \mathrm{CDCl}_{3}\right)$ spectrum of $\mathbf{1 1 8}$
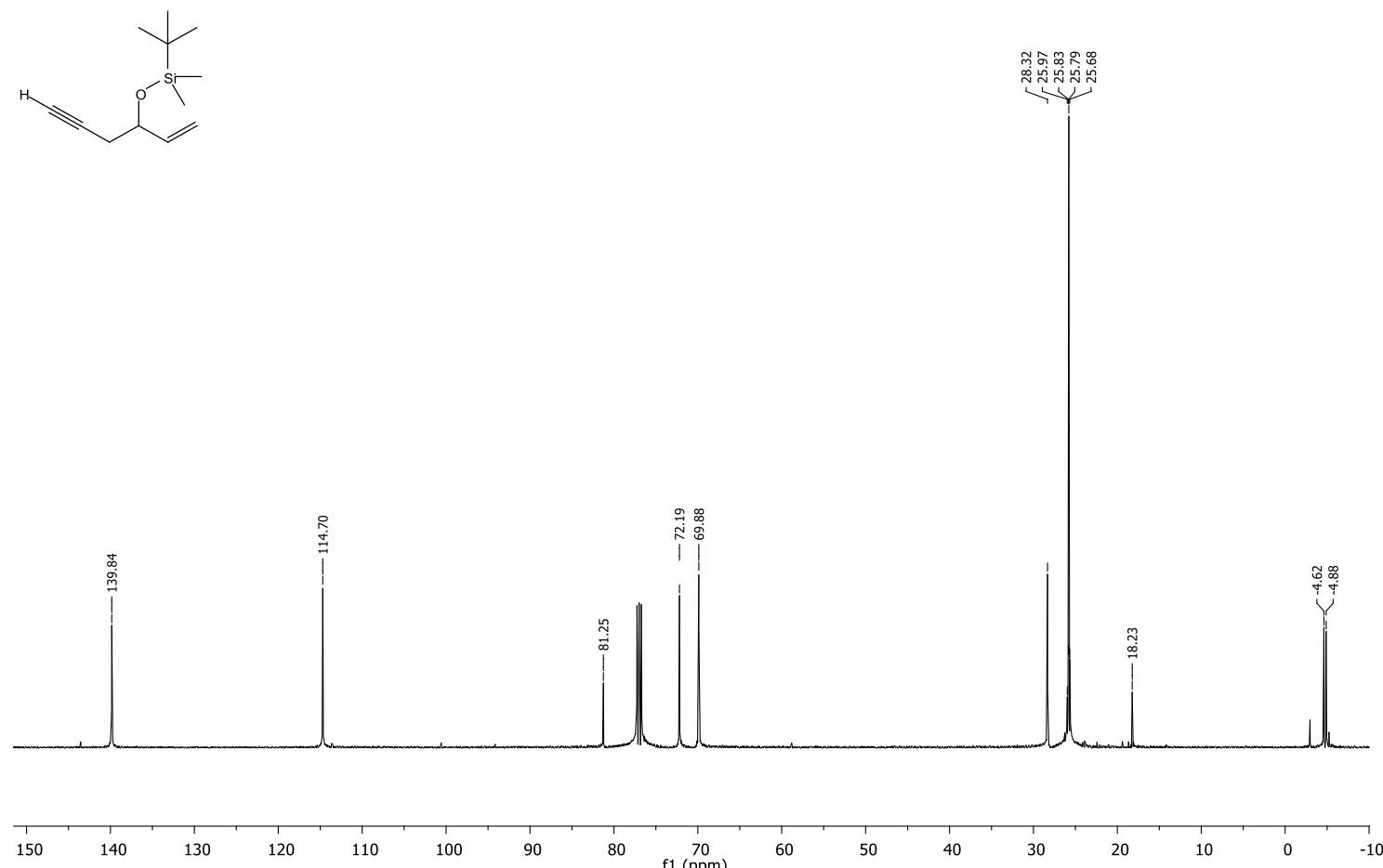

${ }^{13} \mathrm{C}$ NMR $\left(125 \mathrm{MHz}, \mathrm{CDCl}_{3}\right)$ spectrum of 118 
Methyl 5-tert-butyldimethylsilyloxy-6-hepten-2-ynoate (119)
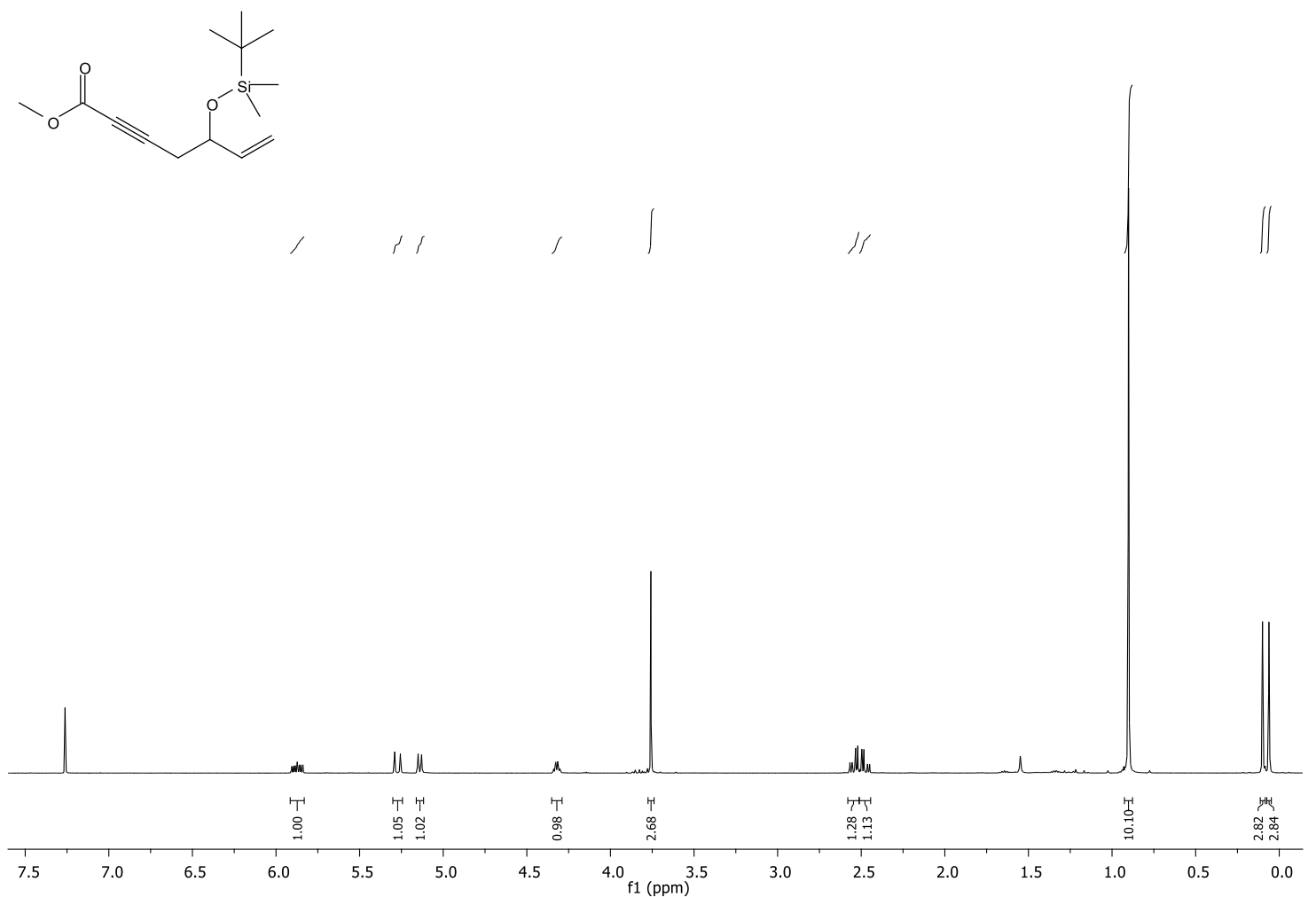

${ }^{1} \mathbf{H}$ NMR $\left(500 \mathrm{MHz}, \mathrm{CDCl}_{3}\right)$ spectrum of $\mathbf{1 1 9}$
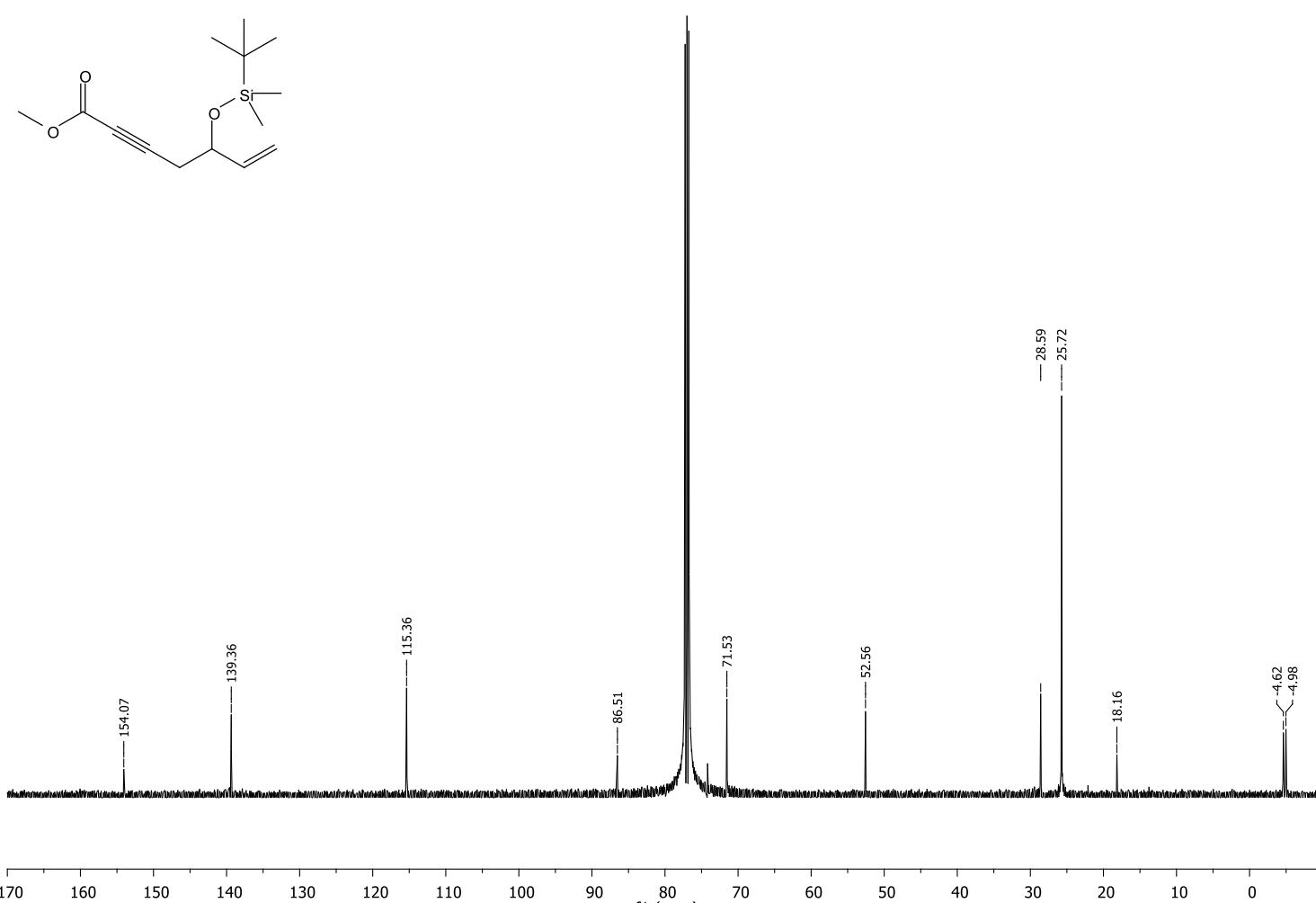

130

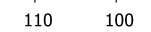

$90 \quad \begin{gathered}80 \\ \mathrm{f} 1(\mathrm{ppm})\end{gathered}$
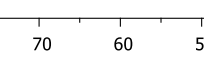

${ }^{13} \mathbf{C}$ NMR $\left(125 \mathrm{MHz}, \mathrm{CDCl}_{3}\right)$ spectrum of $\mathbf{1 1 9}$ 
(2Z)-Methyl 5-(tert-butyldimethylsilyloxy)-3-methyl-2,6-heptadienoate (125)
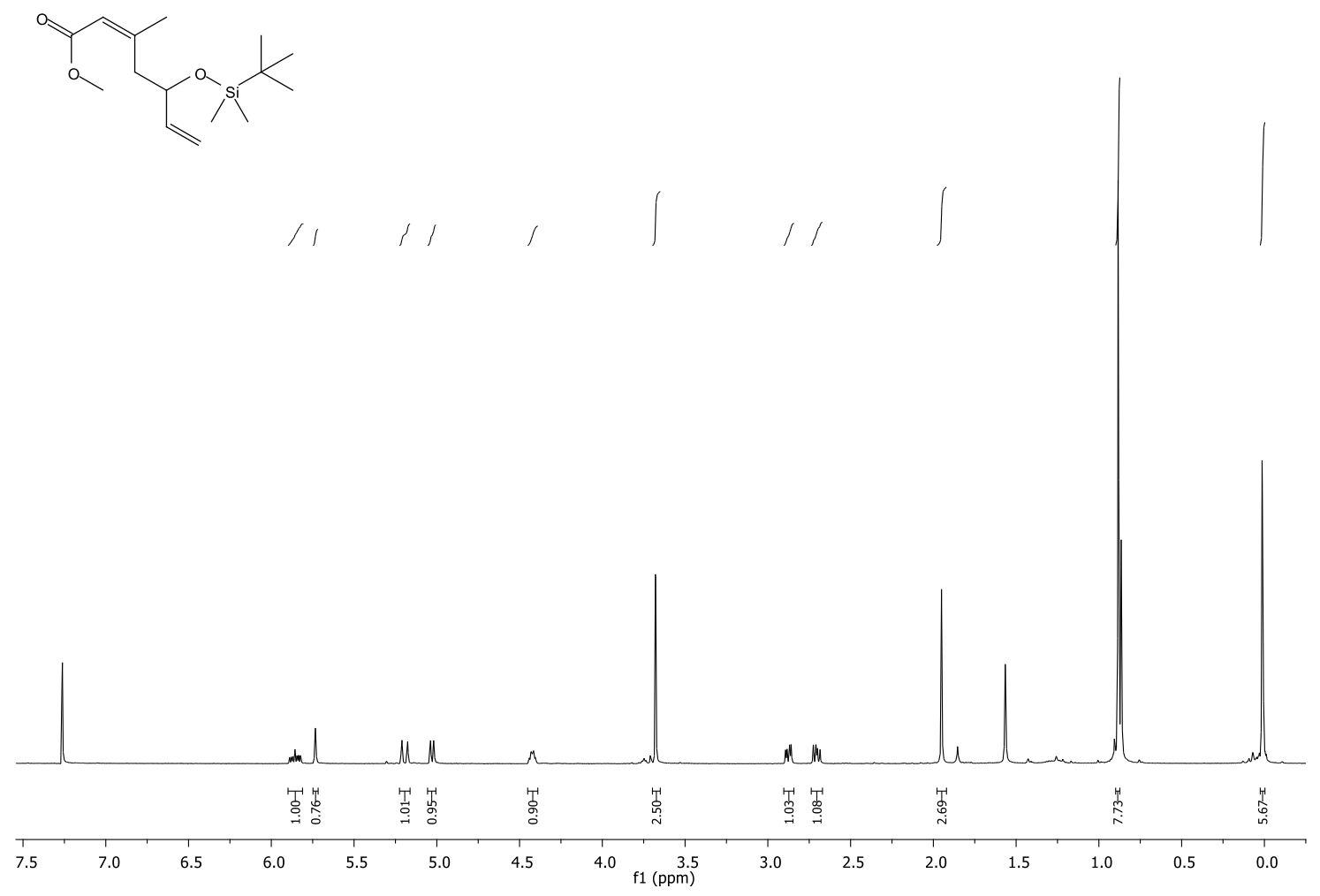

${ }^{\mathbf{1}} \mathbf{H}$ NMR $\left(500 \mathrm{MHz}, \mathrm{CDCl}_{3}\right)$ spectrum of $\mathbf{1 2 5}$

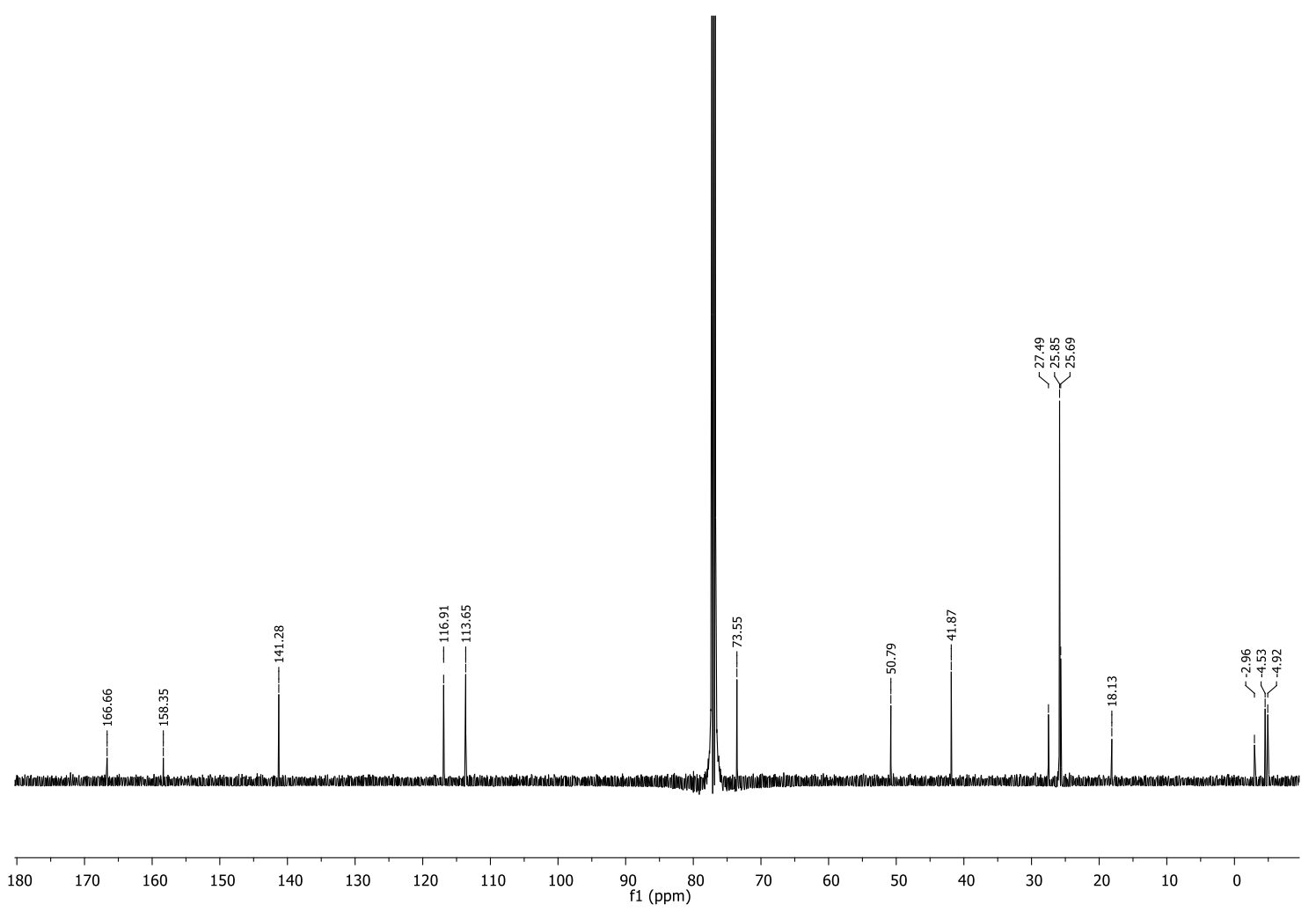

${ }^{13} \mathbf{C ~ N M R}\left(125 \mathrm{MHz}, \mathrm{CDCl}_{3}\right)$ spectrum of $\mathbf{1 2 5}$ 
(2Z)-3-Methyl-5-(tert-butyldimethylsilyloxy)hepta-2,6-dien-1-ol (128)

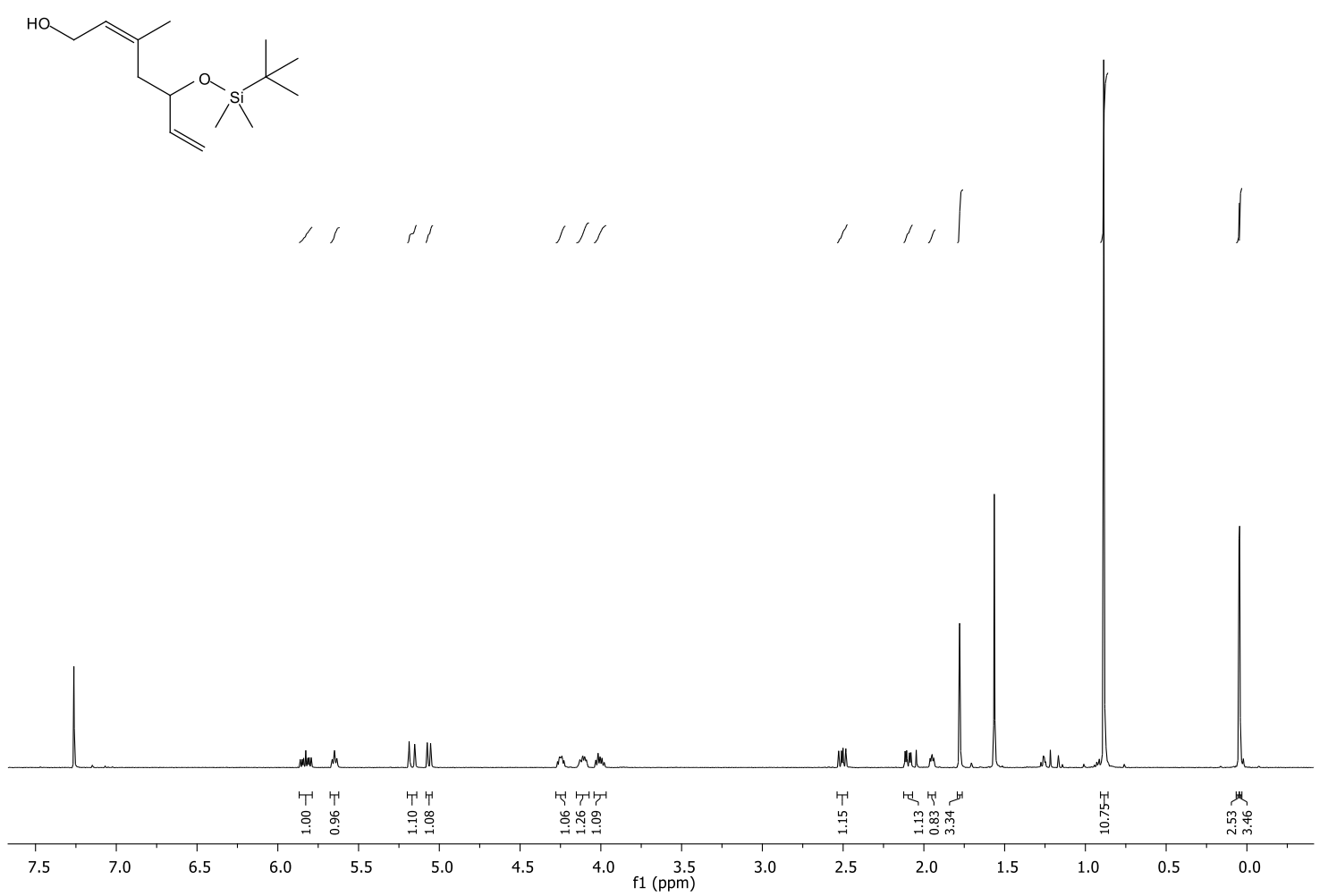

${ }^{1} \mathbf{H}$ NMR $\left(500 \mathrm{MHz}, \mathrm{CDCl}_{3}\right)$ spectrum of $\mathbf{1 2 8}$
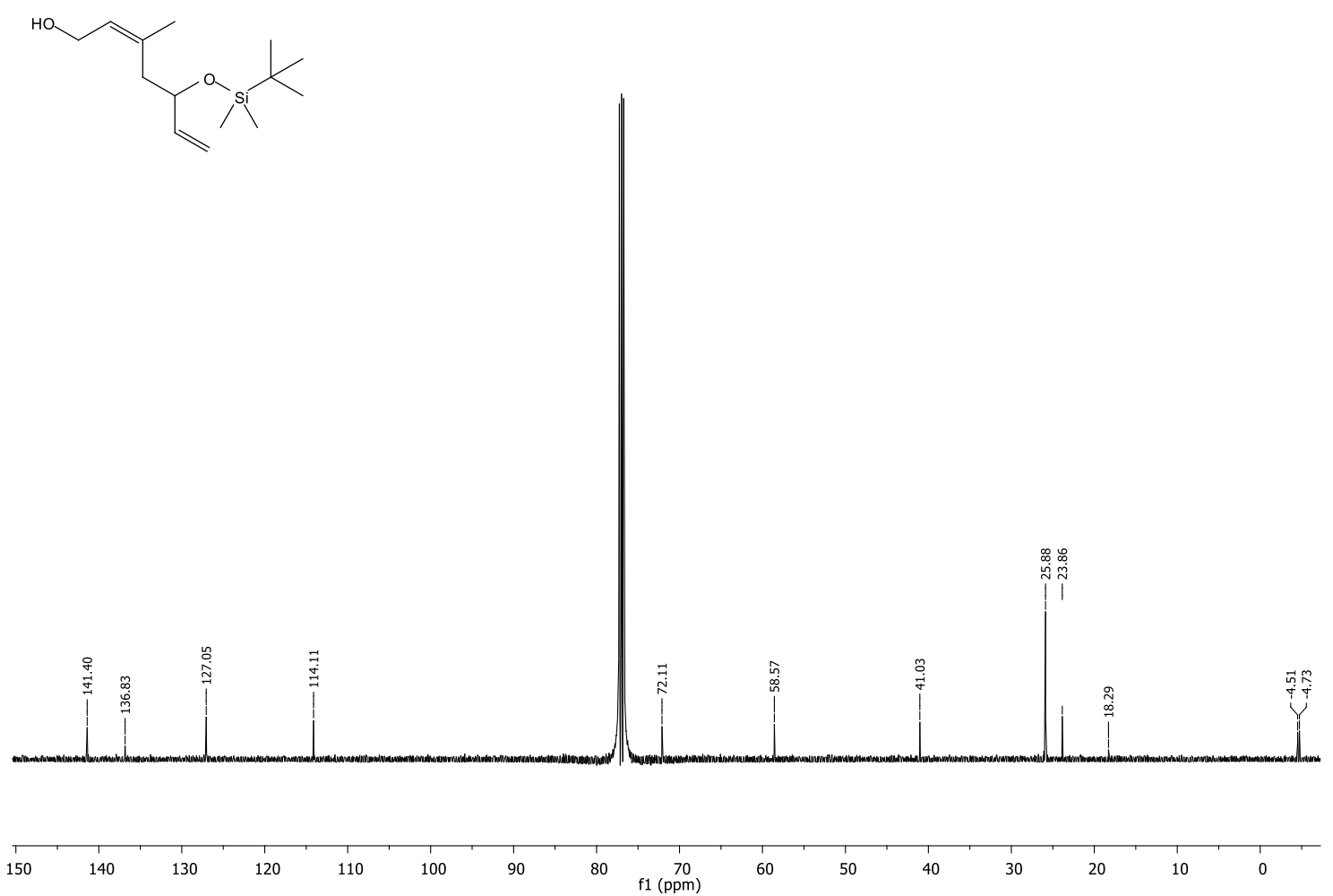

${ }^{13} \mathbf{C ~ N M R}\left(125 \mathrm{MHz}, \mathrm{CDCl}_{3}\right)$ spectrum of $\mathbf{1 2 8}$ 
(2Z)-3-Methyl-5-(tert-butyldimethylsilyloxy)hepta-2,6-dienal (126)

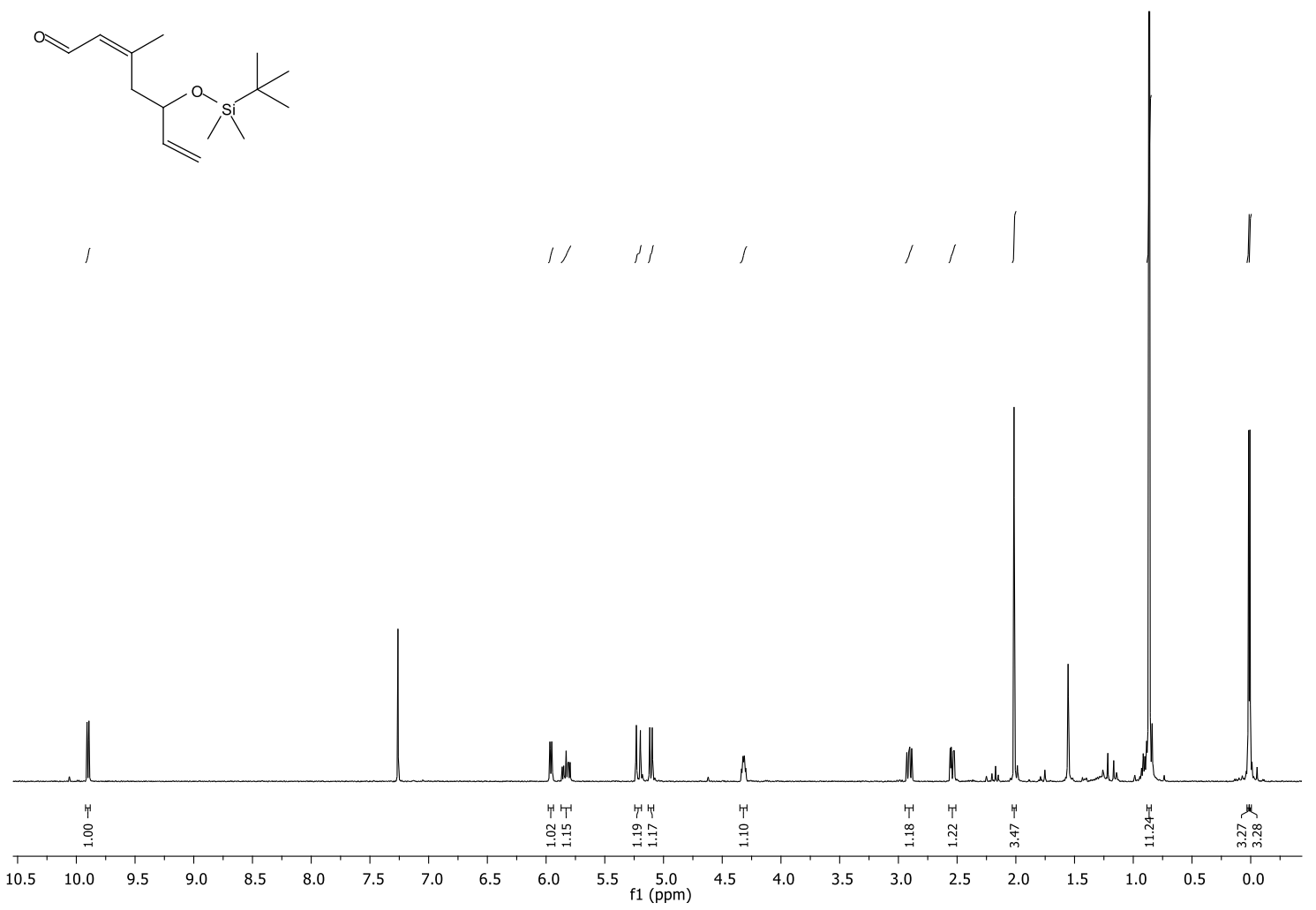

${ }^{\mathbf{1}} \mathbf{H}$ NMR $\left(500 \mathrm{MHz}, \mathrm{CDCl}_{3}\right)$ spectrum of $\mathbf{1 2 6}$
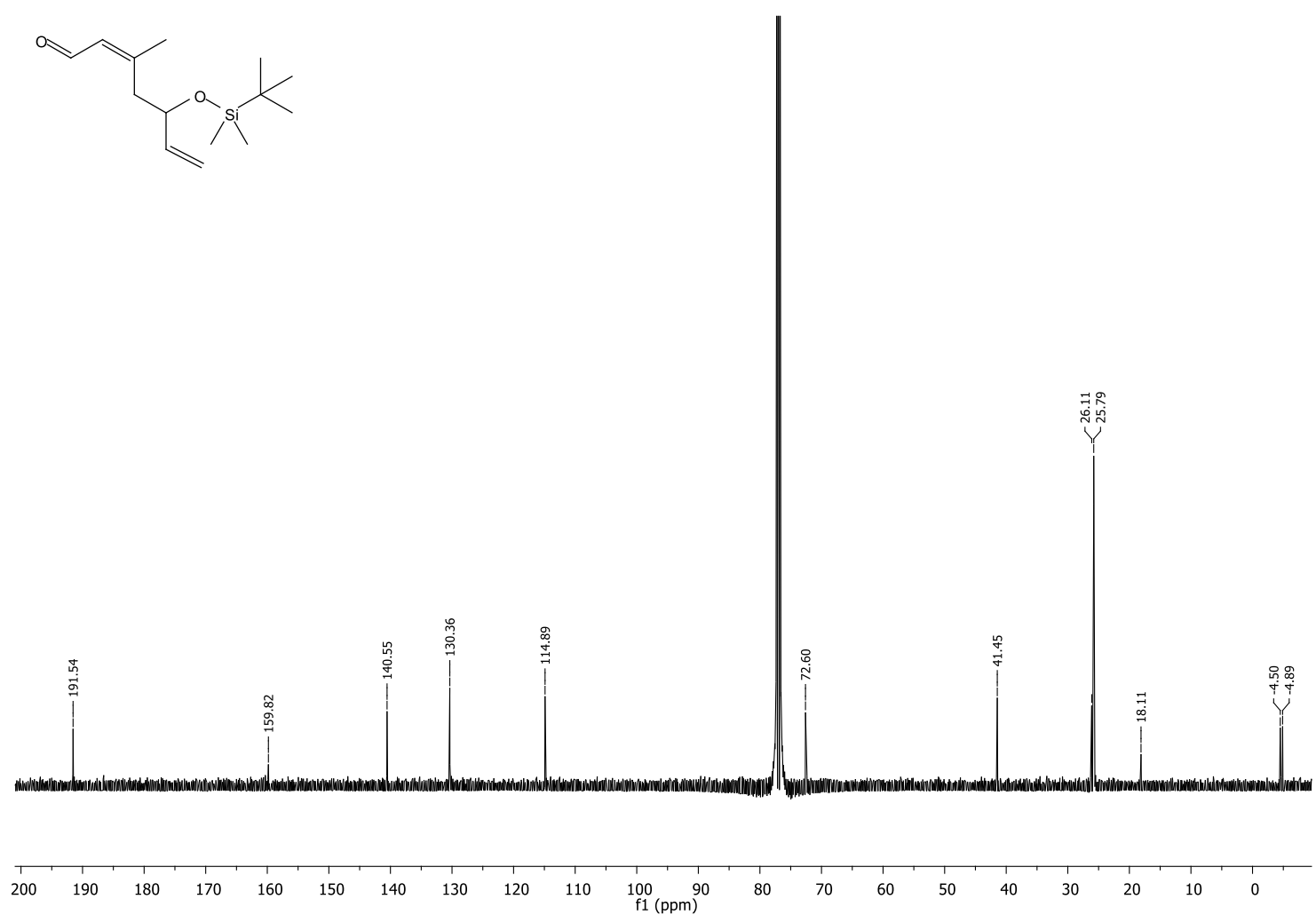

${ }^{13} \mathrm{C}$ NMR $\left(125 \mathrm{MHz}, \mathrm{CDCl}_{3}\right)$ spectrum of $\mathbf{1 2 6}$ 
Mixture of (2Z)-methyl 5-(tert-butyldimethylsilyloxy)-2,6-heptadienoate (130) and (2Z)methyl 5-(tert-butyldimethylsilyloxy)-2-heptenoate (131) (3:2)

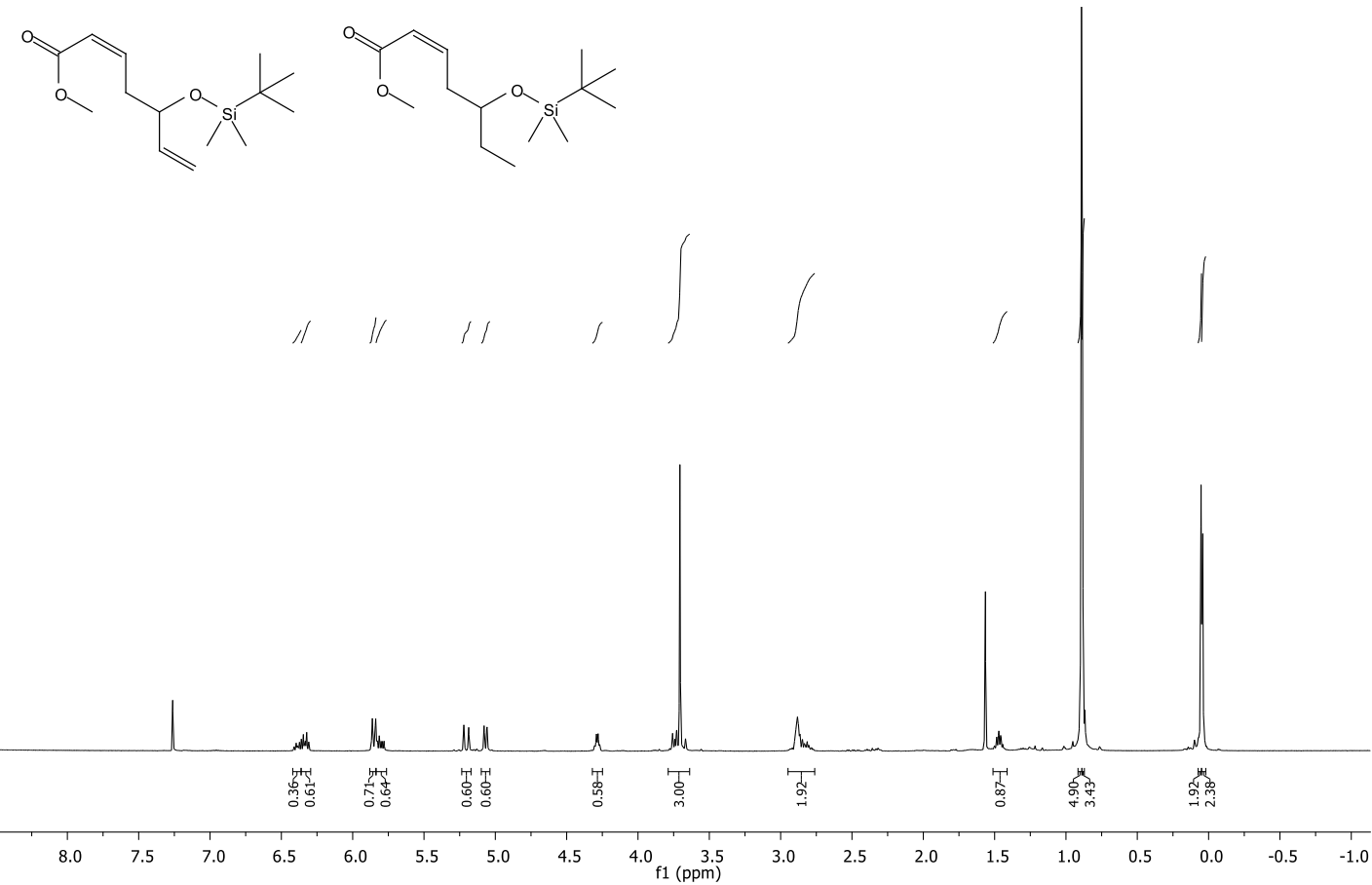

${ }^{1} \mathbf{H}$ NMR $\left(500 \mathrm{MHz}, \mathrm{CDCl}_{3}\right)$ spectrum of $\mathbf{1 3 0}$ and $\mathbf{1 3 1}$
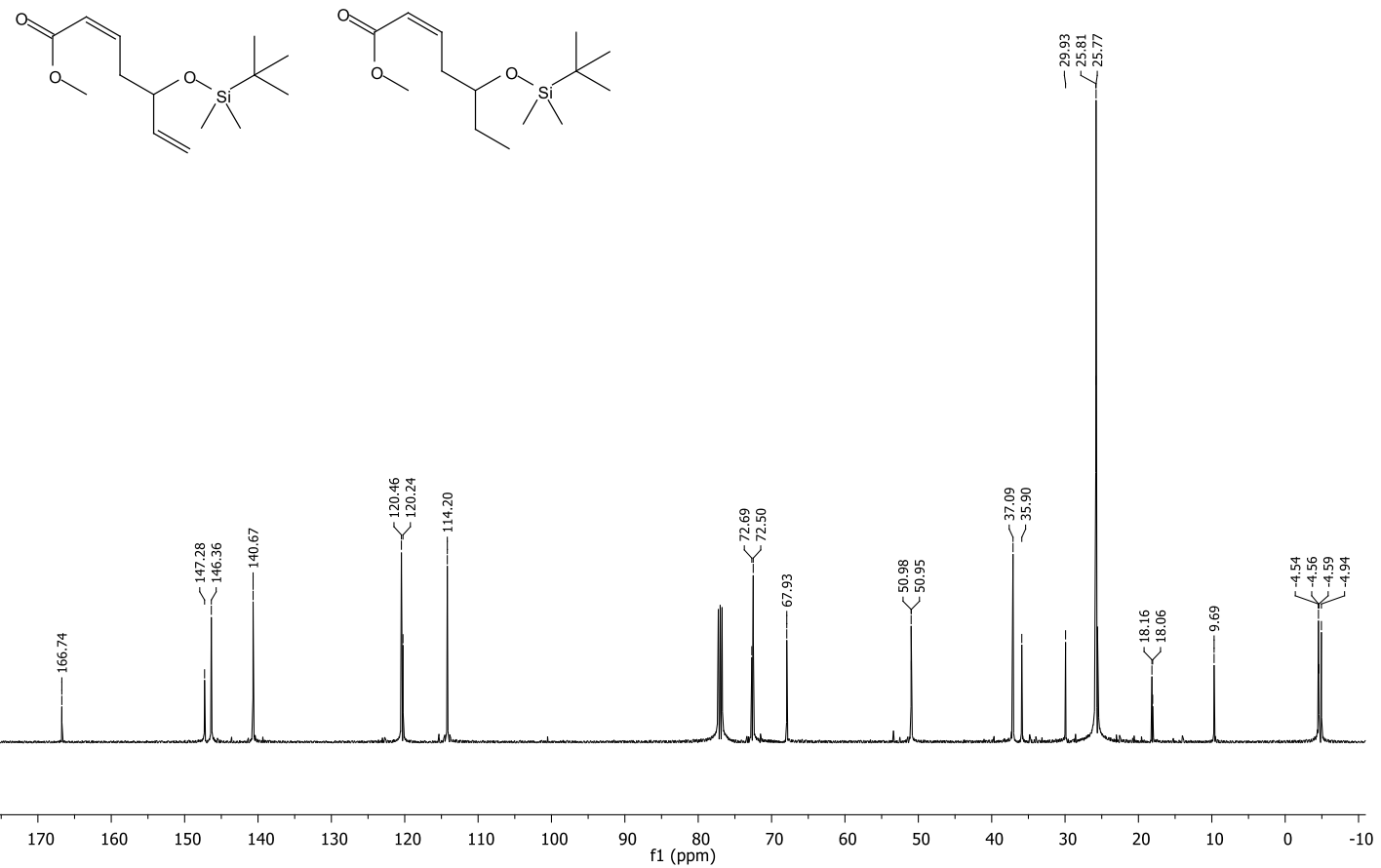

${ }^{13} \mathbf{C ~ N M R}\left(125 \mathrm{MHz}, \mathrm{CDCl}_{3}\right)$ spectrum of $\mathbf{1 3 0}$ and $\mathbf{1 3 1}$ 
5-tert-Butyldimethylsilyloxy-6-hepten-2-yn-1-ol (132)
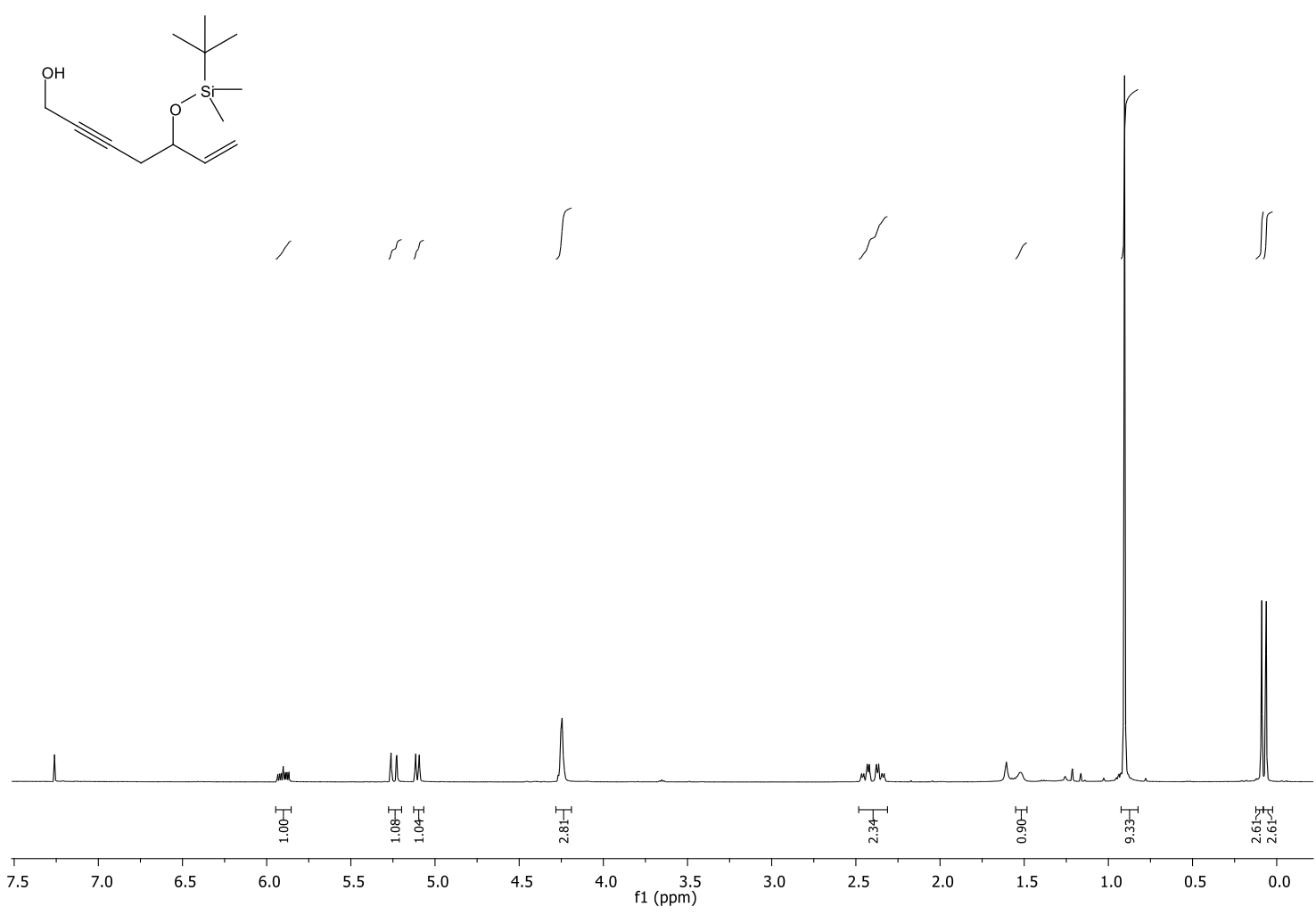

${ }^{1} \mathbf{H}$ NMR $\left(500 \mathrm{MHz}, \mathrm{CDCl}_{3}\right)$ spectrum of $\mathbf{1 3 2}$
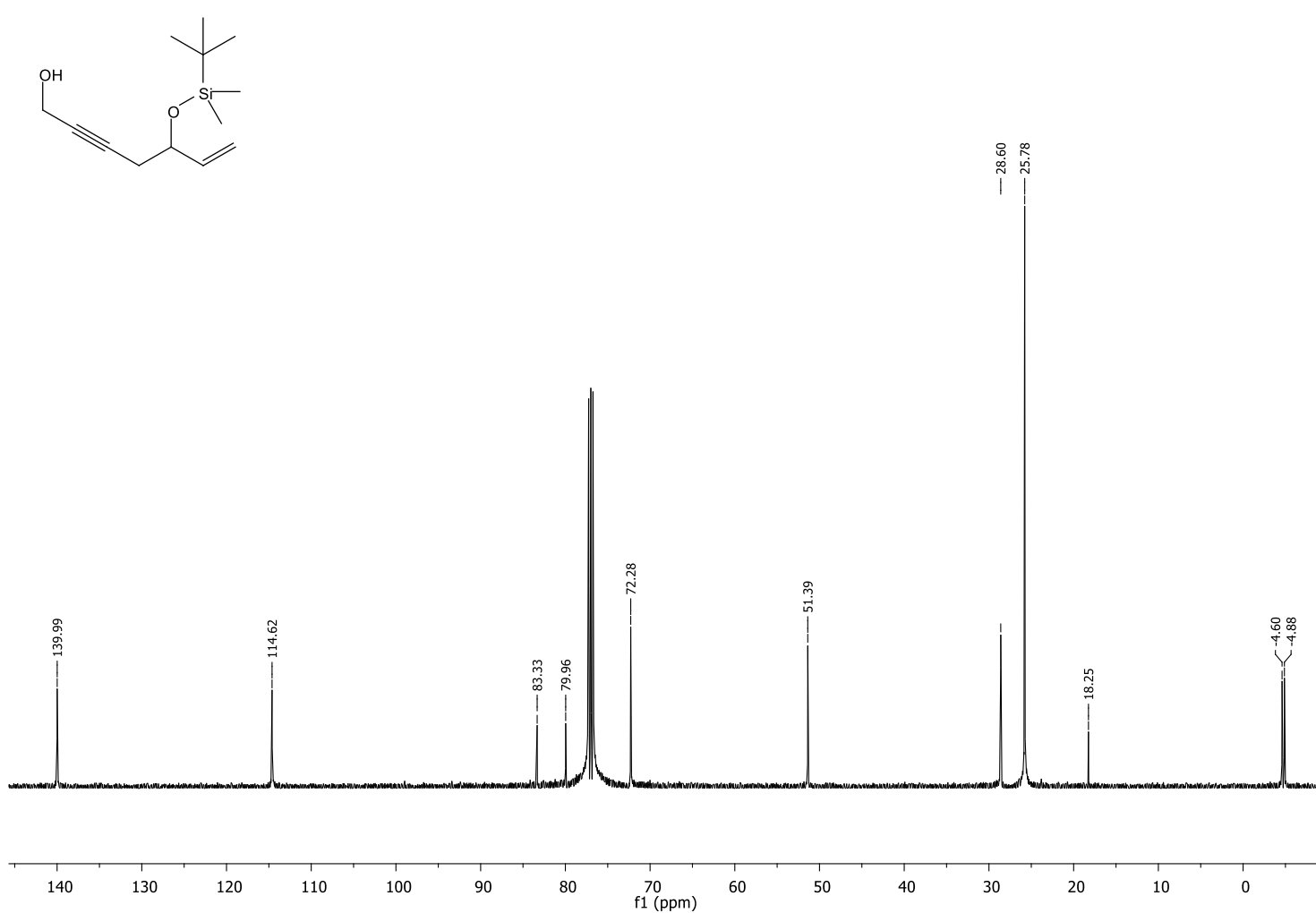

${ }^{13} \mathbf{C ~ N M R}\left(125 \mathrm{MHz}, \mathrm{CDCl}_{3}\right)$ spectrum of $\mathbf{1 3 2}$ 
2E-5-(tert-Butyldimethylsilyloxy)hepta-2,6-dien-1-ol (133)
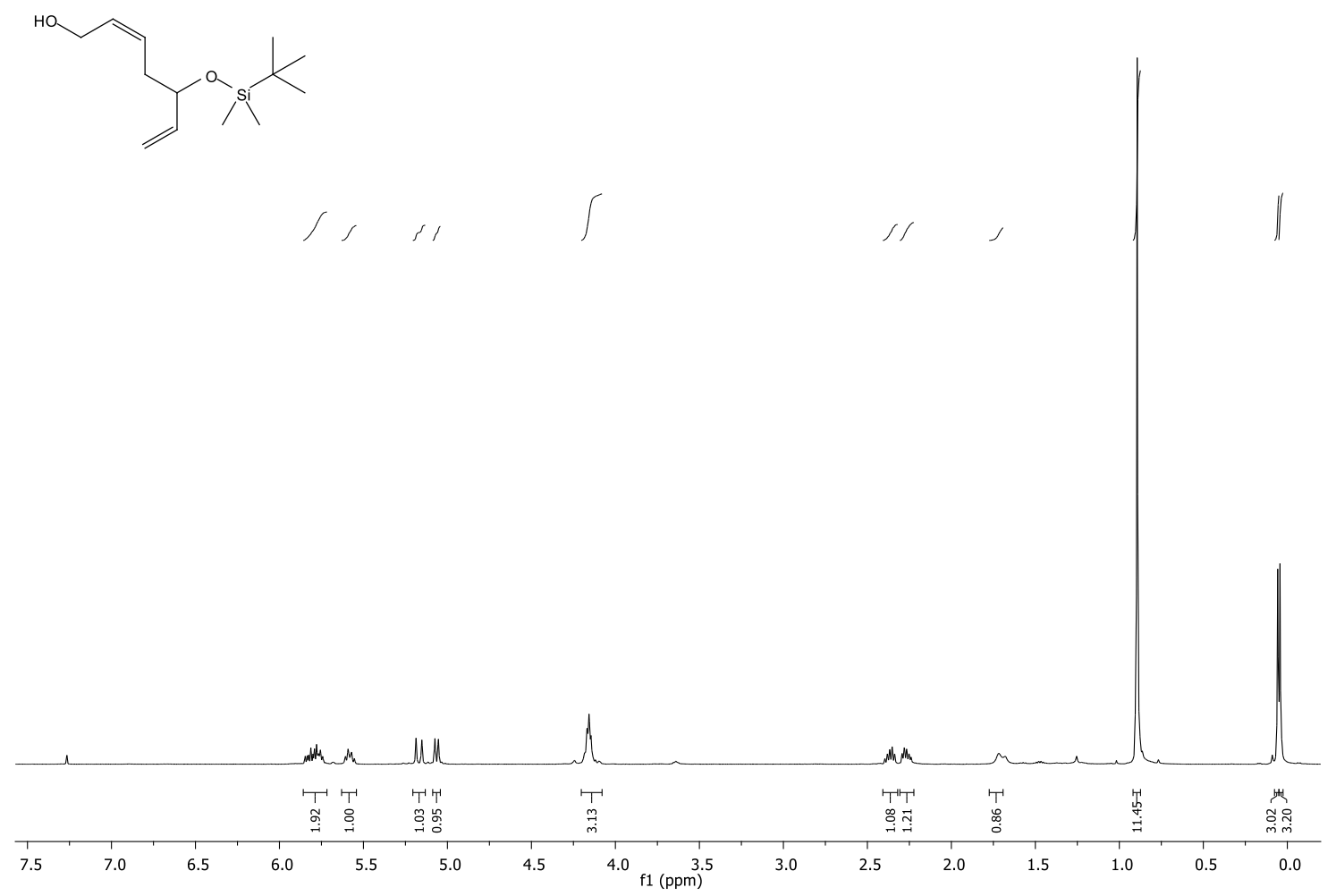

${ }^{\mathbf{1}} \mathbf{H}$ NMR $\left(500 \mathrm{MHz}, \mathrm{CDCl}_{3}\right)$ spectrum of $\mathbf{1 3 3}$
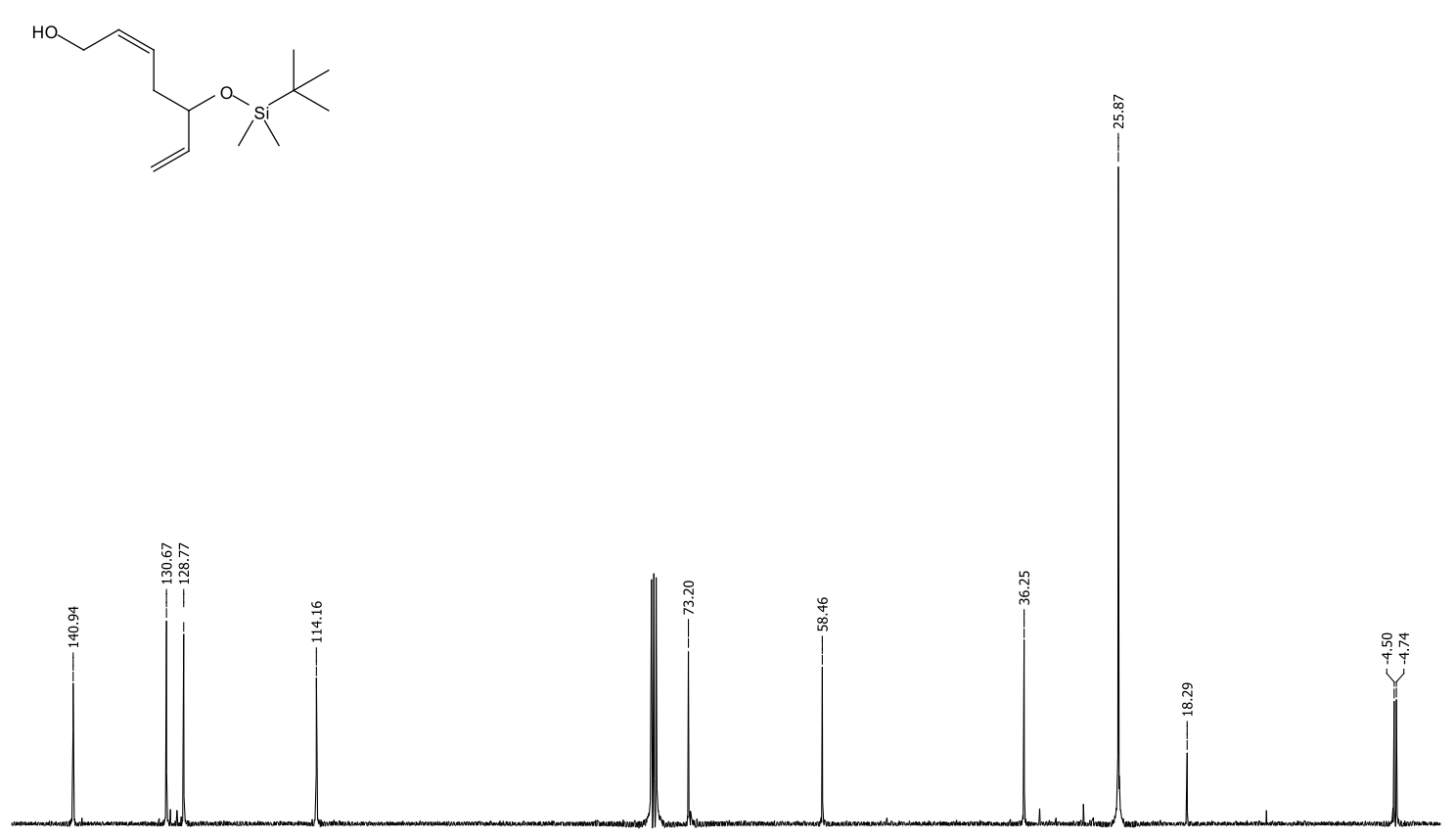

${ }^{13} \mathbf{C ~ N M R}\left(125 \mathrm{MHz}, \mathrm{CDCl}_{3}\right)$ spectrum of $\mathbf{1 3 3}$ 
Mixture of (2Z)-5-(tert-butyldimethylsilyloxy)hepta-2,6-dienal (135) and (2E) 5-(tertbutyldimethylsilyloxy)hepta-2,6-dienal (136) (7:3)
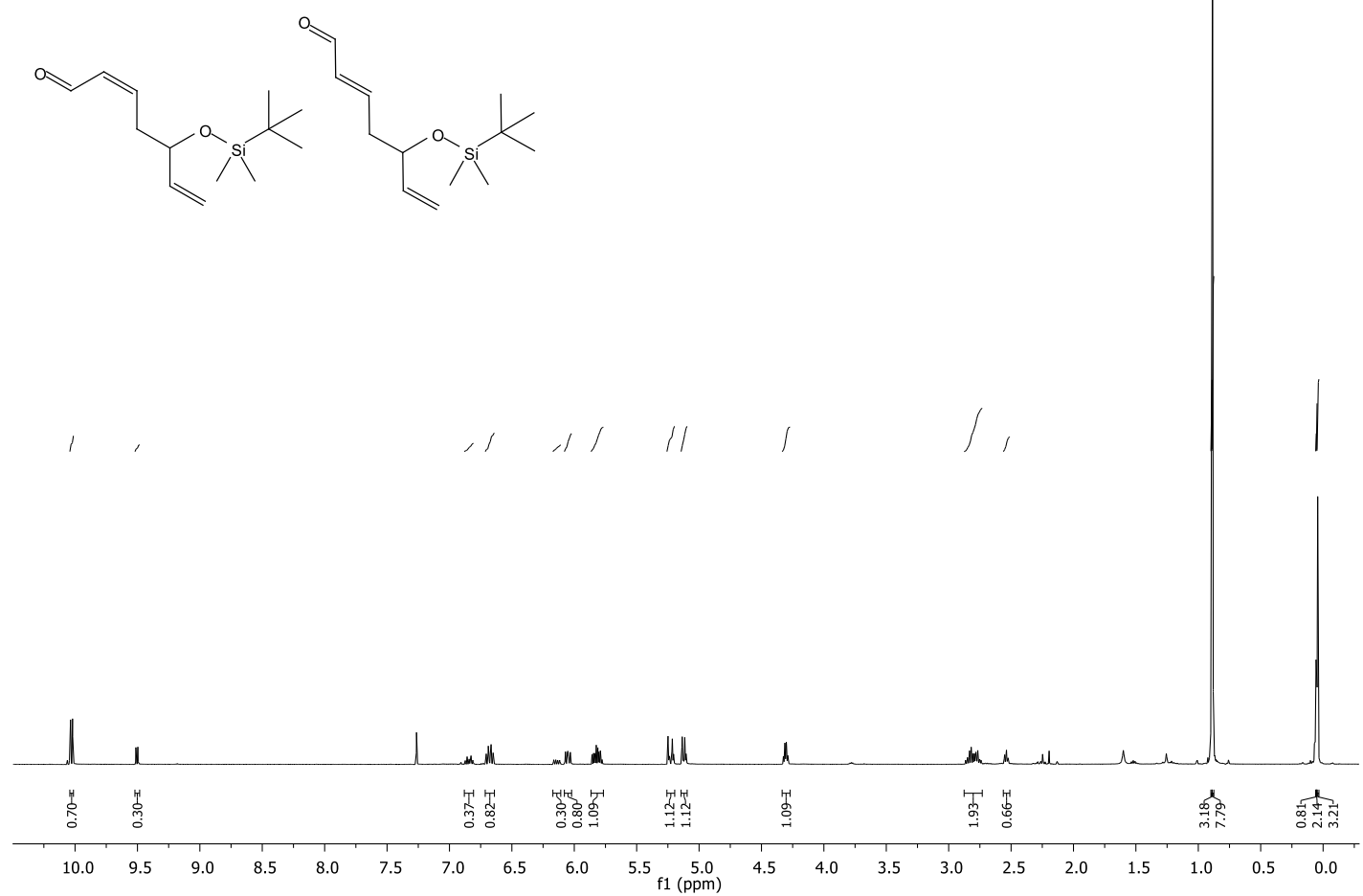

${ }^{1}$ H NMR (500 MHz, $\mathrm{CDCl}_{3}$ ) spectrum of $\mathbf{1 3 5}$ and $\mathbf{1 3 6}$

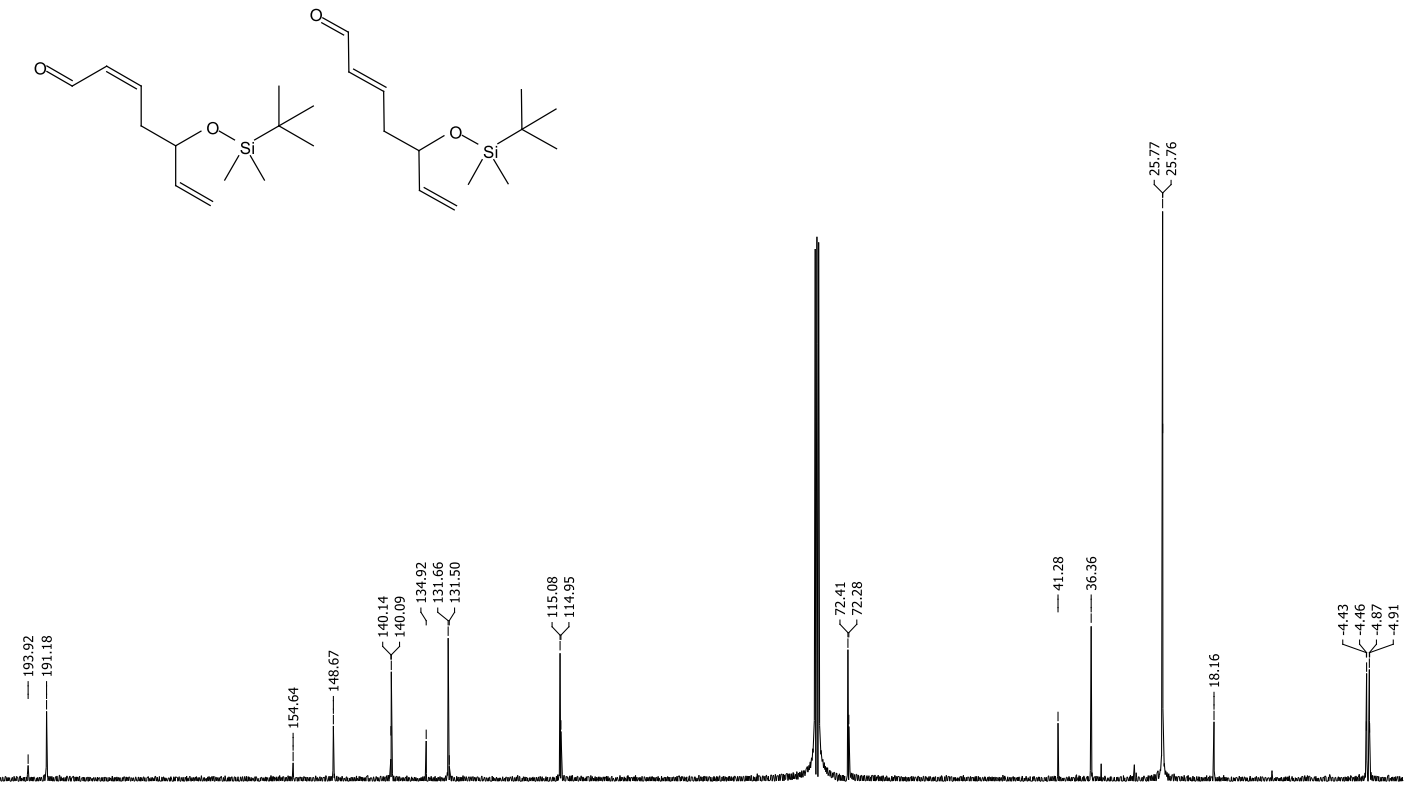

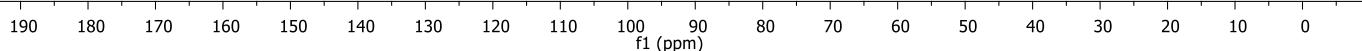

${ }^{13} \mathrm{C}$ NMR $\left(125 \mathrm{MHz}, \mathrm{CDCl}_{3}\right)$ spectrum of $\mathbf{1 3 5}$ and 136 


\section{2-(tert-Butyldiphenylsilyloxy)methyloxirane (140)}
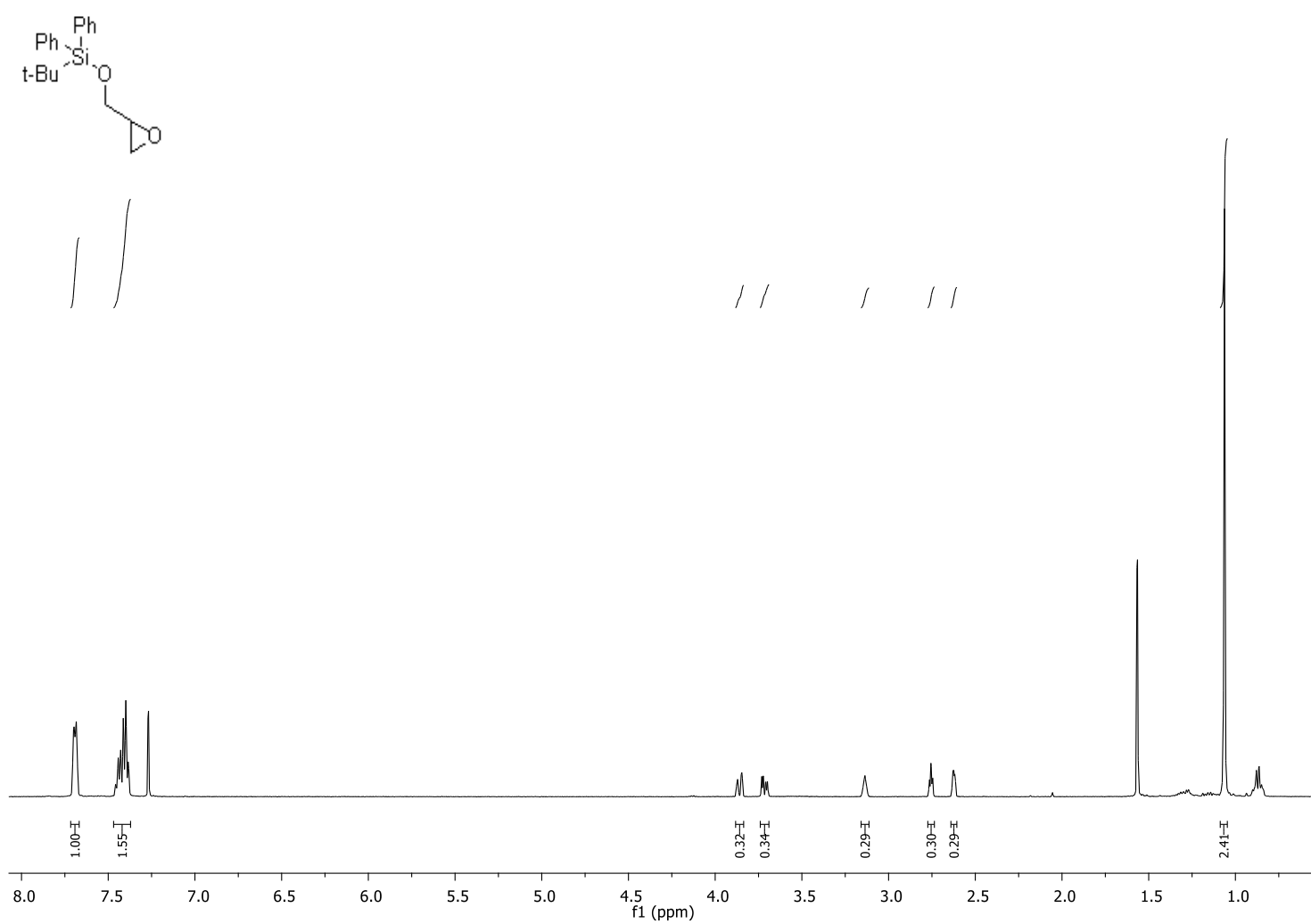

${ }^{\mathbf{1}} \mathbf{H}$ NMR $\left(500 \mathrm{MHz}, \mathrm{CDCl}_{3}\right)$ spectrum of $\mathbf{1 4 0}$
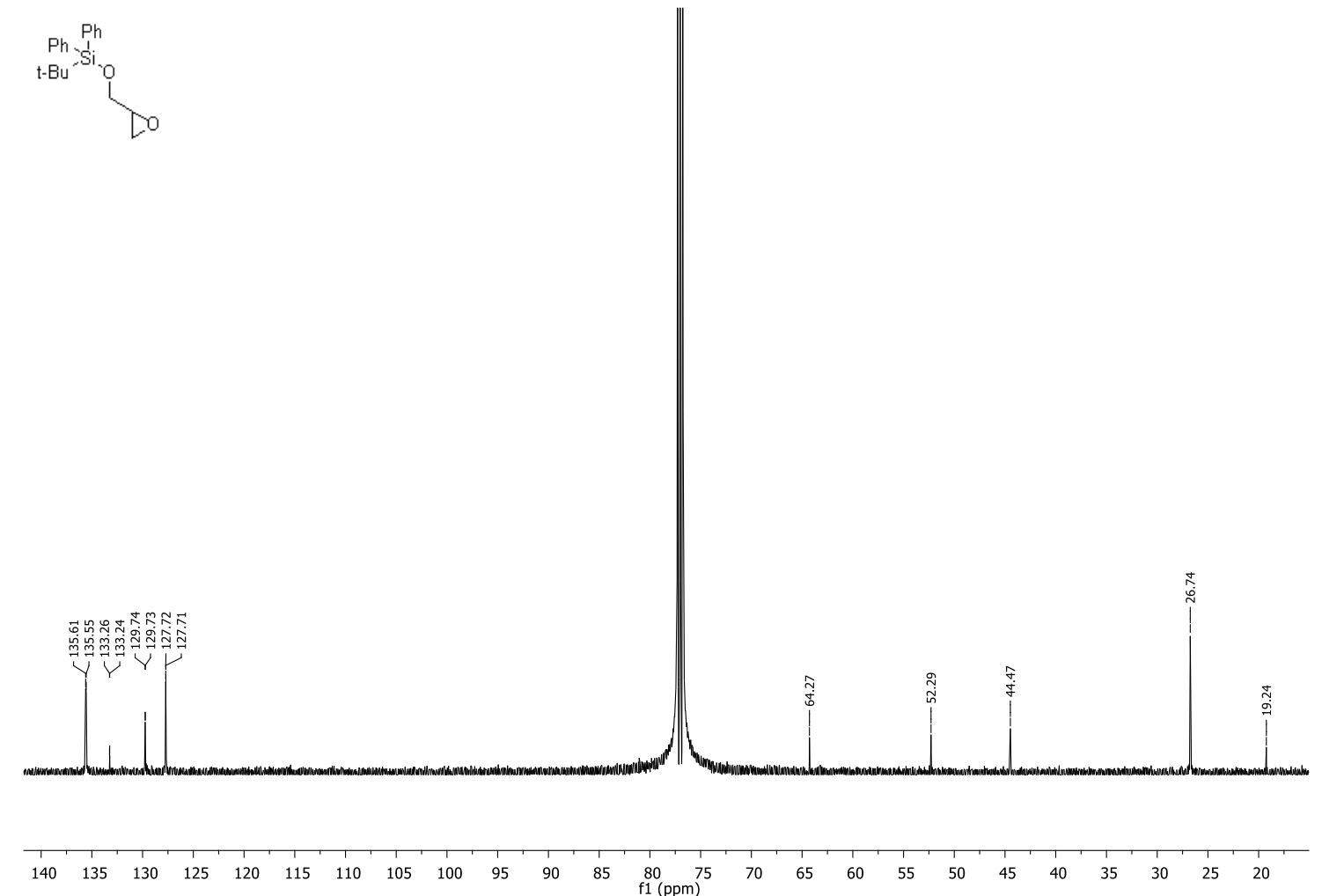

${ }^{13} \mathrm{C}$ NMR $\left(125 \mathrm{MHz}, \mathrm{CDCl}_{3}\right)$ spectrum of $\mathbf{1 4 0}$ 


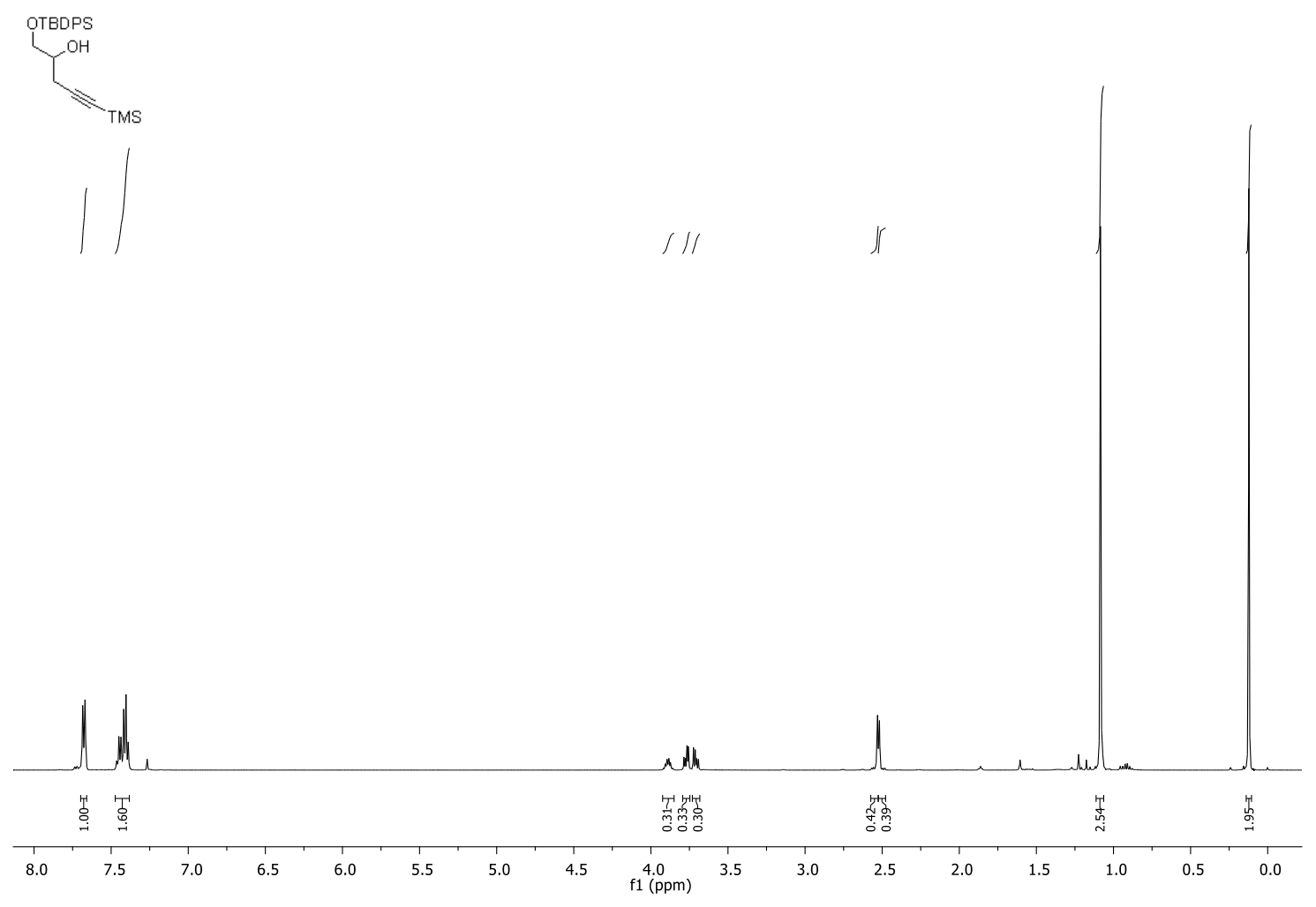

${ }^{1} \mathbf{H}$ NMR $\left(500 \mathrm{MHz}, \mathrm{CDCl}_{3}\right)$ spectrum of $\mathbf{1 4 1}$
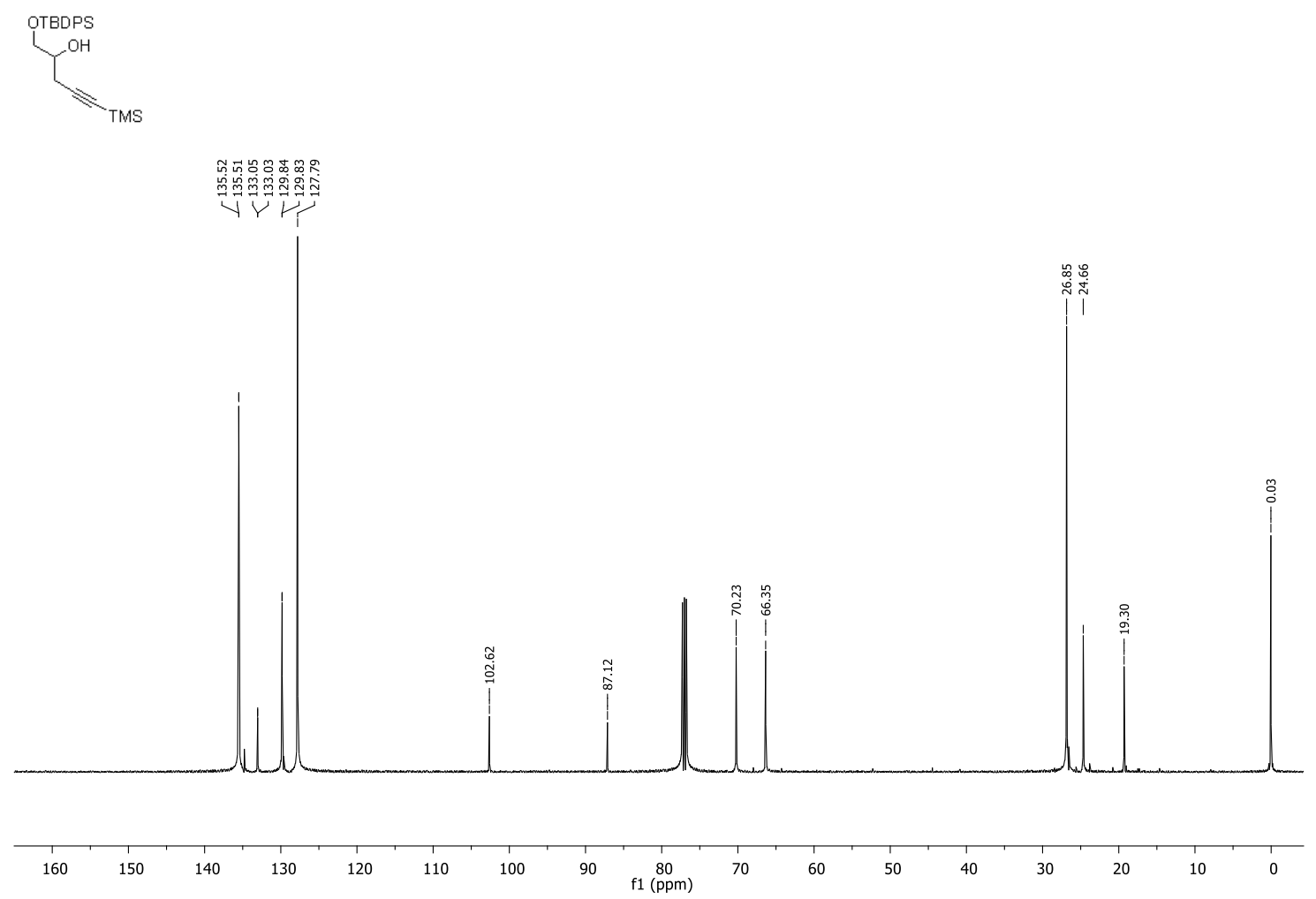

${ }^{13} \mathrm{C} \mathrm{NMR}\left(125 \mathrm{MHz}, \mathrm{CDCl}_{3}\right)$ spectrum of $\mathbf{1 4 1}$ 
(S)-2-(para-Methoxybenzyl)methyloxirane (150)

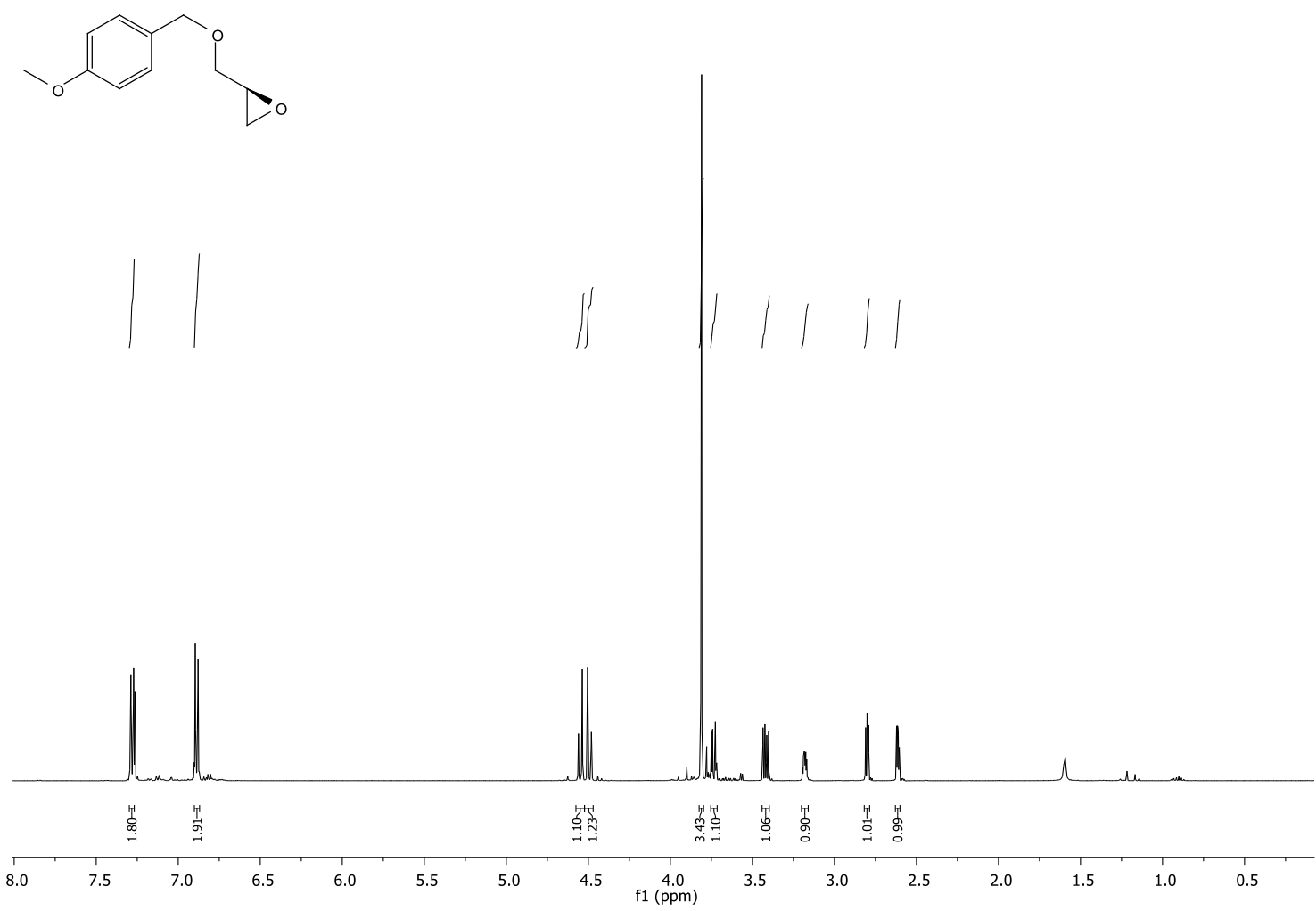

${ }^{1} \mathbf{H}$ NMR $\left(500 \mathrm{MHz}, \mathrm{CDCl}_{3}\right)$ spectrum of $\mathbf{1 5 0}$
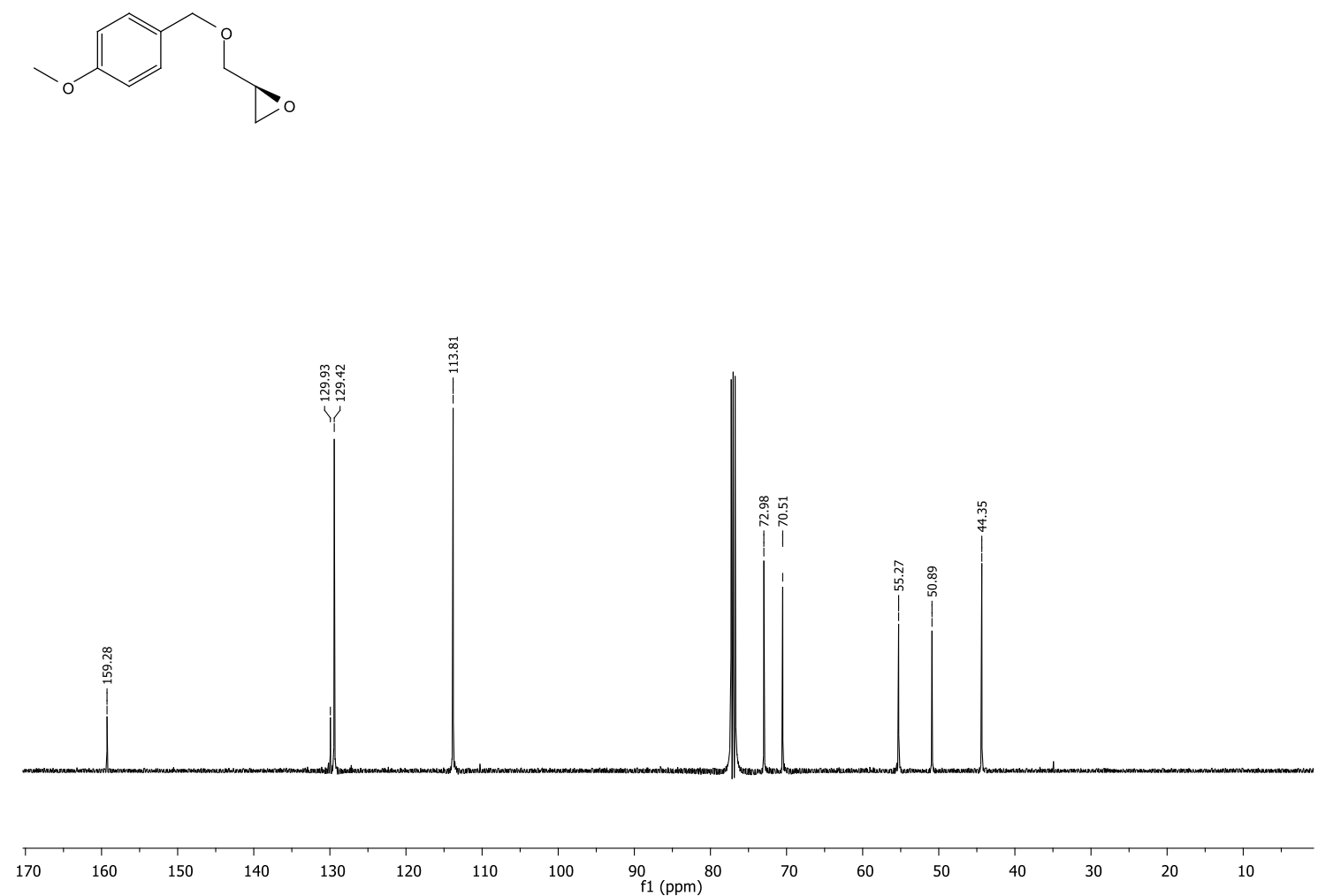

${ }^{13} \mathrm{C}$ NMR $\left(125 \mathrm{MHz}, \mathrm{CDCl}_{3}\right)$ spectrum of $\mathbf{1 5 0}$ 

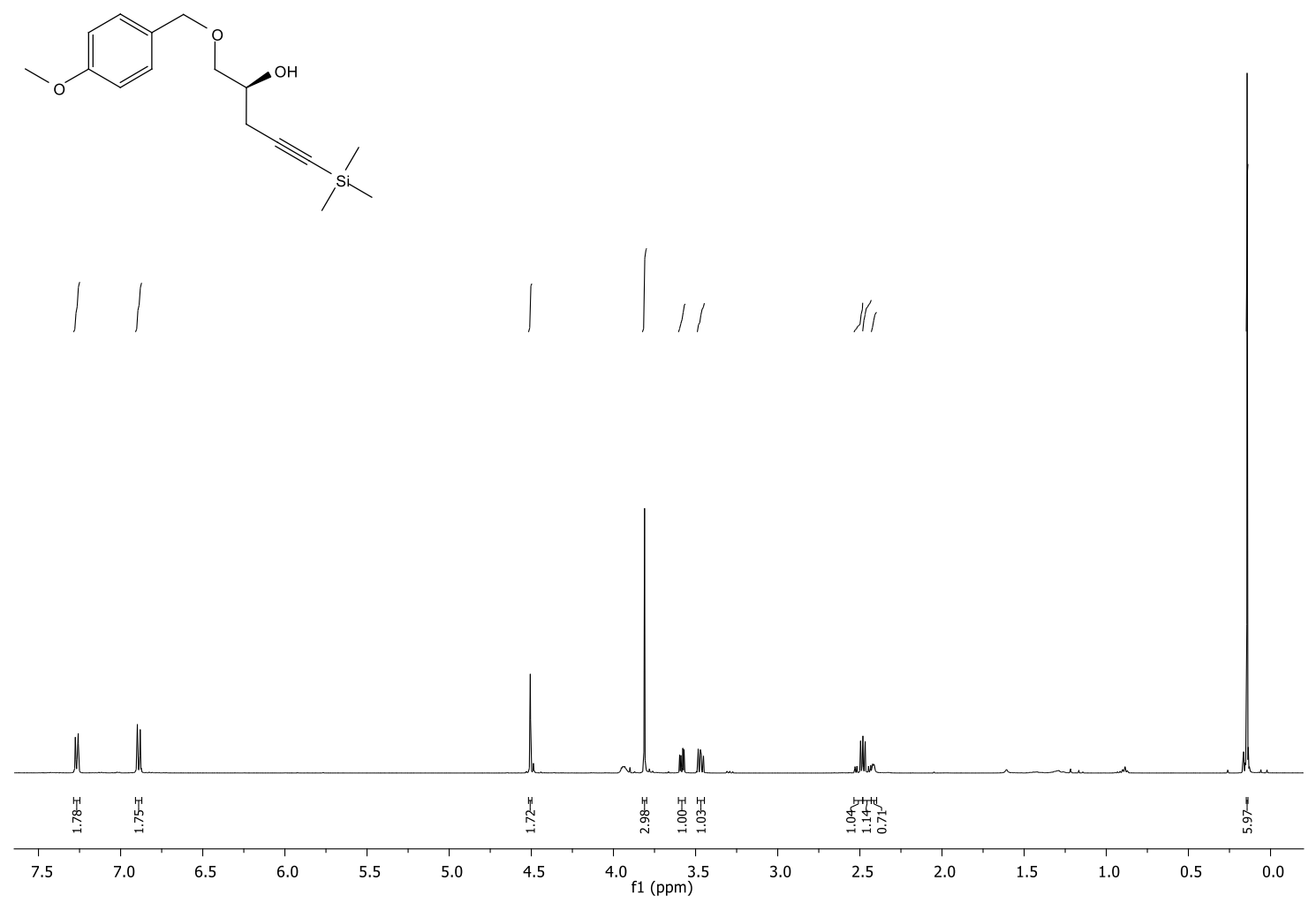

${ }^{1} \mathbf{H}$ NMR $\left(500 \mathrm{MHz}, \mathrm{CDCl}_{3}\right)$ spectrum of $\mathbf{1 4 6}$
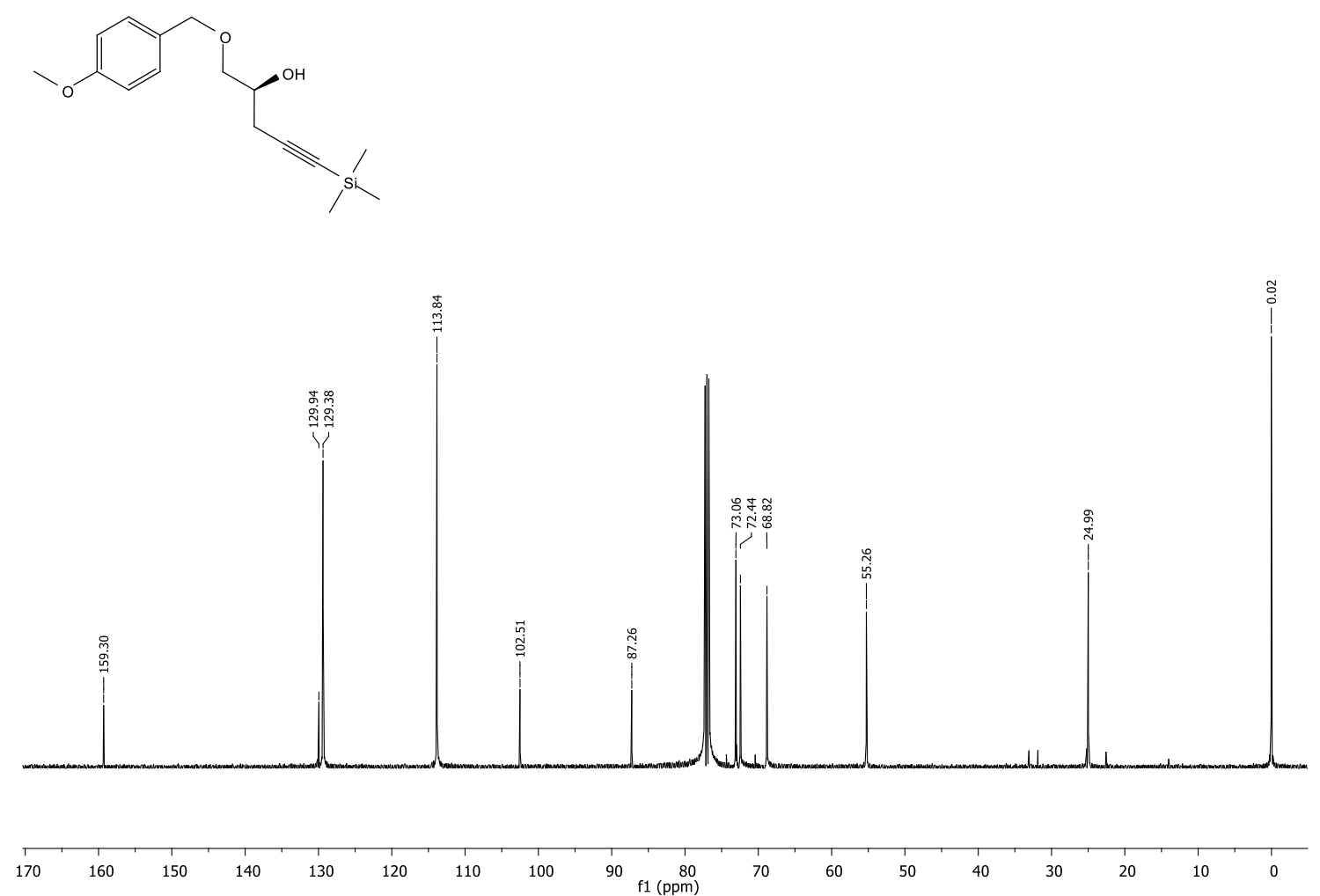

${ }^{13} \mathrm{C}$ NMR $\left(125 \mathrm{MHz}, \mathrm{CDCl}_{3}\right)$ spectrum of 146 
(S)-1-(para-Methoxybenzyl)oxy-4-pentyn-2-ol (152)

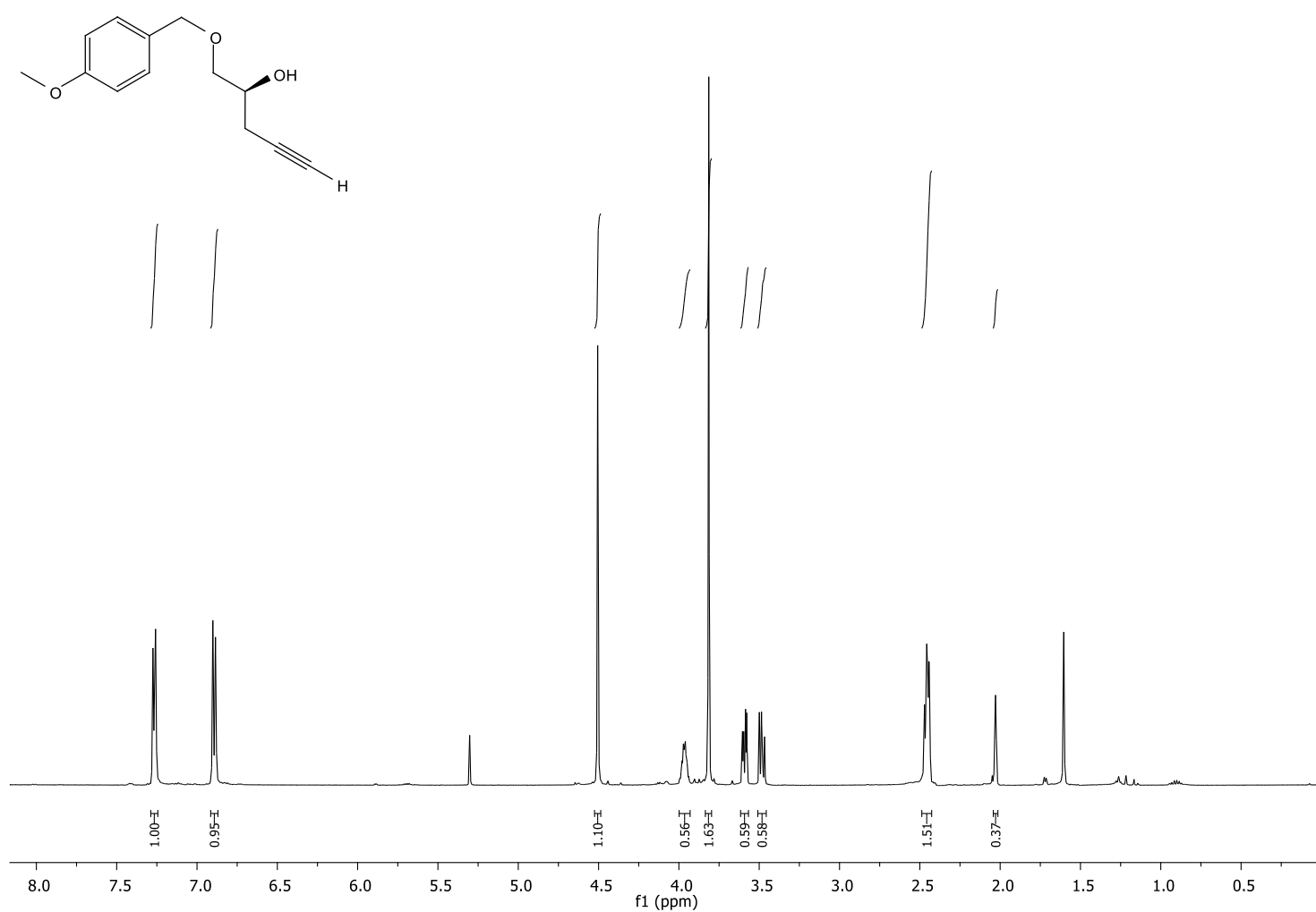

${ }^{1} \mathbf{H}$ NMR $\left(500 \mathrm{MHz}, \mathrm{CDCl}_{3}\right)$ spectrum of $\mathbf{1 5 2}$
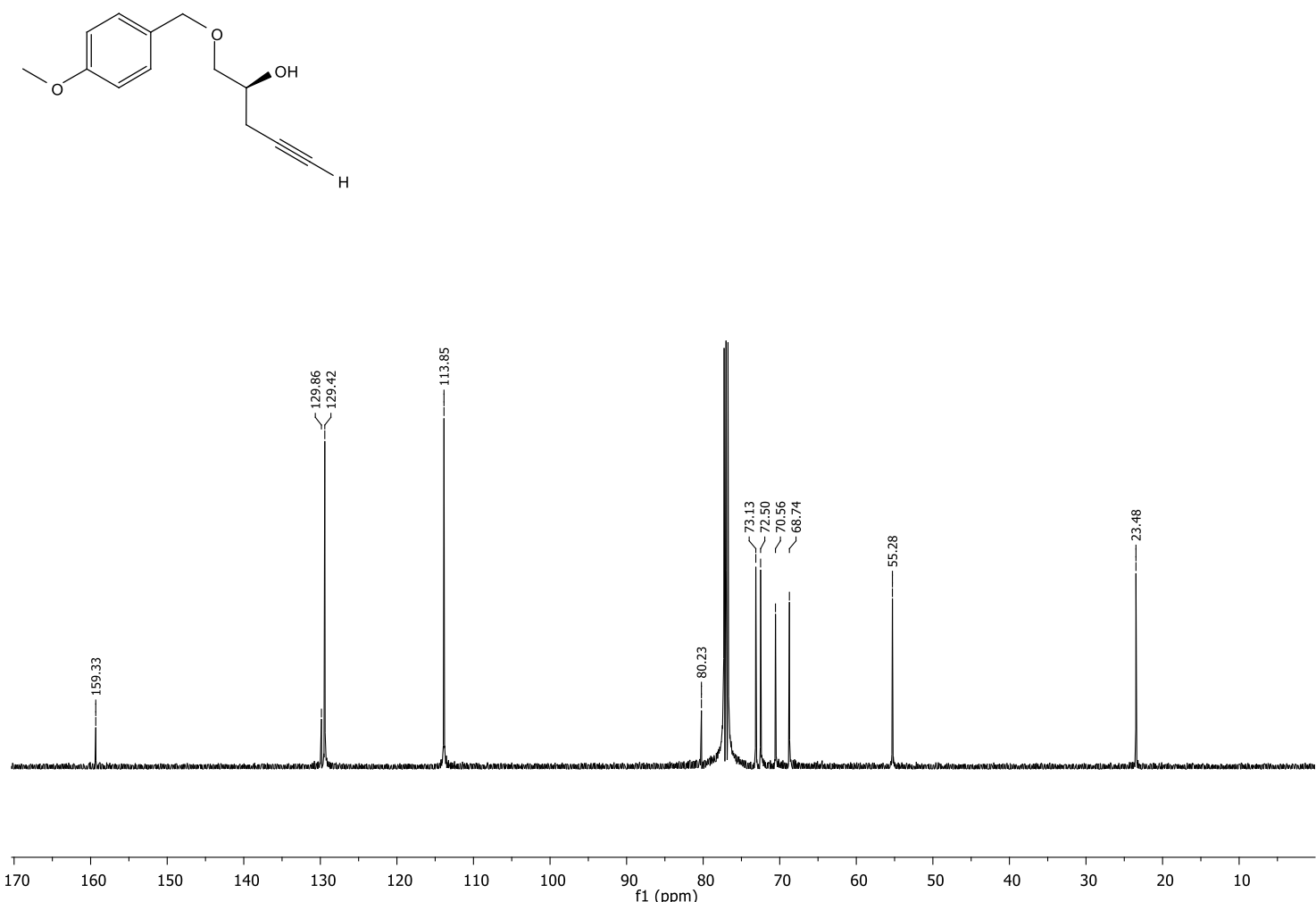

${ }^{13} \mathbf{C ~ N M R}\left(125 \mathrm{MHz}, \mathrm{CDCl}_{3}\right)$ spectrum of $\mathbf{1 5 2}$ 
(S)-Bromosuccinic acid (157)

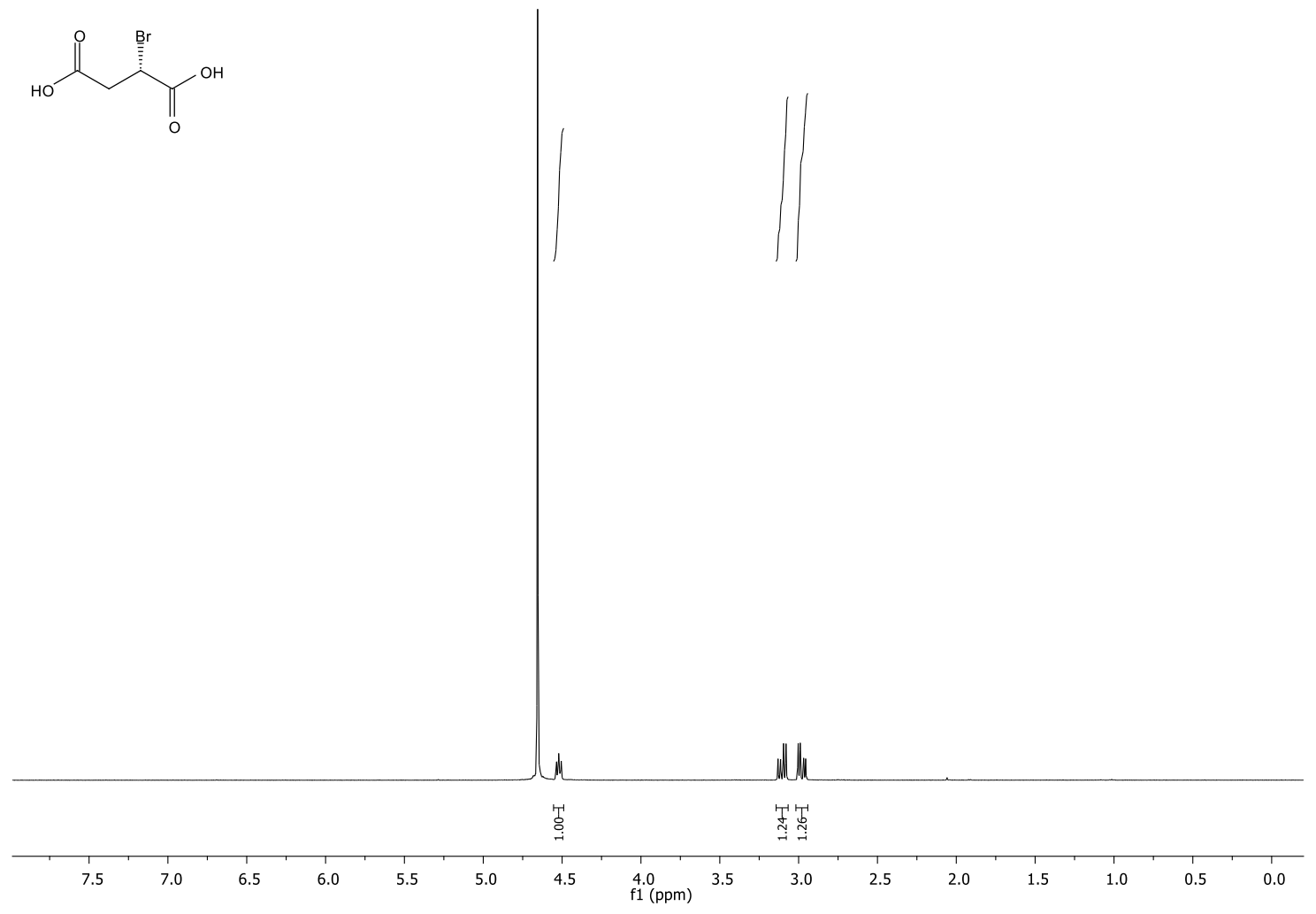

${ }^{1} \mathbf{H}$ NMR $\left(500 \mathrm{MHz}, \mathrm{D}_{2} \mathrm{O}\right)$ spectrum of $\mathbf{1 5 7}$<smiles>C[C@H](CC(=O)O)C(=O)O</smiles>

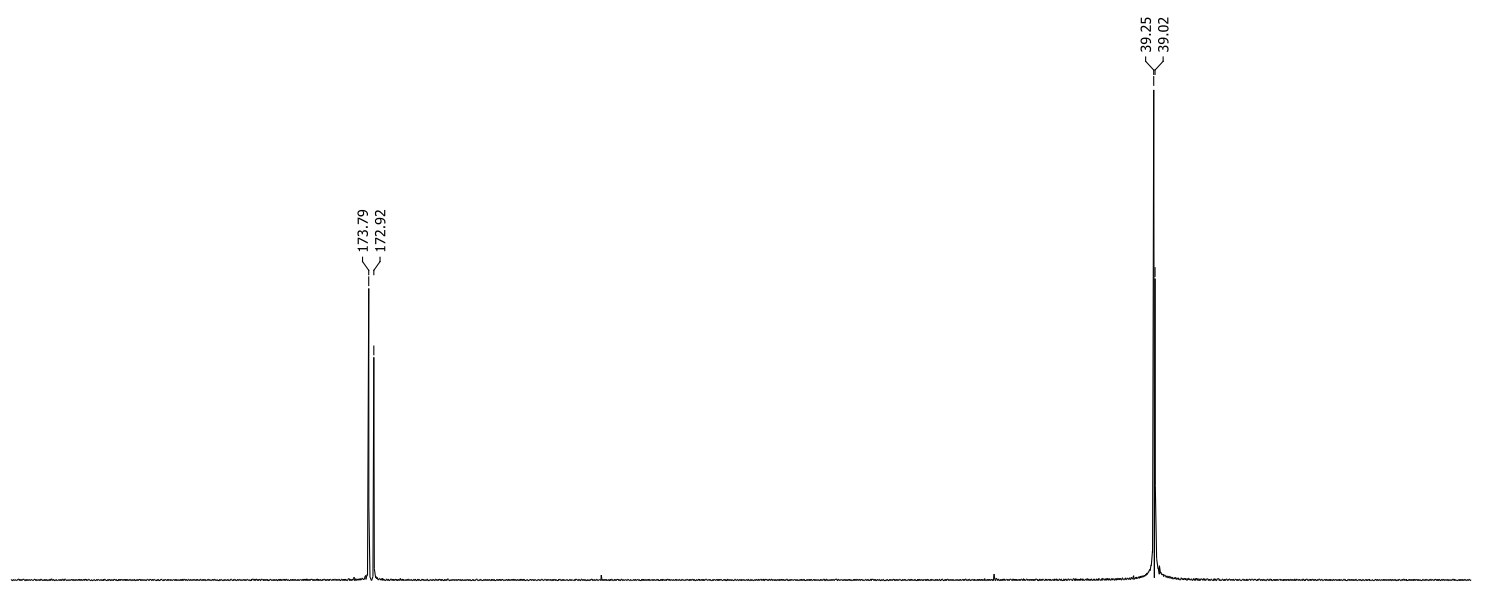

$\begin{array}{lllllllllllllllllllllllllllll}230 & 220 & 210 & 200 & 190 & 180 & 170 & 160 & 150 & 140 & 130 & 120 & 110 & 100 & 90 & 80 & 70 & 60 & 50 & 40 & 30 & 20 & 10 & 0 & -10\end{array}$

$\left.{ }^{13} \mathbf{C ~ N M R ~ ( 1 2 5 ~ M H z , ~} \mathrm{D}_{2} \mathrm{O}\right)$ spectrum of $\mathbf{1 5 7}$ 
(S)-2-Bromobutane-1,4-diol (160)

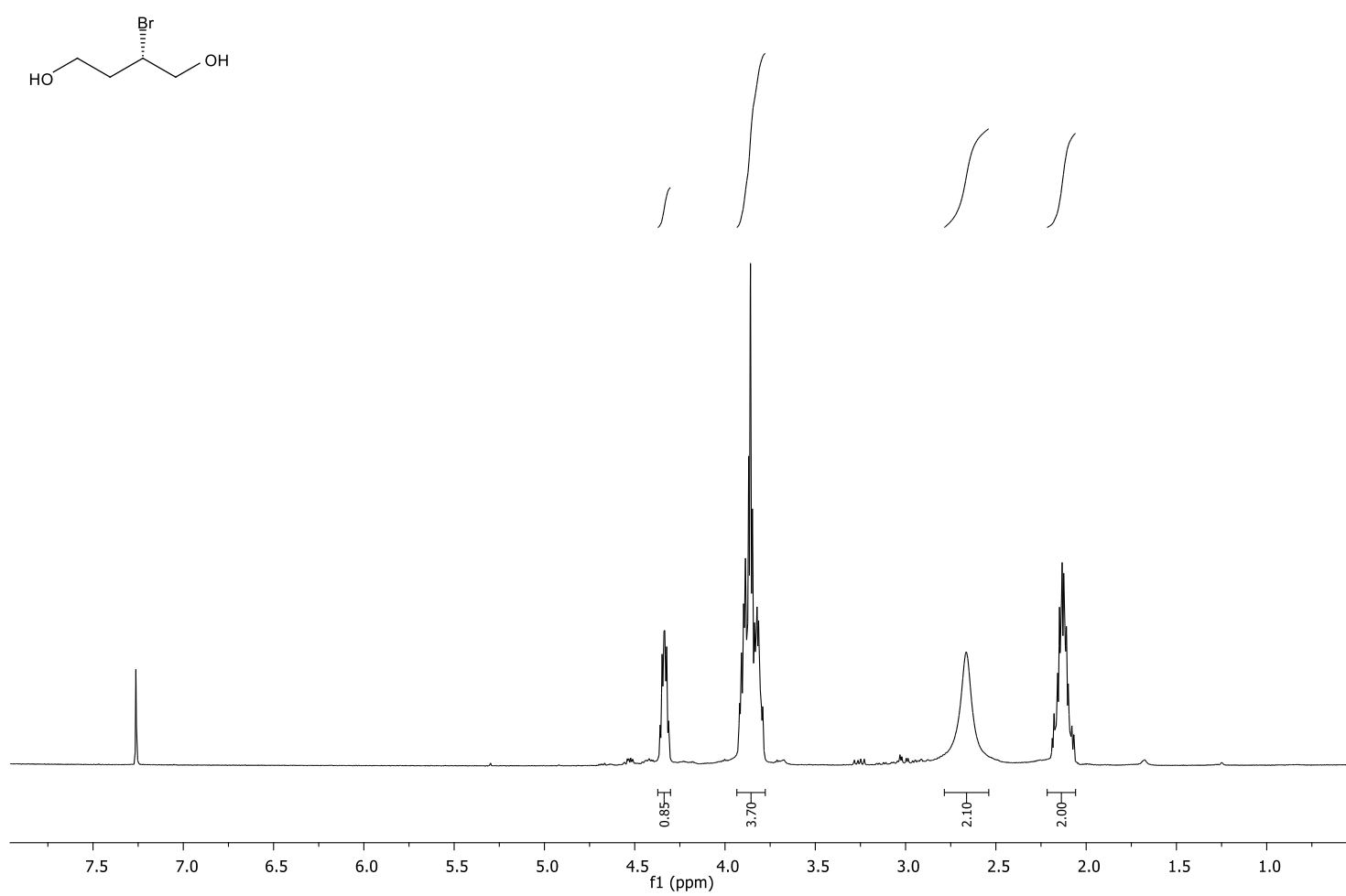

${ }^{1} \mathbf{H}$ NMR $\left(500 \mathrm{MHz}, \mathrm{CDCl}_{3}\right)$ spectrum of $\mathbf{1 6 0}$
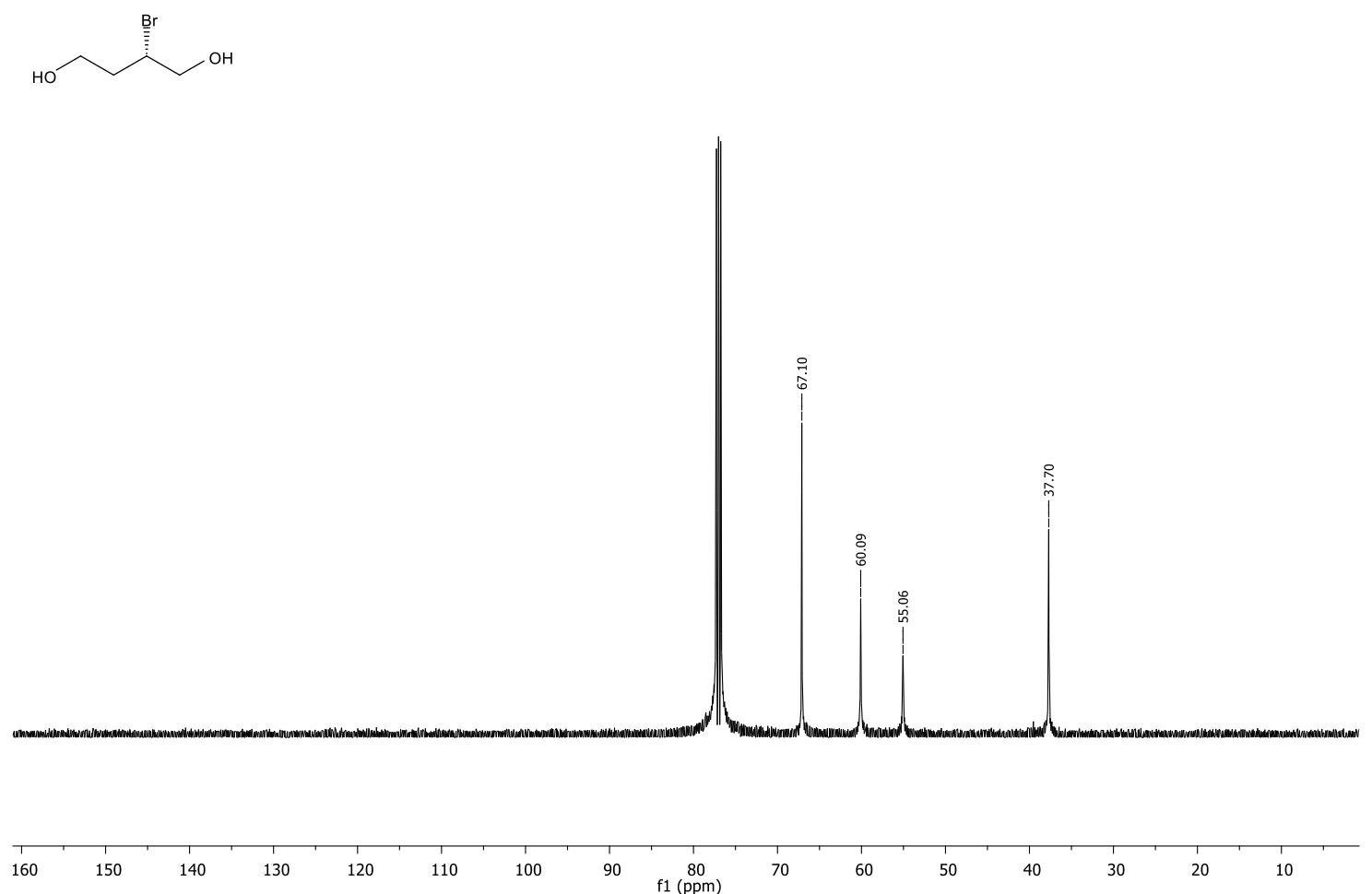

${ }^{13} \mathbf{C ~ N M R}\left(125 \mathrm{MHz}, \mathrm{CDCl}_{3}\right)$ spectrum of $\mathbf{1 6 0}$ 
(R)-Triethyl-(2-oxiran-2-yl)ethoxysilane (155)

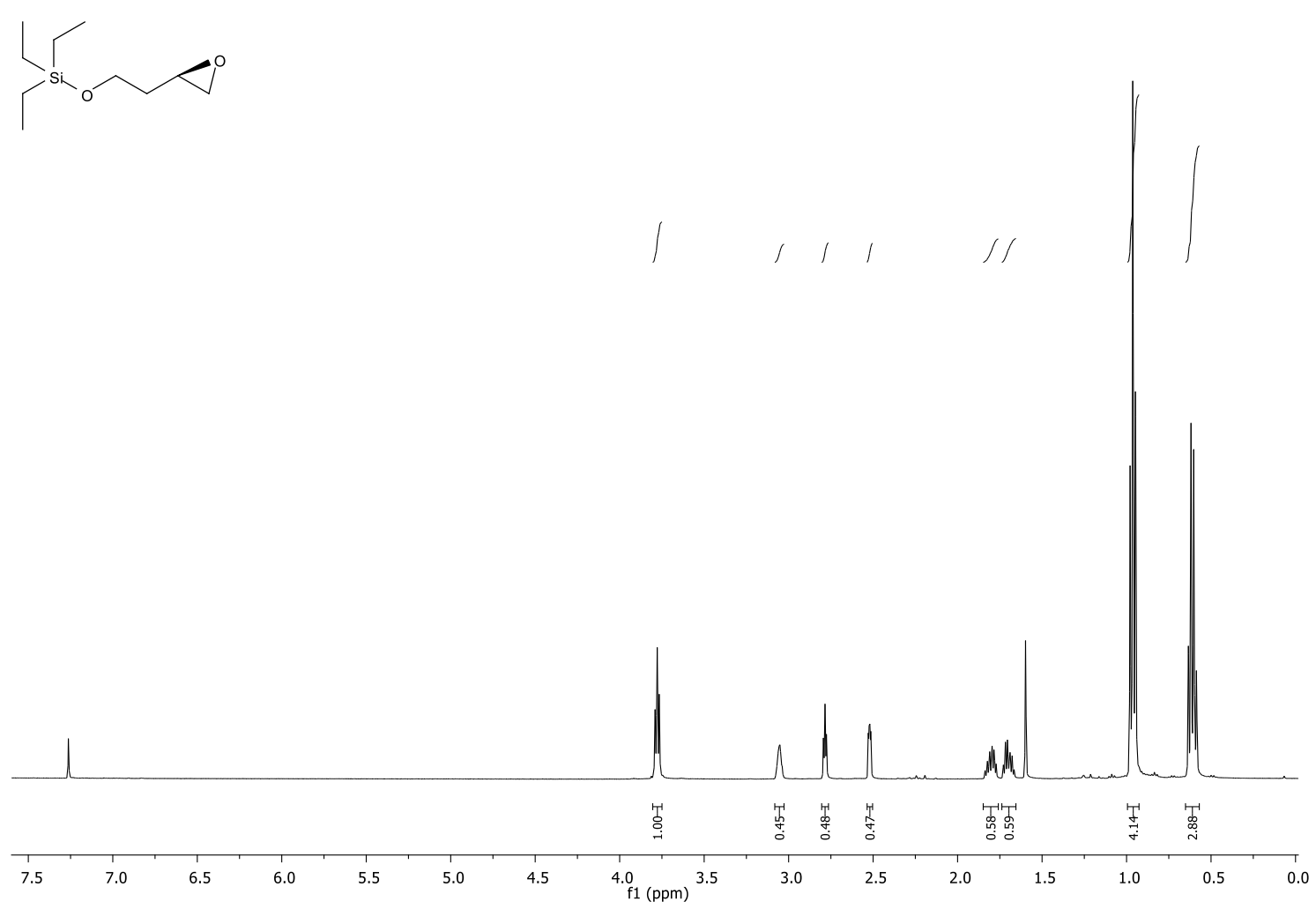

${ }^{1} \mathbf{H}$ NMR $\left(500 \mathrm{MHz}, \mathrm{CDCl}_{3}\right)$ spectrum of $\mathbf{1 5 5}$
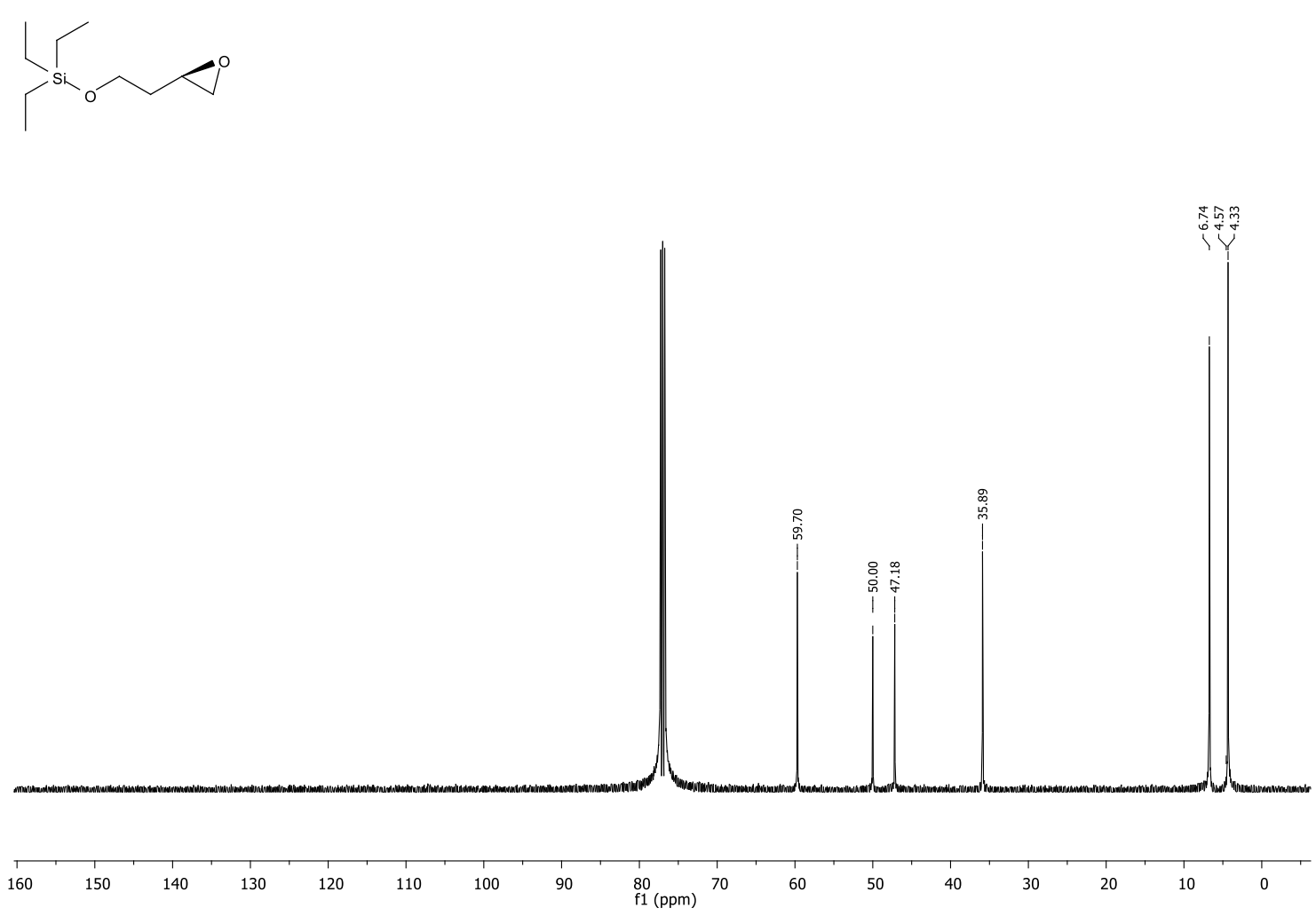

${ }^{13} \mathbf{C}$ NMR (125 MHz, $\left.\mathrm{CDCl}_{3}\right)$ spectrum of $\mathbf{1 5 5}$ 
(S)-Triethyl-(3-hydroxy)hex-5-enoxysilane (156)

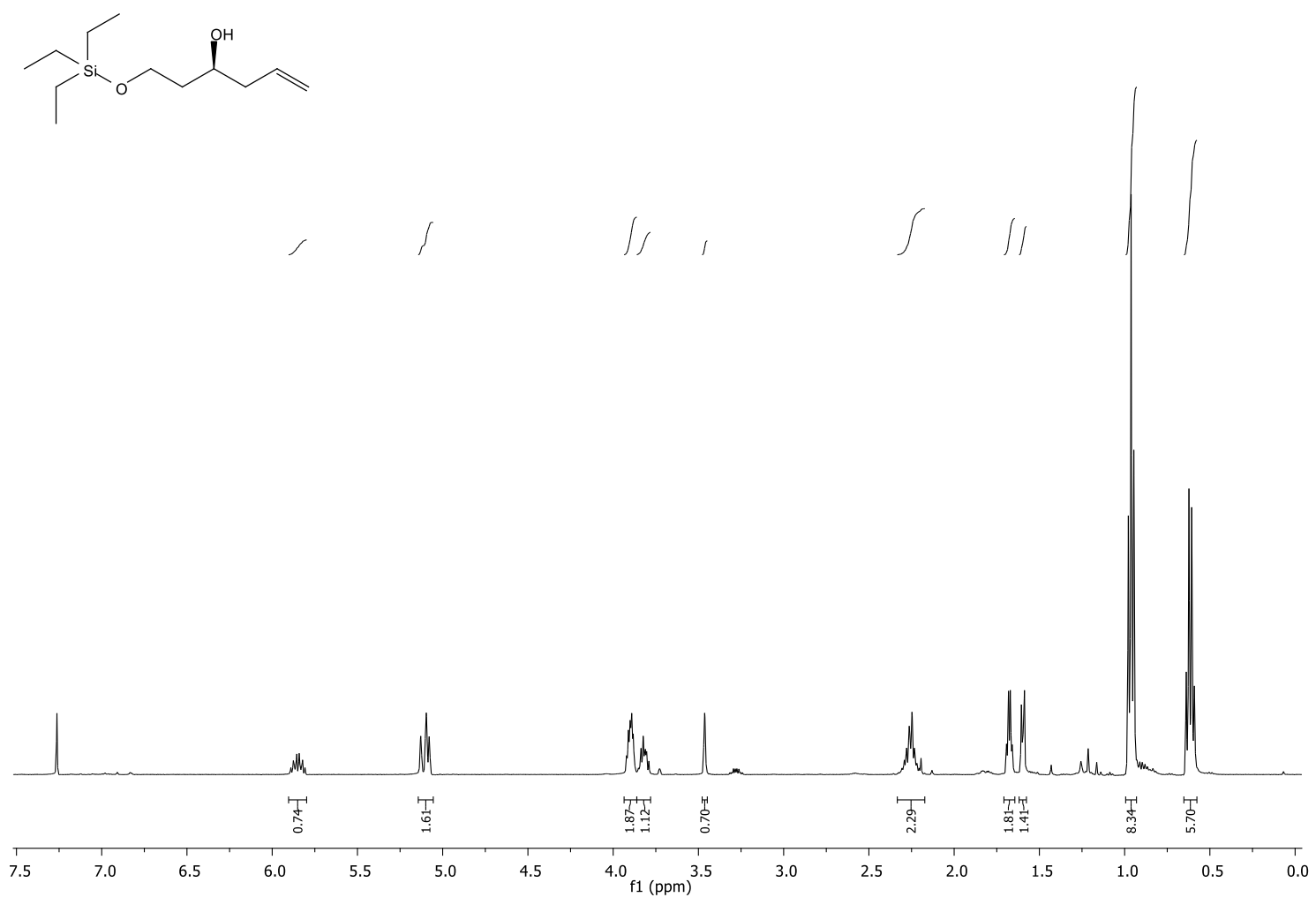

${ }^{1} \mathbf{H}$ NMR $\left(500 \mathrm{MHz}, \mathrm{CDCl}_{3}\right)$ spectrum of $\mathbf{1 5 6}$
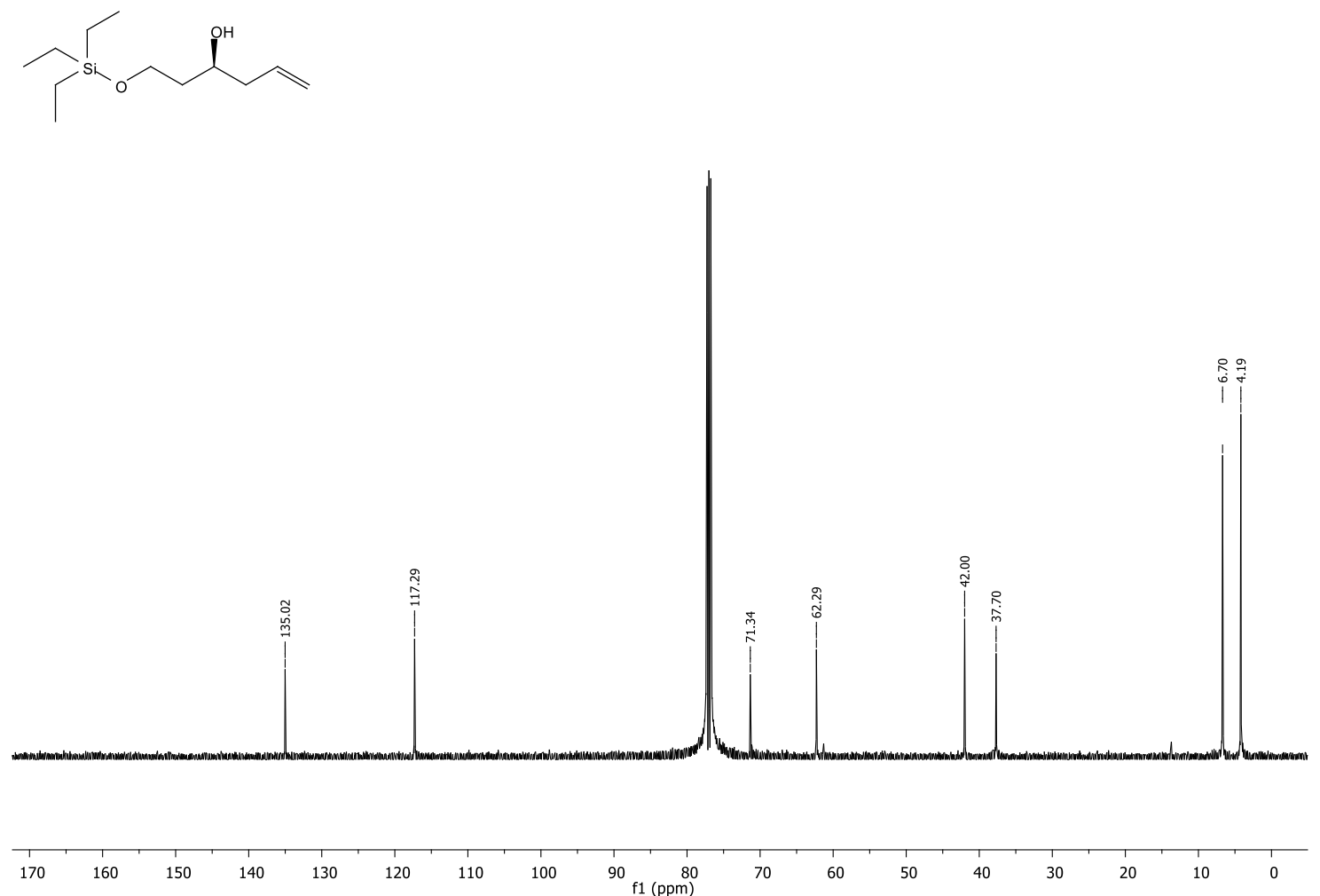

${ }^{13} \mathbf{C ~ N M R}\left(125 \mathrm{MHz}, \mathrm{CDCl}_{3}\right)$ spectrum of $\mathbf{1 5 6}$ 
(S)-1-Triethylsilyloxy-(3-t-butyldimethylsilyloxy)hex-5-ene (161)

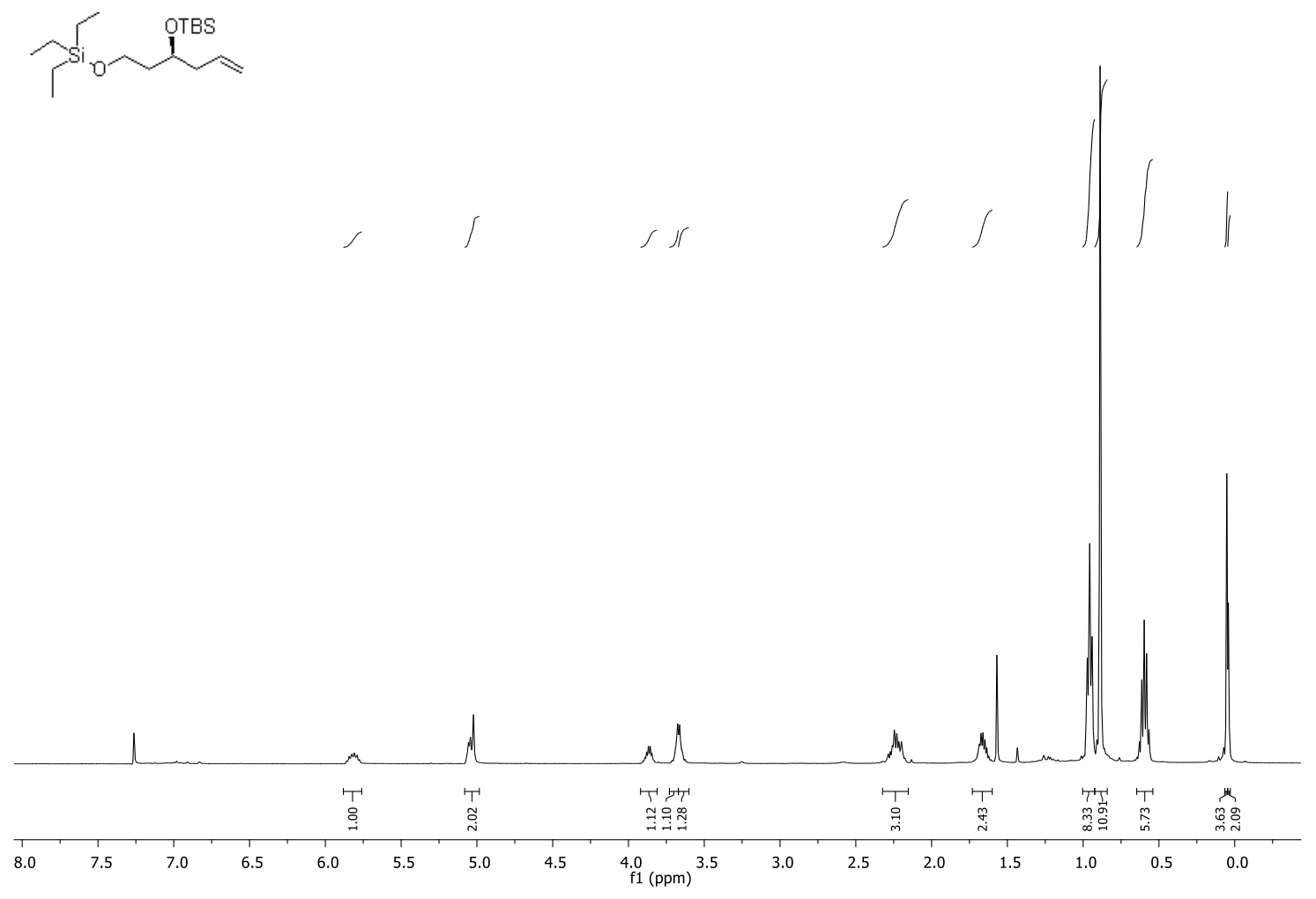

${ }^{1} \mathbf{H}$ NMR $\left(500 \mathrm{MHz}, \mathrm{CDCl}_{3}\right)$ spectrum of $\mathbf{1 6 1}$
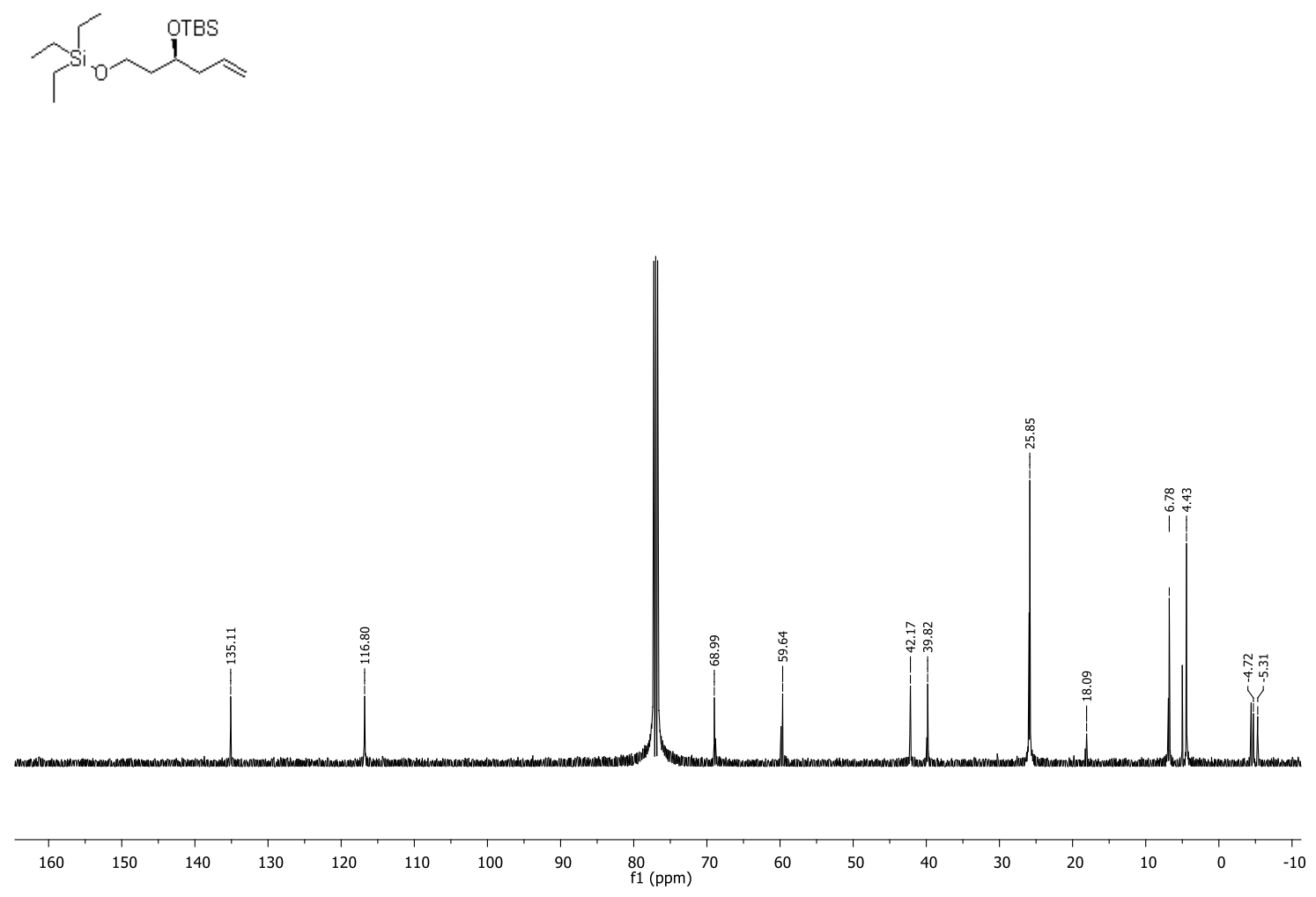

${ }^{13} \mathrm{C} \mathrm{NMR}\left(125 \mathrm{MHz}, \mathrm{CDCl}_{3}\right)$ spectrum of $\mathbf{1 6 1}$ 
2-(But-3'-enyl)-3-hydroxyoct-7-enal (170, in a a mixture)
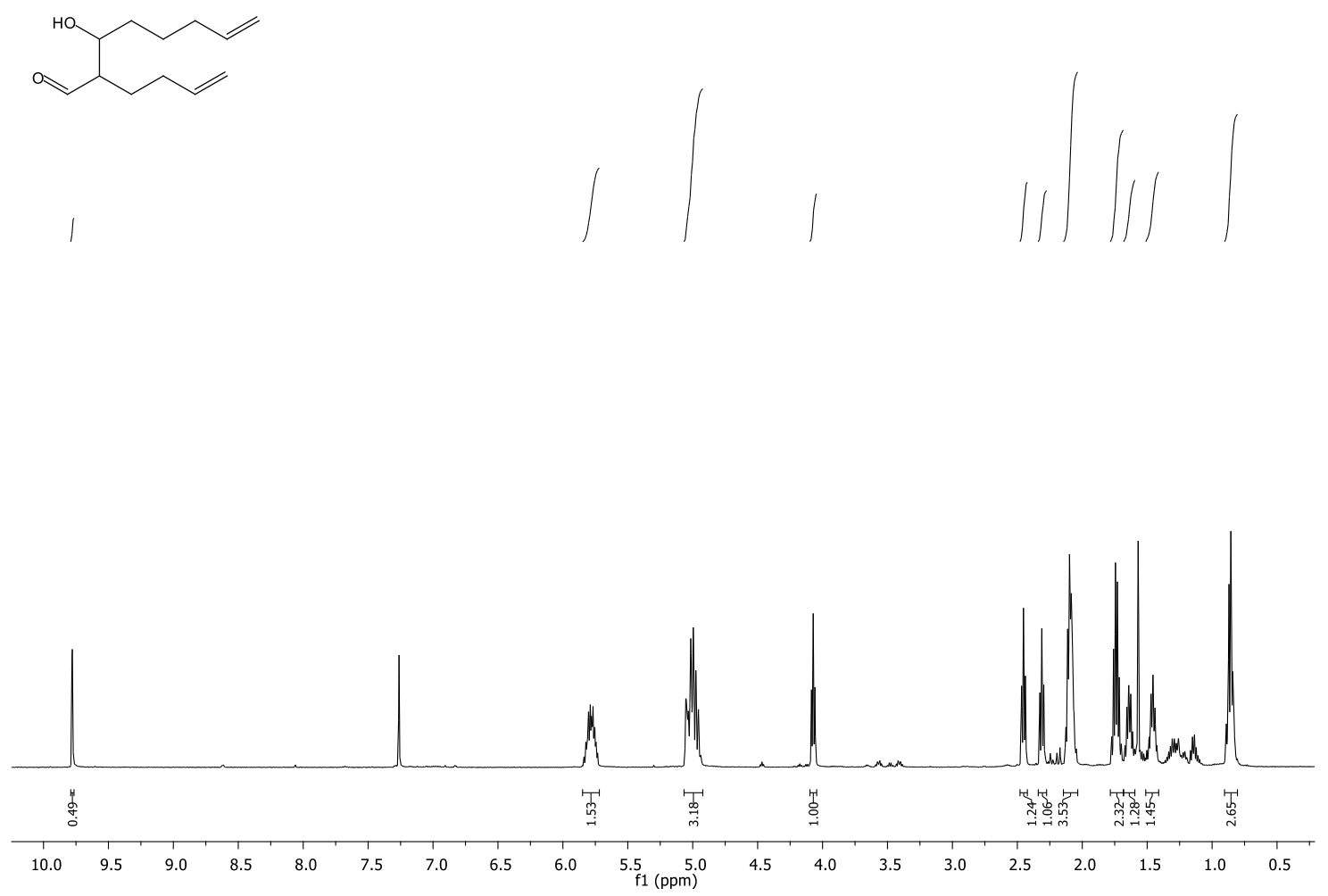

${ }^{1} \mathbf{H}$ NMR $\left(500 \mathrm{MHz}, \mathrm{CDCl}_{3}\right)$ spectrum of $\mathbf{1 7 0}$ mixture
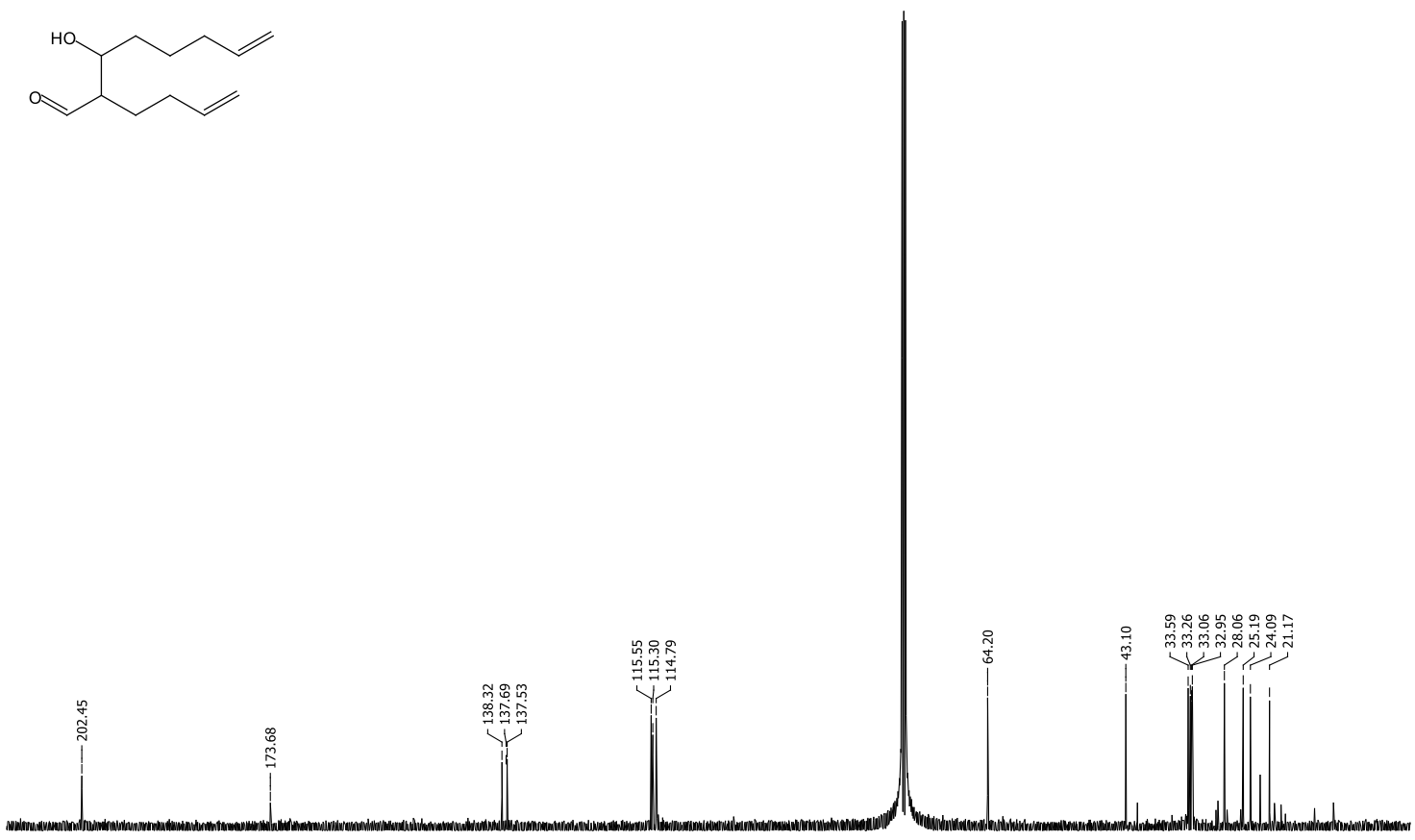

$\begin{array}{lllllllllllllllllllllll}210 & 200 & 190 & 180 & 170 & 160 & 150 & 140 & 130 & 120 & \underset{\mathrm{f} 1(\mathrm{ppm})}{100} & 90 & 80 & 70 & 60 & 50 & 40 & 30 & 20 & 10 & 0\end{array}$

${ }^{13} \mathrm{C}$ NMR $\left(125 \mathrm{MHz}, \mathrm{CDCl}_{3}\right)$ spectrum of $\mathbf{1 7 0}$ mixture 
5-(t-Butyldimethylsilyloxy)pentanal (177)

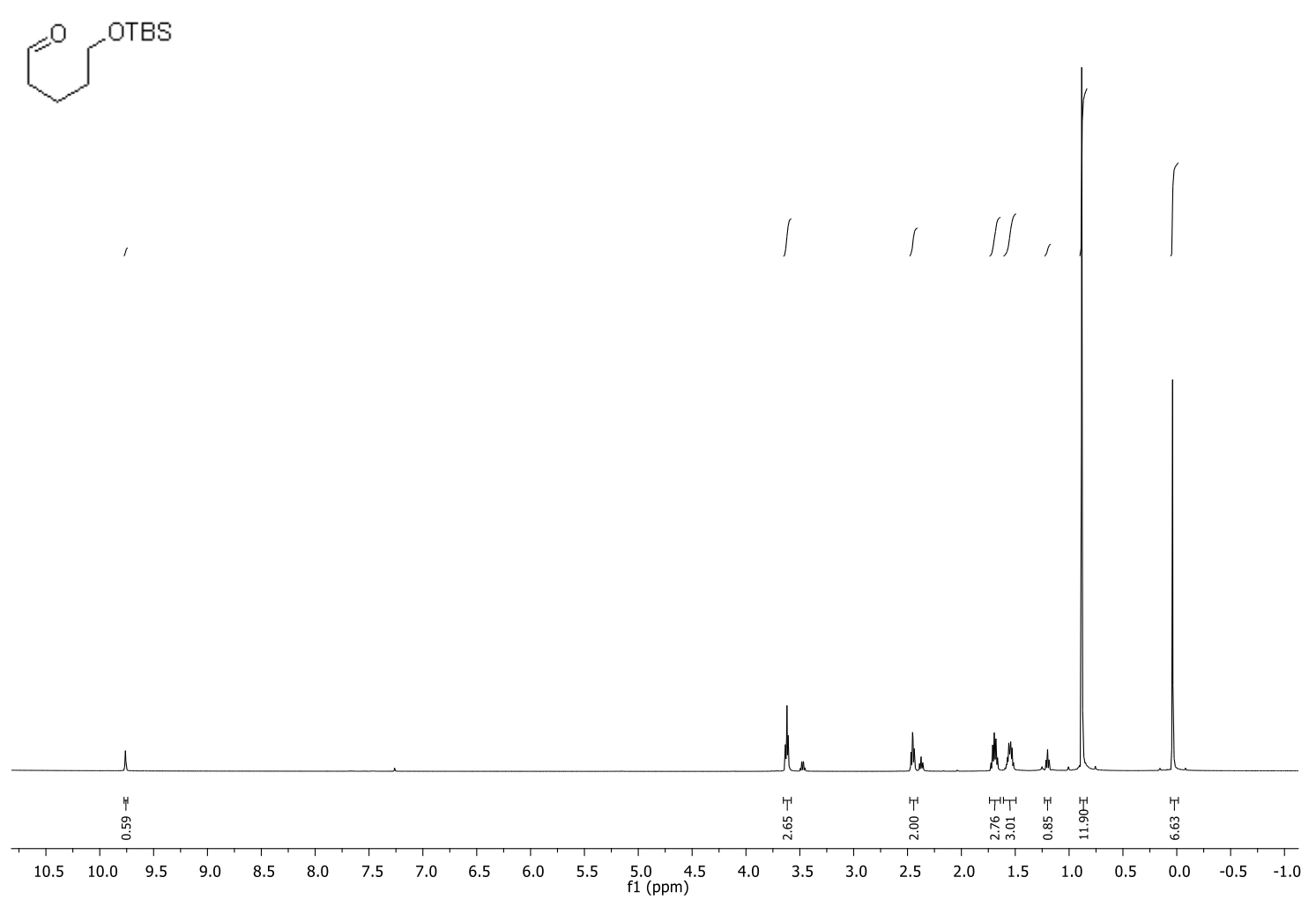

${ }^{1} \mathbf{H}$ NMR $\left(500 \mathrm{MHz}, \mathrm{CDCl}_{3}\right)$ spectrum of $\mathbf{1 7 7}$
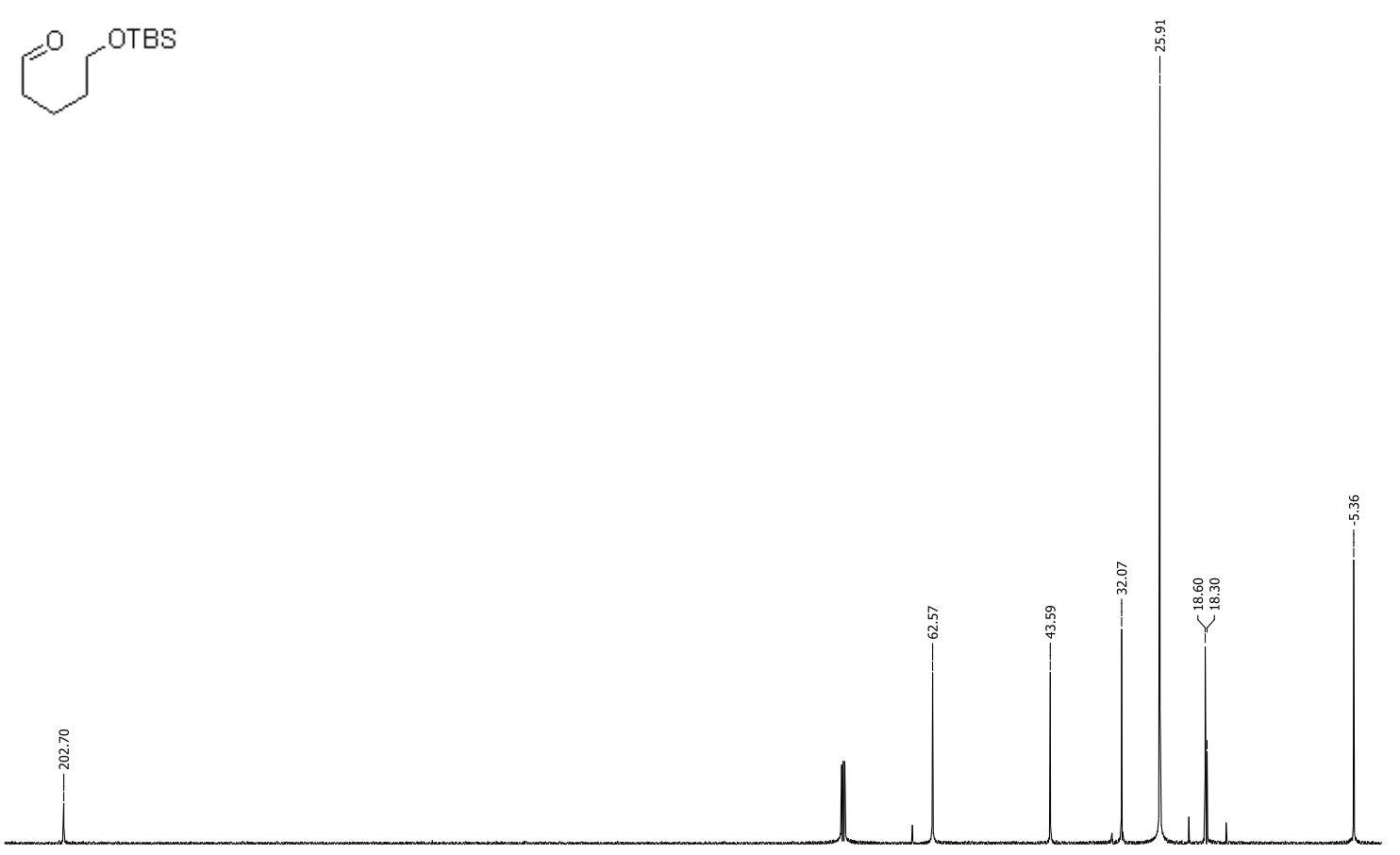

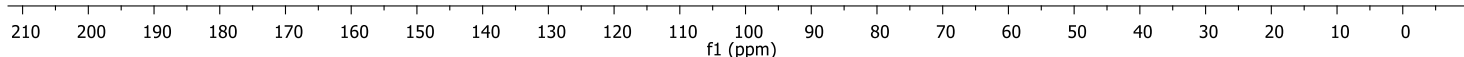

${ }^{13} \mathrm{C}$ NMR $\left(125 \mathrm{MHz}, \mathrm{CDCl}_{3}\right)$ spectrum of $\mathbf{1 7 7}$ 
(Triphenylphosphoranylidene)acetate (179)

$$
\mathrm{Ph}_{3} \mathrm{P} \otimes \stackrel{\mathrm{O}}{\mathrm{Il}}_{\mathrm{OMe}}
$$

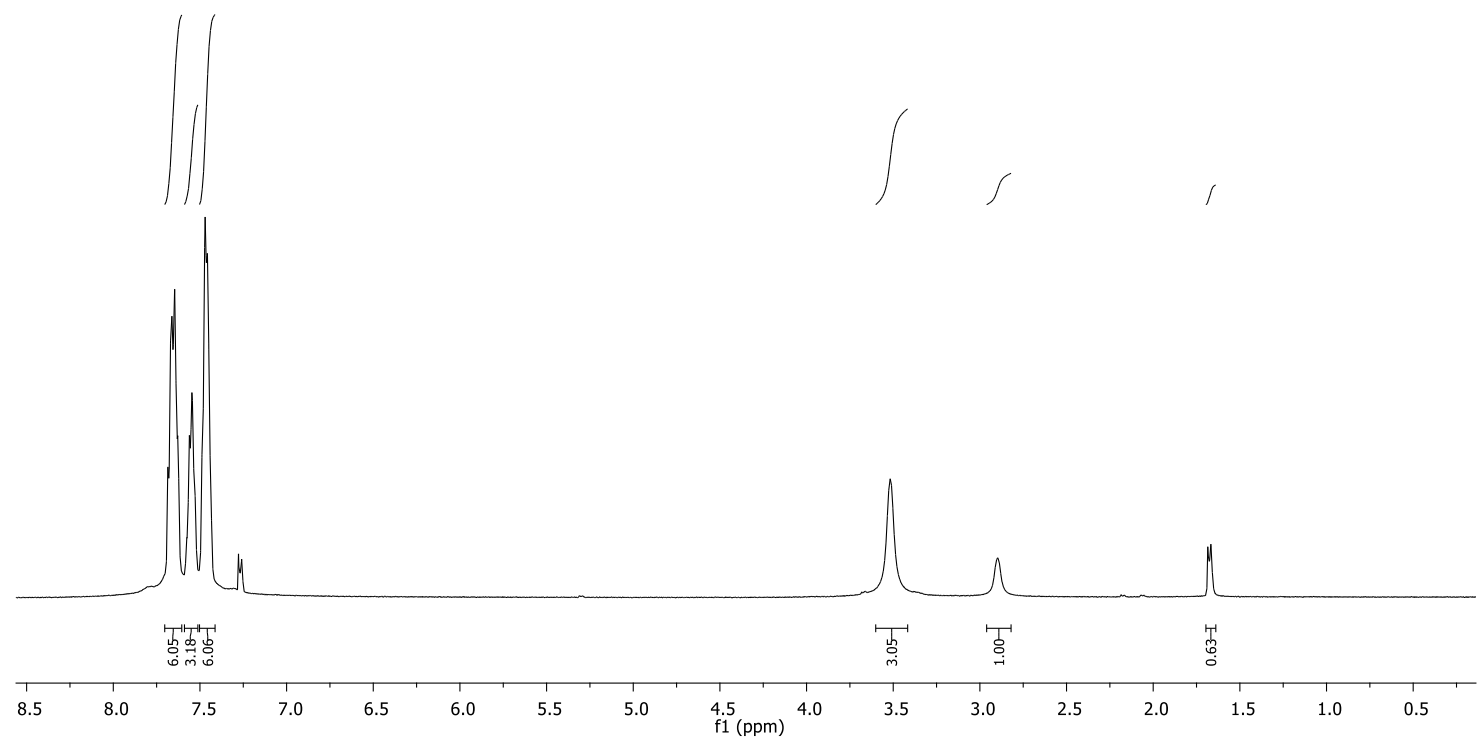

${ }^{1} \mathbf{H}$ NMR $\left(500 \mathrm{MHz}, \mathrm{CDCl}_{3}\right)$ spectrum of $\mathbf{1 7 9}$

$\mathrm{Ph}_{3} \mathrm{P}_{\mathrm{N}} \stackrel{\mathrm{O}}{\mathrm{I}}$
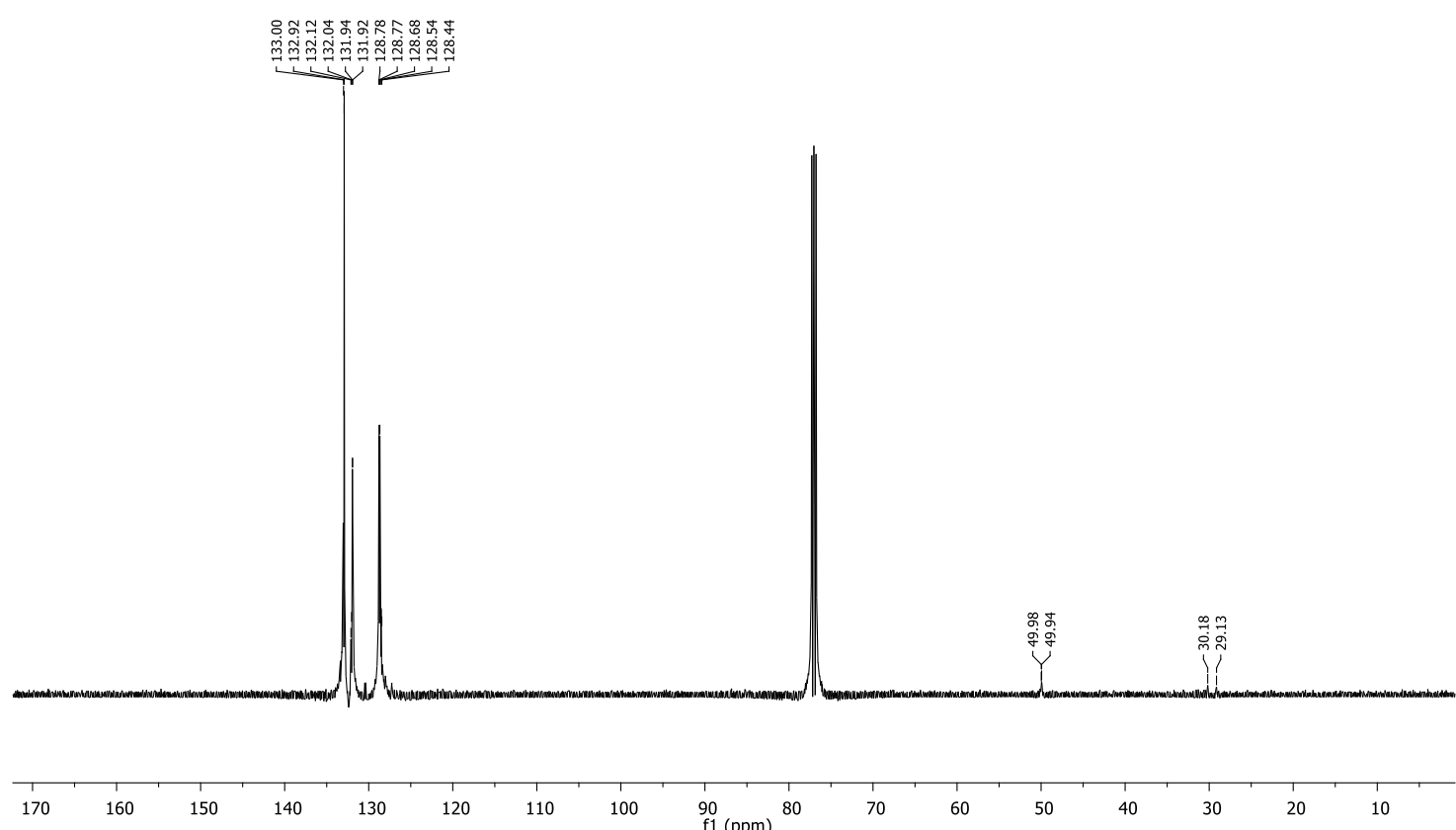

${ }^{13} \mathbf{C}$ NMR $\left(125 \mathrm{MHz}, \mathrm{CDCl}_{3}\right)$ spectrum of $\mathbf{1 7 9}$ 


$$
\mathrm{Ph}_{3} \mathrm{P} \approx \stackrel{\rho}{\mu}_{\mathrm{OMe}}
$$

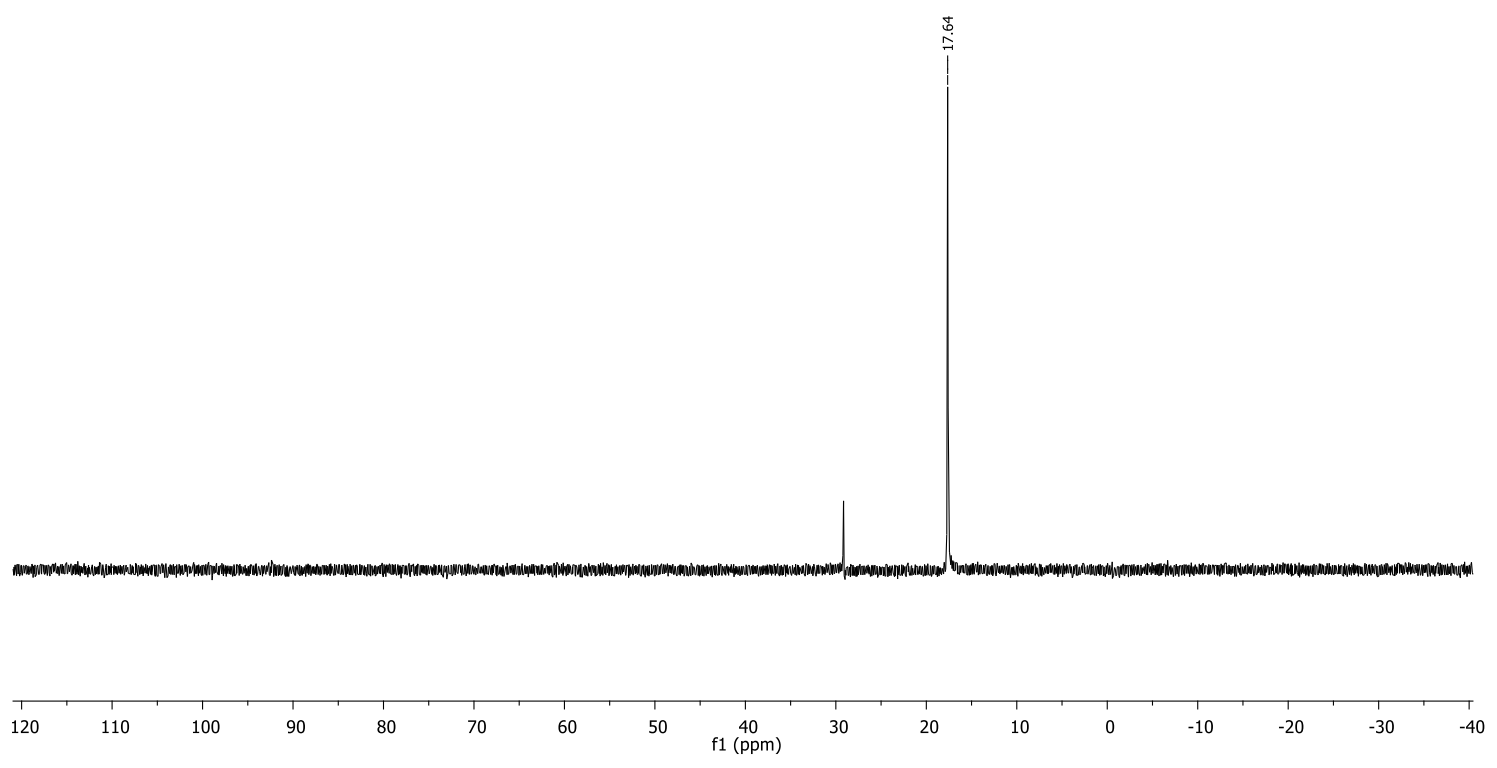

${ }^{31} \mathbf{P}$ NMR $\left(120 \mathrm{MHz}, \mathrm{CDCl}_{3}\right)$ spectrum of $\mathbf{1 7 9}$ 
(Triphenylphosphoranylidene)ketene (178)

$$
\mathrm{Ph}_{3} \mathrm{P}=\mathrm{C}=\mathrm{C}=\mathrm{O}
$$

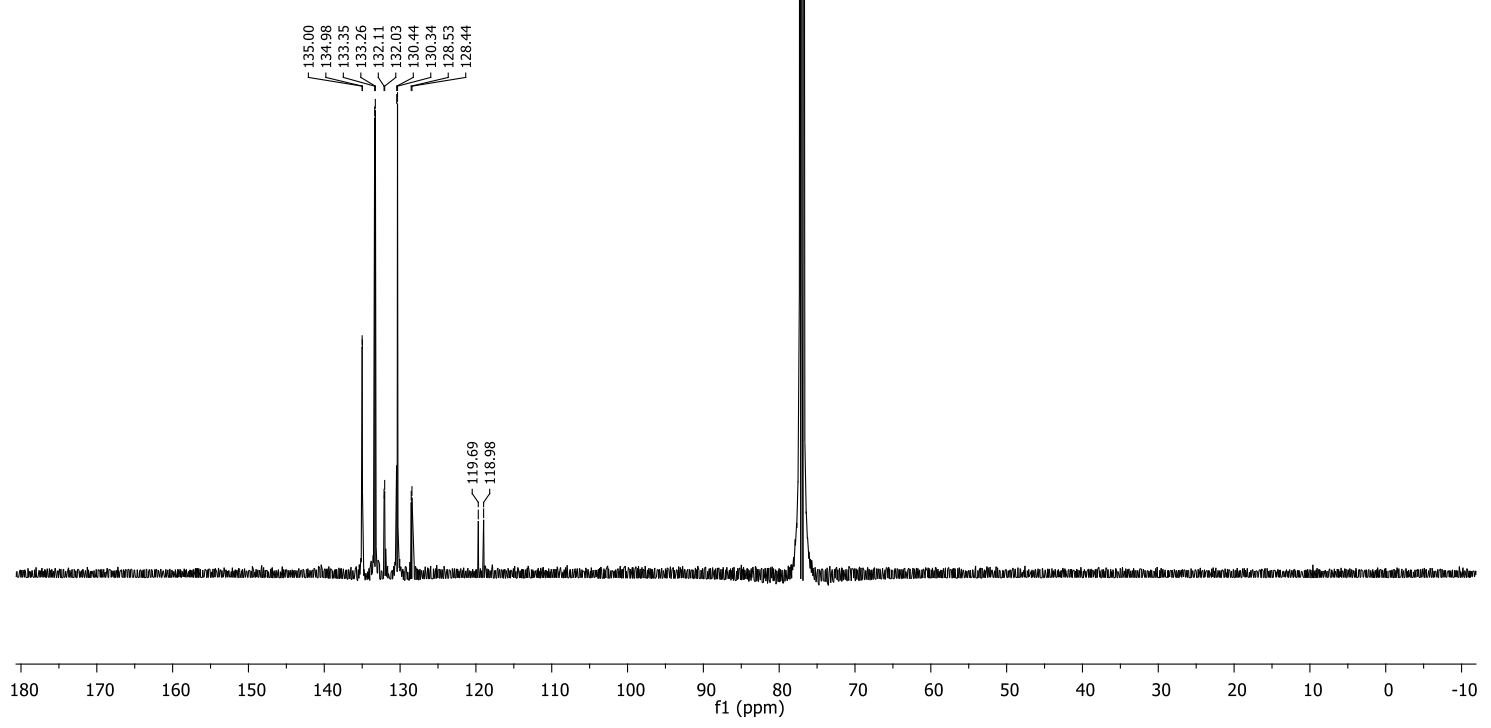

${ }^{13} \mathrm{C}$ NMR (125 MHz, $\left.\mathrm{CDCl}_{3}\right)$ spectrum of $\mathbf{1 7 8}$

$$
\mathrm{Ph}_{3} \mathrm{P}=\mathrm{C}=\mathrm{C}=\mathrm{O}
$$

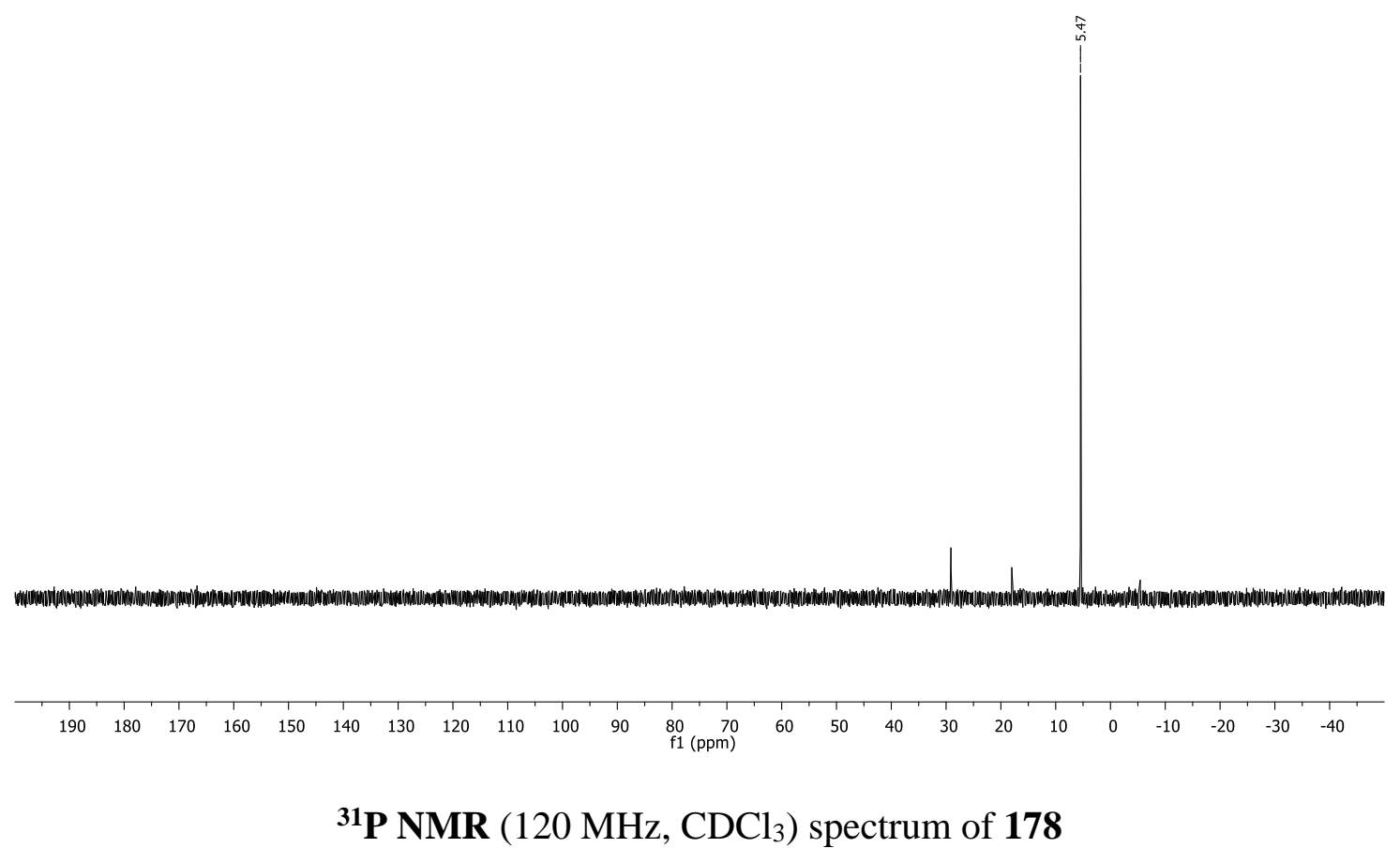




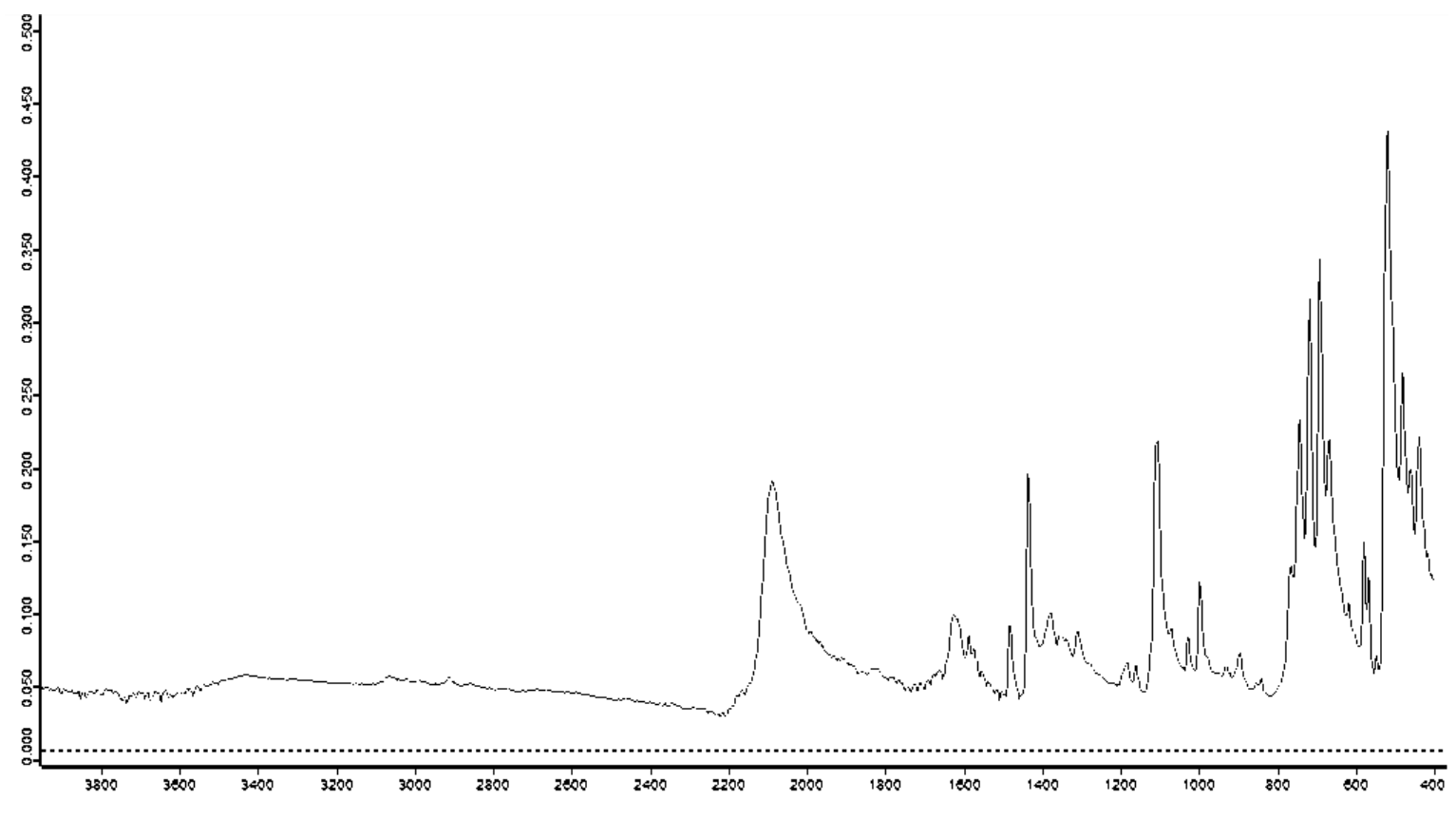

IR (neat) spectrum of $\mathbf{1 7 8}$ 
$\left(2^{\prime} E, 2 E, 4 E\right)$-Hex-2'-enyl 5-phenylpenta-2,4-dienoate (184)
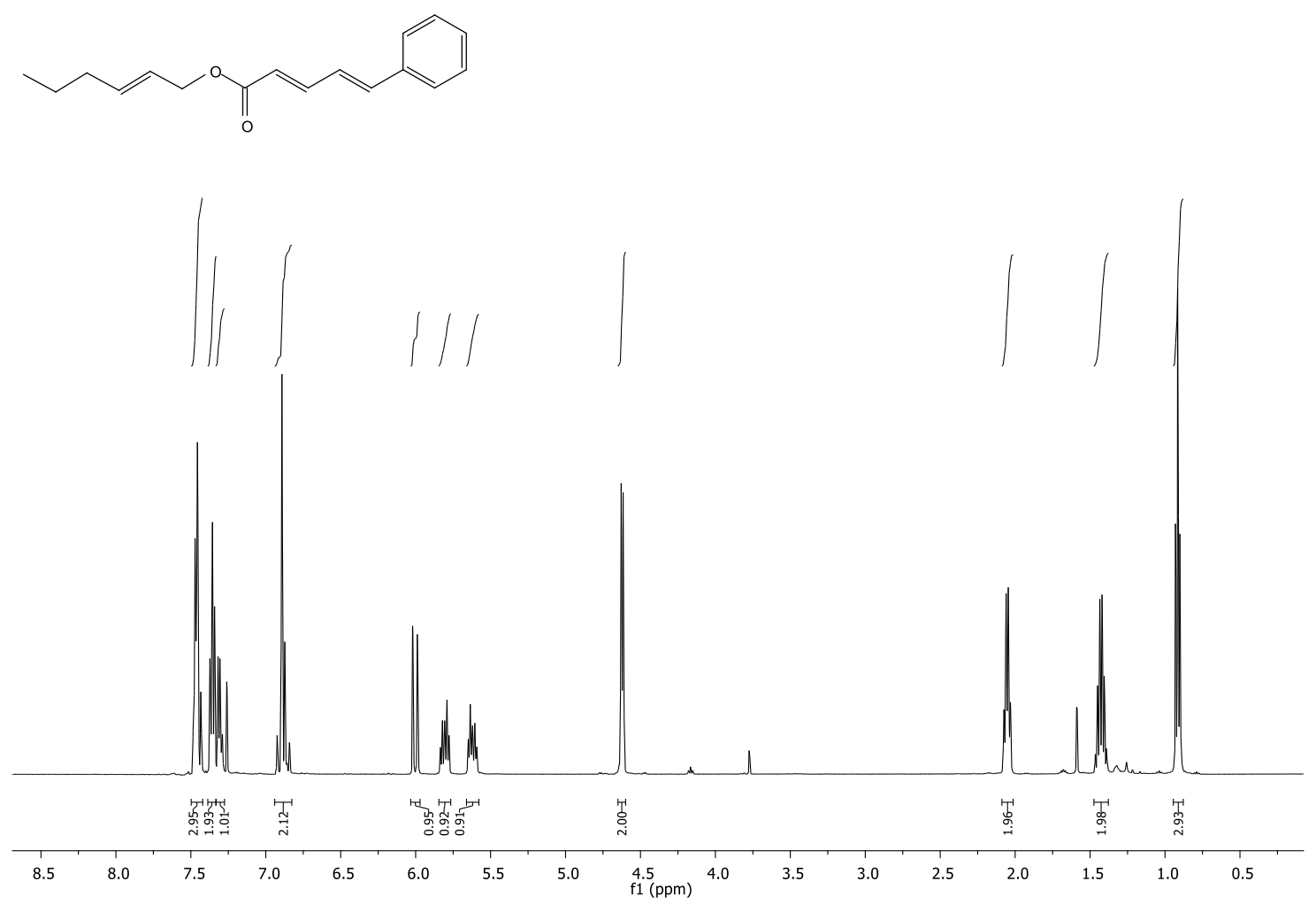

${ }^{1} \mathbf{H}$ NMR $\left(500 \mathrm{MHz}, \mathrm{CDCl}_{3}\right)$ spectrum of $\mathbf{1 8 4}$
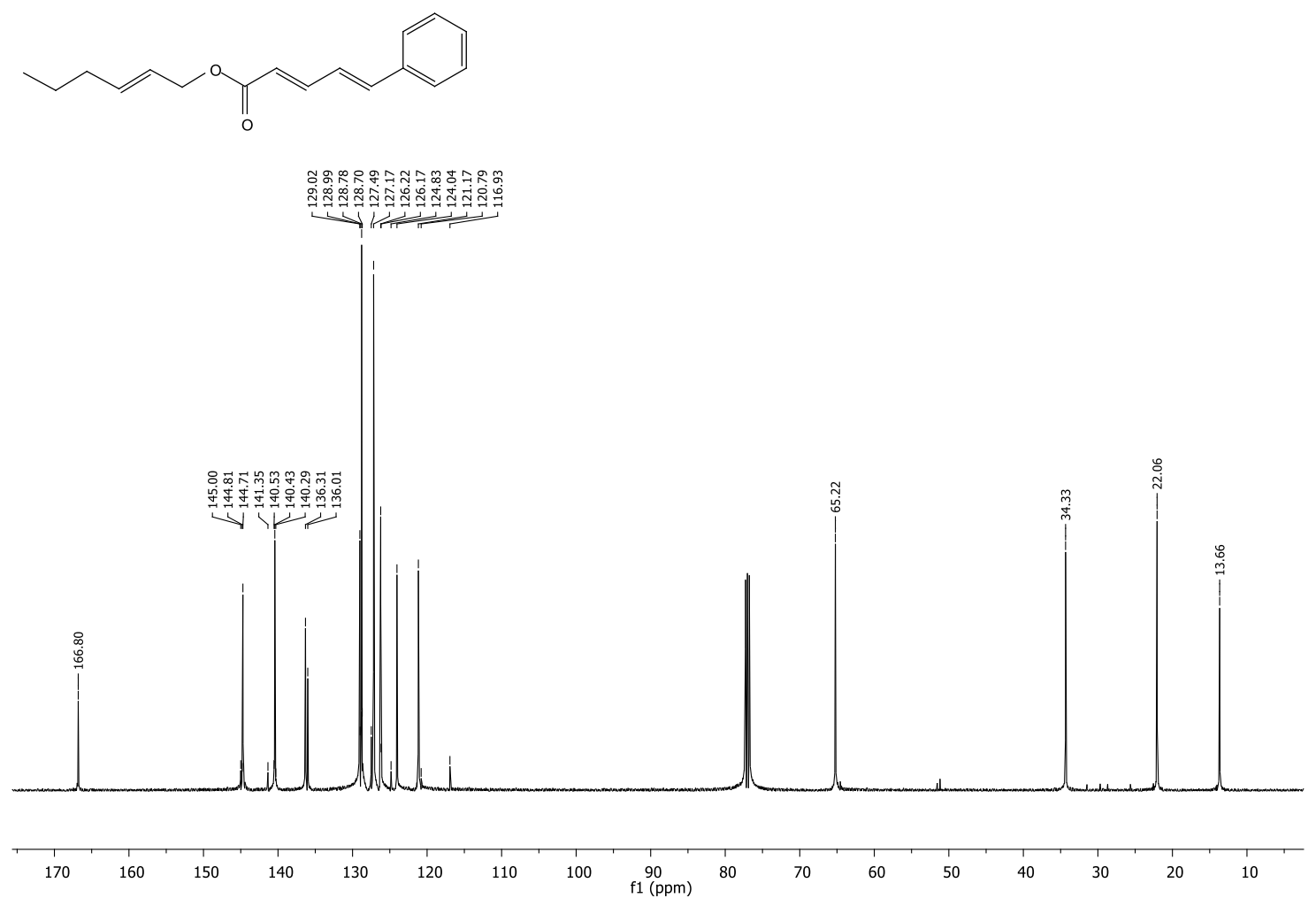

${ }^{13} \mathbf{C ~ N M R}\left(125 \mathrm{MHz}, \mathrm{CDCl}_{3}\right)$ spectrum of $\mathbf{1 8 4}$ 


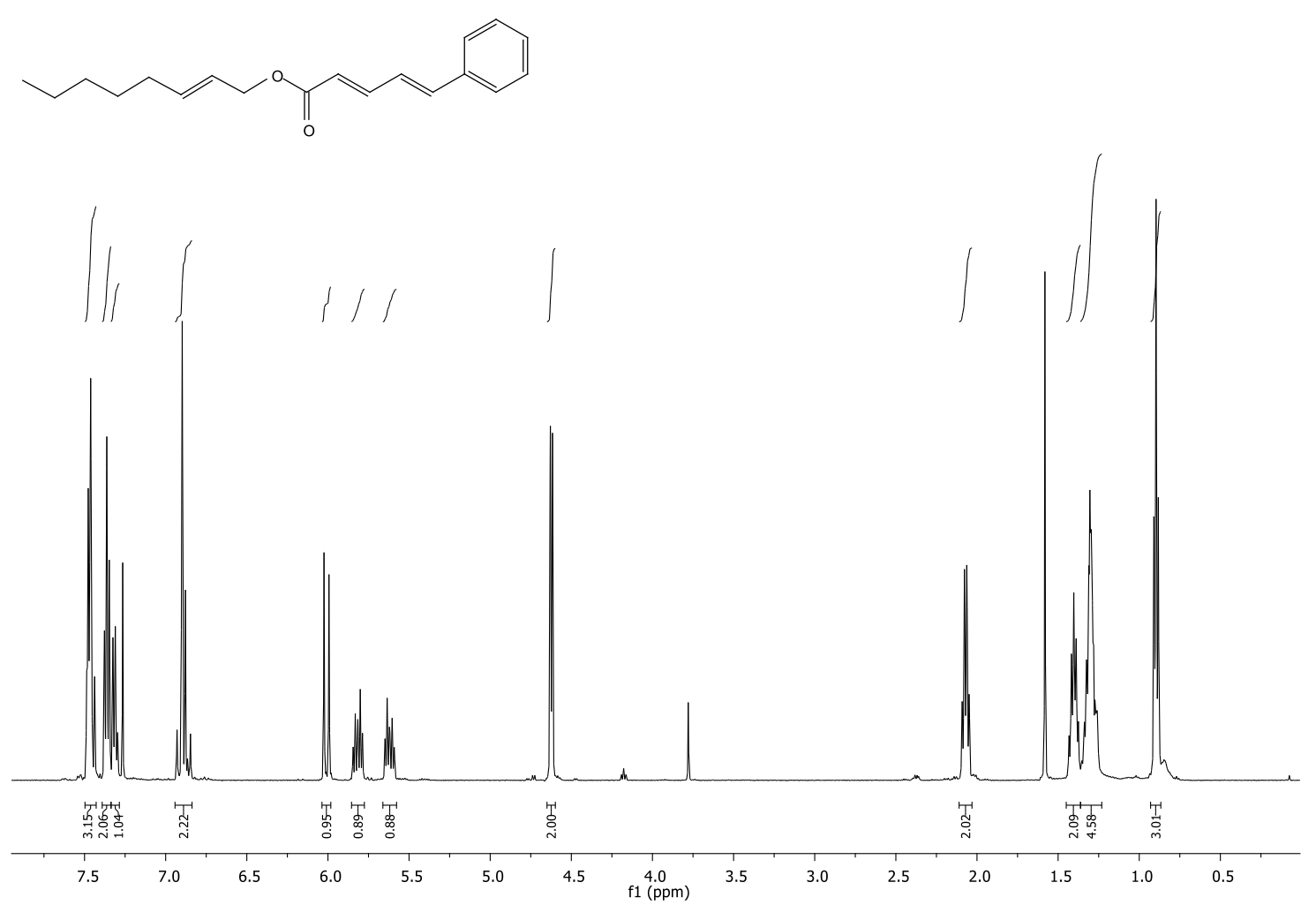

${ }^{1} \mathbf{H}$ NMR $\left(500 \mathrm{MHz}, \mathrm{CDCl}_{3}\right)$ spectrum of $\mathbf{1 8 6}$
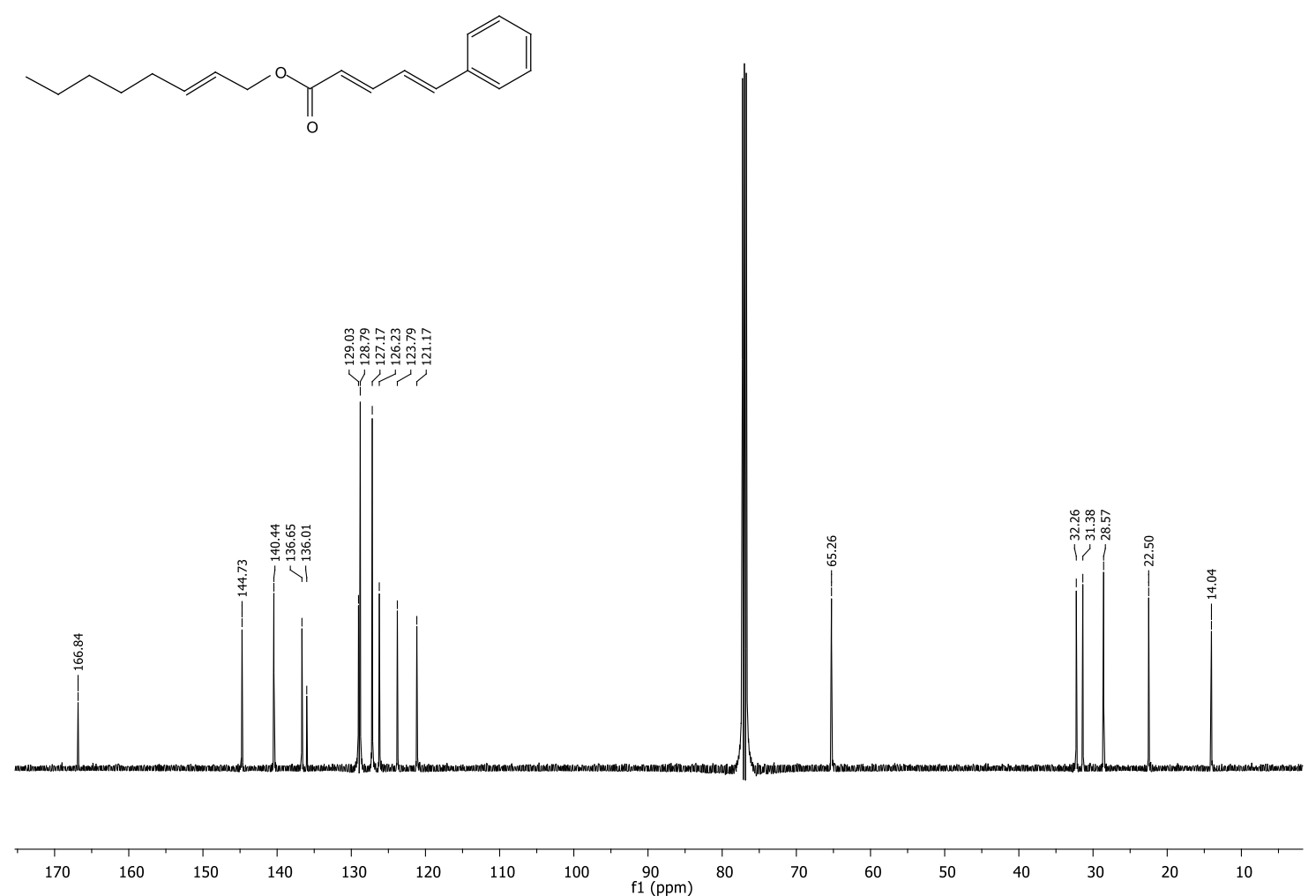

${ }^{13} \mathbf{C}$ NMR (125 MHz, $\left.\mathrm{CDCl}_{3}\right)$ spectrum of $\mathbf{1 8 6}$ 


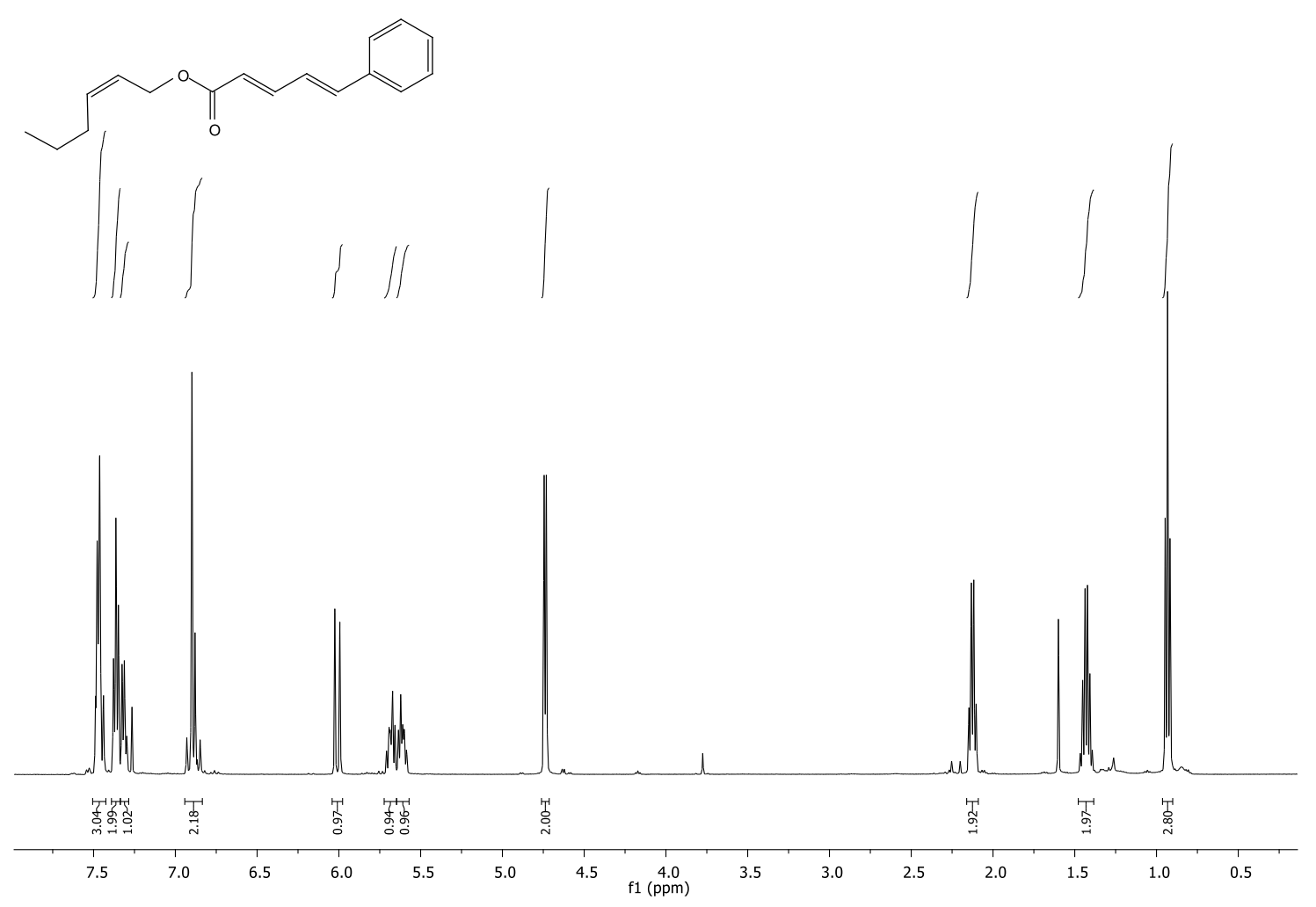

${ }^{\mathbf{1}} \mathbf{H}$ NMR $\left(500 \mathrm{MHz}, \mathrm{CDCl}_{3}\right)$ spectrum of $\mathbf{1 8 8}$
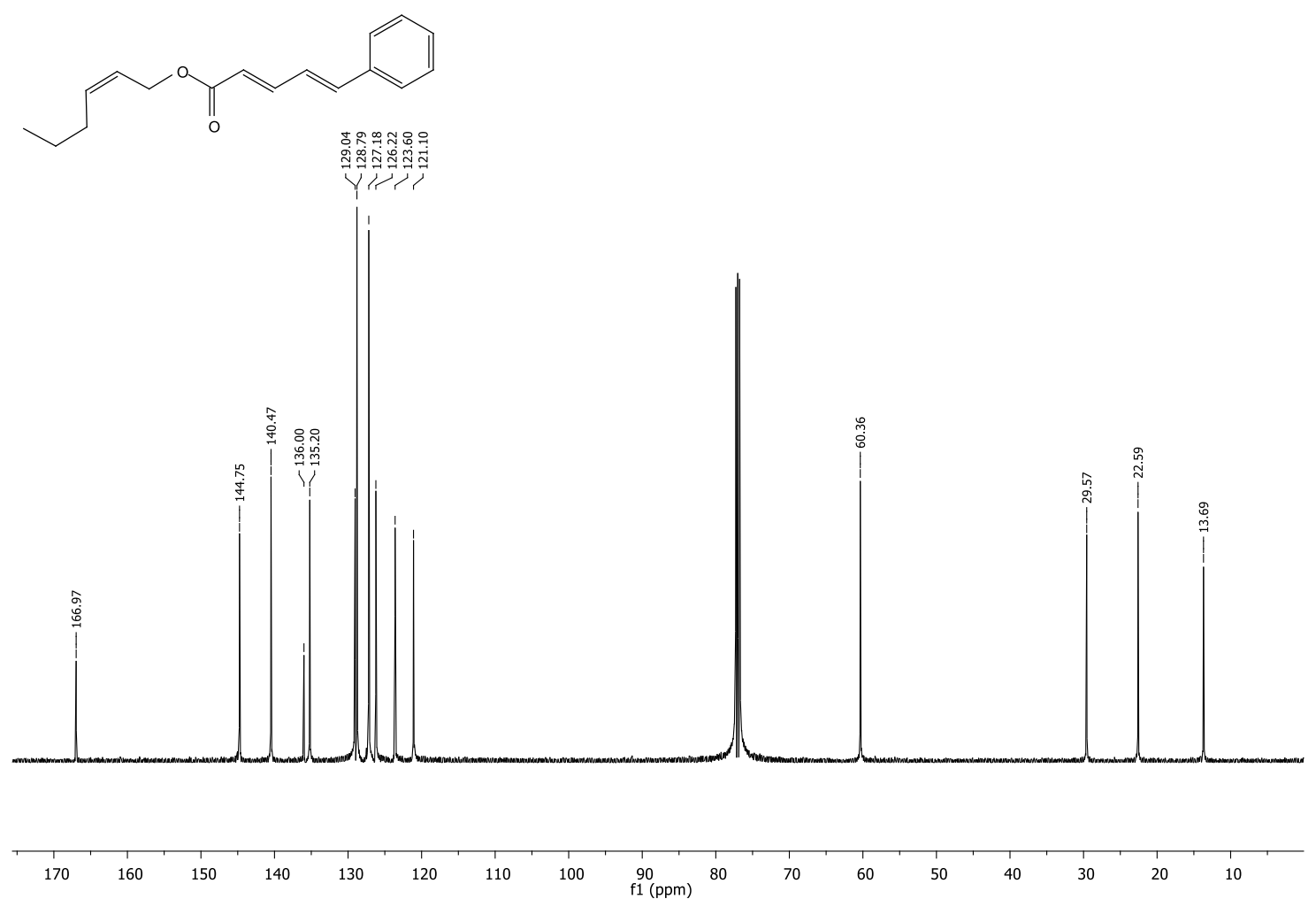

${ }^{13} \mathrm{C} \mathrm{NMR}\left(125 \mathrm{MHz}, \mathrm{CDCl}_{3}\right)$ spectrum of $\mathbf{1 8 8}$ 

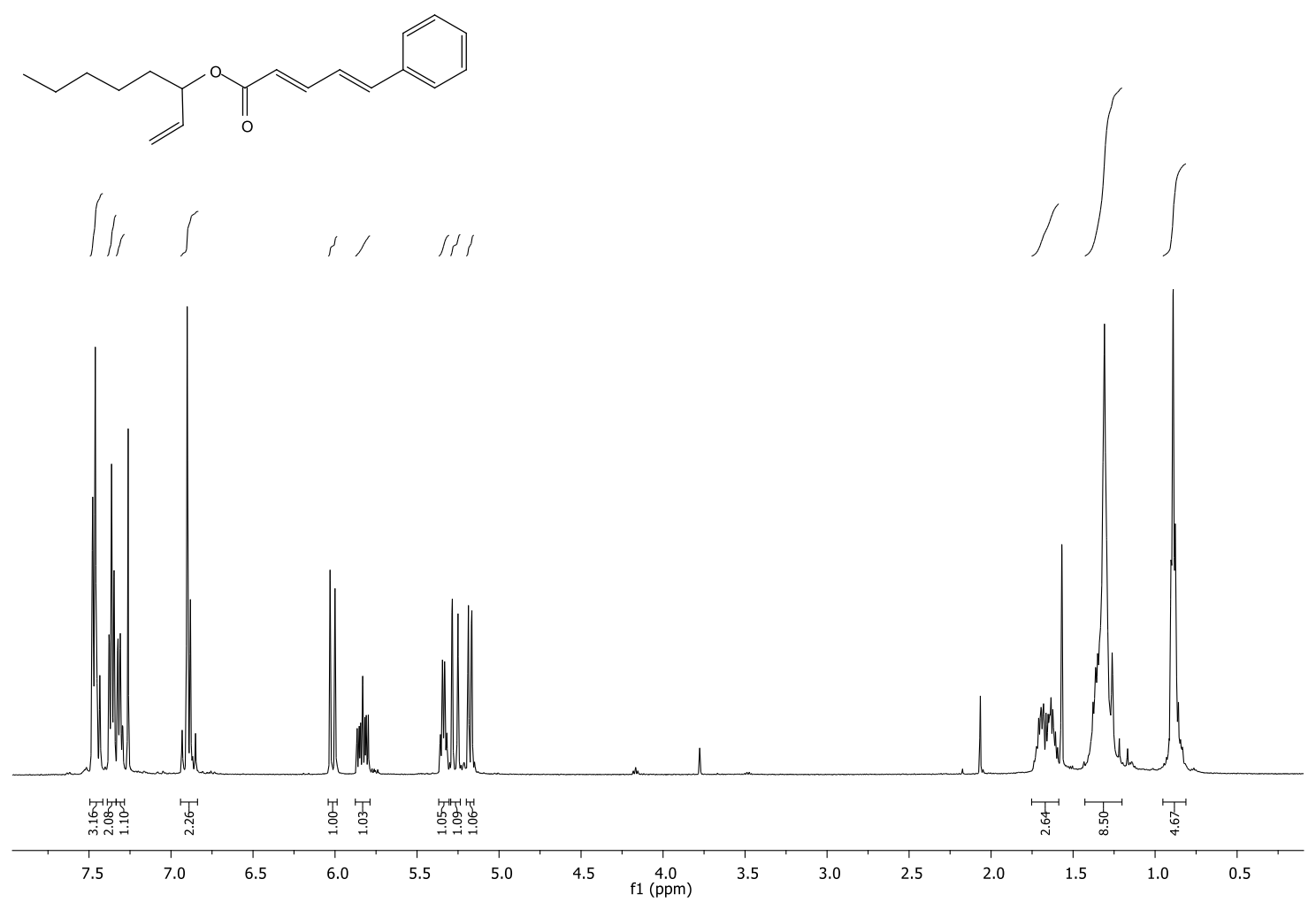

${ }^{1} \mathbf{H}$ NMR $\left(500 \mathrm{MHz}, \mathrm{CDCl}_{3}\right)$ spectrum of $\mathbf{1 9 0}$
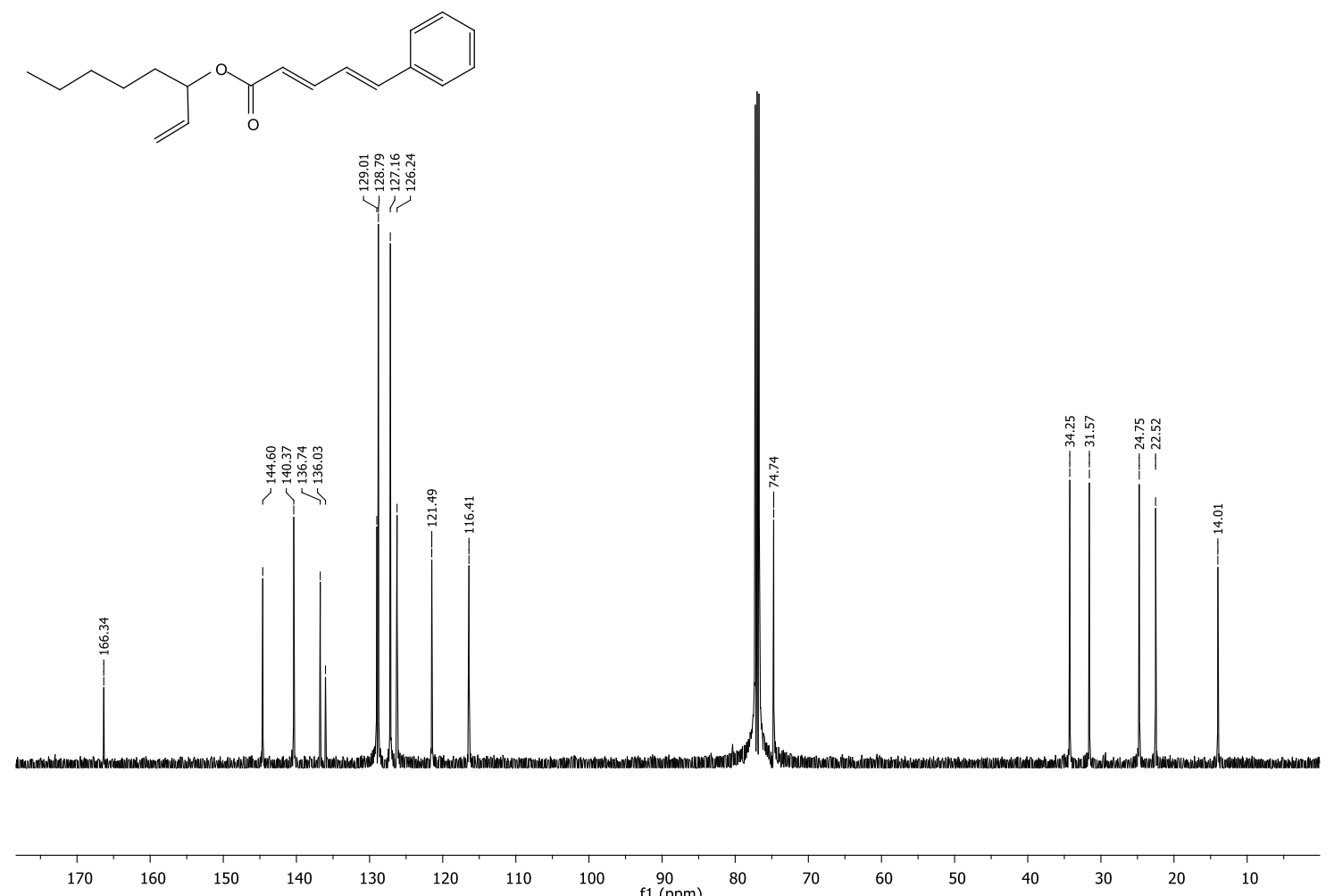

${ }^{13} \mathrm{C}$ NMR (125 MHz, $\left.\mathrm{CDCl}_{3}\right)$ spectrum of 190 
$\left(1 ' R, 2^{\prime} S, 5^{\prime} R, 2 E, 4 E\right)-2^{\prime}$-iso-Propyl-5'-methylcyclohex-1'-yl 5-phenylpenta-2,4-dienoate (192)<smiles>CC1CCC(OC(=O)/C=C/C=C/c2ccccc2)C(C(C)C)C1</smiles><smiles>C#CC=C</smiles>

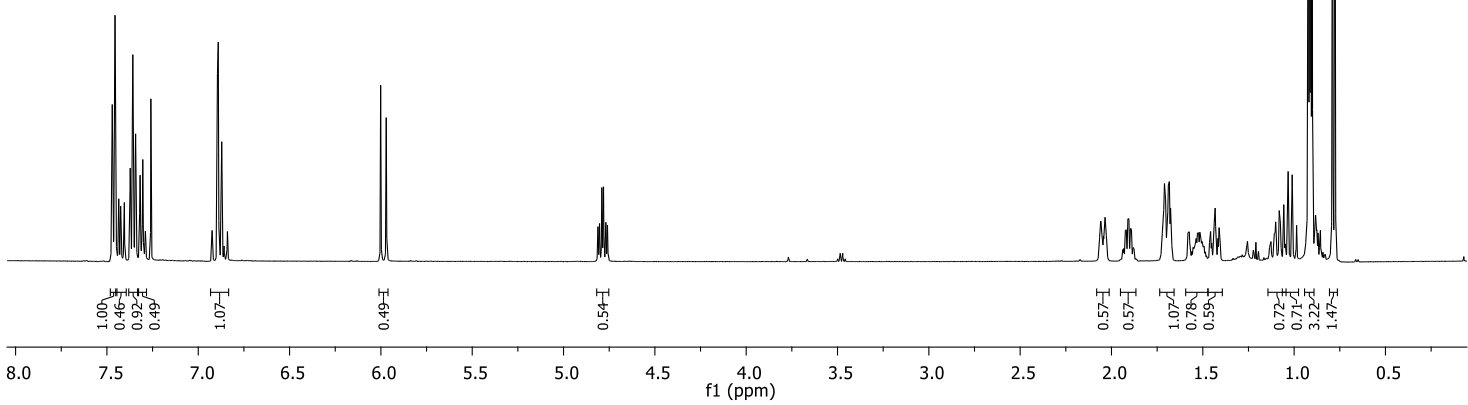

${ }^{1} \mathbf{H}$ NMR $\left(500 \mathrm{MHz}, \mathrm{CDCl}_{3}\right)$ spectrum of 192
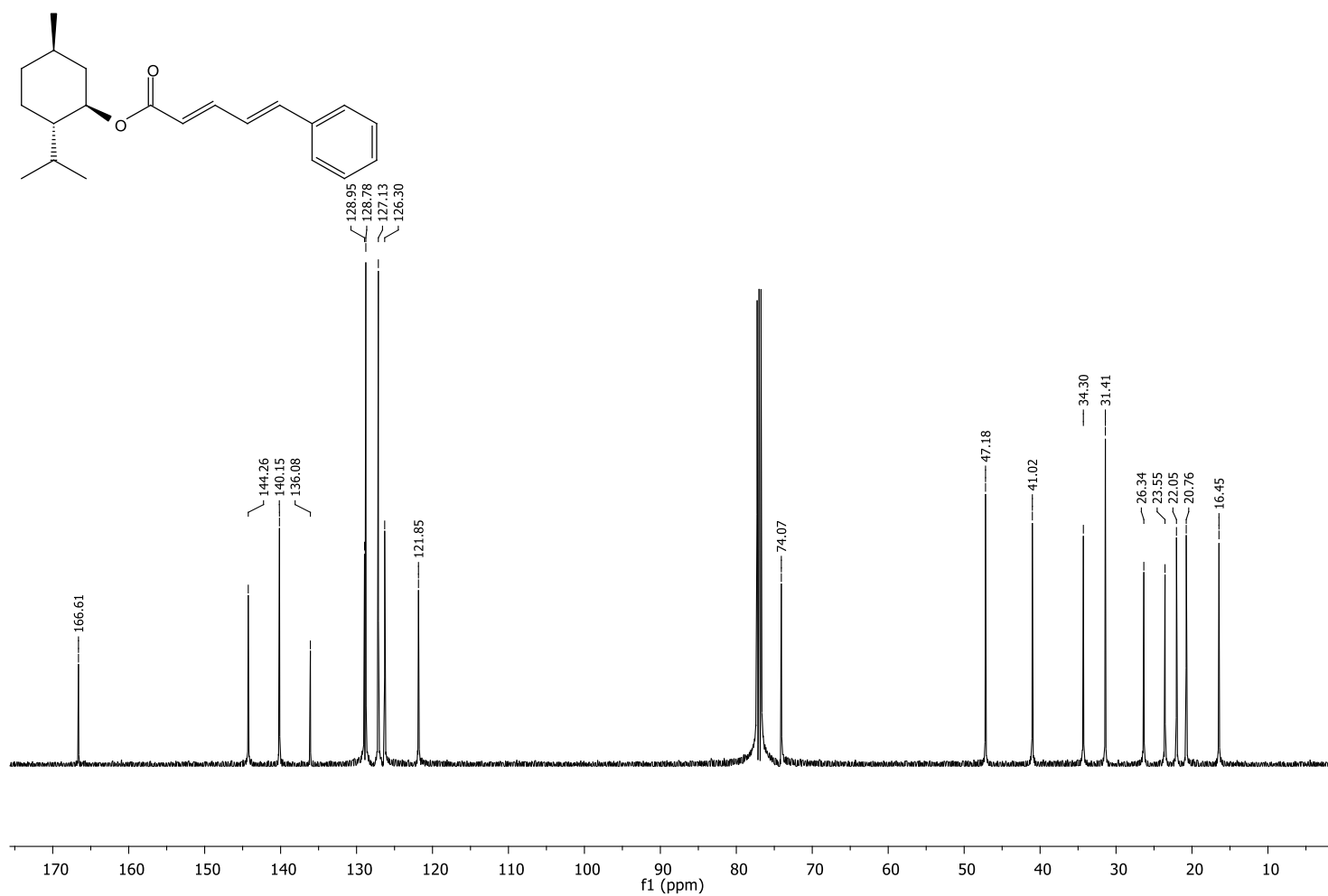

${ }^{13} \mathrm{C}$ NMR $\left(125 \mathrm{MHz}, \mathrm{CDCl}_{3}\right)$ spectrum of 192 
$\left(1^{\prime} R, 2^{\prime} S, 5^{\prime} R, 2 E, 4 E, 6 E\right)$ - 2'-iso-Propyl-5'-methylcyclohex-1'-yl deca-2,4,6-trienoate (194)

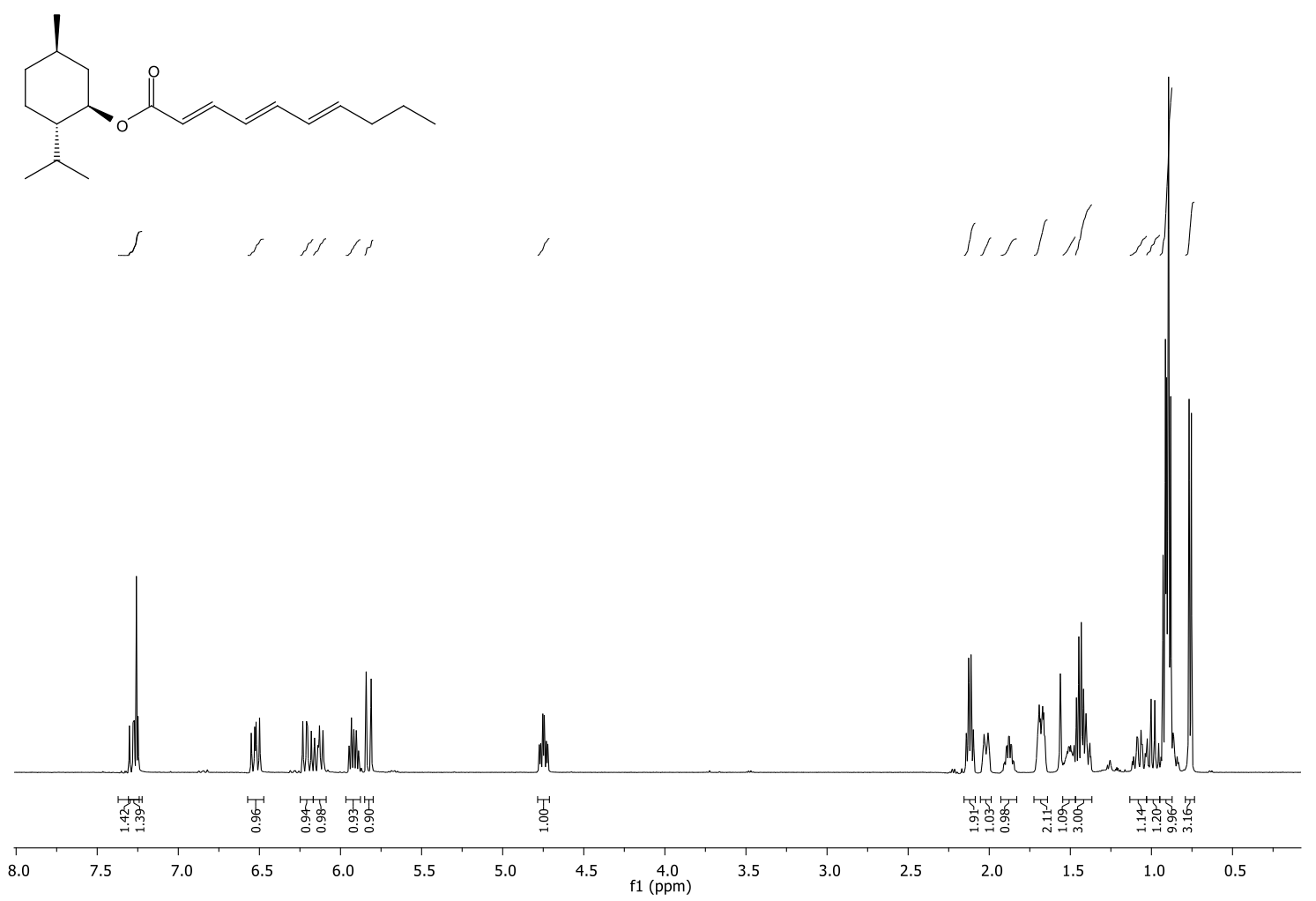

${ }^{\mathbf{1}} \mathbf{H}$ NMR $\left(500 \mathrm{MHz}, \mathrm{CDCl}_{3}\right)$ spectrum of $\mathbf{1 9 4}$
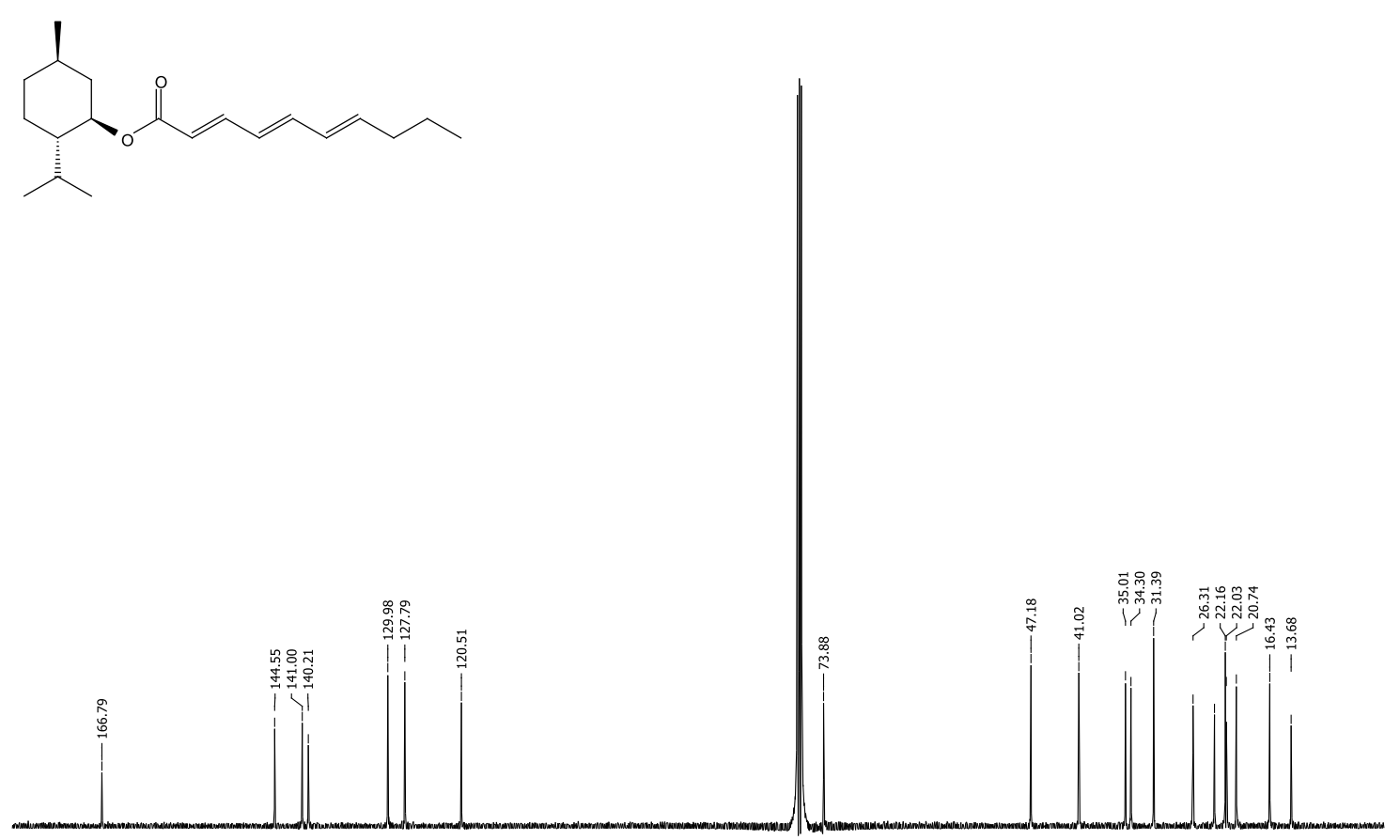

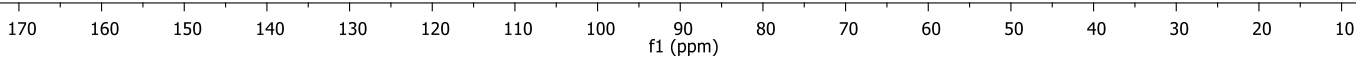

${ }^{13} \mathbf{C ~ N M R}\left(125 \mathrm{MHz}, \mathrm{CDCl}_{3}\right)$ spectrum of 194 
Mixture of $(2 E, 4 E)-\left[1^{\prime}\right.$-(tert-butyldiphenylsilyloxy)-5' -trimethylsilyl]pent-4'-yn-2'-yl 5phenylpenta-2,4-dienoate (196) and the silyl migrated product $(2 E, 4 E)$-[2'-(tertbutyldiphenylsilyloxy)-5'-trimethylsilyl]pent-4'-yn-1'-yl 5-phenylpenta-2,4-dienoate (199)

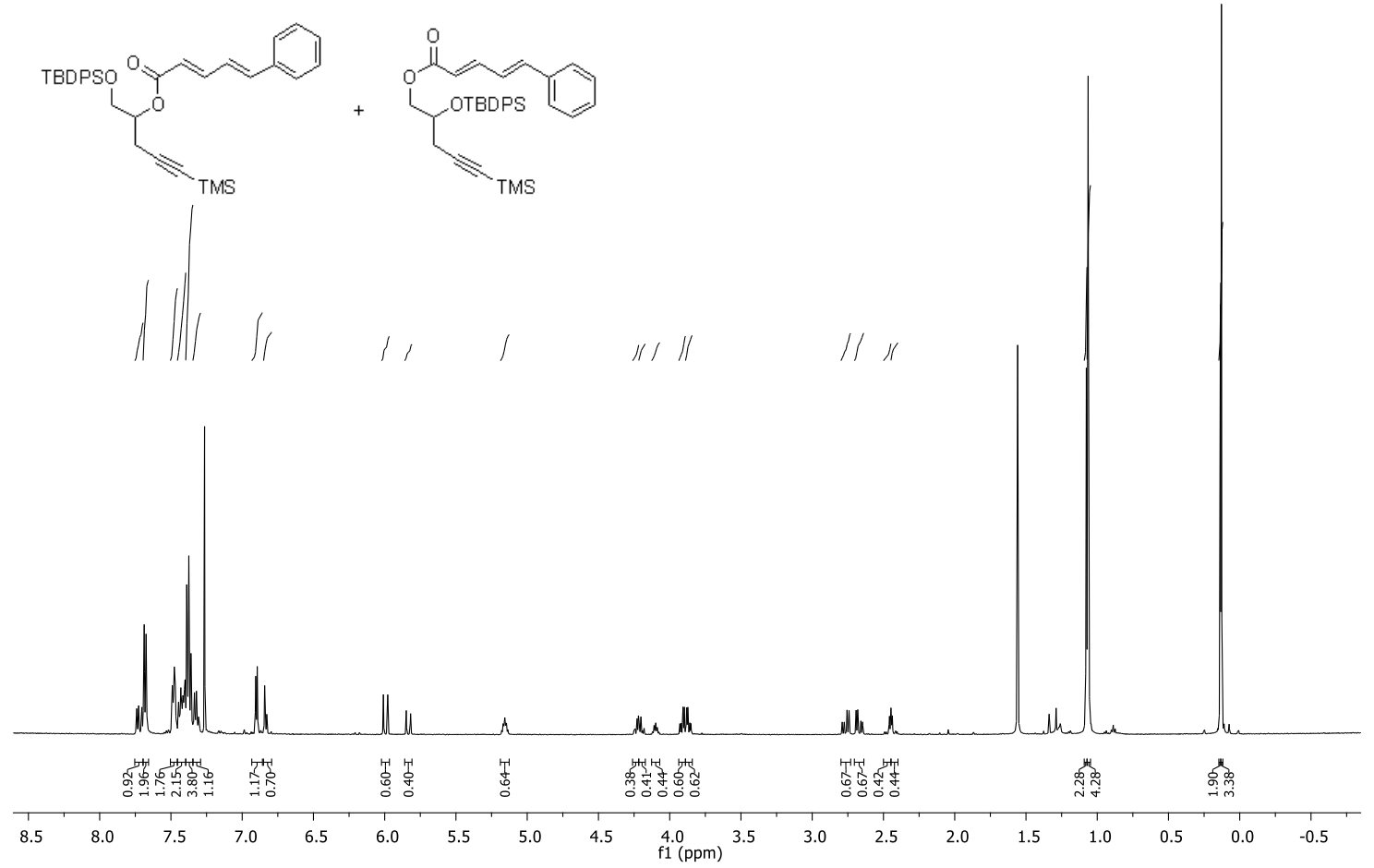

${ }^{1} \mathbf{H}$ NMR $\left(500 \mathrm{MHz}, \mathrm{CDCl}_{3}\right)$ spectrum of 196 and 199
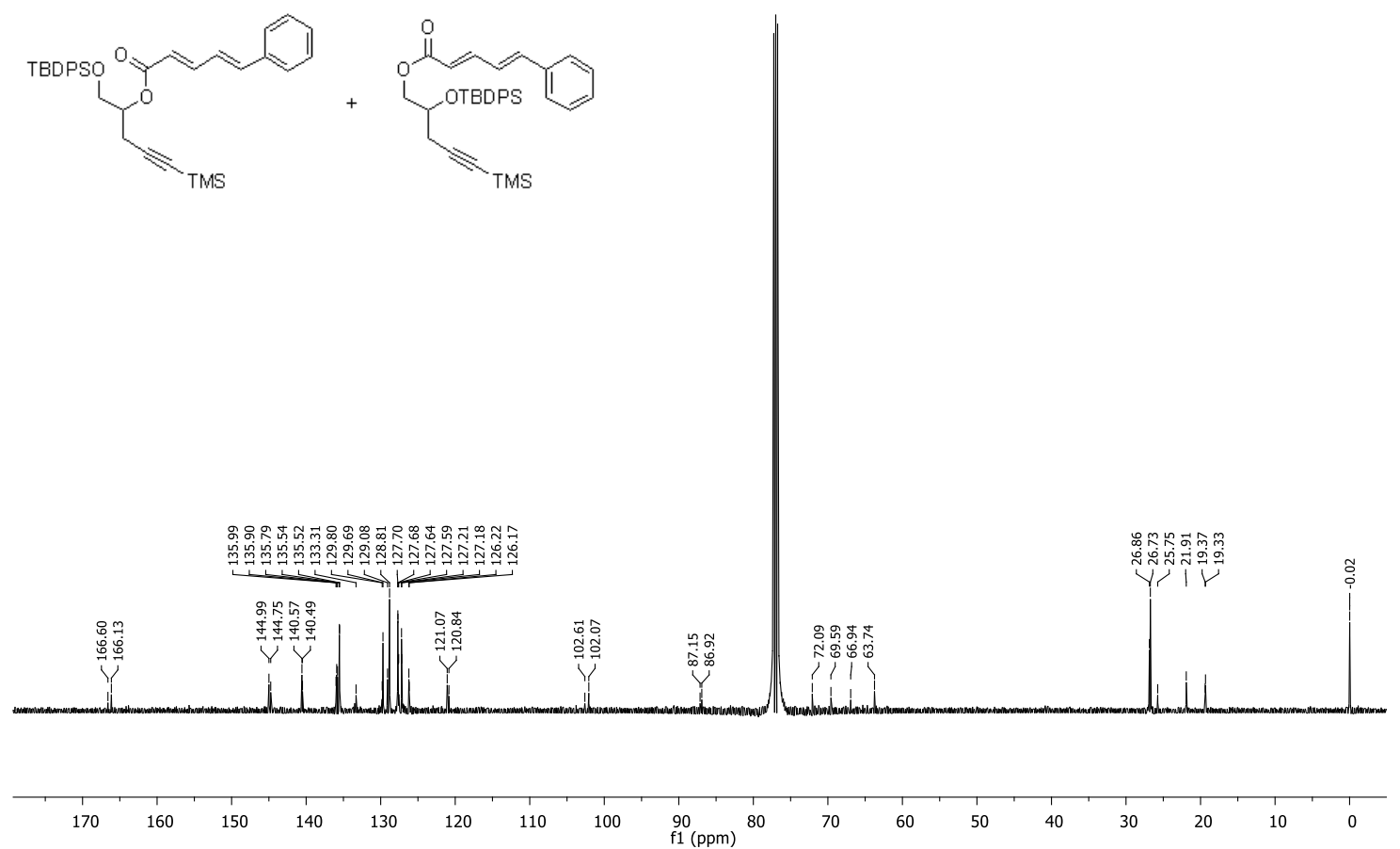

${ }^{13} \mathrm{C}$ NMR $\left(125 \mathrm{MHz}, \mathrm{CDCl}_{3}\right)$ spectrum of 196 and 199 


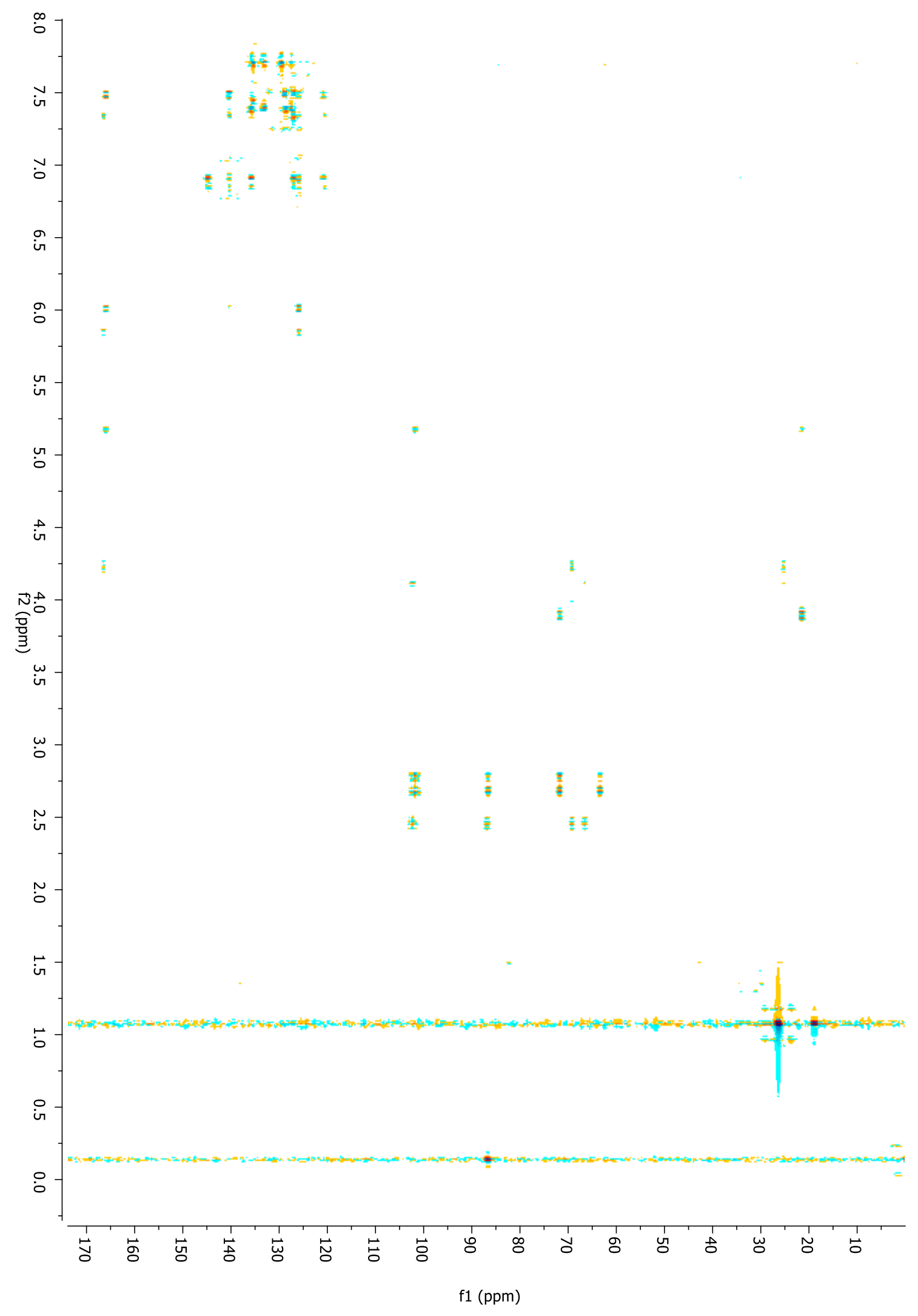

CIGAR-HMBC spectrum of 196 and 199 
Mixture of $(2 E, 4 E)-\left[1^{\prime}\right.$-(tert-butyldiphenylsilyloxy)-5'-trimethylsilyl]pent-4'-yn-2'-yl nona-2,4-dienoate (198) and the silyl migrated product, $(2 E, 4 E)$-[2'-(tertbutyldiphenylsilyloxy)-5'-trimethylsilyl]pent-4'-yn-1'-yl nona-2,4-dienoate

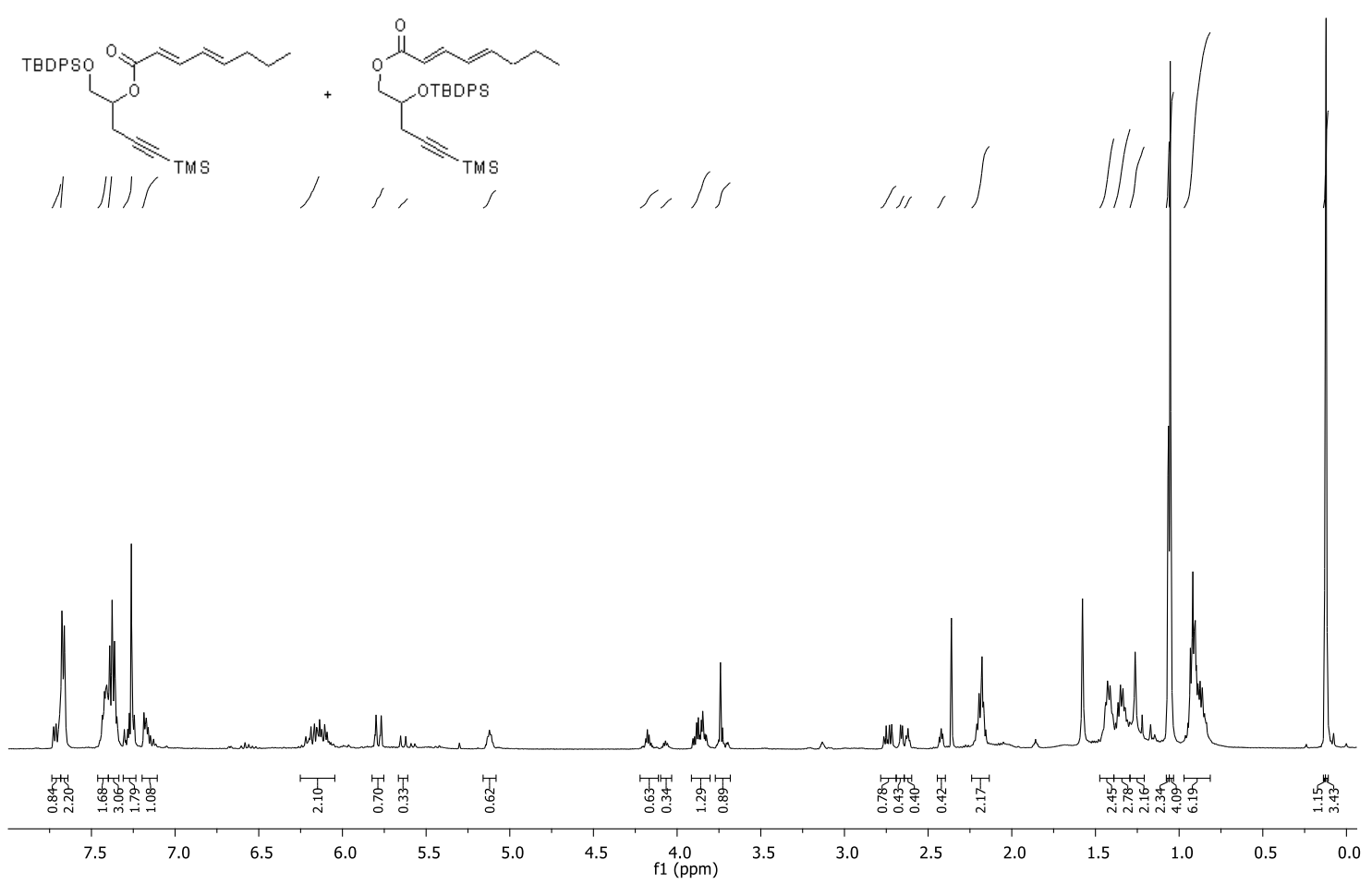

${ }^{1} \mathbf{H}$ NMR (500 MHz, $\mathrm{CDCl}_{3}$ ) spectrum of 198 and silyl migrated product

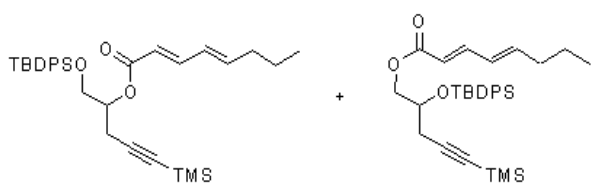

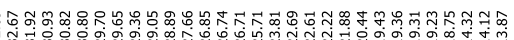

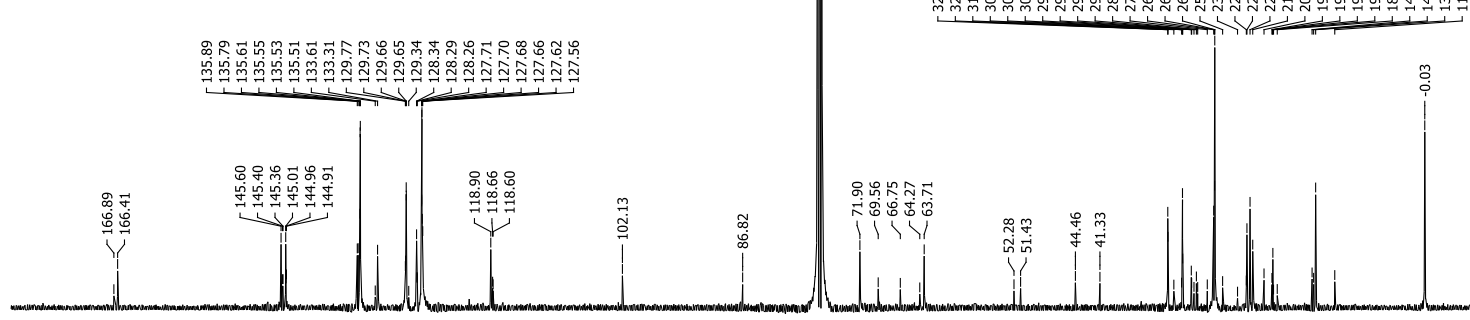

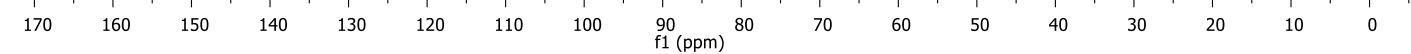

${ }^{13} \mathrm{C}$ NMR $\left(125 \mathrm{MHz}, \mathrm{CDCl}_{3}\right)$ spectrum of 198 and silyl migrated product 
Mixture of $(2 E, 4 Z)-1^{\prime}$-(tert-butyldiphenylsilyloxy)-5'-(trimethylsilyl)pent-4'-yn-2'-yl 7(tert-butyldimethylsilyloxy)-5-methylnona-2,4,8-trienoate (204) and the silyl migrated product, $(2 E, 4 Z)-2$ '-(tert-butyldiphenylsilyloxy)-5' -(trimethylsilyl)pent-4'-yn-1'-yl 7-(tertbutyldimethylsilyloxy)-5-methylnona-2,4,8-trienoate (205)

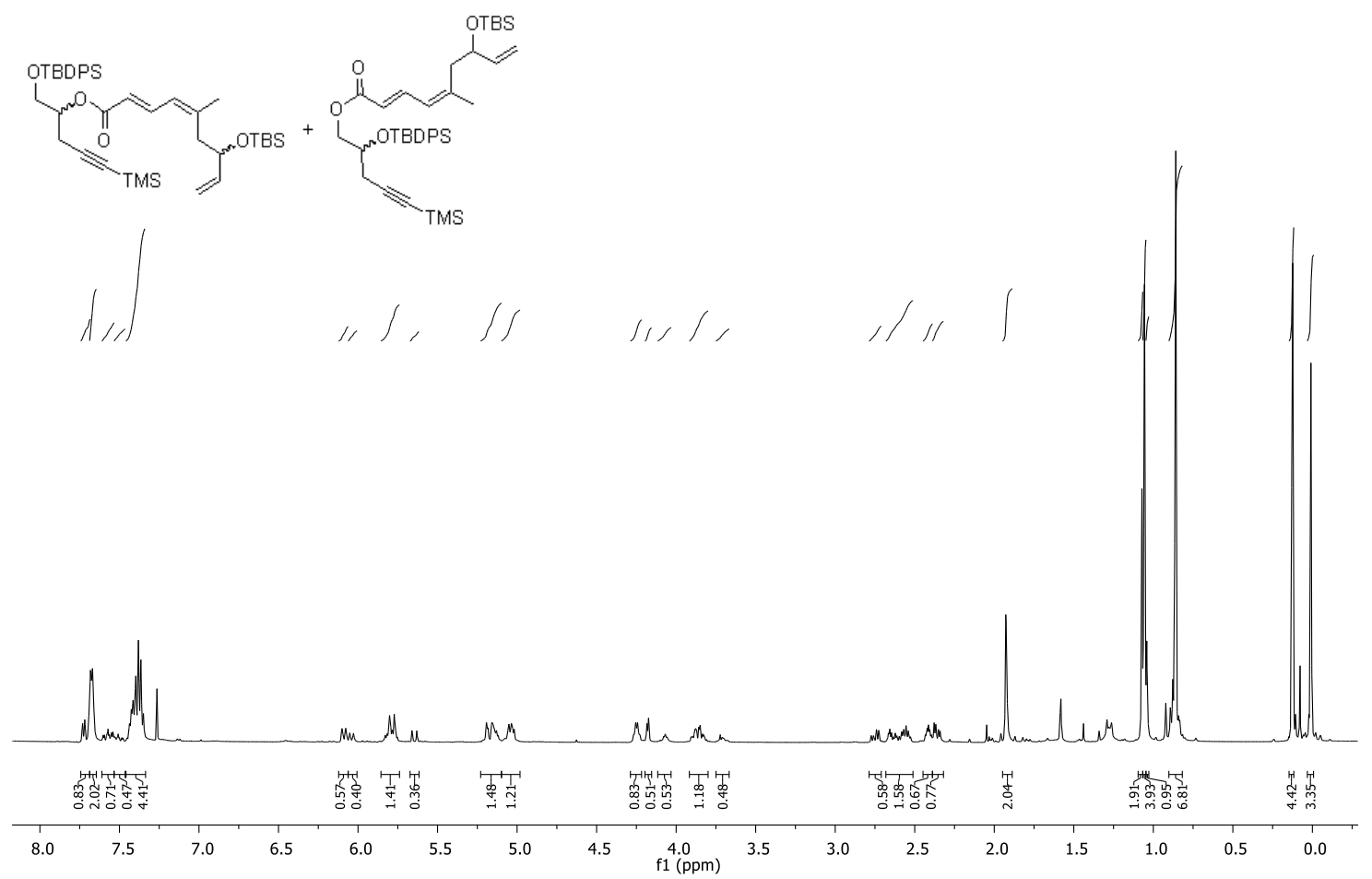

${ }^{\mathbf{1}} \mathbf{H}$ NMR $\left(500 \mathrm{MHz}, \mathrm{CDCl}_{3}\right)$ spectrum of $\mathbf{2 0 4}$ and $\mathbf{2 0 5}$
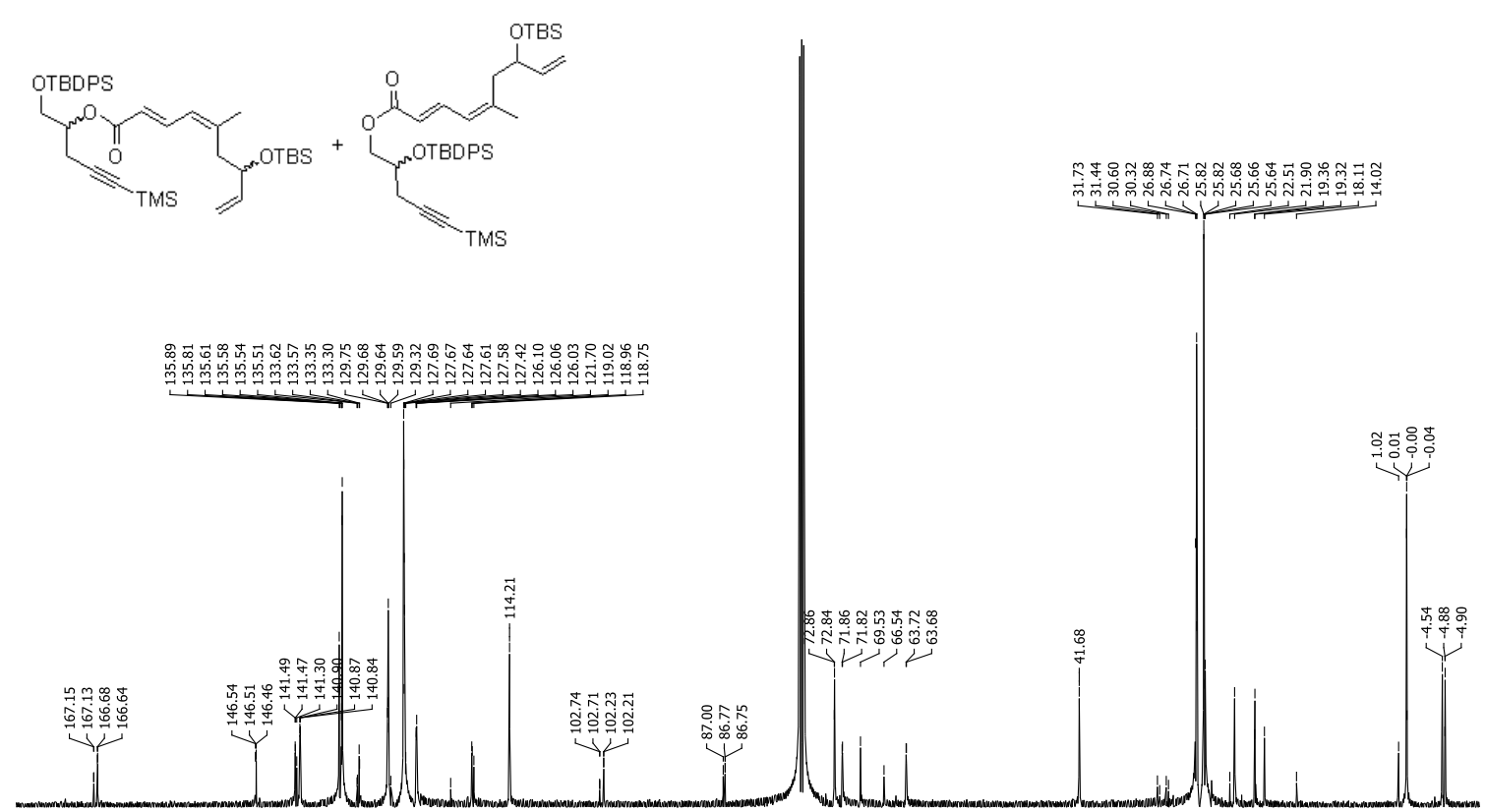

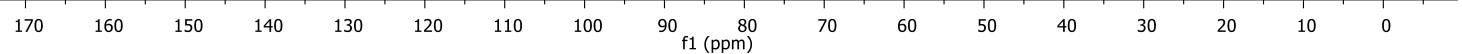

${ }^{13} \mathrm{C} \mathrm{NMR}\left(125 \mathrm{MHz}, \mathrm{CDCl}_{3}\right)$ spectrum of 204 and 205 


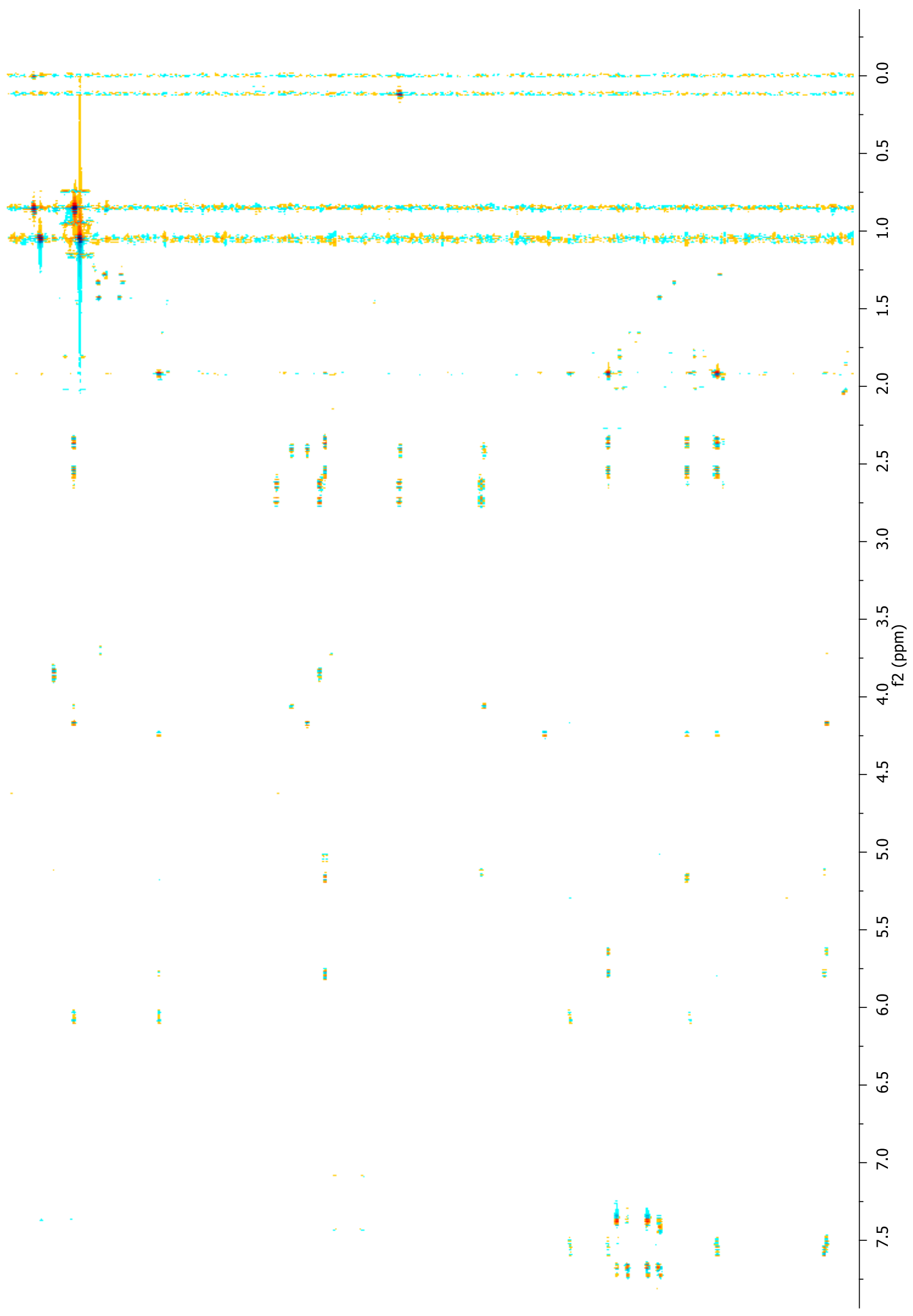

CIGAR-HMBC spectrum of $\mathbf{2 0 4}$ and 205 
$(2 E, 4 E)-\left[1^{\prime}\right.$-(para-Methoxybenzyloxy)-5'-trimethylsilyl]pent-4'-yn-2'-yl 5-phenylpenta-

\section{2,4-dienoate (206)}
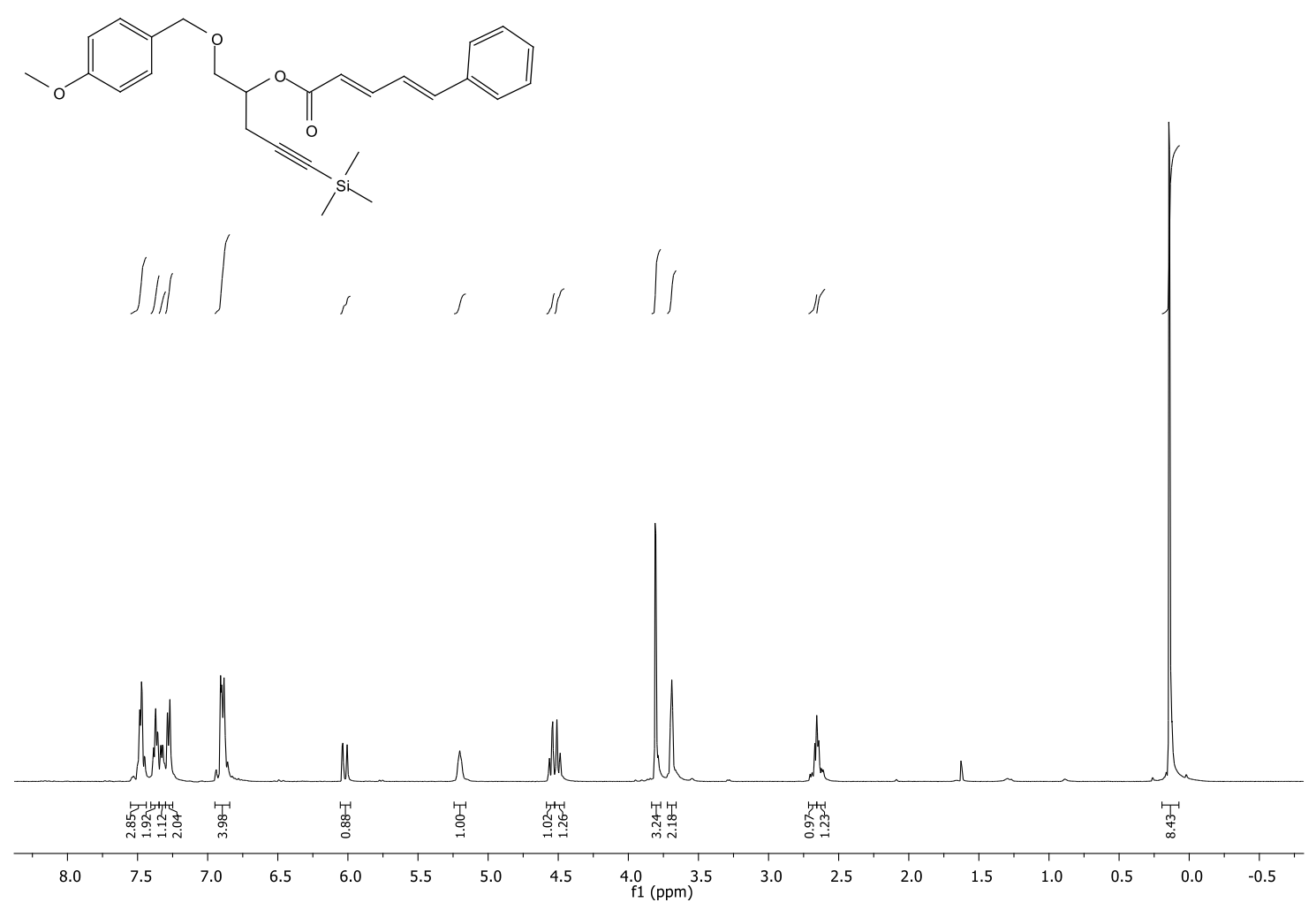

${ }^{\mathbf{1}} \mathbf{H}$ NMR $\left(500 \mathrm{MHz}, \mathrm{CDCl}_{3}\right)$ spectrum of $\mathbf{2 0 6}$
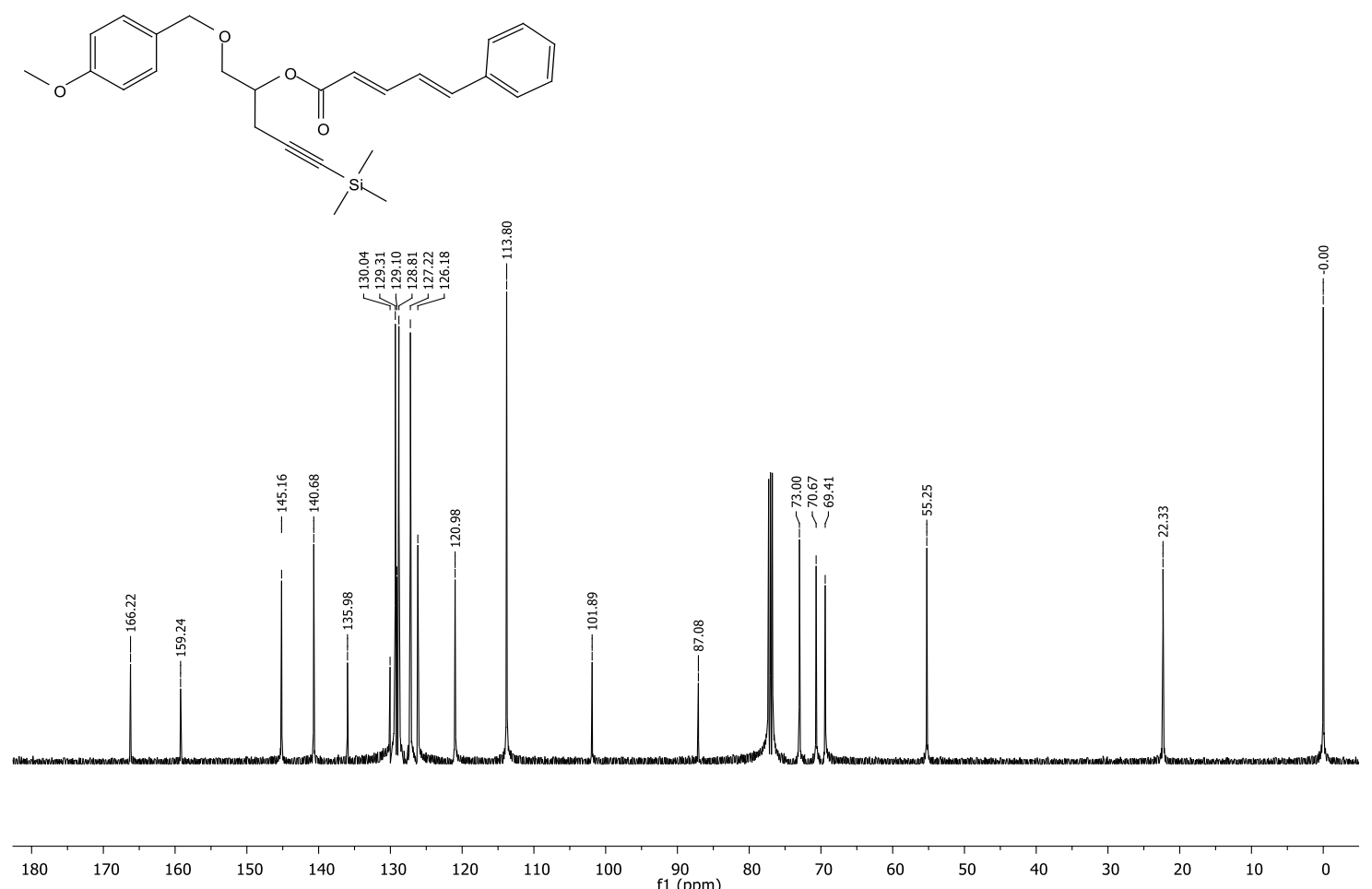

${ }^{13} \mathrm{C}$ NMR $\left(125 \mathrm{MHz}, \mathrm{CDCl}_{3}\right)$ spectrum of $\mathbf{2 0 6}$ 

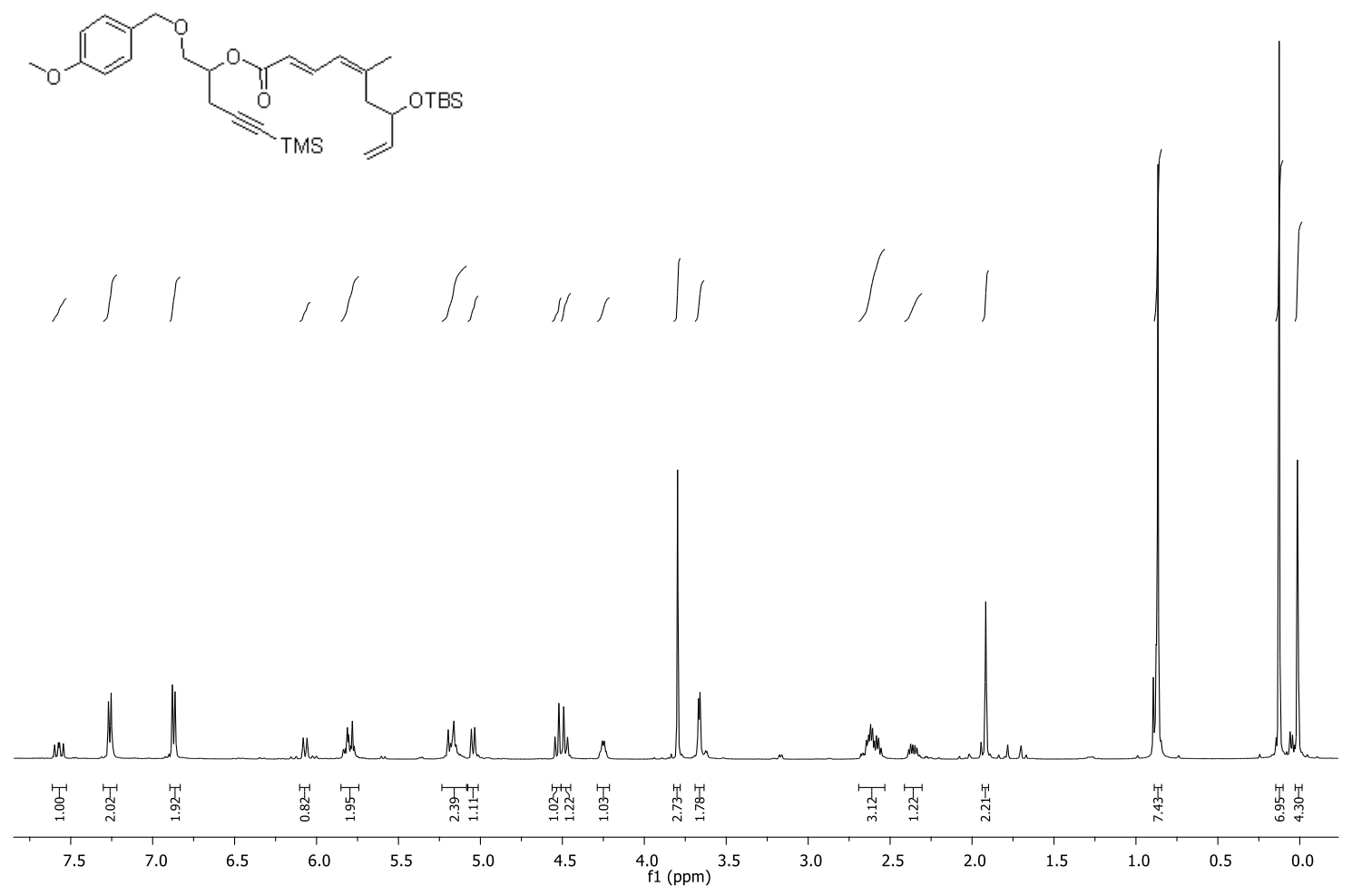

${ }^{\mathbf{1}} \mathbf{H}$ NMR $\left(500 \mathrm{MHz}, \mathrm{CDCl}_{3}\right)$ spectrum of $\mathbf{2 0 7}$
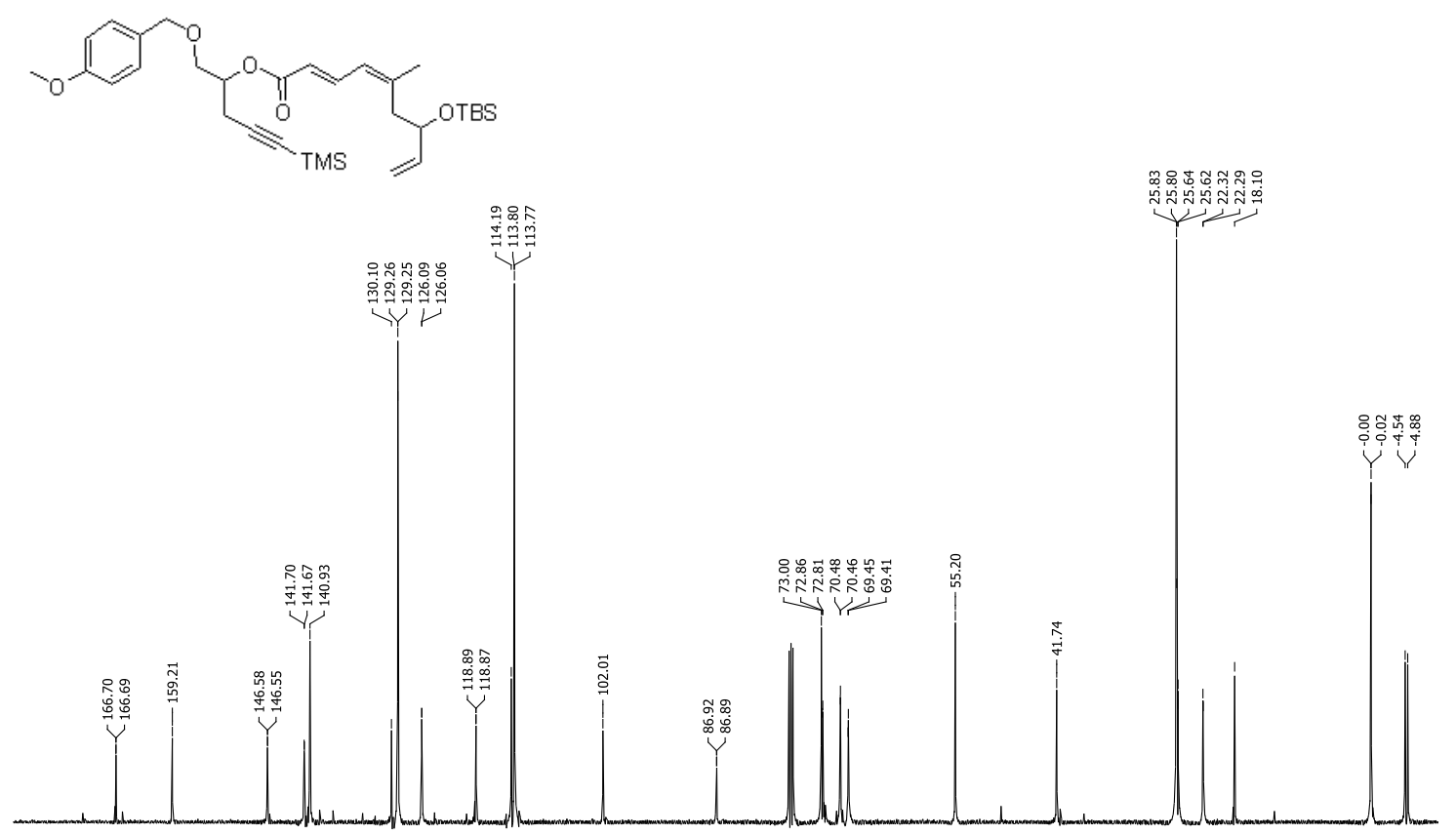

$\begin{array}{llll}180 \quad 170 \quad 160 & 150 & 140\end{array}$

${ }^{13} \mathrm{C}$ NMR $\left(125 \mathrm{MHz}, \mathrm{CDCl}_{3}\right)$ spectrum of $\mathbf{2 0 7}$ 

methylnona-2,4,8-trienoate (208)
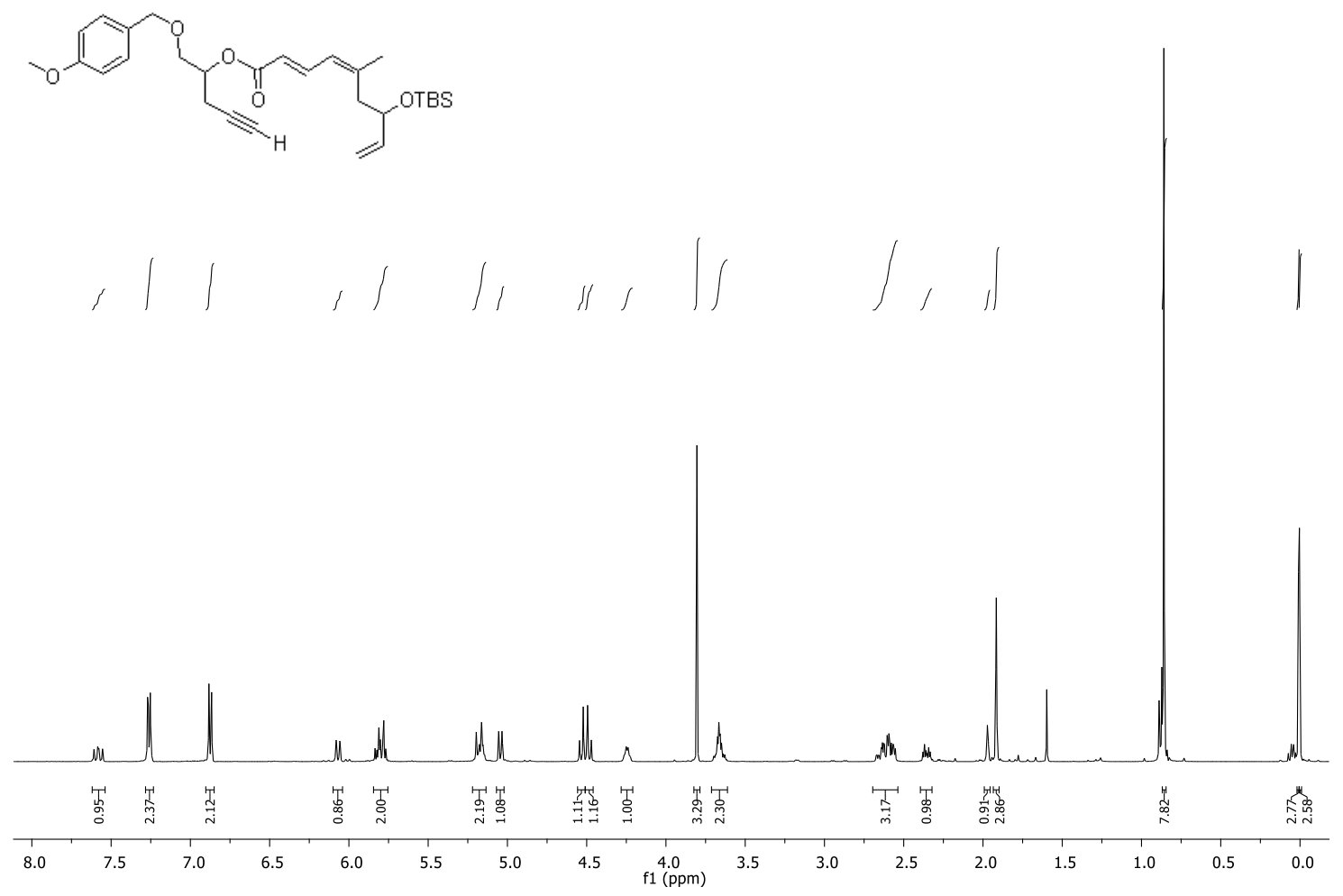

${ }^{\mathbf{1}} \mathbf{H}$ NMR $\left(500 \mathrm{MHz}, \mathrm{CDCl}_{3}\right)$ spectrum of $\mathbf{2 0 8}$
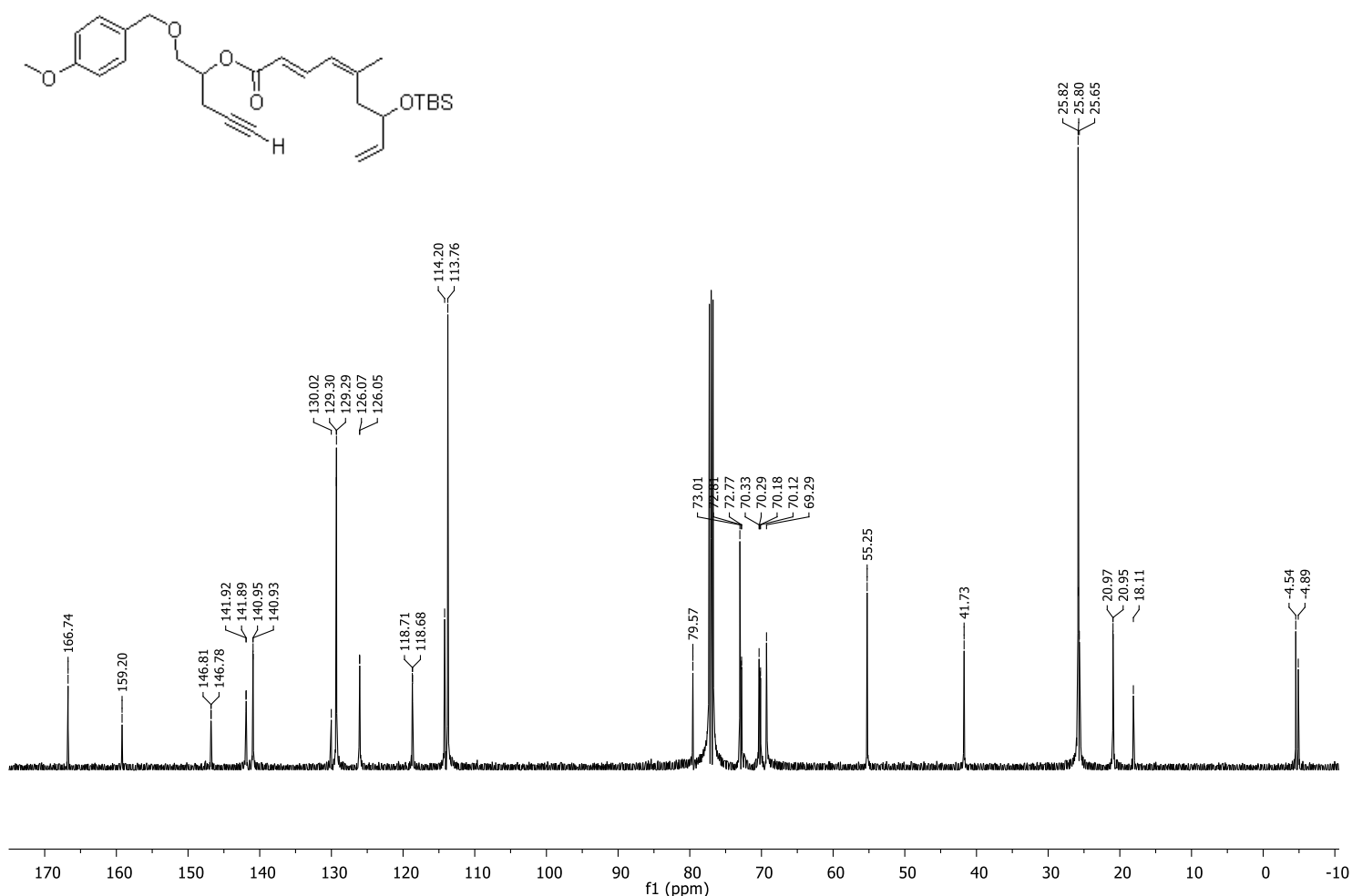

${ }^{13} \mathrm{C} \mathrm{NMR}\left(125 \mathrm{MHz}, \mathrm{CDCl}_{3}\right)$ spectrum of 208 
Methyl 2-hydroxy-3-phenylpropanoate (220)
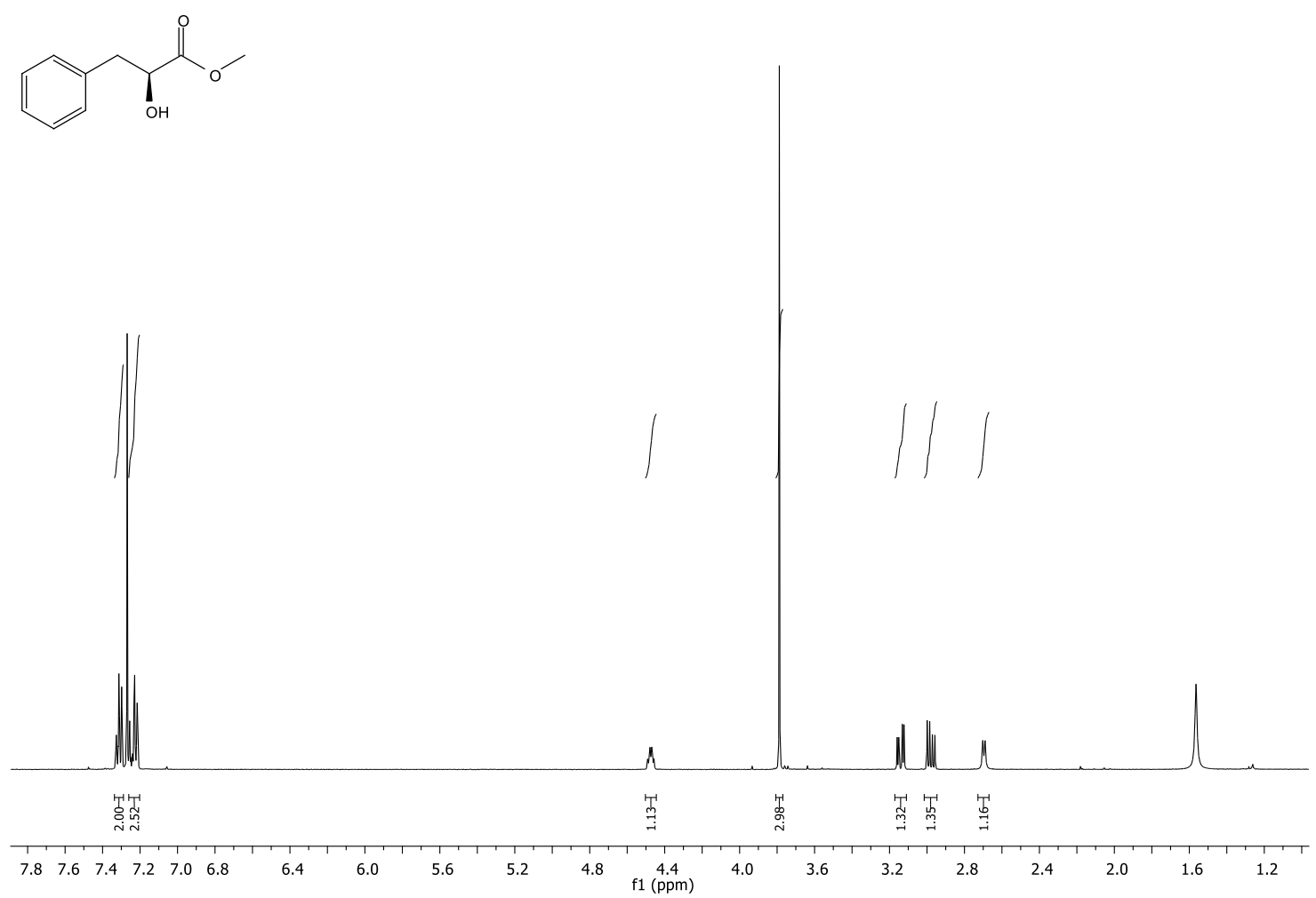

${ }^{\mathbf{1}} \mathbf{H}$ NMR $\left(500 \mathrm{MHz}, \mathrm{CDCl}_{3}\right)$ spectrum of $\mathbf{2 2 0}$
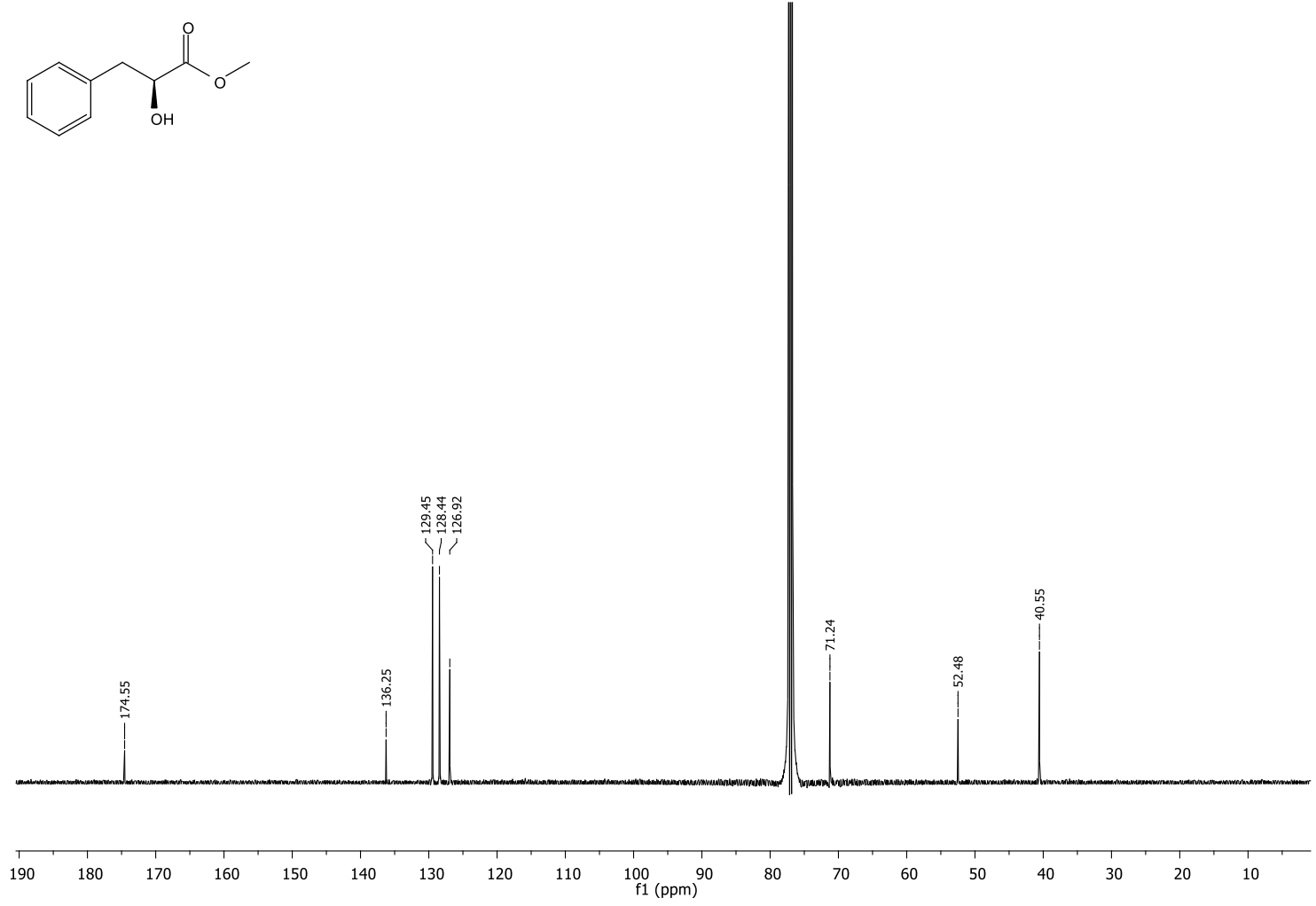

${ }^{13} \mathbf{C}$ NMR $\left(125 \mathrm{MHz}, \mathrm{CDCl}_{3}\right)$ spectrum of 220

219 
2-(t-Butylcarbonate)-3-phenylpropanal (223)

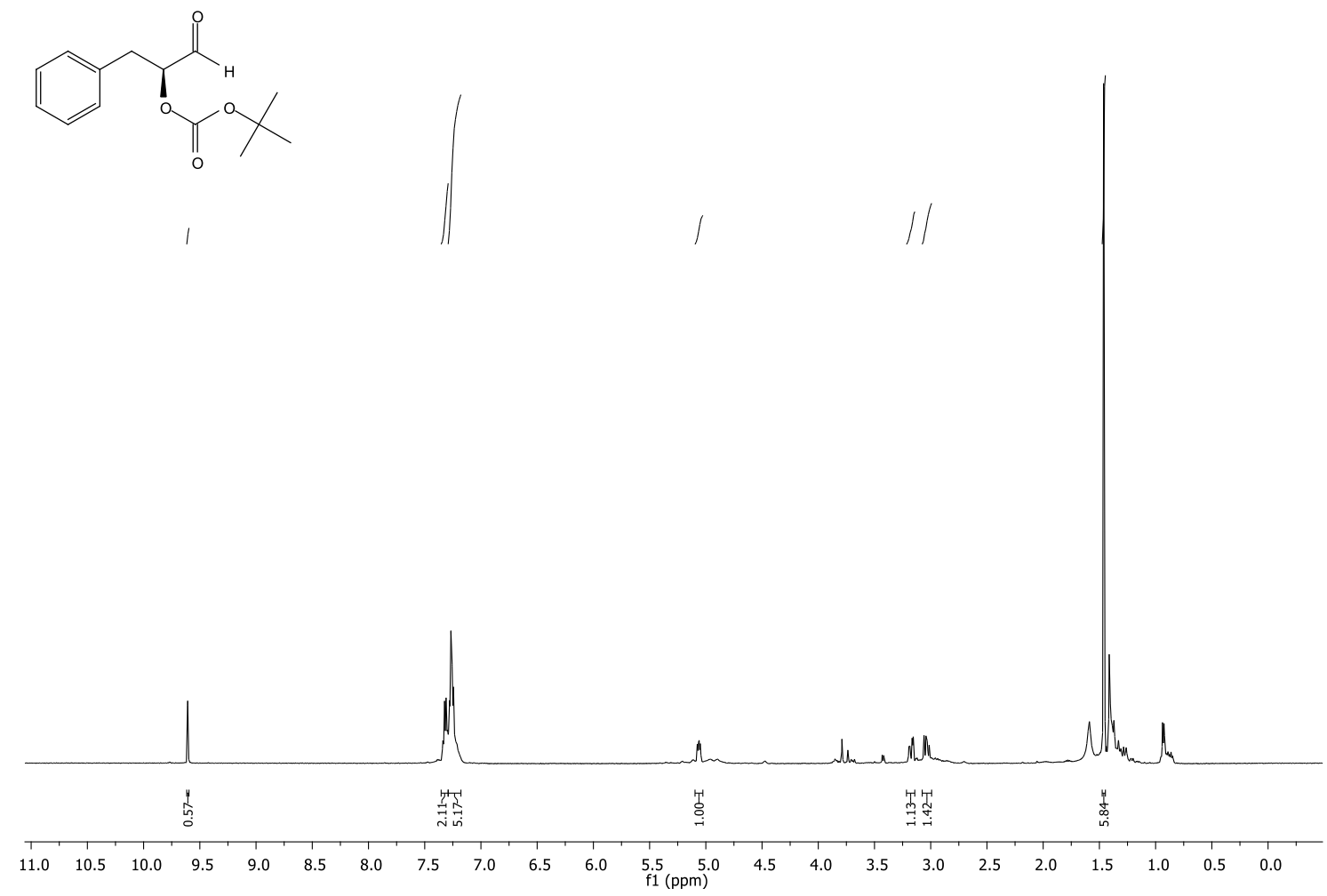

${ }^{1} \mathbf{H}$ NMR $\left(500 \mathrm{MHz}, \mathrm{CDCl}_{3}\right)$ spectrum of $\mathbf{2 2 3}$ 
Methyl 2-(t-butylcarbonate)-3-phenylpropanoate (224)<smiles>C#CC(=O)OC(Cc1ccccc1)C(=O)OC(C)(C)C</smiles>

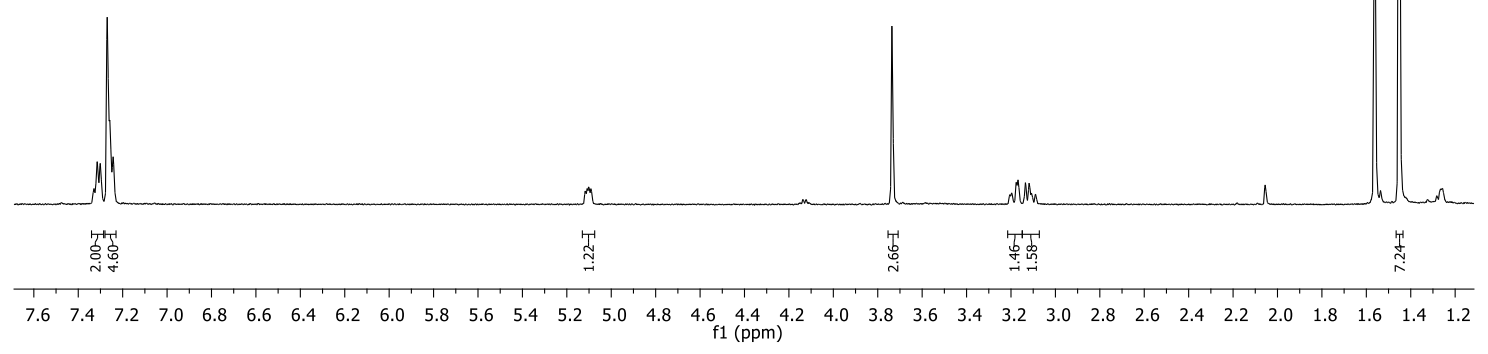

${ }^{1} \mathbf{H}$ NMR $\left(500 \mathrm{MHz}, \mathrm{CDCl}_{3}\right)$ spectrum of $\mathbf{2 2 4}$<smiles>COC(=O)C(Cc1ccccc1)OC(=O)OC(C)(C)C</smiles>
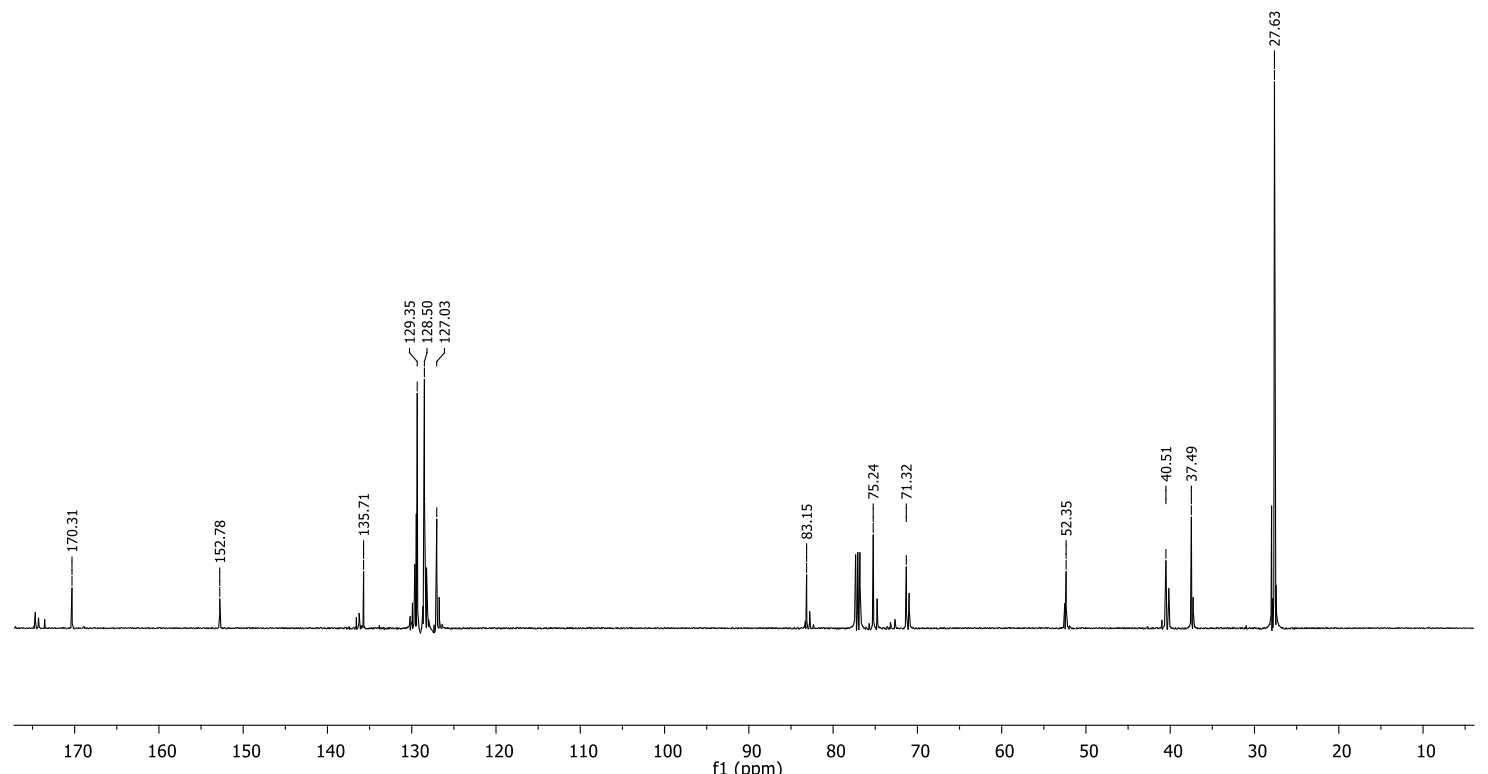

${ }^{13} \mathbf{C ~ N M R}\left(125 \mathrm{MHz}, \mathrm{CDCl}_{3}\right)$ spectrum of 224 
(5'-Trimethylsilyl)pent-4'-yn-2'-yl 5-phenylpenta-2,4-dienoate (227)
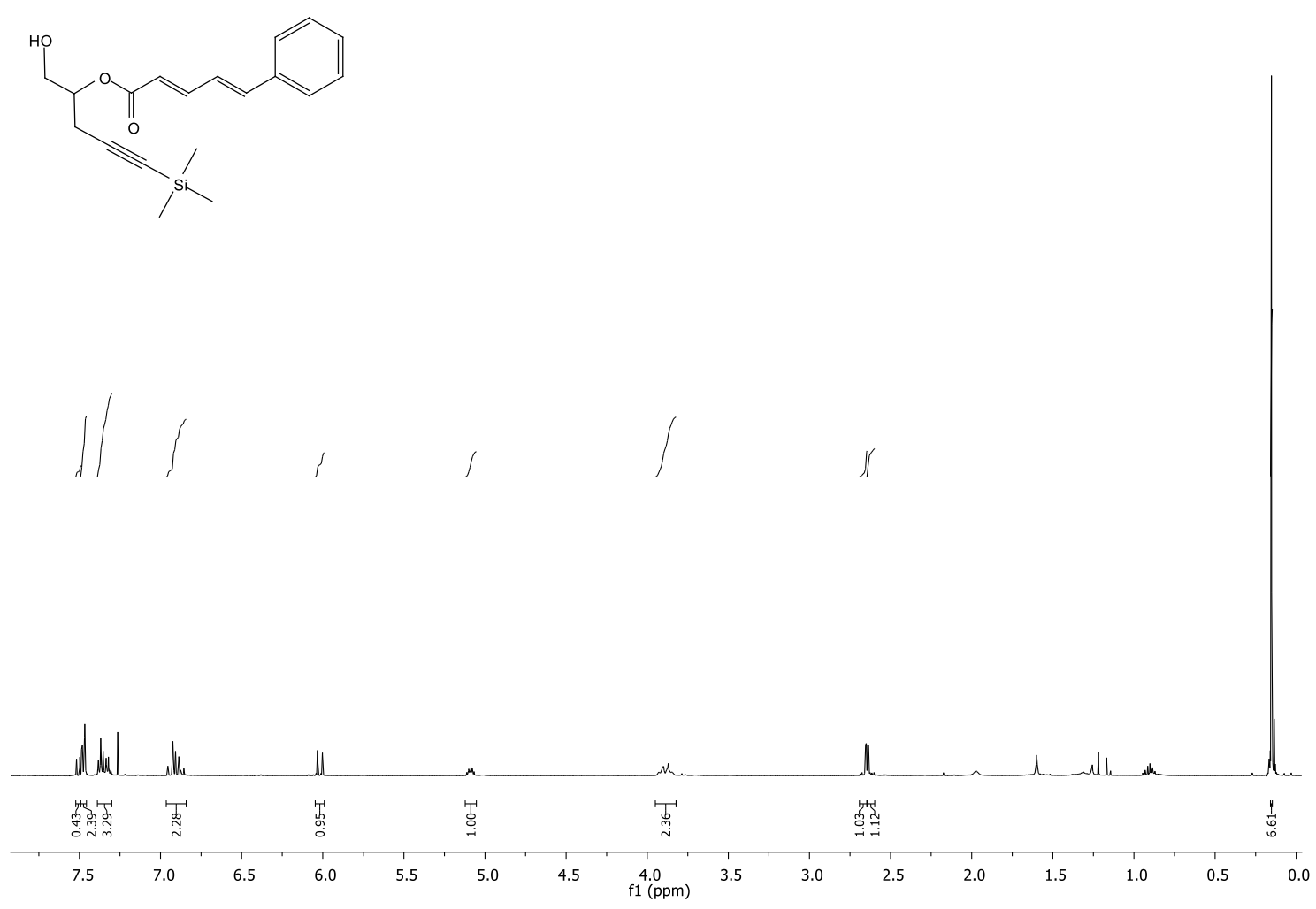

${ }^{1} \mathbf{H}$ NMR $\left(500 \mathrm{MHz}, \mathrm{CDCl}_{3}\right)$ spectrum of 227
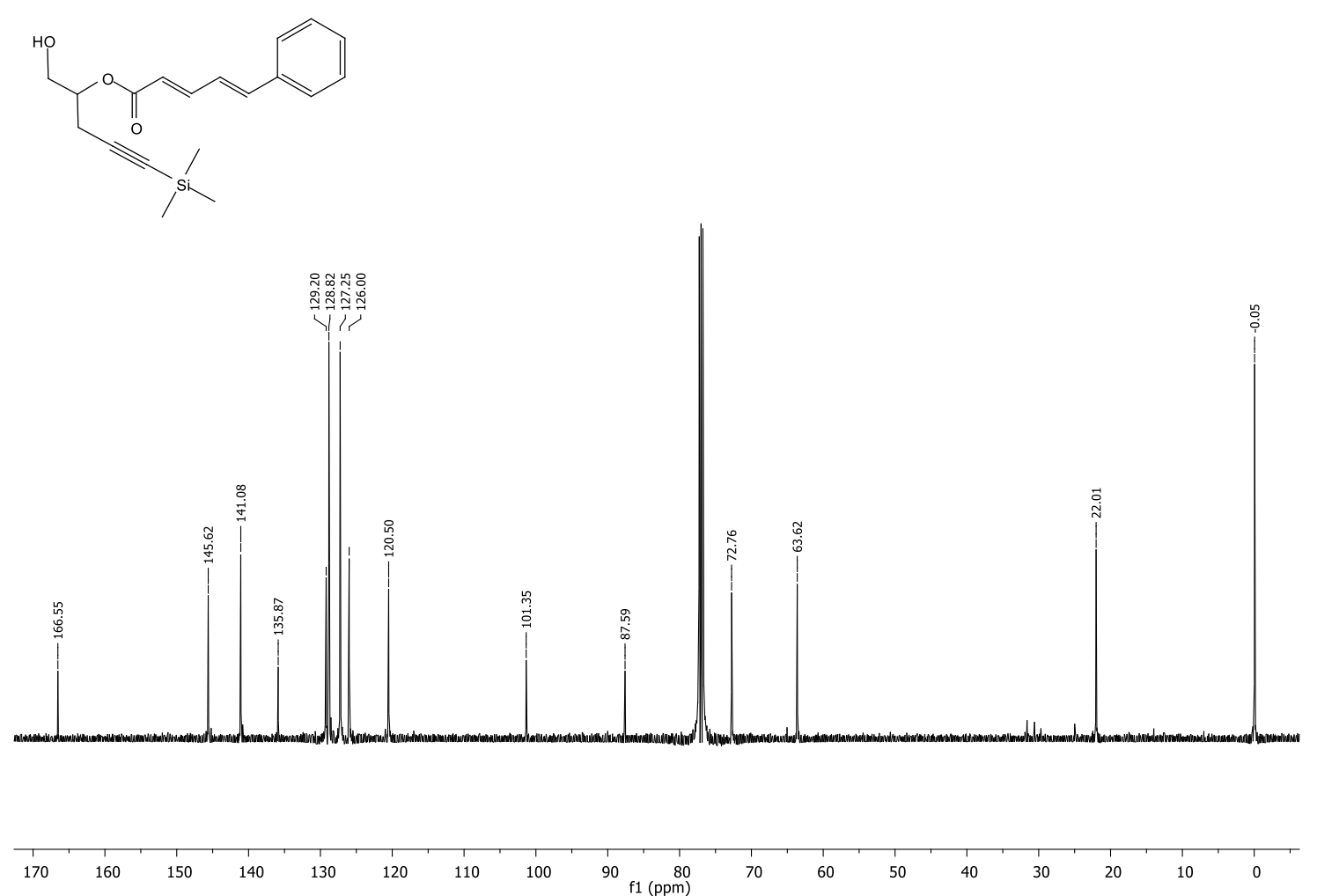

${ }^{13} \mathrm{C}$ NMR $\left(125 \mathrm{MHz}, \mathrm{CDCl}_{3}\right)$ spectrum of 227 
1'-(para-Methoxybenzyloxy)pent-4'-yn-2'-yl 3-phenylprop-2-enoate (234)<smiles>C#CCC(COCc1ccc(OC)cc1)OC(=O)/C=C/c1ccccc1</smiles>

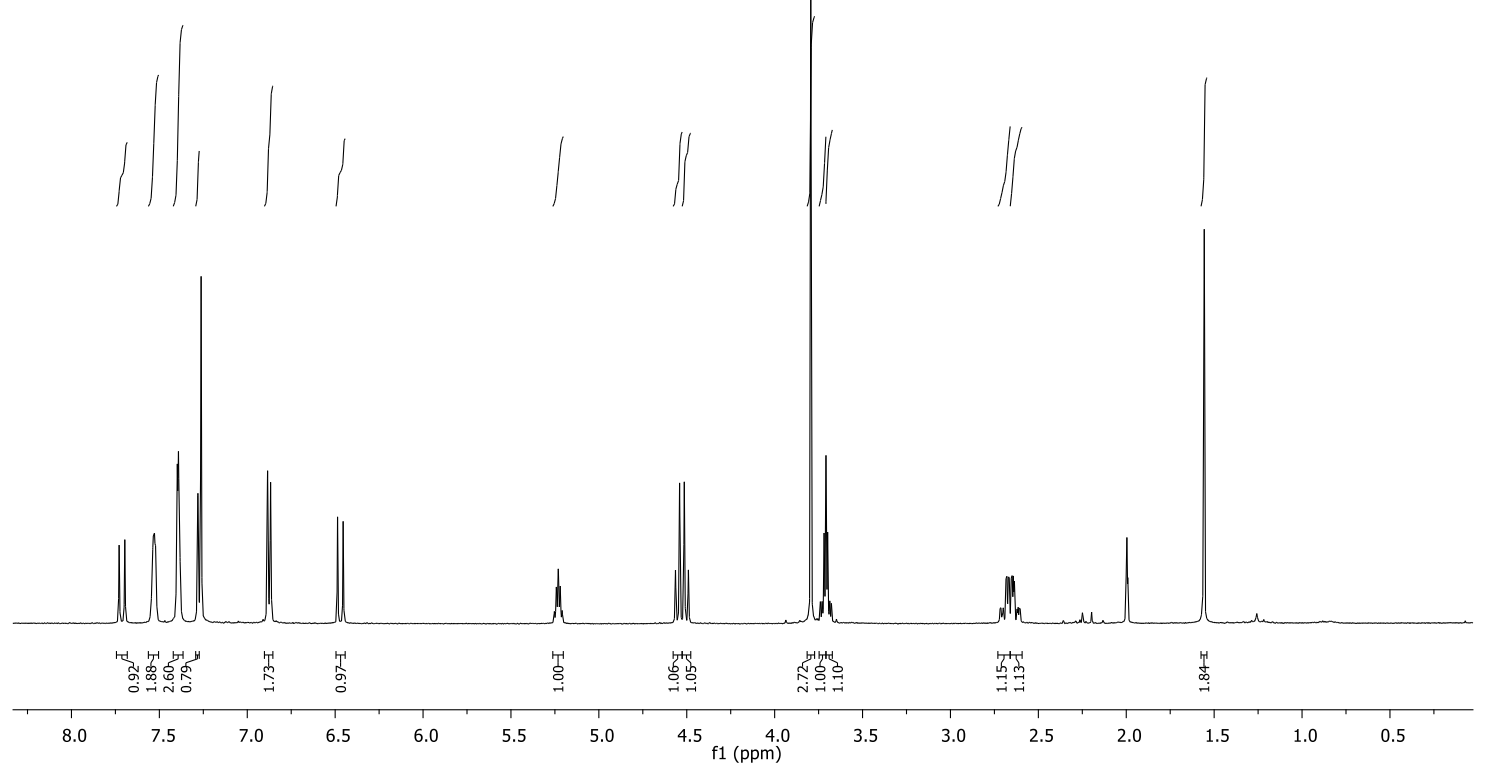

${ }^{1} \mathbf{H}$ NMR $\left(500 \mathrm{MHz}, \mathrm{CDCl}_{3}\right)$ spectrum of $\mathbf{2 3 4}$
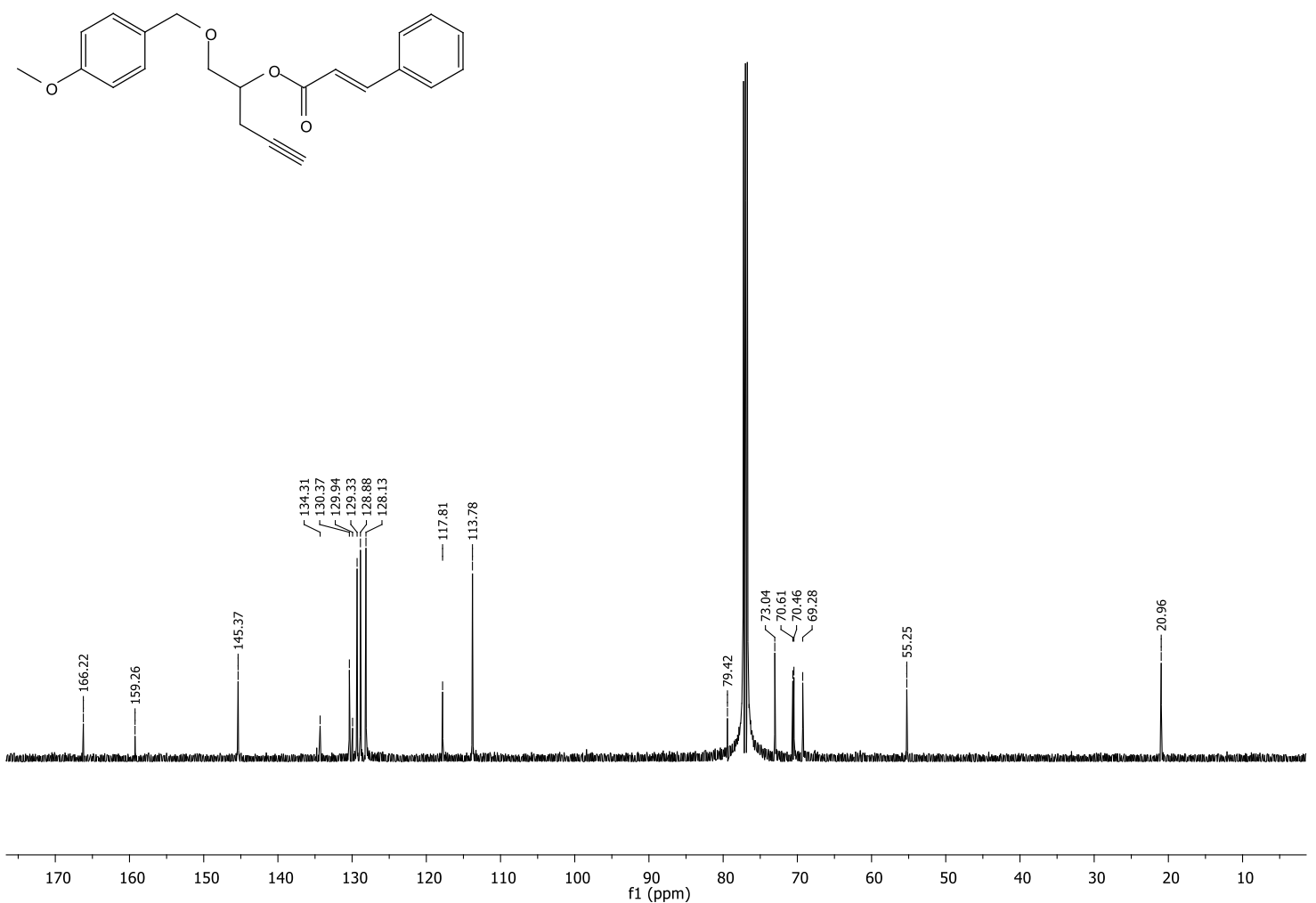

${ }^{13} \mathrm{C} \mathrm{NMR}\left(125 \mathrm{MHz}, \mathrm{CDCl}_{3}\right)$ spectrum of $\mathbf{2 3 4}$ 
(1R,2R)-3-(t-Butyldimethylsilyloxy)-2- $N, N$-dimethylamino-1-(4'-nitrophenyl)propane-1ol (232)

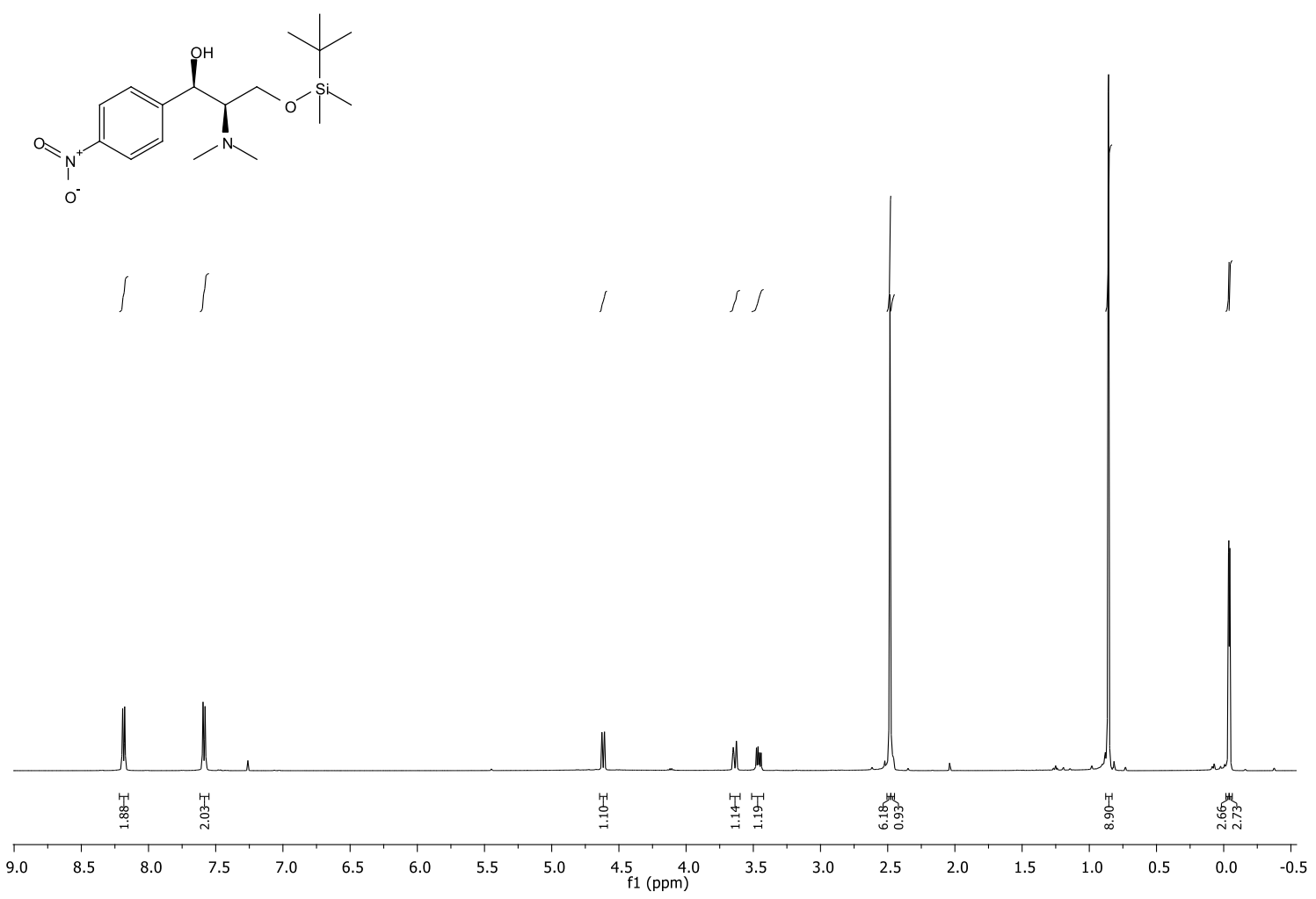

${ }^{\mathbf{1}} \mathbf{H}$ NMR $\left(500 \mathrm{MHz}, \mathrm{CDCl}_{3}\right)$ spectrum of $\mathbf{2 3 2}$
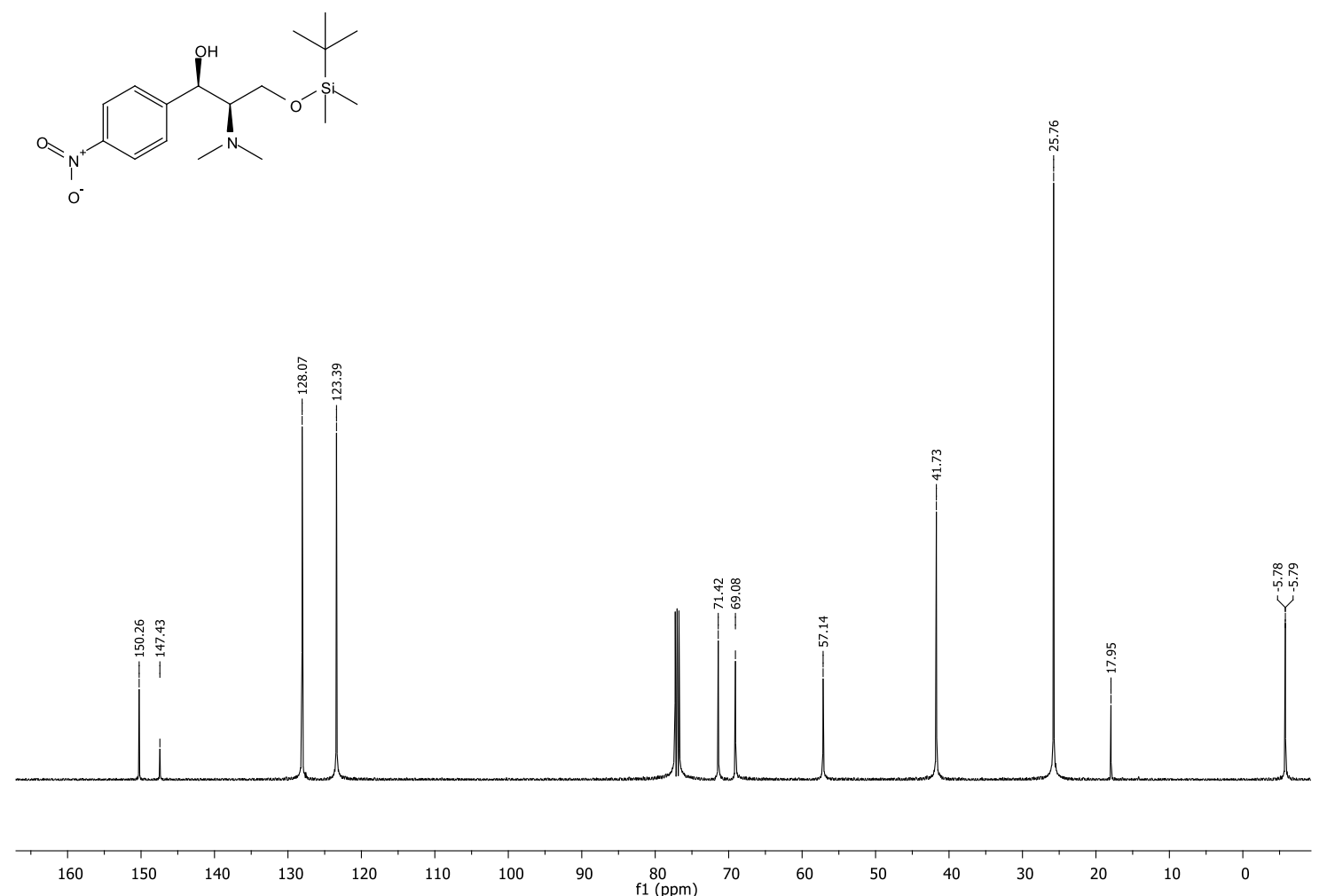

${ }^{13} \mathrm{C}$ NMR $\left(125 \mathrm{MHz}, \mathrm{CDCl}_{3}\right)$ spectrum of 232 
1-Phenyloct-1-yn-3-ol (237)

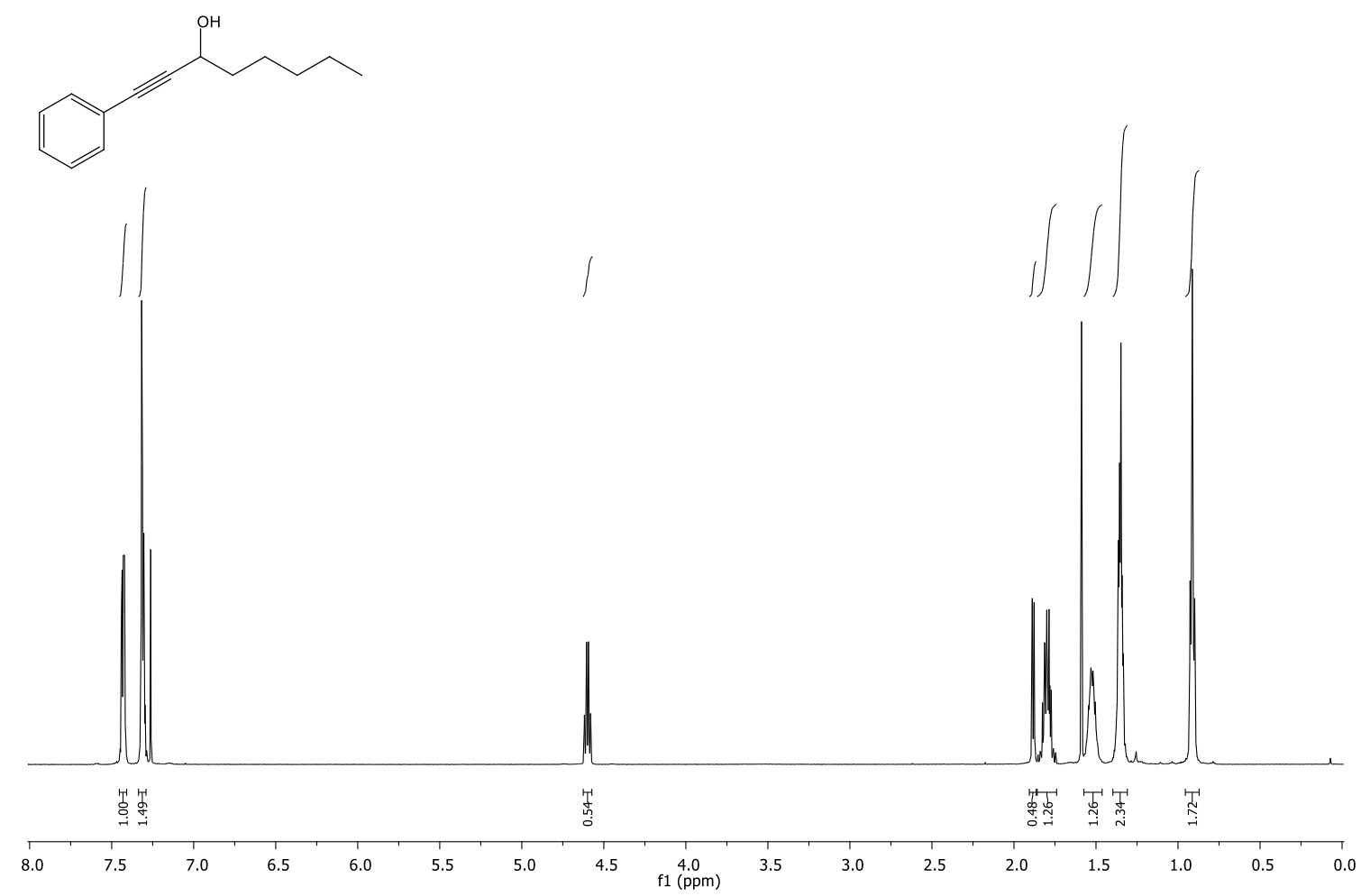

${ }^{\mathbf{1}} \mathbf{H}$ NMR $\left(500 \mathrm{MHz}, \mathrm{CDCl}_{3}\right)$ spectrum of $\mathbf{2 3 7}$
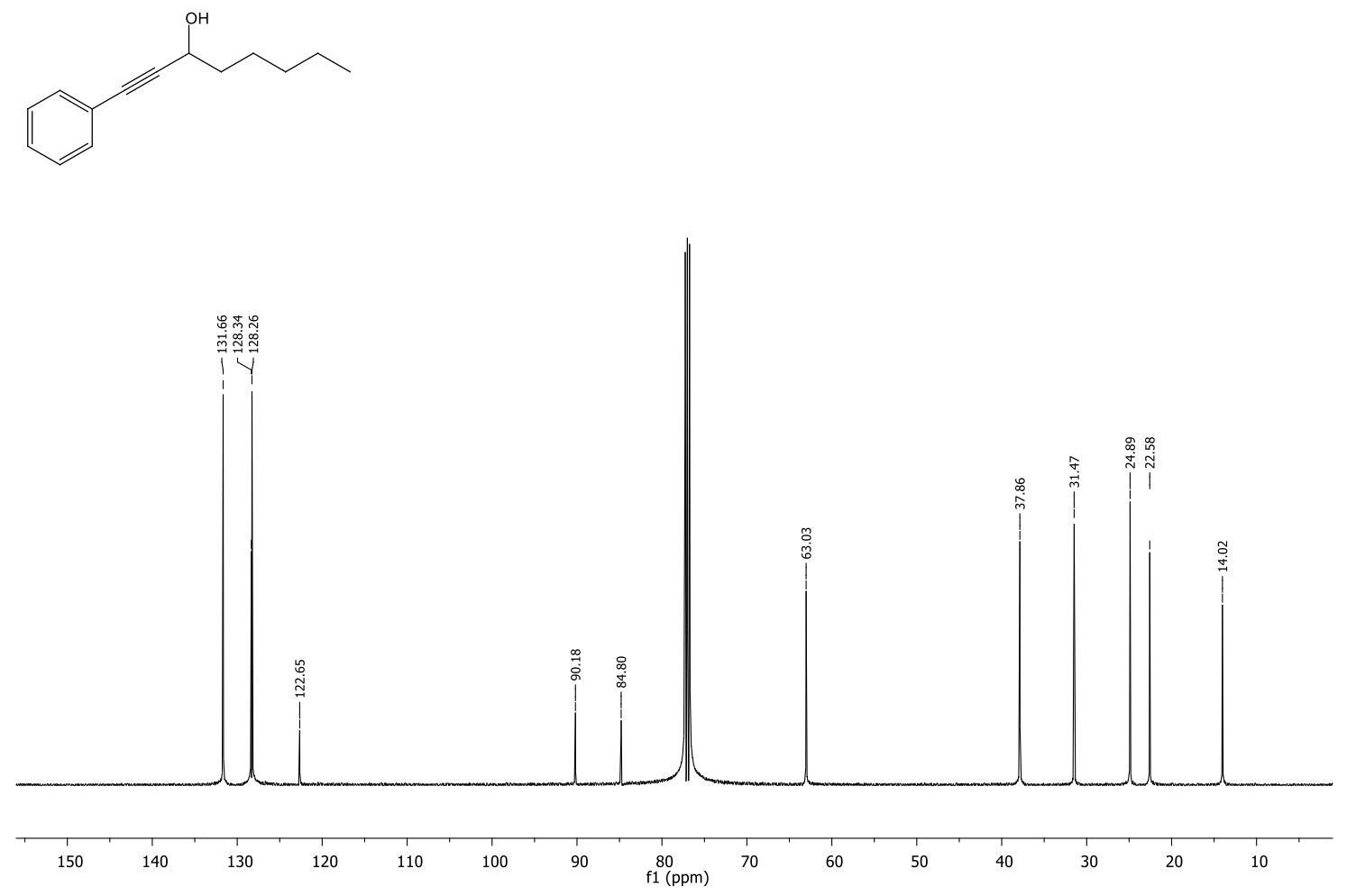

${ }^{13} \mathbf{C ~ N M R}\left(125 \mathrm{MHz}, \mathrm{CDCl}_{3}\right)$ spectrum of $\mathbf{2 3 7}$ 
$(1 R, 2 R)-2-N, N$-Dimethylamino-1-(4'-nitrophenyl)propane-1,3-diol (238)<smiles>CN(C)C(CO)Cc1ccc(N=O)cc1</smiles>

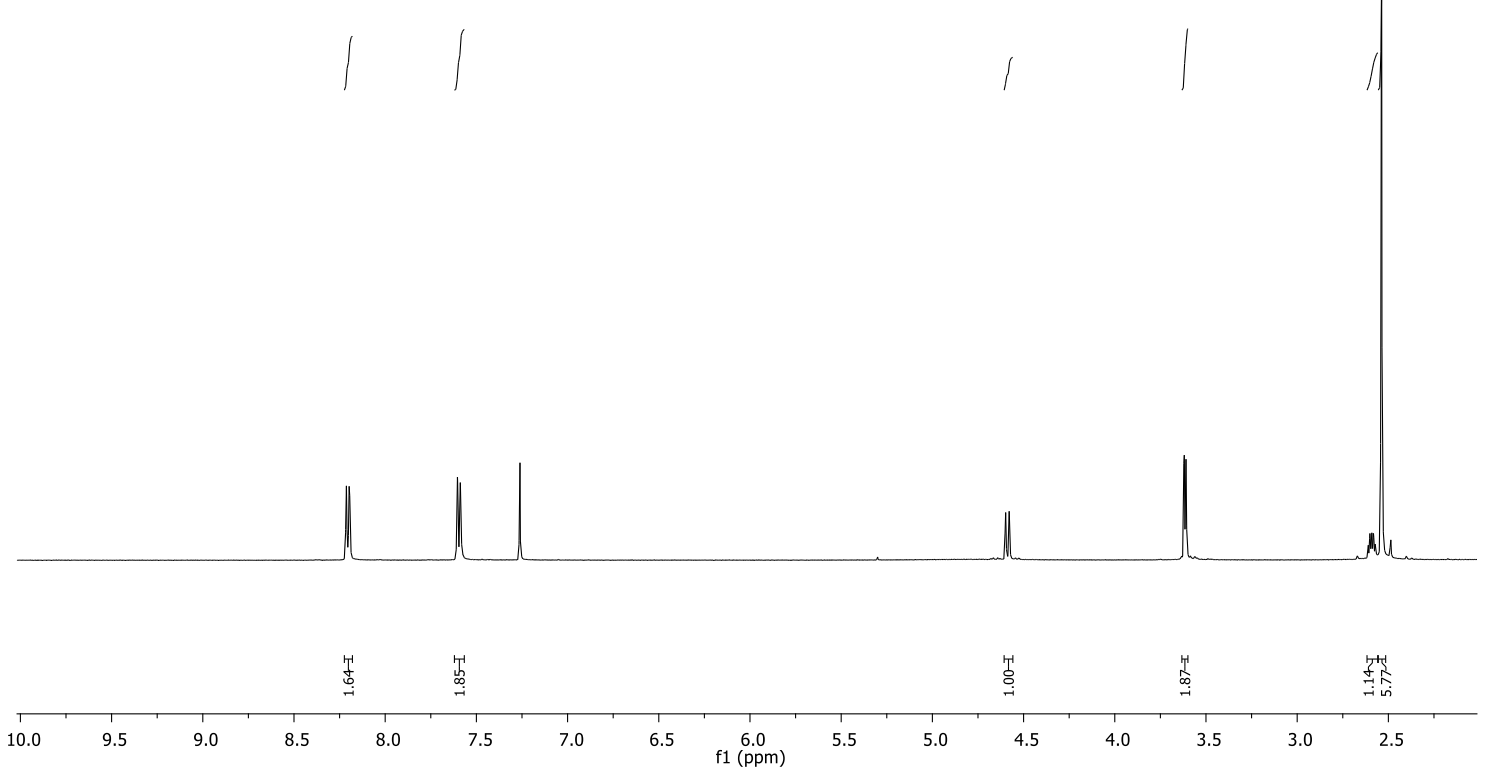

${ }^{1} \mathbf{H}$ NMR $\left(500 \mathrm{MHz}, \mathrm{CDCl}_{3}\right)$ spectrum of $\mathbf{2 3 8}$
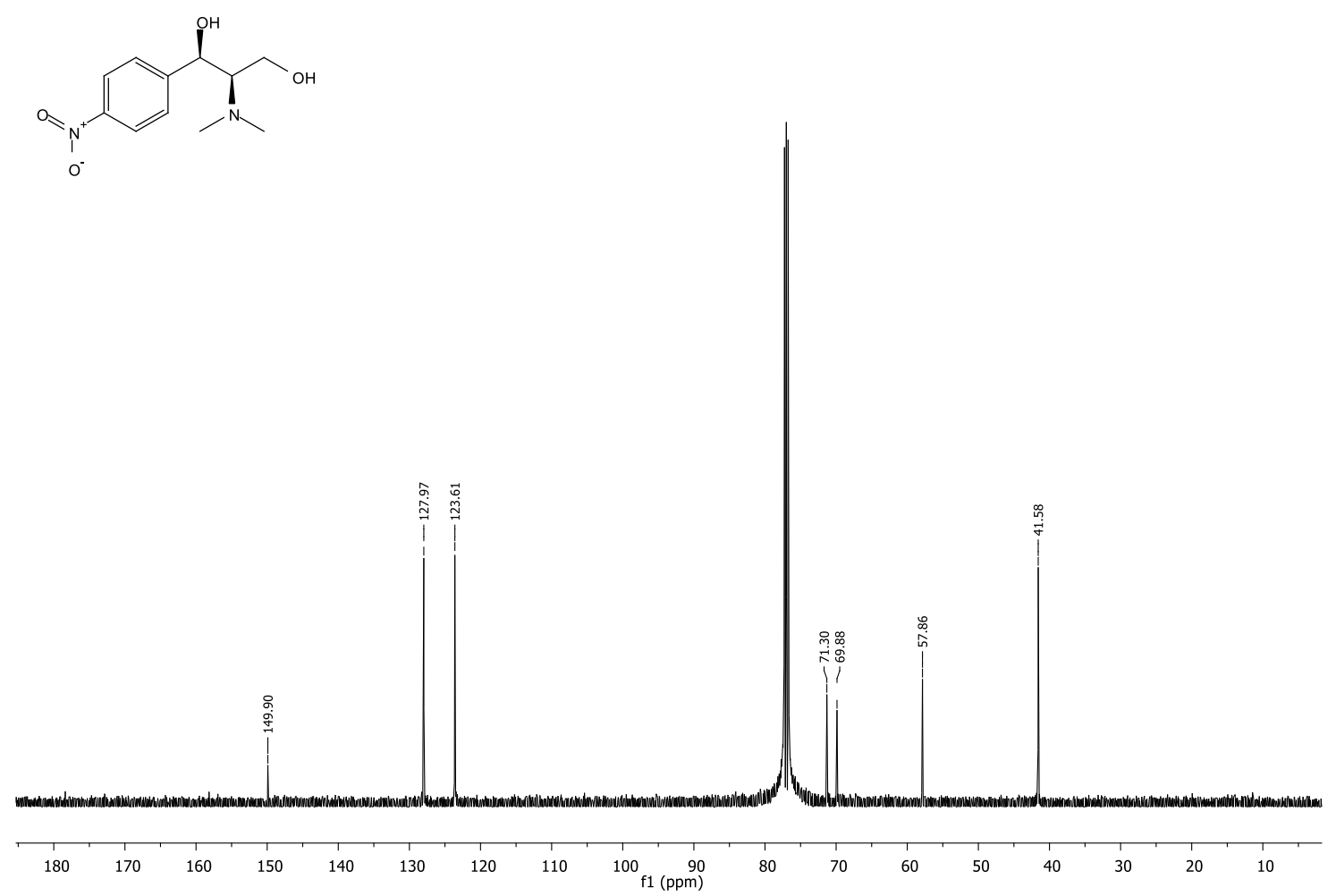

${ }^{13} \mathrm{C}$ NMR $\left(125 \mathrm{MHz}, \mathrm{CDCl}_{3}\right)$ spectrum of 238 
$(1 R, 2 R)-1,3-B i s-(t$-butyldimethylsilyloxy)-2- $N, N$-dimethylamino-1-(4'-nitrophenyl) propane (239)<smiles>[13CH3]OCC([18OH])C([18OH])c1ccc([N+](=O)[O-])cc1</smiles>

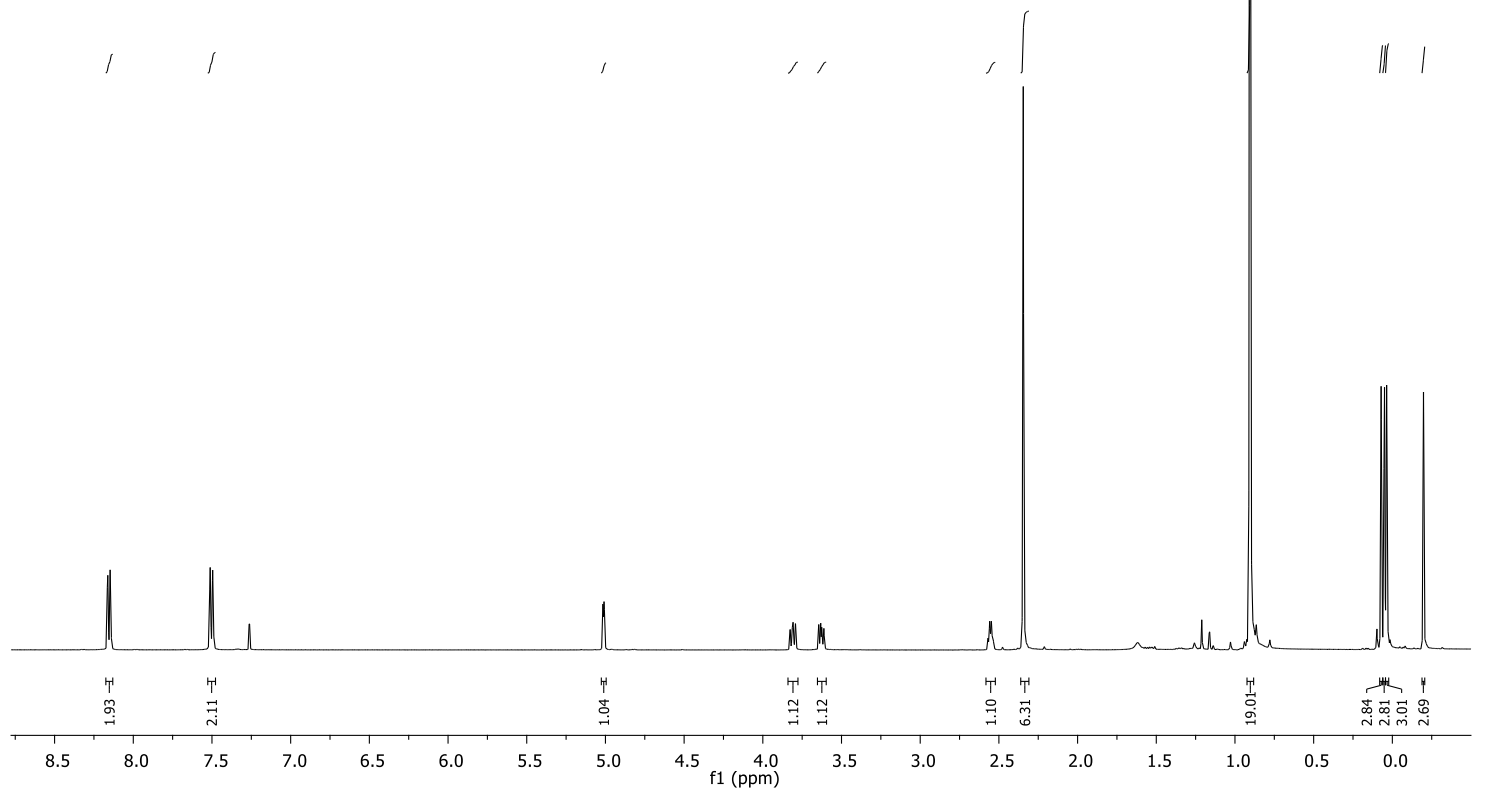

${ }^{\mathbf{1}} \mathbf{H}$ NMR $\left(500 \mathrm{MHz}, \mathrm{CDCl}_{3}\right)$ spectrum of $\mathbf{2 3 9}$

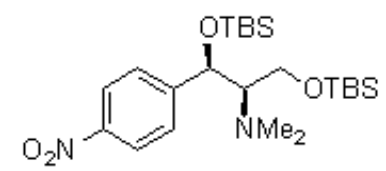

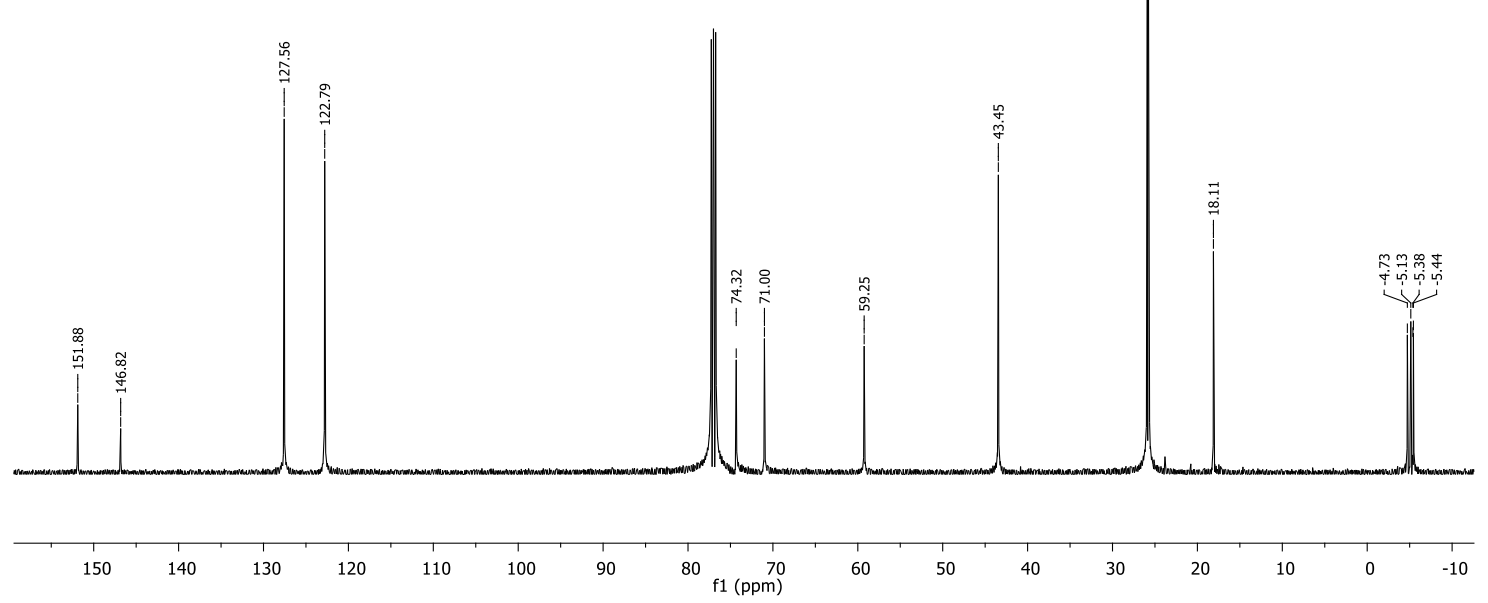

${ }^{13} \mathbf{C ~ N M R}\left(125 \mathrm{MHz}, \mathrm{CDCl}_{3}\right)$ spectrum of 239 
1'-(para-Methoxybenzyloxy)-6'-hydroxy-10'-(t-butyldimethylsilyloxy)dec-4'-yn-2'-yl 3phenylprop-2-enoate (240)

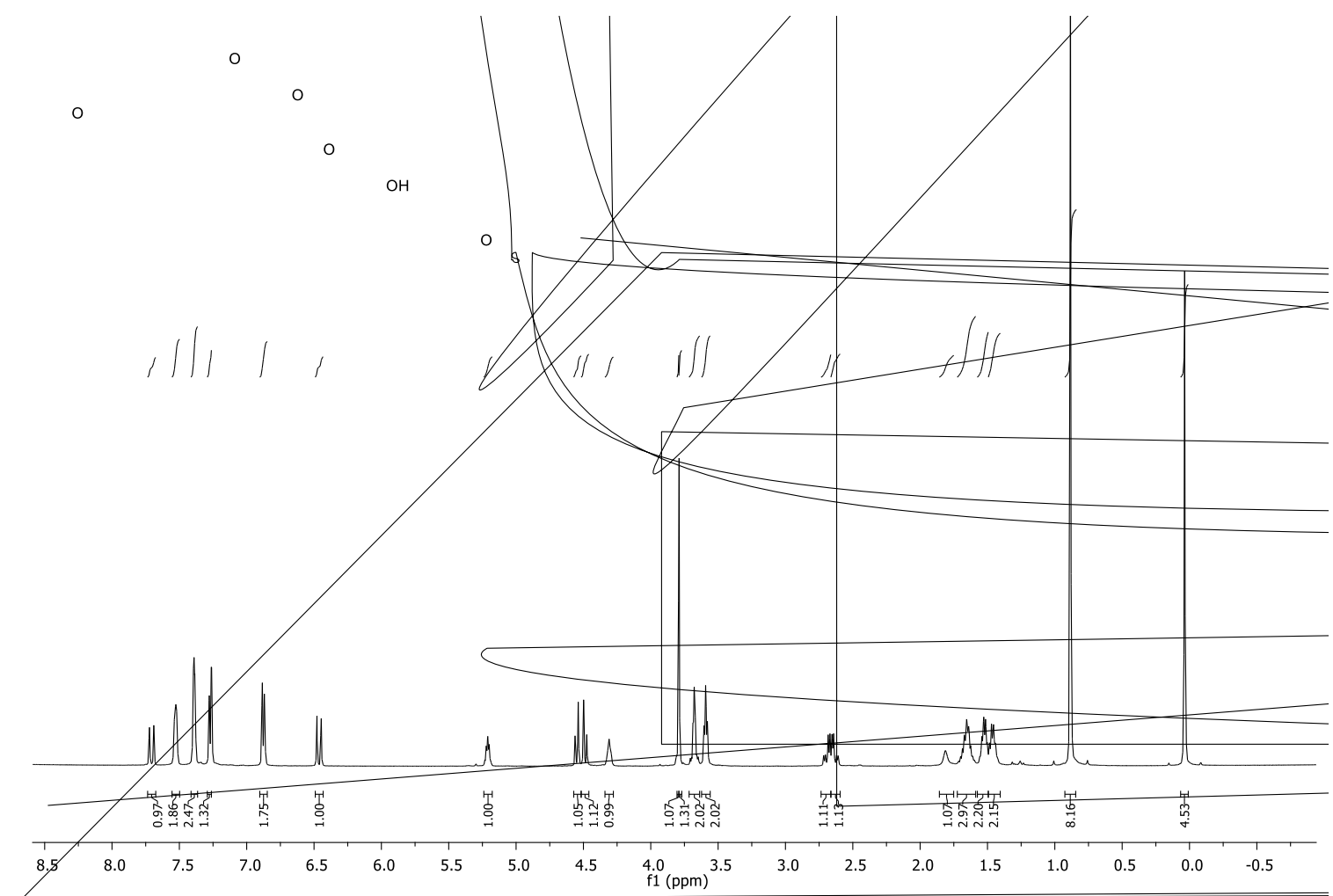

${ }^{\mathbf{1}} \mathbf{H}$ NMR $\left(500 \mathrm{MHz}, \mathrm{CDCl}_{3}\right)$ spectrum of $\mathbf{2 4 0}$

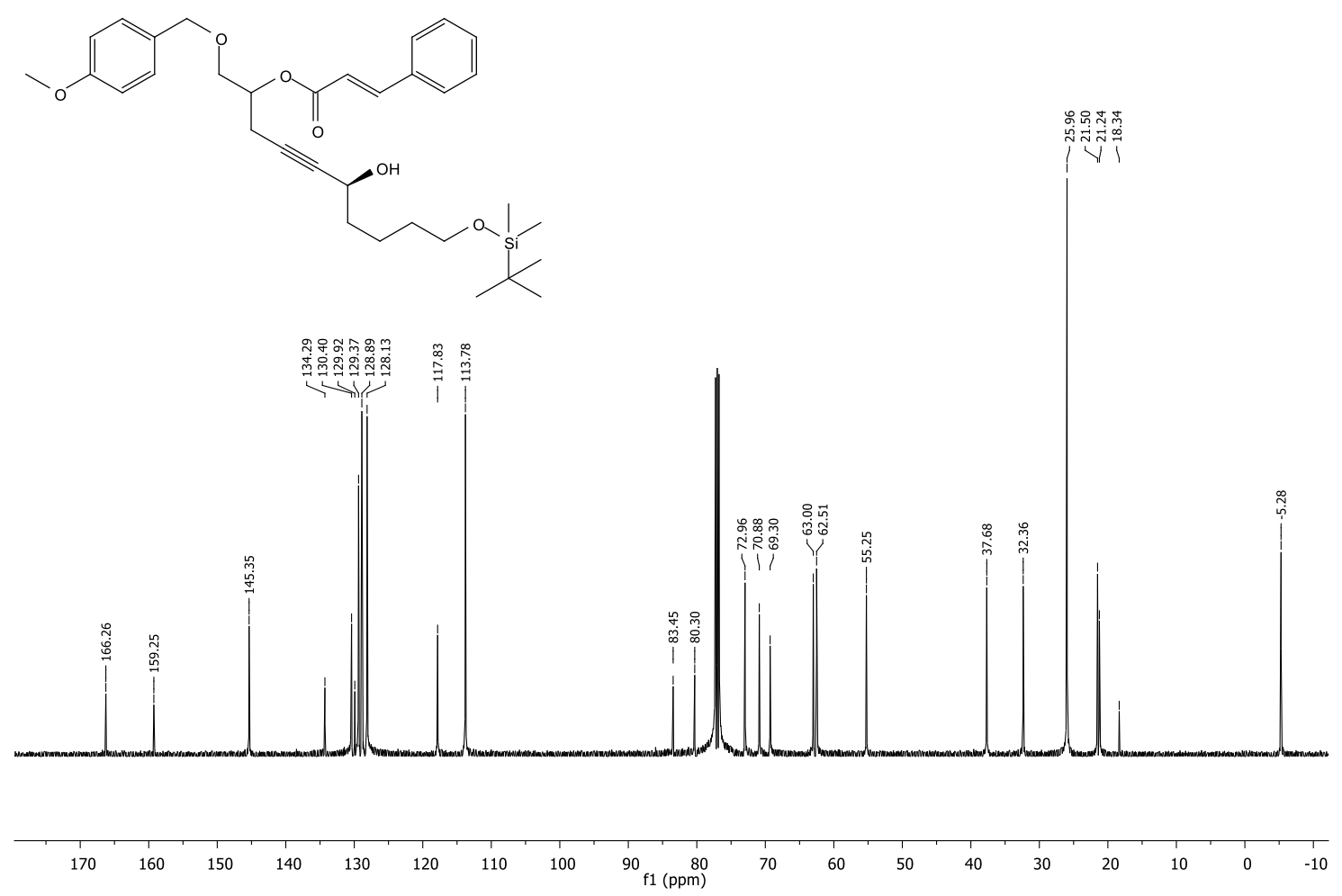

${ }^{13} \mathrm{C}$ NMR $\left(125 \mathrm{MHz}, \mathrm{CDCl}_{3}\right)$ spectrum of $\mathbf{2 4 0}$ 
Mosher's ester of alcohol 240 (241)
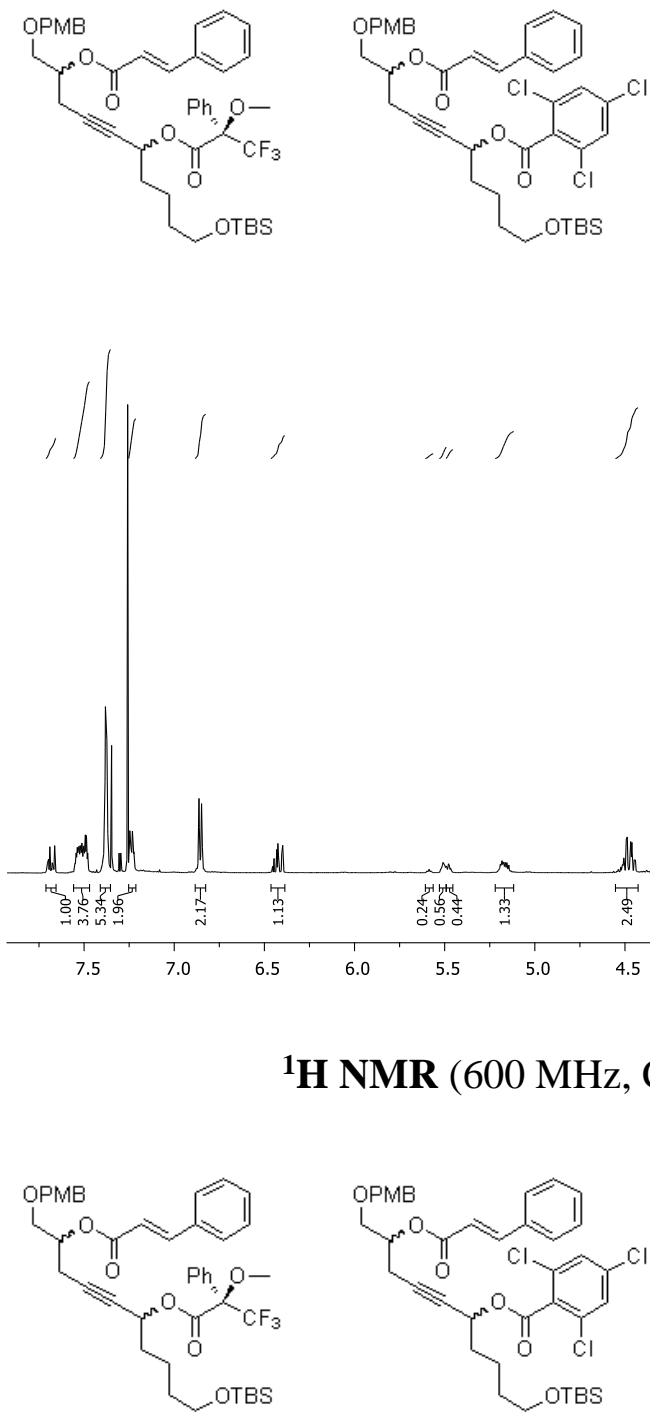

${ }^{1} \mathbf{H}$ NMR $\left(600 \mathrm{MHz}, \mathrm{CDCl}_{3}\right)$ spectrum of $\mathbf{2 4 1}$ and $\mathbf{2 4 2}$

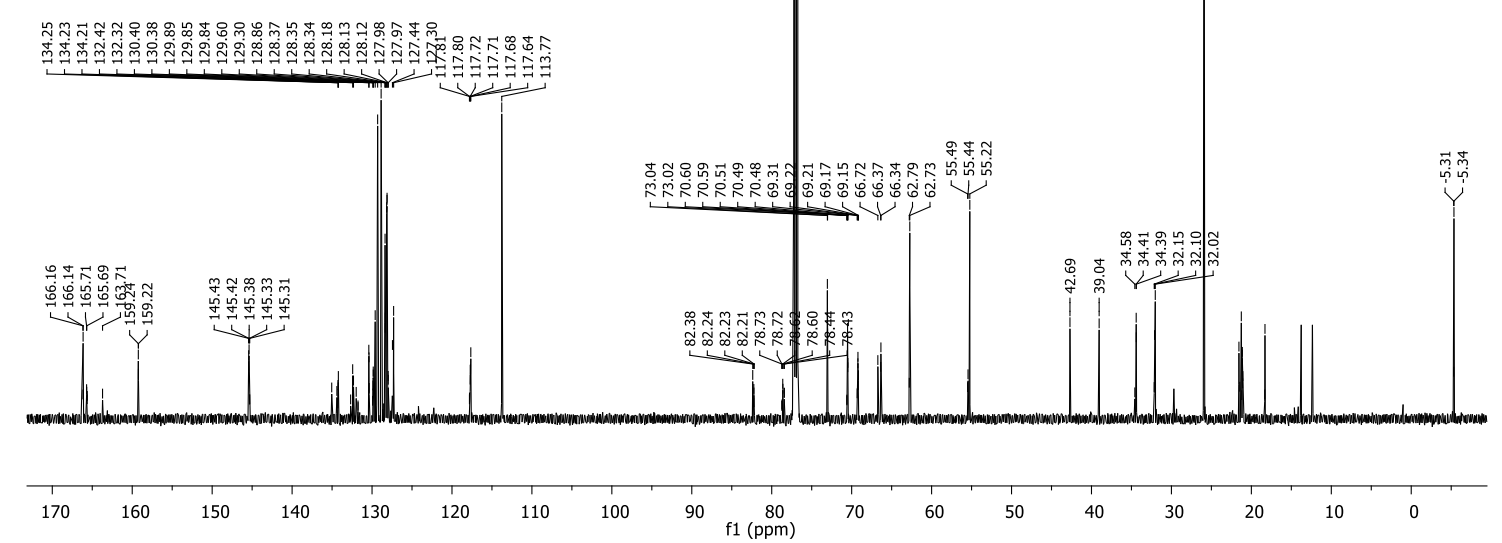

${ }^{13} \mathrm{C}$ NMR $\left(150 \mathrm{MHz}, \mathrm{CDCl}_{3}\right)$ spectrum of 241 and 242 
1'-(para-Methoxybenzyloxy)-6'-hydroxy-10'-(t-butyldimethylsilyloxy)dec-4'-yn-2'-yl 5methyl-7-( $t$-butyldimethylsilyloxy)non-2,4,8-trienoate (244)

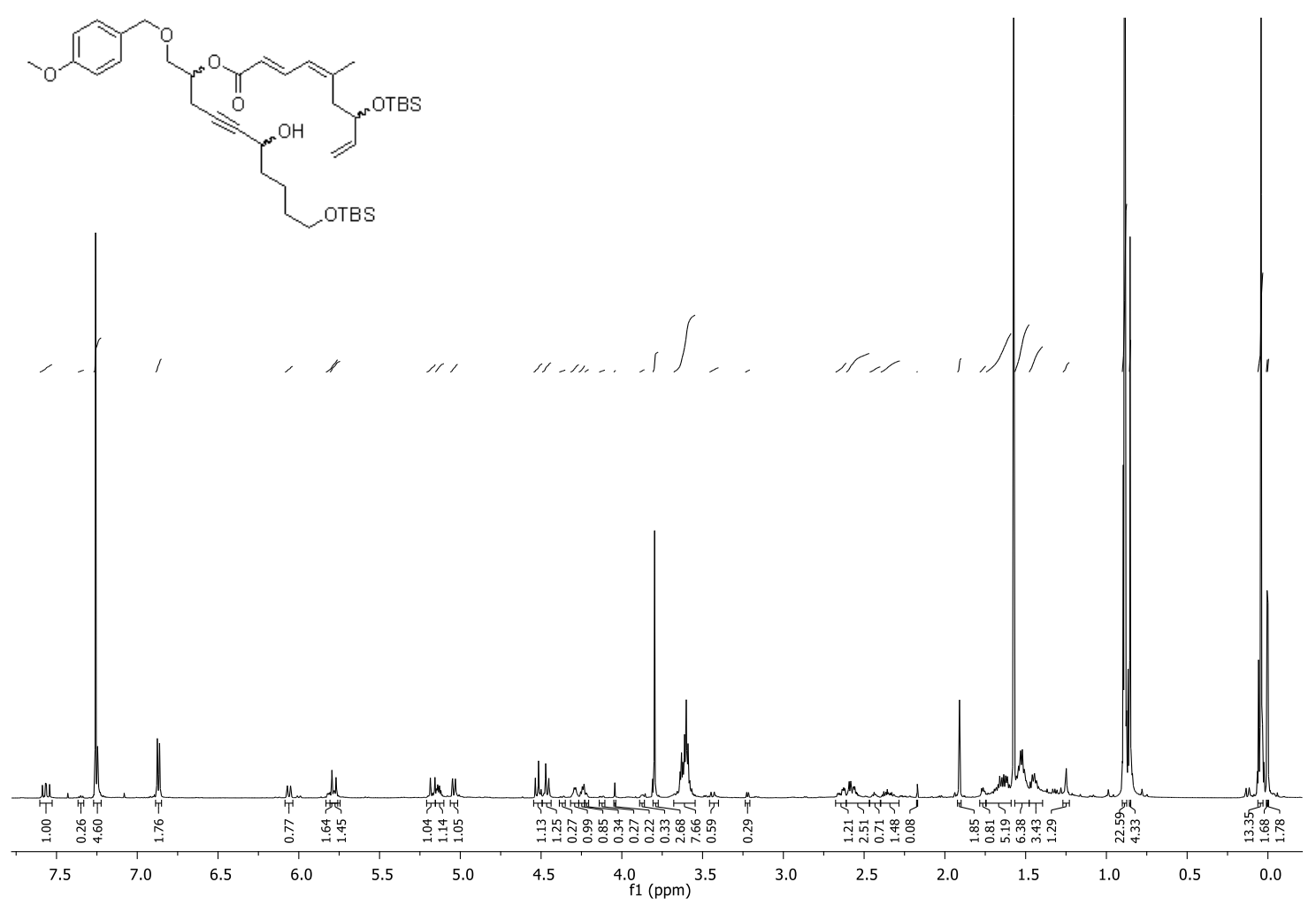

${ }^{1} \mathbf{H}$ NMR $\left(600 \mathrm{MHz}, \mathrm{CDCl}_{3}\right)$ spectrum of $\mathbf{2 4 4}$
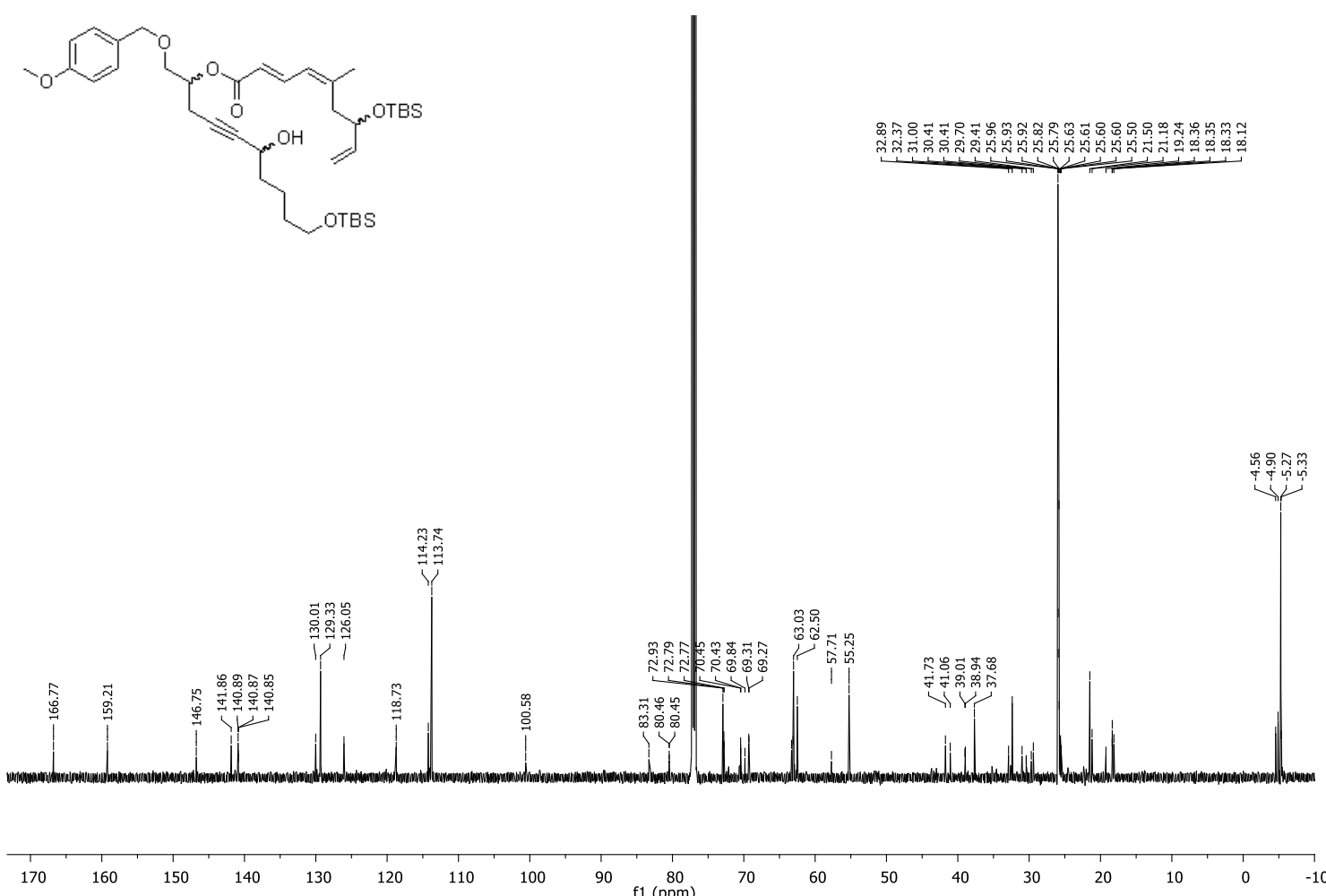

${ }^{13} \mathrm{C}$ NMR $\left(150 \mathrm{MHz}, \mathrm{CDCl}_{3}\right)$ spectrum of 244 